\title{
An Archaeometallurgical Investigation of Iron Smelting Traditions in Southern Rwanda
}

\author{
Jane Ellen Humphris
}

Thesis Submitted for the Degree of Doctorate of Philosophy

University College London Institute of Archaeology

March 2010 


\section{Declaration}

I, Jane Ellen Humphris confirm that the work presented in this thesis is my own. Where information has been derived from other sources, I confirm that this has been indicated in the thesis

Signed:

Dated: 


\section{Abstract}

From the 1950's to the 1980's, research in Rwanda highlighted the country's significant archaeological potential, including some of the earliest evidence for iron production in sub-Saharan Africa. However, years of civil war culminated in the 1994 genocide and the country was left devastated. Further archaeological research to develop the potential already indicated was inappropriate.

In 2006 this research project, to explore Rwanda's past iron smelting traditions, was accepted by the Institute of National Museums in Rwanda. Six months of fieldwork followed, including survey and the excavation of six newly located iron production sites. Archaeometallurgical samples collected in the field have been analysed at the Institute of Archaeology using a variety of different analytical techniques, and the results generated have been interpreted. Thus, aspects of the production techniques represented at each of the smelting locations investigated during this research have been illuminated.

This first systematic exploration of diachronic change within iron smelting traditions in Southern Rwanda has revealed two and a half millennia of dynamic technologies embedded within wider society. A chronological framework has been defined to provide a sound basis for the consideration of the results, which include a high-resolution understanding of Early Iron Age smelting techniques and an appreciation of smelting traditions during the Middle Iron Age. Technological traditions have been contextualised within broader Great Lakes, and specifically Rwandan, history, and the significant potential for such high-resolution studies has been demonstrated. 


\section{$\underline{\text { Table of Contents }}$}

Title page 1

Declaration 2

Abstract 3

Table of contents 4

List of figures $\quad 8$

$\begin{array}{ll}\text { List of tables } & 17\end{array}$

$\begin{array}{ll}\text { Acknowledgement } & 20\end{array}$

\section{Chapter 1}

Introduction: Technological history and the production of iron in Africa

1.1 The significance of iron as a material 26

1.2 Iron in Africa 29

$1.3 \quad$ Iron in Rwanda 31

1.4 Aims and Objectives 33

1.5 Structure of the thesis 34

\section{Chapter 2}

The practicalities of iron production: the potential of archaeometallurgical studies

2.1 Bloomery iron production: an overview 38

$\begin{array}{lll}2.1 .1 & \text { Charcoal production } & 38\end{array}$

2.1.2 Tuyere production $\quad 39$

$\begin{array}{lll}2.1 .3 & \text { Air supply } & 40\end{array}$

2.1.4 Ore collection and preparation $\quad 40$

2.1.5 Constructing the furnace 41

2.1.6 Smelting 42

2.1.7 Smithing the bloom 43

2.2 Bloomery iron smelting: a technical explanation 44

2.3 Variability in African iron production - room for choice 54 
2.4 Some limitations with the archaeometallurgical record

\section{Chapter 3}

A theoretical framework for African iron technology

3.1 Western theory in African archaeology 63

$\begin{array}{lll}3.2 & \text { What is technology? }\end{array}$

3.3 Limitations involved in the study of technology 80

3.4 The potential of studying technology within an evolving Rwandan 82 history

Chapter 4

\section{Iron in Rwanda}

4.1 The geographical context $\quad 84$

4.2 Chronological framework 86

4.3 Early Iron Age 90

4.4 Middle Iron Age 99

$\begin{array}{lll}4.5 & \text { Late Iron Age } & 104\end{array}$

$\begin{array}{lll}4.6 & \text { Discussion } & 111\end{array}$

$\begin{array}{ll}\text { Chapter } 5 & 115\end{array}$

\section{Methodology}

$\begin{array}{lll}5.1 & \text { Field methodology } & 115\end{array}$

$\begin{array}{ll}5.2 \text { Laboratory techniques } & 129\end{array}$

$\begin{array}{lll}5.3 \text { Dating } & 138\end{array}$

$\begin{array}{lll}5.4 & \text { Metallurgical analysis } & 140\end{array}$

Chapter 6 143

The Sites

$\begin{array}{lll}6.1 & \text { Gahondo (GHD) } & 145\end{array}$

6.1.1 Site description and observations 145

$\begin{array}{lll}\text { 6.1.2 Excavations and sample selection } & 148\end{array}$ 
$\begin{array}{lll}\text { 6.1.3 Results } & 157\end{array}$

6.1.4 The site, an overview 166

$\begin{array}{lll}6.2 & \text { Cyamukuza 1 (CMZ 1) } & 171\end{array}$

$\begin{array}{lll}\text { 6.2.1 Site description and observations } & 171\end{array}$

6.2.2 Excavations and sample selection 176

6.2.3 Results 182

6.2.4 Site interpretation 196

6.3 Cyamukuza 2 (CMZ 2) 201

6.3.1 Site description and observations 201

6.3.2 Excavations and sample selection 205

$\begin{array}{lll}6.3 .3 & \text { Results } & 209\end{array}$

$\begin{array}{lll}\text { 6.3.4 Site interpretation } & 219\end{array}$

6.4 Mpinga (MNA) 222

6.4.1 Site description and observations 222

6.4.2 Excavations and sample selection 227

$\begin{array}{lll}6.4 .3 & \text { Results } & 229\end{array}$

6.4.4 Site interpretation 239

6.5 Kamana (KMA) 241

6.5.1 Site description and observations 241

6.5.2 Excavations and sample selection 246

6.5.3 Results 249

6.5.4 Site interpretation 260

6.6 Kamabuye (KBE) 264

6.6.1 Site description and observations 264

6.6.2 Excavations and sample selection 266

$\begin{array}{lll}6.6 .3 & \text { Results } & 270\end{array}$

$\begin{array}{lll}\text { 6.6.4 Site interpretation } & 274\end{array}$

6.7 Summary of archaeometallurgical results 276

6.7.1 Spatial and morphological comparisons 276

$\begin{array}{lll}\text { 6.7.2 Chemical comparisons } & 282\end{array}$ 
Chapter 7

The broader role of iron in Rwanda

7.1 The Early Iron Age (c. 500 BC - AD 800) 290

7.2 The Middle Iron Age (c. 800 AD - 1500 AD) 296

7.3 The Late Iron Age / Kingdom Period (c. 1600 AD - colonial 302 contact)

7.4 Discussion

Chapter 8

Conclusion

8.1 New academic understandings 310

$\begin{array}{lll}8.2 & \text { Social Impact } & 315\end{array}$

8.3 Lessons learnt and projections for future work 316

Appendices: Bulk chemical analysis 319

1A GHD slag and ore samples $\quad 320$

1B GHD ceramic samples $\quad 321$

2A CMZ 1 slag and ore samples $\quad 322$

2B CMZ 1 ceramic samples 323

3A CMZ 2 slag samples $\quad 324$

3B CMZ 2 ceramic samples 325

4A MNA slag samples $\quad 326$

4B MNA ceramic samples $\quad 327$

5A KMA slag samples $\quad 328$

5B KMA ceramic samples $\quad 329$

6A \& 6B slag and ceramic samples $\quad 330$

$\begin{array}{ll}\text { References } & 331\end{array}$ 


\section{$\underline{\text { List of Figures }}$}

\section{Chapter 1}

Introduction: Technological history and the production of iron

\section{in Africa}

1.1 Chulu primary furnace observed in Malawi (after van der Merwe 24 \& Avery 1987, author's own scale)

1.2 Unique furnace design in Northern Cameroon (after David et al 1989)

1.3 Nyanga furnace with breasts (after Chirikure \& Rehren 2004)

\section{Chapter 2}

The practicalities of iron production: the potential of archaeometallurgical studies

$\begin{array}{lll}2.1 & \text { Charcoal production } & 39\end{array}$

$\begin{array}{lll}2.2 & \text { Tuyere production } & 39\end{array}$

2.3 Assembling the bellows 40

2.4 Beneficiating the ore 40

2.5 Constructing the furnace 41

2.6 The smelt in progress 43

2.7 Forging the marriage hoe 44

$2.8 \quad \mathrm{FeO}-\mathrm{Al}_{2} \mathrm{O}_{3}-\mathrm{SiO}_{2}$ ternary diagram illustrating, 'optimal 47 engineering solutions for bloomery smelting'

$2.9 \quad$ Black sand found by a river in Rwanda $\quad 54$

2.10 House foundations made of slag in Buganda 59

2.11 Slag block holding down corrugated iron roofing, located during 59 survey in Rwanda

\section{Chapter 3}

\section{A theoretical framework for African Iron technology}

3.1 Schematic representation of the basic iron production technology 74 
3.2 Interview concerning iron smelting conducted with Veronique

Nyandwi

3.3 Members of the smelting group commissioned in Rwanda

\section{Chapter 4}

\section{Iron in Rwanda}

4.1 Map of the African continent showing the location of Rwanda in 85 Central-Eastern Africa

4.2 Map illustrating the extent of the Great Lakes region 86

4.3 Bark cloth and woven containers in Rwanda 90

4.4 Internal house walls made of wood and woven grasses in $\quad 90$

Rwanda

4.5 Urewe sherd collected during survey in Southern Rwanda 91

4.6 Decorated bricks used in the construction of an EIA furnace 95

$\begin{array}{lll}4.7 & \text { Twisted string roulette } & 107\end{array}$

$\begin{array}{lll}4.8 & \text { Knotted strip roulette } & 107\end{array}$

$\begin{array}{lll}4.9 & \text { Batwa male potter } & 113\end{array}$

\section{Chapter 5}

\section{Methodology}

5.1 Map of Rwanda showing the location of the survey 116

5.2 Typical house compound cultivated with bananas, yams and 117 beans

$\begin{array}{lll}\text { 5.3 Steep and densely cultivated hill slope } & 117\end{array}$

5.4 Sites located during survey marked by red pins; sites excavated 118 marked by yellow pins

$\begin{array}{lll}5.5 & \text { Site recording sheet used during survey } & 118\end{array}$

5.6 Slag and ceramic samples collected from the field during survey 119

5.7 School children learning about the archaeological remains 122

$\begin{array}{lll}5.8 & \text { GHD site plan } & 123\end{array}$

$\begin{array}{lll}5.9 & \text { GHD furnace } 2 \text { after clean-up } & 123\end{array}$

$\begin{array}{lll}5.10 & \text { Example of a typical context sheet } & 124\end{array}$ 
5.11 CMZ 1 Furnace and slag block 126

5.12 CMZ 1 Furnace section 126

5.13 KBE Lifting the slag block 126

$\begin{array}{lll}5.14 & \text { KBE Empty furnace pit }\end{array}$

$\begin{array}{lll}5.15 & 126\end{array}$

$\begin{array}{lll}\text { 5.16 CMZ } 2 \text { lifting slag } & 126\end{array}$

5.17 Example of a typical slag block recording sheet 128

$\begin{array}{lll}5.18 & \text { Sectioning slag blocks } & 129\end{array}$

$\begin{array}{lll}5.19 & \text { Slag block section } & 129\end{array}$

$\begin{array}{lll}5.20 \quad \text { Iron objects after conservation } & 141\end{array}$

5.21 X-ray taken of the objects displaying the level of corrosion 141 affecting the iron metal (X-ray courtesy of Kelly Caldwell).

\section{Chapter 6}

\section{The Sites}

6.1 Location of the sites selected for detailed investigation 144

6.1.1 View from the GHD house compound across the valley 145

$\begin{array}{lll}6.1 .2 & \text { GHD f1 } & 146\end{array}$

$\begin{array}{ll}\text { 6.1.3 GHD f2 before excavation } & 147\end{array}$

6.1.4 Plan of GHD house compound showing the location of f1 and f2 148 as well as the location of the test pits

6.1.5 GHD f1 after excavation 149

6.1.6 GHD f1 sections after excavation 149

$\begin{array}{lll}6.1 .7 & \text { Finds from GHD f1 } & 150\end{array}$

6.1.8 Fragments of tuyere found within the fill of GHD f1 151

6.1.9 GHD f2 after the removal of the top $5 \mathrm{~cm}$, with orange clay 153 features protruding from the pit fill

6.1.10 Example of a brick from GHD f2 154

6.1.11 Decorated bricks excavated by Van Noten in Southern Rwanda 154

$\begin{array}{lll}\text { 6.1.12 Large flows classified as slag } & 155\end{array}$ 
6.1.13 Plan of GHD f2 at $15 \mathrm{~cm}$ below ground level 155

6.1.14 Bricks in GHD tp3 157

6.1.15 Plan of GHD tp3 after excavation 157

6.1.16 SEM BSE image of ore taken from GHD f1, illustrating a 160 banded haematite

6.1.17 $\mathrm{FeO}-\mathrm{Al}_{2} \mathrm{O}_{3}-\mathrm{SiO}_{2}$ phase diagram showing the position of the slag 161 sample analysed from $\mathrm{f} 1$

6.1.18 SEM BSE image of the slag sample from GHD f1 161

6.1.19 SEM SE image of a brick from GHD f1 showing un-cracked 162 quartz and an unvitrified ceramic matrix

6.1.20 $\mathrm{FeO}-\mathrm{Al}_{2} \mathrm{O}_{3}-\mathrm{SiO}_{2}$ phase diagram showing the position of the 164 'slag' and 'ore' samples analysed from $\mathrm{f} 2$

6.1.21 SE image of 'ore', displaying banded haematite 165

6.1.22 PPL Photomicrograph of 'slag', dominated by wüstite 165

6.1.23 SEM BSE image of a sample of ceramics from GHD f2, 165 illustrating quartz grains $(\mathrm{Q})$, throughout the clay matrix

6.1.24 Levels of alumina and silica in the technical ceramics analysed 169 from GHD f1 and f2

6.2.1 View looking south-west towards the site of CMZ 1

6.2.2 The site of CMZ 1

6.2.3 Typical slag block from CMZ 1: side view on the left (block 173 upside-down); top view on the right

6.2.4 CMZ 1 F1 before excavation 175

6.2.5 Plan of CMZ 1 F1 before excavation 175

6.2.6 CMZ 1, showing the locations of f1, f2, the test pits, the 176 interesting ceramic deposit and the slag blocks (1-5) analysed

$\begin{array}{lll}\text { 6.2.7 CMZ 1 SB1 section } & 177\end{array}$

6.2.8 CMZ $1 \mathrm{f} 1$ section after excavation of the northern half 178

6.2.9 CMZ $1 \mathrm{f1}$ after the removal of SB1 and samples for 179 luminescence dating

6.2.10 Finds excavated in CMZ 1 f2: larger pieces of slag (left); smaller 180 slag pieces and ore samples (right) 
$\begin{array}{lll}\text { 6.2.11 TP3 ceramics } & 183\end{array}$

6.2.12 Compositional variation throughout SB1 demonstrated using the 184 coefficient of variation

6.2.13 PPL Photomicrographs of samples taken from throughout CMZ 185 $1 \mathrm{SB} 1$

6.2.14 $\mathrm{FeO}-\mathrm{Al}_{2} \mathrm{O}_{3}-\mathrm{SiO}_{2}$ phase diagram showing the position of the middle sample from CMZ 1 SB1-5

6.2.15 Typical photo micrograph of a slag sample from CMZ 1

6.2.16 The chemically similar signature of the middle sample from each 189 of the slag blocks analysed at CMZ 1

6.2.17 CMZ 1 SB2 sample B, illustrating a higher proportion of free 189 iron oxides within the slag

6.2.18 CMZ $1 \mathrm{f1}$ pit lining, showing the significant amount of quartz 191 (Q), in the fabric

6.2.19 Typical bloomery slag from CMZ 1 f2

6.2.20 Haematite from CMZ $1 \mathrm{f} 2$

6.2.21 Raw bloom (B), attached to slag (S), taken from context $003 \quad 194$

6.2.22 PPL photomicrograph of the bloom once etched 194

6.3.1 CMZ 2 slag blocks 202

6.3.2 CMZ 2; SB1 sat in f1 203

6.3.3 CMZ 2 f2 and SB2 before excavation, viewed in section (left) 203 and in plan (right)

6.3.4 View of the top of SB5 on the left and SB3 on the right 204

6.3.5 Plan of CMZ 2 205

6.3.6 CMZ 2 f1 in section (west-east) after excavation 207

6.3.7 Tuyere fragment found on top of SB2 in f2 208

6.3.8 CMZ 2 f2 section drawings 208

6.3.9 Compositional variation throughout SB5 demonstrated using the 210 coefficient of variation

6.3.10 PPL photomicrographs of samples taken throughout SB5 211

6.3.11 Phase diagram illustrating the variable alumina to silica ratios 213 
between the slag samples taken from $\mathrm{CMZ} 2$

$\begin{array}{lll}\text { 6.3.12 PPL micrograph of SB2 } & 214\end{array}$

$\begin{array}{lll}\text { 6.3.13 PPL image of SB3 } & 214\end{array}$

$\begin{array}{lll}\text { 6.3.14 PPL image of SB4 } & 214\end{array}$

6.3.15 Compositional variation between the middle sample from each 215 of the 5 slag blocks analysed from CMZ 2

6.3.16 Compositional variation between the middle sample from each 216 of the 5 slag blocks analysed from CMZ 2

6.3.17 Levels of alumina and silica in the technical ceramics analysed 217 from the site of CMZ 2

$\begin{array}{lll}6.3 .18 & \text { f1 tuyere } & 218\end{array}$

$\begin{array}{lll}6.3 .19 & \text { f1 pit lining } 218\end{array}$

$\begin{array}{lll}6.3 .20 & \mathrm{f} 2 \text { tuyere } & 218\end{array}$

$\begin{array}{lll}6.3 .21 & \mathrm{f} 2 \text { pit lining } & 218\end{array}$

6.3.22 CMZ 2 F1 and F2 sections compared 220

6.4.1 Largest slag block seen during the research, $500 \mathrm{~m}$ from MNA 223

6.4.2 MNA SB2 sat by the compound tree 224

$\begin{array}{lll}\text { 6.4.3 MNAf1 } & 225\end{array}$

6.4.4 MNA f1 plan 225

6.4.5 MNA tuyere 225

6.4.6 MNA site plan 226

6.4.7 Slag samples taken from MNA SB2 227

6.4.8 Removing SB1 from F1 at MNA 228

6.4.9 MNA f1 after the removal of SB1 228

6.4.10 Section of MNA f1 (dotted line: incomplete pit lining) 228

6.4.11 MNA SB1 coefficient of variation throughout the block 230

6.4.12 Coefficient of variation throughout SB1, SB3 and SB5 233

6.4.13 PPL photomicrograph of MNA SB1 sample C 234

6.4.14 SEM SE image of MNA SB2 sample B 234

6.4.15 $\mathrm{FeO}-\mathrm{SiO}_{2}-\mathrm{Al}_{2} \mathrm{O}_{3}$ phase diagram with the samples taken from 236 MNA plotted

$\begin{array}{lll}\text { 6.4.16 PPL image of sample 1B } & 237\end{array}$ 
6.4.17 PPL image of sample 3B 237

6.4.18 PPL image of sample 5B 237

6.4.19 PPL image of a sample of pit lining from $\mathrm{f} 1$

6.5.1 View looking west from the site of KMA 242

6.5.2 KMA cluster 1 of slag blocks 242

6.5.3 KMA f1 before excavation 242

6.5.4 House foundations at KMA constructed with small, layered slag 243 blocks (S), and grinding stones $(\mathrm{G})$

6.5.5 Plan of the site of KMA 245

6.5.6 KMA SC1 246

6.5.7 KMA f1 plan (top) and section (bottom) 247

6.5.8 KMA f2 pit lining fragment 247

6.5.9 Possible smithing cake excavated in tp2 248

6.5.10 Sterile tp2 248

6.5.11 The coefficient of variation (\%) within each oxide throughout 249 KMA SB5

6.5.12 PPL photomicrograph of sample KMA SB5 sample C 250

6.5.13 PPL photomicrograph of sample KMA SB5 sample B 250

6.5.14 PPL photomicrograph of sample KMA SB5 sample A 250

6.5.15 Coefficient of variation (\%) throughout three slag blocks at 251 KMA

6.5.16 Levels of the main slag components throughout three smelts at 252 KMA

6.5.17 Alumina to silica ratios throughout three smelts at KMA 253

6.5.18 Fuel ash components within the three slag blocks analysed in 253 detail at KMA

6.5.19 Fuel ash components within the five KMA slag blocks 255

6.5.20 Phase diagram with the middle samples of SB 1-5 plotted 255

6.5.21 PPL photomicrograph of sample KMA SB1 B 256

6.5.22 PPL photomicrograph of sample KMA SB2 B 256

6.5.23 PPL photomicrograph of sample KMA SB4 B 256

6.5.24 PPL photomicrograph of sample tp2, illustrating areas of iron 257 
metal and slag

6.5.25 Typical slag block within the house foundations at KMA, showing a layered, flowing effect

6.5.26 PPL photomicrograph of KMA f1 pit lining showing larger fragments of quartz

6.5.27 PPL photomicrograph of KMA f2 pit lining 259

6.5.28 Small, layered slag cakes (S) in the foundations of a house at 262 KMA

6.6.1 KBE furnace pit located in the middle of the road 264

6.6.2 KBE furnace pit, set into the surrounding rock 265

6.6.3 Grinding hollows 266

6.6.4 Plan of some of the grinding hollows 266

$\begin{array}{lll}\text { 6.6.5 } & \text { KBE f1 } & 267\end{array}$

6.6.6 Sectioning SB1 267

6.6.7 KBE f1 sectioned to reveal SB1 sat up against the rock that has 267 been used to form part of the furnace pit itself

6.6.8 KBE f1 after the removal of SB1, clearly illustrating that there 268 had been no technical ceramic pit lining between the slag block and the rock

6.6.9 Extent of the ceramic furnace pit lining used to construct part of 268 the structure of the furnace pit

6.6.10 KBE samples plotted in the $\mathrm{FeO}-\mathrm{Al}_{2} \mathrm{O}_{3}-\mathrm{SiO}_{2}$ phase diagram 271

6.6.11 Coefficient of variation throughout SB1 from the site of KBE 272

6.6.12 PPL photomicrograph of SB1 sample C 273

6.6.13 PPL photomicrograph of SB1 sample B 273

6.6.14 PPL photomicrograph of SB1 sample A 273

$\begin{array}{lll}\text { 6.7.1 GHD f1 section } & 278\end{array}$

$\begin{array}{lll}\text { 6.7.2 } & \text { CMZ } 1 \text { f1 section } & 278\end{array}$

$\begin{array}{lll}\text { 6.7.3 CMZ } 2 \text { f1 section } & 278\end{array}$

$\begin{array}{lll}\text { 6.7.4 MNA f1 section } & 278\end{array}$

$\begin{array}{lll}\text { 6.7.5 KMA f1 section } & 278\end{array}$

$\begin{array}{lll}\text { 6.7.6 KBE f1 section } & 278\end{array}$ 
6.7.7 Reconstructions of Early Iron Age furnace superstructures 279

6.7.8 Shallow furnace pit with no defined superstructure 280

6.7.9 Deep furnace pit with no defined superstructure 280

6.7.10 Shallow furnace pit with defined superstructure 280

6.7.11 Deep furnace pit with defined superstructure 280

6.7.12 A schematic diagram of the furnace constructed during this 281 research

6.7.13 Coefficient of variation throughout oxides within all of the five 284 slag blocks at each site

6.7.14 Coefficient of variation throughout one block from each site 285

6.7.15 Scatterplot of alumina and silica within the slag samples from 286 the sites of CMZ 1, CMZ 2, MNA and KMA

6.7.16 $\mathrm{FeO}-\mathrm{SiO}_{2}-\mathrm{Al}_{2} \mathrm{O}_{3}$ phase diagram of all slag samples 287

\section{Chapter 7}

The broader role of iron production in Rwanda

7.1 Well formed ferrite crystals 294

7.2 Small areas of ferrite and pearlite 294

7.3 Pie chart demonstrating the presence of each type of ceramic 301 style located during survey on the surface alongside iron slag scatters

\section{NB. ALL FIGURES UNLESS OTHERWISE STATED ARE THE AUTHOR'S OWN}




\section{$\underline{\text { List of Tables }}$}

\section{Chapter 5}

\section{Methodology}

5.1 Details of the six sites selected for excavation 120

5.2a Precision test using slag-like certified reference material 133

5.2b Precision test using ceramic-like certified reference material 133

5.3a Accuracy test comparing with slag-like certified reference material 134

5.3b Accuracy test comparing with ceramic-like certified reference 135 material

\section{Chapter 6}

\section{The Sites}

6.1.1 Samples of slag and ore selected for analyses from GHD f1 152

6.1.2 Samples of technical ceramic selected for analyses from GHD f1 152

6.1.3 Samples of slag and ore selected for analyses from GHD f2 156

6.1.4 Samples of technical ceramic selected for analyses from GHD f2 156

6.1.5 (P)ED-XRF compositional data obtained from the slag and ore 158 samples selected from GHD f1

6.1.6 (P)ED-XRF compositional data obtained from the ceramic 158 samples selected from GHD f1

6.1.7 (P)ED-XRF compositional data obtained from the ore and slag samples selected from GHD f2

6.1.8 (P)ED-XRF compositional data obtained from the ceramic samples selected from GHD f2

6.1.9 (P)ED-XRF compositional data obtained from the Urewe shard collected at GHD

6.2.1 Dimensions of the slag blocks investigated at CMZ 1

6.2.2 Samples of slag taken from CMZ 1 and the analytical methods employed

6.2.3 Samples taken from the pit lining of CMZ $1 \mathrm{f1}$; their location and 
the methods of processing 181

6.2.4 Finds collected and analysed 182from CMZ 1 f2

6.2.5 Samples analysed from the test p183its excavated at CMZ 1

6.2.6 (P)ED-XRF compositional data obtained from the samples taken 183 from CMZ 1 SB1

6.2.7 (P)ED-XRF compositional data obtained from the middle sample from each slag block analysed at CMZ 1

6.2.8 (P)ED-XRF compositional data obtained from CMZ $1 \mathrm{f1}$ pit lining 190

6.2.9 (P)ED-XRF compositional data obtained from the slag and 192 possible slag samples taken from CMZ $1 \mathrm{f} 2$

6.2.10 (P)ED-XRF compositional data obtained from the ceramic samples taken from CMZ $1 \mathrm{f} 2$

6.2.11 (P)ED-XRF compositional data obtained from the ceramic samples taken from TP1 at CMZ 1

6.3.1 Dimensions of the slag blocks selected for detailed analysis at CMZ 2

6.3.2 Slag samples analysed from CMZ 2 206

6.3.3 Ceramics taken for analysis from CMZ 2 209

6.3.4 (P)ED-XRF compositional data obtained from the samples taken 210 from CMZ 2 SB5

6.3.5 (P)ED-XRF compositional data obtained from the middle sample taken of each slag block from CMZ 2

6.3.6 (P)ED-XRF compositional data obtained from the ceramics taken from CMZ 2

6.4.1 Dimensions of the slag blocks selected for detailed analysis at MNA

6.4.2 Slag samples analysed from MNA

6.4.3 Ceramics taken for analysis from MNA

6.4.4 (P)ED-XRF compositional data obtained from the samples taken from MNA SB1

6.4.5 (P)ED-XRF compositional data obtained from the samples taken throughout SB1, 3 and 5 
6.4.6 (P)ED-XRF compositional data obtained from the samples taken from the middle samples of each block analysed from MNA

6.4.7 (P)ED-XRF compositional data obtained from the ceramics samples taken from MNA

6.5.1 Dimensions of the slag blocks selected for detailed analysis at KMA

6.5.2 Slag samples analysed from KMA

6.5.3 Ceramics taken for analysis from KMA 248

6.5.4 (P)ED-XRF compositional data obtained from the samples taken from KMA SB5

6.5.5 (P)ED-XRF compositional data obtained from the samples taken from KMA SB2, SB4 and SB5

6.5.6 (P)ED-XRF compositional data obtained from the middle slag samples taken from KMA: SC1 is tap slag, whereas TP2:1 is a smithing cake

6.5.7 (P)ED-XRF compositional data obtained from the additional slag samples taken from KMA

6.5.8 (P)ED-XRF compositional data obtained from the technical ceramics taken from KMA

6.6.1 Samples of slag taken from KBE and the analytical methods employed

6.6.2 Samples taken from the technical ceramics excavated at the site of $\mathrm{KBE}$

6.6.3 (P)ED-XRF compositional data obtained from the slag samples taken from $\mathrm{KBE}$

6.6.4 (P)ED-XRF compositional data obtained from the technical ceramics taken from $\mathrm{KBE}$

6.7.1 Site details 


\section{Acknowledgements}

Permission for this $\mathrm{PhD}$ project to be conducted in Rwanda was granted by Professor Celestine Kanimba Misago, the director of The Institute of National Museums of Rwanda and lecturer at the National University of Rwanda. His support and constant assistance deserves the greatest of thanks. This $\mathrm{PhD}$ was funded by the Arts and Humanities Research Council, while financial assistance was provided throughout the course of the research by the University College London Institute of Archaeology, University College Graduate School, University College London Central research Fund, and The British Federation for Women Graduates. Further backing was provided by the British Institute in Eastern Africa from their fantastic Graduate Attachment program.

After introducing me to Africa in 2001, and encouraging me both in the field and in life since then, my thanks goes to my supervisor and friend, Dr Andrew Reid. I would also like to say a big thank you to Dr Marcos Martinón-Torres, whose unending patience and enthusiasm has guided me through this research. Dr Ceri Ashley has provided years of friendship and excellent academic direction, for which I am very grateful, and Professor Thilo Rehren has been a constant source of assistance and friendship.

In Rwanda the success of this project was a result of the hard work of the people involved in the fieldwork. Alongside their dedication, their involvement made every day fun and enriching: Théophile Sebazungu, André Ntagwabira, Innocent Gakuba, Thomas Baratsinda, Maurice Mugabowagahunde, Dantes Singiza, Isadore, Jerome, Laurie Thraves, Jessica Espey, Sophie Perry, Mackenzie Koster, Marjaana Khotamaki, Maiya, Sarah Luddy, Yvonne Cichoka, Toby Hodgson, Carl King, Rosamund Hanley, Wendy S-Woodiwis and Nshima Doshi. I am also incredibly thankful for the encouragement offered by MarieClaude Van Grunderbeek, who actively supported this project from my first email.

John Giblin, for the years of friendship, the support, the fun and the waragi, as well as being the best Butare housemate, the best Christmas Day chef and the best Usher, my heartfelt thanks to you. My friend Louise Iles, my greatest conference, lab, lunch and slag buddy, thank you! My friends in Rwanda, who through your kindness, sense of fun and love, made 
my time in Rwanda so special and so full of joy, thank you: Coco, Albert, Thierry (m), Thierry (b), Thierry (mt), Manu, Corrie, Maggie, Max, Kim, Rev. Odillo, Tarek, Omar and Hassan. I think about our time together often and miss you everyday.

So many friends should be thanked for their academic and personal contribution to this work and to my life. Without you the last four and a half years would not have been half so rewarding and enjoyable: Professor David Killick, Dr Paul Lane, Xander Veldhuijzen (for the World of Iron!), Simon Groom, Philip, Kevin, Anna Razeto, Tobias Richter, Claire Cohen, Miljana Radivojevic, Steve Matthews, Lorna Anguilano, Ellie Blakelock, Gabe Moss, Lizzy Web, Laura Lindsay, Jessica Amey, Vicky Edwards, Olivia and Becky Wallis, Rebecca Bennet, Larry Owens, Ginny Kingston, Sally Jackson, Helen Lidingtton, Dismas Ongwen, Nick Black, Rob, Elpida, Dimitra, Paulo, Allesandra and all my friends at Tiffany \& Co. in Harrods: Thank you!

My very special Mum and Dad, Allan and Sally Humphris, and my wonderful sisters Anne, Katy and Libby Humphris, you have provided me with constant encouragement (as well as trips to Africa, and the rest!). Your endless love is my rock. My family: Nana, Sue, Pete, Jon, Nikki, Richard, Sophie, Kate, Dan, Jan, George, Neil, Jake, Maman , Nikki, David (for my first archaeology books!), Domi, Lee, Theo, Mickie, Captain Dom, Henry, Jo, Graham, Cynthia, Dan, Bec and Amelia, thank you for your love and support, and for being the greatest family. Finally, my Husband Tim, my One. The very day we got together was the very day I received my AHRC funding. Through thick (lots of it!) and thin, for all of the nights I was away, for supporting me unendingly, more than I ever knew was possible, and for being the best friend I have ever had, thank you from the bottom of my heart. I never would have got here without you.

This $\mathrm{PhD}$ is dedicated to the memory of those who were always so supportive and who would have been so proud, I miss you every day: my wise and perfect Aunt Pippa, and my Grandpa, the kindest man in the world. 


\section{1}

\section{Introduction:}

\section{Technological history and the production of iron in Africa}

'In this way, and through Uganda as a half-way house, the totally savage Negro received his knowledge of smelting and working iron, all his domestic animals and cultivated plants (except those, of course, subsequently introduced by Arabs from Asia and Portuguese from America), all his musical instruments higher in development than the single bowstring and the resonant hollowed log, and, in short, all the civilisation he possessed before the coming of the white man - Moslem or Christian - 1000 years ago' (Johnston 1902: 486).

Given such assertions, it is hardly surprising that African iron production was largely ignored in early colonial Africa. Where the practice was recognised, colonial administrators generally disliked African populations self-sufficiently producing iron tools (especially weapons), while missionaries disapproved of iron production because of its perceived association with ancestral spirits and sexuality. In addition, all too often smelting lay outside the direct control of African rulers and chiefs through whom colonial authority was exercised. As a result, the technology was actively discouraged. Just as significant, however, was the impact that the import of European scrap metal had, eliminating the need for metal working communities to undergo lengthy and laborious smelting operations. Whilst former smelting communities retained knowledge relating to iron working and a pride in their traditions, the rest of society moved on.

In such a cultural atmosphere it is not so surprising that early colonialists regarded iron production as insignificant and largely devoid of style, and believed that any sophisticated technological knowledge originated from a non-African source. In turn, this suggested that once learned, African smelting traditions would be intrinsically unchanging. The implications of this timeless perspective will be considered below, but for the moment it is relevant to focus on the more general implications of the above that technology is a socially mediated and constituted process. Thus, not only must we 
understand and explore the science that underscores the process, but we must also understand the social context within which the technology is undertaken.

A central theme in the study of technology is the embedded nature of these technical practices within wider social and cultural contexts: "Technology is not only the material means of making artefacts, but a dynamic cultural phenomenon embedded in social action, world views, and social reproduction" (Dobres and Hoffman 1994: 211). Thus every stage of any technological process represents the choices made by artisans who are influenced by numerous variables including the requirements of the consumers, as well as belief systems held within the community (Akinjogbin 2004: 61; Collett 1993: 508-511; Rowlands \& Warnier 1993: 522-543). As such, technologies reflect the artisan's position within society and the way in which they perceive the world around them. For the archaeologist therefore, the identification and detailed understanding of a contextualised technology provides an invaluable and unique window into past society (Childs 1991b: 332; Childs \& Herbert 2005: 287-293).

Colonially constructed concepts, typically featuring a movement of people from the 'civilised' North, bringing all forms of complex society and technology to sub-Saharan Africa, still prevail across much of the African continent and the western world (Hall 1990; de Maret 2005: 420-428; Reid \& Lane 2004; Stahl 2005: 1-13). Such theories imply a lack of indigenous African social or technological traditions, and have, in the case of metallurgy, been fuelled by the study of the African ethnographic record: one of the unfortunate consequences of visiting recent technological traditions has been the projection of techniques back into time, encouraging notions of continuity of technological practice and parallels between recent records and artisans working over a thousand years ago.

Where used appropriately, the African ethnographic record (including modern reconstructions) can illustrate the wealth of diverse technological choices within iron production (e.g. Buleli 1993; David et al 1989; Haaland 1985; Rowlands \& Warnier 1993; Schmidt 1997). In fact, the variety of employed methods and materials evident in every stage of the chaîne opératoire, including mining, smelting and forging, are "mind-boggling" (Childs \& Herbert 2005: 284). The rich ethnographic accounts provide 
a fascinating insight into the innovative and adaptive iron production technologies operated across Africa, from small, bellows-powered bowl furnaces with no substantial superstructure (e.g. Celis 1987: 59-78, Schmidt 1997: 239-240), to natural draft furnaces with shafts constructed to a height of over four metres (e.g Martinelli 2004) and everything in between. For example, Malawian, two-stage iron production utilising tall natural draft and then forced draft furnaces has been identified, alongside variation in technique from one end of the country to the other (van der Merwe \& Avery 1987: fig. 1.1). A unique, distinctive furnace design employing a single, vertical tuyere characterises smelting in Northern Cameroon (David et al 1989: fig. 1.2), whilst overtly decorated furnaces intended to symbolise the female form,define production in Nyanga Zimbabwe (Chirikure \& Rehren 2004: fig. 1.3). These significant, synchronic variations in production are well known, ethnographically defined, smelting strategies. However, long-term, diachronic variation in technological traditions has received relatively little attention, and this is certainly the case in East-Central Africa, where this study is focused.
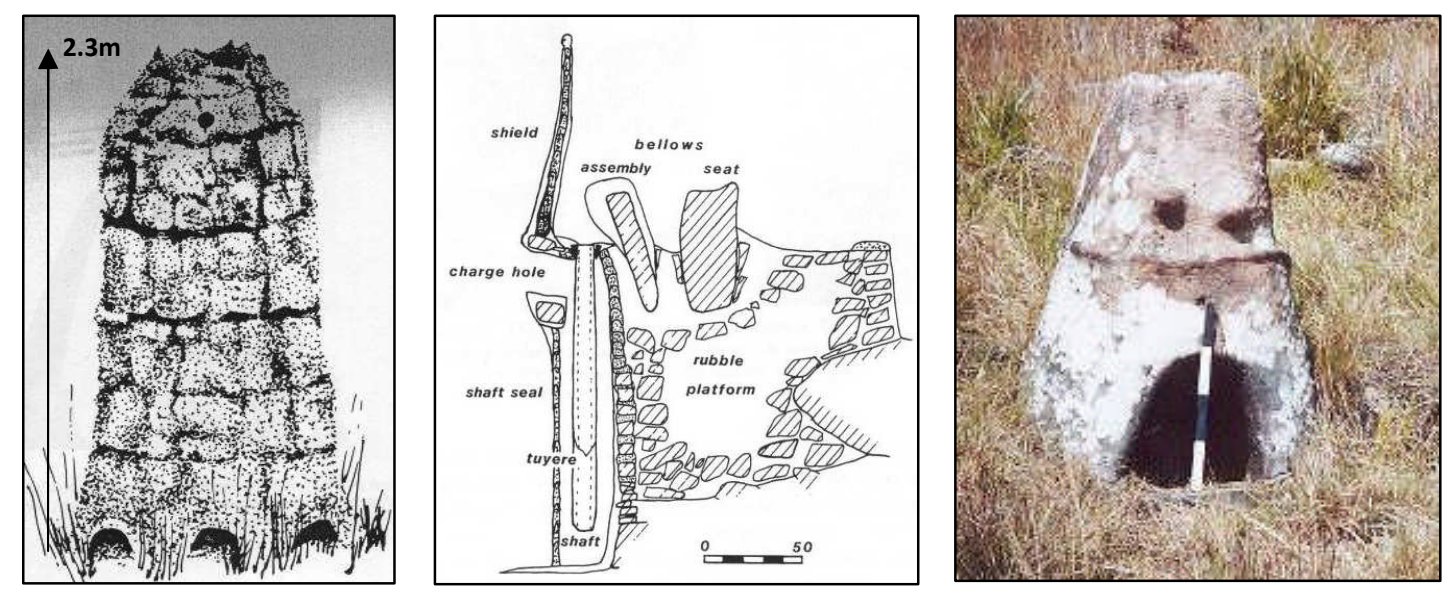

Fig 1.1 (left) Chulu primary furnace observed in Malawi (after van der Merwe \& Avery 1987, author's scale)

Fig. 1.2 (middle) Unique furnace design in Northern Cameroon (after David et al 1989)

Fig. 1.3 (right) Nyanga furnace with breasts (after Chirikure \& Rehren 2004) 
Over the last forty years archaeometallurgy in Africa has flourished. The production of iron in Africa has been recognised in academia as sophisticated and distinct from European ferrous metallurgy, whilst colonial perceptions of inefficient, illogical production have been challenged (Childs 1996; Iles \& Martinón-Torres 2009; Okafor 1993, 2004; Rehren et al 2007). However, two fundamental research focuses have shaped and dictated many of the studies undertaken to date: first, the African ethnographic record, the effects of which have been described above; and second, the sensationalist and emotive topic of the 'origins' of iron production in Africa. The search for the earliest African iron production has resulted in decades of research attempting to solve what remains essentially an unanswerable question, although some areas within the continent do have particularly detailed chronological frameworks for early iron production (Jemkur 2004; Maes-Diop 2004; Okafor 1993; Quéchon 2004). Many would agree that more detailed excavations and dating are necessary (in places such as Meroë), before more generalised conclusions concerning the origins of iron in African can be considered (Killick 2004, 2009). The result is that technological change and transformation that may have taken place within African technological traditions over the last two and a half millennia, have been largely ignored, at least in eastern Africa (although in western Africa the case is very different, e.g. Okafor 1993, 2004). Considering the significance of technology as, "the formal integration of the behaviours performed during the manufacture and use of material culture which, in its entirety, expresses social information" (Childs 1991b: 332), the potential for studying change within technology is substantial.

Focusing on a reconstruction of the archaeometallurgical record of Southern Rwanda, this fine resolution research will develop a long-term perspective and contextualised understanding of technological traditions. The two thousand years of data that will be utilised here illustrates the complex technological knowledge held within the region, and will demonstrate the intricate dynamic between iron production and social, economic, political and religious change.

The following sections of this introductory chapter explain the significance of iron and then positions the importance of this metal within an African, and specifically 
Rwandan, setting. The aims and objectives of this research are laid out, followed by an outline of this thesis.

\subsection{The significance of iron as a material}

To comprehend the importance of iron in society, materials used to produce both utilitarian and decorative objects prior to the appearance of ferrous metallurgy, will briefly be considered. In eastern Africa this includes stone, wood, bone and ceramics. Many of these materials display utilitarian and economically favourable characteristics; for example, stone provided relatively resilient, sharp-edged tools such as arrow-heads for hunting and scrapers for cleaning bones and skins. Such materials were manipulated and used successfully in both functional and decorative roles for thousands of years. However, with the advent of iron, a material emerged which had properties "far in advance" of anything that had gone before (Craddock 1995: 234).

Although the production of iron was more labour and resource thirsty than existing technologies, it provided a material that could be worked in a variety of manners to produce tough, durable objects (Delmonte 1985: 238; Gale 1969: 2-5). The properties of iron, and the vast array of objects that could be produced from it, have led this material to be termed the "most important metal" (Alexander \& Street 1968: 8). From hoes to axes, spears to arrow heads, bracelets to bells (Celis 1987: 170-240; Kanimba \& Kabwete 2000) the malleability of heated iron meant that a smelted bloom could be easily forged and shaped into desired objects with good tensile strength (Keller 1994: 61 ). Thus, the practical significance of iron lay in the vast array of objects that could be produced, as well as the superior mechanical properties of these objects.

It is reasonable to suggest that, in the majority of cases, as a new and rare material, iron objects would have been confined to high-status goods produced by a prestige technology (Pleiner 2000: 23-30). The effects of this metal on day-to-day activities initially may well have been limited, while socio-economic identities may have been constructed in terms of those who had iron, and those who did not. Gradually however, as iron objects became more common, perhaps as the number of artisans with the 
knowledge of how to produce iron grew, or when new more exotic items entered the higher echelons of society, production increased and the wider significance of iron on society began in earnest (Pleiner 2000: 30-35). Across the world, once iron became more commonly produced, agriculture, warfare and often ritual systems were gradually transformed.

The recognition of the importance of iron in World history has been growing since the pioneering work of researchers such as Cleere (1963, 1970, 1971, 1983), Pleiner (1969, 1978, 1993, 2000) and Tylecote (1962, 1965, 1968, 1987). Archaeometallurgy succinctly defined as, "the study of archaeological metal processing waste and intentional metal products in order to reconstruct the processes used, to infer the technological skill of the manufacturers, and to derive a record of the human choices, decisions, and influences involved in metal production and use" (Miller \& van der Merwe 1994: 33) has rapidly developed, so that today it is actively taught in universities across the world. Excavations are taking place in all continents as academics strive to understand how, when and why our ancestors made iron, and how, in turn, technology relates to broader social contexts.

The application of the discipline, combining scientific analysis with the theory and techniques of archaeology (Cleere 1970: 4), has the potential to reveal many parameters of past metallurgical technologies. These include the nature of the raw materials used, the fuel types, the refractory nature of technical ceramics (ceramics utilised during iron production), smelting parameters, and the quality and quantity of the material produced (although limitations apply - see Craddock 1995: 13). Interest in the sub-discipline, and in archaeology as a whole, has led to new approaches (for example the use of experimental archaeology) and new scientific techniques (including the application of luminescence dating to provide a more precise chronological framework) which allow for a greater level of understanding of the archaeometallurgical record. As more archaeometallurgical investigations are carried out, both the dates and the realms of technological complexities that are found to have existed in the past are constantly being pushed back. 
The significance of iron to society has been demonstrated on a global level. Possibly the earliest use of iron was as ochre pigment: colourful iron oxides with yellow-red-brown shades which have been used throughout history as a pigment in art and as decoration for ceramic vessels. Cave art making use of ochre in South Africa has been dated to around 75,000 years ago (Henshilwood et al 2009), whilst it has been suggested that, 'the bright colours of ochre (yellow-red) must have had symbolic meaning' (SchmandtBesserrat 1980: 144).

Later, in its solid natural state, meteoric iron (an iron-nickel alloy that fell from space) was used by various groups who would heat and hammer the material into desired shapes. In Egypt, objects making use of meteoric iron have been dated to as far back as 4000 BC (Van der Merwe 1980: 465), while in Mesopotamia and Anatolia, the first smelted iron objects dating to the $3^{\text {rd }}$ millennium BC have been found (Pleiner 2000: 7).

Beyond Europe and the Near-East, the earliest evidence for iron production in India appears to indicate the production of iron objects at around 700-800 BC, although production phases dating to earlier times in the east of the country have been dated to around the end of the second millennium BC (Craddock 1995: 265; Tripathi 2001: 65$85)$. From the early first millennium AD, iron producers in India began to produce huge iron and steel objects, the Delhi Pillar - a 6 ton inscribed column reaching over $7 \mathrm{~m}$ high - being one of the most famous (Craddock 1996: 266). At this time in India, known as the Golden Period, imperialistic rule had led to far reaching social, economic and political changes, reflected in the "all-round growth of metallurgical skills" (Tripathi 2001: 243).

In China two iron artefacts have been excavated in graves dated to $500 \mathrm{BC}$. These graves are contemporary to the ancient state of $\mathrm{Wu}$ which lay around the mouth of the Yangtze River (Wagner 1996: 51-96). As in other parts of the world, iron became such a vital and integral economic, political and social asset that in the second century BC, iron production was monopolised by the state to ensure control of the industry and its outputs (Wagner 2001: 1). 
From this brief global perspective, metallurgical and societal advances, and subsequent intensification, appear to be linked. In addition, ethnographic observations across the world indicate that at least in later times, at the local level, artisans played the role of innovators and motivated producers (e.g. Barndon 1996; Celis 1987; Childs and Dewey 1996; Schmidt 1997; Tripathi 2001: 148-166). This stands in contrast with the traditional notion of metallurgy as a dispassionate, utilitarian entity. Furthermore, by moving beyond the mere transposition of interpretive models derived from European and Near Eastern archaeology, it is now recognised that the challenge lies in understanding non-Western technologies through the coalescence of systematic scientific investigation alongside specific, local and cultural insights.

\subsection{Iron in Africa}

We are far from understanding the role that the production of iron played in the history of Africa on a continental scale. This is due to a number of factors including the vast areas of the continent still unexplored by archaeometallurgists; the lack of sound preservation of sites and stratigraphy; and also due to various problems with dating iron production sites (explained further in chapter 5). However, across Africa, archaeometallurgists have worked in certain areas for decades to illuminate and understand the function and position of iron within the last two millennia, and most agree that the advent of ferrous metallurgy within African communities was an “important turning point" (de Barros 2000: 147) directly impacting on many vital facets of society, including the development of agriculture (e.g. Akinjogbin 2004; EzeUzomaka 2007; Ige \& Rehren 2003; Okafor 2004; Reid \& Maclean 1995; Schmidt 1996; Schmidt \& Avery 1983; Schmidt \& Childs 1985; Whiteman \& Okafor 2003). Ultimately, iron production provided not only tools and weapons which helped transform agricultural practices and warfare, but as such created a new technological facet to the world, one inextricably linked to social, economic, political and environmental transformation (e.g. de Barros 2000: 147-198; de Maret 1985; Childs 1991a,b,c, 1999; Childs \& Herbert 2005; Childs \& Killick 1993). 
Throughout the African continent, early research biases such as a focus on Stone Age archaeology led to excessive generalisations (e.g. Robertshaw (ed) 1990). Today however, archaeologists appreciate the benefits of more focused and contextualised studies with a sound control over data (e.g. Iles \& Martinón-Torres 2009; Perret \& Serneels 2009) as a necessary step before larger hypotheses or explanations can be posed. For example, rather than seeking the early origins and spread of iron metallurgy in Africa, region-specific studies are key to building up the broader picture of a diverse mosaic of socio-technological histories. Such studies can address iron production as a technology complexly embedded within various layers of society. Furthermore, applying a multidisciplinary approach to the archaeological record is increasingly considered as vital in placing data within its broader context. Thus, linguistic, ethnographic, experimental and historical work are all utilised to the overall benefit of the research. In addition, scientific analytical methodologies and more refined dating techniques allow for a significantly more detailed reconstruction of archaeological pasts and chronological frameworks.

Within the Great Lakes region of Africa, within which this research is based, a variety of different methodological approaches have been applied to the archaeological record: palaeoecology, archaeobotany, zooarchaeology, ceramic studies and linguistics have all been used to gain intricate insights into the past (e.g. Desmedt 1991; MacLean 1994/5; Philipson and Bahuchet 1994/5; Reid 1994/5; Schoenbrun 1994/5; Taylor and Marchant 1994/5; Van Grunderbeek et al 1983; Van Grunderbeek \& Doutrelepont 1988; Van Neer 2000; Wotzka 2006). Additionally, numerous archaeometallurgical studies concerned with the history of iron production throughout the wider area have been conducted, approaching the archaeological record from historical, ethnographic, experimental and science-based analytical perspectives (e.g. Celis 1987; Chirikure 2002; Collett 1993; Craddock et al 2007; Killick 1996, 2001; Reid \& MacLean 1995; Schmidt 1996, 1997; Schmidt \& Childs 1985). Thus, a basic understanding of the evolution of the area on social, economic, political, cultural and technological levels has been tentatively reached: the development of agriculture and pastoralism, the gradual transformation of societies into Kingdom networks, and the role of healers and belief systems are all issues that have been addressed (e.g. Chrétien 2003: 85-139; Vansina 
2004). The dynamic, inextricably linked nature of the wider region as a whole, with lakes and rivers serving as communication channels and passages for trade and information (Kusimba \& Kusimba 2005: 402) has also been illuminated. The resulting picture allows for an understanding of iron production, iron producers, and the iron objects themselves, within the complex history of the general area. The approach to, and the profound importance of such studies, has recently been summarised:

"The ultimate aim is to adopt a rigorous, interdisciplinary and international scientific approach to restore to Africa that profound marker of civilization thus far denied to it: iron ... For Africa, there are some essential issues at stake: historical truth, recognition of its heritage and the possibility of revitalization through its endogenous mastery and knowledge of iron" (Diène 2004: 20).

\subsection{Iron in Rwanda}

The work of Van Grunderbeek (1988; Van Grunderbeek et al 1983, 2001; Van Grunderbeek \& Doutrelepont 1988; 1992), Van Noten (1972, 1982, 1983; Raymaekers $\&$ Van Noten 1986) and Celis (1987), and before them Hiernaux (Hiernaux \& Maquet 1957; 1960), Maquet (1965), and Nenquin (1967) provided insights into early ceramic and iron production in Rwanda, and offered an intriguing window into Rwanda's past (the metallurgical history of Rwanda is reviewed in detail in chapter 4). Over two thousand years of iron production has been identified, including intricate and diverse furnace designs and complex ritual associations defining the country's metallurgical history. However, over the last twenty to thirty years there has been no opportunity to build on the results from earlier projects. Years of turmoil culminating in the 1994 genocide and subsequent unrest left the country and the population devastated, and created a situation wholly inappropriate for archaeological studies.

Following a fluorescence of research in the 1960s, 1970s and early 1980s, the terror of Rwanda's recent history (Eltringham 2004; Gourevitch 2000; Mamdani 2001) left significant questions concerning the archaeological and archaeometallurgical past of Rwanda, unanswered. While at an initial glance this consequence of the troubles can be 
considered as minor, in actual fact today the population relies on previous archaeological excavations to create a sense of pride in the past. However, government support for the Institute of National Museums of Rwanda is more substantial than most countries in sub-Saharan Africa, with seven active museums, two further planned museums, and an annual International Museums Day in May (http://www.museum.gov.rw/). Therefore, to identify and fill these gaps in the knowledge of the past through archaeological research, and so provide data which can contribute to the growing desire to appreciate Rwandan history, is a priority.

For decades, despite the substantial records and descriptions of iron smelting furnaces dating to the Early Iron Age in Rwanda, limited scientific analysis of samples had been carried out to understand the smelting parameters achieved during the production episodes (e.g. Craddock et al 2007). Furthermore, while a number of furnaces had been dated to the $8^{\text {th }}-11^{\text {th }}$ centuries AD (Van Grunderbeek et al 2001: 293; Van Noten 1983: 37), and recognised as distinct from those used during the Early Iron Age (discussed in detail in chapter 4), no research had been undertaken to reveal the technologies in operation following the production of iron in earlier times. In addition, whilst the high demands for iron generated by the later kingdoms were recognised, alongside the symbolic importance of iron to the power structures of these political entities across the region (e.g. de Maret 1985), no investigation had previously been conducted into the industries which had supported this kingdom and met its demands (or how these related to the extensive variation noted in the ethnographic record).

Twelve years after the genocide and following Rwanda's immense efforts to move forwards from those terrible times, in 2006 my proposal for the first archaeometallurgical project since the early 1980s was submitted to the Institute of National Museums of Rwanda. The response was enthusiastic, largely based on the conviction that much of Rwanda's past troubles were caused by distorted colonial histories which were fabricated to enforce the Eurocentric attitudes of the time. The role of history and the construction of a historical past are issues taken very seriously, and in a country with no history syllabus taught in schools at present, it is now widely accepted that archaeology represents the appropriate resource through which Rwanda's heritage 
be accessed, disseminated and then protected. Therefore, between 2006 and 2007, six months of fieldwork was conducted to investigate the iron smelting traditions of Southern Rwanda.

\subsection{Aims and Objectives}

The aims of this $\mathrm{PhD}$ are to illuminate and understand the technological and social history of iron production traditions in Southern Rwanda. The information generated through this archaeometallurgical investigation is used to consider the impact of iron within this region, and in turn the impact the changing demands of society had on the iron industries themselves. Analytical results generated through the application of systematic archaeometallurgical sampling and investigation are contextualised within the broader context of Rwandan and Great Lakes Iron Age history, through the exploitation of the relatively new links between the disciplines of archaeology, science and history. Whilst recognising the complex relationships between these three strands of information (Martinón-Torres 2008: 15-16), this study aims to produce an inclusive understanding of ferrous metallurgy within this area and provide the foundations for future large-scale research on Rwandan iron technology. As such this research has three main areas of academic enquiry:

1. To understand iron production that occurred in the region during the Early Iron Age in terms of the technical parameters of the technologies, through the analysis of newly generated data. A number of iron objects excavated within an archaeologically related burial (Giblin 2008; 2010; et al forthcoming), alongside early iron production sites previously excavated within the region, provide the opportunity to appreciate smelting and smithing techniques, as well as the type of objects being produced during this era.

2. To consider the middle period of the region's metallurgical history, of which next-tonothing is currently known. From approximately AD 700 to 1500, the transformation of iron production traditions is generally recognised but not understood (Van Grunderbeek et al 2001: 293; Van Noten 1983: 37). Emerging linguistic and ceramics evidence suggests simultaneous societal change during this period across the Great Lakes region 
(Posnansky et al 2005; Schoenbrun 1993, 1998). This research aims to reveal the connections between technology and society during this period.

3. The Nyiginya Kingdom (the expanse of which roughly corresponds with today's modern borders of Rwanda: Vansina 2004), was one of the most significant sociopolitical entities of the Great Lakes region from about the sixteenth century, interacting and in some cases competing with the Kingdoms of Burundi to the south, Karagwe to the east, and Buganda and Bunyoro to the north. However, nothing is known of how the iron production industries met the growing demands of the kingdom for iron (not least to supply the armies in their well documented wars of territorial expansion), or how the increased supply of iron stimulated the kingdom's cultural, economic and political growth.

As well as providing a new academic facet to the growing body of knowledge concerning past African iron production traditions, this $\mathrm{PhD}$ includes a significant social aim: to directly tackle colonial legacies such as the common public belief encountered by the author across the wider region and in the Western World that Europeans brought science and technology to Africa.

\subsection{Structure of the thesis}

Chapter 1 has provided an introduction to this $\mathrm{PhD}$ thesis. A brief consideration of the history of iron production around the world has been provided to emphasise the significance of this metal on a global scale, followed by an overview of iron in the Great Lakes Region of Africa, and specifically in Rwanda. The aims and objectives, as well as the structure of the thesis, are outlined.

Chapter 2, 'The practicalities of iron production: the potential of archaeometallurgical studies' outlines the chaîne opératoire of iron production using an ethno-experimental smelt carried out during this research as a general model for bloomery iron smelting. The scientific principals of iron smelting alongside the archaeometallurgical remains available for study are considered in terms of their analytical potential. This is followed by a discussion of the room for choice within the various stages of African iron 
production. The value of this type of research and insights into past technologies which can be revealed through the application of a range of analytical methodologies are ultimately provided, alongside the limitations of archaeometallurgy. Thus, the potential for such an archaeometallurgical study as this is clearly summarised.

The theoretical frameworks underpinning this $\mathrm{PhD}$ are discussed in chapter 3, which begins with a discussion of the relevance of Western archaeological theory and approaches to the African archaeological record. The concept of technology is explored in an attempt to reach a definition and understanding of this complex notion. Once this is established, various ways in which technological traditions can be studied and used as social, cultural, economic, ritual and political markers within the archaeological record are considered. Issues of technological style, chaînes opératoires and the role of the individual are also explored. Consequently, the possibility for this study to elucidate meaning from technology and the identification of technological traditions, and offer a sound diachronic interpretation of technology within Rwandan history is explained.

Chapter 4 focuses on the archaeological and archaeometallurgical record of the broader Great Lakes region of Africa, with a focus on Rwanda, by evaluating the literature concerning this region. A chronological framework is established, allowing for a review of the role and significance of iron technology within the Great Lakes region. Thus, this chapter provides the geographic and broader cultural background within which the metallurgical history of Rwanda is ultimately considered.

The methodological approach to this research is described in chapter 5. This begins with the rationale behind the applied field approaches, including survey, site selection and observations, excavation and sampling strategies. Laboratory techniques including sample preparation, analyses and interpretation are described, as well as the dating methods used. Throughout the chapter, limitations of the methodological approaches are considered to provide a critical approach to this research.

Chapter 6 is divided into seven sections dealing individually with the six iron production sites investigation within this $\mathrm{PhD}$, concluding with a broad comparison 
between the data. The individual sections introduce the location and then discuss the results of macroscopic observations, and laboratory analysis of samples taken from all aspects of the archaeometallurgical and archaeological remains. Each section ends with an interpretation of the technological stages of iron production represented at each site, including any absolute dates obtained, as seen through the archaeometallurgical examination.

Chapter 7 contextualises the results from this research within the history of the broader Rwanda and Great Lakes region, to reveal the technological traditions and the human dimensions of the processes. The position and impact of iron production technologies in Rwanda's past will be illuminated.

The final chapter (chapter 8), presents a summary of the main findings of this research. A discussion concerned both with the lessons learnt from this research, and how future work should progress in this area to maximise the potential of archaeological and archaeometallurgical research, concludes this study. 


\section{2}

\section{The practicalities of iron production: the potential of archaeometallurgical studies}

Perhaps more than any other African technology, iron production generates a significant quantity and diversity of products that survive in the archaeological record. The waste from producing stone tools readily survives, but there are no other by-products of the tool-making process and debitage can be difficult to decipher from naturally occurring material. The manufacture of ceramics also usually leaves no trace of specific production phases, while many other technologies, such as building construction and basketry, utilise degradable materials which do not survive well in the tropical regions of Africa. The process of iron production on the other hand, creates a variety of material remains that can be subjected to a range of analysis. Detailed macroscopic, microscopic and chemical analysis of the remains of the production processes allow for a reconstruction of various fundamental aspects of the original technological sequences, such as the style of the furnaces constructed, the types and quantities of ingredients that were added to the smelt, and further engineering parameters (e.g. Fluzin 2004; Tylecote 1992). This information, combined with the broader historical and cultural context, provides an insight into various features of past technological systems, which in turn may offer a reflection of the past social, ritual, economic and political landscapes within which iron production was embedded. It is this archaeometallurgical potential - the potential of understanding technological characteristics of past societies and the ability to contextualise this information - that makes the study of iron in archaeology so rewarding.

This chapter provides a generalised explanation of the various stages of bloomery iron production, even though, owing to its higher archaeological visibility, smelting will be the main focus of this research. This description is illustrated by an ethno-experimental smelt commissioned by the author in Rwanda, which serves to highlight the requirements necessary for the production of iron. The experiment was carried out in Buramba (central Rwanda) after a rumour was heard by the author of a group of men 
who claimed to be able to smelt. André Nyandwi led the smelt, having helped his father in the 1970's with reconstructions for European observers. A number of old men who had also been involved in these reconstructions formed part of the team, which was twenty men strong. The details of the smelt, including laboratory analysis and quantifications, are currently in preparation for publication. A technical explanation of the smelting process follows, considering the processes of ore reduction and slag formation, as well as an explanation of the resulting archaeometallurgical record and how this can be used to understand original smelting events. A consideration of choices within African iron smelting is then provided, and finally a number of problems encountered when approaching the archaeometallurgy of iron production are explored to develop a critical appraisal of this research.

\subsection{Bloomery iron production: an overview}

The following processes, collectively referred to as the chaîne opératoire of iron production (i.e. the operational sequence: see chapter 3) were involved in the production of an iron hoe in Rwanda. Within each of the stages of production outlined below, the archaeological and ethnographic records have demonstrated significant levels of variation across the African continent (e.g. Childs and Herbert 2005; Childs \& Killick 1993; Schmidt 1996, 1997; Vogel (ed.) 2000). Thus, the illustrations provided below portray one set of choices and one stylistic approach to the technology, although they also reflect the general technical principles of bloomery iron production recorded in Rwanda in the twentieth century (Celis 1987).

\subsubsection{Charcoal production}

Charcoal was the fuel used in African bloomery production. In this particular experiment, twelve men worked for over a week to produce the charcoal for the smelt. Eucalyptus trees (clearly not indigenous to Africa, although for the smelters this posed no problem) were felled, chopped up and stacked into large piles of wood. These were covered in soil and leaves, and slowly combusted over a period of approximately 5 days. The smouldering heaps required 24 hour supervision, with the person responsible constantly monitoring the combustion rates and covering and exposing the wood as appropriate (see fig. 2.1). 

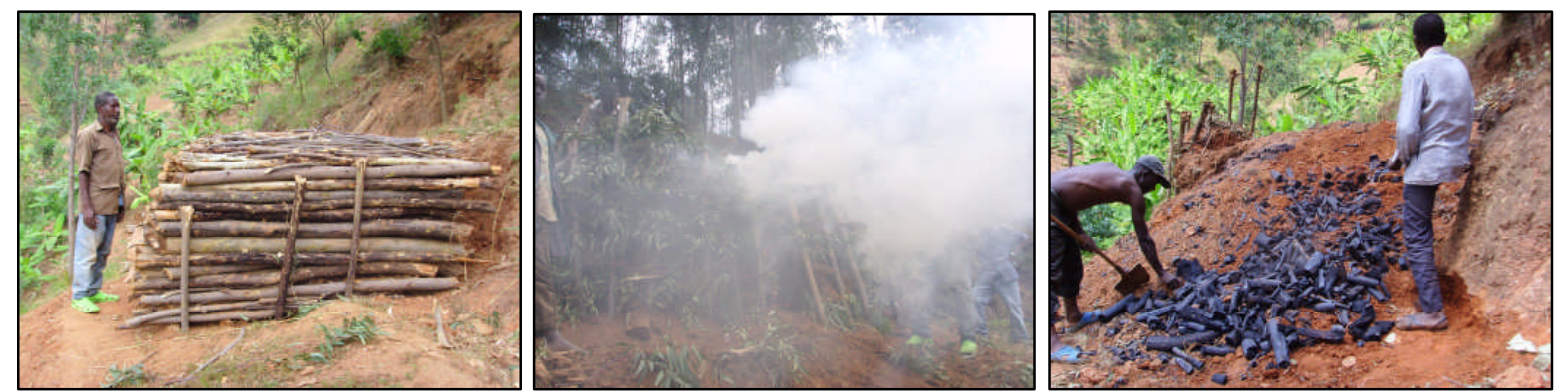

Fig. 2.1 Charcoal production: the wood stacked (left), slowly combusted (middle), and the charcoal revealed (right)

\subsubsection{Tuyere production}

The tuyeres (pipes through which air is channelled into the furnace) were fabricated from a specific clay source near the summit of a nearby hill, which had apparently been found to produce the best tuyeres in the past. This was a different clay source from that used to fabricate the furnace structure itself. The clay was not tempered with any other material, although macroscopic and microscopic inspection revealed a significant amount of naturally occurring quartz grains (up to $1-2 \mathrm{~mm}$ in diameter) visible in the clay matrix. Water was added to create a malleable material which was then moulded around an ash-coated stick with a diameter of approximately $4 \mathrm{~cm}$. The resulting tuyeres were left to dry in the shade for 2-3 days (fig. 2.2). They averaged $30 \mathrm{~cm}$ in length, were $5 \mathrm{~cm}$ wide at the narrow end (which would fit inside the furnace), and flared to $15 \mathrm{~cm}$ wide at the opposite end (to allow for the bellows to be placed almost inside, so as not to lose too much of the air supply). Each tuyere took approximately 15 minutes to fabricate.
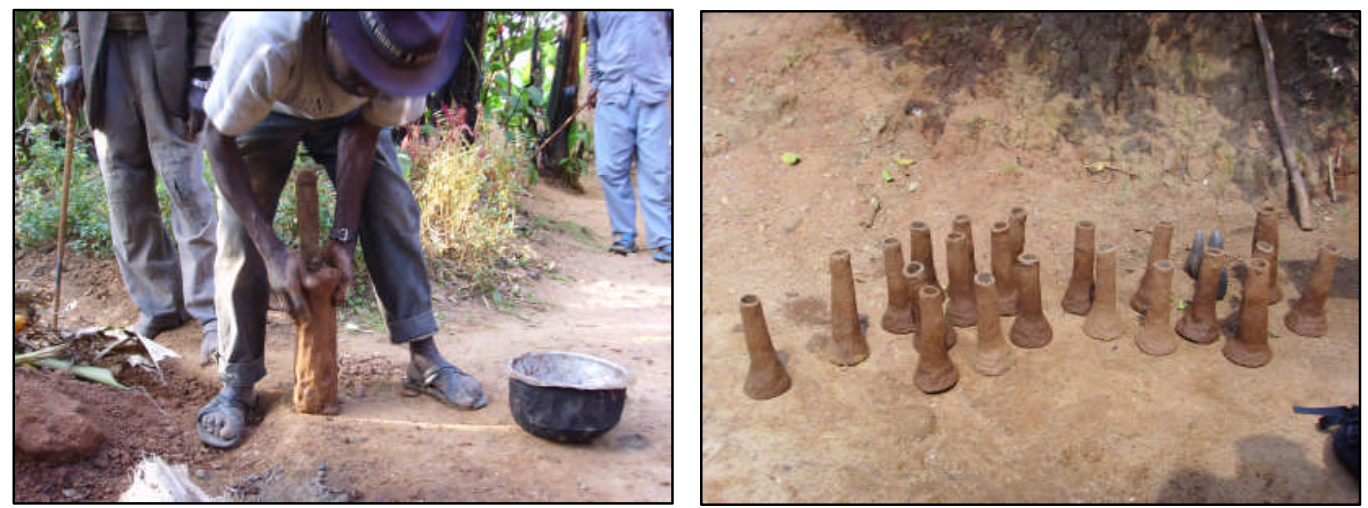

Fig. 2.2 Tuyere production (left), and the finished products (right) 


\subsubsection{Air supply}

Six wooden bellows, each with double pots, were provided for the smelt from people living around the area (in each case, the bellows had belonged to grandfathers who had smelted). Sheep skins were purchased because goat skins, although being more readily available, were apparently not elastic enough for the job. The skins were hammered, buried for two hours, and then greased with cow butter to ensure sufficient suppleness for the hours of bellowing to come. Long lengths of fibre from the ficus tree (the same tree used to make bark cloth) were used to attach the skins to the bellow pots, and bamboo sticks were fastened to each for the men to hold while they were pumping the air into the furnaces. Banana fibres were tied to the tops of each of the bamboo sticks to prevent the hands of the men operating the bellows rubbing too much (fig. 2.3).
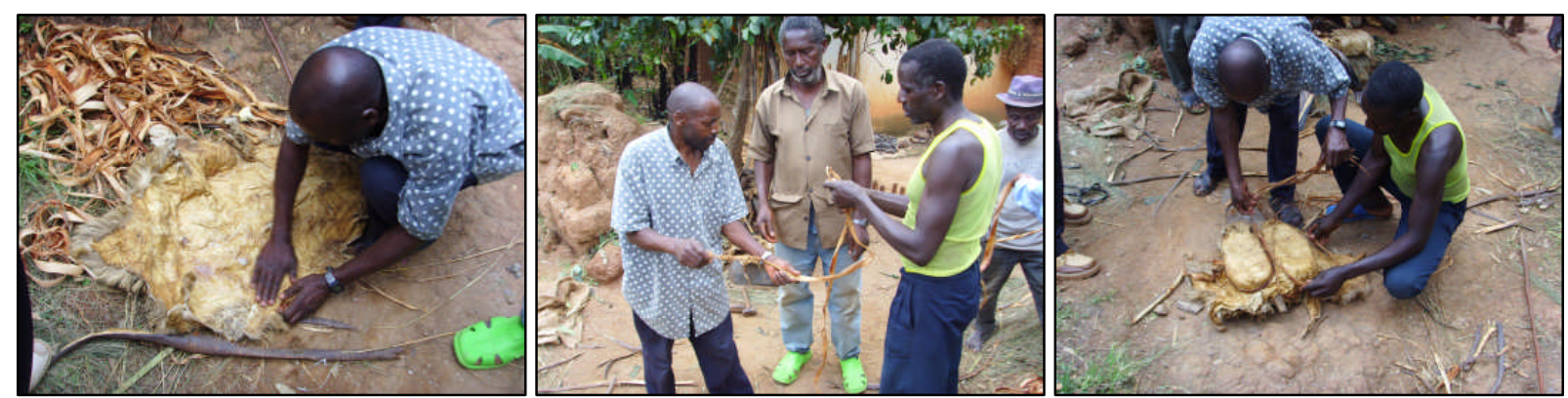

Fig. 2.3 Assembling the bellows: greasing the skins (left), preparing the rope (middle), and attaching the skins (right)

\subsubsection{Ore collection and preparation}

When the ore sources to be used were discussed amongst the group it was found that a number of good sources were known, scattered around the wider area. A total of five ore sources were used, including magnetite black sand from a river bed, and hematite rich, red-silver coloured dense rocks which were collected from ground level. The haematite-rich rocks were all beneficiated by pounding it into grains the size of sand (fig. 2.4) and any material which looked to be impure was removed by hand.

Fig. 2.4 Beneficiating the ore

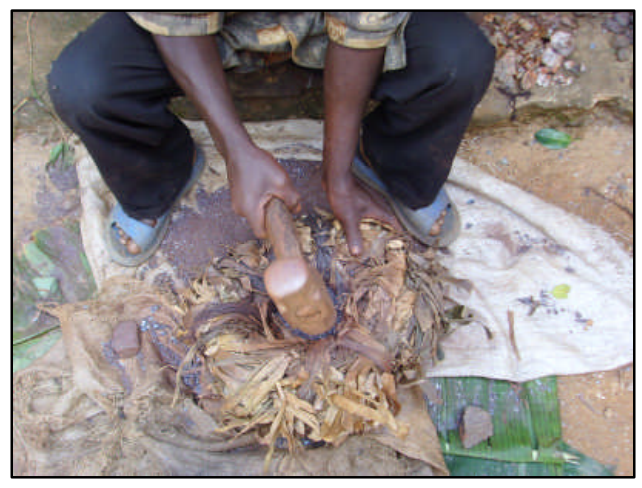




\subsubsection{Constructing the furnace}

The men in the group used clay collected from a nearby valley bottom to construct the furnace. The clay was once again, not tempered, but was processed for a number of hours by having the air squeezed out to prevent the clay from cracking. This was done by the younger men taking it in turns to force the air out of the clay by foot. The area for the furnace pit was marked out and then excavated with a hoe. The pit was then lined with the clay, and then the younger men formed cylindrically shaped clay rolls that the older men coiled around to form the circumference of the furnace shaft (fig. 2.5). The furnace pit was $28 \mathrm{~cm}$ deep and $76 \mathrm{~cm}$ in diameter. The furnace wall was $10 \mathrm{~cm}$ thick at the base and $6.5 \mathrm{~cm}$ thick at the top of the shaft. From the bottom of the furnace pit to the top of the shaft was $98 \mathrm{~cm}$. Overall, $277 \mathrm{~kg}$ of clay were used to construct the furnace, which took two days to complete. The furnace was then covered with banana leaves and left to dry for four days.
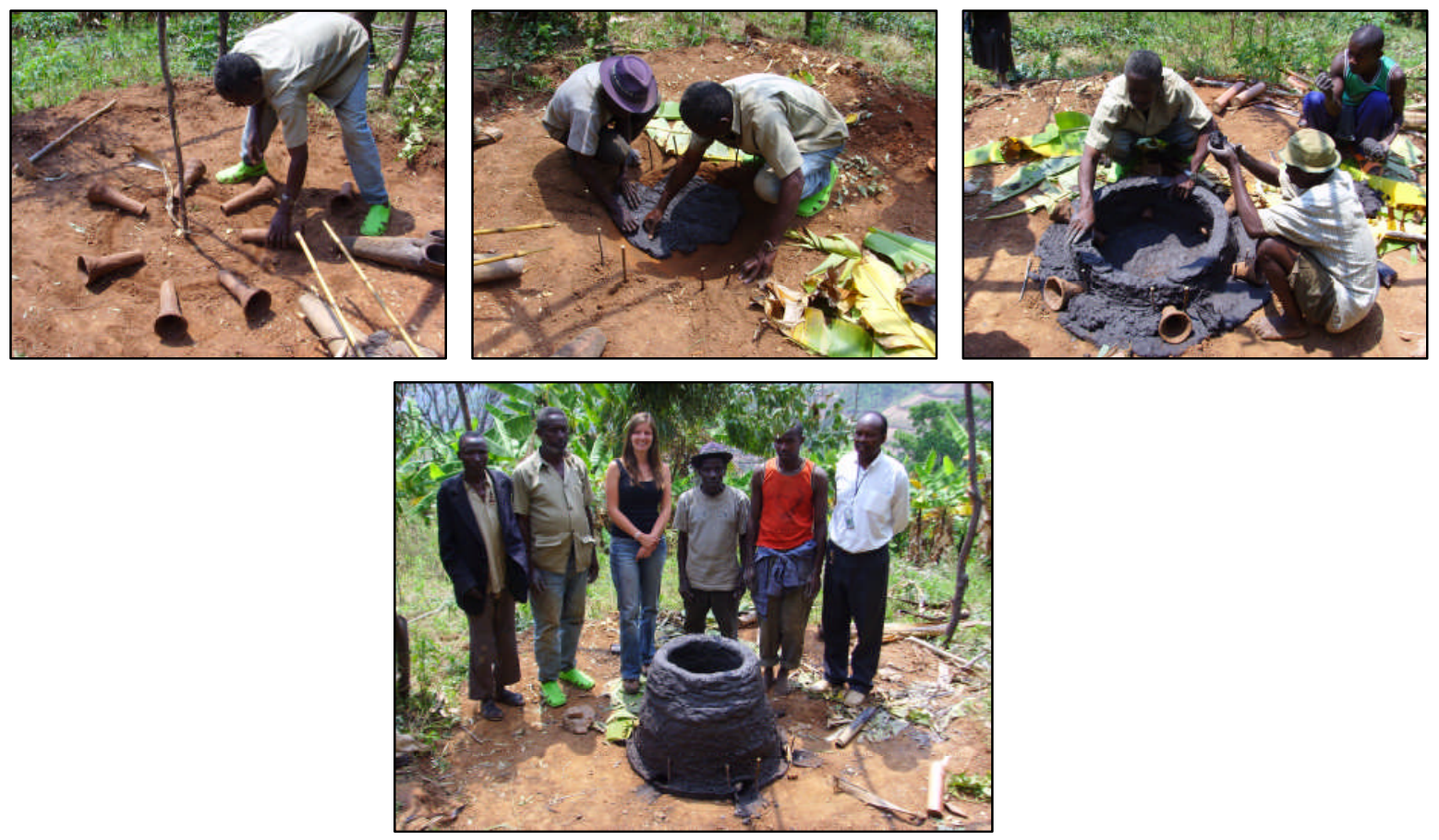

2.5 Constructing the furnace: laying out the tuyeres (top left), lining the furnace pit (top middle), building up the superstructure (top right), the finished furnace structure and the team (bottom) 


\subsubsection{Smelting}

The six tuyeres were inserted into the furnace, protruding approximately $8 \mathrm{~cm}$ inside the structure at roughly a $30^{\circ}$ downward angle to ground level. The bellows were placed in front of the tuyeres and held in place with a large rock to prevent them moving around when the operation began. The procedure commenced when fibres and herbs were placed inside the furnace and lit to slowly heat the structure. Following this, over a period of seven hours, approximately $228 \mathrm{~kg}$ of charcoal and nearly $40 \mathrm{~kg}$ of ore were added (usually in a pattern of approximately $2-3 \mathrm{~kg}$ of charcoal, followed by 2 handfuls of ore). The men operated the bellows furiously to the rhythm of chanting, singing and clapping, and frequently the men working the bellows smoothly swapped with those waiting for their turn, ensuring a constant, rapid air supply to the furnace (fig. 2.6). It quickly became apparent that the wooden bellows would catch fire because flames were escaping down the tuyeres, so the older men took it in turns to keep the ends of the wooden bellows wet to prevent this happening. After six hours of smelting, approximately $1 \mathrm{~kg}$ of crushed sandstone was added to the smelt. When the ore had run out, and the flames above the furnace were more of a blue colour rather than the redorange that they had been for the majority of the smelt, the process was deemed finished by the head smelter. A significant amount of charcoal was added and allowed to burn down. The shaft of the furnace superstructure was prised off using long four large wooden sticks of roughly $2.5 \mathrm{~m}$ in length, to reveal white-hot iron blooms, to the cheers of all present. A feast of banana beer and goat followed. 


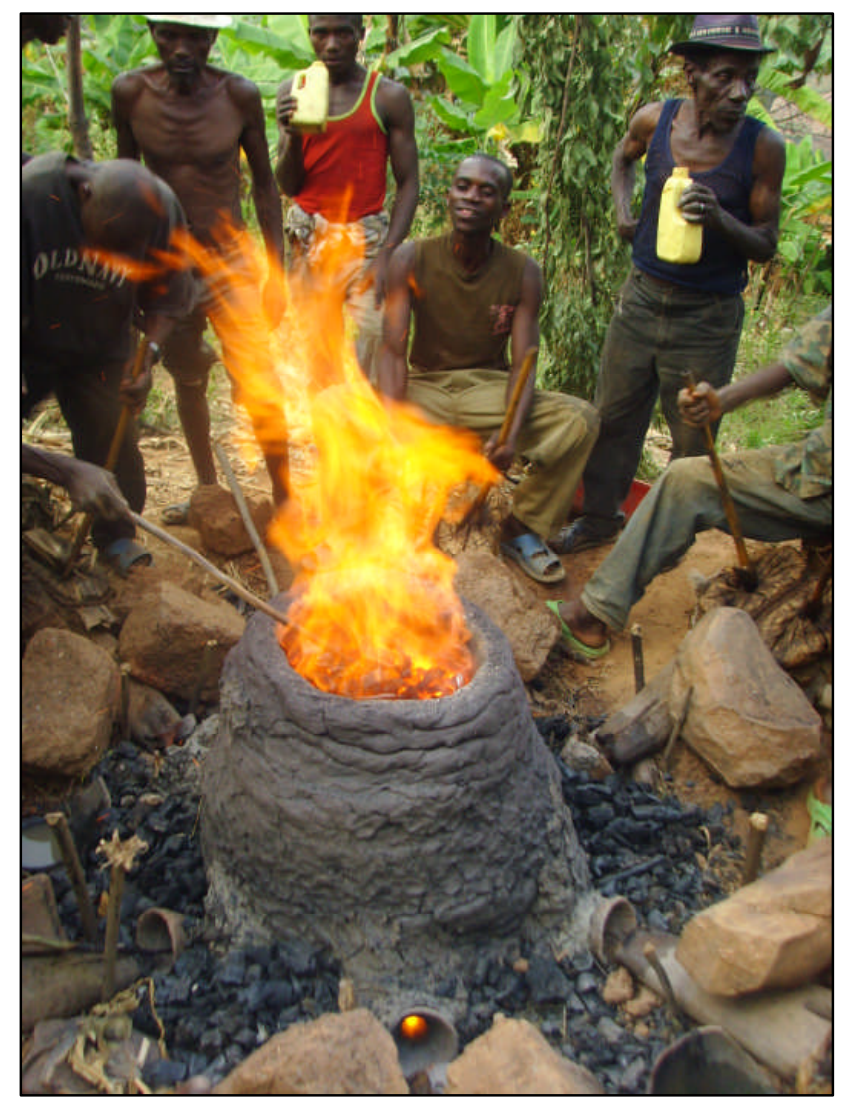

Fig 2.6 The smelt in progress

\subsubsection{Smithing the bloom}

The following day, one of the blooms was forged into a marriage hoe (fig. 2.7). For this a small pit was dug and filled with charcoal. A spare tuyere and a set of bellows were used to heat the forge and a bloom was placed in the fire. For 40 minutes the iron was constantly heated and then placed on the stone anvil and hammered into shape. Sandstone was crushed onto the anvil towards the end of the process. 

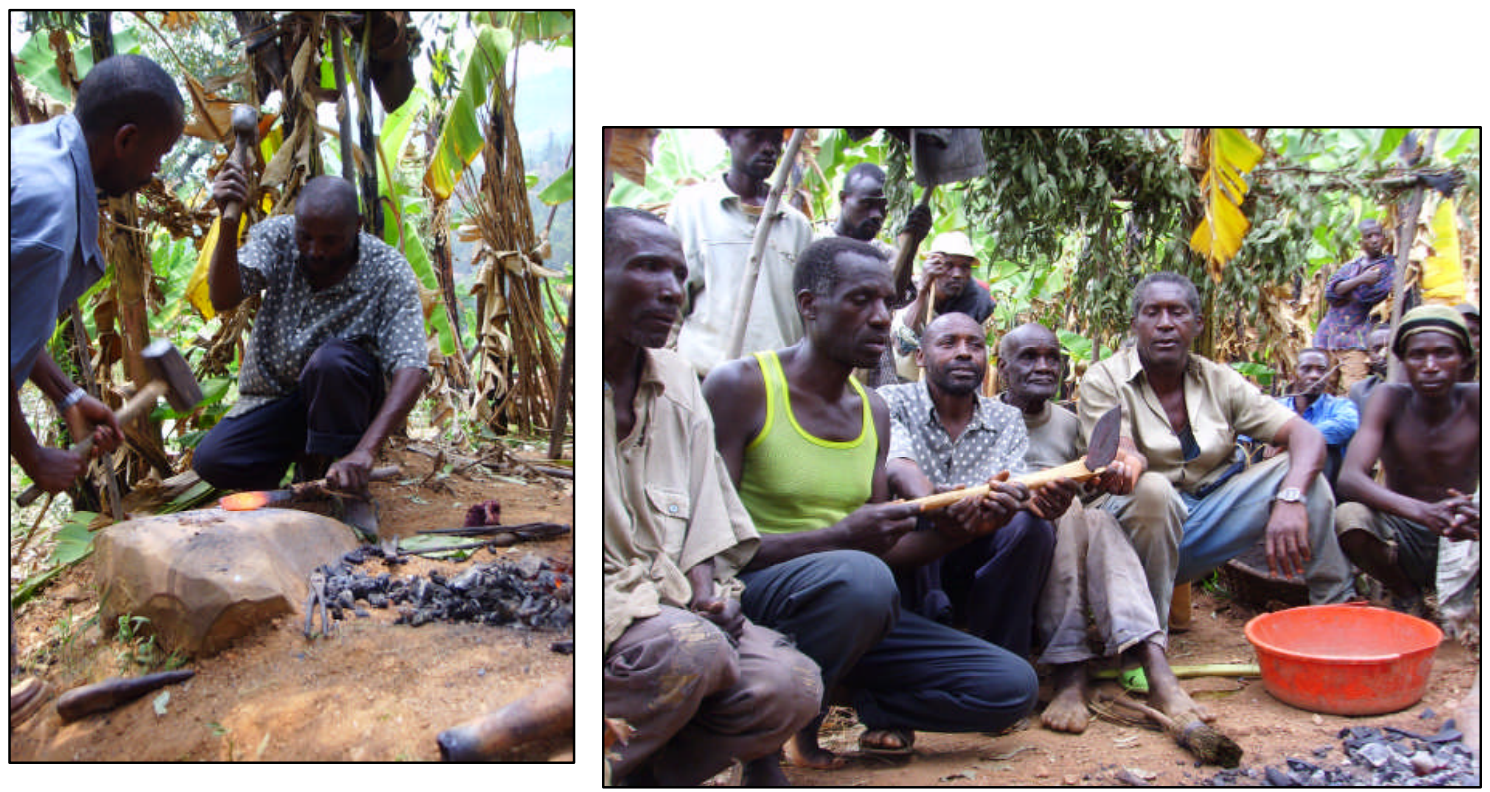

Fig. 2.7 Forging the marriage hoe (left), and the finished product with some of the successful team (right)

The waste products from this smelt (i.e. what will be archaeometallurgical remains in the future) included slag, technical ceramics, charcoal, the anvil and hammerscale. In order to understand the potential of these remains for reconstructing the original smelting event, and the choices made by the smelters, an explanation of the reduction of iron ores into iron metal is provided, and then each of the waste products and products of a bloomery smelt is considered in terms of their archaeometallurgical potential.

\section{2: Bloomery iron smelting: a technical explanation}

In order to understand and interpret the archaeometallurgical remains of iron production and to appreciate them within a chaîne opératoire, it is important to understand the stages involved in the production process: that of reducing iron oxides (e.g. $\mathrm{Fe}_{3} \mathrm{O}_{4}$, $\mathrm{Fe}_{2} \mathrm{O}_{3}$ ) into iron metal (Fe) by subjecting the material to specific temperatures and reducing conditions that allow the production of an economically viable amount of metal (Joosten 2004; Tylecote 1992).

Iron production in Africa made use of the 'bloomery process', also called the 'direct method', which produced iron in a solid state directly through the reduction of iron ore to a workable iron bloom, while resulting in a significant amount of iron being lost into 
liquid slag. This is in contrast to the 'indirect method' of the industrial-era European blast furnaces, which involve a two stage process of smelting the iron ore to produce a high carbon molten metal, and then decarburising this to produce workable iron. Although some African smelting furnaces were capable of producing the high temperatures required to produce molten iron (around $1535^{\circ} \mathrm{C}$ ), they could not do this for a significant period of time whilst maintaining structural stability and producing workable iron metal. The application of the bloomery process was the alternative to this impossible task. During this procedure, the furnaces maintained temperatures of around $1200{ }^{\circ} \mathrm{C}$ (sufficient for the melting of gangue components forming slag), and reached suitable redox conditions within a stable structure, able to maintain the process for a period of time long enough to make the endeavour economically viable (i.e. to ensure enough iron was produced from an undertaking requiring so much in terms of raw material and labour, as illustrated in the example of smelting provide above).

The term 'bloomery smelting', is derived from the desired product, the iron bloom, which is an impure mass of metal that can be forged mechanically to remove impurities and obtain the desired artefact shape (Fluzin 2004: 70-71). The chemical reactions described below provide an idealised sequence of what takes place during a bloomery smelting episode to produce iron. During this process, the waste products from the ore (including the gangue materials as well as a significant amount of iron oxides), part of the technical ceramics, any fluxes added and fuel ash, melt to form liquid slag. This liquid slag envelops and protects the solid particles of metallic iron that progressively coalesce in the form of a bloom.

The oxygen thirsty carbon in the charcoal combines with oxygen (using the energy supplied by the heat) to produce carbon monoxide, creating a reducing atmosphere (due to the high $\mathrm{CO}$ to $\mathrm{CO}_{2}$ ratio produced by the partial combustion of the charcoal).

$$
\mathrm{C}+\mathrm{O}_{2} \rightarrow \mathrm{CO}_{2}
$$

The carbon monoxide then combines with the oxygen in the iron oxide, producing lower oxides, until metallic iron is formed, as summarised by Joosten (2004: 7-9): 


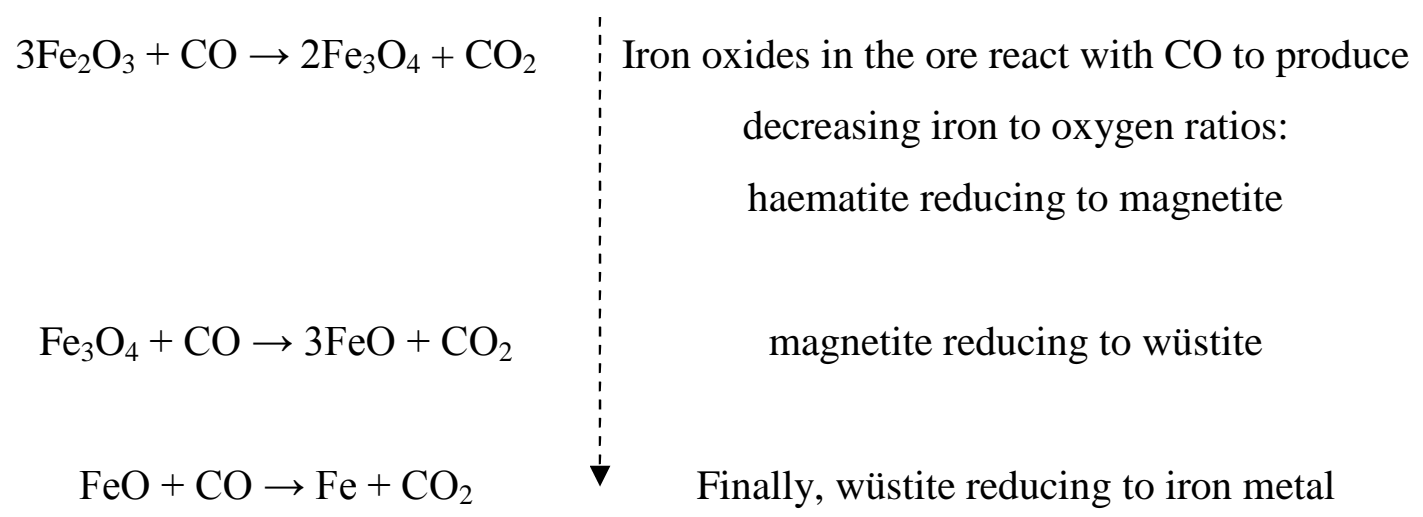

As the charcoal burns, the ore moves down through the various reducing and temperature zones within the furnace (Pleiner 2000: 134), producing the reactions listed above and resulting in the production of a solid iron bloom and liquid slag.

In order for the above reactions to take place, a number of requirements are necessary. These, and the archaeometallurgical remains they would leave behind, are considered below:

- Slag

The principles behind the bloomery process rely on the production of a liquid slag that facilitates the removal of gangue impurities as a liquid, while protecting the forming iron bloom from re-oxidising as the smelt progresses (Joosten 2004: 7). As described above, this slag thus comprises mainly of part-reduced or unreduced iron, as well as gangue materials from the ore (Serneels \& Crew 1997; Tylecote 1987: 47-52), the absorption of various amounts of ceramic input from both the furnace wall and the tuyeres (Crew 2000: 38-48), any fluxes added to the process (Tylecote 1987: 107-108), and fuel ash. Therefore, macroscopic, microscopic and chemical investigations of iron slag can reveal much about the original smelting charge and the processes it underwent (Fluzin 2004; Serneels 1993). The size and shape of a slag block can indicate the size of a furnace pit within which it solidified, whilst any flow patterns or layering effects can indicate that the slag was tapped. 
Due to the particularly high melting temperature of silica and alumina (the main slag components after iron oxide), a substantial amount of the iron oxides in the ore was 'sacrificed' into the slag, in order to obtain a compositional mixture that would remain liquid at lower operating temperatures of around $1200{ }^{\circ} \mathrm{C}$. The $\mathrm{FeO}-\mathrm{Al}_{2} \mathrm{O}_{3}-\mathrm{SiO}_{2}$ ternary diagram below (fig. 2.8) demonstrates the optimum liquidus temperatures for this reaction to occur, with the two 'optimum zones' combining, "low-temperature melting with low-viscosity compositions" (Rehren et al 2007: 212), nominally ranging from $1148^{\circ} \mathrm{C}$ to $1200{ }^{\circ} \mathrm{C}$.

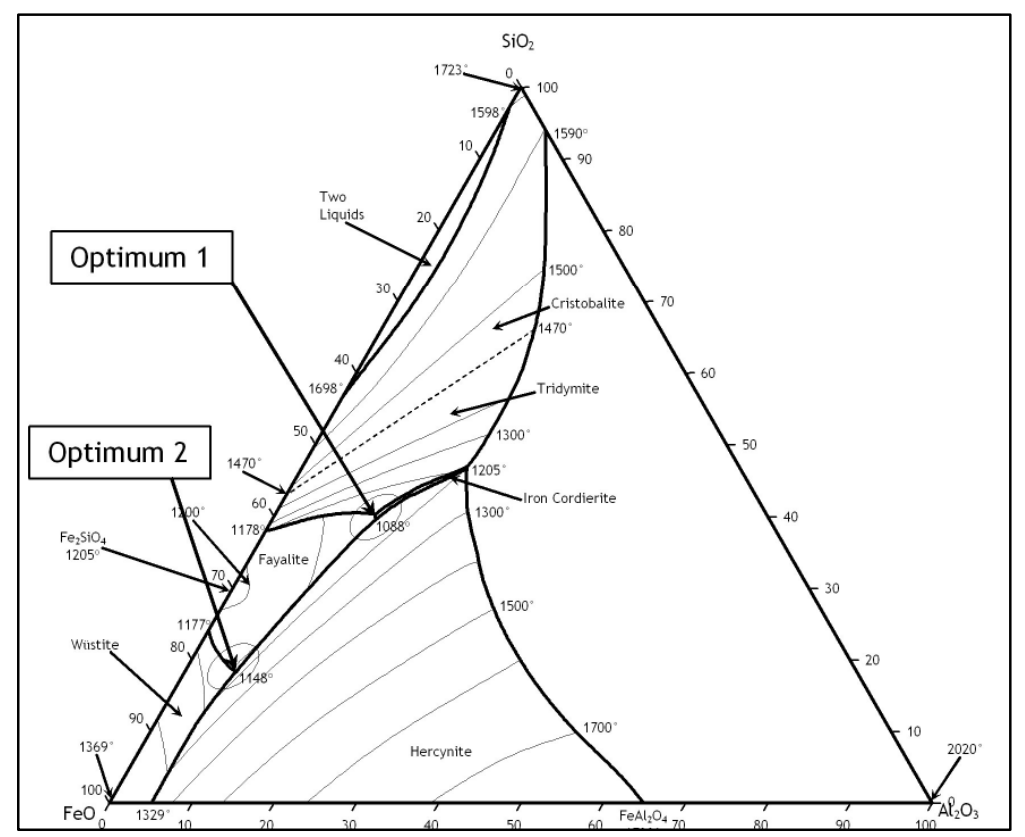

Fig. 2.8 $\mathrm{FeO}-\mathrm{Al}_{2} \mathrm{O}_{3}-\mathrm{SiO}_{2}$ ternary diagram illustrating, 'optimal engineering solutions for bloomery smelting' (after Rehren et al 2007: 212)

As the slag solidifies, the chemical components will begin to crystallise following a specific sequence, and resulting in a specific structure which depends on the chemical make up as well as the cooling regime. The first crystals to form will be those with the highest freezing temperature, and other phases will form depending on the composition of the residual melt. The slag microstructure thus reveals the phases present, their sizes and arrangement, all of which is informative of the charge and operating parameters. 
In the case of ferrous slags, the most typical crystal is the iron oxide-silica olivine fayalite $\left(\mathrm{Fe}_{2} \mathrm{SiO}_{4}\right)$ as these are generally the main components. The larger the fayalite crystals, the relatively slower the cooling rate has been - the crystals have had more time to form and grow. In a fast cooling slag the fayalite crystals will begin to form and freeze quickly, creating a skeletal, lathy appearance. As this phase begins to crystallise, the remaining liquid slag composition changes. Another common phase in iron smelting slag is wüstite $(\mathrm{FeO})$, representing unreduced iron oxides. This phase appears as dendrites or globules of varying sizes. Usually angular hercynite crystals $\left(\mathrm{FeOAl}_{2} \mathrm{O}_{4}\right)$, make up a relatively significant portion of slag in cases where the alumina levels are high. Alkali-rich phases such as leucite $\left(\mathrm{KalSi}_{2} \mathrm{O}_{6}\right)$ and kalsilite $\left(\mathrm{KalSiO}_{4}\right)$ may form depending on the levels of potash within the slag and the ratio of alumina to silica within this phase. The final phase to solidify during slag cooling is the dark glassy matrix, comprised of minor oxides and fuel ash components such as potash and lime.

Identifying the phases described above, in conjunction with the bulk chemical composition of slag samples, therefore provides a window into the ingredients; how these behaved, and under what kinds of conditions, within a smelting episode.

Of course, a major factor when approaching the analysis of slag is a consideration of how representative of the entire smelting episode a particular (invariably very small) slag sample actually is. Throughout a smelt, which can last from a few hours to a few days, ingredients, temperatures, redox conditions and many other factors can evolve and change. Therefore, an arbitrary piece of slag picked up on a smelting site may not be representative of the original smelting operations (Humphris et al 2009). The methodology developed to compensate for this sampling dilemma is outlined in chapter 5 .

A final point to consider concerning the analysis of iron slag, before moving on to consider other archaeometallurgical remains is that, due to its durable nature compared to the remains of other stages in the chaîne opératoire and the significant amount of information that can be gleaned from analysing it, smelting has been prioritised in the global approach to past iron production. It is therefore essential to attempt to access 
other stages that contributed to the production of iron. In practice however, this remains problematic, as will be outlined below.

\section{- Ore}

The main ingredient required for a successful smelt is an economically viable ore, which is reasonably high grade (considering the significant amounts of iron lost into the slag during the process) and present as easily reducible oxides and/or hydroxides (Joosten 2004: 10; Tylecote 1987: 47-52). The collected ore, which has either been mined or collected at ground level, is sometimes beneficiated, usually by density or colour, so that the richer ore minerals are separated from the rest (Craddock 1995: 156166). The ore can also be roasted to enable iron hydroxides or carbonates to become more easily reducible iron oxides and to generally ensure even and successful reducibility during the smelting process (Craddock 1995: 167-169; Joosten 2004: 11). In the archaeological record, mining sites can provide invaluable information concerning the types of ores being mined and the techniques used for this stage of the chaîne opératoire (Childs and Herbert 2005: 282-283; Schmidt 1997: 53-59).

The identification and analysis of ores at a smelting site, in combination with slag analyses, can allow for more detailed reconstruction of mass balance calculations (e.g. Perret \& Serneels 2009) to quantify production. The technical efficiency of the techniques employed at a smelting site can also be more specifically understood when samples of ore are available. It has to be noted, however, that efficiency is contextspecific concept, in that smelting may not be primarily driven to maximise the metal output per ore unit, but rather it may be subject to other constraints such as saving fuel or labour, or simply the adaptation to specific socio-cultural expectations.

The main chemical components of iron ore, in addition to iron oxide, are typically silica, alumina, lime, magnesia, manganese oxide and phosphate, as well as a number of minor and trace elements such as sulphur and copper (Joosten 2004:10-11). Within slag composition, correlations between these oxides, or some of these, can enable an indication of the types of ores and, aside from this, the types of fluxes added or the contribution of technical ceramics to slag formation. Thus, the availability of ore 
samples increases the potential of archaeometallurgy to reveal important aspects of past metallurgical practices.

\section{- Fuel}

Another essential material requirement for the production of iron is fuel, which plays a number of vital roles during the smelting process. Fuel provides energy to enable high temperatures to be reached and maintained, a reducing environment, limited contamination of other elements, and to some extent, structural stability within the furnace. While fuel types such as animal dung, grasses and logs may not meet all of these requirements, charcoal provides the perfect fuel for smelting, being highly calorific, reducing and clean (Craddock 1995: 189; Joosten 2004: 11-12). Charcoal is produced by the incomplete combustion of the selected wood source to produce a carbon rich material perfect for combining with the oxygen held within the iron ores, and also retains a degree of structural strength to provide a platform on which the smelt itself can take place within the furnace. The main components of fuel ash which may be incorporated into slag are potash and lime (Stern \& Gerber 2004). Not only can the addition of fuel ash affect the chemical and microstructural dimensions of iron slag (and this can be identified within slag samples), but the identification of the types of fuel used in past smelting has the potential to allow for a reconstruction of environments and changing land use, depending on the tree species identified from sampled furnace charcoal (e.g. Van Grunderbeek \& Doutrelepont 1988).

Comparing palaeoecological data and modern data, landscape changes can be mapped over millennia, and the environmental impacts of such a fuel thirsty technology as iron production may be revealed. Such an approach, utilising charcoal found in furnaces, depends on the existing reference collection of identified tree species, past and present. Currently this reference collection is relatively limited in this region (Thompson and Young 1999), although there is a vast potential database of tree species in eastern Africa (as opposed to Rwanda, which is largely deforested and now planted with fast growing Eucalyptus to slow soil erosion). Of course, one of the greatest potentials of charcoal found within the archaeometallurgical record is for radiocarbon dating and for the 
construction of chronological frameworks for the archaeometallurgical remains themselves. Problems associated with radiocarbon dating will be reviewed in chapter 5 .

\section{- Technical ceramics - a furnace and tuyeres}

In general, technical ceramics, i.e. those used during iron production activities, can be defined as, "material intended to withstand during use temperatures greater than those normally encountered in a domestic hearth of the particular period under consideration" (Freestone 1989: 155). For a successful smelt, an enclosed environment, usually in the form of a furnace superstructure of some style, is required. This structure retains heat energy, maintains a reducing atmosphere, and controls the whole process by containing and funnelling the charcoal, ore, and molten slag. To allow the smelt to progress, the slag is allowed to flow either down into a pit, in the case of pit furnaces, or out of the side of the furnace structure, in slag tapping furnaces. The furnace must be able to maintain structural stability throughout the process for the smelt to proceed successfully, withstanding temperatures in excess of $1200{ }^{\circ} \mathrm{C}$ for long periods of time. In addition to a furnace structure, the other use of technical ceramics is for tuyeres, the pipes through which the air enters the furnace structure (either pumped through manually or channelled in by natural draft - see below).

To be able to withstand high temperatures for prolonged periods of time, the ceramics themselves would generally have to be as refractory as possible. Such clays could expect to display, on a microscopic level, a significant amount of tempering with quartz grains (added either naturally or manually), grog, grasses or even slag, to prevent fatal cracking (Childs 1989; Freestone 1989: 156-159; Joosten 2004: 15). Compositionally, silica and alumina can be expected to form main constituents, followed by iron oxide, which is lower in particularly kaolinitic clays, making them even more refractory (Rehren \& Papachristou 2003). Other oxides, notably magnesia, lime and potash, are also often present in relatively significant levels (Freestone 1989; Rehren \& Papachristou 2003), albeit in much smaller concentrations, particularly in more refractory fabrics. Accordingly, by observing both the chemical and microscopic details of technical ceramics in conjunction with domestic ceramics, much can be learned about 
the smelter's knowledge concerning the properties of various materials, and the lengths they went to, to ensure the success of the smelts.

Tuyeres and furnace pit lining can be relatively durable within the archaeometallurgical record because they are fired to high temperatures during a smelt. However, furnace superstructures and often the remains of furnace pits and small fragments of tuyere can easily be broken down over time by the weather, or constant human or animal interference.

When a variety of technical ceramics, especially alongside contemporary domestic ceramics, are found to have survived in the archaeological record, analysis of these materials can reveal much about the choices artisans were making in terms of resource selection and manipulation. The opportunity to analyse domestic alongside technical ceramics provides comparative material so that it becomes clearer whether or not specific clays were selected for iron producing activities (for example due to their refractory qualities), or whether the same clay or clay-mixture was in fact used to produce everything from cooking pots to furnace superstructure.

Where a range of structural remains are present, the spatial relationship between these can reveal much about the organisation of production (Schmidt and Childs 1985), and various stylistic choices, for example the use of decorated clay rolls to build furnaces dated to early periods of iron smelting in north-western Tanzania, Rwanda and Burundi (Schmidt and Childs 1985, 1996: 186-233; Van Noten 1983; Van Grunderbeek et al 1983, 2001).

\section{- Air supply}

To provide energy to heat the furnace charge to the required temperatures of approximately $1200{ }^{\circ} \mathrm{C}$, an air supply is required. The air supply is typically controlled either by forced draft (the air enters the furnace by being blown in by manually powered bellows) or by natural draft (whereby the air is sucked into the furnace due to the chimney effect created by the furnace itself). Usually, the air enters the furnace via the tuyeres. In the archaeological record, bellows are difficult to access. However, in the 
field, speaking with people in a former smelting area can often lead to them producing the bellows once used by grandfathers, and so information concerning the style of these, including whether they were made of wood or clay, for example whether they were one or two-pot bellows, and hand or foot operated, is accessible. Thus, with the correct investigative approach, the stylistic methods of this fundamental facet of the chaine opératoire of smelting can be revealed.

\section{- Iron}

Iron is relatively rarely found in the archaeometallurgical record in wetter regions such as equatorial Africa - the objects having either corroded, been too precious to be discarded, or often having been recycled again and again. Corrosion altering the macroscopic, chemical and microscopic nature of samples, is a specific problem for archaeometallurgists operating across wetter regions of the world. Occasionally however, part of an iron bloom is found on a site. This iron bloom can give some indication to the quality of the metal (Scott 1991), but ideally iron objects are required for a better understanding of this aspect - not least, the important discrimination between iron and steel, hardly visible in slag - and the smithing techniques being employed to produce the objects. Smithing slag cakes and microscopic hammerscale are the other ferritic materials to be found on iron production sites - the latter giving a clear indication that smithing was being carried out at the location. Running a magnet around a feature will immediately reveal if hammerscale is present.

\section{- Non-material requirements}

While all the above materials are essential in order to produce an iron object, nonmaterial requirements were equally crucial to ensure a successful smelting operation. A labour force, negotiated access to resources, and sometimes ritual/symbolic acts and ingredients such as medicines to ensure the success of the smelt were necessary for a successful smelt to be performed (e.g. Childs and Killick 1993; Rowlands \& Warnier 1993; Schmidt 1997: 231-261). As with the material requirements listed above, a vast array of variation for all of these dimensions of production existed across Africa, both temporally and geographically, as will be described below. 


\subsection{Variability in African iron production - room for choice}

Across Africa, high levels of variability have existed within each stage of the chaîne opératoire of iron production, as seen in the archaeological and ethnographic records described below.

Ore is often procured throughout Africa by digging a series of pits along veins deposits, as documented in Toro (Childs 1998), Buganda (Humphris 2004), South-West Ethiopia (Haaland 2004), North-West Tanzania (Schmidt 1997: 57), and throughout the rest of the continent (Cline 1937). Ore can also be found in river beds, often as black magnetite sands (fig. 2.9; Cline 1937: 26; David et al 1989: 191). However in some areas iron rich ore lays on the surface and can simply be collected by hand (Celis 1987: 95; Humphris in press). For example, the town in Rwanda around which this $\mathrm{PhD}$ investigation was conducted is called Butare, the word meaning 'iron stone' in Kinyarwanda (Vansina 2004: 16), and ore lies abundantly on the surface. In the archaeological record, evidence of mining or gathering ore from the surface has proved relatively difficult to identify, and so most of this evidence for variation comes from the ethnographic record. However, given the geological variations across the continent, it can be expected that in the past variation also existed in the way in which ore was obtained.

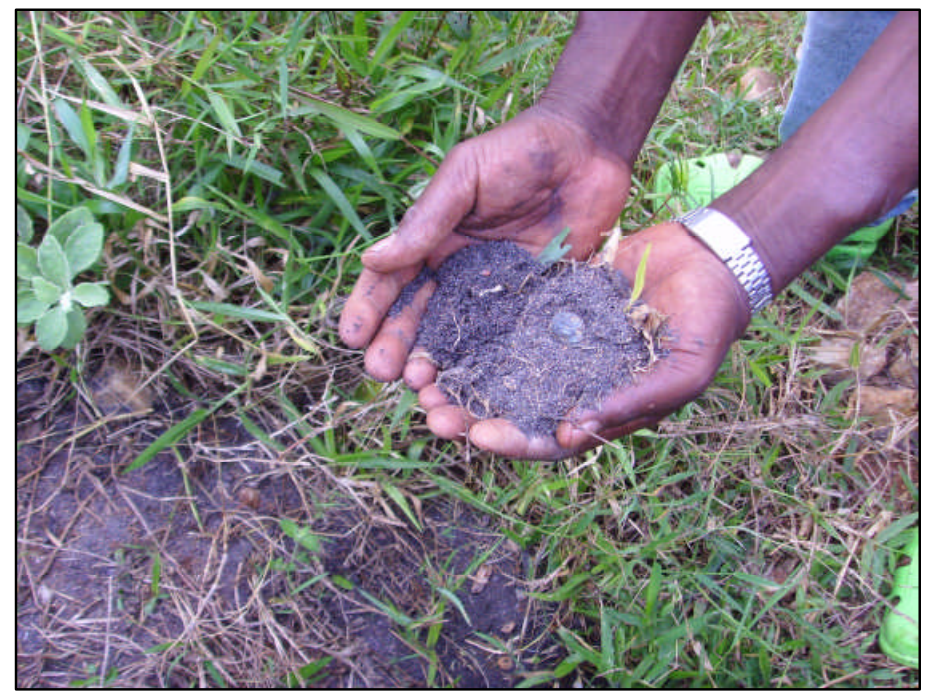

Fig. 2.9: Black sand found by a river in Rwanda 
The same principle applies when considering ore beneficiation or handling - again very difficult to identify in the archaeological record. In ethnographic accounts from across Africa, beneficiation (for example see Cline 1937: 30-31; Haaland 2004: 68; Schmidt 1997: 56-57) and ore roasting (for example see Celis 1987: 80; Cline 1937: 31; Schmidt 1997: 71-74) have been recorded.

There are many ethnographic examples of smelters in Africa mixing different types of ores, with some of these examples linked to various cosmological concepts, such as a hard and soft ore signifying male and female contributions to the production of an iron bloom. This has been noted among the smelters of Toro, while Childs' description of the process of locating ore illustrates the complex sociological backdrop to this venture, including ritual, ancestral and fertility related issues that have to be managed (Childs 1998). Herbert (1993:37-39), also describes the association of ores with concepts of fertility, with frequent references in the ethnographic record. The fertility associations of iron smelting, epitomised through the concept of the coming together of male and female to produce a bloom, is exemplified in other sections of the chaine opératoire (see below). However, not all ethnographic records talk of such issues, and of course the ethnographic record has to be applied with caution to the archaeological record (Lane 1994/5).

Studies throughout the African continent have highlighted the variation in fuel types used in pyrotechnological traditions, for example during pottery firing. Gosselain documents eight different fuels used to fire pots, from palmfronds in Nigeria to cow dung in Namibia, and logs in Congo (1992: 245). Sillar (2000), has illustrated the complex social and economic factors associated within fuel choice for Andean potters, and how these choices are embedded within wider aspects of societies such as agriculture and spatial organisation within houses. Again, while notoriously difficult to establish from the archaeological record or through archaeometric analysis, the types of fuel used and how these were prepared for the smelt may well have varied significantly from smelting group to smelting group, depending on what was available and whether or not specific tree species hold any particular medical/spiritual/technical significance. It can certainly be said that managing a smouldering heap of wood for days without 
allowing it to fully ignite or burn out requires specific skill and knowledge and is a craft specialisation in its own right.

In the Great Lakes region it is rare to find furnace superstructure left standing, due to weathering and erosion of the hilly landscapes and dense habitation and cultivation of the land. Sometimes, however, the remains of furnace bowl linings, visible as circular shapes in the ground, are found. The furnaces in operation throughout the Kingdom period in the Great Lakes region were for the most part pit furnaces that would probably have had some kind of superstructure, to be able to hold and process enough material to produce a slag block weighing over $100 \mathrm{~kg}$, such as those often encountered in the archaeological record (Humphris 2004; Humphris et al 2009; Reid \& MacLean 1995). However, technological variation within this smelting tradition was widespread throughout the region (Childs \& Herbert 2005; Schmidt 1996). Across the continent, the scale of technological variation is outstanding. Furnace style has been classified by some into main groups - furnaces without walls, furnaces with walls, tall natural draft furnaces, and furnaces with vertical tuyeres (Childs 1991b; Cline 1937; Killick 1981). At least 22 different types of furnace designs have been documented in the Niger bend alone (Martinelli 2004: 173). Variation within each group is spectacular when one considers why and how this technological variation exists (see chapter three), and what we as Africanist archaeological scientists can learn from it (see below).

It is not only the furnace shape and style which can exhibit a vast degree of variation but also the use of the furnace structure itself. For example, the furnace superstructure can be built as a portable feature, lifted off the furnace pit following a smelt and moved to the next pit. Furnace pits can be reused with a new superstructure built on top for the next smelt. Smelts can last for a few hours (in a small bowl furnace) to a few days (in a tall natural draft furnace: Martinelli 2004: 172-181). Bloomery smelting can even involve two stages, such as the style of iron producing developed by the Phoka and Chulu of Malawi, who have to contend with poor quality ore which is refined in the first furnace and then re-smelted in the second furnace (van der Merwe \& Avery 1987). Variability is also seen in the make-up of the charge, the fuel to ore and ore to flux 
ratios, redox conditions, bellowing rates and other parameters related to the operation of the furnace structure, many of which can be detected in the slag.

Also variable is the role of the tuyeres during the smelt (as well as the number of tuyeres used). For example, in the relatively recent observation of the Mafa iron smelters in North Cameroon, a single vertical tuyere was designed and built specifically to melt and flow into the smelting process, both to act as a flux and to create more room as the bloom grew upwards (David et al 1989). However, in Buganda, some smelting groups deliberately used kaolin to produce especially refractory tuyeres that would suffer very limited thermal erosion during the process (Humphris 2004). While natural draft furnaces often required numerous tuyeres, small bowl furnaces sometimes required only one or two tuyeres. Tuyeres were also incorporated into the cosmological view of some smelting groups, as components of the analogy to fertility, with the tuyeres viewed as phallic male components of the smelt, providing air (powered by men) to the female furnace to enable her to give birth to the iron bloom (Herbert 1993: 32-55; Schmidt 1997: 229). Bellows also exist in the ethnographic record in variable forms and are again sometimes associated with the male-female fertility aspects of some smelting groups (e.g. Childs \& Killick 1993; Cline 1937: 102-106; Herbert 1993: 32-55).

The specific clays necessary to produce technical ceramics were often sourced at specific locations (Childs 1989). These locations could have been under the control of a family or clan group, and so access could have been restricted and negotiated accordingly. As noted in the ethno-experiment described above, the construction of one single furnace could require over $200 \mathrm{~kg}$ of clay, again requiring a coordinated labour force. Knowledge of, and access to, ore sources could also presumably have been controlled, as would access to any ritual/medicinal items needed for a successful smelt, such as specific, perhaps fertility enriching plants. The extent of control over resources and coordination of required labour also varied from location to location. For example, during large scale, industrial iron production, a frequent and significant supply of charcoal would have been necessary. Whether it was the individual smelting groups who felled trees and produced charcoal, or if this was done by specialists, and how access to the tree sources were controlled and negotiated, would have been just one 
complex facet of the chaîne opératoire of iron production embedded within the particular society.

The addition of medicines to ensure a successful, fertile smelt has also been identified as a practice amongst some smelting groups both archaeologically and ethnographically. In the archaeological record, this is suggested by the very occasional occurrence of pots placed within the furnace pit, for example in Early Iron Age smelting furnaces excavated by Schmidt in Buhaya (1997: 253-268), in Rwanda by Van Noten (1983: 932) and in later furnaces excavated in Tanzania by Mapunda in Ufipa (1995). These have often been interpreted as medicine pots, placed below the furnaces to ensure a successful smelt and ward off evil spirits. A further non-material requirement of a smelt, widely documented in the ethnographic record, is the incorporation of fertility rituals and symbols, involved during iron smelting to ensure the success of the smelt (e.g. Childs \& Killick 1993: 325-329; de Maret 2004: 131-134).

Whether seasonal or continual, performed by shunned castes or revered groups, and on a large or small-scale, all aspects of the production process were variable (Childs \& Herbert 2005; Childs \& Killick 1993; de Maret 1985; Herbert 1993: 25-55). It is therefore clear that levels of heterogeneity existed not only in the physical ingredients and practical application of the technology, but also in the socio-economic context of iron production. Knowledge of the culturally and chronologically specific nature of iron production highlights the importance of archaeometallurgical reconstructions focused on distinct areas within key time periods. By building up our appreciation of small scale production regions and time periods with higher resolution studies in relatively small areas the broader picture may be reconstructed as data is accumulated.

\subsection{Some limitations with the archaeometallurgical record}

The above sections have highlighted some of the great informative potential of iron production remains (Crew 1991; Fluzin 2004; Schmidt and Childs 1985). As in any archaeological approach, however, caution must be exercised when trying to make 
sense of the past technologies. What follows are some of the main limitations relevant to this particular study.

It is relatively common for the remnants of iron production episodes, and especially iron slags, to be moved around and utilised by people living amongst these remains. Whereas, a hundred years ago people may have felt a sentimental affinity to the waste produce of such laborious work, these days slag offers many possibilities. In Rwanda and Uganda several uses for iron slag have been noted by the author: to provide foundations for houses (fig. 2.10); for use in new road foundations; to provide weights to prevent corrugated iron roof sheets from blowing away (fig. 2.11); to mark out flower and garden borders; for grave markers. Therefore, the mobile and useful nature of these archaeometallurgical remains must be considered when examining the archaeometallurgical record on a macroscopic level in the field and when considering field observations. While an isolated cluster of slag blocks may represent the work of a group of smelters who tried to keep their work secret, it may also represent the work of the more recent land owner, moving the blocks into their current position to avoid breaking a hoe, or a toe.
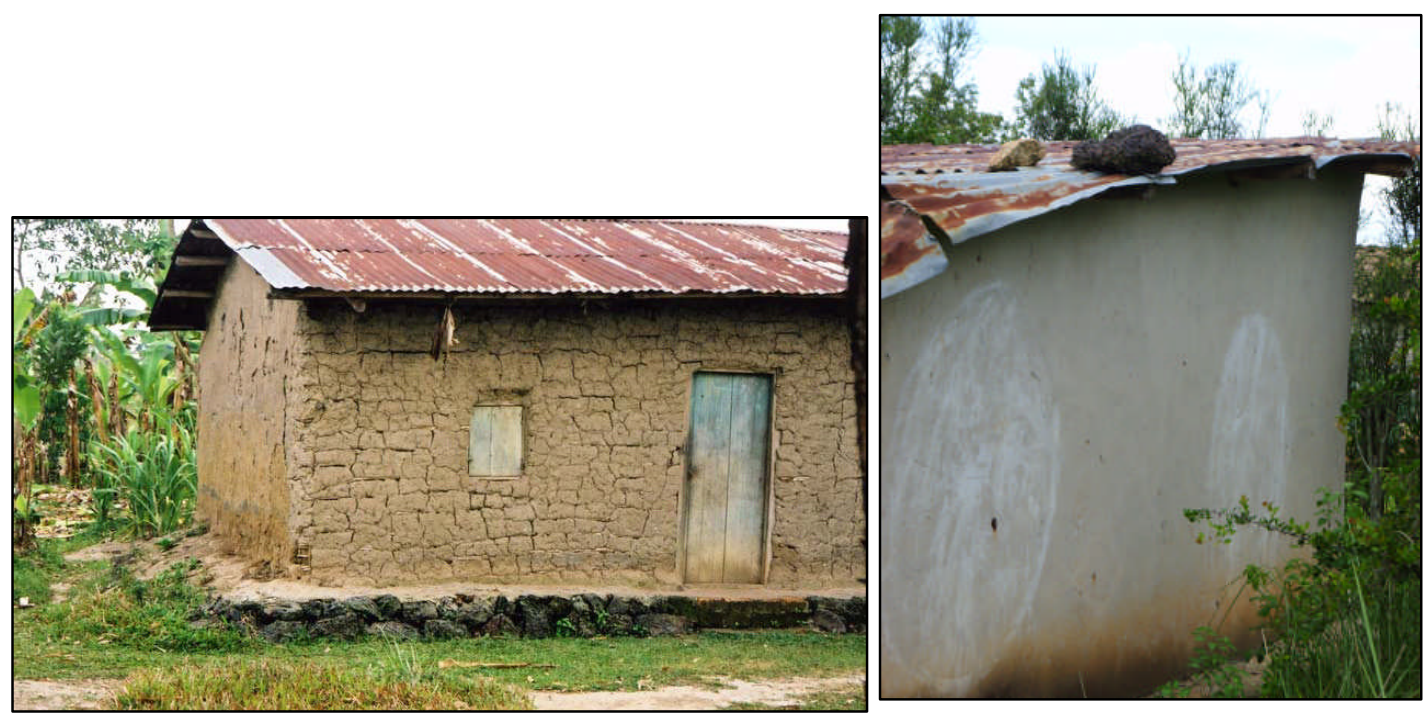

Fig. 2.10 House foundations made of slag in Buganda

Fig. 2.11 Slag block holding down corrugated iron roofing, located during survey in Rwanda 
A further consideration is that it is very rare to locate the remains of furnace structures in the archaeological record, especially in a country such as Rwanda, which is one of the most densely populated (and cultivated) parts of the world. Instead, rare, faint, circular outlines in the ground tend to be the only remnants of the former structures (described further in chapter 6). Over a number of years working on smelting sites throughout the Great Lakes region the author has never seen surviving furnace superstructures. While some archaeologists have reconstructed the 'original' shape and height of excavated furnaces based on the angle and depth of the furnace pit (e.g. Van Grunderbeek et al 1983, 2001), I believe the vast variety of furnace styles, shapes and sizes seen in the archaeological and ethnographic record across the continent (see Cline 1937 for a general ethnographic summary; Childs 1991b; Chirikure \& Rehren 2004; Collett 1993; David et al 1989; Haaland 1985; Killick 2004; Martinelli 2004: 173; de Maret 1985; Okafor 2004; Reid \& MacLean 1995; Schmidt 1997), and indeed even across relatively small areas (Celis 1987), make such reconstructions dangerous. Additionally, preservation of furnace remains also depends on the type of furnace constructed, and also on the locations of the smelts. For example, Chirikure (2006) located furnaces in Zimbabwe still intact with decoration that had been applied to the furnace structure still preserved. However, these furnaces were relatively recent $\left(18^{\text {th }}\right.$ century), and situated far from the nearest settlements and not on fertile land, and so had not suffered from human disturbance. They also feature a large rake hole for the removal of slag and bloom, enabling the re-use of the superstructure, ensuring constant maintenance of the furnace for the life-time of the smelting location. In the case of a pit furnace with truncated walls, there are instances recorded when the removal of the iron bloom necessitated the complete destruction of the furnace itself (see this chapter, section 2.1.6), with the superstructure being pushed over to gain access to the bloom. Clearly, such technological approaches would dramatically affect the survival of the original structure of the furnace.

Other aspects of the archaeometallurgical record are difficult to access within the chaîne opératoire. These include charcoal production: usually conducted by burning logs in a pile (see this chapter, section 2.1.1; Schmidt 1996: 91, 1997: 66-69) covered with leaves and soil for a specific time in a controlled and monitored environment. However, not 
only is it almost impossible to locate charcoal production sites in the archaeometallurgical record, in eastern Africa existing reference collections of charcoal are limited, meaning it is very difficult to identify tree species from charcoal found in furnace pits. Additionally, certain information regarding the technical ceramics used during the smelt is difficult to access, namely, where in relation to the smelting location that the clay was sourced.

The ore originally used in a smelt is also often difficult to establish in the archaeometallurgical record, especially as the ethnographic record indicates that various ores could be mixed. The processing of the ores before the smelt is also hard to infer. Although, in some areas, informants have been able to lead archaeologists and ethnographers to old mines, it is often very difficult to access these mines safely to extract ore from the original mining pits for archaeometric analysis. It is also often impossible to determine how access to the mine and its ore was controlled in the past.

The final stage of iron production, that of forging the bloom, is also a component of the chaîne opératoires involving specialist knowledge and skill, and a stage notoriously difficult to access as an archaeometallurgist. Ethnographic data again illustrates the variable nature of the task (including the type of anvils, flux and smithing tools and techniques: e.g. Celis 1987: 158-169; Maquet 1965), as well as the relationship between the smelters and smiths, and the smiths and the local communities (e.g. Childs \& Killick 1993: 326-331; Herbert 1993: 97-128). Although smithing slag cakes can be identified in the archaeological record, forges are more difficult to locate - often simply being an un-lined shallow pit with some charcoal thrown in. Even more importantly, the role and status of the smith in the chaîne opératoire is also difficult to access, with recurrent ideas such as that of the 'Smith King' (see de Maret 1985), illustrating important and widespread concepts that existed alongside local variation.

Based on the above, one should be wary of the dangers of broad temporal and geographical generalisations, which may be inadequate for both technical and symbolic approaches to iron production. However, the huge potential for archaeometallurgical investigations is also clear, especially in a region such as Butare in Rwanda where 
archaeometallurgical remains are abundant (Van Grunderbeek et al 1983; Van Noten 1983). The study of the types of materials outlined within this chapter, and specifically of slag and technical ceramics, allow the discipline to go beyond macro-comparisons and dangerous generalisations based on furnace type alone. When technical data are contextualised and interpreted within a suitable theoretical frame, the archaeometallurgical approach offers exciting possibilities to reveal much about past iron producers: the knowledge they possessed; the choices they made; how their technologies fitted into the broader cultural context of the time. All of these issues will be investigated in the following chapters, while the limitations of such an endeavour are continuously considered. 


\section{3}

\section{A theoretical framework for African Iron technology}

The following chapter positions this research within a theoretical framework. In doing so, the role of 'Western' theory in African archaeology is first explored. In contemplating this issue, a critical evaluation of researching African history from a Western perspective, as well as working within the continent under the shadow of colonialism, is discussed. Following on from this, clarification of the notion of technology is provided, which demonstrates the value of studying technology as a social facet within the archaeological record. By first considering what technology is, the theoretical approaches to this phenomenon can then be discussed. These approaches include utilising the notion of chaînes opératoires, and agency theory (also known as the theory of practice), as well as ethnoarchaeology, experimental archaeology, and archaeological science. By applying these particular theoretical approaches, past technological systems can be revealed and explained, and the choices made by past metallurgists can be examined. Extrapolated data can be contextualised within the broader cultural, political and economic situation to reveal the role of technology and technicians within society. Thus, the richness of the information that can be generated and appreciated from identifying and understanding specific past technological actions is revealed (e.g. Lemonnier 1992). As chapter 2 established the potential for archaeometallurgical studies, so this chapter summarises the possibilities generated by utilising a theoretical framework in the study of technology.

\subsection{Western theory in African archaeology}

The late Bassey Andah believed that the imposition of western theories and practice in Africa was "inappropriate" (Andah 1994: 96). In his opinion, imposing western science and conjecture on African cultures creates a past irrelevant to African people today, and provides a framework that "neglect[s] the study of actual peoples" (1994: 101). For Andah, archaeology in Africa needed to "liberate itself from the shackles of colonialism" (1995: 179). According to such a view, utilising theories developed for, 
and within, a Western academic environment appears to encompass two major flaws. In the first instance, such an approach is illogical, due to the differences between Western and African histories and cultures. In the second, such practice invokes a continuation of the oppression of Africa's past by the sustained imposition of colonial perceptions concerning the history of the continent. Therefore the question arises: can African archaeometallurgy work within a theoretical framework formed using western anthropological theory and science as a basis? (Andah 1994, 1995; de Barros 1990; Champion \& Ucko 1998; Musonda 1990; Reid 2001; Shaw \& MacDonald 1995).

To consider the concept of a Western approach to the African archaeological record as inappropriate and illogical engages the notion of "the tyranny of hidden prejudices" (Gadamer 1975: 239; see also Shaw 1989: 4). As Thomas has recently explored in detail, modernity and the West can be considered as different from past societies, and so archaeologists unavoidably interpret the archaeological record from a subjective point of view: "archaeology as we presently practice it is intimately connected with the modern experience, and indeed amounts to a distillation of a modern sensibility" (Thomas 2004: 2). In other words, the way we perceive our lives within our capitalist, global world, is more than likely very different from how people living in the past experienced life. People living in the past, whether in Europe or in Africa, experienced a very different cultural milieu. Thus as $21^{\text {st }}$ century, Western archaeologists, we must be aware of the implications of our own modernity on our comprehension of the African past. This is obviously a difficult task: "archaeology has been made possible by modernity, yet it is our position within the modern world that makes it difficult for us to comprehend the distant past" (Thomas 2004: 241).

However, rather than an emphasis on differences between 'us' and 'them' (the people of the past), instead our innate similarities as humans can be highlighted (Gardner 2004: 118-121). Hence as humans, we can in fact empathise and understand the thoughts and feelings of our ancestors, regardless of our individual cultural backgrounds. Such a stance can be taken further to suggest that the concept of the West, and of Modernity, based on the philosophy of Enlightenment and the birth of science (Thomas 2004: 135 ), is in itself flawed. Such a hypothesis is illuminated by the fact that a significant 
proportion of Western people living in a world supposedly transformed through the Enlightenment period and founded on scientific principles, still believe in God. Thus, 'modernity' and its effects on Westerners can be seen as a "smaller element in the stories of humanity" (Gardner 2004: 121). Therefore, by approaching the archaeological record with an open, balanced mind, and considering the natural bias that our own situations bring, perhaps Western archaeologists can appreciate and understand the African past, and the situation is not as dire as Andah believed.

Nevertheless, Andah's apprehension concerning the continuation of colonial ideology through the application of Western archaeological agenda and the interpretation of the African archaeological record by Western archaeologists are understandable. During the colonial period in Africa, much archaeological research and anthropological observation focused on exploring the nature of the local populations based on an initial assumption of their primitive nature (for a summary of such colonial notions, see Shaw 1989), as the following quotes demonstrate:

"The Masai did not know the art of smelting until they had conquered the Sirikwa, a cultured race of people ... Many Kenyan officials either doubt or deny that this legendary race ever existed ... I have come to the conclusion that some cultured people once occupied the Uashin Gishu plateau, if not more of East Africa ... When one finds principles of physics, no matter how elementary, explained by simple natives unaffected by European influence, one must accept the statement. It involves a knowledge that no Bantu native would have at his command from Bantu culture” (Galloway 1934: 500504).

"[T]he Semitic became tainted with Negro blood, the half-cast tribes intermarried again with the primitive race, and became still more degraded in feature and form" (Stanley 1890: 355).

Such colonial theories of African populations as unaccomplished and uncivilised, abound in the history of archaeological research on the African continent and elsewhere across the World (Robertshaw 1990; Segobye et al 1990; Trigger 1996: 220-223). For 
example, the treatment of the site of Great Zimbabwe, from the point of colonial contact to relatively recently, expresses the colonial desire to emphasise the 'uncivilised' nature of the native African populations (Connah 2001; Ndoro 2001; Shaw 1989). For a hundred years, the complex and technically impressive stone architecture, spatial organisation, trade networks and material culture of the site were attributed to everyone from the Phoenicians to the Queen of Sheba and King Solomon: in short, any population other than an African one (Connah 2001: 223; Garlake 1973: 209; Shaw 1989: 4-6).

Even when amateur archaeologists operating within the colonial era (e.g. missionaries, explorers and administrators), attempted archaeological research, it was usually without practical training, a comprehension of history, or funding (de Maret 1990: 109-115). Initially such work resulted in generalisations, evolutionary models, diffusionist perspectives and a focus on the Stone Age, and was ultimately influenced by, "a more or less unconscious racial prejudice" (de Maret 1990: 122). To give a pertinent example, one such western theoretical framework that has been imposed upon the history of the African continent is the overarching chronological theory of the 'Three Age System'. This concept, based on the theory that 'man' evolved in his technological mastery over the World from simple to complex technological application: stone $\rightarrow$ bronze $\rightarrow$ iron (Trigger 2006: 104-105), was generally speaking appropriate for some regions:

"we may question (for example) whether the transition from the Neolithic to the Early Bronze Age really marks a great social and cultural change as that from Middle to Late Bronze Age; or we may debate whether the Mesolithic should really be named so, or should be referred to as the Epi-Palaeolithic. But the fact that we can even argue in such terms demonstrates the all-pervasive strength of the fundamental Stone-BronzeIron classification" (Rowley-Conwy 2007: 1).

On the African continent however, people continued to make and use stone tools until very recently, and much of the continent lacks a bronze age, instead appearing in the archaeological record to jump from stone to iron production (Alpern 2005; Childs \& Killick 1993: 319-322; Killick 2004, 2009). Although the Three Age System is 
therefore largely irrelevant, archaeologists continue to work within it (Stahl 2005: 6-7). In this thesis, the concept of 'Iron Age' is used, for lack of a more appropriate phraseology. Space and time constraints make it impossible to attempt to construct an alternative terminology within this $\mathrm{PhD}$, however this period of time is recognised from the outset as dynamic and heterogeneous, and the major role played by other material aspects of society, such as ceramics, is appreciated. This period of time is furthermore divided into three sub-sections: early, middle and late, and these divisions are recognised as indicative of the fluid nature of time and technology rather than compartmentalised eras.

Although within Africanist academia the technological achievements of past African societies are now well recognised, the result of the colonial influence on the continent's history is that today, it seems largely irrelevant to much of the continent's population (Andah 1995: 149; de Maret 2005: 420; Stahl 2005: 4). Amongst the general public, many Africans (educated and un-educated) and Westerners believe that Africa has a very limited and static history, and certainly that Europeans brought science and technology to Africa. Considering the importance of the past for people (MbunweSamba 1994: 117), archaeology in Africa must overcome these problems.

Ultimately, the fact remains that in any academic endeavour, the ability to justify the intellectual solidity of the pursuit - to explain the theory behind the questions being asked - is of paramount importance. Therefore when the fundamental question, 'Why study iron production in Pre-Colonial Rwanda?' is asked, the response must be linked to theoretical concepts. The need to carry out systematic archaeological research in Africa, not least in an attempt to overcome the negativity instilled in the African and Western mindset concerning Africa's past as a result of colonial times, has been established.

In order to move beyond colonialism and to avoid a neo-colonialist label, this project has been conducted in association with the Institute of the National Museums of Rwanda, with Rwandan students, officials and the local community involved and consulted at every stage. It is accepted that western-trained, non-African academics can never fully overcome the issues associated with their western perspective (as described 
above). However, by self-critically assessing the archaeological approach, and emphasising the local context of the project, this research has attempted to be as objective as possible. Having recognised the validity of this pursuit, the theoretical framework used during this research can now be considered. In this case, the phenomenon of 'embedded technology' (the notion of technological actions being embedded within and moulded by society), recognises that the archaeology of technology has the potential to reveal a great deal about the past (Gosselain 2000; Lemonnier 1992, 1993; Sillar 2006).

\subsection{What is technology?}

Without a sound understanding of technology that moves beyond, "the way people do things" (Sigaut 2002: 420), the time, effort and resources spent researching this aspect of past societies from the archaeological record remain worthless, resulting in practical description rather than versatile inference. Fortunately, as anthropologists and theorists have recently discussed (e.g. Ingold 1990, 2000; Lemonnier 1992, 1993; Pfafferberger 1992; Sigaut 2002; Sillar 2005) the anthropological and archaeological approach to technology has developed much over the last few decades. Theory of technology has moved away from a number of fundamental concepts which are dominant features within Pfaffenberger's Standard View of technology, listed below (Pfaffenberger 1992, 494):

1. "necessity is the mother of invention".

A concept which suggests that innovation is seen only as a response to external factors such as environmental change.

2. "Form follows function".

A stance which ascribes the intended use of the object as its dominant characteristic.

3. Technology as a "unilinear progression" over time from the 'simple' to the more 'complex'.

These three points imply that people are passive, and that technology is an adaptive, functional, linear sequence of events. Instead technology is now viewed as a cycle, or 
web of transformative, conscious actions, all of which (including the actions and the actors) play a role, or a number of different roles, within broader society. The consequences of the actions, whether an object or an event, effect and have meanings within society. A technology itself is the skilled, transformational manufacture of objects, and has roots within all aspects of broader society. Ultimately as an integral aspect of society encompassing social relations, organisational systems, bodies of knowledge and material objects, the study of technology provides a glimpse into the lives and culture of people in the past (Costin 2005: 1037).

Technology therefore should be studied not just in terms of physical actions, but also in the sense of social relevance: "there is no such thing as a non-social technique" (Sigaut 2002: 436). Hence when studying technology, it is the people behind the actions that are being accessed: What did they want to achieve? How did they choose to do this? What were the consequences of the actions and the choices made? (Sillar \& Tite 2000: 2). Pfaffenberger (1992) terms this perception of technology within society a "sociotechnical system": active, goal-oriented knowledge-driven techniques (actions) linked to material culture, operating within society. Indeed if objects are considered as social productions, it follows that the actions and actors that produced these objects are ultimately social and so imbued with social meaning (Gosselain 2000; Ingold 1990; Lemonnier 1990; Pfaffenberger 1992).

Thus technology is formed of skill-based actions embedded within a socio-technical system, and permeated with meaning. The job of the archaeologist therefore, is to identify the actions, recognise who was responsible for them, and then access meanings behind the actions, interpreting this information within the broader cultural context within which they were occurring. Assuming all of this is possible, the reason why archaeologists study technology is clear - the window into the past that such an endeavour can reveal is immense. In theory, by accessing the above information, not only does the archaeologist have a sound understanding of knowledge systems held within societies and the choices the artisans were making, but as a result of the embedded and intertwined nature of technology within society, also an understanding of 
power structures, labour divisions, economics, exchange systems, rituals and belief systems.

The potential to recognize choices through the classification of variation in technological style (Hegmon 1992) can in some cases allow for the identification of particular groups or identities and their own specific social and belief systems (e.g. Gosselain 2000). The identification of choice in technology, and decisions made by individuals, is to identify society and meaning through material culture. In other words: "all kinds of technical practices are influenced by more general and varied social phenomena" (Lemonnier 1993: 23). Thus, by studying technology and technological change, archaeologists reveal certain aspects of past societies and so have a greater chance of understanding the socially influenced meaning behind the actions.

Technology, as the action or series of actions that combine to produce objects, represents a knowledge system, which in itself can represent a history of experimenting or of the diffusion of skills from elsewhere. On a broader level, technology represents a control over access to resources, labour organisation and communication between artisans operating within the same web of production. It signifies the relationship between the artisans and the wider community, in terms of who is the producer and who is the consumer, and how they view each other. Roles of gender, power structures and aspects such as social stratification, as well as numerous other broad socio-cultural components all influence and impact the meaning behind technology in society. The archaeologist who can identify stages of production and date technological events can illuminate the diachronic role of technology and technological traditions, and so reveal the position of the technology within the socio-economic, political, religious and environmental arena within which it was being practiced. As a reflection of society and societal demands, technology is a key to unlocking fundamental aspects of the past. A number of fundamental theoretical concepts can aid archaeologists in achieving this, outlined below. 


\section{- Chaînes Opératoires}

The concept of chaînes opératoires was pioneered and explored by Leroi-Gourhan, who, through his work, developed "a strong commitment to technology as the point of access for understanding human cultures and to technical activities (both past and present) as instrumental, communicative, symbolic and culturally constructed" (White, in Berger's translation of Leroi-Gourhan 1993: xvii). Leroi-Gourhan's view of Operational Sequences is summarised as follows:

"The technical life of the hunter, and later of the farmer and the artisan, involves a large number of sequences that correspond to the many actions needed for their material survival. These sequences are empirical, borrowed from a collective tradition that one generation passes down to the next. Their principal trait, for all the unity of their broad outlines and their extension over vast polyethnic territories, is their strongly marked local and individual character. Everything humans make - tools, gestures, and products alike - is impregnated by group aesthetics and has an ethnic personality ... Individuals introduce their personal variations into the traditional framework and, safe in the knowledge of belonging to the group, draw some of their sense of existing as individuals from the margin of freedom allowed them" (Leroi-Gourhan 1993: 253, translated by Berger).

Thus, during his research in the 1940's to the 1960's, Leroi-Gourhan recognised that technological systems were made up of a series of actions which were influenced by society as a whole, but that were also controlled by artisans who could impart their own individuality onto the stages within the particular operational sequence. For that reason, by revealing these stages and choices within the archaeological record, social and ethnic information concerning past technologists can be revealed.

In the field therefore, the first stage in the study of technology or production is to identify the stages of production and the techniques used - the skill-based actions. Here the concept of chaînes opératoires - the operational sequence described above, which leads to the creation of an object, comes into play: "The concept of the chaîne opératoire provides a framework for describing the structure or logic of specific sequences of 
action in material, temporal and spatial terms" (Edmonds 1990: 57). By providing the framework within which archaeologists can focus on reconstructing a sequence of actions before using this as a base from which to move on to consider the social inferences which can be made, the concept of chaînes opératoires has allowed the study of past technologies to flourish - it has simplified the complexities of sociotechnical systems for the archaeologist with little data with which to work, allowing for a confident approach to the archaeological record. The challenges lie in understanding the limitations of the approach, and using the results to move beyond description and into interpretation. In order to do this we not only have to understand the technology, but also the technological choices being made by the artisans (Costin 2005).

Chaînes opératoires as a research method is particularly useful when viewed with a specifically social spin: the "material sequence of manufacture and use are social practices undertaken in peopled contexts and conducted by the hands of individual agents connected to the body politic" (Dobres 2000: 165). Put simply, whilst describing the techniques we can observe and infer from the archaeological record, we must constantly consider the complexity of broader elements, including social, political, economic and ritual aspects of technological actions. The concept of the chaines opératoires as the empirical description of sequential processing (Dobres 2000: 164167) offers a reconstruction of ancient technologies in as much detail as possible, which of course is pointless in isolation. However when combined with linguistic, ethnographic, archaeological and science based data, it can go far in understanding and interpreting not only the past technological operations, but their relevance on an individual and societal level.

For any chaîne opératoire approach to work, it must be encompassed within a "successful sociotechnical system" (Pfaffenberger 1998: 296), and the creation of this system to incorporate cultural, social, political, economic and cosmological facets of society, is complex (e.g. Childs \& Killick 1993: 318). In Pfaffenberger's 1998 article, the focus is on industrial mining communities in North America, and he illustrates the complexities of the fundamental stage of ore mining in the chaîne opératoire. Despite intending to describe industrial mining communities, he recognises that, "Like any 
sociotechnical system, industrial mining is fabulously complex. Its components include vast hinterland supply regions, transport systems ... equipment, political arrangements ... laws and regulations, labour unions, management styles, and much more" (1998: 296). Similarly, Child's article in the same volume illustrates that in many African examples, the same principles apply, despite differences of geography and scale. Her description of the complexities surrounding the mining of iron ore in Toro (Uganda) provides a fascinating insight into this particular step (which in itself encompasses an entire chaîne opératoire) within the overall chaîne opératoire of iron production: the location of the ore source; the rituals surrounding the purification and protection of the ore; the social laws dictating ownership of the source; the management and application of mining techniques (Childs 1998). Importantly however, these intertwined and essential aspects of this one vital stage within the chaîne opératoire of iron production are usually unidentifiable within the archaeometallurgical record, as are other vital stages such as charcoal production (as described in the previous chapter). Therefore our general understandings of chaînes opératoires of technology in the past are dictated to a large degree by archaeological preservation and recognition.

The basis of understanding the chaînes opératoires, therefore, is to reveal the process of creating an object through a series of chosen techniques by following the life of an object from its inception to use as an object embedded with social meaning. In the case of iron production, as illustrated in chapter 2, a number of fundamental chaînes opératoires (sub-stages) must operate within the overall chaîne opératoire for the production of an iron object. All of these sub-stages, such as charcoal production and ore processing, fall under the influence of over-arching themes such as organisation of labour and access to resources. This concept, of the complex, interdigitated nature of an overall chaîne opératoire, complete with its sub-stages, and in turn the intertwined nature of the chaînes opératoires to the whole of society, are summarised in fig. 3.1 below. 


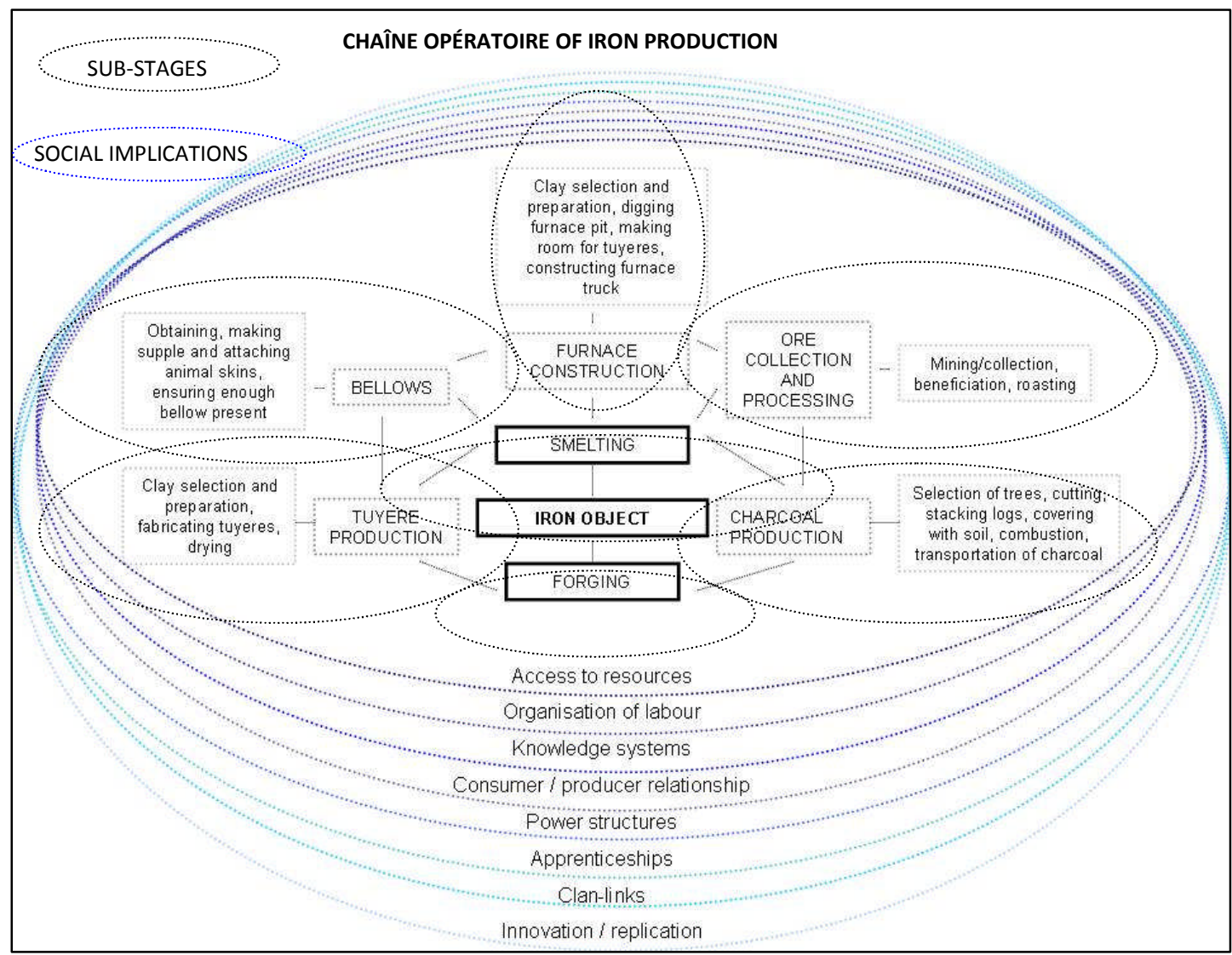

Fig. 3.1 Schematic representation of the basic iron production technology, moving from the iron object in the centre outwards to the main stages of the chaines opératoire, and then to the substages of production, with some overarching socially interdigitated themes and considerations circling the entire process

It is known that within the archaeometallurgical record there may well be traces of certain events within the chaîne opératoire of iron production which are more easily accessible than others. These include furnace construction, revealed through the remains of the furnace, and smelting, revealed through the waste products, of slag, as well as tuyeres and other remnants of the smelting episodes. What is also known, is that many of the vital stages in producing iron, for example charcoal production, tuyere and bellows manufacture, and smithing, are notoriously difficult to identify. Therefore, it is usually impossible in the archaeological record, to "delineate the manufacturing process from beginning to end" (Dobres 2000: 169). Nevertheless, the use of the theory of chaînes opératoires allows archaeologists to do this as fully as possible, and to consider aspects which are unobtainable within the production process. 


\section{- Agency Theory (The Theory of Practice)}

As has been described above, an important element within the study of technology is the consideration of the role of the individual in making technical decisions. Within this human dimension of chaînes opératoires two spheres of influence are involved. The first is the individual, and the choices they make to actively influence the technologies which they practice. The second is the role of social structure, or traditions governed by social action (Bourdieu 1977; Giddens 1984). In other words, although individual technicians make decisions and choices which are reflected within the archaeological record, the extent to which these decisions are determined by the wider social structure within which they live, or their own innovative creativity (which in itself is a reflection of what the technicians have learnt and experienced in life), is a consideration for the archaeologist.

By studying technology as a series of socially embedded actions, the actors themselves and their cognitive behaviour must be, and can be, considered. Such a theory is succinctly defined as "the capacity that all individuals (or agents) have to actively shape and transform their world" (Gardner 2008: 95). Hence it must be remembered for example, that iron wasn't just smelted. People decided to smelt, used the knowledge they had learned and possibly developed themselves, organised labour, arranged natural resources, worked together in teams and produced objects which had both symbolic (people's power over nature) and functional (a tool to clear fields or fight territorial battles) meaning. Iron producers were not just performing a complex technological chaîne opératoire with numerous sub-stages involved, but they were also producing the revolutionary tools which were transforming society and social mechanisms. However, they were also performing these actions within the social environment of the time, and influenced by the world around them. For example, when analysing a piece of iron slag, what is revealed are the actions and choices of a group of individuals, perhaps operating around a head smelter, employing both learned skills and rational choices. Thus the actions are also indicative of "interactions" between the iron workers themselves, between the ironworkers and their own immediate communities and consumers, and in some cases between the ironworkers and the governing political power body (Gardner 2008: 99-101). Agency should be viewed therefore as a series of relationships between 
individuals and each other, and individuals and the social and material worlds (Gardner 2008: 103).

Therefore, during the study of technology, it is ideal to identify the overall chaine opératoire; the sub-stages within this (for example charcoal production in its own right as a complex technology, rather than just a stage in the making of iron); the individuals actively creating these processes; and the broader social context within which they were operating. The initial job of the archaeologist interested in technology is the empirical description of the actions observable in the archaeological record and then in the scientific analysis. Only then can the techniques and knowledge systems that existed within the spatial and temporal arena be extrapolated. From this point, a coalescence of a much wider body of data (as described above) can occur.

However as archaeologists, there are other, complementary theoretical and methodological approaches which can inform and transform our observations into more detailed understanding of past technologies: Ethnoarchaeology (observing present communities to understand those living in the past); Experimental archaeology (reconstructing technological operations to understand how these were performed in the past); and Archaeological Science (utilising science to understand past activities).

\section{-Ethnoarchaeology}

The principle of ethnoarchaeology is that by studying living communities and individuals, the understanding of the archaeological record can be enriched (David \& Kramer 2001). By observing and participating in the interaction between material culture and society, much can be learned about the past through the use of analogy (Atherton 1983: 75-76; David \& Kramer 2001: 1; Lane 2006: 402). Therefore by watching people working with traditional objects or practicing traditional crafts, as well as interviewing members of the community (fig. 3.2), much information can be gleaned regarding technologies at work within existing socio-technical systems, both past and present. By recording and seeking to understand culturally specific information, archaeological problems and situations can be solved in a more relevant manner (Lane 2006: 404). The use of ethnoarchaeology, in combination with observations recorded in 
the past, including the writings of early explorers, can illuminate aspects of past technological practices that are otherwise inaccessible (for an example of early writing, see Roscoe's description of smelting practices in Buganda, Uganda - Roscoe 1911).

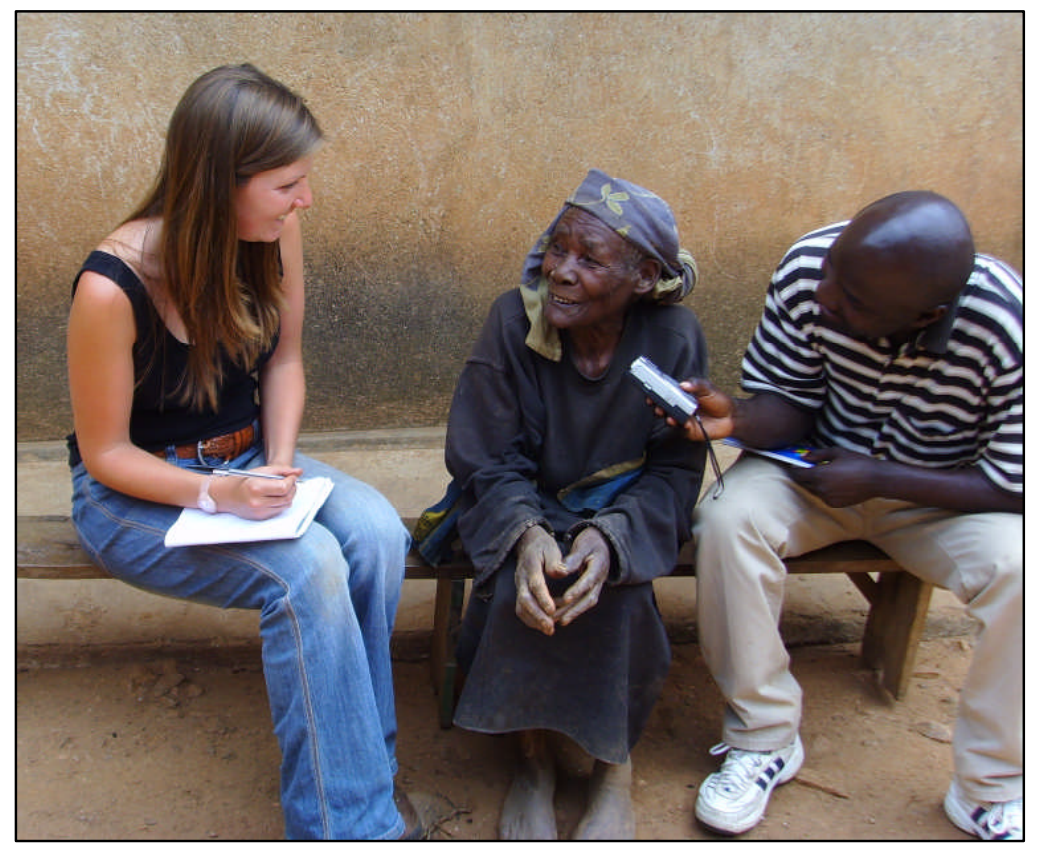

Fig. 3.2 Interview concerning iron smelting conducted with Veronique Nyandwi, mother of André Nyandwi, the leader of the smelt commissioned during the research for this $\mathrm{PhD}$

\section{-Experimental Archaeology}

A further aid to understanding technology within the archaeological record is the use of experimental archaeology, a practice utilised since the $19^{\text {th }}$ (Forrest 2008: 61-67). The theory behind the use of experimental archaeology is that through the replication of producing objects, the techniques utilised by artisans in the past can be revealed and understood. Experimental archaeology allows the archaeologist to visualise and understand the artisan as, "an inventor, a technician, a craftsman, an artist, and a human being" (Coles 1979: 2). To access such information is to understand past technical skills and also isolate choices made within the chaîne opératoire of the particular technology. Constructing an experiment to reveal such information and to attempt to replicate the past should therefore be carried out under strict scientific control which will allow 
certain hypotheses to be tested in order to, "provide or enhance analogies for archaeological interpretation" (Mathieu 2002: 1).

During the study of iron production, experimental smelts have been carried out in Europe, America and across Africa to understand, for example, how and why certain furnace shapes and materials were used, and also to offer quantifications of large-scale archaeological iron producing sites (e.g. see Nørbach (ed) 1997). Ideally when utilising such an approach, the focus should be on control of input and output, scientific analyses of both, and a reasonable assurance that the materials and construction methods reflect those used in the past. Experimental iron smelts such as those led by Peter Crew in Plas Tan y Bwlch (Snowdonia National Park, Wales) have not only provided a significant amount of information concerning the ancient iron production conducted in the area in the past (Crew 1991), but importantly have also allowed numerous archaeometallurgists and students to observe and so understand better the preparations leading to a smelt and the operating parameters involved during the smelt itself. Such observations are invaluable and provide an appreciation of technology and certain facets of the chaîne opératoire far beyond that which can be gained from the classroom alone (fig. 3.3).

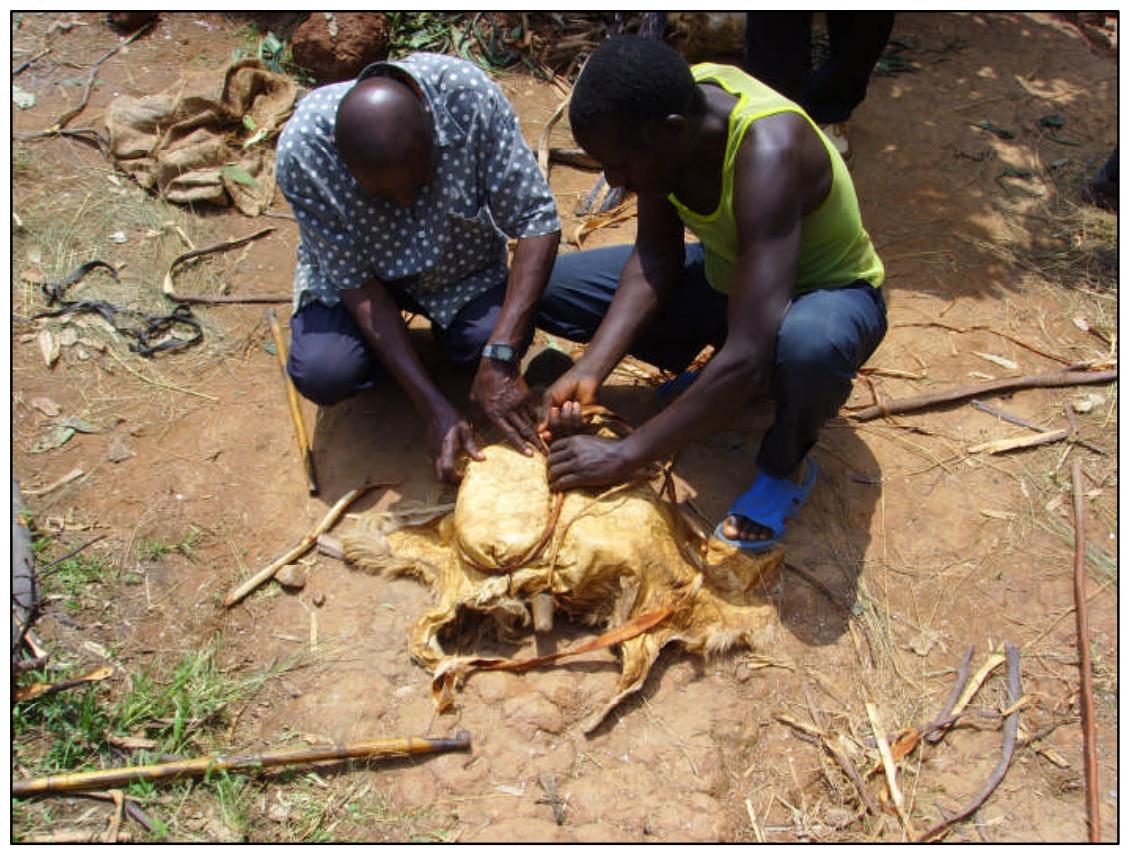

Fig. 3.3 Members of the smelting group commissioned in Rwanda, attaching sheep skins to wooden bellows 
In African archaeometallurgy such experiments have been carried out with varying degrees of success. For example in Karagwe in north-western Tanzania, a smelt was commissioned with the aim of gaining, "a fuller understanding of the technological processes and social organisation involved in the production of iron" (Reid \& MacLean 1995: 146). As with many of the experimental smelts conducted on the African continent, the artisans employed had not smelted for decades, and as is generally recognised were quite possibly affected by being watched by outsiders, fading memory and possibly also the desire to keep secret sensitive information concerning elements such as ritual. Although this smelt failed to produce iron, numerous questions became apparent concerning a variety of components of the production process that may not otherwise have been considered had the experiment not been attempted, for example concerning women in relation to a smelting episode.

Also in Tanzania, a series of experimental smelts were conducted under scientific control, analysing temperature and input/output of materials (Schmidt 1997: 45-108). The information generated was used to support a pre-heating theory: that air blown into the furnace though tuyeres placed a significant degree within the furnace itself, would heat up as it passed though the tuyeres, therefore increasing the temperatures reached during the smelt and enabling the smelters themselves to operate the furnaces more efficiently. All stages in the preparation of the operation were observed and recorded and a successful smelt was attributed to the preheating of the furnace. Subsequently however this theory has been disproved (Killick 1996), emphasising the danger of applying observations and theories generated through experimental operations onto the archaeological record.

Overall, in most cases of experimental smelting in Africa, or indeed anywhere in the world, the people involved (both academics and local groups) have benefitted on a scientific and personal level. Certainly during the smelt commissioned during this research in Rwanda, not only was a greater insight gained into the scientific and social implications of a smelt (in the past and in the present), but the smelters themselves were 
happy to have the opportunity to show a younger generation the skills which, without such commissioned experiments, would be lost.

\section{-Archaeological Science}

The final theoretical approach that will be utilised during this research is that of Archaeological Science (Sillar \& Tite 2000). A scientific approach follows the notion that the concise and replicable nature of accurate archaeological excavation combined with archaeometric analysis results in a significant body of empirical data. Ten years ago the analytical stage of a project such as this would have been carried out by scientists who had received the material from an archaeologist. Today however, the opportunity is available to combine training and expertise in both fields. The benefits of the excavator being the analyser (as an archaeological scientist) are immense because the researcher has training in both cultural and scientific methods of analysis (MartinónTorres 2008). The ability to understand cultural considerations within an archaeological investigation and apply archaeological theory to a data set, alongside a sound understanding of the scientific principles, equipment and data processing allows material to be processed and results to be extrapolated in a much more thorough manner. In conjunction with this approach, archaeological science recognises and encourages the benefits of collaborative work between varieties of specialists, ultimately to produce conclusions that are both detail-specific and wide-ranging.

\subsection{Limitations involved in the study of technology}

Problems associated with the study of technology within the archaeological record initially focus on the archaeologists' pre-conceived biases and the ways in which the individual archaeologist approaches and interprets the actions of past artisans, (Pfaffenberger 1992: 501). The heterogeneous and evolving nature of society and its individual agents cannot be overemphasised - world views, knowledge systems and roles of the agents vary depending on fundamentals such as gender, age, status, and so on. Thus for archaeologists trying to identify socio-technical systems, and agents within these, the task is vast: "sociotechnical systems are all but invisible through the lenses provided by Western economic, political and social theory" (Pfaffenberger 1992: 500). 
The ideal way to overcome this huge obstacle is to approach the archaeological record and all other sources of evidence with objective impartiality, but of course, this is not something many would claim to be able to do, despite their best efforts.

By focusing on small scale technology and then viewing the results in terms of the broader context, while continually self-criticising use of evidence and the evidence selected in the first instance, archaeology can go someway to achieving an impartial approach. The second contribution to achieving a sound study of technology would be to consider the role of the individual (aided by ethnography and experimental approaches), whilst accepting the limited insight into this particularly personal sphere of the past that can be gained by studying material such as iron slag (Sigaut 2002: 439442). Ultimately, unavoidable "cultural blindness" (Sigaut 2002: 450) forms one obstacle in the attempt at an impartial inference on the part of the western archaeologist in the approach to technology or indeed any aspect of past society, compounded by the constantly evolving and changing nature of societies in the past.

As alluded to above, a further problem in the study of technology which focuses on iron production are the significant archaeological blind spots within the chaîne opératoire and the sub-stages which create this. For example, rarely can the archaeologist access the location of clay sources used to make the tuyeres, or how exactly the tuyeres were made, or even the number of tuyeres used during a smelt. Not only do these gaps in archaeological knowledge lead to a disparity in our understanding of various aspects of smelting, but unavoidably produce a supposition that the act of smelting was the most important and complex action in the overall chaîne opératoire of producing iron. This is because smelting itself is the component, or stage, of the overall operation which survives in an adequate nature in the archaeological record. Many sub-stages of the overall exploit are unobtainable in the archaeological record (depositing limited traces in the archaeological record), leaving blank spaces where these components of the overall socio-technical systems should be. This is further emphasised in the African ethnographic and archaeological record where in numerous cases evidence supports the use of ritual and symbolism as integral parts of iron smelting (e.g. Childs \& Killick 
1993). Not only is it usually impossible to locate such aspects in the archaeological record, but also to interpret them.

While ethnoarchaeology in East Africa has been conducted with some degree of success (for example see Haaland 1985; Reid \& MacLean 1995; Schmidt \& Childs 1996), there is a huge dilemma (especially in this post-colonial period) of studying people in the present to interpret the lifestyles of people in the past, especially when it comes to ritual or symbolic aspects of society. This practice can and does continue to contribute to concepts of 'primitive' and unchanging African societies (e.g. Huffman 1986, 1993, 2007). The problems associated with the application of an experimental approach to aid in the understanding of the archaeological record concern both the impartiality of the practitioner and the repeatability of the event. It is easy to watch a smelt being conducted and see immediate parallels in the archaeological record, but as with the ethnographic record, such inferences have to be handled as possibilities but not certainties. Additionally, when working in the field, and especially when dealing with such a complex and multi-dimensional technology as iron smelting, it is unfeasible to expect to produce a controlled and repeatable experiment (Hansen 2008: 70). Thus the use of both ethnography and experimental research provide useful information concerning past technologies, but, as with all archaeological information, this must be handled and applied with self-critical care.

\subsection{The potential of studying technology within an evolving Rwandan history}

If it is possible to identify the techniques and the social significance of technology and the practitioners in the archaeological record using the theoretical frameworks outlined above, the role of the technology and the artisans in society becomes accessible. In other words, the more that is understood about these past social processes and processors, the greater the quality of information that can be pieced together with complimentary data to build a picture of Rwanda's past.

In Rwanda, societal change over the last two millennia has been hypothesised from archaeological and historical data and will not be explored in this chapter in detail (see chapter 4 for a specific history of Rwanda). Based on the theoretical positions 
considered within this chapter, it is in theory possible to ask a number of socio-technical questions of the archaeological record: What role did specialist iron production play in the evolving history of Rwanda? Vice versa, what role did society and its changing demands on metal workers play in the evolution (or even inception) of the technology? Like the 'chicken and egg' concept, were societal demands the stimulus for increased metal production, leading to a change in production technique, or was an increase in specialised iron producers, who could provided more iron tools to increase agricultural production and equip armies, a major contributing factor in the shift towards a centralised society? Can the remains of iron production in the archaeological record, and the results generated through the analysis of these remains, be used as markers to trace societal change?

The general importance of iron to power structures throughout the Great Lakes region is clear, signified in later times within Kingdom origin myths and royal regalia (de Maret 1985; Herbert 1993: 131-163; Reid \& MacLean 1995), let alone in the remains of industrial scale iron production which litters the region. Studying the technology of iron production in Rwanda within the remits of the complementary theoretical concepts outlined above, this research is able to explore the relevance of the technology of iron production within Rwanda's past. Considering the misgivings that Andah had of such attempts (1994, 1995), and considering the theoretical tools available to archaeologists today, it would seem that such a study can achieve much from an academic viewpoint, whilst also generating a window into history applicable and relevant to everyone. 
4

\section{Iron in Rwanda}

The following chapter provides the socio-cultural setting for this research through a review of available archaeometallurgical, archaeological, linguistic, historical and ethnographic data concerned with the 'Iron Age'. First, the geographic context of this $\mathrm{PhD}$ is presented, outlining the broader region within which the current research exists. Second, following a consideration of current archaeological data, a chronological structure is provided. Third, the spatial and temporal contextualisation of the research, the Iron Age, and the role of iron in Rwanda, will be reviewed. Hence this chapter provides the framework within which the results of this project will be interpreted.

\subsection{The geographical context}

Rwanda lies in Central-Eastern Africa, surrounded by Uganda to the north, Tanzania to the east, Burundi to the south and by the Democratic Republic of Congo to the west (fig. 4.1). 


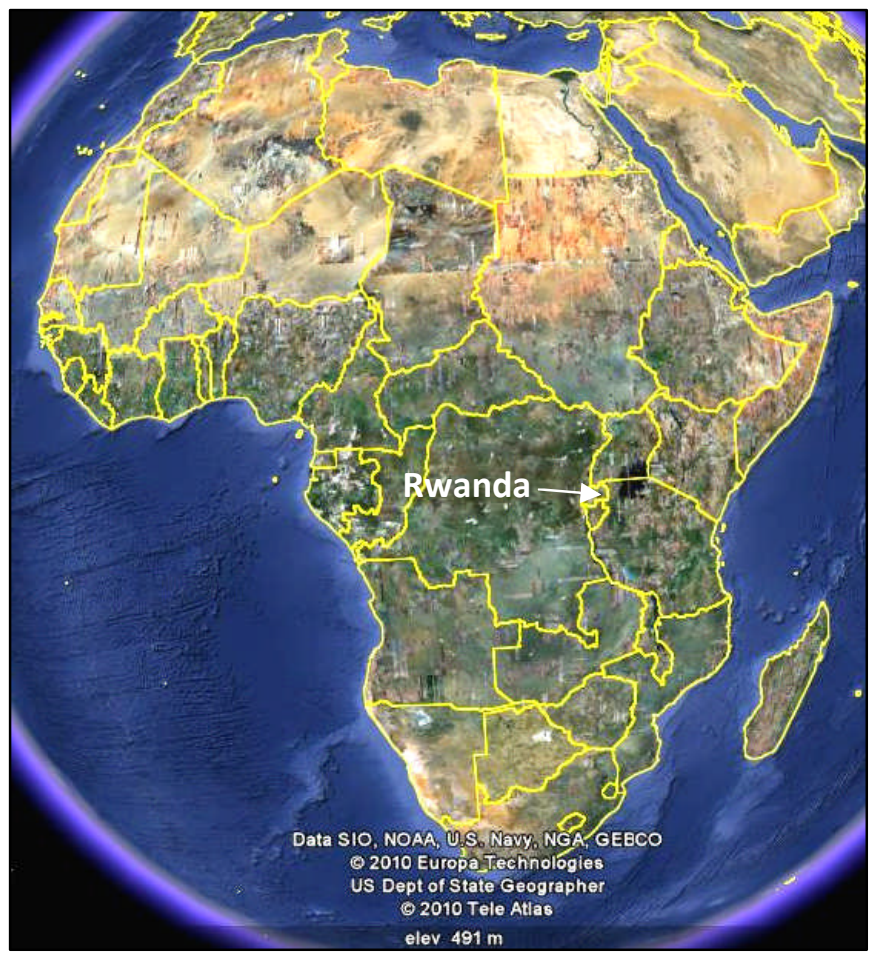

Fig 4.1 Map of the African continent showing the location of Rwanda in Central-Eastern Africa (taken from Google Earth Maps)

Rwanda forms part of the Great Lakes region, encompassing the Lake Victoria basin, including "forests, woodlands, grasslands, mountains and swamps crosscut by numerous rivers" (Kusimba \& Kusimba 2005: 402). This area, as diverse in environments as in ethnicities and histories, can be utilised as a generally defined archaeological region due to a broadly linked cultural, economic, political and linguistic past (e.g. Ashley 2005, forthcoming; Kusimba \& Kusimba 2005: 402-403; McMaster 2005; Reid 1994/5; Schoenbrun 1998: 3-28; Soper 1971, 1985; Stewart 1993; Sutton 1993). The region today is dominated by Bantu language speakers, but also represents an amalgamation of major African linguistic groups over millennia (Schoenbrun 1998: 22-23). The fluid, dynamic nature of this broad region, within which lakes and rivers have acted as paths of exchange and communication for thousands of years, is becoming more evident as research continues (Kusimba \& Kusimba 2005; Lane 2004; de Maret 2005: 421; Posnansky et al 2005; Schoenbrun 1998). This inextricably linked, culturally heterogeneous interlacustrine region, today encompasses Rwanda, North Western Tanzania, Burundi, Eastern DRC, Uganda and Western Kenya (fig. 4.2), although 
regions further afield are not necessarily excluded when considering the broader regional history.

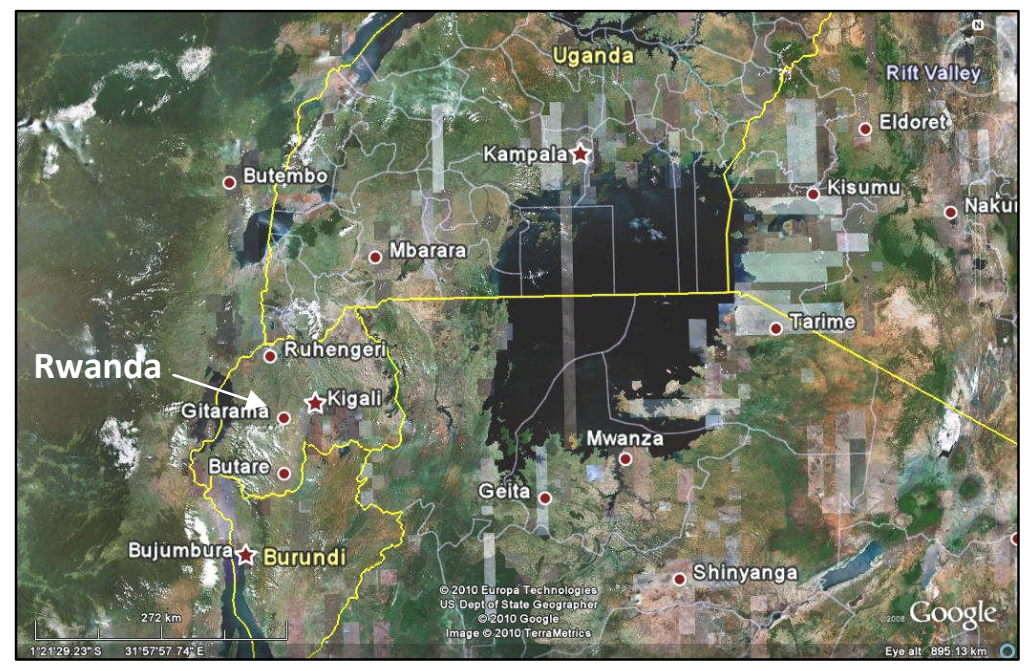

Fig. 4.2 Map illustrating the extent of the Great Lakes region (taken from Google Earth Maps)

Although Rwanda is the focus of this research, wider geographical perspectives provided by the Great Lakes region allows for technology to be understood within its broader cultural landscape. Drawing on evidence from further afield grounds the results of this investigation in the complex web of social interactions, economic developments and political change that will be outlined in this chapter.

\subsection{Chronological framework}

Traditionally, the archaeological chronology of the Iron Age within the Great Lakes region has been divided into two components: the Early Iron Age, and the Late Iron Age (MacLean 1994/5; Reid 1994/5; Stewart 1993; Sutton 1993; Van Grunderbeek et al 1983; Van Grunderbeek 1992; Van Noten 1979, 1983). The Early Iron Age is traditionally associated with Urewe ceramics across much of the broader Great Lakes region (Ashley 2005, forthcoming; Hiernaux \& Maquet 1960; MacLean 1994/5; Posnansky 1961; Reid 1994/5; Stewart 1993; Van Grunderbeek 1988, 1992; Van Grunderbeek et al 1983). In addition, a distinctive stylistic approach to iron production, making use of furnaces constructed in part from decorated clay rolls, or bricks, characterises this period of time within the southern limits of the region (Hiernaux \& 
Maquet 1960; Nenquin 1971: 183-187; Schmidt \& Childs 1985, 1996; Van Grunderbeek 1988; Van Grunderbeek et al 1983; Van Noten 1983).

The Early Iron Age in the Great Lakes region as a concept is relatively well established following decades of archaeological, palaeoecological and linguistic research, which will be reviewed below. However, limited archaeological evidence means that specific understandings of life during this period remain restricted (see MacLean 1994/5; Reid 1994/5). Exact dating for this period of time is also problematic (Clist 1987; Killick 2004; Miller \& van der Merwe 1994; Van Grunderbeek 1992), due to significant error margins within radiocarbon dating, and the integrity of the dates produced.

The issue of 'old wood', whereby charcoal selected for dating is actually much older than the archaeological context (Killick 1987; Schmidt \& Childs 1985, 1996: 202-203), combined with the flattening of the radiocarbon calibration curve from $600 \mathrm{BC}$ to 300 BC (resulting in calibrated age ranges of up to \pm 500 years), means that it is often impossible to construct a precise chronological framework for archaeological sites dating to the early phases of this era. Furthermore, even in the rest of the Early Iron Age (and beyond), radiocarbon dates usually have a significant degree of error, attesting to the need for high-resolution luminescence dating to create more accurate dating frameworks (Killick 1987; 2004: 100-101). These shortfalls of radiocarbon dating were particular issues that this research originally aimed to directly tackle.

Across the region a synthesis of Early Iron Age radiocarbon dates has been provided by Van Grunderbeek (1992; Van Grunderbeek et al 2001; see also Clist 1987; Wotzka 2006), and a general summary of dates across the continent by Killick (2004; see also Alpern 2005; de Maret \& Thiry 1996). A number of original dates for iron production before $1000 \mathrm{BC}$ are now considered more than likely to be erroneous (Schmidt \& Childs 1996: 205-206; Van Grunderbeek et al 2001: 276; Killick 2004: 100-101). However, the shear volume of such early dates does suggest that in the future, research may well corroborate evidence for the existence of established iron production technologies during the early first millennium BC and even before (de Maret 1985: 138139). 
The majority of dates for the Early Iron Age (based on charcoal from ancient furnaces), lie between approximately $400 \mathrm{BC}$ and the end of the eighth century $\mathrm{AD}$, when a change in furnace type is noted, and the beginning of the "Age du fer recent" denoted (Van Grunderbeek 1992: 58). Combined with this eighth century AD date for a later furnace style (Van Grunderbeek et al 1983: 58), is roulette decorated pottery, which appears in Rwanda from the ninth century $\mathrm{AD}$, indicating that a profound change within the wider material culture of the area (de Maret 1985: 143). It has been suggested that the tenth century AD is a more appropriate conclusion to the Early Iron Age (Van Noten 1983: 61-62), while to the east, around the Kenyan side of Lake Victoria, roulette decorated pottery has been dated to around 1000 AD (Robertshaw 1991: 67). However, for this study, the end of the Early Iron Age period will be attributed to the era ending at $800 \mathrm{AD}$, from which time relatively coarsely produced, roulette decorated ceramics begin to dominate the archaeological record (Soper 1985).

One formal sub-division of the Late Iron Age period has been made in Western Kenya by Robertshaw (1991). On identifying an assemblage of ceramics which appeared later than the Urewe ceramics at Gogo Falls, and recognising the difference between this new pottery and the roulette decorated ceramics of later times, they were classified as "Middle Iron Age" (1991: 168-171). Sutton (1993: 60-63), also recognises a period of change in technology, politics and economics, "about half way through the Iron Age" (Sutton 1993: 60), and notes this period as one of "revolution" (1993: 63). However, this provisional classification has since not been adopted within the wider archaeology of the region. Instead, the period of time from the $9^{\text {th }}$ century AD has continued to be classified as the Late Iron Age, with the situation occurring in the middle of this period recognised as confusing (de Maret 2005: 424-425).

Therefore, it would seem that rather than categorising this research into an Early Iron Age and a Later Iron Age, a more suitable chronological framework would involve the revitalisation of the term Middle Iron Age, based on a number of concepts. Whereas the Three Age System has been documented as inadequate within the African continent (see chapter 3), so it seems that the term Late Iron Age is inappropriate for the period 
following the appearance of roulette decorated ceramics and continuing until colonial times. Instead, here the term Middle Iron Age is proposed, to account for the period of time during which diverse technological, social, economic and political transitions were occurring across the Great Lakes landscape, from c. AD 800-1600. This period, as will be discussed below, is categorised by new and heterogeneous social and political organisations, new industrial technological production, and changing economic systems. This phase ultimately led to the creation of an entirely new period, that of the Kingdoms, from around AD 1600.

Using this temporal framework, the Late Iron Age would then coincide with the very different era, that of the Kingdoms, which dominated the region from around the seventeenth century until colonial contact.

Whether or not such a chronological system can be adopted more widely, not least in light of the more limited ceramic data available for the last millennia, is unclear. However, when considering iron production, and its changing position within society, it is believed that this tertiary framework is warranted. Through an exploration of the links between technology (iron production and ceramic production) and society throughout this proposed temporal structure, current understandings of the past two millennia of history within the Great Lakes, and specifically in Rwanda, will be illuminated within this chapter.

Before considering current and past research, it is important to briefly evaluate the archaeological remains available within this region and for the period under consideration. The most prominent technologies within the archaeological record are the remains of iron production, and fragments of ceramic vessels. The general lack of other forms of material culture within the archaeological record of the Great Lakes region may be a result of acidic soils (Van Neer 2000: 163), significant erosion, and the biodegradable nature of the processes and finished objects of other technologies that were known to have played major roles in the history of the region (Robertshaw 1994: 128; see also Young \& Thompson 1999). These include weaving reeds to produce 
baskets and containers, making bark cloth (fig. 4.3), and building structures from mud, wood and grasses (Fig. 4.4).

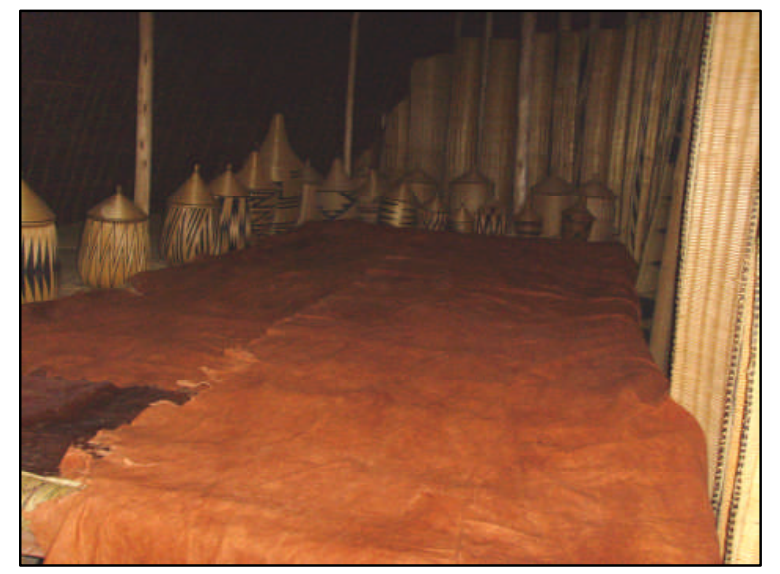

Fig. 4.3 Bark cloth and woven containers in Rwanda

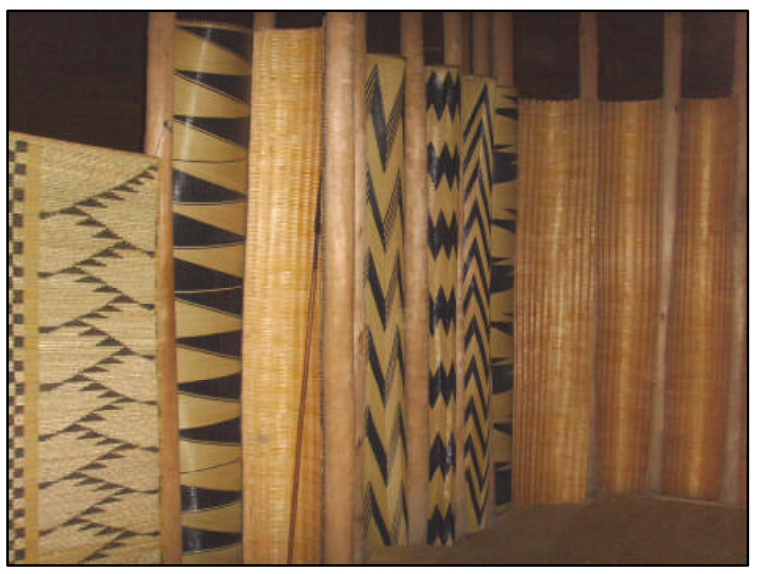

Fig. 4.4 Internal house walls made of wood and woven grasses in Rwanda

Hence, rather than reflecting a representative picture of the way people were living in the past, the archaeological record instead contains a particularly subjective reflection of the past. It must not be forgotten during such a pronounced archaeometallurgical investigation as the present study, that ferrous metallurgy operated within a plethora of other technological skills and cultural activity. The invariable segregation and prominence given here to iron production, as well as the paramount importance applied to this particular technology through the application of the term, 'Iron Age', is ultimately misleading. Nevertheless, as archaeologists we can only work with the available data, however it is still important to remember the partial nature of the archaeological record.

\subsection{Early Iron Age}

The archaeological record suggests that from around the early - mid first millennium $\mathrm{BC}$, a broad social complex characterised in the archaeological record by Urewe ceramics, existed in Rwanda, Burundi, Eastern DRC and around the shores of Lake Victoria (Ashley forthcoming; Clist 1987; MacLean 1994/5; Posnansky et al 2005: 8283; Reid 1994/5; Van Grunderbeek 1988, 1992). Urewe ceramics are often classified by 
thick bevelled rims and incised decoration (fig. 4.5) of parallel lines, triangles and circles (Ashley 2005; Hiernaux \& Maquet 1960; Leakey et al 1948; Posnansky 1961; Stewart 1993;Van Grunderbeek 1988). These ceramics tend to have a particularly fine clay matrix and vessel formation, as well as distinctive, intricate decorative motifs which display, "extensive and laborious effort in manufacture" (Posnansky et al 2005: 82). The existence of this type of complex ceramic technology, in conjunction with iron production remains, has been used to suggest a level of organisation within society from the beginning of the EIA (Schmidt 1997: 265-288; Schmidt \& Childs 1996: 229; Van Grunderbeek et al 1983).

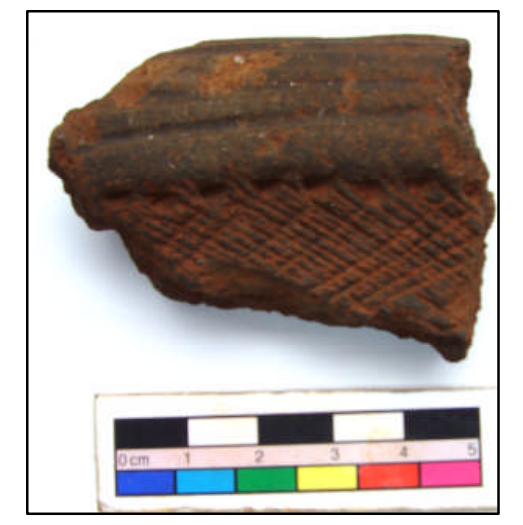

Fig. 4.5 Urewe sherd collected during survey in Southern Rwanda (BPS 036; photograph courtesy of John Giblin)

From ceramic data alone, it is difficult to suggest who the Urewe vessels were produced for, and why. It could be suggested, considering the finds of Urewe decorated vessels in a high status, or ritual, burial (see Giblin 2008, 2010; Giblin et al forthcoming), and in the bases of some early furnaces (Van Noten 1983), that the fine ware Urewe vessels were made for an elite class, and had particularly significant, symbolic functions (see also Stewart 1993). More recent considerations however, conclude that Urewe was produced and used in domestic contexts across the region (Ashley forthcoming), whilst at the same time, the vessels and their decoration played a distinctive, non-utilitarian role, cementing family relationships, the importance of the home, and being used in more ceremonial settings (Ashley forthcoming; see also MacLean 1998). 
Radiocarbon dates collected from across Central Africa indicate that there was a peak in social activity covering roughly the 1000 years or more during the Early Iron Age (Wotzka 2006: 285). Unfortunately, evidence concerning social organisation during this period is scarce, with a general lack of Urewe ceramics in association with habitation sites (Reid 1994/5; Stewart 1993). However, during the excavations of the Kemondo Bay sites in North Western Tanzania, a house floor (the only floor yet located associated with Early Iron Age activity) was excavated approximately $10 \mathrm{~m}$ to the west of a number of furnace features, dating to the period of time during which smelting was being carried out at the site (Schmidt \& Childs 1996: 197-199; see also MacLean 1994/5). Such remains could indicate occupation at the smelting site, although whether this was a general occupation site, or one used by the smelters during their production episodes, is unknown.

Palaeoecological research (based on pollen cores) focusing on early land use and subsistence patterns in south western Uganda identified slight fluctuations in environmental aspects of the last 7000 years (Taylor \& Marchant 1994/5). However, low intensity human activity is unlikely to leave a significant signature in pollen records - a serious problem for palaeoecological interpretations of this key period in Great Lakes history (Taylor \& Marchant 1994/5). Nevertheless, this work identified episodes of clearance and burning from around $200 \mathrm{BC}$. It is also intriguing that this work focuses on a range of swamps at different altitudes, suggesting that agricultural practices during this early period was selective and by no means uniform.

Recent research on phytoliths identified in cores taken from swamps at the site of Munsa in Uganda, have revealed that bananas may have been grown from very early times (Lejju et al 2006). However, as the authors also recognise, this is a controversially early date, and it is not until the early second millennium AD that linguistic research can explain or identify more terms for banana (Schoenbrun 1993, 1998), suggesting that this was the period when banana cultivation flourished. A variety of cereal pollen has now been identified in pollen cores taken from southern Rwanda, and in the most recent review of early subsistence, mixed farming including agriculture and herding, was 
found to have been practiced throughout these early periods (Van Grunderbeek \& Roche 2007; although see Reid 1994/5: 305 for earlier criticism).

This domestic use of land (including the production of charcoal for iron production), combined with climatic evidence, contributes to changing environmental and land use patterns (Van Grunderbeek \& Doutrelepont 1988). So it appears that communities during this early period were practicing agriculture (MacLean 1994/5: 299; Van Grunderbeek et al 1983: 42) and small-scale stock-keeping, as well as combining hunting and fishing into subsistence strategies (Marshall \& Stewart 1994; Van Neer 2000: 182-183; Schoenbrun 1998).

Furthermore, during survey in southern Uganda, it was found that sites associated with the Late Stone Age hunter-gatherer (and/or fisher) microlith using groups were situated in poor locations such as on the tops of steep hills where no evidence for food production has been found (MacLean 1994/5, 1996). In contrast, all Early Iron Age sites were found in association with the best agricultural land, where food production would have been maximised (MacLean 1994/5: 298-299). In Rwanda and Burundi, again populations can be documented as gradually moving from poorer lands to those better suited to agriculture (Van Grunderbeek et al 1983: 50). Thus, as food systems and settlement patterns developed, societies moved towards more 'complex' forms of organisation focused on the exploitation of the best land and the production of resources (Reid 1994/5).

These areas, such as that to the east of Butare where this research is focused, combined sympathetic climates (compared to the highlands), with good land for agriculture, as well as ore and wood resources for iron production. Butare, being an area of favourable conditions (i.e. good soils for cultivation, as well as the availability of iron ore and wood for charcoal), is therefore relatively dense in Early Iron Age archaeology (Van Grunderbeek et al 1982: 48-51).

Linguistic evidence has also corroborated the concept of food production gradually developing throughout the Early Iron Age, and suggests that early societies interacted 
and traded with one another (Schoenbrun 1993: 45). Indeed, the recent discovery of a cowrie shell in an Urewe burial in Southern Rwanda by Giblin (2010; Giblin et al forthcoming), indicates contact or exchange networks in existence between central Africa and the Indian or Atlantic coasts (at least $1000 \mathrm{~km}$ away) during these early periods.

As mentioned, the beginning of the first millennium AD marked the pinnacle of the technological, economic and subsistence prowess of the EIA communities, and was a period when populations, "left a lasting impression on the landscape" (Schoenbrun 1993: 45-46; see also Van Grunderbeek et al 1982: 48-51; Wotzka 2006: 285) through, "cultural, economic and technological developments" (MacLean 1994/5: 299). Furthermore, contact with the outside world was growing. From around the fourth century and intensifying through time, exchange between Eastern Africa and the Indian Ocean, and even as far as China, existed for the procurement of ivory and slaves (Oliver \& Fagan 1975: 192-193). Of course, the Great Lakes region lies hundreds of kilometres from the East African Coast, but the cowrie shell mentioned above, and the likely presence of banana, indicates that such long-distance contact did exist, if only on a minimal scale during these early periods.

Archaeometallurgical investigations of iron production traditions during this time in Rwanda, Burundi and north western Tanzania (Maquet 1965; Raymaekers \& Van Noten 1986; Schmidt 1996; Schmidt \& Childs 1985; Van Grunderbeek et al 1983; 2001; Van Noten 1979, 1983), has provided some of the earliest evidence for iron technology in sub-Saharan Africa. The metallurgical practitioners constructed conical/cylindrical furnace shafts made of bricks (in part decorated), over a pit filled with vegetation into which slag drained throughout the process (Craddock et al 2007; Schmidt \& Childs 1985; Van Grunderbeek et al 1983, 2001). There is no evidence of any pre-smelting pyro-technology, or any developing technological parameters prior to the earliest evidence for smelting techniques in the region.

One feature that appears to link this phase of early iron production across NorthWestern Tanzania, Rwanda and Burundi is the unique furnace construction methods, 
namely the use of bricks used to construct furnace superstructure, some of which are decorated (Raymaekers \& Van Noten 1986; Schmidt \& Childs 1985; 1996; Van Grunderbeek et al 1983, 2001). The decoration on the brick features have been linked to the stylistic design of contemporary Urewe ceramics (Van Grunderbeek et al 2001), but continue to cause controversy in terms of how or why they were applied to the furnace design (were they intended for functional, or aesthetic purposes?), as well as why some bricks appear to be decorated, while others do not (Raymaekers \& Van Noten 1986, Schmidt 1996: 221). The form and decoration appears to vary, with two types identified in Rwanda (Raymaekers \& Van Noten 1986:76-77), and five types recognised in NorthWestern Tanzania (Schmidt \& Childs 1985: 83). Decorations including c-shaped patterns (fig. 4.6), s-shapes, and lined ridges have also been documented (Schmidt \& Childs 1996: 224; Van Grunderbeek et al 1983; Raymaekers \& Van Noten 1986).

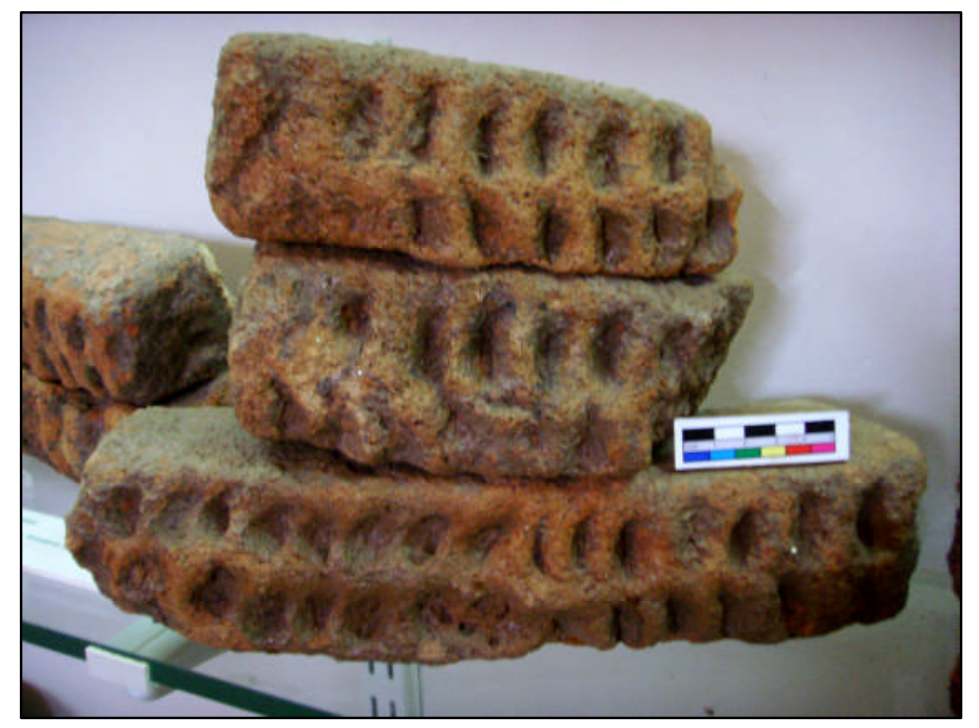

Fig. 4.6 Decorated bricks used in the construction of an EIA furnace (housed in the National Museum of Rwanda)

The ores being used during these early periods were advantageous for smelting. While the Rwandan ores were rich haematite, which when analysed and normalised to $100 \%$, display iron oxide contents of over 95\% (Craddock et al 2007: 10; Raymaekers \& Van Noten 1986: 75; chapter 6 below), the North-Western Tanzanian ores were self-fluxing, porous limonite, which were roasted to maximise their smelting potential (Childs 1996: 286; Schmidt \& Childs 1985: 75). The particularly rich ores used in the Butare region 
imply some form of flux, or mixing of less iron rich ores, in order to successfully produce liquid slag essential for the production of an iron bloom. Recent chemical and microscopic analysis of archaeometallurgical samples from three different sites in Rwanda and Burundi (Craddock et al 2007) demonstrate a relatively alumina-rich, hercynitic slag being produced during the Early Iron Age, at temperatures of around or above $1250^{\circ} \mathrm{C}$, under slightly variable conditions from smelt to smelt (Craddock et al 2007).

It has been suggested that iron objects were relatively common during this early period, but that iron producers probably set themselves apart from communities, and kept their work exclusive and secret (Childs 1996: 280). Thus the hills around Butare could well represent specific communities of iron producers. A further possibility is the hypothesis that the decoration on these early furnaces may have been applied to confuse outsiders: "a concerted attempt was made to make furnaces meaningful, distinctive and accessible, but only to those who knew how to understand and use them" (Childs 1996: 280). Further symbolism and ritual which served to both ensure the success of smelting and keep the practitioners and their knowledge separate from the community as a whole (as well as discouraging others from attempting to smelt iron), may also have been in the use of ritual pits or pots, which were apparently filled with secret medicines and placed below the bases of some furnaces (Schmidt 1997: 231-264). However, this interpretation is based on ethnographic observations and the oral traditions of the modern Haya and other peoples, and has been constructed from only one or two archaeological examples (Childs 1996: 281).

The decoration on the bricks utilised to construct the furnaces may also have symbolic connotations. As has been mentioned above, the decoration found on Urewe vessels, or at least the attention to detail and the artistic skill necessary to produce this, has been likened to the decorated bricks used in the construction of iron production furnaces operating contemporaneously (MacLean 1998). Not only do the bricks appear to have been fabricated accurately, with the dimensions of bricks and ways in which they were made to slot together very exact, alongside the striking, continuous and repeated decoration (Raymaekers \& Van Noten 1986; Van Grunderbeek et al 1993), but the fact that they may have been deliberately built up, and then dismantled after the smelt, to be 
reused again is potentially significant. This investment of time and skilled labour to produce and use the bricks, is reflective of the time and skill also applied to the finely made, elaborate Urewe vessels.

While a broad and traditional link between iron production across the region exists in the use of the decorated bricks, from location to location levels of variation are apparent (this is also a situation represented across the continent - see Rehren et al 2007). Whether it be in the style of the decorated bricks, in the size of the furnace pit, or the presence or absence of a 'ritual pit' below the furnace base (Schmidt 1996: 211-212). As with Urewe ceramics, local producers applied their own local interpretations to this particular technology. The individual choices made by the smelters at different stages of the chaîne opératoire, whether based on the availability of local resources, access to labour, or personal preference to stylistic design, are reflected in the archaeometallurgical record. This in turn reflects the confidence and individuality of the producers themselves, as well as the knowledge they had of the broader technological complexes within which they operated.

Information regarding the spatial organisation of iron technology in the Kemondo Bay iron production sites in North-Western Tanzania (Schmidt \& Childs 1985, 1996: 186233), exceeds that in Rwanda and Burundi. This may be due to a much greater level of preservation and a more limited level of erosion at the Tanzanian sites. While Schmidt's excavations were centred on relatively flat and undisturbed areas, those conducted in Rwanda and Burundi encountered badly eroded and intensely cultivated hills, resulting in a diminished level of contained archaeological features (Schmidt \& Childs 1985: 57). Some features at the KM sites, such as the size of the furnace pits, the presence or absence of a small hole in the furnace pit floors, vary slightly throughout the use of the site, but the general principles of furnace construction, continue (Schmidt \& Childs 1985, 1996). Due to error margins with absolute dates, the exact chronological use of each furnace in relation to one another is impossible to determine (although the use of the site spans hundreds of years), but certainly furnaces were constructed in close proximity to each other, and refuse pits were utilised next to furnace structures (Childs \& Schmidt 1985; 1996) 
In Burundi an archaeometallurgical study including electromagnetic prospection (Vignati-Pagis 1995, 1997), was carried out to provide an insight into both the early iron producing industries and the iron industries that existed in the country on the eve of colonial contact. It was again found that EIA smelting furnaces were constructed in part from decorated clay bricks, and also found in association with Urewe ceramics. Smelting locations appear to be focused towards the top of hills (as in Rwanda). Overall a very similar technological, social and economic picture is painted of these early times in Burundi, as in Rwanda and Tanzania (Vignati-Pagis 1995).

Thus, during the Early Iron Age, iron production was bound within wider economic transformations in farming and herding, which demanded labour and land, as well as advances within various technologies, iron technology being just one of a number of influencing factors:

"Ironworking, as an agent of environmental change, population movement and social stratification has been returned to the role of participant (rather than unambiguous leader) in the wider world of early African social and agricultural history" (Schoenbrun 1998: 71).

Such a concept is supported by Chrétien: "The development of metallurgy, agriculture and cattle keeping during this time contributed to the general success of the area" (2003: 61-63).

Thus, during the Early Iron Age, across the area finely decorated Urewe ceramics are ubiquitous, while furnaces built using specifically decorated bricks are found in the archaeometallurgical record. While the meaning behind the decoration within these two forms of technological expression is unknown, the artistic skill and desire to decorate, and the intricate approach to technological expression, is significant. It would seem probable that to make the number of identically decorated bricks necessary for one furnace structure (acknowledging that bricks were re-used, and that not all of the superstructure of furnaces may have utilised these bricks), time and artistic dedication 
was required. Such artistic skill is also clear within the Urewe ceramics of the time. Furthermore, the direct link between Urewe ceramics and Early Iron Age smelting was illuminated by the Urewe decorated pot at the base of a furnace at Kabuye in Rwanda (Van Noten 1983), as well as the presence of iron objects and Urewe ceramics in what is presumed to be a high status or ritual burial dating to the period (Giblin 2010; Giblin et al forthcoming).

It is a visible transition away from these intricate decorative approaches, within both of these dominating technological spheres, which ultimately demarcates an archaeological change, at around the $9^{\text {th }}$ century $\mathrm{AD}$, and the beginning of the Middle Iron Age.

\subsection{Middle Iron Age}

According to the available archaeological record, significant technological transformations are visible during this period. Ceramic production and use moves away from Urewe ceramics to Roulette decorated ceramics, while iron production practices change from decorated-brick built furnaces producing smaller flows of slag, to apparently undecorated furnaces which can produce large blocks of slag weighing over $100 \mathrm{~kg}$ (of course the very early furnace may also have produced large blocks of slag, that have not survived archaeologically). The lack of precisely dated archaeological and archaeometallurgical sites, combined with the original research focus being on finding the earliest iron production, has however provided a limited amount of knowledge concerning these metallurgical transitions and the reasons behind them. As such this transitional period has not been recognised to a great extent in wider literature. This is unfortunate as the embedded nature of technology (already discussed in chapter 3), means that such transitions could reflect complex social interactions, changes or independent innovations.

Broadly speaking there are a variety of gradual societal transformations during this period, whereby corporate identity was increasingly consolidated in growing populations, and the evolution of centralised power began. Furthermore, exchange networks, increasing manipulation of the environment and control of food production, 
and traditional technological expertise were well established by this time, allowing for the social, economic and political structure of these groups to develop (Vansina 1990: 68-69). Linguistic evidence suggests that sedentary populations became interlinked with mobile pastoralists (in need of more grazing), laying the path for later struggles over power and land (Schoenbrun 1993: 24-29). Across the region, growing focus on enigmatic leaders, rather than family based groups, also paved the way to future forms of centralised industry and power structures, with the power of "Big Men" supported through symbols and rituals which would ultimately evolve into "sacred kingship" (Vansina 1990: 73-74). It is during these early stages that the names for the kingdoms which later dominated the landscape first arise, for example, Ganda, (Schoenbrun 1998: 47).

From an archaeological perspective it is difficult to reconstruct what exactly was happening during this period, both due to a lack of archaeological investigations, and a lack of archaeology, especially to the east of the region. Whether this represents, "a demographic downturn, a lack of visibility of the remains, a change in the nature of the sites, or a lack of interest on the part of archaeologists" (de Maret 2005: 424) is unknown, but it is possibly a combination of all. However, by recognising and defining this era of transition as an archaeological entity for the first time, broader reconstructions of the past are available through a more detailed and specific consideration of the data for this particular period. The key lies in recognising the variety of transitions that were occurring, rather than assuming one homogenous model. Furthermore, a greater amount of objective archaeological evidence (i.e. from research uninfluenced by later political structures), is needed within the region for this period, to allow for both an understanding of social organisation during this time, as well as how these changed over the centuries that followed (Sutton 1993: 41).

It has been suggested that as agricultural abilities and strategies for storing food evolved, people began exploiting previously uninhabited lands (Reid 1991), and populations grew as a result of more stable food supplies. The environment evolved as a result of land clearance for agricultural systems and possibly charcoal production. Thus, competition for more and better land grew, leading to the movement of people, with 
their already established pastoral organisation, agricultural and technological abilities, into new areas, seen for example in central and western Uganda (MacLean 1994/5; Reid 1994/5).

To the north-east of Rwanda, the large occupation sites of Bigo and Ntusi, the ritual sites at Mubende Hill and Munsa, and the major salt trade from Kibiro, all indicate a move towards centralisation of communities and power, with very mixed economies and very diverse social structure from the $10^{\text {th }}$ century AD onwards (Connah 1996; Sutton 1993; Reid 1996; Robertshaw 1999). It is during this period that the Luzira figures and Entebbe figurine appear in the archaeological record, with the human depictions possibly reflecting the new focus on powerful individuals and new forms of cosmological expression (Ashley \& Reid 2008). Much further to the south-west of Rwanda, cemetery sites such as those at Sanga dating to $7^{\text {th }}-9^{\text {th }}$ century AD contain burials and grave goods indicative of stratified, centralised groups operating vast trade networks spanning hundreds of kilometres (de Maret 1985). The technical skill displayed within the array of metal objects deposited within these burials (Nenquin 1971: 197), is significant in terms of the level of mastery over iron by this period. Even further away, to the west, it is known that the Kongo kingdom was "a centralised political state" (de Maret 2005: 426), by the late $15^{\text {th }}$ century when the Portuguese arrived: however, the roots of this political structure could be hundreds of years older.

Technological change during the Middle Iron Age is just beginning to be understood. Within the ceramic data, this transitional phase has recently been re-addressed (Ashley forthcoming; Ashley \& Reid 2008; Posnansky et al 2005), and, rather than the apparent jump between two sets of material culture (namely fine Urewe to coarse Roulette pottery), an intermediary, Transitional Urewe, has been identified. This type of pottery displays, "devolution with regard to fabric, form and decoration" (Posnansky et al 2005: 85). Unfortunately problems of precise dating and of locating sound stratigraphy and occupation sites mean that understanding the relationship between the early Urewe culture, Transitional Urewe, and Roulette pottery is difficult, although "chronological change and temporal variation" (Posnansky et al 2005: 85) seem likely factors in this region-wide shift. Furthermore, the broadly synonymous appearance in the 
archaeological record of other forms of ceramics, such as thick-rimmed Entebbe pottery (Ashley forthcoming; Posnansky et al 2005), support the idea of this middle period being one of local, heterogeneous technological transition. Considering the concept of the embedded nature of technology within society discussed in the preceding chapter, society and technology can therefore be seen changing together in varieties of ways across the region. Ashley has suggested that these transitional ceramics reflect a change in socio-political structures (Ashley forthcoming).

Erosion and decreased soil fertility due to the increase in agriculture and possibly as a result of the use of trees for fuel during iron smelting, had created a scarcity of land by 800 AD (Schoenbrun 1993: 46). Therefore, the period around 1000 AD was (by necessity), "one of expansion, diversification and specialisation, with the opening up of new territories and more efficient exploitation of the environment" (Reid 1994/5: 309). Thus the importance of banana cultivation grew in the northern area of the Great Lakes, as well as other forms of specialists agriculture and pastoralism. Such specialisation, it is argued, acted as a platform for the growing emergence of social complexity and an elites, based on differential access to resources and economic wealth.

Linguistic and archaeological evidence allow the explanation of such specialist strategies such as food production during this Middle Iron Age. Historical roots of words describing the colour, horn size and shape of cattle, alongside terms for banana and other agricultural expressions, exploded during this period, suggesting an increasingly complex attitude to agriculture and pastoralism (Schoenbrun 1993, 1998). These were perhaps the most vital aspects of these Middle Iron Age societies, and as these dynamic economies transformed during this era, "new responses" were ultimately required of the various political and religious situations (Schoenbrun 1993: 42).

In the archaeological record the establishment of large centres such as those of Ntusi in Uganda are evident during this middle period, where large scale cattle activity alongside agricultural practices has been recorded (Reid 1996). Linguistic studies also suggest general developments from the ninth to the fifteenth centuries in the organisation and protection of social hierarchies and a shift from lineage based groups, to more 
personalised power associated with enigmatic individuals, or chiefs (Schoenbrun 1998: 131-134). The concept of hierarchy therefore appears to have been refined throughout the Middle Iron Age in a variety of ways across the region, to ultimately materialise as the kingdoms of the seventeenth century, which will be discussed in the next section.

At first glance it would appear from the archaeological record that iron production decreased in scale during this period in the Great Lakes region due to the handful of sites dated to this period (Van Grunderbeek et al 1983). Furnaces were dated to the eleventh century AD (Van Noten 1983), confirming the continuation of smelting from the Early Iron Age into later times in southern Rwanda, although Chrétien suggests a "technical regression" along with a "disappearance of furnaces" (Chrétien 2003: 56). However, this situation could also be based on the lack of archaeometallurgical remains dated to this period, which reflects the lack of interest on the part of archaeologists working in the country. What is clear, is that the use of decorated bricks as a technological choice ends, and it is fair to say that little else is known until the historical and ethnographic work relating to later periods (Celis 1987; Vansina 2004). However, considering the general technological simplification of ceramic production described above (with those produced during this period representing "a general simplification ... with a reduced number of vessel forms and less ornate decoration and embellishment": Ashley forthcoming), it would appear that iron production may have followed, with smelters no longer investing time producing the decorated bricks of the Early Iron Age.

It is suggested that towards the end of this middle, transitionary period, iron production intensified alongside the socio-economic and political shift towards kingships, to eventually become a cultural pillar in the iconography of kingdoms (de Maret 1985; Reid \& MacLean 1995). The increase in cattle and agriculture, and the general diversification of the economy during this period, would have resulted in an increase in demand for pottery for cooking, and iron for clearing land and protecting herds. Thus the importance of iron, and controlling iron production, was more than likely well established by this period (Sutton 1993: 60-61). 


\subsection{Late Iron Age}

From around the seventeenth century and throughout the later centuries, evidence indicates a further cumulative transition of societies and power towards defined kingdoms such as Nyiginya (Vansina 2004), Karagwe (Reid \& MacLean 1995), Buganda (Wrigley 1996), and Bunyoro (Robertshaw 2003), with social structure based around a king and a top-down level of organisation and power (Sutton 1993). As the references for the literature concerning these Kingdoms suggest, much of our current understandings of these socio-political structures comes from oral histories, court accounts, and the writings of early explorers. The sources are therefore restricted and must be critically assessed (Sutton 1993: 34-39; Vansina 1990: 17, 2004: 5-13). However, throughout all the information collected concerning the history of these kingdoms, diversity and complexity, as well as a sense of broadly associated characteristics (Sutton 1993: 39-41), is highlighted:

"These 'great powers ' had much in common, including quite closely related languages, yet in constitutional structure, in the internal distribution of power and (so far as such things can be defined) in social and cultural values they differed from one another as least as sharply as the historical states of Europe" (Wrigley 1996: 35).

From the seventeenth century, new and developing socio-political configurations emerged in Rwanda (as they had elsewhere in the region), formulating the Nyiginya Kingdom (Chrétien 2003: 107). Through careful examination of oral traditions and king lists, it is known that centralisation of power begins to materialize in the region situated within the bend of the Nyabarongo river (Vansina 2004: 44-65). From this time, through conquests and raids, more land and people became incorporated within this kingdom, under the power of kingship supported by ritual institutions. However, power and the boundaries of the Kingdom fluctuated. The court became organised around symbolic legitimisation of the king, including the Queen Mother, and dynastic drums and herds, surrounded by over-arching rituals associated with the power of the King (Celis 1987: 28-55; Vansina 2004: 55). Kingship was continually enforced: "the royal institution was everywhere embedded in a network that controlled the supernatural" (Chrétien 2003: 132). 
As the mobile and rich court of Nyiginya grew, groups were charged with organising all the supplies for the court, and there may have been specific groups responsible for providing items such as iron hoes (Vansina 2004: 58-59). The extensive armies of the Nyiginya Kingdom, which apparently involved thousands of warriors, (Vansina 2004: 60-78), must have demanded a considerable supply of iron weapons. People were controlled through the imposition of ubuhake contracts of debt, the foundation of the courts power, ensuring every member of society was loyal to the king and court (Vansina 2004: 58-59).

The archaeological excavations of the tomb of the seventeenth century King Cyirima Rujugira, has demonstrated the importance of iron within the symbolism of kingship and the power of the kingdom (Van Noten 1972, Celis 1987). Although this tomb represents a colonial period re-burial of the King (who was not buried at the time due to a lack of a designated successor), the objects (if not necessarily the placement of these within the tomb), are thought to be reasonably authentic. Two iron hammers, used during smithing form the headrest for the king, symbolising the king as a blacksmith, and the importance of this role to the kingdom at this time (Celis 1987: 19-20; de Maret 1985).

Pockets of evidence also exist for industrial iron production during these times (from ca. $17^{\text {th }}-18^{\text {th }} \mathrm{CE}$ ), associated with this shift towards centralised power structures, and the creation of a huge demand for iron and so the impetus for adaptation and innovation to maximise production. This has been documented from the archaeometallurgical and historical record in Buganda (Humphris et al 2009), where the State held significant control over production: "During Nakibinge's reign the blacksmiths were the king's favourites because they made deadly arrows and spears which helped to conquer the enemies" (Kagwa 1934: 160). In 1911, Roscoe documented the wide array of industries which thrived within Buganda, including iron smelting and smithing (Roscoe 1911: 378-379). Various ritual beliefs are outlined, such as the prohibition of contact by the smelters with their wives, but no reasons are given for this. The iron technologies across the region were generally defined by large pit furnaces requiring significant labour and 
resources, although once again, the lack of an archaeologically defined social context is frustrating (Humphris 2004; Reid \& MacLean 1995).

Extensive ethnographic studies of forging (Maquet 1965) and iron production (Celis 1987), demonstrated the significant variety of iron production techniques and styles that developed in the region. This included four physically distinct furnace types which were in operation by the time of colonial contact: furnaces without walls (one type with a pit, one without), furnaces with truncated furnace walls, and furnaces with cylindrical walls (Celis 1987: chapter 2), as well as a number of distinct methods of processing and creating iron objects (Maquet 1965: chapter 9). Insight into the secret, ritual aspects of the iron production processes, which varied from smelting group to smelting group, were also revealed through ethnographic work in Rwanda (Celis 1987). This includes the symbolic importance of the hammer, a trait shared between Burundi and Rwanda, with its fabrication remaining secret, a festival following its completion, and associated with certain kings and chiefs (Vignati-Pagis 1995: 43).

The Roulette decorated pottery which dominates the period from the Middle Iron Age, through the Late Iron Age and into the modern era, exists in a variety of forms of decoration including twisted string roulette (TGR) and knotted strip roulette (KPR) (fig. 4.7 and 4.8). As noted above, in comparison to earlier technological approaches to pottery production (i.e. Urewe), these ceramics represent a simpler, less intricate artistic design. The roulette allows mass production, with more of society potentially involved in production, compared to the specialists who produced the fine Urewe ceramics. 


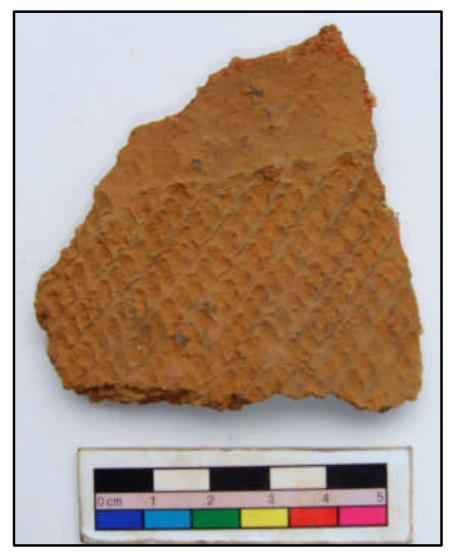

Fig. 4.7 Twisted string roulette

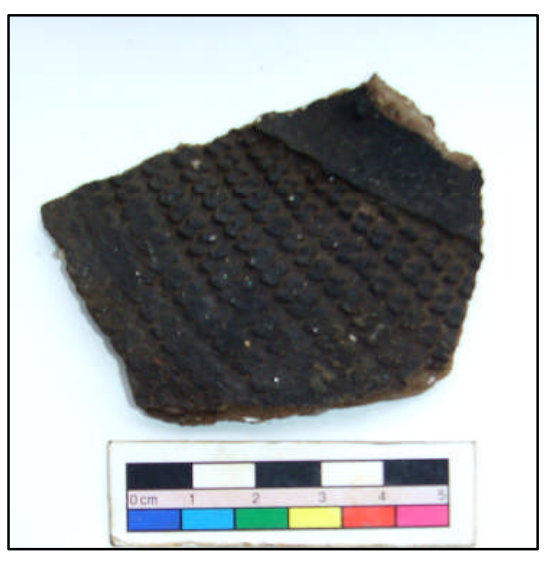

Fig. 4.8 Knotted strip roulette

The iron production of later times also focuses on mass production as the demands placed on these industries by the population and by the court increased. The technological approach to the style of production during later times, lacks the artistic expression (in the form of decorated bricks), or the attention to detail of earlier times. Instead, it appears that increased production seems to be emphasised, in what Wengrow (2001) terms, "the evolution of simplicity". To coincide with this practical, more simplistic approach, which ultimately enabled the production process to be carried out more quickly, the fluorescence of ritual and symbolism can be seen, in which control of the technology is innately linked to the power of the King and the structure of the Kingdom.

Origin myths from kingdoms across the region often feature the founder being associated in one way or another with the ability to make iron, as well as other vital aspects of successful society, including agriculture, women, cattle and pots (Chrétien 2003: 98- 121). The kings often claimed descent from the original smith, thereby holding the power of this symbolic lineage. This allowed the king to maintain power over the most essential producers in the kingdom - the iron workers, as well as commanding the respect of his subjects who recognised the importance of iron to the fertility and power of the kingdom (de Maret 1985; Herbert 1993: 131-165). Public expression of the links between the king, iron and iron producers, endorsing the power of the king, were therefore complex and heterogeneous. 
However, these relationships were rooted in the fact that, "metallurgist and ruler must be paired because they both have the means to manipulate the forces that undergird the cultural and natural worlds ... they mediate not only between male and female fields but also between the ecological, technical, and social divisions of the cosmos" (Herbert 1993: 159). The ritual significance of iron to the power of the king and kingdom is therefore represented in rituals and objects associated with the king (Van Noten 1972; Celis 1987: chapter 1), and the use of iron iconography in the royal rituals to confirm the central theme of the king's power.

Thus, alongside the royal drums, the royal sacred hammers (the symbol of a smith and a king) featured heavily in royal rituals including those associated with hunting, fire, the beginning of the dry season, harvest, war, enthronement, which all invoke the symbolic hammers and hoes, and emphasise the king's connection with iron (Celis 1987; Kanimba \& Kabwete 2000). This complex and embedded facet of the technology of iron production (the symbolic association with kingship), influenced the king, the iron workers themselves, and the entire population, entrenching iron within the foundations of stability and security offered by the State.

While the position and role of iron in societies was both culturally specific and diachronic, many ethnographic studies suggest that those with the knowledge and skills necessary to produce the metal were both revered and feared, recognised as vital but often disassociated from society because of their power, of turning rock into valuable iron metal (Childs 1991b, c; de Maret 1985; Reid \& MacLean 1995). This mystical process of transformation was, at times, linked to origin myths, once again demonstrating the importance of the metal to society (Chrétien 2003: Chapter 2). De Maret (1985) describes the complex link that existed in many parts of Central Africa between iron workers and leadership, essentially combined under the concept of ensuring the fecundity of society, sometimes also incorporating rainmaking roles, and emphasising the importance of iron in ensuring the fertility of society. Thus control of iron meant continual supply of hoes to ensure the fruitfulness of the harvest and also a supply of weapons to protect the populations. This powerfully entwined nature of iron and leadership is displayed in various ways throughout the study area. For example, 
ceremonial anvils have been documented in Karagwe, where two aspects vital to the survival and prosperity of the kingdom - cows and iron, are physically connected, and then directly associated with the king through the anvils decorated with horns within the royal regalia (Reid \& MacLean 1995).

The combination of power, fertility and iron with the concept of the smith-king, has been well documented across the region (Chrétien 2003: Ch. 2; Herbert 1993: 115-163; de Maret 1985; Reid \& MacLean 1995). In Rwanda, according to the accounts of Celis (1987: 17-55), sacred iron hammers and the role of the king as forger of iron are symbolically incorporated into the words and symbols of numerous royal rituals, as illustrated in the following example:

"When the king has become another,

He is dispatched as a descendent of Muhinda.

He goes to Nganzo-lez-Mushongi

And hits the iron to make a hoe of unity...

He hits the iron for four axes

He also hits the iron for two bells

One which rings

and the other which is silent.

He also hits the iron for four hoes.

The ritual follows: 'A forge is installed

And the Tsoobe action the bellows

They tell of the hoe of unity

The descendents of Muhinda turn the hammer over

They say: here is the hammer that your father bequeathed

It had the power to defeat Burundi,

It had the power to defeat Bunyabungo,

It had the power to defeat all countries"

(Celis 1987: 44-46, translated from the original French by the author) 
The cultural significance of iron during later periods is described in detail by Childs (1991), who stresses the integral role of iron to society and more importantly the social position of master smelters. She considers cultural influences and styles displayed in furnaces and associated cultural material as reflecting choices made by the smelters involved (based on both tradition and conscious decisions). Thus, these choices provide a window into the socio-cultural context of the time. Childs \& Killick (1993) also summarise various cultural aspects of iron production seen throughout Africa that could point to the significance of iron to many recent societies. For example, the consideration of furnaces as women giving birth to an iron bloom, noted in Tanzania among the Fipa (also noted in ethnographic studies in south-west Ethiopia by Haaland, 2004), and in parts of Malawi and DRC (1993: 326), as well as in the respect given to metal workers across much of Bantu speaking Africa (1993: 329).

A further consideration of iron technology within the Late Iron Age is the difference between the smelter and the smith in Rwanda. Celis suggests that while all smelters could smith, most smiths did not have the knowledge to smelt (1987: 17). According to Kanimba \& Kabwete, the smiths exchanged supplies or animals for blooms (2000: 14). Smithing was done in small workshops (a simple open construction), often next to roads or near markets, usually owned and operated by a group of artisans, and apprentice systems were used to transfer knowledge (Kanimba \& Kabwete 2000). The archaeological evidence provided by this study has provided further insights into these relationships in the past (explored in chapter 7).

The final theme to be considered before moving on, is that of archaeological preservation. As previously described, furnaces built of decorated clay bricks are a fundamental characteristic of Early Iron Age production. However, the assumption that no decoration or complex techniques were used on furnace superstructures in later times, is based on a lack of any archaeological remains. However, such features may simply not have been preserved in the archaeological record. The ethnographic record documenting other forms of furnace decoration in some parts of the continent are known, for example in Southern Tanzania, (Schmidt \& Mapunda 1997:77-79), in 
Darfur (Haaland 1985), and Nyanga complex in Zimbabwe (Chirikure \& Rehren 2004), although in Rwanda this does not seem to have been the case (Celis 1987). However, during the Middle Iron Age and Early Late Iron Age it is possible that such practices existed and have not been preserved in the archaeological record. Based on the archaeological and ethnographic record so far obtained for Rwanda, it appears that in early times, furnaces were constructed intricately and in a time-consuming manner with the production of decorated clay bricks, and that this elaborate technical approach did not continue in later times.

\subsection{Discussion}

Within this chapter, three periods of time have been defined (although the fluid nature of time is appreciated, and these periods are not viewed as compartmentalised entities): the technologically intricate Early Iron Age, followed by the transitional, heterogeneous Middle Iron Age, culminating in the Kingdom dominated Late Iron Age. Throughout the last two and a half millennia, technology can be mapped to reveal more about the societies of these periods.

Outlined above are concepts of how technology changed and evolved in parallel to societal transformations (and therefore the changing demands placed on technology), as well as parallels between the changing nature of iron production and ceramic production. These similar technological changes both reinforce the concept of embedded technology discussed in chapter 3, and could indicate a practical link between the two technologies. Such a relationship could manifest itself in a number of ways. For example, the concept of the furnace metaphorically interpreted as a woman, and so inherently related to the concept of procreation, has been observed in the historic and ethnographic records across much of eastern and southern Africa, with furnaces referred to as a womb, and taboos focused on the smelters being faithful to their pregnant wives (the furnaces), to ensure a successful smelt (for example see Childs \& Killick 1993; Collett 1993: 502-504; Schmidt 1997). Procreation is often symbolised by heat, as are the transformation processes within the furnace, during which time the male smelters make and successfully deliver an iron bloom. The concept of heat and fertility 
is also incorporated into the symbolism of ceramic pots, cooking being the production of food via heat (Collett 1993: 509; MacLean 1998). Thus women, furnaces and cooking pots, are in various ways analogous to fertility in some parts of the continent (Childs \& Killick 1993: 328). It has also been suggested that the decorative forms on Urewe vessels and on the bricks used to construct early furnaces were representative of the female form or female decoration, and so the concept of fertility (Childs \& Killick 1993: 328).

While this symbolic, cosmological link between iron, pots and women has been outlined above, the second, more practical link lies in the technological role of women and men within ethnographic accounts, whereby men produce iron and their wives, or at least the women of the same groups, produce the pots (Childs \& Herbert 2005: 287; Herbert 1993: 200). Such a link between the technicians producing iron and pots could neatly explain the almost parallel changes within the approach to technology visible in the archaeological record. However, certainly within the ethnographic literature this is not always the case. In Rwanda it was the Batwa group who were (and still are) associated with the production of pots, while the agriculturalists were responsible for producing iron (Celis 1987: 17). Furthermore, in groups such as the Batwa of Rwanda as well as those such as the Royal potters in Buganda, men share or dominate the role of pottery making (fig. 4.9). It is clear that exact relationship between the two technologies is far from being understood in the past, and the present it is far from uniform, although tentative practical and symbolic links can be suggested. Certainly, both technologies and both sets of practitioners were embedded within social structures and were subject to the same social influences. 


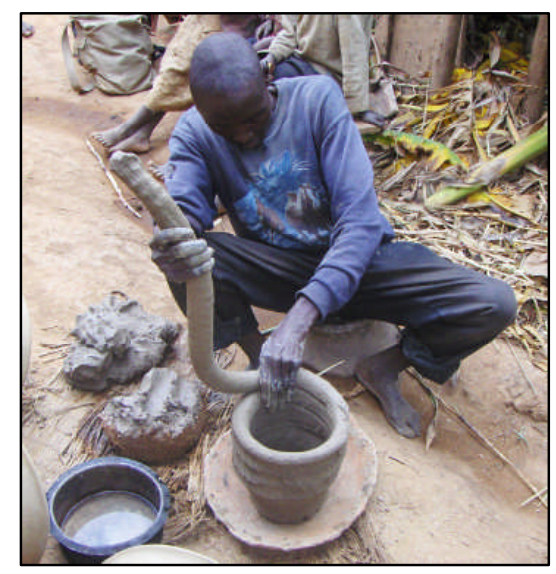

Fig. 4.9 Batwa male potter (photograph courtesy of Marjaana Kohtamaki)

The physical and symbolic parallels between the two technological spheres are most overtly demonstrated at a practical level. The foundations of the Kingdoms and Kingship of later times were innately interwoven with concepts of the power to produce and control iron (de Maret 1985; Celis 1987; Herbert 1993: 131-163), while pots and ceramic production also feature (although to a lesser extent), in royal iconography throughout the region (Herbert 1993: 200-201). Links between the concept of fertility and the power of the king (e.g. Reid \& MacLean 1995), have also been observed amongst groups of potters. For example the Royal potters of Buganda (men charged with producing pots of the court, as opposed to the women who made all other pots), mixed the same herbs given to pregnant women to aid in a healthy birth, into the clay fabric. In addition, the chief of the Royal potters is known as Sedegalla (literally "medicine man"), and so again, the idea of ensuring the success and fertility of the production is mirrored (Giblin 2003).

Ultimately, it is within the complex and evolving web of social structures, including agriculture, pastoralism, healers and belief systems, environment and climate change, and leadership described above, that iron technology is firmly embedded over the last two and a half millennia in the Great Lakes region. The general summary of Great Lakes history provided above enables this web to be untangled so that the role of iron can be accessed. Questions that need to be answered are clear: What were the factors that influenced the production of iron over time? How did technology change over time 
any why? What was the impact of a supply of iron on society over time? The answers to these questions provide the key to understanding the true significance of iron in the region, and in Rwanda.

It is recognised that accessing the reasons behind social and technological change or continuation will remain problematic and must remain speculative (de Maret 2005: 435). Spanning two and a half thousand years within the archaeological record are two key themes: first are the parallel technological traditions, within which local variation and individual expression, is visible; second are the deep-rooted, complex ritual beliefs associated with production and use of these technological traditions, which evolve over time to suit changing societal and technological roles. By providing a more complex scientific reconstruction of early technologies including smelting and smithing; by illuminating iron production during the middle iron age; and by considering the role of iron during the kingdom period, the relationships and interaction between consumers and producers during this period can be revealed. 


\section{5}

\section{Methodology}

The methodology described below was formulated to ensure a thorough and representative investigation of iron production in the Butare area, and to provide the opportunity for comparison between earlier studies and this new research. In the field, the methodology was four-stage: survey; site selection; excavation; sample collection. Each stage was designed to allow for the precise recording of the archaeometallurgical sites and field observations, alongside systematic sample collection. Once in the laboratory, a methodology was implemented to seek a comprehensive understanding of the chemical and microscopic information contained within the samples collected from the field, while taking into consideration problems associated with sample selection (mainly the unavoidably subjective nature of this undertaking), and the limitations of the analytical equipment and time frame available. The analytical techniques were applied following well-established sample preparation and analytical methodologies. Thermoluminescence dating strategies were designed through collaboration with Lorna Anguilano (UCL Institute of Archaeology) and the Universitai Milano Bicocca, while radiometric and AMS dating were carried out by Beta Analytic Inc. The overall methodology outlined here builds upon previous experience researching iron production remains in the wider region (Humphris 2004; Humphris et al 2009).

\subsection{Field methodology}

\section{- Survey strategies}

A high resolution understanding of technological history was required from this research to achieve the aims of this $\mathrm{PhD}$ and to provide a solid base for future largescale research. Therefore a focus on a relatively small geographic area was deemed more appropriate than attempting to demarcate broad technological traditions within the wider region. The locale to the east and north east of Butare town (fig. 5.1) was selected 
as the study area for this investigation due to the well established archaeometallurgical potential identified by previous studies (as described in chapter 4). A $15 \times 15 \mathrm{~km}$ area provided enough scope for a consideration of technological practices across a landscape, as well as ensuring relatively inclusive survey coverage, and so the opportunity to understand the archaeology of the area as intricately as possible. Had the archaeometallurgical record within the chosen locality proven weak, the survey area would have been expanded.

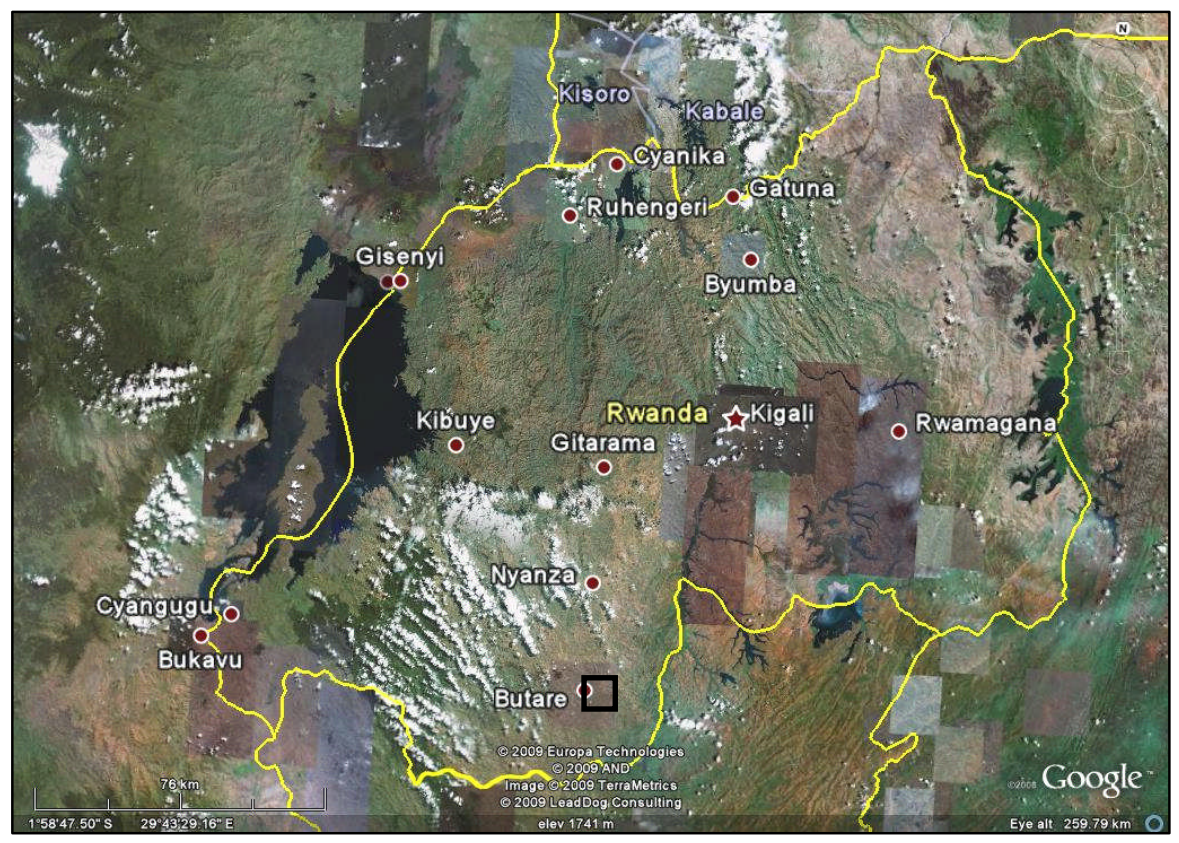

Fig 5.1 Map of Rwanda showing the location of the survey area (illustrated by the black box: map taken from Google Earth)

While a systematic transect survey strategy had been planned (with the team spread out at 5-10m intervals walking across the landscape in parallel lines following established archaeological practice), once on the ground, a number of factors prevented this from being accomplished. First, Rwanda is one of the most densely populated regions of Africa, with a high level of cultivation and habitation across the landscape which makes archaeology difficult to observe on the surface (fig. 5.2). Furthermore, land owners change frequently within the terrain, necessitating frequent interruptions to explain the research to each new land owner and to gain permission to continue with the survey. Another major problem was the topography of the area - Rwanda is known as 'The 
Land of a Thousand Hills' for good reason (fig. 5.3). Much of the survey area is dominated by hill slopes too steep for archaeological remains to cling to, or presumably for people in the past to have inhabited. In addition, the valley bottoms are often waterlogged, while the slopes of the hills suffer from erosion with bedrock frequently exposed. These issues, combined with the legacy of the recent civil war and genocide which have left people suspicious and nervous of strangers, meant that a systematic approach was futile.
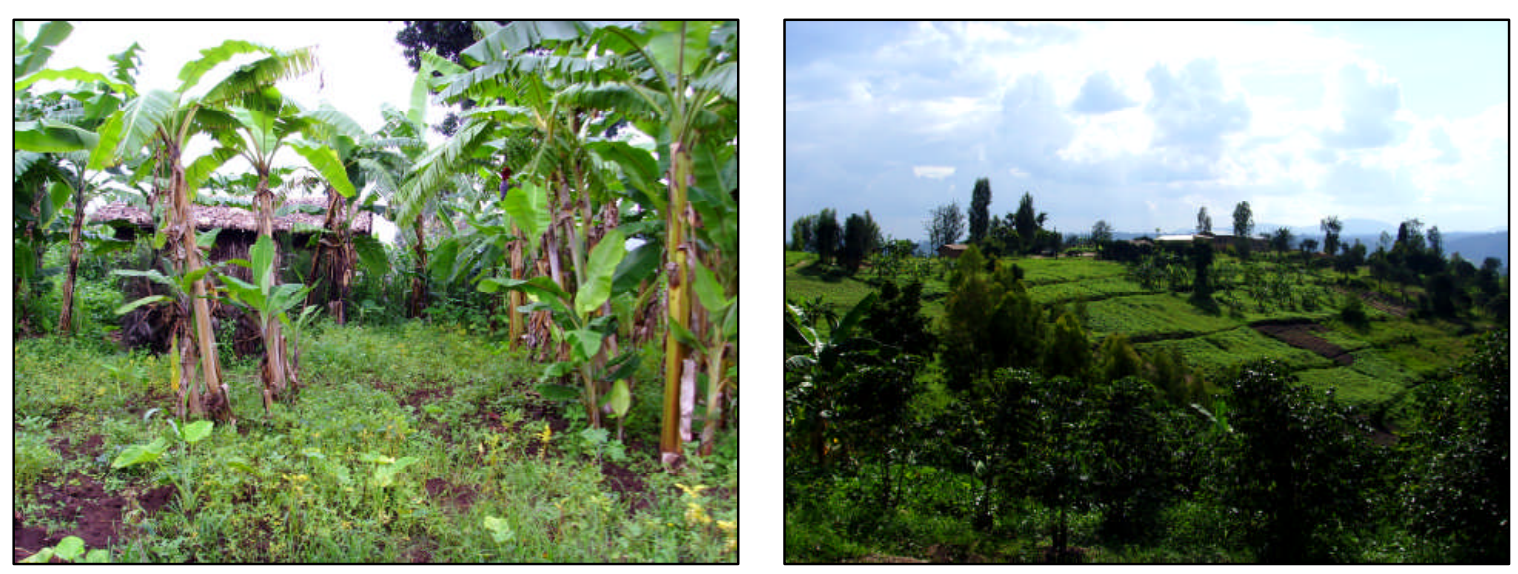

Fig. 5.2 (left) Typical house compound cultivated with bananas, yams and beans

Fig. 5.3 (right) Steep and densely cultivated hill slope

Fortunately, the road networks throughout Rwanda lead into towns and past villages following the easiest routes around the hilly landscape, and therefore generally demarcate areas viable for habitation and cultivation, preferable locations which in all probability have changed little in the last two thousand years. As it was essential to the success of the survey methodology that local people were encountered frequently in order to discuss features of interest that they may be aware of on their land, a pragmatic survey strategy was applied whereby the survey team led by John Giblin (UCL Institute of Archaeology), and including one or two Rwandans (either Museum employees or University students), and varying numbers of British and American students, drove down all passable roads in the study area. Armed with pieces of slag and decorated pottery, at every settlement, market or town along the way local people were asked if they recognised the material and if they had seen any within the local area. Despite many leads which proved unsuccessful, over fifty previously unrecorded sites were 
located in four weeks using this methodology (fig. 5.4). All located sites were recorded thoroughly in a site database, with the GPS coordinates, the type of site and potential for excavation clearly noted (fig. 5.5). General trends noted from the survey data are discussed in chapter 7.

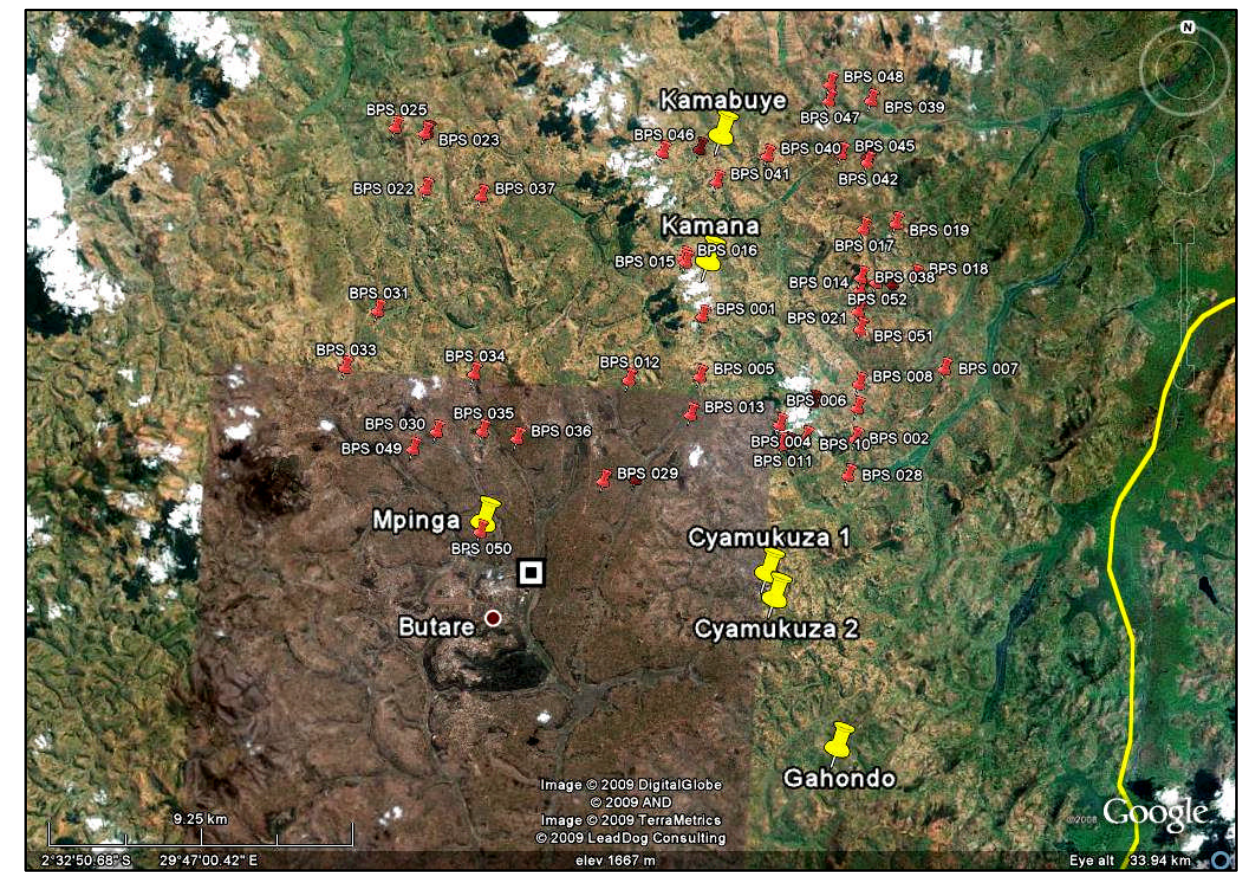

Fig. 5.4 Sites located during survey marked by red pins; sites excavated marked by yellow pins (map taken from Google Earth).

\section{Butare Site Details (pragmatic survey)}

\begin{tabular}{|c|c|c|c|c|c|c|c|c|}
\hline $\begin{array}{c}\text { Site } \\
\text { number }\end{array}$ & Date & Site name & Site Type & Land Use & Access & S & E & Elevation \\
\hline $\begin{array}{c}\text { BPS } \\
001\end{array}$ & $27 / 10 / 06$ & Mugiogwe & $\begin{array}{c}\text { Slag } \\
\text { concentration }\end{array}$ & $\begin{array}{c}\text { Cultivation/ } \\
\text { Habitation }\end{array}$ & Road & 0230.779 & $\begin{array}{c}029 \\
48.044\end{array}$ & $1633 \mathrm{~m}$ \\
\hline
\end{tabular}

\begin{tabular}{|c|c|c|c|c|c|c|c|}
\hline Orientation & $\begin{array}{c}\text { Surface } \\
\text { visibility }\end{array}$ & Site description & $\begin{array}{c}\text { Surface } \\
\text { materials }\end{array}$ & $\begin{array}{c}\text { Materials } \\
\text { collected }\end{array}$ & $\begin{array}{c}\text { Density of } \\
\text { finds }\end{array}$ & Preservation & Comments \\
\hline $\begin{array}{c}\text { Near hill } \\
\text { top }\end{array}$ & Average & $\begin{array}{c}\text { Large slag } \\
\text { concentration } \\
\text { around house and } \\
\text { within house } \\
\text { foundations }\end{array}$ & Slag, KPR & Slag, KPR & High & Variable & $\begin{array}{c}\text { Recommended } \\
\text { for test } \\
\text { excavation }\end{array}$ \\
\hline
\end{tabular}

Fig. 5.5 Site recording sheet used during survey 


\section{- Site selection}

The majority of sites located during survey were identified by the presence of fragments of iron slag (fig. 5.6), as well as sherds of rouletted and occasionally Urewe ceramics. Although fifty three archaeological sites were located during the survey stage of the project, due to time constraints, not all of these could be selected for investigation. From the detailed field observations it was noted that a number of the located sites contained a diversity of archaeometallurgical remains including slag, furnace bases and tuyere fragments. These sites could be expected to contain more detailed archaeometallurgical information, and perhaps more pertinently, could provide more relevant material for dating, including technical ceramics for luminescence dating and charcoal for radiometric dating. Therefore, although it is recognised that by prioritising sites displaying more obvious and extensive archaeometallurgical remains this study may well overlook less obtrusive smelting traditions, in light of the time available and the specific goals of this study, six of the most 'complete' smelting sites were selected for excavation. However, samples of slag were collected from each site located across the survey zone and macroscopic observations of the study area as a whole are considered in chapter 7.
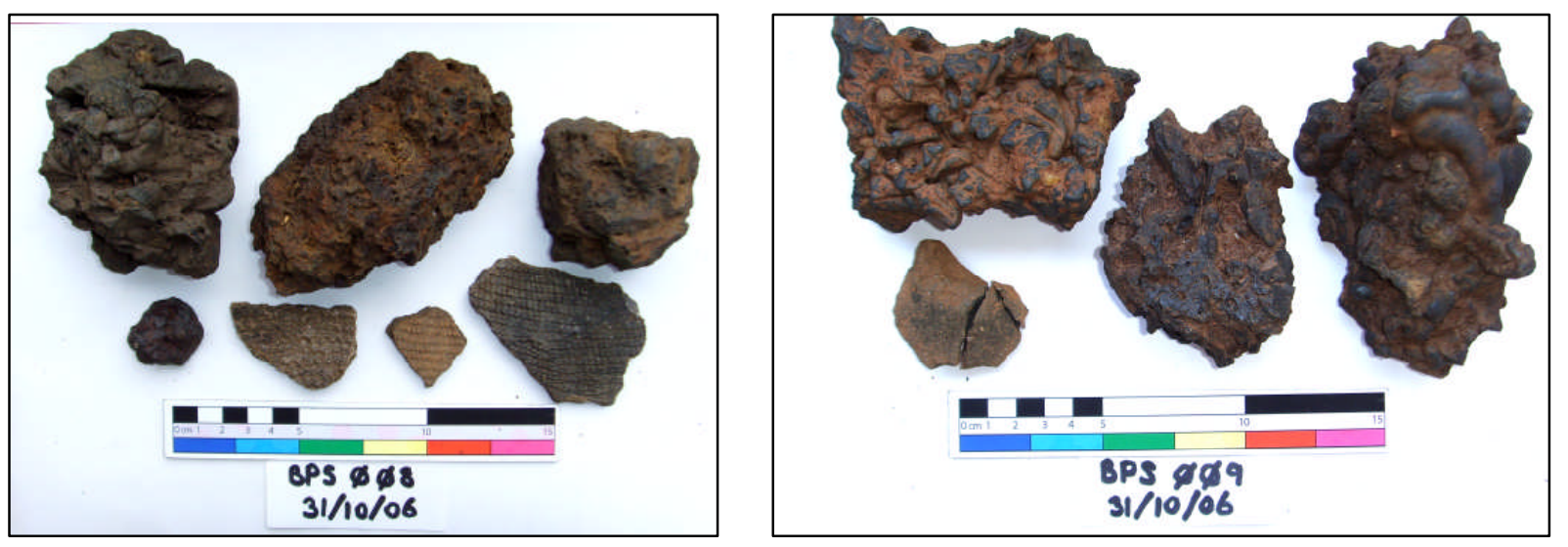

Fig. 5.6 Slag and ceramic samples collected from the field during survey

The six sites selected for excavation contained the remains of smelting structures and waste products that had survived the years, the troubles, and intensive habitation and cultivation. The sites are dispersed across the study area rather than being clustered 
together, allowing for an overall view of smelting technology across the area, and macroscopic variations in smelting techniques were visible between each site. Table 5.1 describes the sites chosen for excavation, their exact location, the approximate time period to which they are associated (based on macroscopic similarities to sites excavated previously within the region) and the archaeometallurgical remains visible before excavations began.

\begin{tabular}{|c|c|c|c|}
\hline Site & Location & $\begin{array}{l}\text { Estimated } \\
\text { time period }\end{array}$ & Archaeometallurgical remains \\
\hline $\begin{array}{l}\text { Gahondo } \\
\text { (GHD) }\end{array}$ & $\begin{array}{l}\text { S } 0238.03 .8 \\
\text { E } 02950.40 .0 \\
\text { Elevation } 5304 \mathrm{ft}\end{array}$ & Early Iron Age & $\begin{array}{l}\text { One very obvious furnace base outline and the } \\
\text { partially eroded outline of a further furnace } \\
\text { base }\end{array}$ \\
\hline $\begin{array}{l}\text { Cyamukuza } 1 \\
\text { (CMZ 1) }\end{array}$ & $\begin{array}{l}\text { S } 0235.242 \\
\text { E } 02949.310 \\
\text { Elevation } 5413 \mathrm{ft}\end{array}$ & Later Iron Age & $\begin{array}{l}\text { Approximately } 23 \text { large blocks of slag scattered } \\
\text { across an area roughly } 10 \times 10 \mathrm{~m} \text {, including a } \\
\text { furnace pit containing a slag block in situ }\end{array}$ \\
\hline $\begin{array}{l}\text { Cyamukuza } 2 \\
\text { (CMZ 2) }\end{array}$ & $\begin{array}{l}\text { S } 0235.38 .8 \\
\text { E } 02949.27 .5 \\
\text { Elevation } 5578 \mathrm{ft}\end{array}$ & Later Iron Age & $\begin{array}{l}\text { Approximately } 45 \text { large slag blocks scattered } \\
\text { over an area roughly } 20 \times 40 \mathrm{~m} \text {, as well as the } \\
\text { remains of two furnace pits with slag blocks in } \\
\text { situ }\end{array}$ \\
\hline $\begin{array}{l}\text { Mpinga } \\
\text { (MNA) }\end{array}$ & $\begin{array}{l}\text { S } 0234.421 \\
\text { E } 02944334 \\
\text { Elevation } 5752 \mathrm{ft}\end{array}$ & Later Iron Age & $\begin{array}{l}\text { Approximately } 15 \text { slag blocks within a } 5 \times 5 \mathrm{~m} \\
\text { area with one very large furnace base with slag } \\
\text { block in situ }\end{array}$ \\
\hline $\begin{array}{l}\text { Kimana } \\
\text { (KMA) }\end{array}$ & $\begin{array}{l}\text { S } 0230.568 \\
\text { E } 02950.390 \\
\text { Elevation } 5164 \mathrm{ft}\end{array}$ & Later Iron Age & $\begin{array}{l}\text { Approximately } 20 \text { slag blocks within a } 20 \times 30 \\
\mathrm{~m} \text { area, as well as one furnace pit. House } \\
\text { foundations comprised of numerous slag blocks } \\
\text { and grinding stones }\end{array}$ \\
\hline $\begin{array}{l}\text { Kamabuye } \\
\text { (KBE) }\end{array}$ & $\begin{array}{l}\text { S } 0228.096 \\
\text { E } 02948.553 \\
\text { Elevation } 5098 \mathrm{ft}\end{array}$ & Later Iron Age & $\begin{array}{l}\text { Partially visible outline of a furnace base } \\
\text { apparently build into the surrounding rock with } \\
\text { pieces of slag visible within the pit }\end{array}$ \\
\hline
\end{tabular}

Table 5.1 Details of the six sites selected for excavation

Excavating six sites allowed for approximately three weeks to work at each once weekly Gacaca days (genocide courts), local holidays, Sundays, tree planting days, Umuganda days (obligatory community work days), and any other days when archaeological work was impossible were taken into account. This also took into 
account the significant time involved in conforming to the bottom-up style of local government, whereby a rubber stamped document granting permission for excavation had to be obtained from the mayor at the district office, and then presented to the local sub-district office, and then to the local representative. Only when all concerned were satisfied, could work begin at a site.

\section{- Applied field methods: community discussions; excavation; sampling}

The initial phase of work at each site involved explaining and discussing the proposed archaeological investigation and any inconvenience that may be caused with the relevant land owner and then negotiating a sum of compensation. This sum recognised the fact that some crops would be unavoidably damaged as a result of the work (every effort was made to minimise this), and also provided the land owner with a wage for protecting the excavations throughout the work.

Once these matters were resolved, a community meeting was called for the following day to make certain everyone in the local area had notice. With the help of an interpreter the team was introduced, the background to the project explained, and the research described in detail. This included an explanation of what the archaeometallurgical remains littering the area represent in terms of Rwandan socio-technological history: high temperature metallurgical traditions which supported the growth and power of society in the region for millennia. It was sad but not unexpected (after working in Uganda) that local people immediately asked when the Europeans had introduced the technologies to Rwanda. The widely held belief that Europeans brought science and technology to Africa is one aspect of colonial legacy that this project directly tackled within the groups of people who were exposed to this research. Questions and debates followed, and eventually, when all interested people were content with the research and with the team, work could begin. School children were also invited to visit the sites during the excavations (fig. 5.7). 


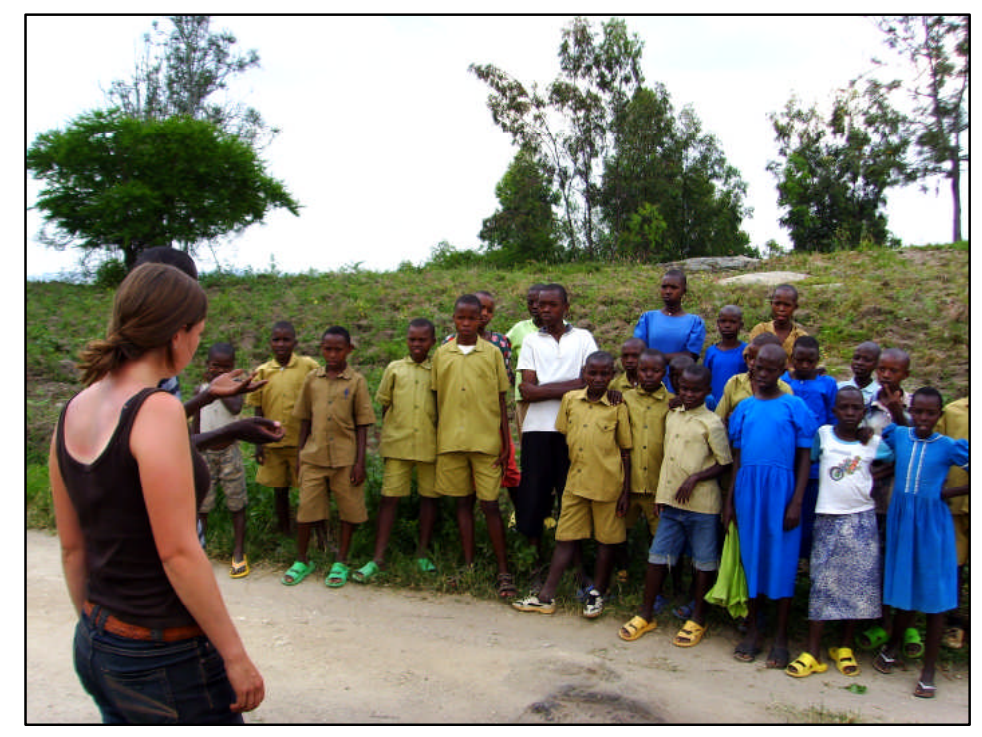

Fig. 5.7 School children learning about the archaeological remains

At each of the six sites excavated the primary goal was the accurate recording of field observations, and the representative sampling of archaeometallurgical and associated features. The extent of the archaeological deposits at each site was established through small-scale transect survey across the excavation area, and field observations were carefully recorded. A plan of the entire site was drawn, including each slag block and other features to be investigated, along with locations of test pits (for example see fig. 5.8). All smaller features, such as furnace pits and slag clusters, were then planned on a larger scale to allow more specific characteristics to be shown (for example see fig. 5.9). Numerous photographs were taken at all stages. The field strategy then comprised of three tasks: test pit excavation across the site; furnace/special feature excavation; slag block recording and sampling. 


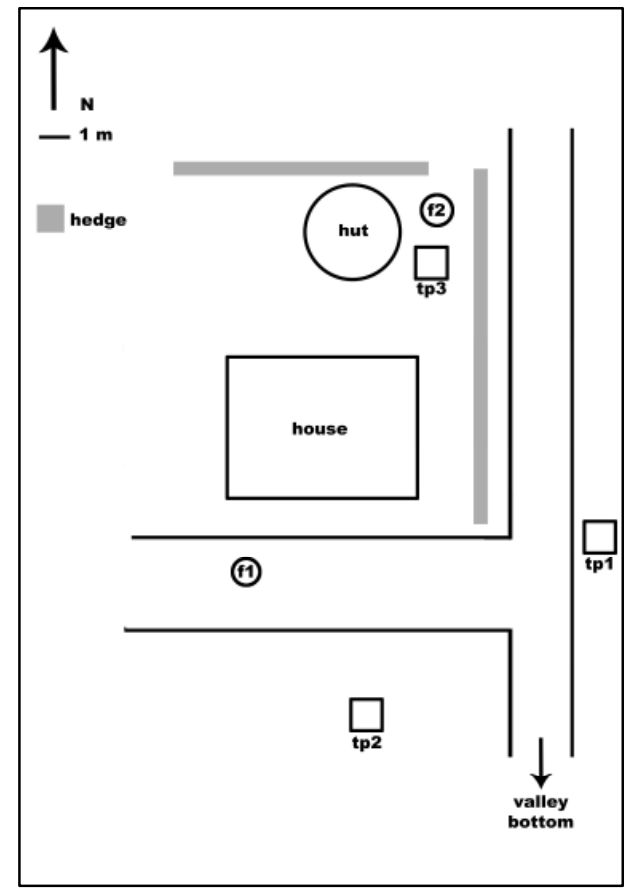

Fig. 5.8 (left) GHD site plan

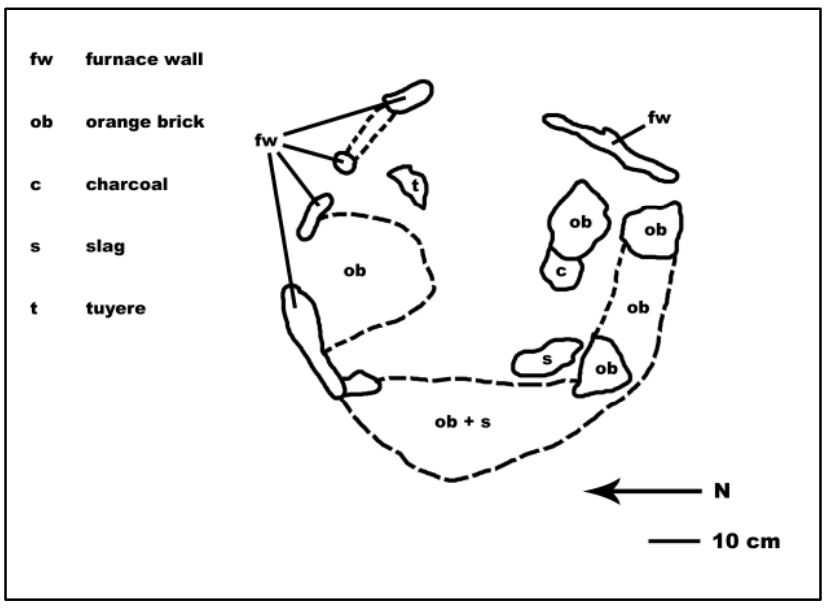

Fig. 5.9 (above) GHD furnace 2 after clean-up

At each site a number of test pits were dug to test for the existence of associated archaeological remains and the potential for contained stratigraphy within the study area such as post holes or refuse pits, which could provide further contextual information concerning the organisation or use of the site as a whole. The test pits were located around the archaeometallurgical features and up to $20 \mathrm{~m}$ away, and were set up as either $1 \mathrm{~m} \times 1 \mathrm{~m}$, or $1 \mathrm{~m} \times 2 \mathrm{~m}$ units. The top 10-20 $\mathrm{cm}$ layer of each test pit (being disturbed due to cultivation and/or habitation), was removed quickly with a hoe. Following this, the test pits were excavated either in contexts or in $5-10 \mathrm{~cm}$ spits depending on the nature of the deposits, and recorded using standard context sheets (see fig. 5.10). Where possible, all soil was sieved for finds. Where the soil was too clay-like, as in the case of MNA and CMZ 2, it was sorted through by hand. None of the test pits yielded any stratigraphically contained cultural or archaeological information either in section or in finds; in fact at GHD, CMZ 1, CMZ 2 and $\mathrm{KBE}$, the deposits were no more than $30 \mathrm{~cm}$ deep before hitting bed rock - demonstrating the extent of the erosion problem facing parts of Rwanda. 


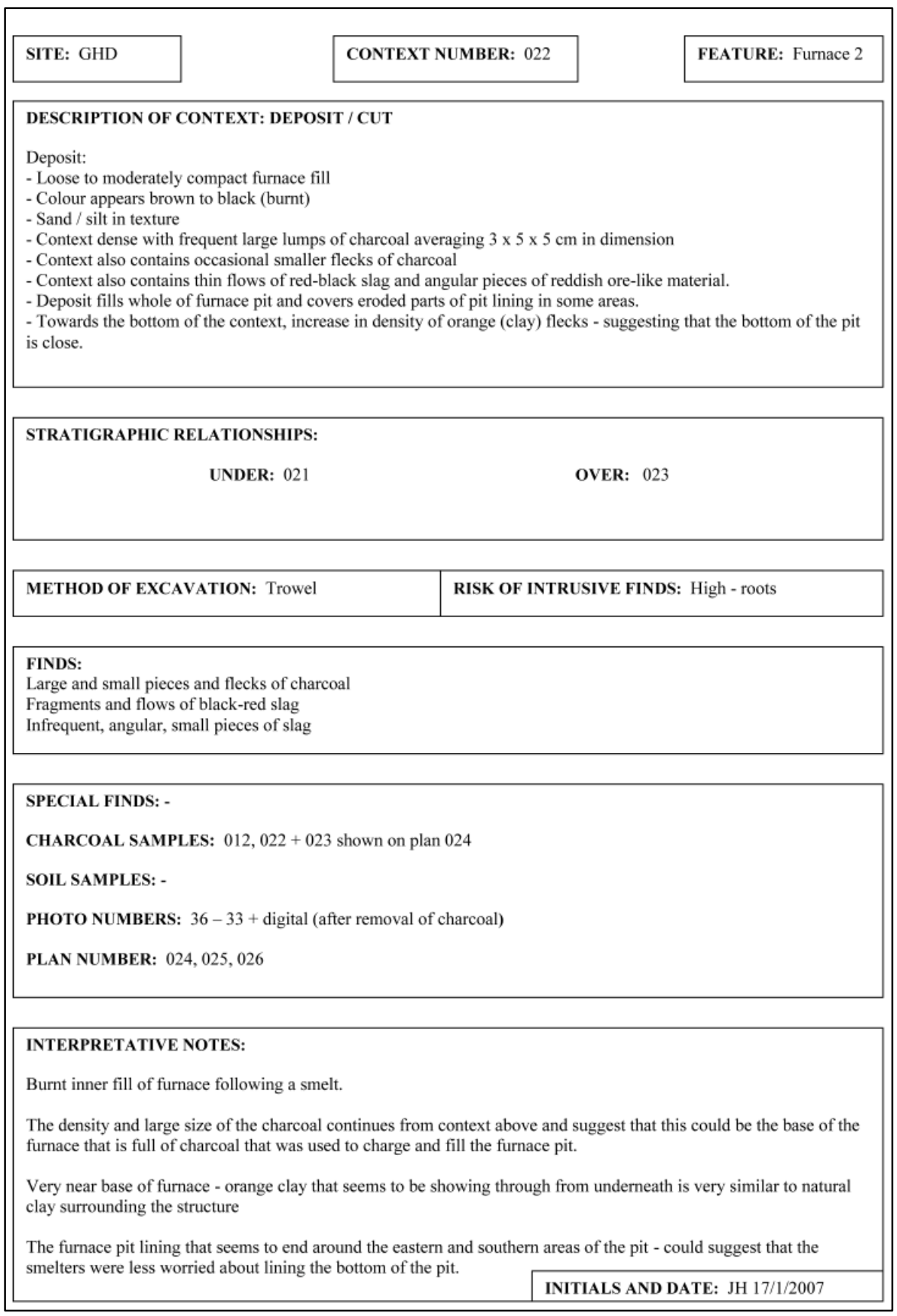

Fig. 5.10 Example of a typical context sheet

The excavation methods consisted of two approaches due to the differences between the archaeometallurgical remains encountered at GHD (the Early Iron Age site) in comparison to the sites dating to later periods. As table 5.1 illustrates, while at the later sites the majority of the archaeological finds were large blocks of slag, at GHD this was 
not the case. Therefore the excavation method applied at GHD will be described first, followed by the consistent method used at the other five sites.

At GHD it became clear as soon as the areas surrounding the two furnace pits had been cleared that the furnaces themselves were more complicated than any other furnaces encountered before by the author, and that these complexities were the result of smelting traditions dating to the Early Iron Age (indicated by the presence of specifically decorated clay bricks, as described in chapter 4). Due to the random deposits of the bricks and slag flows throughout the pit itself, it was decided that the best way to excavate was not to section the feature but to excavate in $5 \mathrm{~cm}$ spits and photograph and plan at each new context. Each fragment of slag, brick and other material including ore, was numbered and then removed, thus all material from the furnace pits at GHD can be associated with their exact horizontal and vertical position within the features.

The approach to the excavation of furnace features at the later sites was different and had to be adapted depending on the situation encountered. At CMZ 1, CMZ 2, MNA and KBE, furnace bases remained with the waste (a large slag block) of the final smelt still in situ and very firmly stuck in the furnace structure (for example see fig. 5.11). In order to obtain a section of the feature, at $\mathrm{CMZ} 1$ and $\mathrm{KBE}$, half of the furnace base was excavated away from the slag block and underneath it. This left a good section with the slag block sat in the furnace base (for example see fig. 5.12). The slag block was then prised off the furnace base using a car jack, allowing for a slow and gradual lift to preserve the furnace base as much as possible for recording (for example see fig. 5.13; 5.14). This was also the safest way of lifting the slag blocks, some of which weighed nearly $100 \mathrm{~kg}$. 


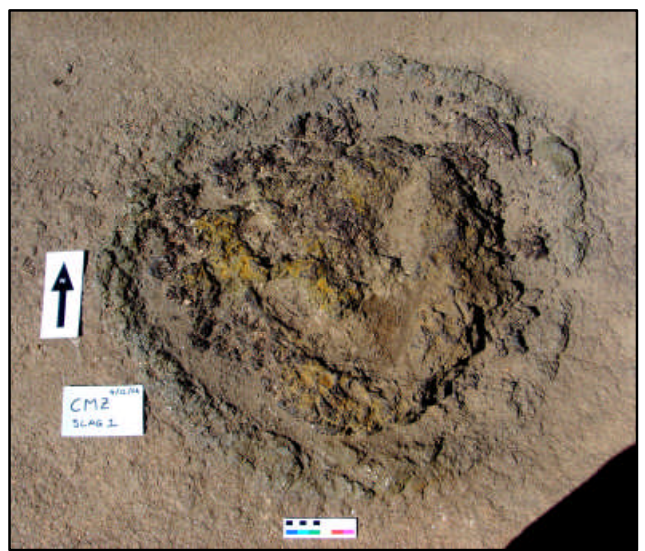

Fig. 5.11 CMZ 1 Furnace and slag block

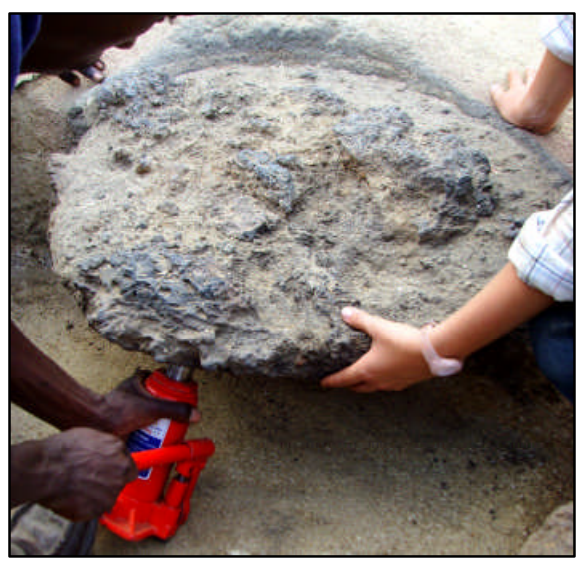

Fig. 5.13 KBE Lifting the slag block

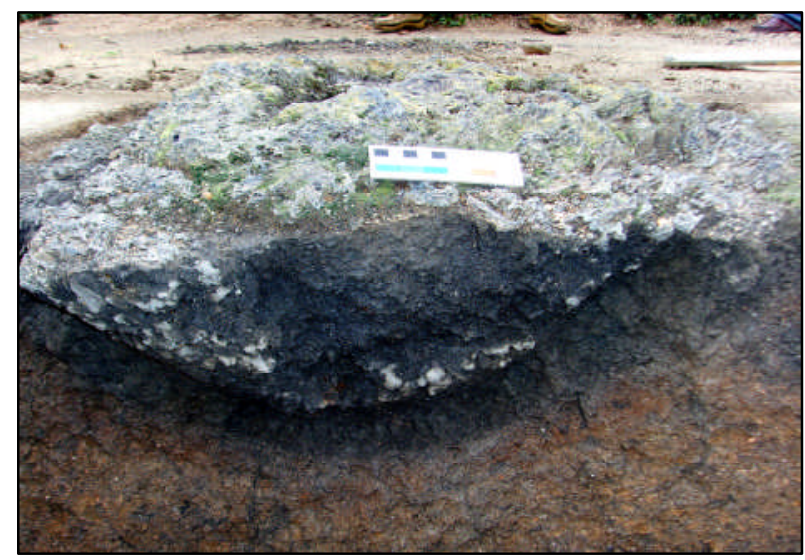

Fig. 5.12 CMZ 1 Furnace section

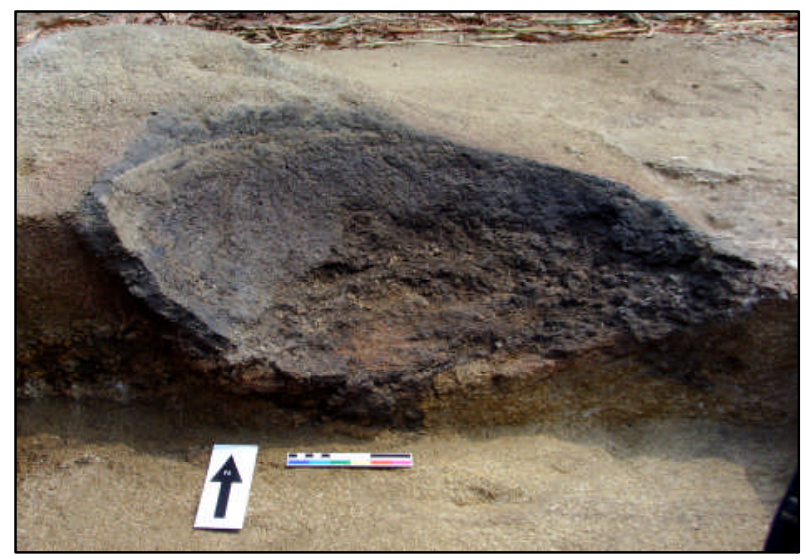

Fig 5.14 KBE Empty furnace pit

At MNA and CMZ 2, furnace bases were left intact and the slag blocks lifted out (fig. 5.15; fig. 5.16), while at KMA the furnace base did not contain a large slag block.

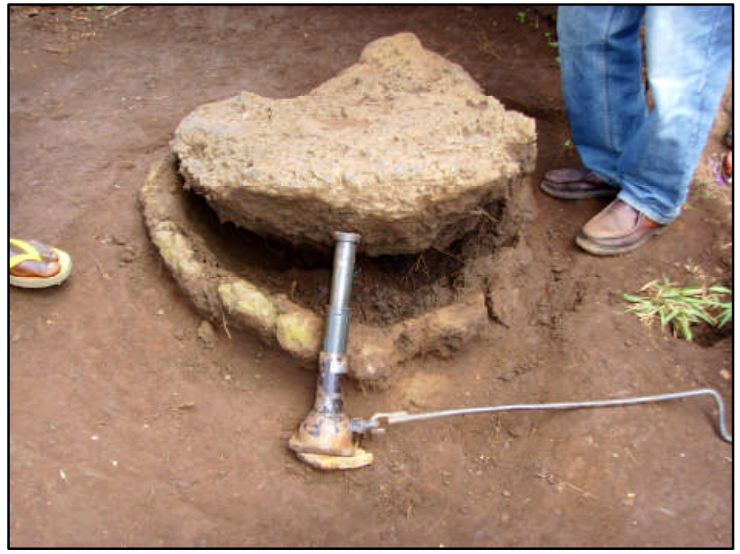

Fig. 5.15 MNA lifting slag

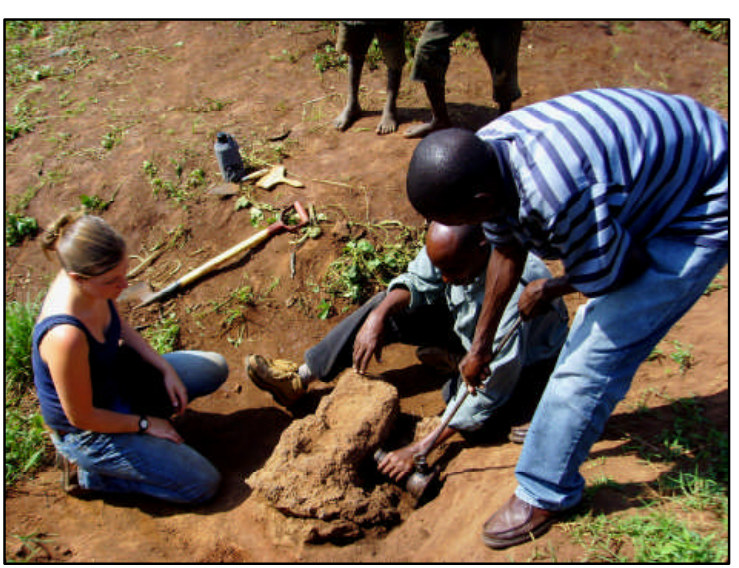

Fig. 5.16 CMZ 2 lifting slag 
In each case, samples of the furnace pit lining were taken from either the north and south sides, or the east and west sides, depending on the best preservation. Samples of any tuyere fragments found on site, as well as samples of domestic pottery and any other associated features were all taken from the sites in clearly labelled sample bags.

At the five sites dating to later periods, the large slag blocks were sampled following a well defined procedure developed in Uganda during previous research by the author (Humphris 2004; Humphris et al 2009). Five of the most visually typical and complete slag blocks at each site were selected for recording and sampling. Each slag block was drawn, photographed and described in a specially designed 'slag sheet' (fig. 5.17), and then sectioned with a sledge hammer (fig. 5.18). The section was then drawn and photographed, and all of the fragments from the block weighed. Three samples were then taken from each slag block: samples from the top, middle and bottom of the block (fig 5.19). Taking samples from throughout each block in this manner allows for a detailed study of smelting parameters from the beginning to the end of each smelt to be reached using the analytical results from each sample. 


\begin{tabular}{|c|c|c|}
\hline & SLAG RECORD & \\
\hline SITE: CMZ 1 & SLAG NUMBER: 2 & DATE: $8 / 12 / 06$ \\
\hline \multicolumn{3}{|c|}{ LOCATION AND DESCRIPTION OF SLAG BLOCK: } \\
\hline \multicolumn{3}{|c|}{$\begin{array}{l}\text { Slag block dumped in south east corner of the unit. Block was lying on its side with } 25 \mathrm{~cm} \text { of its volume below } \\
\text { ground surface. }\end{array}$} \\
\hline \multicolumn{3}{|c|}{ Smooth bowl-shaped base and rough top: macroscopically very similar to the other slag blocks at the site. } \\
\hline \multicolumn{3}{|c|}{$\begin{array}{l}\text { Does not appear to have lost very much of its original bulk through erosion of breakage - appears very } \\
\text { complete. }\end{array}$} \\
\hline WEIGHT: 94 kg & DIMENSIONS: $60 \times 29.5 \times 49 \mathrm{~cm}$ & \\
\hline \multicolumn{3}{|l|}{ SAMPLES TAKEN: } \\
\hline $\begin{array}{l}\text { A }=\text { Top } \\
B=\text { Middle } \\
\text { C }=\text { Base }\end{array}$ & $\begin{array}{l}\text { D }=\text { Bowl section }, \text { side }, \text { middle } \\
\text { E }=\text { Top section }, \text { side }, \text { middle }\end{array}$ & \\
\hline
\end{tabular}

\section{CHARCOAL SAMPLES:}

None found within the section of the block

\begin{tabular}{|lll|}
\hline PHOTOS: & PLANS: & SECTIONS: \\
$18=$ top & 011 & 003 \\
$17=$ bottom & 012 & 004 \\
$16=$ section & & \\
\hline
\end{tabular}

\section{INTERPRETATIVE NOTES:}

Very easy to distinguish between the top and the bottom of the block.

Section displays no cold interfaces - slag block is the result of a continuous smelt, as is the case with the other slag blocks at the site

Overall shape, weight and section when compared to the other blocks suggests a very uniform methodology in operation during smelting episodes at CMZ 1

Fig. 5.17 Example of a typical slag block recording sheet 


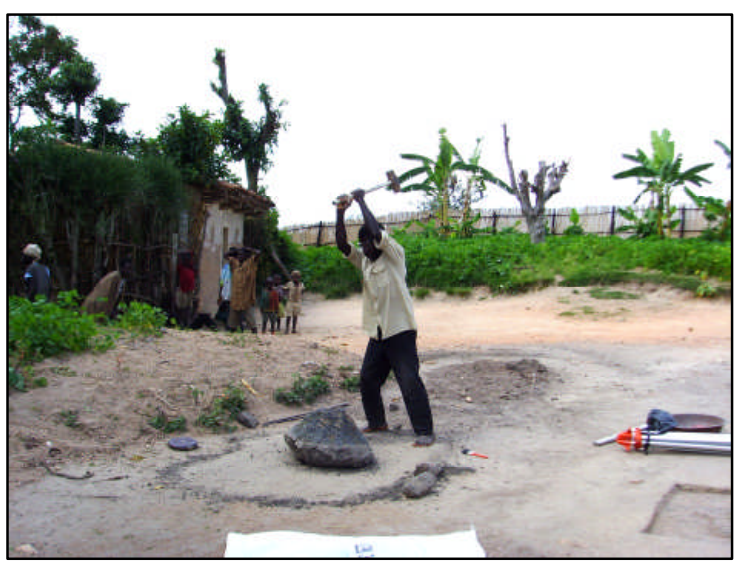

Fig. 5.18 Sectioning slag blocks

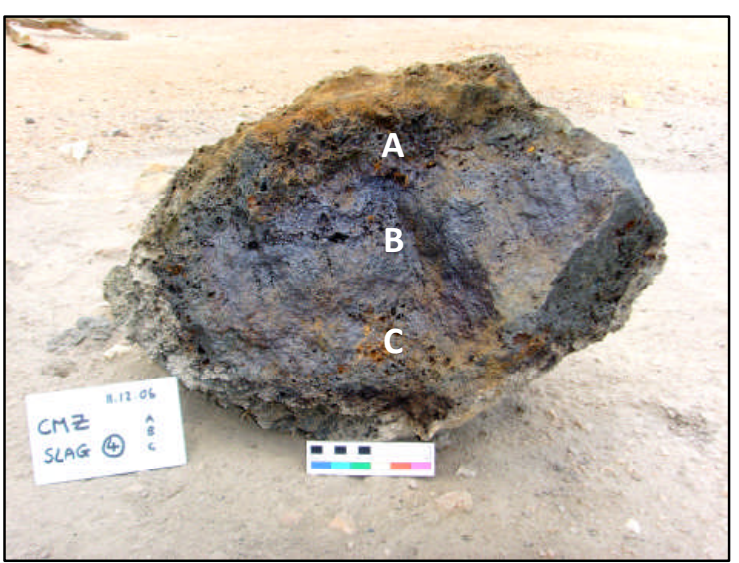

Fig. 5.19 Slag block section

A site report log was kept daily and any field observations noted and deliberated continually. A detailed report was prepared for the National Museum of Rwanda, including the locations of the excavated sites, a catalogue of samples collected and a request for permission to export samples to the UCL Institute of Archaeology for analyses. In the field, each sample collected (with the exception of the slag samples which are bulky and which provide little information unless subjected to extensive laboratory analyses) was halved, with half going to the National Museum of Rwanda (clearly marked and labelled) and half going to the UK for analyses. The samples were exported to the Wolfson Archaeological Science Laboratories at the UCL Institute of Archaeology.

\subsection{Laboratory techniques}

A variety of laboratory techniques were utilised to gain a detailed understanding of each sample collected in the field, including slag, ore, technical ceramic and domestic pottery. Each laboratory method required specific sample preparation, analysis and data processing. The techniques used and described below were invariably constrained by the availability of equipment, although every effort was made to ensure as exhaustive an analysis as possible. 
As would be expected, a degree of corrosion was present within the slag samples. To overcome this issue and to ensure the bulk compositional results were not affected by such post depositional alteration, areas of visible corrosion were removed from each sample using a tile cutter. The optical microscopy investigations (OM) and the images and analysis generated using the scanning electron microscope (SEM) of each slag sample were used to confirm that any areas of corrosion remaining in the sample following this step were negligible.

\section{- (P)ED-XRF}

Polarising energy dispersive X-ray fluorescence using a Spectro X-Lab Pro 2000 with five secondary targets at a maximum accelerating voltage of $40 \mathrm{KeV}$ and an evaluation method optimised for iron-rich materials (Veldhuijzen 2003) was used to obtain bulk chemical compositions of each sample. A different evaluation programme, Turboquant, was used for ceramic samples.

Samples for (P)ED-XRF analyses were prepared by milling ca. $20 \mathrm{~g}$ from each sample in a tungsten carbide planetary mill with counterweight to achieve a particle size of approximately $50 \mu \mathrm{m}$. Here a further limitation of the research becomes evident - due to the considerable cost of exporting material from Rwanda, each of the samples taken from the field was kept to a minimum in terms of weight and volume. Whether $20 \mathrm{~g}$ of a sample is representative of the total volume from which it was taken is presumed, but not known for certain. However, by analyzing a number of samples from each slag block, such a limitation is partly negated.

The powdered samples were dried in an oven overnight at $100^{\circ} \mathrm{C}$ and then thoroughly mixed with a small amount of industrial wax. This mixture was subjected to $15 \mathrm{~T}$ of pressure in a $32 \mathrm{~mm}$ diameter mould to produce a homogenous pellet. Each pellet was analysed three times, the compositional values presented in this thesis being the averages of these three XRF analyses. Major and trace elements were converted to oxides by stoichiometry and the results normalised to $100 \%$ by weight to allow a clearer comparison between samples. The original total before normalising is presented to provide an accurate indication of the quality of the data, as mentioned above. 
The (P)ED-XRF cannot detect the oxidation state of the elements present within the samples (for example $\mathrm{Fe} ; \mathrm{Fe}^{2+} ; \mathrm{Fe}^{3+}$ ). In this study, iron values are reported as $\mathrm{FeO}$ because wüstite, fayalite and hercynite are the main microscopic phases identified across the sample range. However, the problem with this stochiometric conversion is apparent within the given analytical totals, which are not always precisely $100 \%$. One further issue with the methodology described above is that using powder pellets for bulk analyses produces slightly diminished accuracy levels due to the variable nature of the mineralogical make-up of the samples. Fused beads are considered the optimum method for obtaining more accurate compositional data for major elements in the type of archaeological samples discussed here, however this method is not available within the UCL Institute of Archaeology, and previous studies have shown powder pellets to be sufficient for this type of investigation (for example Charlton 2006; Chirikure 2005; Veldhuijzen 2005).

The precision and accuracy of the $(\mathrm{P}) \mathrm{ED}-\mathrm{XRF}$ results were tested through repeated analyses of certified reference materials (CRMs) of compositions comparable to the archaeological samples. For comparison with the slag samples the following three CRMs were utilised: Swedish Slag (Kresten \& Hjlirthner-Holdar 2001); ECRM 651-1 Lincolnshire Iron Ore (Bureau of Analysed Samples Ltd (BAS) 2009); ECRM 681-1 Iron Ore (BAS 2009). While the BAS data has been included in this study as reported (see below), the results for the analysis of the Swedish slag are not certified but have been taken using averages from previous analyses (without including the outlying figures). All figures have been converted into oxides for comparison with the data from this study.

For comparison with the ceramic material, the following three CRMs were utilised: SARM 69 (clay potsherd from an iron age site - Department of Geology, University of the Free State); NIST 76a (Burnt refractory - National Institute of Standards and Technology, USA); ECRM 776-1 Firebrick (BAS 2009). The CRMs were included whenever archaeological samples were being analysed in the machine. 
To test the level of precision, the coefficients of variation have been calculated for the three XRF runs and compared for each of the days (table 5.2). To assess accuracy, the average results of the CRMs were compared to the certified or given values, and the $\delta$ absolute and the $\delta$ relative have been calculated (table 5.3). 


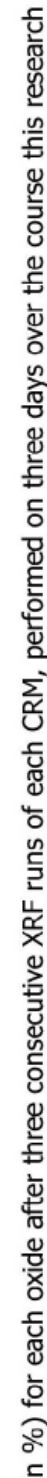

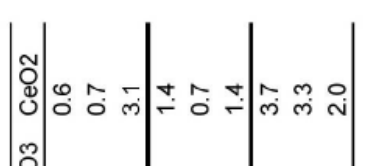

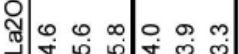
然 ชิ \%ั 귀ำ कำ 竞

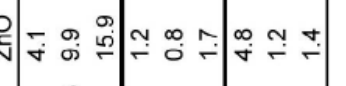

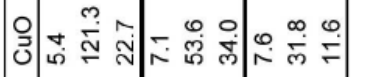
을 จิ๊

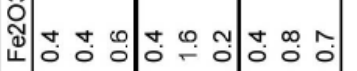
产 ญับ

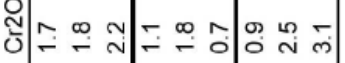
ถุ

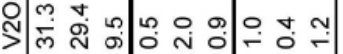
กิ m

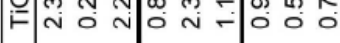

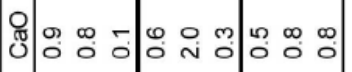

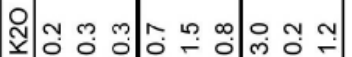
ט 눙

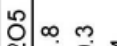

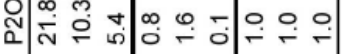
ํํำ 눙 प्रे 悹

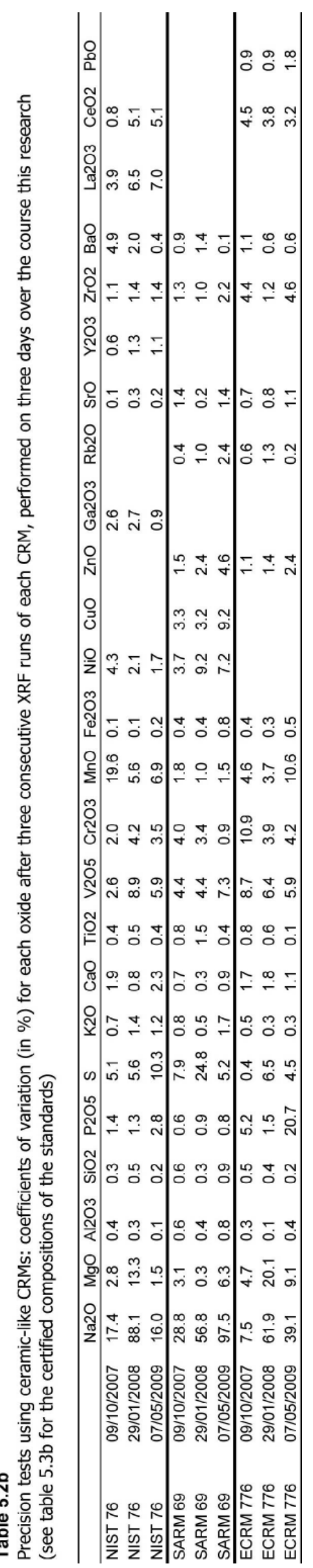




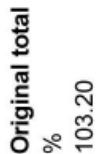

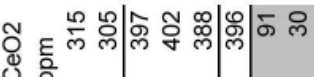

ชิ ซี ํㅡㅇ

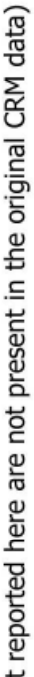

\section{品}

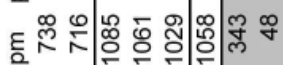

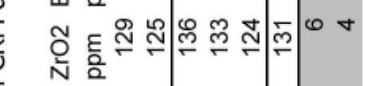

栥

은

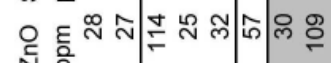

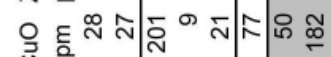$$
\text { (0) }
$$

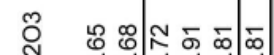

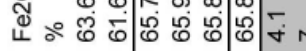

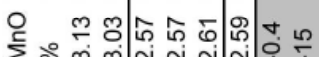

$$
\text { 饮 }
$$

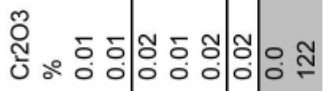

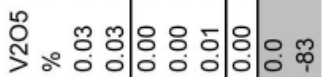

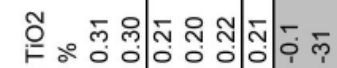

రำ

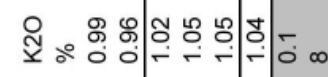

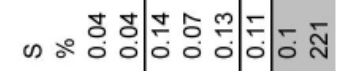

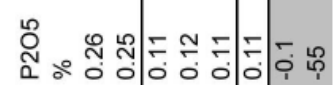

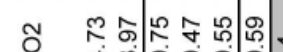

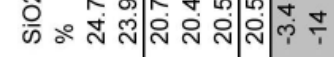

瓷 。

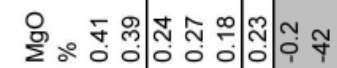

敢

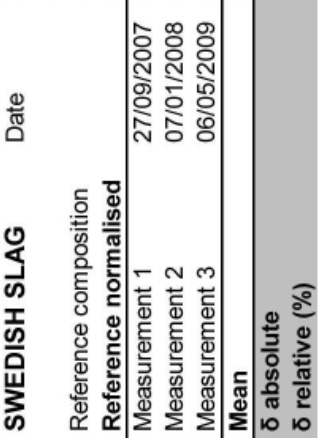

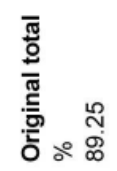

产总

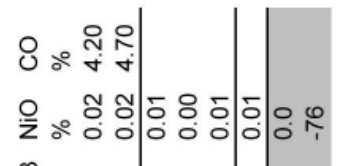

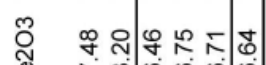

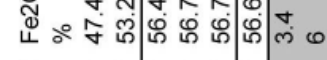

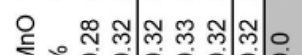

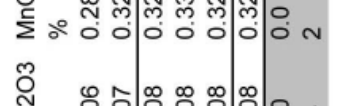
帒

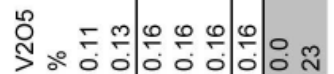
约

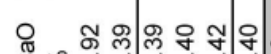

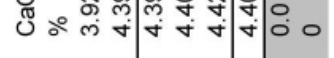

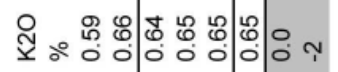
v ๙

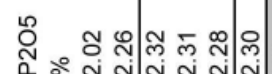

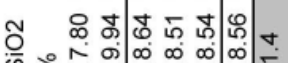

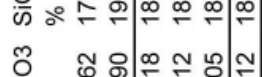
歪 。을

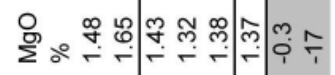

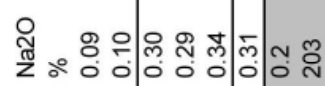

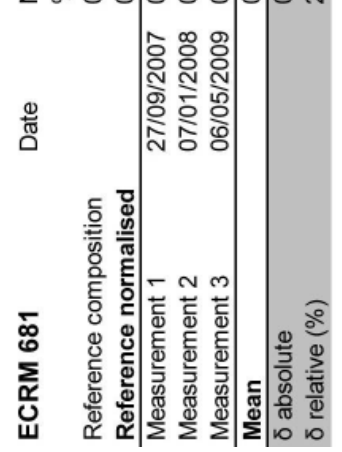

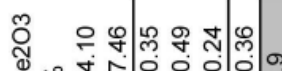

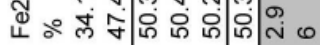
立。 ญับำ ०००० 水。

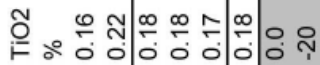

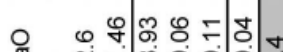
ชึ。

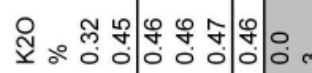

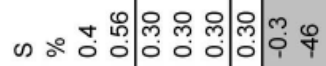

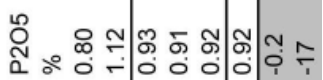
ธิ ग कवर्तनक का

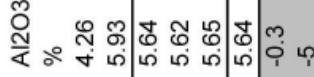
产。年

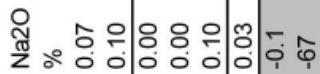

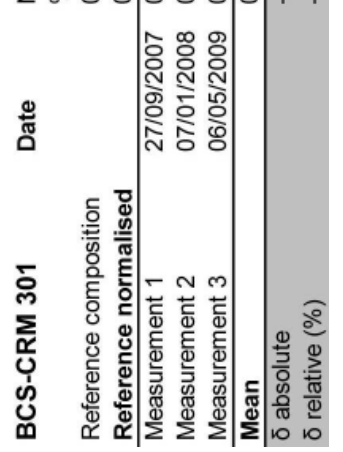




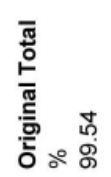

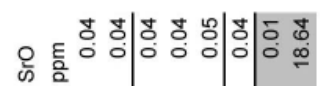

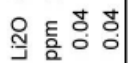

苞 。

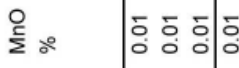

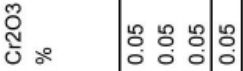

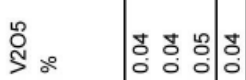

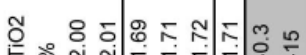

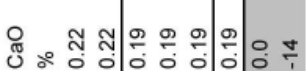

గî

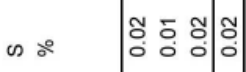

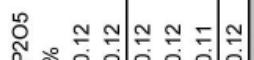

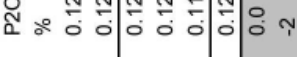

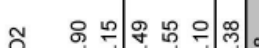

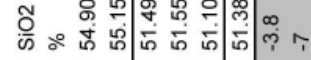

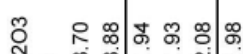

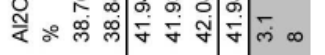

高。药

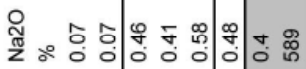

웡웡

ปั๊

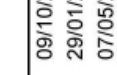

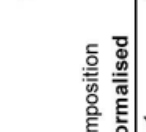

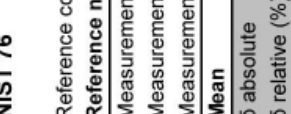

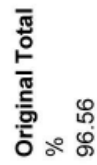

올 틈

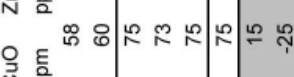

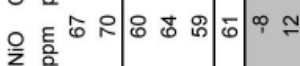

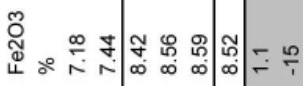

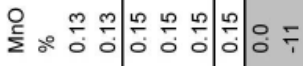

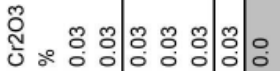

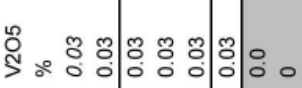

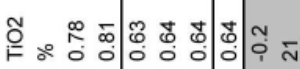

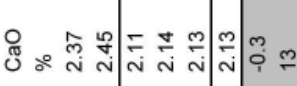

ชิ ஃ。

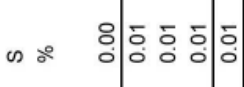

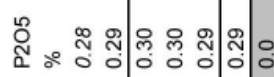

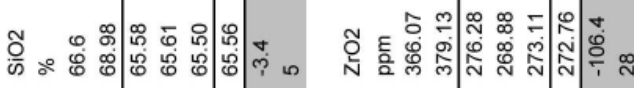

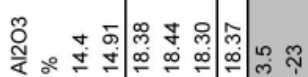

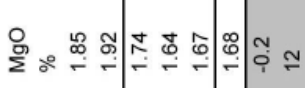

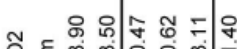

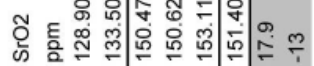

¿્خ

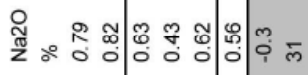

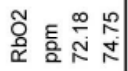

ััँ

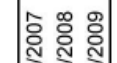

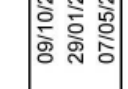

등

을

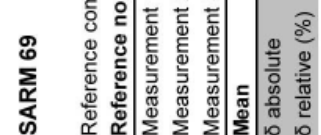

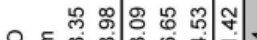

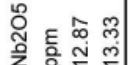

ธัँ

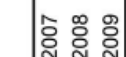

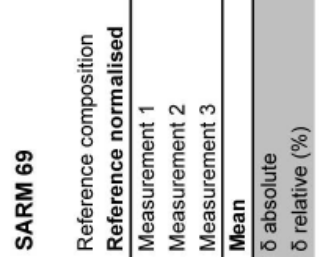

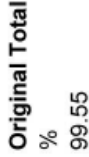

으 틈 옹 하

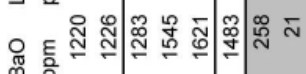

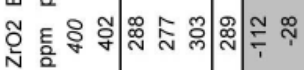

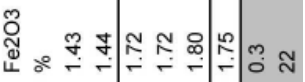

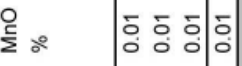

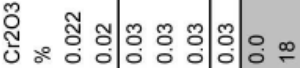

帘。

:

סิ

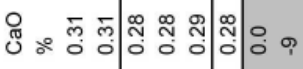

ชิํำ

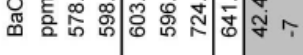

is o

흥 흥 힝훙

苋 。융

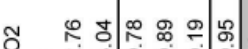

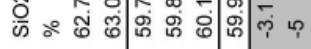

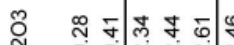

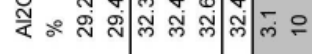

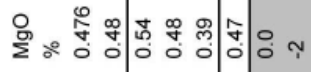

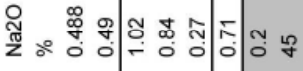

응요

ัั

흥 옹ㅇํㅇ 
The results show that the XRF machine used for this study maintained a good level of precision over the course of a few years. Only lighter oxides (notably soda and magnesia), alongside those oxides present in parts per million are problematic. The variability in the levels of phosphorous detected within the Swedish slag is due to its low concentration $(<0.5 \%)$, and this is not repeated in the levels of phosphorous within the other two slag-like CRMs. Also displaying variability are the results for sulphur and to a certain extent manganese in the ceramic-like CRMs, although again these are present in the ppm range. Importantly, the major oxides that this study is concerned with (e.g. alumina, silica, lime and iron oxide, which typically show coefficients of variation below $2 \%$ ), display low levels of variation throughout the precision tests.

Relative accuracy errors are lower than $20 \%$ for the major oxides found in iron slag and ceramics, and often lower than $10 \%$. However the calculated errors for oxides in the ppm levels were occasionally higher - the accuracy decreases as the level of the oxides in the sample becomes less than $1 \%$ generally. Alumina, silica, lime and titania are almost always slightly underestimated throughout the sample range and across the time period of the study, while the levels of other oxides are not consistently underestimated or overestimated.

Overall the levels of precision and accuracy were deemed sufficient for the results outlined in chapter 6 and discussed in chapter 7 and 8 to be considered with confidence. Given that this thesis is concerned with general compositional trends and internal comparisons, more sophisticated numerical manipulations are unnecessary. Hence, no correction factors were applied to the data, but precision and accuracy values are reported here to facilitate future comparisons.

\section{- Optical microscopy and SEM-EDS}

One specimen from each sample was prepared for optical microscopy with a crosssection of approximately $1 \mathrm{~cm}^{2}$, set in resin and polished down to a grain size of 0.25 $\mu \mathrm{m}$ following established procedures, producing a mirror-like finish. 
Optical microscopy, utilising plane polarised light (PPL), and cross-polarised light (XPL) where suitable, was used to provide an insight into the internal microstructure of the sample. This gives an indication of different phases present and thus of the type of processes which created the specific slag composition and appearance. Through careful examination of samples at up to x500 magnification, detailed descriptions were made of crystal structure and arrangements, allowing the smelting techniques to be categorised for example in terms of homogeneity and cooling rates, and the presence of residual minerals or metals. Features typical or unusual to each sample were identified through microscopic examination, and samples of interest selected for SEM-EDS investigation.

Samples chosen for SEM-EDS were coated in carbon to prevent them from charging. A Hitachi S-3400N scanning electron microscope with an attached Oxford Instruments energy dispersive spectrometer (SEM-EDS) running on Inca software was used for this analytical procedure. The instrument was operated at an accelerating voltage of $20 \mathrm{kV}$, with a process time of 75 seconds and a deadtime of $\approx 40 \%$. The analytical distance used was $10 \mathrm{~mm}$, although due to the lack of a Faraday cup the variable beam size and hence the average size of the areas analysed can only be estimated: approximately 5-6 $\mu \mathrm{m}$ when analysing ceramics and iron-poor slag; 1-2 $\mu \mathrm{m}$ when analysing iron rich material.

This great depth of magnification allows specific chemical compositions of various phases of the samples to be analysed, providing greater clarification of the makeup of the slag and the corresponding raw materials and process parameters. Thus an understanding of the nature of the internal phases present (generated as secondary electron (SE) and back-scattered electron (BSE) images), and their chemical composition, was achieved. The instrument was recalibrated every 30 minutes using a cobalt standard to ensure the reliability of the results. As with the XRF, oxygen was added to the results by stoichiometry where appropriate, and the results normalised to $100 \%$. 


\subsection{Dating}

It was hoped that funding for radiometric and luminescence dating would be found to date the material collected from Rwanda to provide the most accurate chronology possible for the smelting events being studied. Radiocarbon dating has already proved inadequate in the wider region because of oscillations within the radiocarbon calibration curves at key periods under consideration (the middle half of the first millennium BC and the latter half of the second millennium AD) which makes it very difficult to establish precise chronological frameworks for the material (Killick 2004). It was hoped that using both radiocarbon and luminescence dating would help overcome this issue, as well as that of 'old wood' (Killick 2004) which can also lead to inaccurate dating of sites. Producing both radiometric and luminescence dates would add credibility to the overall dates provided and allow a critical consideration of both the very early, and the later dates expected from the material.

Following the fieldwork reported here, through personal contacts it was found that the Universitai Milano Bicocca was looking for material to develop a luminescence dating program for iron slag. It was agreed that in exchange for samples of slag (500 $\mathrm{g}$ of milled powder for each sample prepared under infrared), ceramics and charcoal, their laboratory would use thermoluminescence to date the slag and ceramics, and radiocarbon dating to date the charcoal for cross-referencing and so to check the success of their methods. In theory this was going to provide this project with an extensive and accurate chronological framework for all of the sites excavated.

Thermoluminescence (TL) dating works on the principle that all things inorganic will absorb radiation at a certain rate. When fired to temperatures above $500{ }^{\circ} \mathrm{C}$ the material's radiation clock will be zeroed. Following this extreme heating event, the material will then begin to absorb radiation again. Thus in theory, the radiation levels in the quartz contained within material such as ceramics and slag (quartz being currently the ideal crystal for TL measurement), would be zeroed during a smelting event. Therefore, by measuring the radiation levels within the technical ceramics and the slag, the smelting episode can be dated. A gamma meter was used to collect rudimentary background radiation readings for each of the sites to aid the precision and calibration of 
the TL dates. This method of dating has been applied successfully in other areas of the continent using ceramics (for example see Godfrey-Smith \& Casey 2003).

Unfortunately, the Universitai Milano Bicocca realised that it was impossible to date the quartz grains within the technical ceramics collected in Rwanda using thermoluminescence methods. While a number of paths of enquiry have been launched to discover why this may have been the case, it is believed that either the radiation traps within the quartz grains are inhabited by something which prevents radiation from collecting, or that the radiation is present in levels too low for TL to detect, and that perhaps optically stimulated luminescence (OSL), would be more appropriate. The situation has been discussed in detail with various experts including Dr Jean-Luc Schwenninger (Research Laboratory for Archaeology and the History of Art, University of Oxford), as well as Professor David Killick (University of Arizona). Dr Schwenninger has attempted to test whether or not the samples could be dated using optically stimulated luminescence and is confident that this would work, which supports the theory that the radiation levels within the samples are very low.

As a consequence of the disappointing results from the ceramics, the Universitai Milano Bicocca decided not to pursue their attempts to date the slag samples (as there would be a lack of comparative data). They also decided, at a very late stage in the project, that they would not proceed with the radiometric dating of the charcoal samples submitted. At such sort notice, only a limited amount of additional funding for dates could be obtained. This was enough to pay for two radiocarbon dates and two AMS dates, which will be discussed in chapters 6 and 7. Although these dates have a significant margin of error, they do provide an indication of the approximate time period within which the smelts were taking place. The most disappointing factor of this process remains the sites that are now undated, however in the future it is hoped funding will be obtained for OSL dating of the ceramics excavated at those sites. 


\subsection{Metallurgical analysis}

As part of this investigation, metallographic analysis was carried out on a piece of bloom (chapter 6.6.1), and on two iron objects (chapter 7). The iron objects were excavated very near to the Early Iron Age production site of Gahondo (chapter 6.6.1) by John Giblin ( $\mathrm{PhD}$ candidate, UCL Institute of Archaeology).They were located in an Early Iron Age burial, dated to AD 417 to 554 (2 sigma calibration). Within this burial, conditions were not only adequate enough to preserve iron objects, but also human bone, alongside highly decorated Urewe vessels, beads and a cowrie shell which must have originated from a distant coast. Thus, it can be said from the outset that this was a high status burial or one of ritual significance, with trouble taken to fill the grave with prestigious grave goods. The iron objects were all body adornments, including two bracelets, one necklet, and one hollow iron disk (fig. 5.20). The fact that these iron items are made to be decorative, and that the person wearing them may well have been important, provide the first insight into the use of iron produced during these early periods.

On arrival at UCL these objects were assigned to Kelly Caldwell, an MSc Conservation student, for conservation treatment (see appendix A). She initially cleaned the objects to remove as much corrosion as possible, and then stabilised them in preparation for display in the National Museum of Rwanda (mindful of the Museum's lack of climate control facilities). 


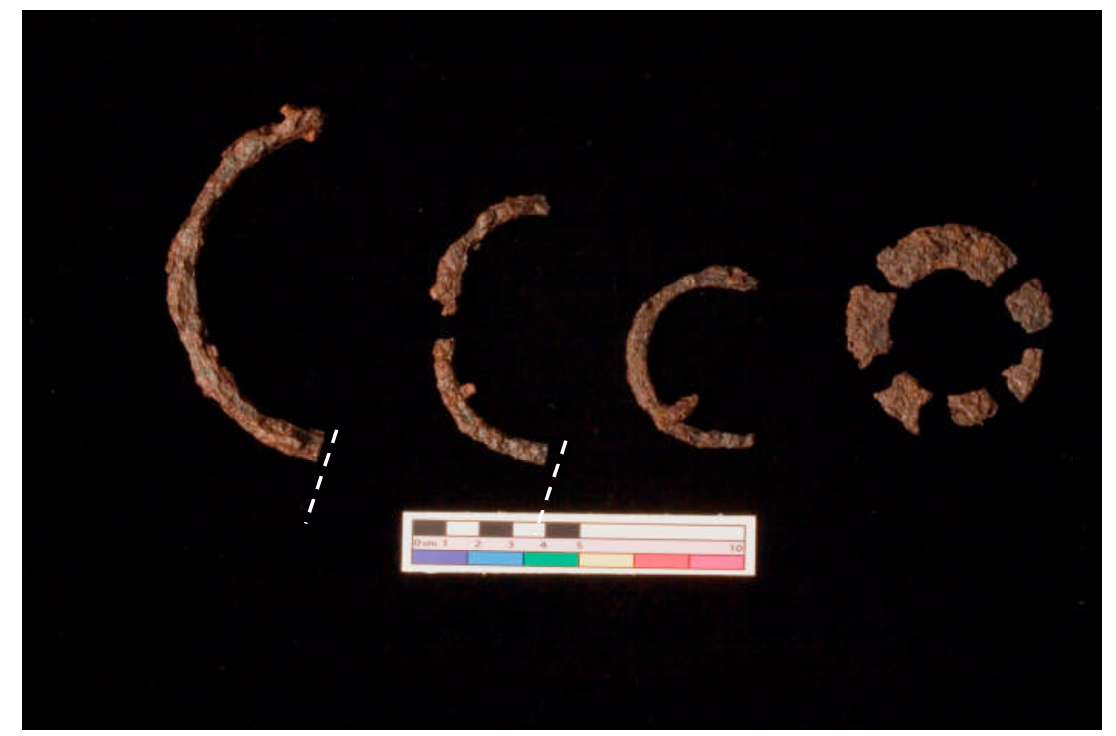

Fig. 5.20 Iron objects after conservation. From left to right: necklet; bracelet; bracelet; iron disk (photograph courtesy of Kelly Caldwell, UCL MSc Conservation student). Samples taken for analysis are marked by the white dotted lines

One sample was taken from the end point of the necklet (sample A), and one from a bracelet (sample B), after permission was obtained for such sampling from the National Museum of Rwanda. These sampling areas were selected to cause limited damage to the overall appearance of the objects. Additionally, the choice of sampling was influenced by x-rays of the objects, which illustrated that while much of the iron metal within the iron disc had corroded (presumably due to its flatter shape, at only a few mm thick, and so greater ratio of surface area to iron metal), the integrity of the metal within the iron necklet and bracelets was more significantly preserved (fig. 5.21).

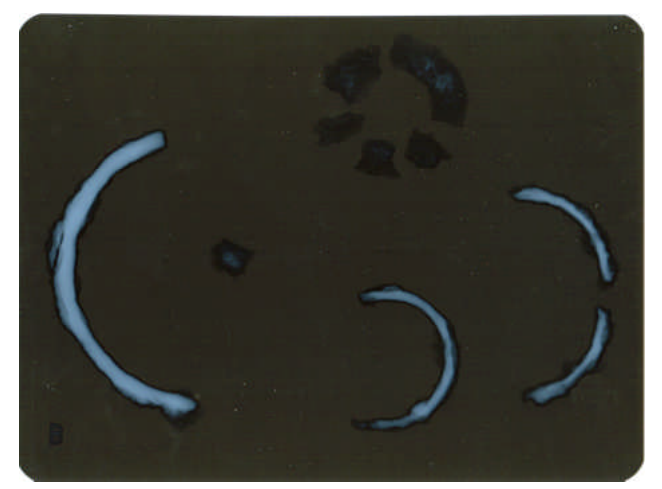

Fig. 5.21 X-ray taken of the objects displaying the level of corrosion affecting the iron metal (X-ray courtesy of Kelly Caldwell). 
The samples were slowly sawn off using a slow-speed mini Dremel saw. Using a larger instrument (such as a tile cutter), although quicker, may have generated too much heat and thus affected both the metal structure as well as the integrity of the objects themselves. Standard laboratory techniques were used to mount the samples in epoxy resin blocks, with the largest cross-section possible visible for laboratory examination. The resin blocks were polished down to a grain size of $0.25 \mu \mathrm{m}$ following established procedures, producing a mirror-like finish.

The hardness of the samples was tested using the Vickers Micro-hardness test, which subjects the metal to a certain load (100g in this case) using the microscopic point of a diamond pyramid to make a small indentation within the surface of the metal. The size of this indentation is dependant on the resistance of the metal, and is measured under a microscope. The measurement of the pyramid is then matched to a scale of hardness (Bailey 1972: 168-169; Scott 1991: 77). Optical microscopy utilising plane polarised light (PPL), was used to provide a general view of the samples. Following this the samples were etched in nital for 1-3 minutes to reveal the internal microstructures, and then carbon coated and examined using the SEM-EDS to provide greater understanding of both the microstructure and phase compositions. The same sample preparation and analysis were also carried out on the piece of bloom excavated from a later furnace pit.

Through the application of the methodology described in this chapter it was believed that it would be possible to generate a detailed record of iron production events in the Butare area. Clearly an essential component of this methodology was to be able to explore the nature and characteristics of individual smelting episodes, but the work also needed to be able to make effective comparisons between episodes. In this way it would be possible to consider the issues of tradition and variation in the overall production of iron in the area. The following chapter describes the results obtained through the application of the methodology described above and provides a site interpretation for each of the six sites investigated in detail. 


\section{6}

\section{The Sites}

This chapter documents each of the six iron production sites located during survey which were selected for detailed investigation over the course of this $\mathrm{PhD}$ : Gahondo (GHD); Cyamukuza 1 (CMZ 1); Cyamukuza 2 (CMZ 2); Mpinga (MNA); Kamana (KMA); and Kamabuye (KBE) (fig. 6.1). For each location, a description of the site and observations made in the field are provided. The excavations and samples taken are explained, followed by the results of chemical and microscopic analyses. Each section concludes with a site interpretation, drawing together all of the information, including dating, a tentative quantification of production scale (where possible), field observations and scientific investigation. The iron production activities carried out at each individual smelting location are thus characterised. An overall summary of the data collected, considering the iron production locations set within a broader diachronic framework, concludes this chapter, while the results are discussed further and interpreted in chapter 7. 


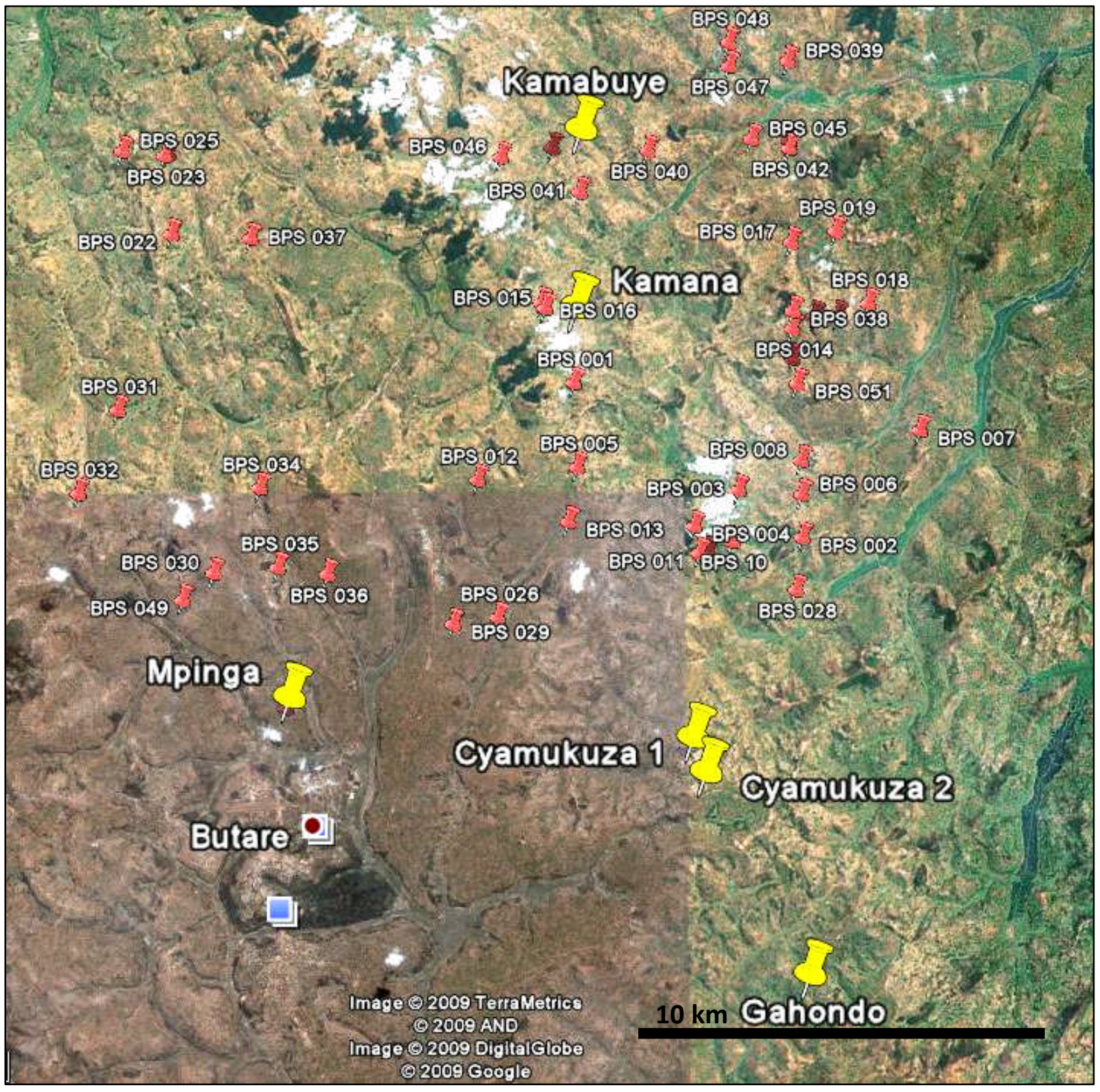

Fig. 6.1 Location of the sites selected for detailed investigation. Yellow markers indicate the excavated sites; red markers are the other iron production sites identified during survey 


\subsection{Gahondo (GHD)}

\subsubsection{Site description and observations}

The site at Gahondo is situated half-way down a very long, gently sloping hill with spectacular views south across the valley bottom and onto the slopes of surrounding elevations (fig. 6.1.1). The hillside upon which the site is located has been heavily eroded in places; it lacks established tree cover for much of its distance and bedrock is visible across the area. Towards the middle of the slope is a house compound surrounded by land currently cultivated with beans and bananas. The path from the top of the hill runs southwards towards the bottom of the valley and passes alongside the eastern edge of the house enclosure, within which iron smelting remains were identified. The compound is located approximately $500 \mathrm{~m}$ from the valley bottom.

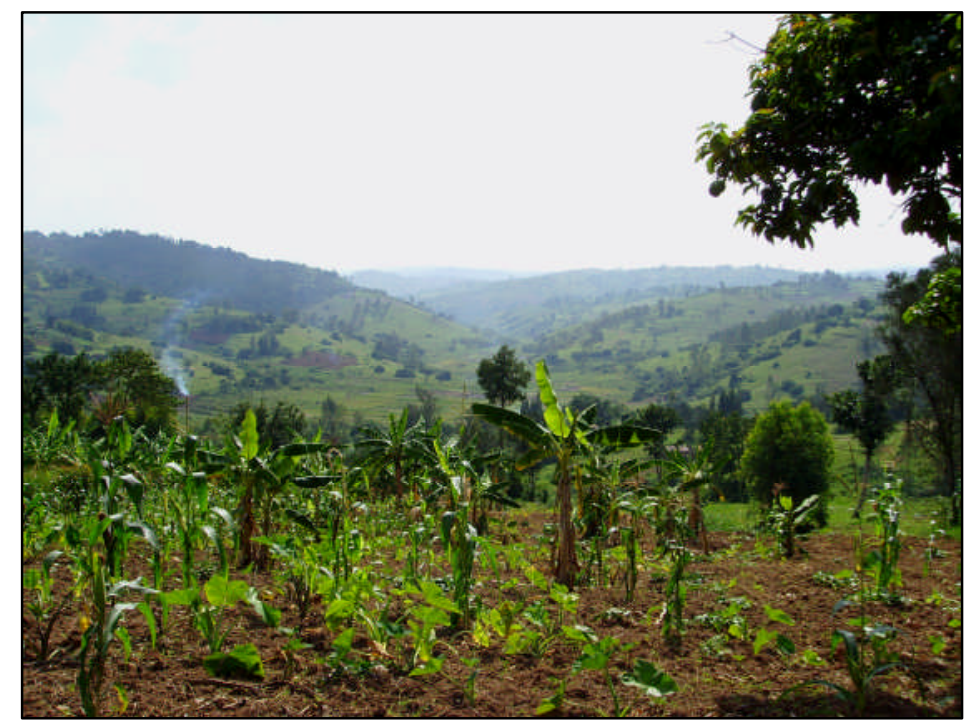

Fig. 6.1.1 View from the GHD house compound across the valley

Two furnace features were identified following survey within the compound and the surrounding area, visible as circular outlines in the ground. No fragments of slag or large slag blocks were noticeable within the immediate vicinity or elsewhere on the hillside, although a few fragments of tuyere were found. On a macroscopic level it is worth noting that this particular characteristic - the lack of slag littering the site - 
immediately set this site apart from the other locations chosen for excavation, all of which were identified due to the presence of significant slag scatters (of course heavy erosion may account partly for this).

Furnace one (GHD f1), was clearly visible as a prominent circle in the middle of a well swept path running along the southern edge of the house (fig. 6.1.2). At ground level the pit had a north-south diameter of $65 \mathrm{~cm}$ (from the inner edge of the furnace pit lining), and an east-west diameter of $63 \mathrm{~cm}$. The burnt pit lining (which was a very similar brown - orange colour to the surrounding earth), was on average $8 \mathrm{~cm}$ thick, while the pit itself appeared to be filled with the same compacted earth as the path. No distinguishing features other than the outline of the pit wall could be identified within or around this feature before excavation.

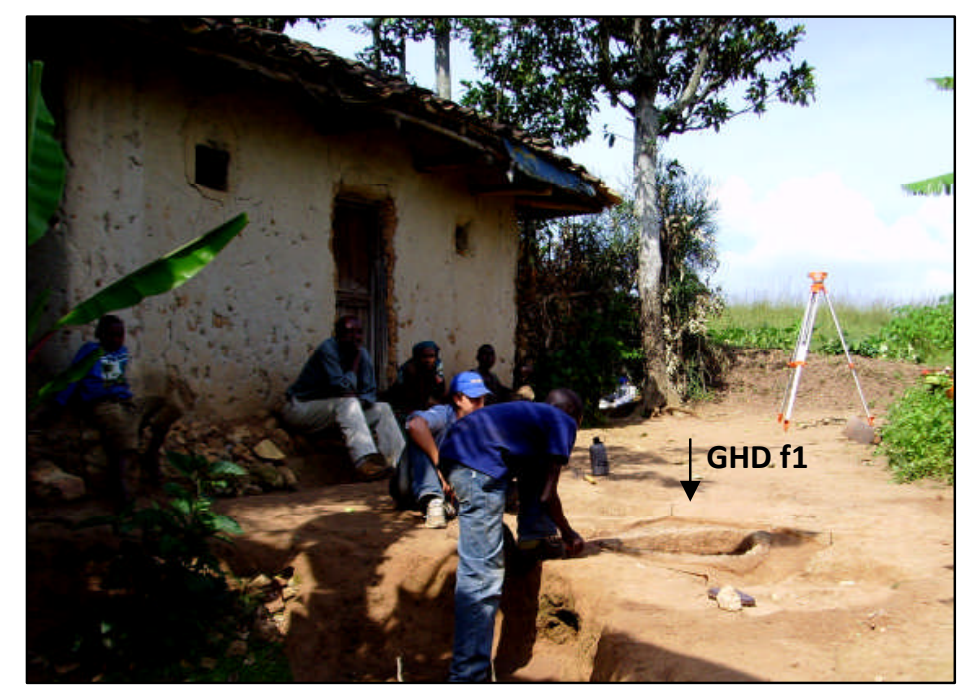

Fig. 6.1.2 GHD f1

Furnace two (GHD f2) was located within the house compound, situated between a hedge (which demarcated the house enclosure), and a small hut, and underneath a large tree. This furnace pit lay approximately $12 \mathrm{~m}$ in a direct line north-west from the first furnace pit. GHD f2 was more elusive than GHD f1 and only just recognisable by the very thin, incomplete outline of burnt furnace pit lining, which was bright orange in colour. Where visible, the pit lining was approximately $3 \mathrm{~cm}$ thick. At ground level the furnace had a north-south diameter of approximately $70 \mathrm{~cm}$ and a west-east diameter of 
approximately $68 \mathrm{~cm}$. Again the furnace seemed to contain similar soil to that of its surroundings (fig. 6.1.3). The risk of contamination within both furnace pits, from the roots of surrounding vegetation, from the daily activities of the people living in the house compound, and from rain water washing down the hill, appeared high.

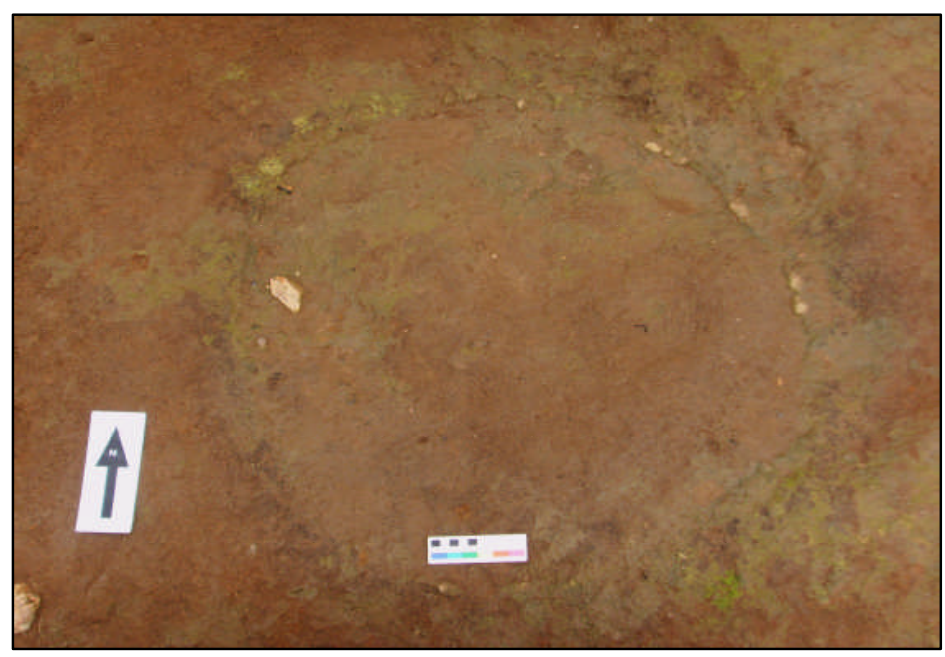

Fig. 6.1.3 GHD f2 before excavation

Three 1x1 m test pits (tp1-3) were excavated at various distances around the two furnaces to test for associated archaeological material or stratigraphy. The location of these test pits was in part dictated by the location of remaining soil deposits (as opposed to the significant patches of bedrock), and in part by the boundaries of the plot of land owned by the host family. If these test pits had revealed any significant features, or if more archaeometallurgy had been observed outside the land boundaries, then further negotiations with neighbouring land owners would have ensued and more test pits dug across the hill. However, this was not deemed necessary in view of the disappointing results from the excavations of these test pits and due to a general lack of visible archaeology within the surrounding area. The overall layout of the site is illustrated in fig. 6.1.4 below. 


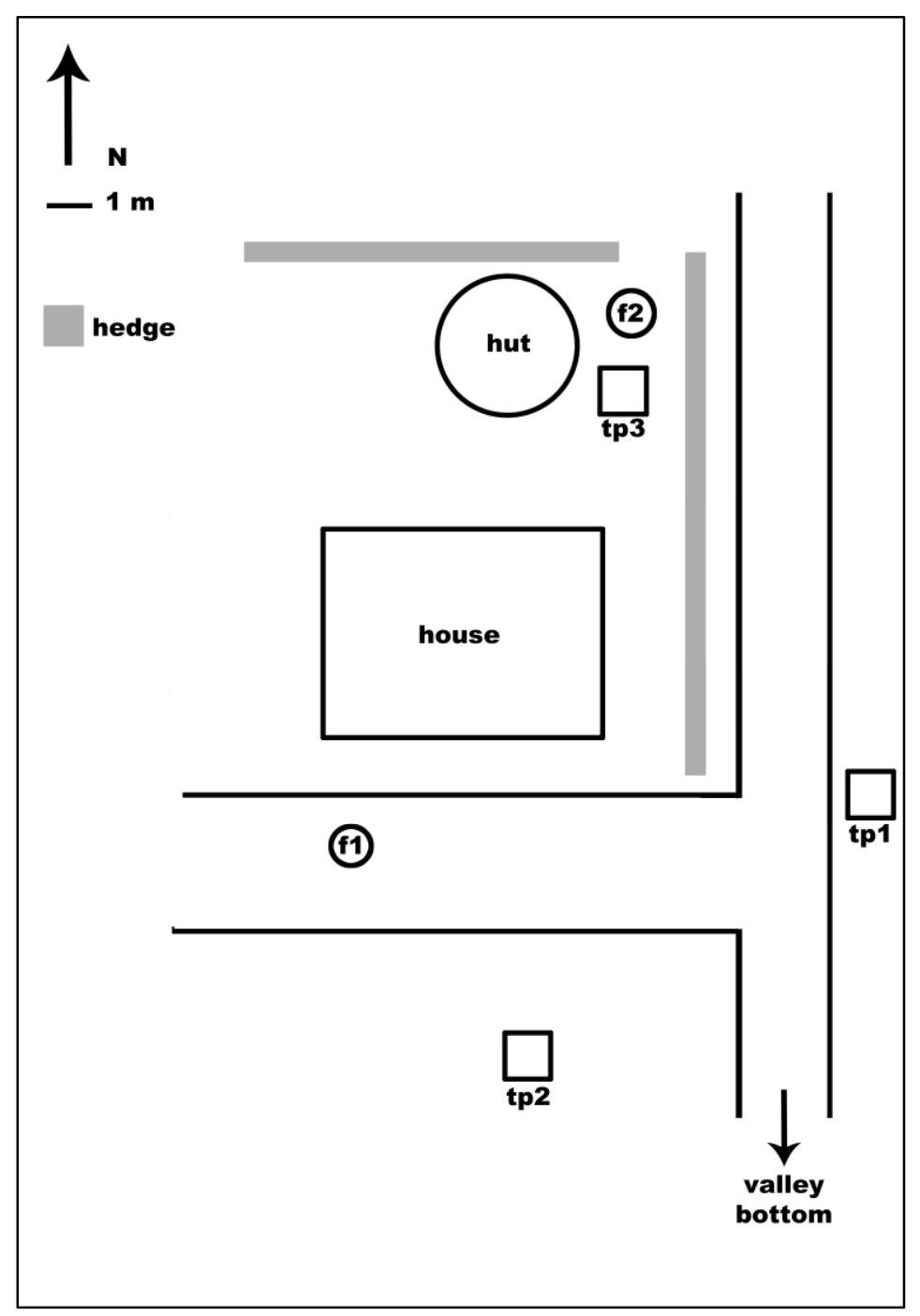

Fig. 6.1.4 Plan of GHD house compound showing the location of f1 and $\mathrm{f} 2$ as well as the location of the test pits

\subsubsection{Excavations and sample selection}

- GHD f1

A $1 \times 1 \mathrm{~m}$ square was laid out around GHD $\mathrm{f} 1$ and the deposits surrounding the edges of the pit were excavated to test for any remaining tuyeres lying outside the furnace. This proved not to be the case, and as expected, the soil on this well-trodden path was very 
compact and difficult to excavate. Following excavation of the furnace pit fill, it was found that the pit itself descended $45 \mathrm{~cm}$ below the surface, almost perpendicular to ground level in places (fig. 6.1.5; fig. 6.1.6). The pit lining was intact throughout the pit until the bottom, where the furnace pit ended and sterile clay was reached. The floor of the pit was not lined, and $20 \mathrm{~cm}$ of clay-rich soil was excavated below the base of the furnace pit to investigate whether or not a 'ritual pot' (as documented in early furnaces in the Great Lakes region - see Chapter 4) had been placed below this feature; no such item was found. Overall, the furnace pit lining was well preserved and well defined, although, as with the remains of any furnace pit, it is impossible to determine whether a significant level of erosion in the years since the smelting activity has left the pit significantly shallower than it was originally.

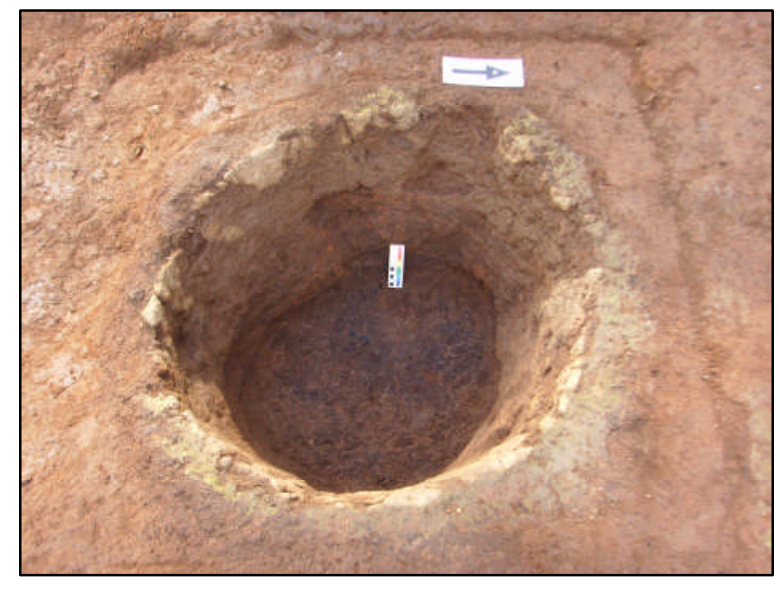

Fig. 6.1.5 GHD f1 after excavation

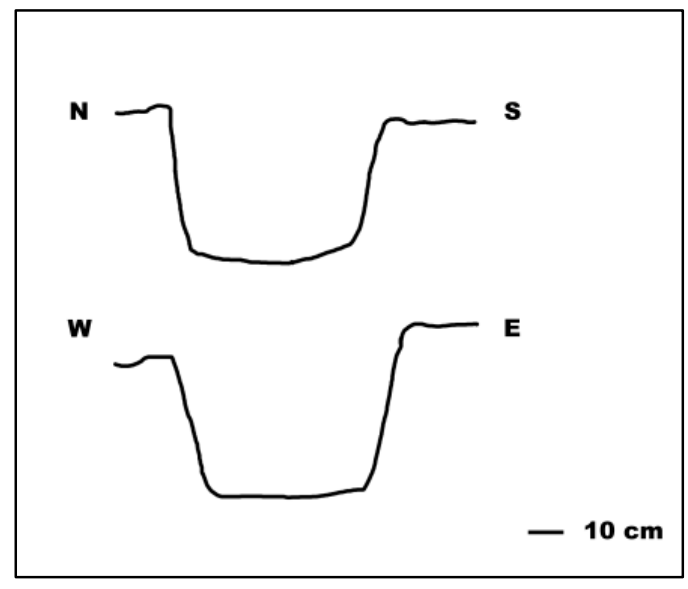

Fig. 6.1.6 GHD f1 sections after excavation

The finds within the bottom half of the pit fill (from 45-20 cm below ground level) consisted of tuyere fragments and occasional quartz stones, ore fragments and pieces of orange burnt clay, as well as pieces of slag present as small drips and blobs. The fill deposit was mainly comprised of lumps and flecks of charcoal, from which four charcoal samples were taken for dating. The bottom half of the pit fill appeared well contained and at minimal risk of contamination from external influences.

Above this contained context, at between $20-15 \mathrm{~cm}$ below the surface, charcoal flecks were rarer within the furnace pit fill. Tuyere and slag fragments were still present, but 
the pit appeared to be filled, at this level and above, with more mixed deposits similar to the surrounding soil. Pieces of ore and of quartz (not bigger than $7 \mathrm{~cm}$ long), and some fragments of burnt orange clay in lumps of up to about $5 \times 2 \times 2 \mathrm{~cm}$, were also excavated in this context (fig. 6.1.7).
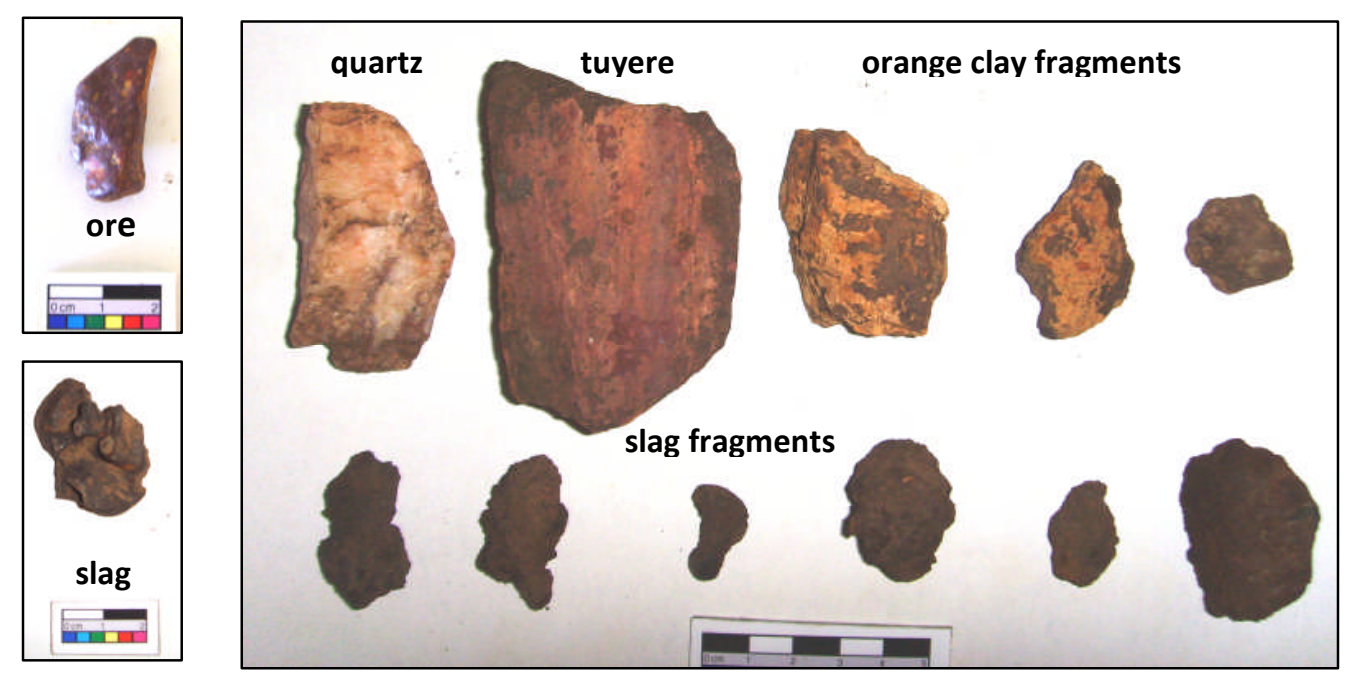

Fig. 6.1.7 Finds from GHD f1: on the left a piece of ore above a fragment of slag; on the right a variety of samples including a piece of quartz, a section of tuyere, and orange clay fragments

The top $15 \mathrm{~cm}$ of the pit fill was very compact and mixed, again containing pieces of tuyere including parts of the flared end that would have been placed in front of the bellows, and one fragment of the opposite end of a tuyere with slag fused onto it (fig. 6.1.8). Most of the tuyere fragments found within GHD $\mathrm{f} 1$ were $5-10 \mathrm{~cm}$ long and had approximate internal diameters of $3-8 \mathrm{~cm}$. The fabric of the tuyeres appeared macroscopically very similar across the finds, being orange - light orange in colour, with a variety of different sizes and shapes of quartz temper. Also in this upper context were small pieces of slag (2-4 cm long), some small pieces of burnt orange clay, and a number of large $(7-10 \mathrm{~cm}$ long) quartz pieces. 

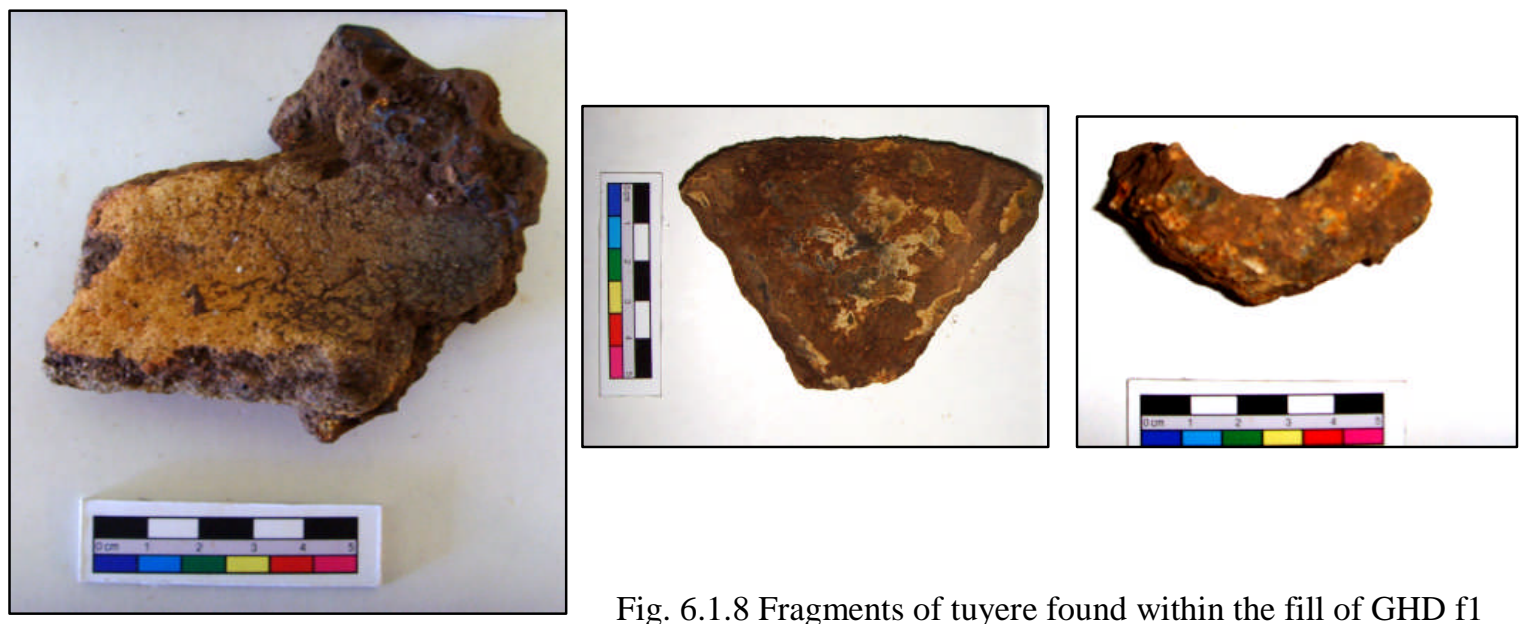

Fig. 6.1.8 Fragments of tuyere found within the fill of GHD f1

Overall the fill of GHD f1 appeared to represent two major contexts. While the deposits within the bottom half of the pit appeared relatively well contained and probably largely representative of the remains of the final smelting operation, the upper levels of the pit appeared very disturbed and mixed, probably due to rain water running down the path within which the pit is located and mixing the deposits, as well as human activity such as sweeping the path. The presence of the large quartz stones in the bottom half of the pit was quite disconcerting, presumably not being representative of the original pit fill. These may have slowly dropped into the lower deposit of the pit fill over time, as no evidence of animal activity was observed. Alternatively the quartz could have been added into the furnace during a smelting event, although macroscopically none of the larger quartz pieces appeared affected by extreme heat. Only a few samples of ore and slag were sampled on the whole from GHD f1 due to the arbitrary nature of the deposits, and so conclusions reached concerning iron production in this furnace will be tentative.

The samples selected for analysis from this furnace pit, their location within the furnace (in terms of depth from ground level), and the types of analyses selected for each of the sample, are illustrated below (table 6.1.1; table 6.1.2). No samples were taken from the top $10 \mathrm{~cm}$ of the pit fill due to contamination risks. As explained in Chapter 5, not all samples were chosen for SEM-EDS analyses; only those that could provide a specific insight into an unusual feature or those which could provide 'typical' samples for 
characterisation purposes, as well as interesting comparative data. Only two slag fragments were selected for investigation due to the corroded nature of the ferrous material within this furnace pit.

\begin{tabular}{cccccc} 
Context & $\begin{array}{c}\text { Sample } \\
\text { type }\end{array}$ & $\begin{array}{c}\text { Depth }(\mathbf{c m}) \text { from } \\
\text { ground level }\end{array}$ & ED-XRF & OM & SEM-EDS \\
\hline 011 & slag & 25 & & $\bullet$ & \\
013 & ore & 30.5 & $\bullet$ & $\bullet$ & \\
016 & ore & 42 & $\bullet$ & $\bullet$ & \\
016 & slag & 42 & $\bullet$ & $\bullet$ & $\bullet$
\end{tabular}

Table 6.1.1 Samples of slag and ore selected for analyses from GHD f1

\begin{tabular}{cccccc} 
Context & $\begin{array}{c}\text { Sample } \\
\text { type }\end{array}$ & $\begin{array}{c}\text { Depth }(\mathbf{c m}) \text { from } \\
\text { ground level }\end{array}$ & ED-XRF & OM & SEM-EDS \\
\hline 007 & tuyere & 10 & $\bullet$ & $\bullet$ & \\
009 & red brick & 20 & $\bullet$ & $\bullet$ & $\bullet$ \\
011 & tuyere & 25 & $\bullet$ & $\bullet$ & \\
pit & pit lining & 10 & $\bullet$ & $\bullet$
\end{tabular}

Table 6.1.2 Samples of technical ceramic selected for analyses from GHD f1

- GHD f2

Again, a 1x1 m square was laid around GHD f2 and the area outside the pit excavated to a depth of around $5 \mathrm{~cm}$; no protruding tuyeres were found. After the removal of the top $5 \mathrm{~cm}$ of pit deposit (discarded because of the risk of contamination), protruding orange features were revealed within the pit. These were found to be relatively well preserved bricks made of orange clay (fig. 6.1.9). It should be noted that the term 'bricks' (rather than the term 'rolls' used by Van Grunderbeek, e.g. 1983) is used here because of their defined shape and characteristics such as, in one case, a concave end which would have facilitated the slotting together of these features to create the furnace superstructure. The term 'brick' however, is not used to imply a uniform shape or design to these features. 
The more complete bricks ranged from approximately $10-15 \mathrm{~cm}$ in length and were roughly 5-10 cm wide. Some of the bricks were decorated with 'C'- shaped curves on one side (fig. 6.1.10), similar to the bricks excavated in early furnaces previously in Rwanda (fig. 6.1.11: Craddock et al 2007; Raymaekers \& Van Noten 1986; Van Grunderbeek et al 2001).

The majority of the bricks were found as much smaller, obscure lumps of orange clay (macroscopically identical to the orange clay lumps excavated in GHD f1), throughout the furnace pit. All of these features appeared on a macroscopic level to contain a high quartz content. Also visible in GHD f2 after the removal of the top $5 \mathrm{~cm}$ were the edges of pieces of slag and more of the very thin (and in places completely eroded/washed away) furnace pit lining, which appeared to be fabricated from the same orange clay as the bricks.

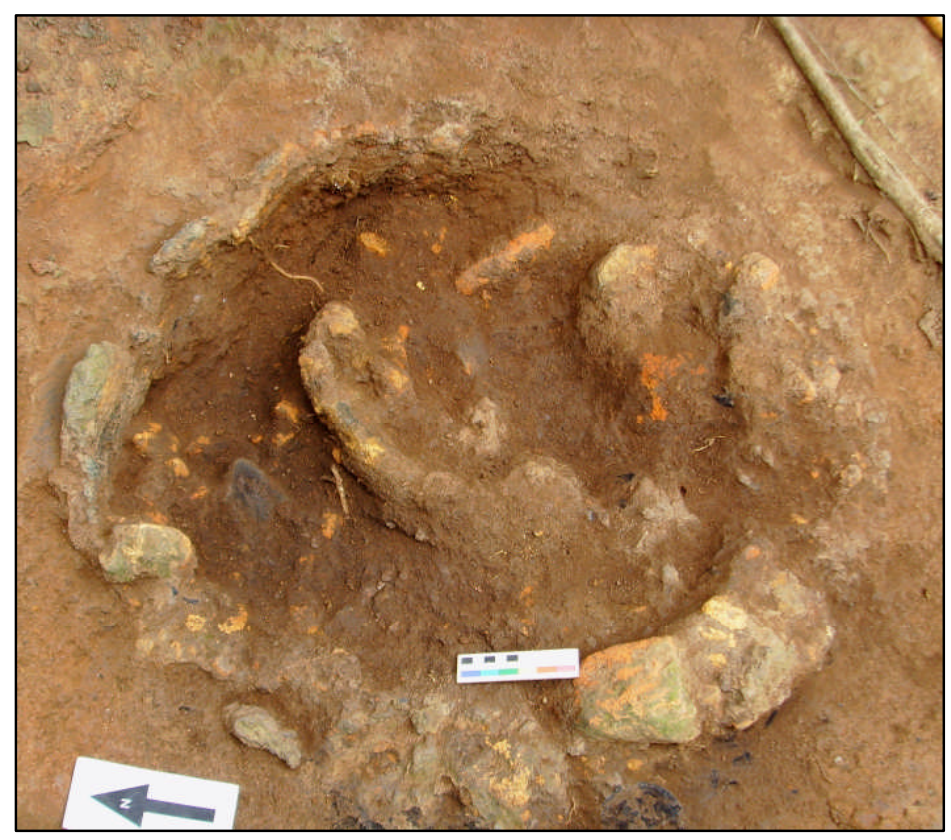

Fig. 6.1.9 GHD f2 after the removal of the top $5 \mathrm{~cm}$, with orange clay features protruding from the pit fill 


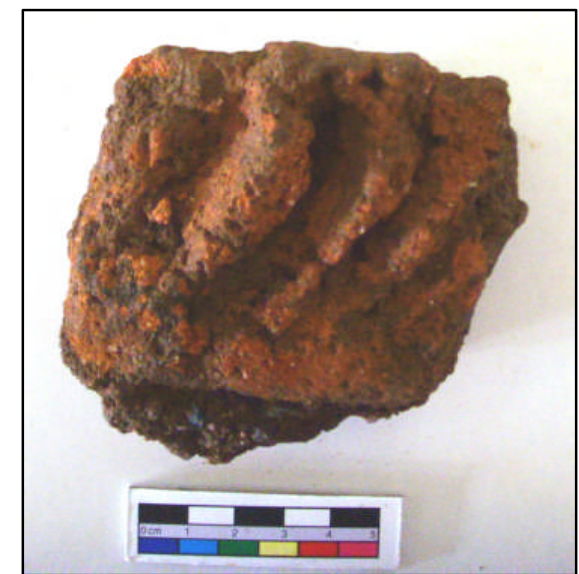

6.1.10 Example of a brick from GHD f2

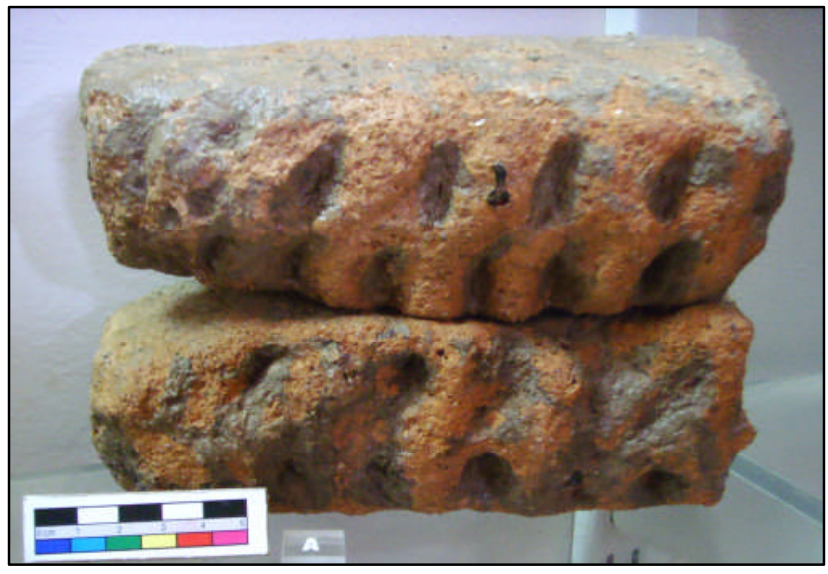

Fig 6.1.11 Decorated bricks excavated by Van Noten in Southern Rwanda (on display in the National Museum of Rwanda)

The base of the furnace pit (which reached a depth of $40 \mathrm{~cm}$ in places), was identified where the pit lining came to an end - again the bottom of the pit was unlined. Thirty $\mathrm{cm}$ of clayey soil below the pit was excavated to test for any 'ritual' pots or any other features - again this was found not to be the case. During the excavations of GHD $\mathrm{f} 2$, black-silver dense debris which had clearly once been molten and had solidified into flows, were classified as 'slag', while small fragments with more angular edges and a reddish colour were termed 'ore'. Examples of both were found throughout the furnace pit fill. For the sake of consistency, the field categorisations are maintained throughout this chapter. However, analytical study showed that these classifications were not as straightforward as they initially seemed.

In the bottom layers of the pit (40-30 cm below ground level) were found large 'slag' flows attached to the furnace pit walls (fig. 6.1.12), and large lumps of charcoal from which samples were taken for C14 dating. Above this (from $25 \mathrm{~cm}$ in depth below ground level), the pit fill was almost completely made up of flecks of charcoal and fragments of orange brick, as well as small pieces of slag and stones which may have been washed into the pit and mixed in with the furnace debris (fig. 6.1.13). The furnace fill in the very upper layers was relatively disturbed by animal activity (mainly ants) and also by roots from the neighbouring tree and hedge. Samples taken for analysis from GHD f2 are shown in table 6.1.3 and table 6.1.4. 

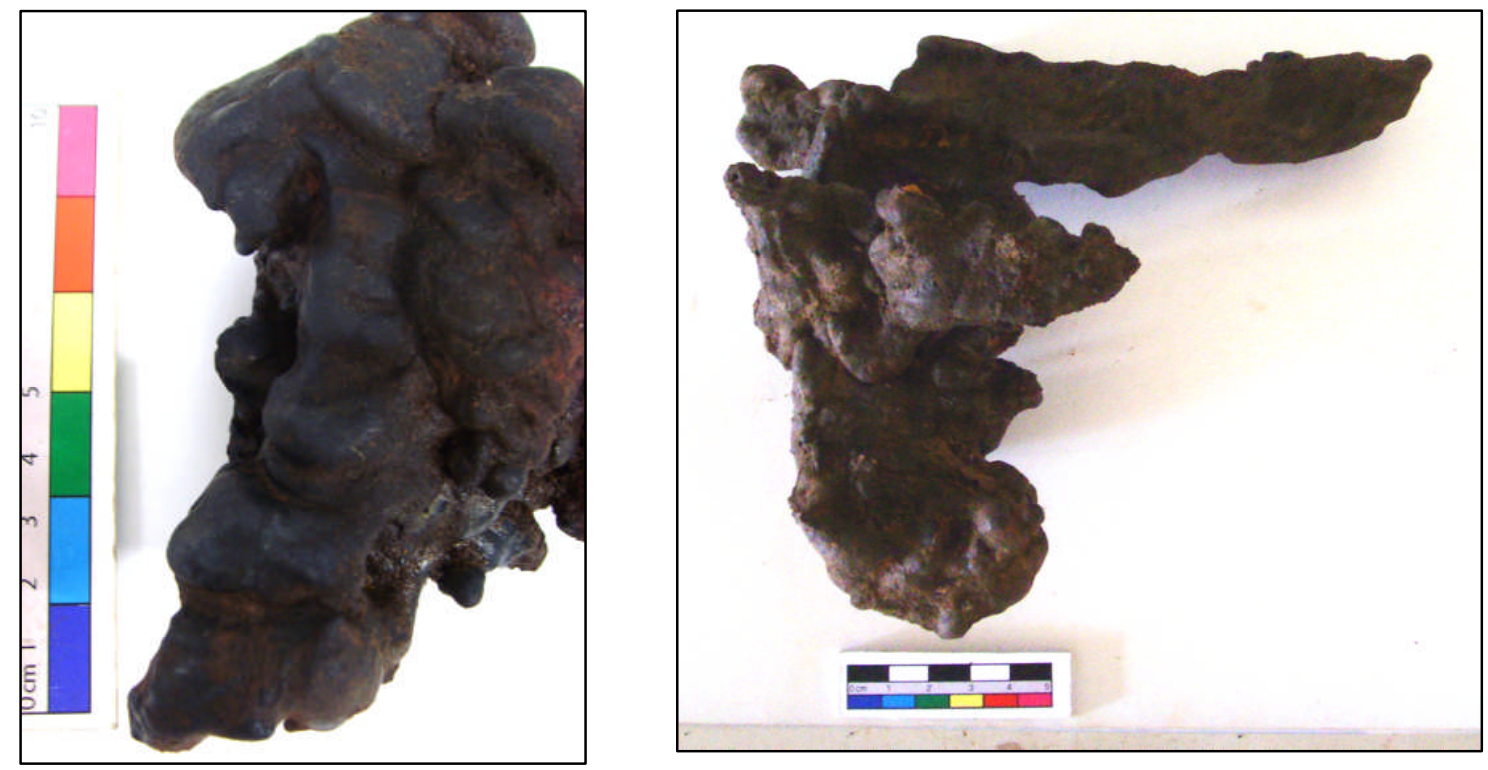

Fig. 6.1.12 Large flows classified as slag, found attached to the wall of GHD f2

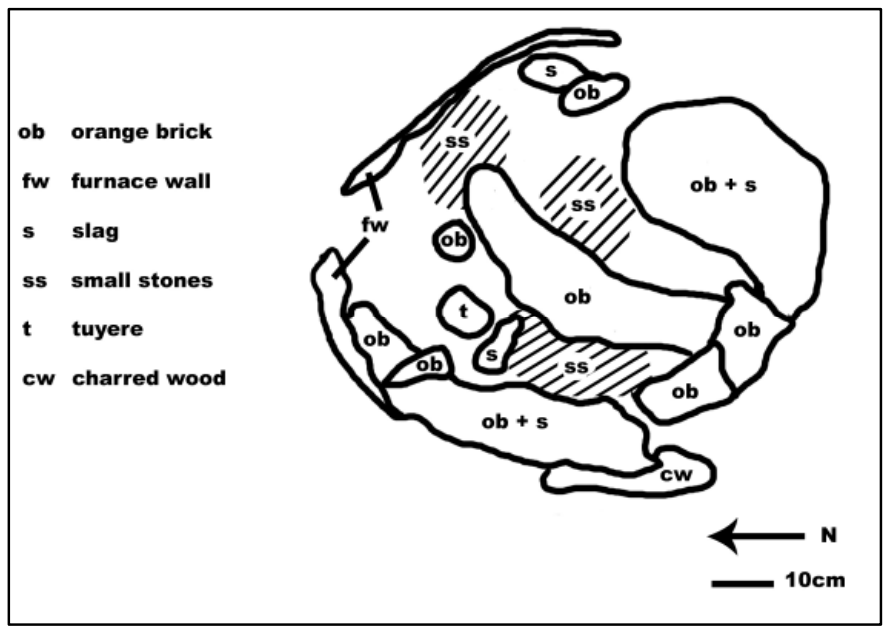

Fig. 6.1.13 Plan of GHD f2 at $15 \mathrm{~cm}$ below ground level 


\begin{tabular}{cccccc} 
Context & $\begin{array}{c}\text { Sample } \\
\text { type }\end{array}$ & $\begin{array}{c}\text { Depth (cm) below } \\
\text { ground level }\end{array}$ & ED-XRF & OM & SEM-EDS \\
\hline 006 & ore & 15 & $\bullet$ & $\bullet$ & $\bullet$ \\
012 & slag 10 & 18 & $\bullet$ & $\bullet$ & $\bullet$ \\
018 & slag 2 & 20 & $\bullet$ & $\bullet$ & \\
021 & ore & 24 & $\bullet$ & $\bullet$ & $\bullet$ \\
021 & slag 1 & 24 & $\bullet$ & $\bullet$ & \\
021 & slag 2 & 24 & $\bullet$ & $\bullet$ & \\
022 & slag 1 & 30 & $\bullet$ & $\bullet$ & $\bullet$
\end{tabular}

Table 6.1.3 Samples of slag and ore selected for analyses from GHD f2

\begin{tabular}{ccccc} 
Context & $\begin{array}{c}\text { Sample } \\
\text { type }\end{array}$ & $\begin{array}{c}\text { Depth }(\mathbf{c m}) \text { below } \\
\text { ground level }\end{array}$ & ED-XRF & OM \\
\hline 006 & Tuyere & 15 & $\bullet$ & $\bullet$ \\
012 & red brick a & 18 & $\bullet$ & $\bullet$ \\
012 & red brick b & 18 & $\bullet$ & $\bullet$ \\
pit lining & pit lining & 5 & $\bullet$ & $\bullet$
\end{tabular}

Table 6.1.4 Samples of technical ceramic selected for analyses from GHD f2

- GHD Test pits

For each of the three test pits excavated, a 1x1 $\mathrm{m}$ square was laid out. Soil was excavated in $5 \mathrm{~cm}$ spits due to the lack of observed archaeological stratigraphy, and all of the removed soil was sieved. Tp1 was excavated to $20 \mathrm{~cm}$ depth before bedrock was reached, while tp2 ended at bedrock at a depth of $15 \mathrm{~cm}$, and no finds were recorded in either unit. Tp3 was positioned $1 \mathrm{~m}$ south of GHD f2, where a number of bricks could be seen protruding from the ground (fig. 6.1.14). This area was excavated and altogether five bricks were found. Although the area containing these bricks was initially interpreted as a dump used by the smelters, it was found during interviews that the people who lived in the compound had also been digging pits across the area over preceding years to store avocadoes for ripening, and at least one of their pits cut through 
the possible 'archaeological pit' (fig. 6.1.15), thus the integrity of this 'brick dump' cannot be assured.

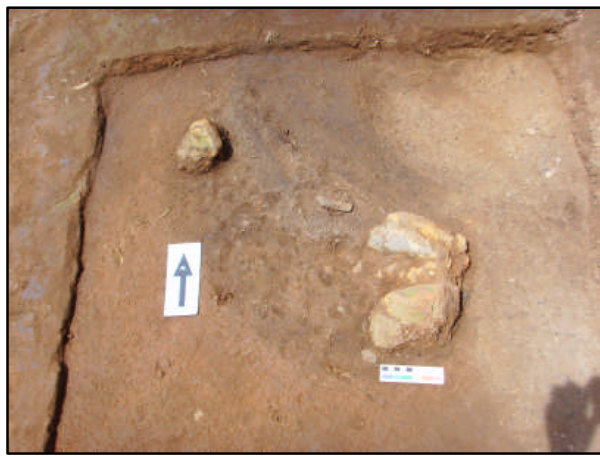

Fig. 6.1.14 Bricks in GHD tp3

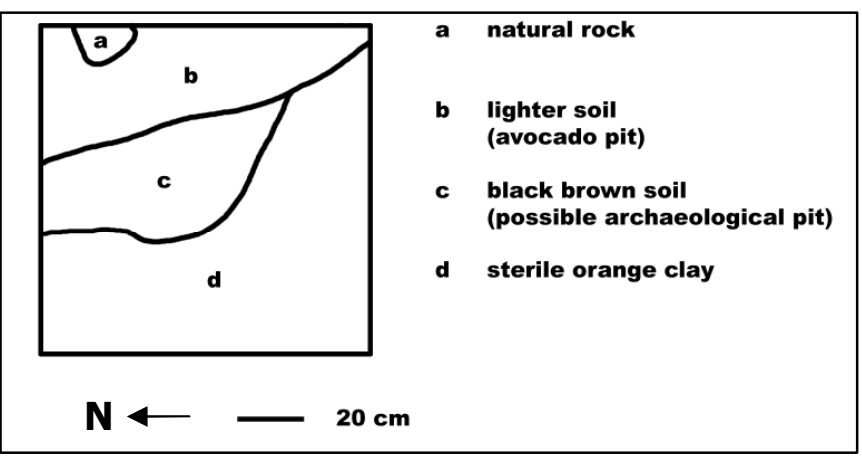

Fig. 6.1.15 Plan of GHD tp3 after excavation

One other find of significance that was collected at GHD was a decorated sherd of Urewe pottery, found on the surface slightly higher up the hill from the house compound. While this find could be expected at such a site (furnaces constructed with decorated bricks being associated with Urewe ceramics in the archaeological record: Raymaekers \& Van Noten 1986; Van Grunderbeek et al 2001), it provided the opportunity for comparison between the fabric of Urewe ceramics and the technical ceramics used in furnace construction during the Early Iron Age.

\subsubsection{Results}

The following section outlines the results for all of the samples analysed first from GHD f1, then from GHD f2, and finally from other samples taken from the site. The XRF data are provided and explained, followed by a consideration of these results in combination with the optical microscopy and/or SEM-EDS analyses.

- GHD f1

The ED-XRF results of the samples taken from f1 are shown below in table 6.1.5 ('slag' and 'ore' samples) and table 6.1.6 (technical ceramic samples). 


\begin{tabular}{cccccccccccccc} 
& $\mathrm{Na}_{2} \mathbf{O}$ & $\mathbf{M g O}$ & $\mathrm{Al}_{2} \mathbf{O}_{\mathbf{3}}$ & $\mathbf{S i O}_{2}$ & $\mathbf{P}_{\mathbf{2}} \mathbf{O}_{\mathbf{5}}$ & $\mathbf{S}$ & $\mathbf{K}_{\mathbf{2}} \mathbf{O}$ & $\mathbf{C a O}$ & $\mathbf{T i O}_{2}$ & $\mathbf{V}_{\mathbf{2}} \mathbf{O}_{\mathbf{5}}$ & $\mathbf{C r}_{2} \mathbf{O}_{3}$ & $\mathbf{M n O}$ & $\mathbf{F e O}$ \\
& $\%$ & $\%$ & $\%$ & $\%$ & $\%$ & $\%$ & $\%$ & $\%$ & $\%$ & $\%$ & $\%$ & $\%$ & $\%$ \\
\hline 013 ore A & 0.00 & 0.00 & 1.50 & 1.98 & 0.00 & 0.02 & 0.01 & 0.00 & 0.02 & 0.02 & 0.01 & 0.03 & 96.40 \\
016 slag & 0.07 & 0.46 & 6.90 & 20.91 & 0.23 & 0.06 & 0.91 & 3.66 & 0.25 & 0.05 & 0.02 & 0.19 & 66.21 \\
016 ore B & 0.63 & 0.02 & 23.68 & 24.65 & 0.04 & 0.05 & 2.84 & 0.01 & 0.69 & 0.08 & 0.10 & 0.01 & 47.03
\end{tabular}

\begin{tabular}{cccccc} 
& $\mathbf{R b}_{\mathbf{2}} \mathbf{O}$ & $\mathbf{S r O}$ & $\mathrm{ZrO}_{2}$ & $\mathbf{B a O}$ & $\begin{array}{c}\text { Original } \\
\text { total }\end{array}$ \\
& ppm & ppm & ppm & ppm & $\%$ \\
\hline 013 ore A & bdl & bdl & 26 & bdl & 100.03 \\
016 slag & bdl & 157 & 168 & 339 & 97.55 \\
016 ore B & 137 & 47 & 635 & 704 & 83.47
\end{tabular}

Table 6.1.5 (P)ED-XRF compositional data obtained from the slag and ore samples selected from GHD f1. Results have been normalised to $100 \%$, and taken from the average of three XRF runs. Only trace elements above $50 \mathrm{ppm}$ are shown; bdl - below detection limits. Full results are given in appendix 1A

\begin{tabular}{cccccccccccccc} 
& $\mathbf{N a}_{\mathbf{2}} \mathbf{O}$ & $\mathbf{M g O}$ & $\mathrm{Al}_{\mathbf{2}} \mathbf{O}_{\mathbf{3}}$ & $\mathbf{S i O}_{\mathbf{2}}$ & $\mathbf{P}_{\mathbf{2}} \mathbf{O}_{\mathbf{5}}$ & $\mathbf{S}$ & $\mathbf{K}_{\mathbf{2}} \mathbf{O}$ & $\mathbf{C a O}$ & $\mathbf{T i O}_{2}$ & $\mathbf{V}_{\mathbf{2}} \mathbf{O}_{\mathbf{5}}$ & $\mathbf{C r}_{\mathbf{2}} \mathbf{O}_{3}$ & $\mathbf{M n O}$ & $\mathbf{F e O}$ \\
& $\%$ & $\%$ & $\%$ & $\%$ & $\%$ & $\%$ & $\%$ & $\%$ & $\%$ & $\%$ & $\%$ & $\%$ & $\%$ \\
\hline 007 tuyere & 0.30 & 0.29 & 23.65 & 67.33 & 0.15 & 0.11 & 1.30 & 0.11 & 0.72 & 0.02 & 0.01 & 0.07 & 5.85 \\
009 brick & 0.39 & 0.14 & 25.56 & 66.70 & 0.14 & 0.08 & 0.58 & 0.06 & 0.57 & 0.02 & 0.02 & 0.06 & 5.55 \\
011 tuyere & 0.09 & 0.30 & 18.92 & 72.56 & 0.09 & 0.03 & 1.32 & 0.09 & 0.67 & 0.02 & 0.03 & 0.09 & 5.62 \\
pit lining & 0.45 & 0.24 & 40.99 & 49.65 & 0.16 & 0.21 & 0.75 & 0.08 & 0.68 & 0.02 & 0.01 & 0.03 & 6.65
\end{tabular}

\begin{tabular}{cccccc} 
& $\mathbf{Z n O}$ & $\mathbf{R b}_{2} \mathbf{O}$ & $\mathbf{Z r O}_{2}$ & $\mathbf{B a O}$ & $\begin{array}{c}\text { Original } \\
\text { total } \\
\%\end{array}$ \\
& ppm & ppm & ppm & ppm & $\%$ \\
\hline 007 tuyere & 58 & 147 & 292 & 284 & 79.62 \\
009 red brick & 88 & 101 & 202 & 156 & 77.65 \\
011 tuyere & 63 & 161 & 282 & 326 & 81.03 \\
pit lining & 73 & 118 & 241 & 163 & 72.46
\end{tabular}

Table 6.1.6 (P)ED-XRF compositional data obtained from the ceramic samples selected from GHD f1. Results have been normalised to $100 \%$, and taken from the average of three XRF runs. Only trace elements above $50 \mathrm{ppm}$ are shown. Full results are given in appendix 1B

The XRF results from the ore samples analysed from GHD f1 could suggest that two different types of ore were being used to smelt. If this is the case, one ore is a high grade 
ore, seen in the sample taken from context 013, which has an iron oxide level of over $95 \%$ and contains very little else (e.g. less than $2 \%$ of either silica or alumina). This sample is lacking in trace compounds such as the oxides of zirconium and barium, which are seen in the slag sample taken from GHD f1. Thus, if this sample is representative of the ore employed, these compounds should have entered the slag from another source. The particularly iron rich nature of this sample was also confirmed during the SEM-EDS analysis, which produced a BSE image illustrating a banded haematite (fig. 6.1.16), very similar to that found in GHD f2 (below: fig. 6.1.21). The other possible ore source added to the smelt is seen in the sample taken from context 016. This second ore is rich in silica (25\%), an essential component for a fluid slag to form and protect the bloom from re-oxidising, as well as containing trace oxides present in the slag, but is correspondingly poor in iron.

Therefore, there are three alternative explanations for the archaeometallurgical situation encountered within this furnace. First, high grade and poor grade ores could have been deliberately mixed to create an ideal ore balance. Second, two grades of the same ore source are represented within the limited samples collected from this furnace. However, due to differences in the alumina to silica ratios within the ore samples and the slag samples, it is unlikely that the silica in the slag originated within the ore sample alone. Much more likely is the addition of a clean silica source, similar to the large quartz pieces noted above, found within the furnace pit. Furthermore, oxides such as potash, titania, zirconia and barium oxide are higher in the ore sample than in the slag sample. If the second ore was being used in the smelt, it would be expected that correspondingly enriched levels of these oxides would be present within the slag, even with a significant dilution from ore one. Therefore, the most likely explanation is, as suggested, an addition of a source of silica during the smelt. 


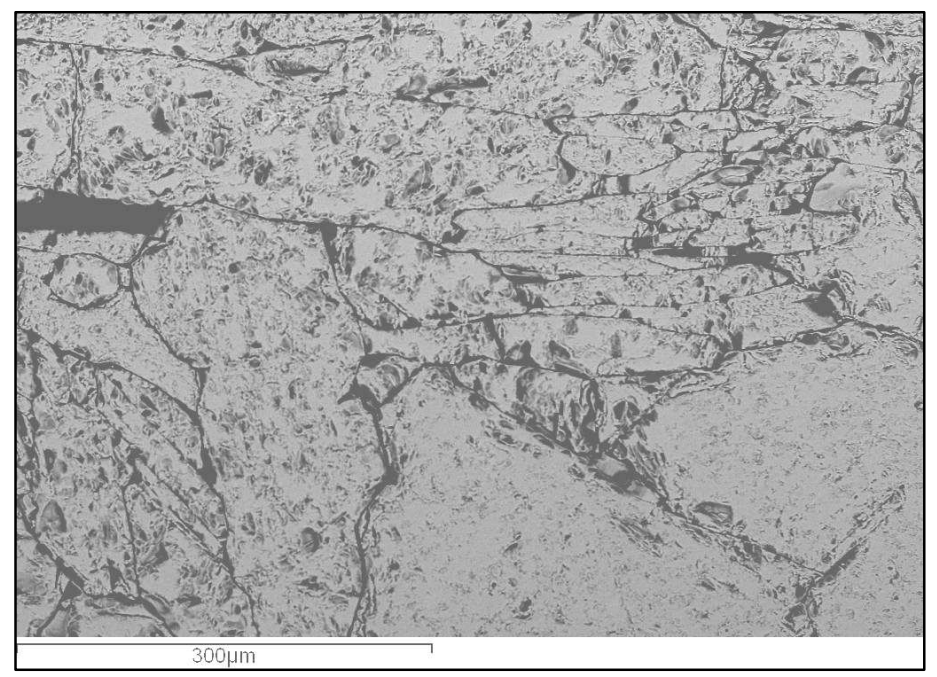

Fig. 6.1.16 SEM BSE image of ore taken from GHD f1, illustrating a banded haematite

The slag produced in GHD f1 is a typical bloomery slag, with $66 \%$ iron oxide content, $21 \%$ silica and a moderate amount of alumina at $7 \%$. The lime level in the slag sample is relatively high, at nearly $4 \mathrm{wt} \%$, especially considering it is not present in such quantities in the ore samples analysed, and interestingly it cannot derive from the melting of any of the technical ceramics during the smelt (table 6.1.6) - all of the ceramics have a much more limited amount of lime within their composition. It seems likely that the higher levels of lime in the slag sample simply derive from the incorporation of fuel ash. Magnesia and strontia (typically found in fuel ash compositions) are also found in higher levels in the slag sample than in the ore samples or in the ceramics, endorsing such an assumption.

The typical nature of the bloomery slag found in GHD f1 is illustrated by its location on the $\mathrm{FeO}-\mathrm{Al}_{2} \mathrm{O}_{3}-\mathrm{SiO}_{2}$ phase diagram along the fayalite/hercynite trough (fig. 6.1.17) and close to the 'optimum two' zone, which denotes operating temperatures around $1150^{\circ} \mathrm{C}$ to create a fluid slag (Rehren et al 2007). The characteristic bloomery slag is also highlighted in the SEM-EDS image and analysis (fig. 6.1.18), with the sample dominated by long feathery fayalite crystals containing some lime and magnesia. The sample also shows thin dendrites of wüstite and the occasional prill of metallic iron, within a glassy matrix enriched with alumina, lime and potash. Unfortunately the slag 
sample taken from context 011 from GHD f1 was revealed to be highly corroded when microscopically examined, and so no conclusions are provided based on this sample.

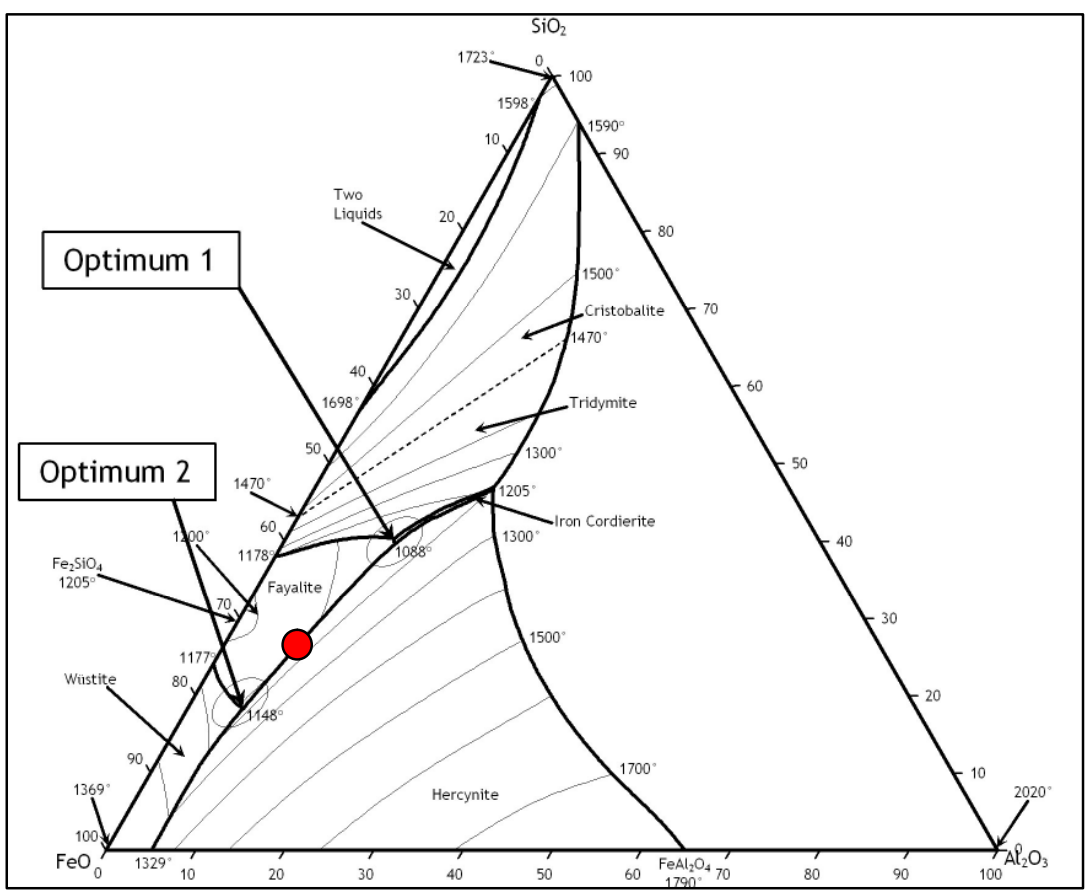

Fig. 6.1.17 $\mathrm{FeO}-\mathrm{Al}_{2} \mathrm{O}_{3}-\mathrm{SiO}_{2}$ phase diagram showing the position of the slag sample analysed from $\mathrm{f} 1$ (depicted with the red circle; phase diagram after Rehren et al 2007: 212)

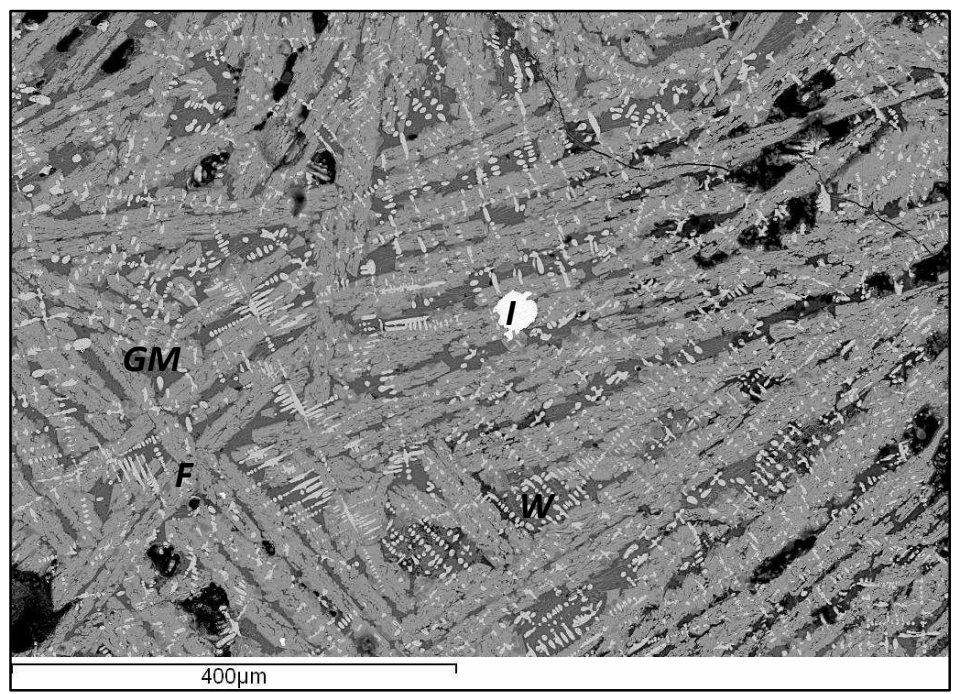

Fig. 6.1.18 SEM BSE image of the slag sample from GHD $f$ 1.

$\mathrm{F}=$ fayalite; $\mathrm{W}=$ wüstite; $\mathrm{I}=$ metallic iron; $\mathrm{GM}=$ glassy matrix 
Overall the ceramic chemistry seems not to have significantly affected that of the slag samples within the pit. The data shows that non-calcareous, kaolinitic clays have been employed to make the technical ceramics, although the rather variable (18-40\%) alumina levels could be indicative of changeable additions of quartz sand (diluting the bulk silica levels), possibly to improve structural stability during the smelt itself. This variable alumina level could also be due to a non-standardised provision of clay. It would appear that only a very limited amount of technical ceramic melted into the slag within GHD f1: the ceramics themselves are all unvitrified and have not been affected by high temperatures, shown by the lack of cracking in the quartz within the sample (fig. 6.1.19).

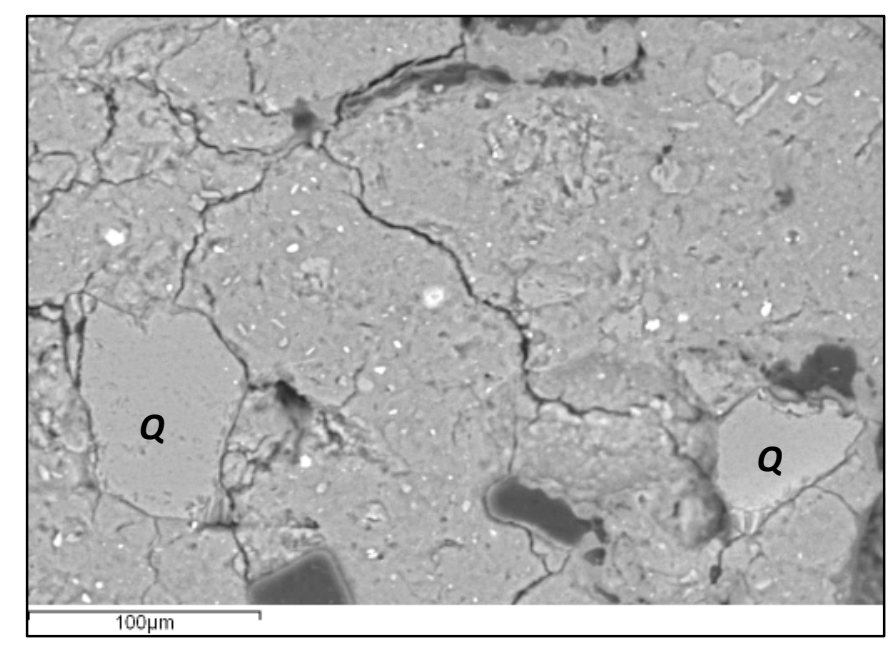

Fig. 6.1.19 SEM SE image of a brick from GHD f1 showing un-cracked quartz and an unvitrified ceramic matrix. $Q=$ quartz grain

- GHD f2

The XRF results from the 'slag' and 'ores' selected for analysis from GHD f2 (table 6.1.7), as well as the results from the technical ceramics taken from this furnace pit (table 6.1.8) are shown below. 


\begin{tabular}{|c|c|c|c|c|c|c|c|c|c|c|c|c|c|c|}
\hline & $\mathrm{Na}_{2} \mathrm{O}$ & MgO & $\mathbf{A l}_{2} \mathbf{O}_{3}$ & $\mathrm{SiO}_{2}$ & $\mathbf{P}_{2} \mathbf{O}_{5}$ & $\mathbf{S}$ & $\mathbf{K}_{2} \mathbf{O}$ & $\mathrm{CaO}$ & $\mathrm{TiO}_{2}$ & $\mathrm{~V}_{2} \mathrm{O}_{5}$ & $\mathrm{Cr}_{2} \mathrm{O}_{3}$ & MnO & $\mathrm{FeO}$ & Original \\
\hline & $\%$ & $\%$ & $\%$ & $\%$ & $\%$ & $\%$ & $\%$ & $\%$ & $\%$ & $\%$ & $\%$ & $\%$ & $\%$ & $\%$ \\
\hline 006 ore $\mathrm{A}$ & 0.04 & 0.00 & 0.00 & 0.59 & 0.00 & 0.02 & 0.00 & 0.01 & 0.00 & 0.01 & 0.01 & 0.03 & 99.29 & 96.06 \\
\hline 012 slag 10 & 0.03 & 0.02 & 0.65 & 2.11 & 0.00 & 0.26 & 0.00 & 0.10 & 0.02 & 0.03 & 0.02 & 0.05 & 96.71 & 133.73 \\
\hline 016 slag 2 & 0.03 & 0.21 & 1.67 & 3.62 & 0.02 & 0.08 & 0.18 & 0.61 & 0.05 & 0.03 & 0.02 & 0.06 & 93.43 & 102.69 \\
\hline 021 ore $\mathrm{B}$ & 0.00 & 0.00 & 0.97 & 1.48 & 0.00 & 0.01 & 0.01 & 0.00 & 0.02 & 0.03 & 0.01 & 0.04 & 97.41 & 96.34 \\
\hline 021 slag 1 & 0.00 & 0.03 & 1.82 & 3.86 & 0.03 & 0.07 & 0.03 & 0.13 & 0.05 & 0.02 & 0.01 & 0.04 & 93.89 & 95.98 \\
\hline 021 slag 2 & 0.00 & 0.03 & 1.41 & 3.59 & 0.01 & 0.23 & 0.07 & 0.42 & 0.03 & 0.02 & 0.01 & 0.05 & 94.11 & 103.99 \\
\hline 022 slag 1 & 0.03 & 0.03 & 1.28 & 2.84 & 0.02 & 0.23 & 0.05 & 0.26 & 0.03 & 0.02 & 0.01 & 0.05 & 95.14 & 103.75 \\
\hline
\end{tabular}

Table 6.1.7 (P)ED-XRF compositional data obtained from the ore and slag samples selected from GHD f2. Results have been normalised to $100 \%$, and taken from the average of three XRF runs. Full results are given in appendix 1A. No trace elements are provided because none were present in levels over $50 \mathrm{ppm}$

\begin{tabular}{cccccccccccccc} 
& $\mathrm{Na}_{2} \mathbf{O}$ & $\mathbf{M g O}$ & $\mathrm{Al}_{2} \mathbf{O}_{3}$ & $\mathbf{S i O}_{2}$ & $\mathbf{P}_{2} \mathbf{O}_{\mathbf{5}}$ & $\mathbf{S}$ & $\mathbf{K}_{2} \mathbf{O}$ & $\mathbf{C a O}$ & $\mathbf{T i O}_{2}$ & $\mathbf{V}_{2} \mathbf{O}_{5}$ & $\mathbf{C r}_{2} \mathbf{O}_{3}$ & $\mathbf{M n O}$ & $\mathbf{F e O}$ \\
& $\%$ & $\%$ & $\%$ & $\%$ & $\%$ & $\%$ & $\%$ & $\%$ & $\%$ & $\%$ & $\%$ & $\%$ & $\%$ \\
\hline 006 tuyere & 0.48 & 0.35 & 34.24 & 58.12 & 0.13 & 0.03 & 0.73 & 0.21 & 0.74 & 0.01 & 0.01 & 0.11 & 4.76 \\
012 red brick & 0.61 & 0.28 & 33.96 & 55.96 & 0.11 & 0.02 & 1.29 & 0.08 & 0.62 & 0.02 & 0.01 & 0.06 & 6.87 \\
012 red brick & 0.47 & 0.24 & 36.83 & 53.04 & 0.16 & 0.08 & 1.04 & 0.05 & 0.67 & 0.02 & 0.01 & 0.05 & 7.23 \\
pit lining & 0.50 & 0.22 & 38.28 & 52.98 & 0.17 & 0.14 & 0.79 & 0.04 & 0.63 & 0.02 & 0.01 & 0.03 & 6.12
\end{tabular}

\begin{tabular}{cccccc} 
& $\mathbf{Z n O}$ & $\mathbf{R b}_{\mathbf{2}} \mathbf{O}$ & $\mathbf{Z r O}_{2}$ & $\mathbf{B a O}$ & $\begin{array}{c}\text { Original } \\
\text { total }\end{array}$ \\
& ppm & $\mathrm{ppm}$ & $\mathrm{ppm}$ & $\mathrm{ppm}$ & $\%$ \\
\hline 006 tuyere & 115 & 78 & 280 & 117 & 81.01 \\
012 red brick & 89 & 160 & 184 & 308 & 78.20 \\
012 red brick & 105 & 109 & 196 & 251 & 77.02 \\
pit lining & 79 & 123 & 220 & 162 & 73.62
\end{tabular}

Table 6.1.8 (P)ED-XRF compositional data obtained from the ceramic samples selected from GHD f2. Results have been normalised to $100 \%$, and taken from the average of three XRF runs. Only trace elements above $50 \mathrm{ppm}$ are shown. Full results are given in appendix 1B

Immediately obvious when considering the 'slag' and 'ore' samples is that they are all extremely rich in iron oxide, with concentrations ranging from $93-99 \%$, as illustrated in figure 6.1.20. It is initially hard to imagine how these remains could represent the waste 
products of a successful smelt. Sample '012 slag 10' had significant areas of metallic iron when microscopically analysed, leading to such a high original total.

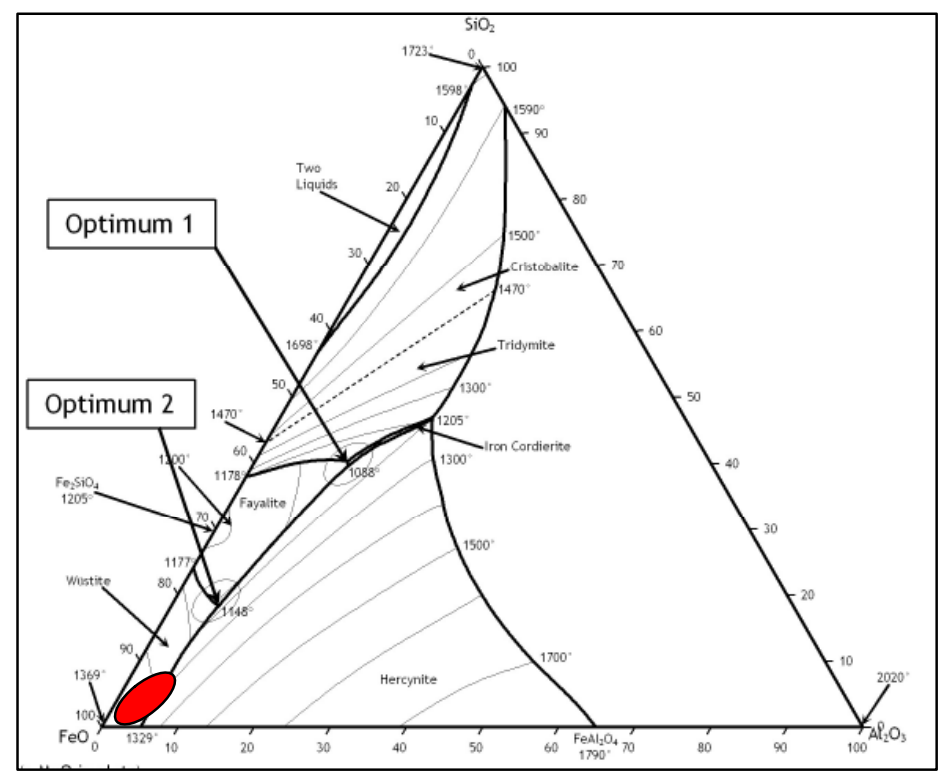

Fig.6.1.20 $\mathrm{FeO}-\mathrm{Al}_{2} \mathrm{O}_{3}-\mathrm{SiO}_{2}$ phase diagram showing the position of the 'slag' and 'ore' samples analysed from $\mathrm{f} 2$ (their location within the phase diagram depicted with the red ova; phase diagram after Rehren $e t$ al 2007: 2121)

When the corresponding photomicrographs and SEM BSE images are examined and considered in relation to the XRF results, it is clear that the angular ore pieces collected in the field are un-reacted, banded haematite (fig. 6.1.21), while the once molten 'slag' samples are packed with wüstite, which could possibly have resulted from the incomplete reduction of haematite (fig. 6.1.22). Another interesting factor within the 'slag' sample, is the two layers which appear to be present within the sample (marked in fig. 6.1.22 with a red dotted line). Such a layering effect is caused by successive dripping episodes, which have cooled at different rates. The wüstite crystal structure displayed in the upper layer of the photomicrograph has cooled at a slower rate, meaning the crystals have had more time to develop before solidifying. This sample of ore has clearly melted, partly reduced, and solidified, while the sample of ore depicted in fig. 6.1.21 has not, and retains its natural crystallographic structure. 


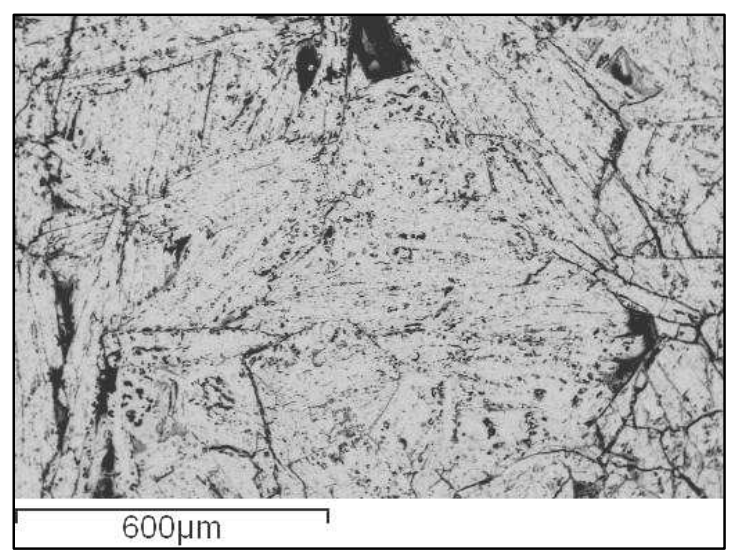

Fig. 6.1.21 SE image of 'ore', displaying banded haematite

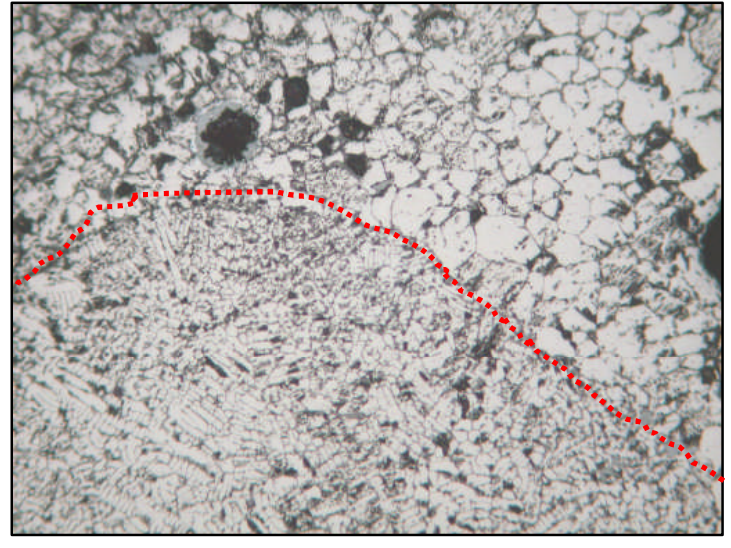

Fig 6.1.22 PPL Photomicrograph of 'slag', dominated by wüstite

(100x, image width $1 \mathrm{~mm})$

When considering the technical ceramics sampled from GHD f2, a very similar fabric composition is apparent in the tuyeres, bricks and pit lining. The material used for the three different types of the technical ceramics may well have been collected from the same source. Microscopically the sample of brick taken from GHD f2 appears generally similar to that taken from GHD f1 (fig. 6.1.23). The alumina level in these ceramics is much less variable throughout the sample range than the ceramics analysed from GHD f1, although the tuyere samples from the latter show slightly higher levels of iron oxide and potash.

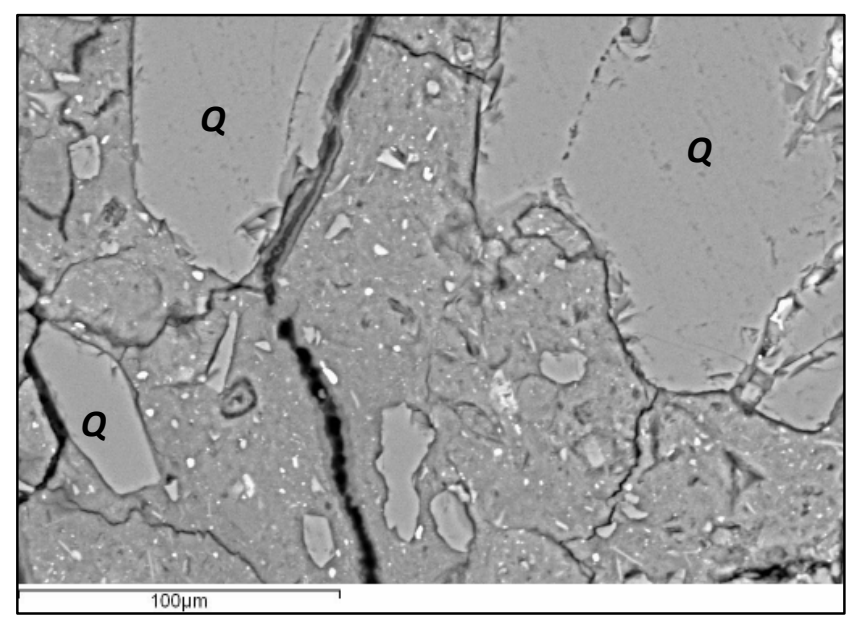

Fig. 6.1.23 SEM BSE image of a sample of ceramics from GHD f2, illustrating quartz grains (Q), throughout the clay matrix 
When the XRF results from the ceramics analysed from GHD f1 and GHD f2 are compared with the analysis of the piece of Urewe pottery (table 6.1.9), the results are dissimilar, with the Urewe sherd having somewhat different levels of both major, minor and trace oxides (most notably magnesia, potash, lime, barium oxide and rubidium oxide), as well as different silica to alumina ratios. This would suggest that a different source of clay is being utilised for the production of domestic ceramics. It could also indicate that the Urewe pottery was produced at a different location and exchanged for use at the smelting location.

\begin{tabular}{|c|c|c|c|c|c|c|c|c|c|c|c|c|c|}
\hline & $\begin{array}{c}\mathrm{Na}_{2} \mathrm{O} \\
\%\end{array}$ & $\begin{array}{c}\mathrm{MgO} \\
\%\end{array}$ & $\begin{array}{c}\mathrm{Al}_{2} \mathbf{O}_{3} \\
\%\end{array}$ & $\begin{array}{c}\mathrm{SiO}_{2} \\
\%\end{array}$ & $\begin{array}{c}\mathbf{P}_{2} \mathbf{O}_{5} \\
\%\end{array}$ & $\begin{array}{l}\mathrm{S} \\
\%\end{array}$ & $\begin{array}{c}\mathbf{K}_{2} \mathbf{O} \\
\%\end{array}$ & $\begin{array}{c}\mathrm{CaO} \\
\%\end{array}$ & $\begin{array}{c}\mathrm{TiO}_{2} \\
\%\end{array}$ & $\begin{array}{c}\mathbf{V}_{2} \mathbf{O}_{5} \\
\%\end{array}$ & $\begin{array}{c}\mathrm{Cr}_{2} \mathrm{O}_{3} \\
\%\end{array}$ & $\begin{array}{c}\text { MnO } \\
\%\end{array}$ & $\begin{array}{c}\mathrm{FeO} \\
\%\end{array}$ \\
\hline \multirow[t]{3}{*}{ Urewe } & 0.59 & 0.51 & 28.48 & 61.58 & 0.12 & 0.04 & 1.80 & 0.25 & 0.64 & 0.02 & 0.02 & 0.08 & 5.76 \\
\hline & & & uO & $\mathrm{ZnO}$ & Rb2O & $\mathrm{ZrO2}$ & $\mathbf{B a C}$ & & $\mathrm{CeO2}$ & PbO & \multicolumn{2}{|c|}{$\begin{array}{c}\text { Original } \\
\text { total }\end{array}$} & \\
\hline & & & pm & ppm & ppm & ppm & ppr & & ppm & ppm & $\%$ & & \\
\hline
\end{tabular}

Table 6.1.9 (P)ED-XRF compositional data obtained from the Urewe shard collected at GHD. Results have been normalised to $100 \%$, and taken from the average of three XRF runs. Only trace elements above $50 \mathrm{ppm}$ are shown. Full results are given in appendix 1B

\subsubsection{The site, an overview}

The evidence of decorated clay bricks having been used to form the superstructure of GHD $\mathrm{f} 2$ indicated that this furnace belonged to the Early Iron Age smelting tradition (see chapter 4). Furthermore, the similarities in the archaeometallurgical material found in GHD $\mathrm{f} 1$ to that found in GHD f2, mainly the numerous fragments of orange clay and the lack of large slag blocks which characterise later smelting sites, led to the inference that the two structures were broadly contemporary. Charcoal samples from the bases of both structures were sent for $\mathrm{C} 14$ dating, and a radiometric 2 sigma calibrated age of 420-660 AD was provided for GHD f1, and 350-570 AD for GHD f2. Thus these furnaces date to the mid-first millennium $\mathrm{AD}$ and represent the later stages of the long- 
lasting, geographically broad Early Iron Age production tradition (which made use of distinctive decorated bricks to construct furnace superstructures). Such a stylistic approach had been practiced throughout the region for approximately the previous thousand years (e.g. Craddock et al 1997; Raymaekers \& Van Noten 1986; Schmidt and Childs 1985, 1996; Van Grunderbeek et al 1983), although local levels of variation are evident within the decoration style. Unfortunately it is impossible to suggest whether or not the two furnaces at Gahondo were used by the same smelters, or if they were constructed and used generations apart (information that was hoped to have been obtained from the TL dating). However, both can offer interesting insights into the technical expertise of the iron producers working during this time.

A quantification of the level of iron production at this site is unattainable, mainly because the type of production which took place in GHD f2, using high grade ores and producing apparently very little in the way of slag. In the experimental smelt carried out as part of this research (see chapter 2), the hematite ores used were also very rich in iron oxide, averaging $93 \% \mathrm{FeO}, 5.5 \% \mathrm{SiO}_{2}$, and less than $2 \%$ of any other oxide. However, this was mixed with black magnetite sand with an iron oxide content of $76 \%$ and a silica content of $20 \%$ (normalised to $100 \mathrm{wt} \%$ ). Additionally, $1 \mathrm{~kg}$ of sandstone, with $90 \%$ silica, was added by the smelters towards the end of the process. Such a technique has been postulated above. The slag produced in this experiment was minimal compared to the five very large blooms, and present in small blobs and flows which displayed normal chemical compositions for bloomery slags. Furthermore, previous analysis of material excavated from EIA smelting furnaces within the region constructed in part with decorated bricks (Craddock et al 2007: 8) suggested a 'typical' bloomery process in action, with $\mathrm{FeO}$ contents of $58 \%-72 \%, \mathrm{SiO}_{2}$ contents of $14 \%-29 \%$, and $\mathrm{Al}_{2} \mathrm{O}_{3}$ contents of $9 \%-10 \%$, relatively similar to the slag sample analysed.

Within GHD f2, the fact that the molten material interpreted as slag had solidified and attached itself to the furnace pit lining demonstrates that it was definitely formed within the structure. If this material is considered representative of the charge and atmospheric conditions achieved during the smelt, it would appear that this was not a successful smelt: the conditions within the furnace had not been sufficiently reducing, and there 
was not enough silica present to form a liquid slag. Alternatively, the operations performed in this furnace could have been 'ore preparation', partly reducing the ore prior to re-smelting, although this seems technically unnecessary. If this was the case, the 'prepared' ore could have been utilised in GHD f1, as the 'rich' ore. Such a practice has been observed in modern Haya smelting in Tanzania. Here the smelters lay ore around the edges of the furnace pit, in order that this will partly reduce during the smelt proper, to be collected and used during the next smelt (Avery \& Schmidt 1979; Childs 1996: 286).

Another alternative could be that the remains excavated from the pit of GHD f2 could be the waste representing the less reacted parts of the charge of the furnace that had fallen through the structure, melted at the high temperatures and stuck to the sides of the pit without having been reduced. It is possible that 'typical' slag was also formed in this furnace, and this could have been removed and thrown away elsewhere (or could have been missed during sampling within this furnace). This would allow further smelts to be carried out using the same furnace structure. Perhaps therefore, either owing to the subjective nature of sampling, or to a deliberate action of the smelters to remove some of the pit fill following the smelt, this has resulted in a situation where the archaeometallurgical remains are difficult to reconstruct.

In general, both furnace pits appear to represent aspects of technological traditions already well established in the area by the mid first millennium AD, with GHD f1 apparently representative of a typical bloomery smelt, possibly with the addition of an additional silica source to complement the high grade ore.

On a macroscopic level the ceramics used in both $\mathrm{f} 1$ and $\mathrm{f} 2$ appear very similar. The tuyeres appear of a similar size and style, while the orange brick fabric appears to have been utilised throughout both features (although, as mentioned above, the use in $\mathrm{f} 1$ is not as clear at that in $\mathrm{f} 2$ because the clay lumps are so degraded). A further similarity is that both sets of ceramics remained unvitrified - both were moderately to highly refractory, due to their overall kaolinitic nature, and the XRF results from both furnace structures suggest little of the technical ceramics used in the processes at GHD were lost 
into the smelts. However, the XRF data suggests that different clay sources, or methods of processing the clays, were exploited. The consistent alumina levels in the GHD f2 ceramics are not replicated in the GHD f1 ceramics, which are generally less standardised. Levels of magnesia, sulphur and lime vary significantly between the two sets of data, and the ratios of alumina to silica within the ceramics are slightly different, with those used in GHD f2 more standardised that those used in GHD f1 (fig. 6.1.24). The average alumina to silica ratio within the clays used in $\mathrm{f} 1$ is $1: 3$ (excluding the pit lining), whereas the ratio in the $\mathrm{f} 2$ ceramics averages $1: 1.5$. The trace oxides present in the technical ceramics over $50 \mathrm{ppm}$ are the same and are generally comparable. Other major and minor oxides are also broadly similar. It could be suggested that the differences seen in the ceramics are therefore due to processing rather than to different sources of clay being utilised.

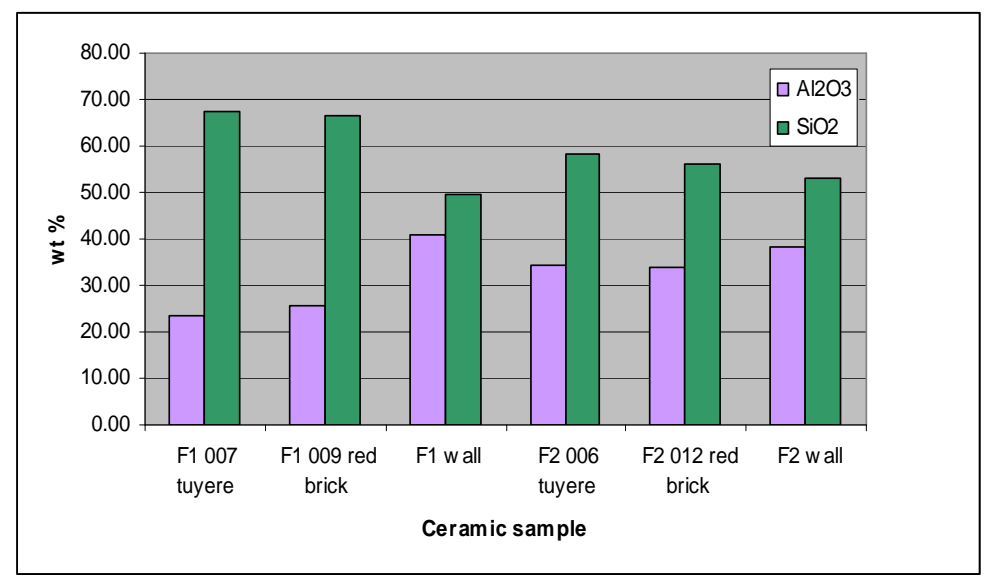

Fig 6.1.24 Levels of alumina and silica in the technical ceramics analysed from GHD f1 and f2

Overall, although a variety of interpretations are available for the furnaces at this early site iron production site at Gahondo, the excavations and analytical results have provided another documentation of early technological traditions. The smelters used refractory clays to construct their furnaces bricks, some of which were decorated, following a long-lived traditional technological approach. The smelters also could have been making use of two different types of ore, although this cannot be said for certain. There is also the possibility that smelting here was a two stage process, with ore being partly reduced in an initial process, and then smelted. Furthermore, the lack of associated archaeology at the site of Gahondo also presents a problem. This could 
reflect the organisation of iron production during these early times - smelting was taking place outside the locations of domestic activity. Such a technological choice has been recorded in ethnographic examples, to ensure the secret nature of the technology and that outsiders were not able to access iron production knowledge, and also in association with various taboos against women, across the region (e.g. de Barros 2000: 164-174; Childs \& Killick 1993: 325-330; Herbert 1993: 78-96; Reid \& MacLean 1995; Schmidt 1997: 154-189). However, this archaeological situation could also reflect the high level of recent habitation activity (sweeping compounds, house building, pit digging), as well as cultivation, and of course general erosion due to weathering. The overall contextualisation of the results generated from the excavations and analysis of samples taken from the site of GHD will be provided in chapter 7. 


\subsection{Cyamukuza $1(\mathrm{CMZ} 1)$}

\subsubsection{Site description and observations}

The site of CMZ 1 is located on the ridge of a heavily eroded hill, with a fairly shallow slope to the east (connecting the hill with the surrounding hills) and steeper slopes into deeper valleys to the west, north and south (fig. 6.2.1). The iron production site lies directly on the crest of the hill in the middle of the path leading to the local primary school, which is situated at the western end of the hill ridge; this path is used daily by over one hundred pupils, thus excavation at this site was scheduled to coincide with the school holiday. The excavation was therefore carried out at the height of the dry season; the ground was difficult to excavate, being compacted by the human and animal activity and also being sun-baked. Also located on the hill ridge to the north and south side of the archaeometallurgical remains are two houses with cultivated areas (mainly bananas, beans and cassava) to the sides and around the back of each. No members of these households had memories connected to the archaeological remains, but both families said they had lived on the land for at least the last two generations. However, it is worth mentioning that the residents were reluctant to discuss the past in any detail. Cattle were daily routed over the site, as well as chickens and the occasional pig. 


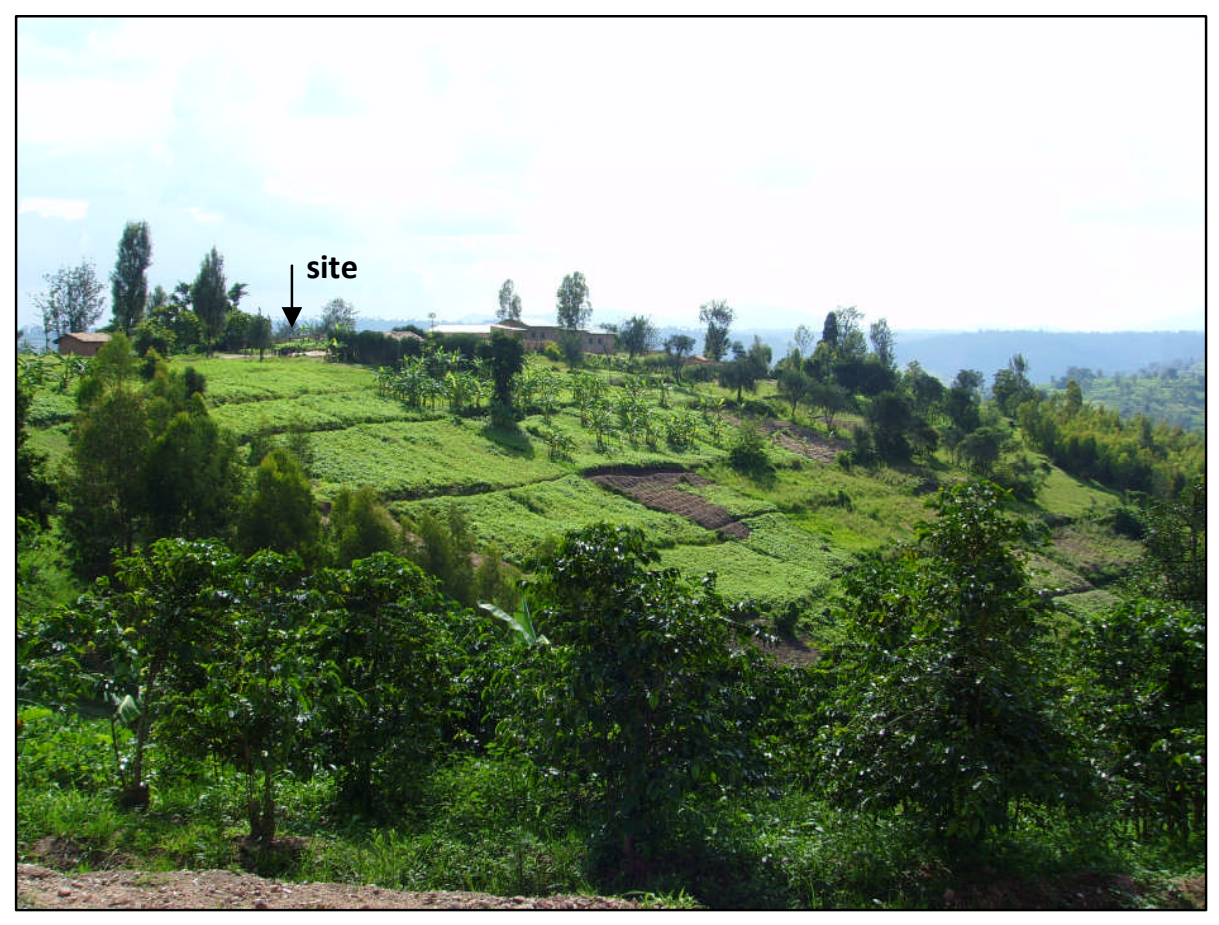

Fig 6.2.1 View looking south-west towards the site of CMZ 1

The site itself consists of 9 blocks of slag in an area of $8 \mathrm{~m} \mathrm{x} 7 \mathrm{~m}$ (with a further 10 blocks distributed at a distance outside this area), as well as two furnace pit features: CMZ 1 f1 and CMZ 1 f2 (fig. 6.2.2). The slag blocks across the site appeared macroscopically very similar in size and shape. Each slag block was a conical shape (indicative of the bowl-shaped furnace pit), with the very smooth, narrow end of the cone being the base of the block, representing the slag which had initially flowed into the furnace pit. The blocks had much rougher, more irregular top surfaces (fig. 6.2.3). 


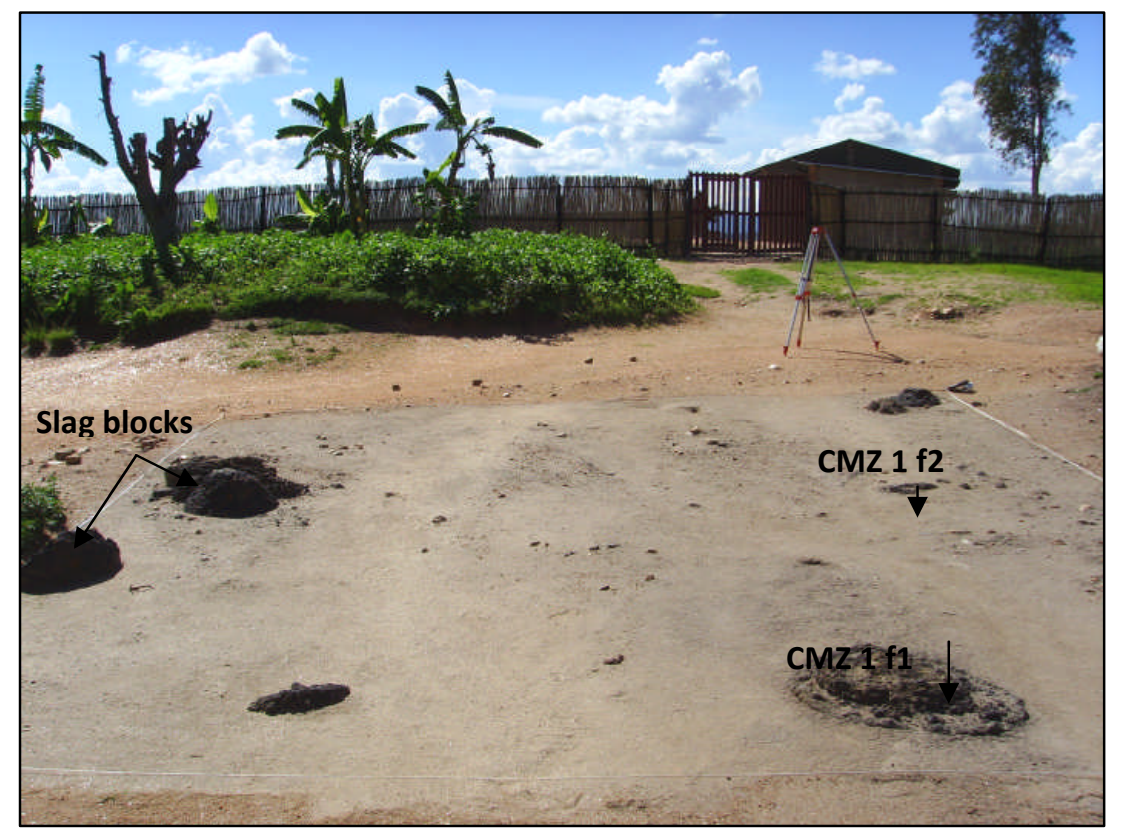

Fig. 6.2.2 The site of CMZ 1
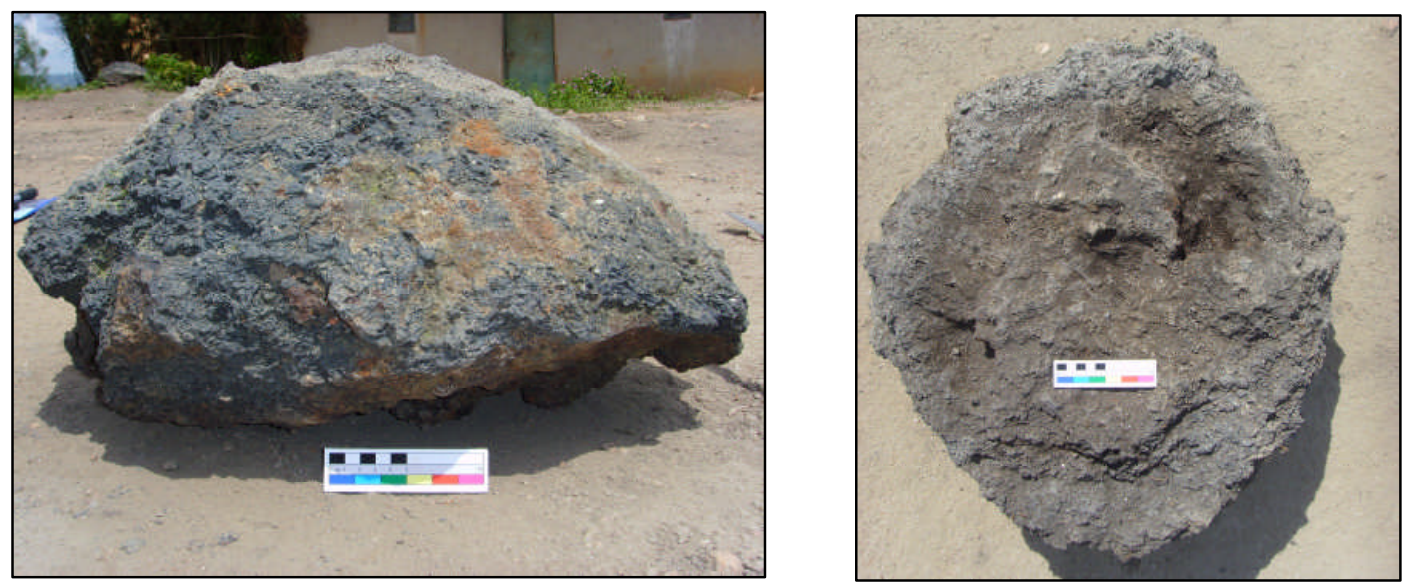

Fig. 6.2.3 Typical slag block from CMZ 1: side view on the left (block upside-down); top view on the right

As described in the methodology (chapter 5), to gain a comprehensive understanding of the smelting technologies being performed at each of the smelting sites selected for detailed investigation, five of the most visually representative slag blocks were selected for archaeometric analysis (SB1-5). The dimensions of the five blocks analysed from CMZ 1 are shown in table 6.2.1. 


\begin{tabular}{cccc} 
Slag block & Diameter $(\mathbf{c m})$ & Depth $(\mathbf{c m})$ & Weight $(\mathbf{k g})$ \\
\hline 1 & 56 & 37 & 41 \\
2 & 60 & 29.5 & 94 \\
3 & 55 & 39 & 92 \\
4 & 60 & 34 & 100 \\
5 & 55 & 36 & 64
\end{tabular}

Table 6.2.1 Dimensions of the slag blocks investigated at CMZ 1. SB1 and SB5 were missing sections of the blocks (having been knocked off or fallen off over the years) which is reflected in the overall lower weight of the blocks, but the maximum dimensions could still be determined

Alongside macroscopic examinations of the slag blocks in the field which illustrated the remarkably uniform appearance of the slag block produced at CMZ 1, following the sectioning of the blocks, the internal structures were also seen to be visually very comparable, with limited levels of obvious porosity and corrosion (notably in the very middle of the blocks), few obvious plant impressions throughout the slag formation, and no internal interfaces.

No tuyere fragments were found at the site of CMZ 1. This could suggest that a limited number of tuyeres were utilised during the smelts at this site, although it more probably reflects the human and environmental impact on the archaeological remains; while erosion and rain water could have washed such light, small remains down the hill slopes, human and other animal activity could well have reduced such features to rubble. Interestingly, while surveying the hill just below the eastern end of the hill ridge for further archaeometallurgical remains (approximately $50 \mathrm{~m}$ from the site) a few tuyere fragments were recorded in an erosion bank. This was identified as an isolated find, and so the location was not investigated further.

As mentioned above, two furnace pit features were recorded and excavated at CMZ 1. The first, CMZ 1 f1, contained SB1 still sat in situ, having been left in place since forming during a smelting event. The outline of the pit and the slag block were clearly visible as prominent features of the site (fig. 6.2.4). The furnace pit was approximately 
$60 \mathrm{~cm}$ in diameter north-south, and $65 \mathrm{~cm}$ in diameter east-west. At ground level the pit lining ranged from 6-12 cm in thickness (fig. 6.2.5), and appeared lighter grey than the surrounding soil and heavily tempered with quartz. The slag block rose to $8 \mathrm{~cm}$ in height from ground level in places, suggesting that the pit lining had eroded as the surface of the hill had been weathered and subjected to human and animal activity.

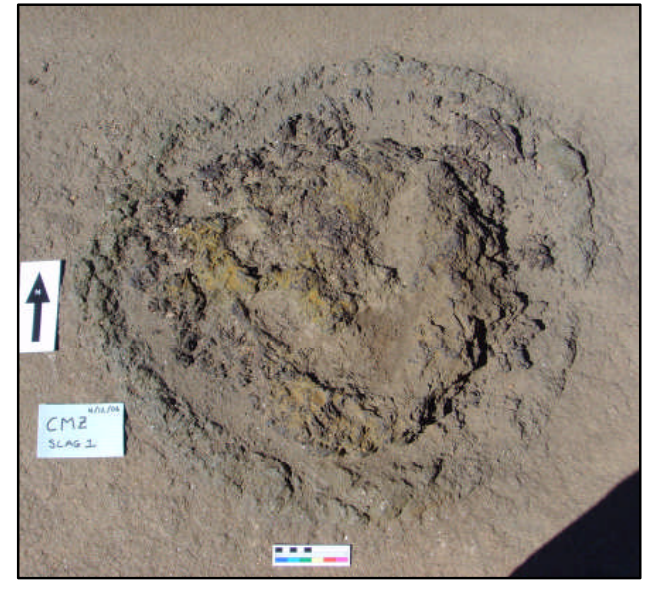

Fig. 6.2.4 CMZ 1 F1 before excavation

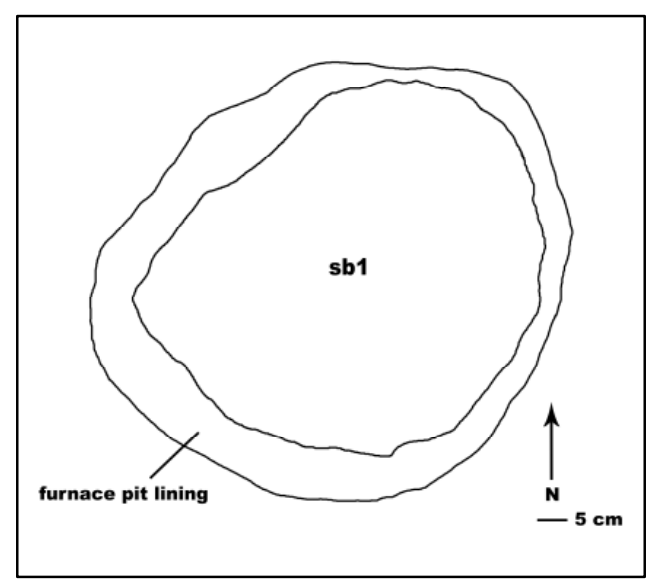

Fig. 6.2.5 Plan of CMZ 1 F1 before excavation

The second furnace pit (CMZ 1 f2) was only just visible once the site area had been trowelled back to remove the loose gravel, and even then, less than half of the external circumference was obvious. The pit was at a distance of approximately $3 \mathrm{~m}$ from the western edge of CMZ $1 \mathrm{f} 1$. At ground level CMZ $1 \mathrm{f} 2$ was roughly $40 \mathrm{~cm}$ in diameter from north to south; it was not possible to distinguish the east-west diameter before excavation. The pit lining appeared to be $5-8 \mathrm{~cm}$ thick, and to have been re-lined at some point along the western edge. The fill of the pit appeared to be a mix of the surrounding soil that had been washed in and become compacted around some pieces of slag that could be seen protruding from inside the pit.

Four test pits were excavated across the site to test for associated archaeological features or stratigraphy (fig. 6.2.6). In between the two furnace pits (approximately $1 \mathrm{~m}$ from the north-west corner of CMZ $1 \mathrm{f} 1$ ), some ceramic fragments were seen protruding from the ground, and so this location was chosen for one of the test pits. Three further 
test pits were excavated around a number of the slag blocks chosen for analysis, to test for associated archaeometallurgical remains.

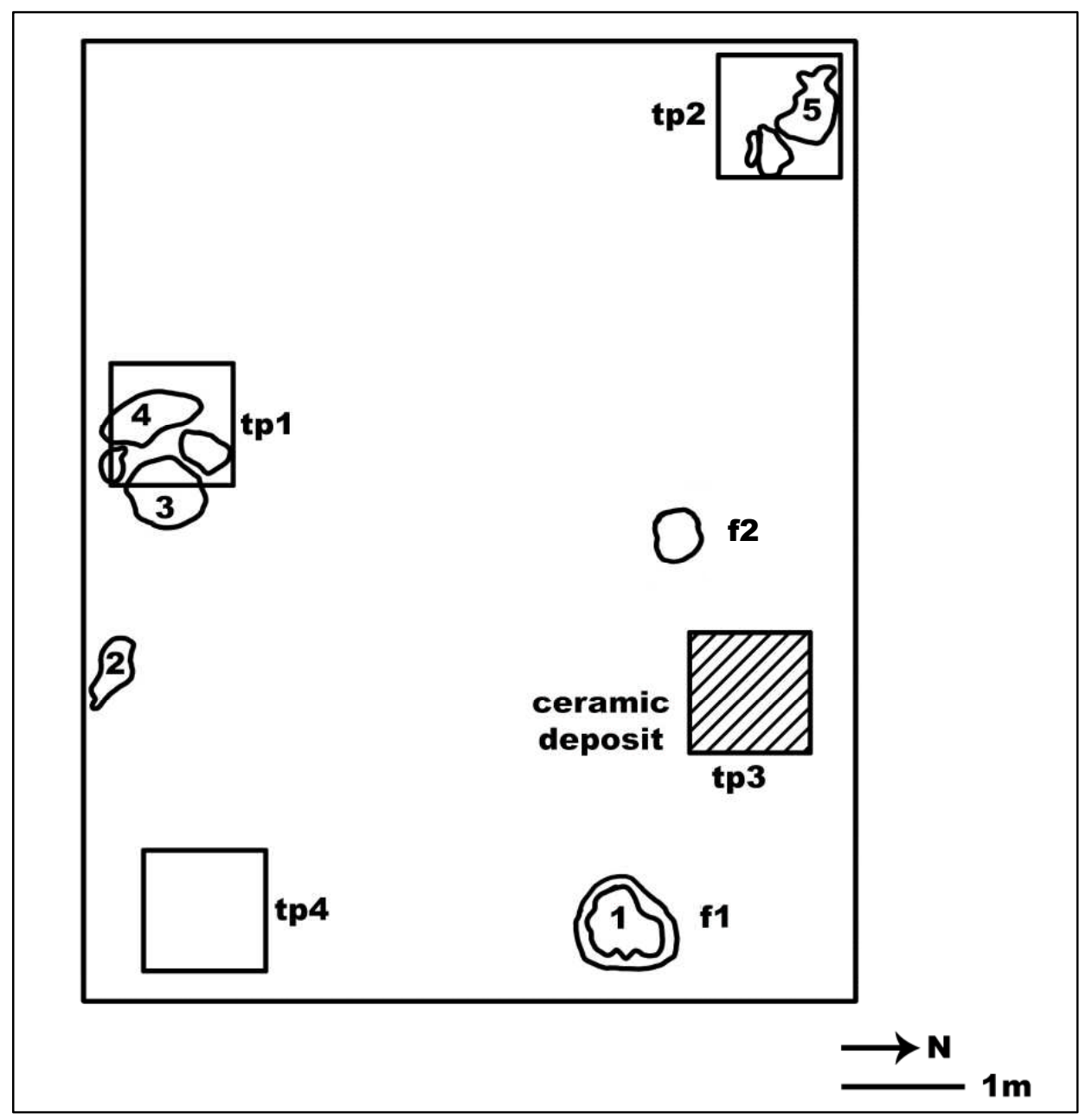

Fig. 6.2.6 CMZ 1, showing the locations of $\mathrm{f} 1, \mathrm{f} 2$, the test pits, the interesting ceramic deposit and the slag blocks (1-5) analysed

\subsubsection{Excavations and sample selection}

\section{- Slag blocks}

As mentioned above, the five slag blocks selected for detailed study at CMZ 1 were macroscopically very similar. The top surface of the blocks averaged $57 \mathrm{~cm}$ in diameter, and only displayed $5 \mathrm{~cm}$ in total variation between the blocks (from $55-60 \mathrm{~cm}$ ). The depth of each slag, from top to bottom, ranged from 29 to $39 \mathrm{~cm}$. 
The slag blocks were recorded, sectioned and sampled. The sections confirmed that the blocks represent the remains of single smelting episodes due to their lack of cold interfaces (fig. 6.2.7). The slag samples taken for analysis and the type of analysis used to investigate each sample are illustrated in table 6.2.2.

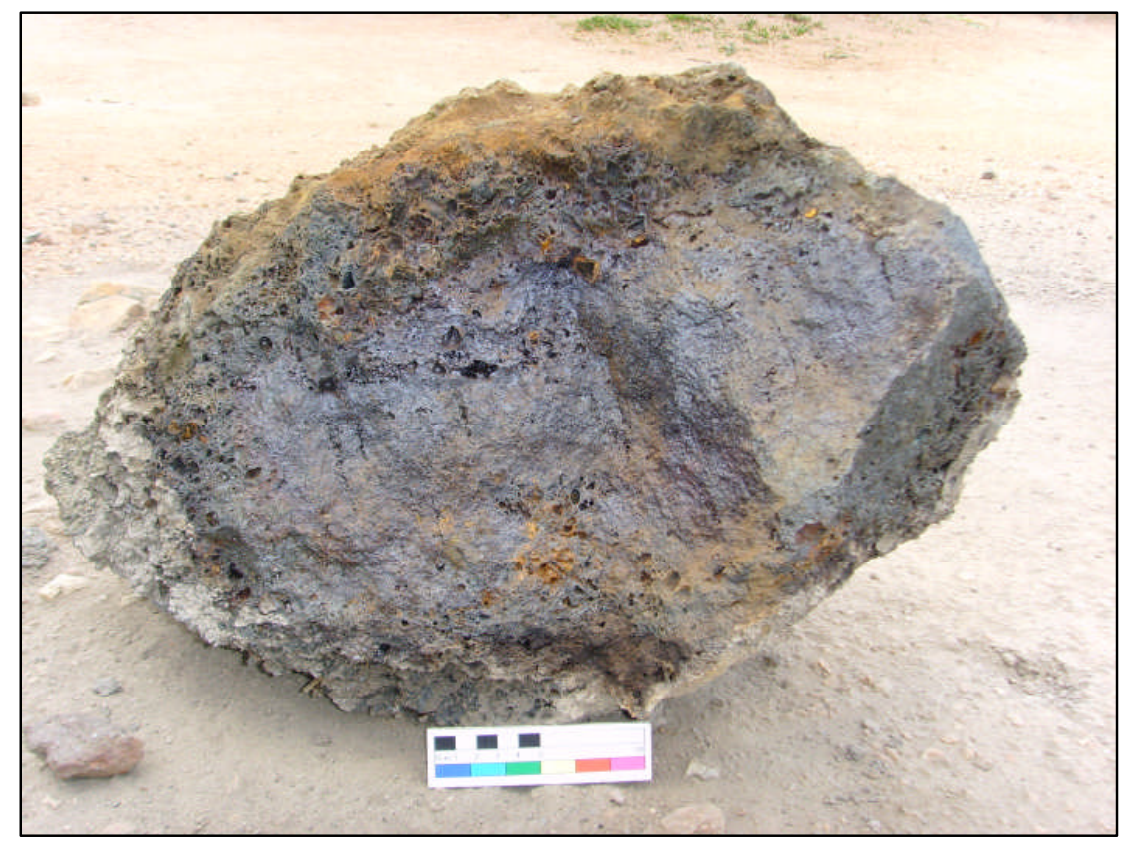

Fig. 6.2.7 CMZ 1 SB1 section

\begin{tabular}{ccccc}
$\begin{array}{c}\text { Slag } \\
\text { block }\end{array}$ & Sample & ED-XRF & OM & SEM-EDS \\
\hline 1 & A & $\bullet$ & $\bullet$ & \\
1 & B & $\bullet$ & $\bullet$ & \\
1 & C & $\bullet$ & $\bullet$ & $\bullet$ \\
2 & B & $\bullet$ & $\bullet$ & \\
3 & B & $\bullet$ & $\bullet$ & \\
4 & B & $\bullet$ & $\bullet$ & $\bullet$ \\
5 & B & $\bullet$ & $\bullet$ &
\end{tabular}

Table 6.2.2 Samples of slag taken from CMZ 1 and the analytical methods employed 
- $C M Z 1 f 1$

As mentioned, SB1 was sat firmly in $\mathrm{f} 1$, and therefore an excavation strategy had to be resolved that would enable the entire structure to be seen in section to reveal how deep the furnace pit was, and how the pit was lined. Another aim was to remove SB1 with minimum damage to both the furnace pit structure and to the slag block to allow for accurate recording. For want of a better technique, a section line was set up running east to west across the middle of the furnace, and the north half was excavated to reveal the furnace pit in section. This meant excavating underneath the bottom of the north half of the furnace pit, which was done in $5 \mathrm{~cm}$ spits. Additionally, $5 \mathrm{~cm}$ of sediment were removed from the southern half of the furnace to look for tuyeres that may have been left in situ: none were found around the entire pit. This method of excavation proved very successful, and the section was excavated to bedrock, which was reached at a depth of approximately $35 \mathrm{~cm}$. Having excavated under the bottom of the north half of the furnace pit, the pit lining from this half of the furnace was removed. This revealed a very consistent pit lining of approximately 6-8 $\mathrm{cm}$ across the entirety of the bottom of the pit (fig. 6.2.8).

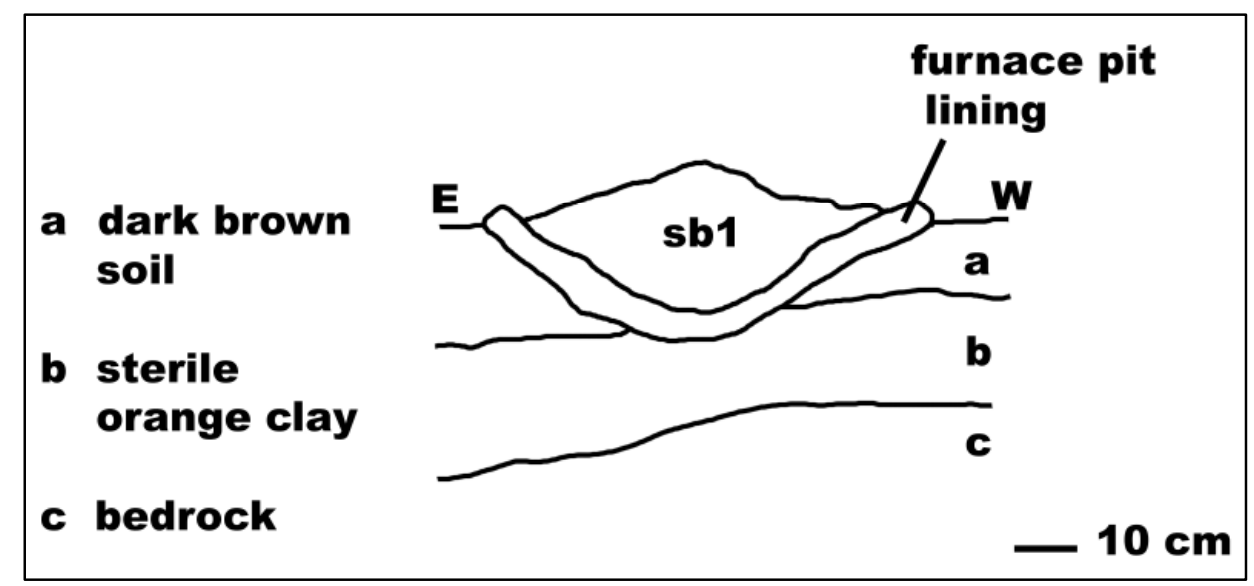

Fig.6.2.8 CMZ 1 f1 section after excavation of the northern half

As mentioned in chapter 5, a goal of this research was to select samples for thermoluminescence dating, therefore samples of the furnace pit had to be taken before exposure to daylight. Great care was taken when slowly lifting SB1 out of the pit using a car jack. The entire operation was performed under the ground sheet of a tent (chosen 
because of its opaque nature), to the amusement of all present. The collected samples of pit lining were placed immediately in tinfoil and sealed in a zip lock bag without being exposed to the light of day. Fig. 6.2.9 shows the furnace pit after the removal of SB1, and a gap in the pit lining where the sample collected for luminescence dating was taken. As described in the methodology, samples of technical ceramics were taken for the NMR (National Museum of Rwanda) for their own collections, for UCL for laboratory analysis, and for the University of Milan for TL dating (table 6.2.3).

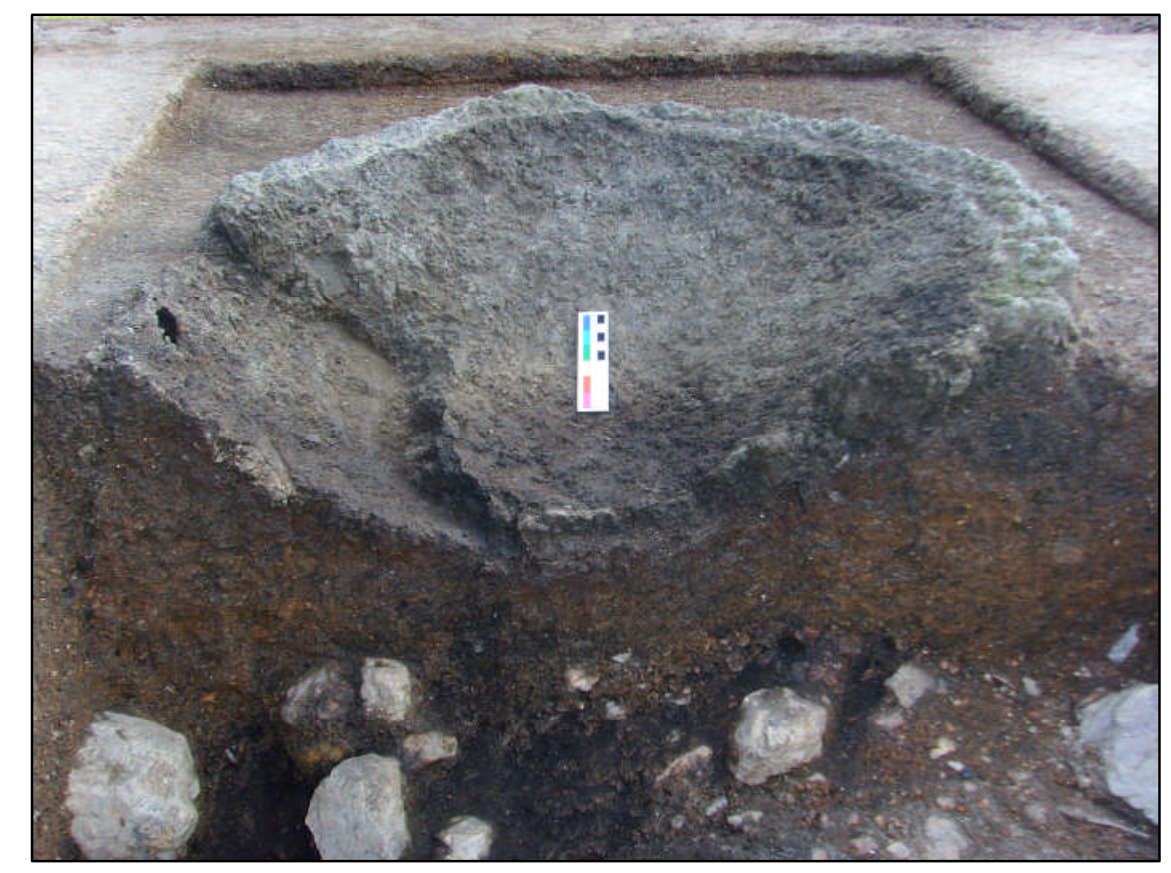

Fig. 6.2.9 CMZ $1 \mathrm{f1}$ after the removal of SB1 and samples for luminescence dating

\begin{tabular}{ccccc}
$\begin{array}{c}\text { CMZ 1 f1 } \\
\text { sample }\end{array}$ & $\begin{array}{c}\text { Destination } \\
\text { of sample }\end{array}$ & ED-XRF & OM & TL dating \\
\hline pit lining & NMR & & & \\
pit lining & UCL & $\bullet$ & $\bullet$ & \\
pit lining & Milan & & & $\bullet$
\end{tabular}

Table 6.2.3 Samples taken from the pit lining of CMZ $1 \mathrm{f1}$; their location and the methods of processing. (NMR - National Museum of Rwanda; Milan - TL dating laboratory) 
- CMZ 1 f2

The second furnace pit investigated at the site was a very complicated structure to excavate and to understand due to the very mixed nature of the deposits. After removing the top soil, the outline of the pit became more pronounced and it was clear that the pit was surrounded by, and filled with, large fragments of slag. The pit fill consisted of smaller pieces of slag, flecks of charcoal, and possible pieces of ore (fig. 6.2.10). The furnace pit was $18 \mathrm{~cm}$ deep in total and conical in shape, and thus similar in style to CMZ $1 \mathrm{f} 1$, and representative of the style of pit which would have produced the slag blocks recorded across the site. Table 6.2.4 illustrates the samples chosen for analysis from CMZ $1 \mathrm{f} 2$. These include a possible piece of bloom found attached to slag in the upper level of the pit fill, while the slag and ore samples selected for analysis were taken from the bottom of the pit fill to avoid contamination. A piece of ceramic was excavated in the mixed pit-fill, and two samples of pit lining were taken: lining A, which appeared to form part of the original pit lining, and lining B, which appeared to represent an episode of re-lining.
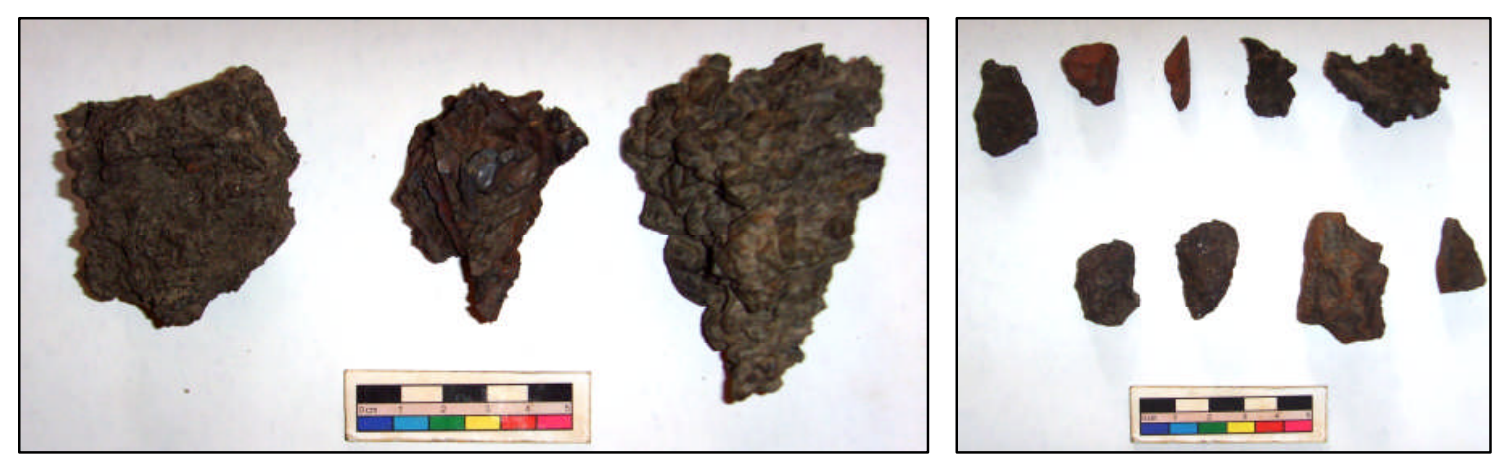

Fig. 6.2.10 Finds excavated in CMZ $1 \mathrm{f} 2$ : larger pieces of slag (left); smaller slag pieces and ore samples (right) 


\begin{tabular}{ccccc}
$\begin{array}{c}\text { CMZ 1 f2 } \\
\text { context }\end{array}$ & $\begin{array}{c}\text { Finds } \\
\text { analysed }\end{array}$ & ED-XRF & OM & SEM-EDS \\
\hline 003 & bloom & & $\bullet$ & $\bullet$ \\
005 & ceramic & $\bullet$ & & \\
007 & slag 1 & $\bullet$ & & $\bullet$ \\
007 & slag 2 & $\bullet$ & $\bullet$ & \\
007 & ore & $\bullet$ & $\bullet$ & $\bullet$ \\
pit lining A & pit lining & $\bullet$ & $\bullet$ & \\
pit lining B & pit lining & $\bullet$ & $\bullet$ &
\end{tabular}

Table 6.2.4 Finds collected and analysed from CMZ 1 f2

\section{- Test Pits}

The excavation of tp1 incorporated SB3 and SB4, while tp2 was excavated around SB5, to investigate if these slag blocks were indiscriminately dumped or if in fact they lay next to associated archaeological features such as further furnace structures. The final test pit was excavated in the south-east corner of the unit to test the extent of the archaeometallurgical deposits. During the excavations it was found that each of the slag blocks were surrounded both by complete blocks, as well as numerous slag fragments of varying sizes (as seen in the fill of CMZ $2 \mathrm{f} 2$ ). Bedrock was reached by $28-35 \mathrm{~cm}$ across the site, and the walls of the test pits exhibited no definitive stratigraphy, leading to the assumption that the blocks had been randomly dumped across the site, and that those blocks visible on the surface were not representative of the total extent of past smelting activities at the site. Tp3 was set up as a $1 \times 1 \mathrm{~m}$ unit around the protruding ceramics visible between the two furnace pits. Within this test pit, by $8 \mathrm{~cm}$ depth, the ceramic remains were totally revealed. The ceramic vessel (a large pot) was decorated with knotted strip roulette decoration below the neck, and an embossed triangular pattern around the top of the decoration. The ceramic pieces were photographed and planned (fig. 6.2.11) and then removed. The test pit was sterile following the removal of the ceramics, and reached bedrock within $30 \mathrm{~cm}$. Samples of the pottery were taken for comparative analyses from the test pit (fig. 6.2.11). 


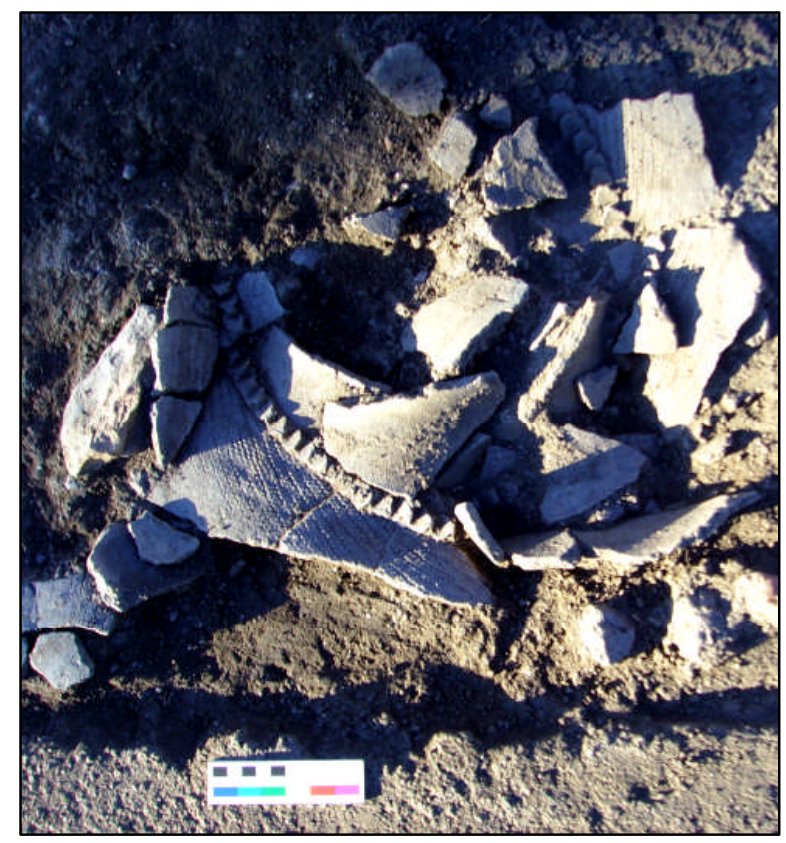

Fig. 6.2.11 TP3 ceramics

\begin{tabular}{cccc} 
Context & Sample & ED-XRF & OM \\
\hline tp3 002 & triangular decoration & $\bullet$ & $\bullet$ \\
tp3 002 & non-triangular decoration & $\bullet$ & $\bullet$
\end{tabular}

Table 6.2.5 Samples analysed from the test pits excavated at CMZ 1

\subsubsection{Results}

The following section outlines the results for all of the samples analysed, first from the CMZ 1 slag blocks, then CMZ $1 \mathrm{f} 1, \mathrm{CMZ} 1 \mathrm{f} 2$, and finally from other samples taken from the site. The XRF data are provided and explained, followed by a consideration of these results in combination with the optical microscopy and/or SEM-EDS analyses.

\section{- Slag Blocks}

Macroscopic observations in the field revealed that the slag blocks at CMZ 1 are the result of single smelting events, while the smaller fragments of slag identified across the site appear to be pieces which have broken away from the larger blocks (matching the 
breaks visible on many of these). The smaller pieces could also represent slag that had never coalesced with larger furnace masses during smelting operations, although due to the general site observations concerning slag morphology and the dominance of large blocks, this seems less likely. That these smaller slag fragments are not related to smithing activities is supported by the lack of any hammer scale at the site (tested using a magnet dragged across the area and in the test pits), and that no plano-concave/convex shaped slags, typical of smithing activities, were found.

As described in the methodology, the coefficient of variation within one slag block was tested initially to determine the level of homogeneity within chemistry and microstructure, and thus to asses the representative nature of a single sample from the block (table 6.2.6; fig. 6.2.12).

\begin{tabular}{cccccccccccccc} 
& $\mathrm{Na}_{2} \mathbf{O}$ & $\mathrm{MgO}$ & $\mathrm{Al}_{2} \mathrm{O}_{3}$ & $\mathrm{SiO}_{2}$ & $\mathbf{P}_{2} \mathbf{O}_{5}$ & $\mathbf{S}$ & $\mathrm{K}_{2} \mathbf{O}$ & $\mathbf{C a O}$ & $\mathbf{T i O}_{2}$ & $\mathbf{V}_{2} \mathbf{O}_{5}$ & $\mathbf{C r}_{2} \mathrm{O}_{3}$ & $\mathrm{MnO}$ & $\mathbf{F e O}$ \\
& $\%$ & $\%$ & $\%$ & $\%$ & $\%$ & $\%$ & $\%$ & $\%$ & $\%$ & $\%$ & $\%$ & $\%$ & $\%$ \\
\hline $1 \mathrm{~A}$ & 0.31 & 0.27 & 9.91 & 26.20 & 1.84 & 0.12 & 2.07 & 1.44 & 0.57 & 0.04 & 0.02 & 0.16 & 56.94 \\
$1 \mathrm{~B}$ & 0.36 & 0.20 & 9.26 & 27.12 & 1.86 & 0.14 & 2.02 & 1.02 & 0.58 & 0.04 & 0.01 & 0.14 & 57.17 \\
1C & 0.40 & 0.38 & 10.05 & 25.06 & 1.88 & 0.06 & 2.16 & 1.34 & 0.49 & 0.03 & 0.02 & 0.20 & 57.83
\end{tabular}

\begin{tabular}{|c|c|c|c|c|c|c|c|}
\hline & $\mathbf{R} \mathbf{b}_{2} \mathbf{O}$ & SrO & $\mathrm{ZrO}_{2}$ & $\mathrm{BaO}$ & $\mathbf{L a}_{2} \mathbf{O}_{3}$ & $\mathrm{CeO}_{2}$ & $\begin{array}{c}\text { Original } \\
\text { Total }\end{array}$ \\
\hline & Ppm & Ppm & $\mathrm{ppm}$ & ppm & ppm & ppm & $\%$ \\
\hline $1 \mathrm{~A}$ & 78 & 139 & 168 & 384 & 61 & 155 & 94.79 \\
\hline 1B & 88 & 90 & 160 & 358 & 42 & 130 & 90.76 \\
\hline $1 \mathrm{C}$ & 100 & 115 & 138 & 454 & 51 & 139 & 94.33 \\
\hline
\end{tabular}

Table 6.2.6 (P)ED-XRF compositional data obtained from the samples taken from CMZ 1 SB1. Results have been normalised to $100 \%$, and taken from the average of three XRF runs. Only trace elements above $50 \mathrm{ppm}$ are shown. Full results are given in appendix $2 \mathrm{~A} . \mathrm{A} \mathrm{A}=$ top of block $/$ end of smelt, $1 \mathrm{C}=$ bottom of block / beginning of smelt 


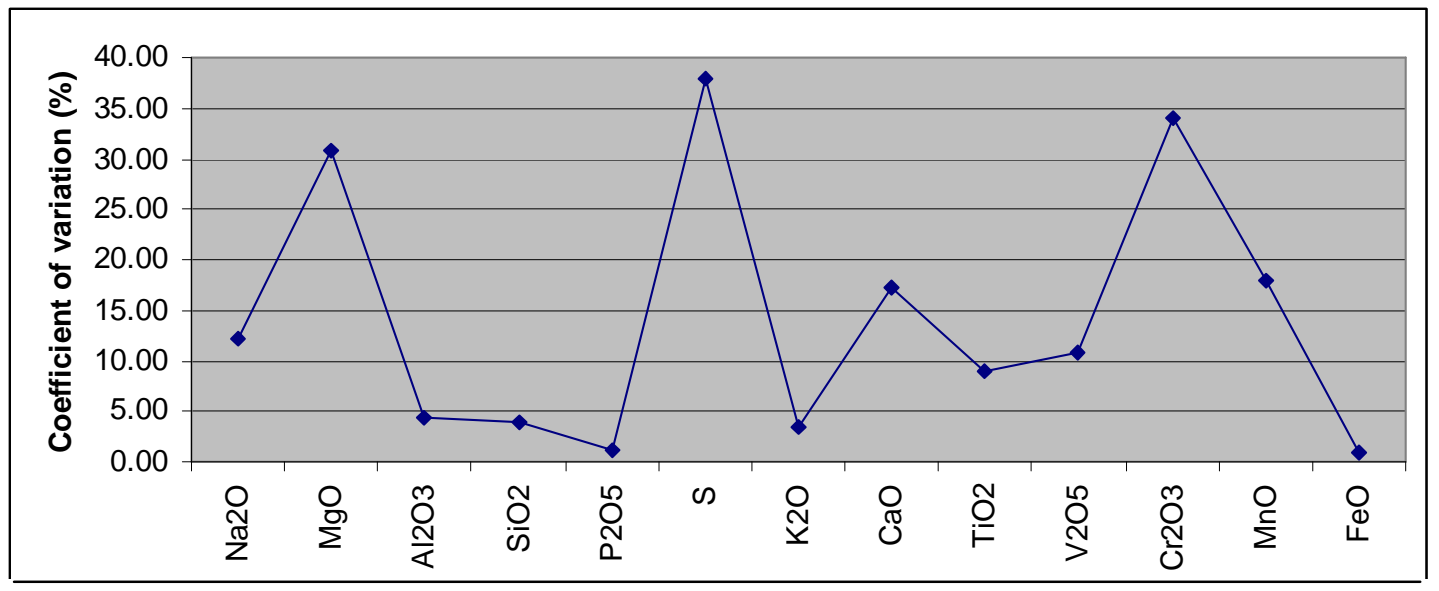

Fig 6.2.12 Compositional variation throughout SB1 demonstrated using the coefficient of variation

The chemical coefficients of variation within CMZ 1 SB1 demonstrate that importantly, the overall levels of variation are minimal for the main oxides. For the main constituents of iron slag - iron oxide, silica, and alumina - the relative level of variation from the beginning to the end of the smelt is less than $10 \%$, suggesting that the smelting parameters for the entirety of this production episode were kept relatively constant. Other oxides vary up to $30 \%$, but are either lighter oxides or those present in much lower levels, both of which factors can easily result in a higher level of relative variation and analytical uncertainty. The general smelt represented is indicative of controlled and uniform smelting methods which were precisely implemented by the artisans.

The microstructure of the samples taken from throughout SB1 (fig. 6.2.13 below) also reflects a significant level of homogeneity throughout the smelting event. All of the samples are dominated by fayalite (F - lighter grey phase), occasional hercynite and areas of kalsilite ( $\mathrm{K}$ - darker grey phase). Generally the crystal structures are large and well formed, indicating a slow cool, as would be expected in a bloomery slag pit. Furthermore, few free iron oxides are visible, in agreement with the moderate bulk iron content noted in the XRF data. 

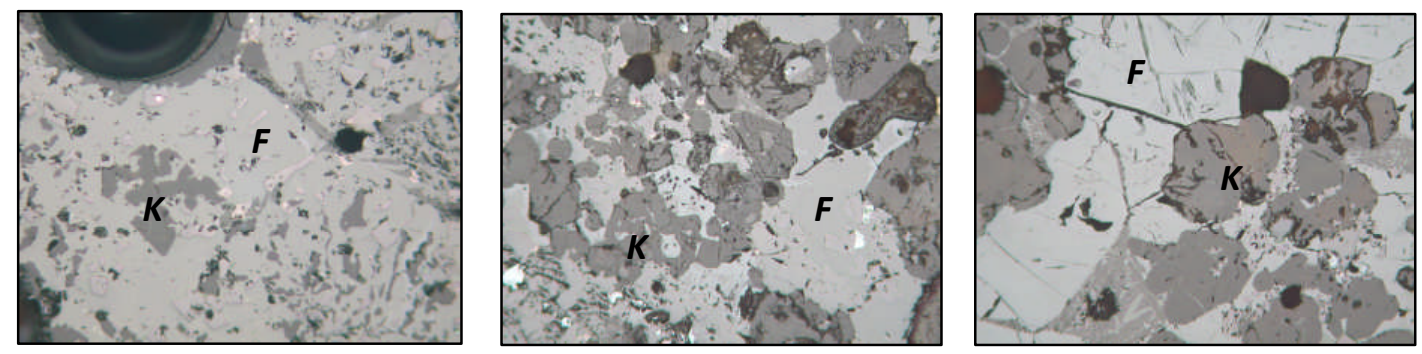

Fig. 6.2.13 PPL Photomicrographs of samples taken from throughout CMZ 1 SB1. Sample 1C (left: 100x, image with $1 \mathrm{~mm}$ ), representing the slag produced during the beginning of the smelt; 1B (middle: 50x, image width $2 \mathrm{~mm}$ ), representing the middle period of the smelt; and 1A (right: 50x, image width $2 \mathrm{~mm}$ ), representing the end period of the smelt

Therefore, due to the apparent homogeneity of the slag blocks at CMZ 1, the results obtained from the analysis of the middle samples of each of the five investigated slag blocks (which can be presumed to represent the middle time period of the smelt and so most likely the predominant smelting environment), will be used to represent the smelts being carried out at this site (table 6.2.7). 


\begin{tabular}{|c|c|c|c|c|c|c|c|c|c|c|c|c|c|}
\hline & $\mathrm{Na}_{2} \mathrm{O}$ & MgO & $\mathrm{Al}_{2} \mathbf{O}_{3}$ & $\mathrm{SiO}_{2}$ & $\mathbf{P}_{2} \mathbf{O}_{5}$ & $\mathbf{S}$ & $\mathbf{K}_{2} \mathbf{O}$ & $\mathrm{CaO}$ & $\mathrm{TiO}_{2}$ & $\mathbf{V}_{2} \mathbf{O}_{5}$ & $\mathrm{Cr}_{2} \mathrm{O}_{3}$ & MnO & $\mathrm{FeO}$ \\
\hline & $\%$ & $\%$ & $\%$ & $\%$ & $\%$ & $\%$ & $\%$ & $\%$ & $\%$ & $\%$ & $\%$ & $\%$ & $\%$ \\
\hline 1B & 0.36 & 0.20 & 9.26 & 27.12 & 1.86 & 0.14 & 2.02 & 1.02 & 0.58 & 0.04 & 0.01 & 0.14 & 57.17 \\
\hline $2 B$ & 0.25 & 0.29 & 8.07 & 16.48 & 2.75 & 0.13 & 1.75 & 0.81 & 0.23 & 0.02 & 0.03 & 0.18 & 68.88 \\
\hline $3 B$ & 0.21 & 0.29 & 7.95 & 21.45 & 2.02 & 0.04 & 1.71 & 1.49 & 0.52 & 0.05 & 0.01 & 0.19 & 63.96 \\
\hline $4 B$ & 0.30 & 0.18 & 8.70 & 22.85 & 1.41 & 0.04 & 1.80 & 0.88 & 0.46 & 0.06 & 0.02 & 0.30 & 62.87 \\
\hline $5 B$ & 0.18 & 0.15 & 9.28 & 24.54 & 2.32 & 0.08 & 3.25 & 0.87 & 0.12 & 0.00 & 0.02 & 0.16 & 58.89 \\
\hline
\end{tabular}

\begin{tabular}{cccccccccc} 
& $\begin{array}{c}\mathbf{C u O} \\
\mathrm{Znm}\end{array}$ & $\begin{array}{c}\mathrm{ZnO} \\
\mathrm{ppm}\end{array}$ & $\begin{array}{c}\mathrm{Rp} \mathbf{b}_{\mathbf{2}} \mathbf{O} \\
\mathrm{Ppm}\end{array}$ & $\begin{array}{c}\mathrm{SrO} \\
\mathrm{ppm}\end{array}$ & $\begin{array}{c}\mathbf{Z r O}_{2} \\
\mathrm{ppm}\end{array}$ & $\begin{array}{c}\mathbf{B a O} \\
\mathrm{ppm}\end{array}$ & $\begin{array}{c}\mathbf{L a}_{2} \mathbf{O}_{3} \\
\mathrm{ppm}\end{array}$ & $\begin{array}{c}\mathbf{C e O}_{2} \\
\mathrm{ppm}\end{array}$ & $\begin{array}{c}\text { Total } \\
\%\end{array}$ \\
\hline 1B & 38 & 39 & 88 & 90 & 160 & 358 & 42 & 130 & 90.76 \\
2B & 83 & 92 & $\mathrm{Bdl}$ & 131 & 118 & 630 & 83 & 187 & 98.64 \\
3B & 68 & 61 & $\mathrm{Bdl}$ & 152 & 119 & 504 & 57 & 154 & 98.44 \\
4B & 100 & 88 & 6 & 70 & 124 & 793 & 24 & 104 & 97.55 \\
5B & 81 & 73 & 117 & 75 & 102 & 516 & 103 & 190 & 93.79
\end{tabular}

Table 6.2.7 (P)ED-XRF compositional data obtained from the middle sample from each slag block analysed at CMZ 1. Results have been normalised to $100 \%$, and taken from the average of three XRF runs. Only trace elements above 50 ppm are shown; bdl - below detection limits. Full results are given in appendix $2 \mathrm{~A}$

The XRF results for the CMZ 1 slag blocks show fairly typical African bloomery slag compositions, with an average of $62 \%$ iron oxide, $23 \%$ silica and $9 \%$ alumina. The average alumina to silica ratio is 1:2.7 (ignoring SB2 which is a slightly different case), which is again typical for bloomery smelting slags. The smelt that produced SB2 appears to be somewhat different from the rest of the sample range, especially in the level of silica in the sample which is low at $16 \%$, while the iron oxide level is therefore higher, at $69 \%$. This results in a higher iron oxide to silica ratio, as well as a higher alumina to silica ratio (1:2 compared to an average of $1: 2.7)$.

Alkali and alkali earth oxides are relatively low (totalling less than 5\%), indicating a limited fuel ash contribution. Significant, correlated levels of phosphate, lanthanum oxide and cerium oxide (present in much lower levels in the ceramics at the site) indicate the presence of monazite $\left((\mathrm{Ce}, \mathrm{La}) \mathrm{PO}_{4}\right)$ in the ore charge, particularly in $2 \mathrm{~B}$ and 
5B. Other oxides linked to a contribution from ore during a smelt, including titania and manganese oxide, are also present in low levels.

When plotted in a $\mathrm{FeO}-\mathrm{Al}_{2} \mathrm{O}_{3}-\mathrm{SiO}_{2}$ phase diagram, the slag samples plot near the optimum two zone, overlap the fayalite and hercynite region, denoting a technology producing sufficient quantities of iron, with relatively low slag melting temperatures (fig. 6.2.14). The chemical composition of the slag blocks, and this positioning within the phase diagram, is mirrored within the microstructure of the samples, which are dominated by blocky, well formed fayalite crystals, indicative of a slow cool, as well as some hercynite and virtually no free iron oxides (fig. 6.2.15).

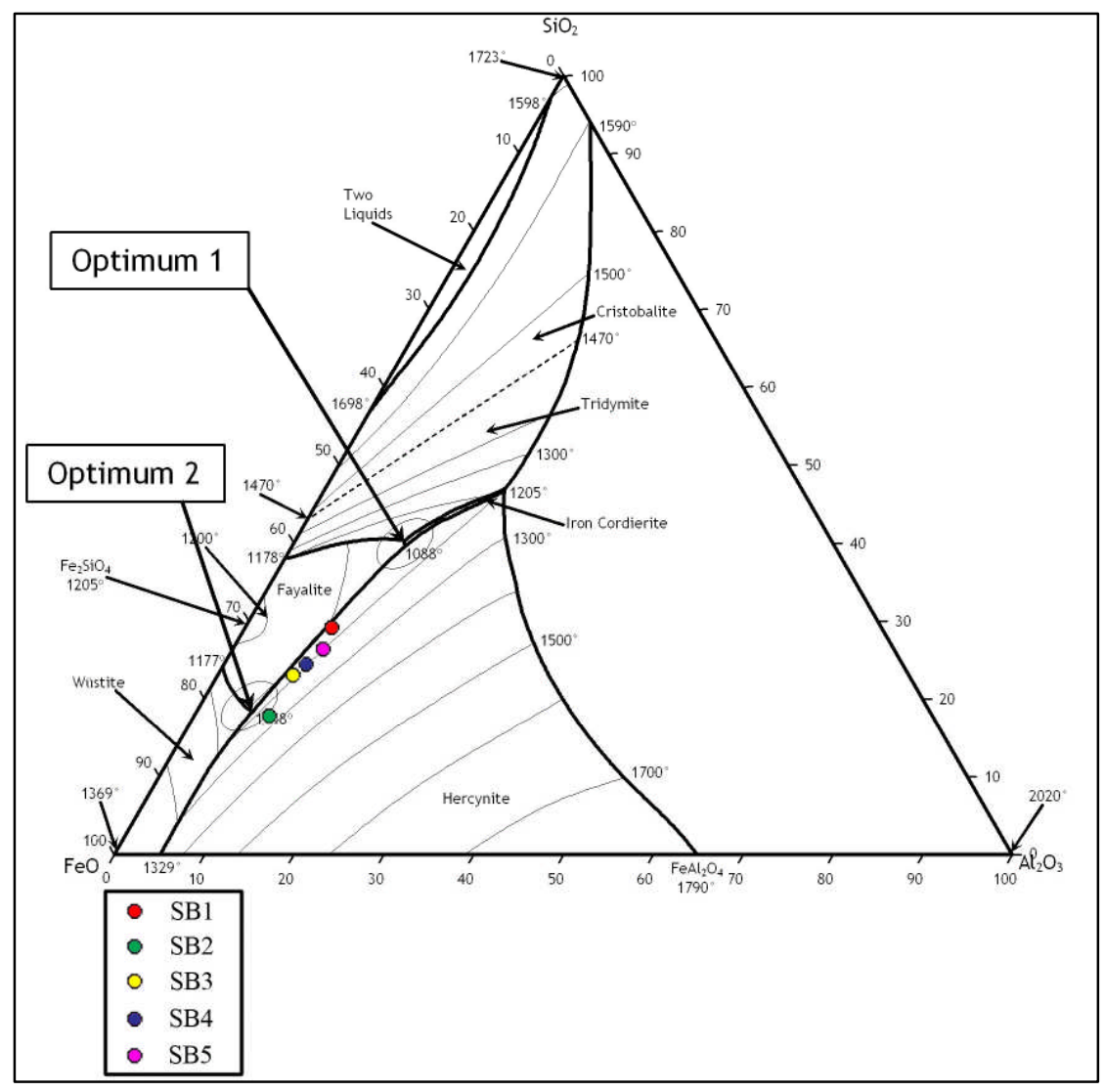

Fig. 6.2.14 $\mathrm{FeO}-\mathrm{Al}_{2} \mathrm{O}_{3}-\mathrm{SiO}_{2}$ phase diagram showing the position of the middle sample from CMZ 1 SB15 (after Rehren et al 2007: 212) 


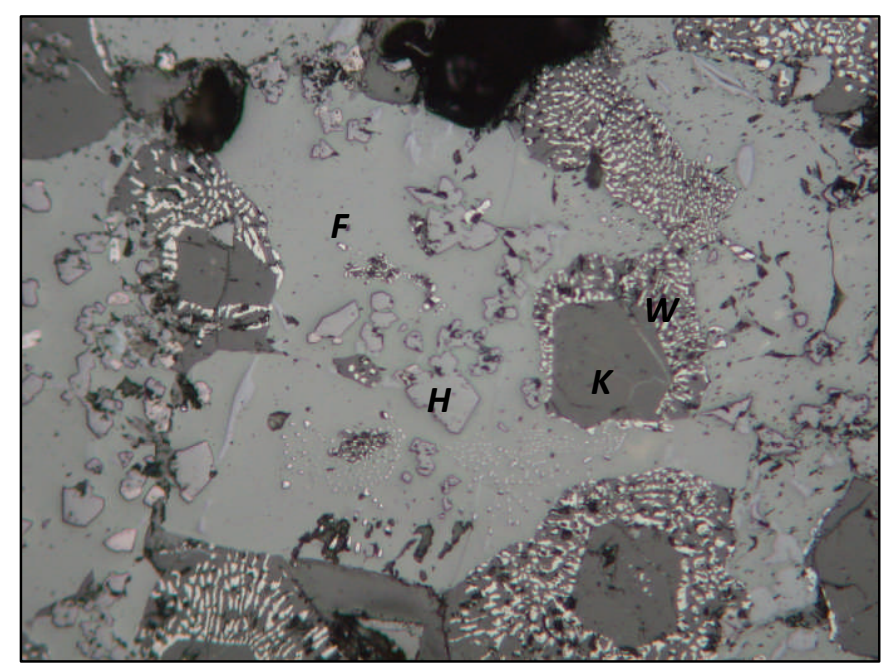

Fig. 6.2.15 Typical photo micrograph of a slag sample from CMZ 1 (SB3), showing light grey fayalite $(\mathrm{F})$, mid-grey hercynite $(\mathrm{H})$, and dark grey kalsilite $(\mathrm{K})$ within which can be seen eutectic wüstite $(\mathrm{W})$ (PPL 100x, image width 1mm)

Overall the results illustrate that the middle samples from each of the slag blocks analysed from CMZ 1 have very similar chemical compositions, suggesting that these blocks were produced in a very similar manner in terms of the methodological approach to the technology and the ingredients used. This similarity in chemical composition between the slag blocks is illustrated in fig. 6.2.16 below. However, SB2 has a higher alumina to silica ratio compared to other slag blocks at the site, which could perhaps have been the reason for a less efficient operation, and so the higher iron losses (i.e. higher quantities of wüstite within the sample) during the smelt (fig. 6.2.17). 


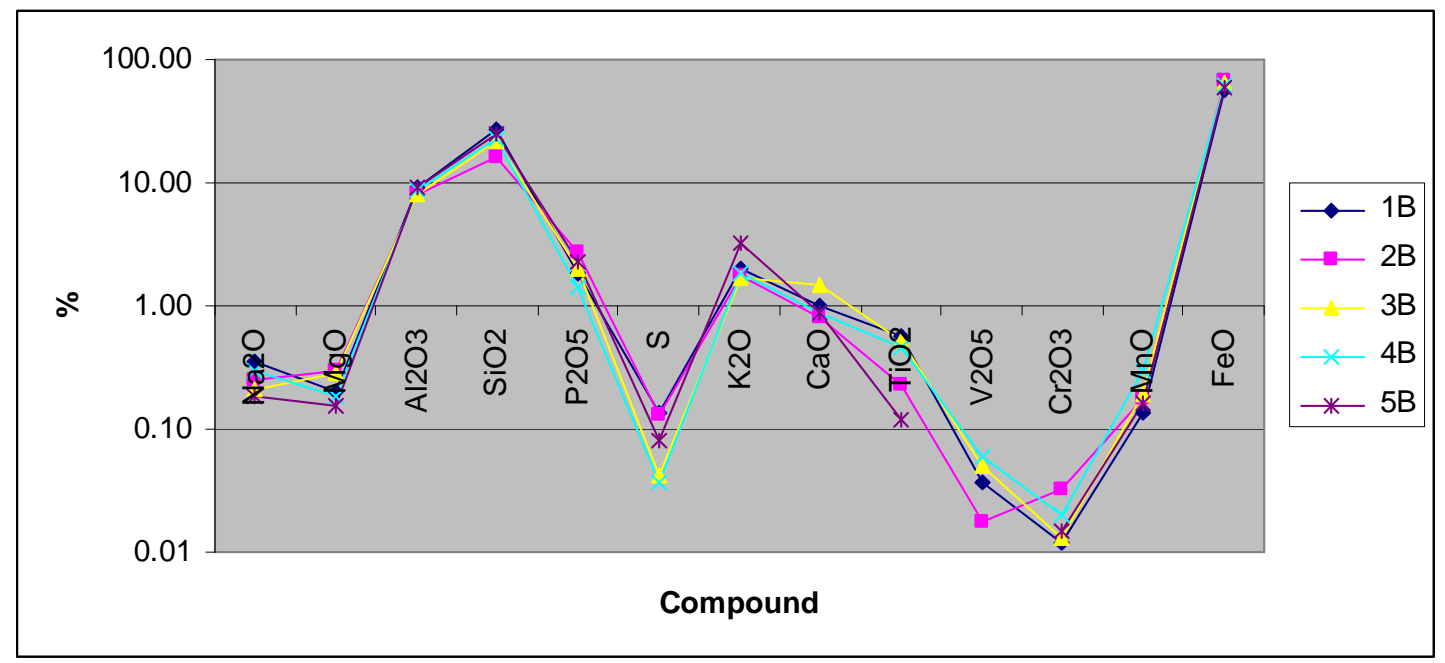

Fig. 6.2.16 The chemically similar signature of the middle sample from each of the slag blocks analysed at CMZ 1

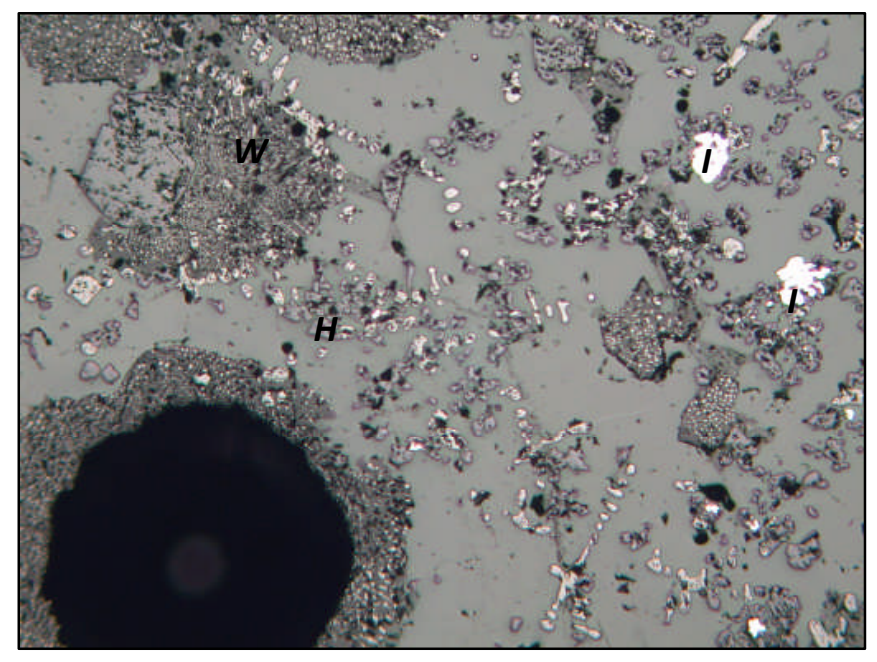

Fig. 6.2.17 CMZ 1 SB2 sample B, illustrating a higher proportion of free iron oxides within the slag (as wüstite $-\mathrm{W}$ ), and also iron metal (I) within the sample, and a generally greater amount of hercynite $(\mathrm{H})$. This agrees with the XRF data, indicative of a less efficient smelt, and higher alumina levels (PPL 100X, image width $1 \mathrm{~mm}$ ) 


\section{$-C M Z 1 f 1$}

The XRF results of the sample of furnace pit lining analysed from CMZ 1 (table 6.2.8), show relatively high levels of silica, in agreement with the significant amounts of quartz within the sample (fig. 6.2.18 below), which could be present either naturally, or added manually as temper to the material. The use of a material high in quartz is widespread practice for the production of technical ceramics for use in iron smelting, when the ceramic fabric has to withstand high temperatures for long periods of time. The quartz improves temperature resistance and overall stability of the ceramic by decreasing the likelihood of fatal cracking; the particles acting as a barrier to prevent cracks spreading (Tite et al. 1985). The most remarkable aspect of the ceramic fabric is the high alumina and relatively low iron oxide content, making this clay kaolinitic in nature and thus particularly thermally and chemically refractory. The unusually high phosphate content of this sample may be a result of some kind of post-depositional alteration, probably related to cattle grazing, or the more generally mobile nature of phosphate in soils.

\begin{tabular}{cccccccccccc} 
& $\begin{array}{c}\mathrm{Na}_{2} \mathbf{O} \\
\%\end{array}$ & $\begin{array}{c}\mathrm{MgO} \\
\%\end{array}$ & $\begin{array}{c}\mathrm{Al}_{2} \mathbf{O}_{3} \\
\%\end{array}$ & $\begin{array}{c}\mathrm{SiO}_{2} \\
\%\end{array}$ & $\begin{array}{c}\mathbf{P}_{2} \mathbf{O}_{\mathbf{5}} \\
\%\end{array}$ & $\begin{array}{c}\mathrm{S} \\
\%\end{array}$ & $\begin{array}{c}\mathbf{K}_{2} \mathbf{O} \\
\%\end{array}$ & $\begin{array}{c}\mathbf{C a O} \\
\%\end{array}$ & $\begin{array}{c}\mathrm{TiO}_{2} \\
\%\end{array}$ & $\begin{array}{c}\mathrm{MnO} \\
\%\end{array}$ & $\begin{array}{c}\mathbf{F e O} \\
\%\end{array}$ \\
\hline $\begin{array}{c}\text { f1 pit } \\
\text { lining }\end{array}$ & 0.74 & 0.35 & 29.14 & 61.46 & 2.85 & 0.02 & 1.37 & 0.80 & 0.33 & 0.07 & 2.86
\end{tabular}

\begin{tabular}{ccccccc} 
& $\mathbf{Z n O}$ & $\mathbf{R b}_{2} \mathbf{O}$ & $\mathrm{SrO}$ & $\mathrm{ZrO}_{2}$ & $\mathbf{B a O}$ & $\begin{array}{c}\text { Original } \\
\text { total } \\
\%\end{array}$ \\
\hline f1 pit & 85 & 127 & 297 & 95 & 202 & 81.37 \\
lining & & & & & &
\end{tabular}

Table 6.2.8 (P)ED-XRF compositional data obtained from CMZ 1 f1 pit lining. Results have been normalised to $100 \%$, and taken from the average of three XRF runs. Only trace elements above $50 \mathrm{ppm}$ are shown. Full results are given in appendix 2B 


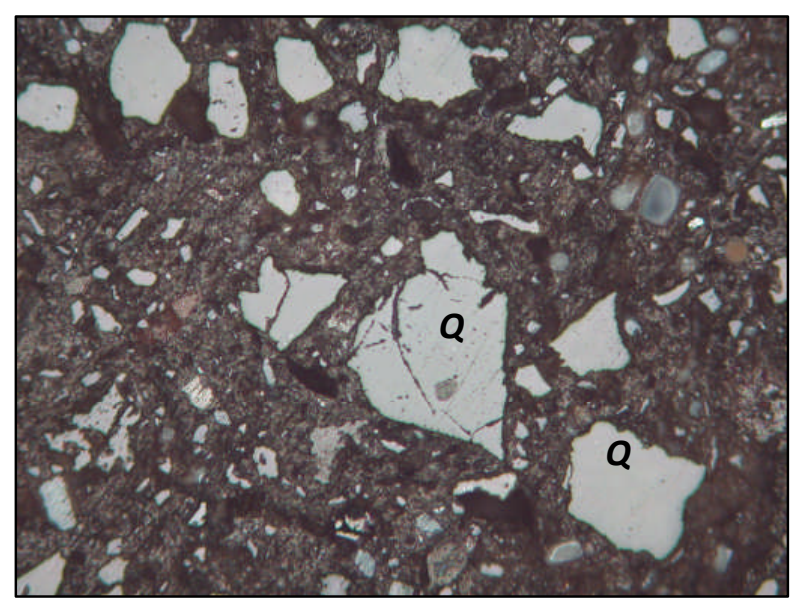

Fig. 6.2.18 CMZ $1 \mathrm{f} 1$ pit lining, showing the significant amount of quartz (Q), in the fabric (PPL 100x, image width 1mm)

SB1 has a lower alumina to silica ratio $(\sim 1: 3)$, than the ceramic pit lining of CMZ $1 \mathrm{f} 1$ $(\sim 1: 2)$. Therefore the higher level of alumina in the slag cannot be explained solely as a contribution from the technical ceramics during the smelt (presuming the same ceramic mix was used to produce any tuyeres which were utilised during the process). This supports the XRF results, which suggest a chemically refractory fabric in use for the technical ceramics at this site, and indicates that the ore would have been relatively alumina-rich (consistent with the ore sample examined below from CMZ f2.

- $C M Z 1 f 2$

As mentioned, CMZ 1 f2 was a very complicated furnace pit to excavate. However, the pit did contain slag, alongside a possible ore sample and a piece of possible bloom, allowing for a detailed reconstruction of the smelting event which took place in this furnace pit. Table 6.2.9 below gives the XRF results from samples of ore and slag taken from this feature, while table 6.2.10 illustrates the results of the ceramics taken from the pit. 


\begin{tabular}{cccccccccccccc} 
& $\mathbf{N a}_{2} \mathbf{O}$ & $\mathbf{M g O}$ & $\mathrm{Al}_{2} \mathbf{O}_{3}$ & $\mathbf{S i O}_{2}$ & $\mathbf{P}_{2} \mathbf{O}_{5}$ & $\mathbf{S}$ & $\mathbf{K}_{2} \mathbf{O}$ & $\mathbf{C a O}$ & $\mathbf{T i O}_{2}$ & $\mathbf{V}_{2} \mathbf{O}_{5}$ & $\mathbf{C r}_{2} \mathbf{O}_{3}$ & $\mathbf{M n O}$ & $\mathbf{F e O}$ \\
& $\%$ & $\%$ & $\%$ & $\%$ & $\%$ & $\%$ & $\%$ & $\%$ & $\%$ & $\%$ & $\%$ & $\%$ & $\%$ \\
\hline slag 1 & 0.18 & 0.44 & 5.81 & 17.47 & 1.32 & 0.22 & 1.70 & 1.67 & 0.14 & 0.00 & 0.01 & 0.11 & 70.79 \\
slag 2 & 0.20 & 0.25 & 7.31 & 29.87 & 0.96 & 0.30 & 2.09 & 1.45 & 0.23 & 0.01 & 0.01 & 0.19 & 56.99 \\
possible ore & 0.44 & 0.38 & 20.35 & 42.01 & 2.08 & 0.06 & 1.90 & 0.75 & 0.25 & 0.00 & 0.01 & 0.08 & 31.54
\end{tabular}

\begin{tabular}{cccccccccc} 
& $\mathbf{C u O}$ & $\mathbf{Z n O}$ & $\mathbf{R b}_{2} \mathbf{O}$ & $\mathbf{S r O}$ & $\mathrm{ZrO}_{2}$ & $\mathbf{B a O}$ & $\mathbf{L a}_{2} \mathbf{O}_{3}$ & $\mathbf{C e O}_{2}$ & $\begin{array}{c}\text { Original } \\
\text { total }\end{array}$ \\
& ppm & ppm & ppm & ppm & ppm & ppm & ppm & ppm & $\%$ \\
\hline slag 1 & 320 & 17 & bdl & 149 & 82 & 301 & 164 & 210 & 100.88 \\
slag 2 & 360 & 33 & 101 & 133 & 96 & 567 & bdl & 76 & 95.63 \\
possible ore & 65 & 109 & 178 & 182 & 140 & 832 & 10 & 80 & 86.51
\end{tabular}

Table 6.2.9 (P)ED-XRF compositional data obtained from the slag and possible slag samples taken from CMZ 1 f2. Results have been normalised to $100 \%$, and taken from the average of three XRF runs. Only trace elements above $50 \mathrm{ppm}$ are shown; bdl - below detection limits. Full results are given in appendix $2 \mathrm{~A}$

\begin{tabular}{cccccccccccccc} 
& $\mathrm{Na}_{2} \mathbf{O}$ & $\mathbf{M g O}$ & $\mathrm{Al}_{2} \mathbf{O}_{3}$ & $\mathrm{SiO}_{2}$ & $\mathbf{P}_{2} \mathbf{O}_{5}$ & $\mathbf{S}$ & $\mathbf{K}_{2} \mathbf{O}$ & $\mathbf{C a O}$ & $\mathbf{T i O}_{2}$ & $\mathbf{V}_{2} \mathbf{O}_{5}$ & $\mathbf{C r}_{2} \mathbf{O}_{3}$ & $\mathbf{M n O}$ & $\mathbf{F e O}$ \\
& $\%$ & $\%$ & $\%$ & $\%$ & $\%$ & $\%$ & $\%$ & $\%$ & $\%$ & $\%$ & $\%$ & $\%$ & $\%$ \\
\hline pit lining A & 0.51 & 0.46 & 31.81 & 60.19 & 0.98 & 0.02 & 1.86 & 0.59 & 0.35 & 0.01 & 0.01 & 0.10 & 3.01 \\
pit lining B & 0.45 & 0.39 & 30.73 & 56.56 & 0.39 & 0.03 & 1.44 & 0.47 & 0.32 & 0.01 & 0.01 & 0.12 & 8.97 \\
005 ceramic & 0.39 & 0.41 & 19.89 & 66.43 & 1.28 & 0.02 & 1.91 & 0.62 & 0.55 & 0.03 & 0.02 & 0.04 & 8.25
\end{tabular}

\begin{tabular}{|c|c|c|c|c|c|c|c|}
\hline & $\mathrm{CuO}$ & $\mathrm{ZnO}$ & $\mathbf{R} \mathbf{b}_{2} \mathbf{O}$ & SrO & $\mathrm{ZrO}_{2}$ & $\mathrm{BaO}$ & $\begin{array}{c}\text { Original } \\
\text { total }\end{array}$ \\
\hline & ppm & $\mathrm{ppm}$ & $\mathrm{ppm}$ & ppm & $\mathrm{ppm}$ & $\mathrm{ppm}$ & $\%$ \\
\hline pit lining $\mathrm{A}$ & 22 & 81 & 196 & 201 & 131 & 334 & 83.47 \\
\hline pit lining B & 41 & 172 & 193 & 82 & 110 & 267 & 81.08 \\
\hline 005 ceramic & 80 & 67 & 251 & 235 & 185 & 768 & 82.72 \\
\hline
\end{tabular}

Table 6.2.10 (P)ED-XRF compositional data obtained from the ceramic samples taken from CMZ $1 \mathrm{f} 2$. Results have been normalised to $100 \%$, and taken from the average of three XRF runs. Only trace elements above $50 \mathrm{ppm}$ are shown.. Full results are given in appendix 2B

The XRF and microscopic results indicate that the slag present in this furnace pit is again typical bloomery slag, and generally similar in composition to the other slag 
blocks at this site. The corresponding microstructure is also of a similar nature to that seen in the slag blocks analysed, with fayalite $(F)$ dominating and interspersed with hercynite $(\mathrm{H})$ and wüstite $(\mathrm{W})$, along with sparse wüstite in a kalsilitic matrix (fig. 6.2.19) The sample taken of possible ore did appear to be dominated by unreduced haematite, as seen in the very red colour visible in a cross polarised light image below (fig. 6.2.20). However, noting the low iron oxide level, and the high silica and alumina content of this sample, this ore would have had to be mixed with a higher quality one to make the process economically viable.

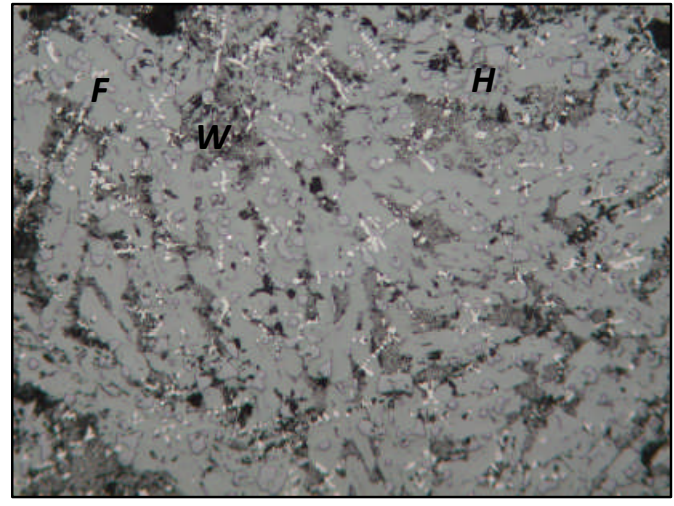

Fig. 6.2.19 Typical bloomery slag from CMZ $1 \mathrm{f} 2$ (100x, image width $1 \mathrm{~mm})$

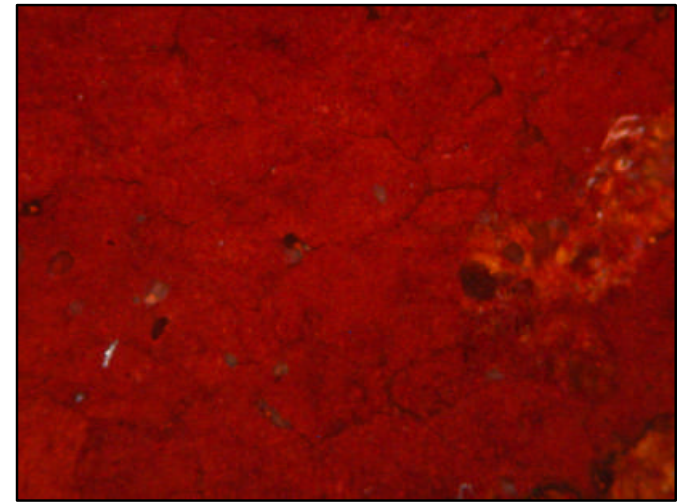

Fig. 6.2.20 Haematite from CMZ 1 f2 (100x, image width $1 \mathrm{~mm})$

The piece of bloom found in the very top context of the furnace pit was revealed to be still attached to slag (fig. 6.2.21). It would seem that the majority of the bloom was removed and this small piece left behind by the smelters. The slag in this sample is poor in iron oxides, all of which have entered the bloom. 


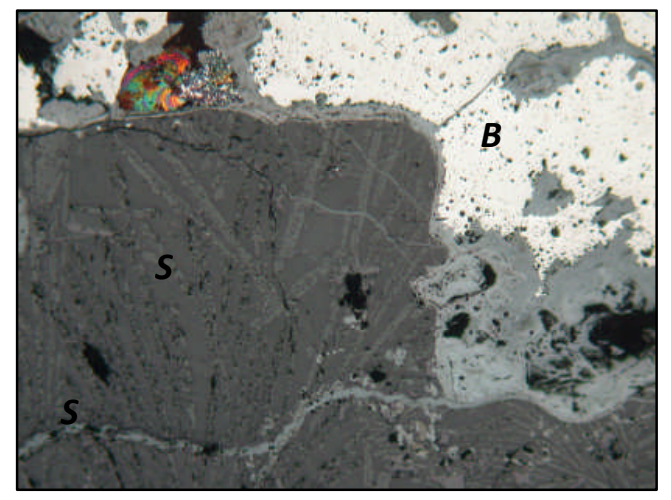

Fig 6.2.21 Raw bloom (B), attached to slag (S), taken from context 003 (PPL 50x, image width 2mm)

As it was presumed that this sample would represent typical ferritic iron bloom, it was etched with 5\% nital. As illustrated below, the microstructure was surprising (fig. 6.2.22). SEM-EDS analysis of an area of the iron reported $4 \%$ phosphorous and $96 \%$ iron, while the Vickers hardness test revealed hardnesses of between $250 \mathrm{HV}$, up to $300 \mathrm{HV}$ within the globular phases. The discolouration of the sample is due to the use of an etchant suitable for ferritic samples, rather than one used for phosphoric iron.

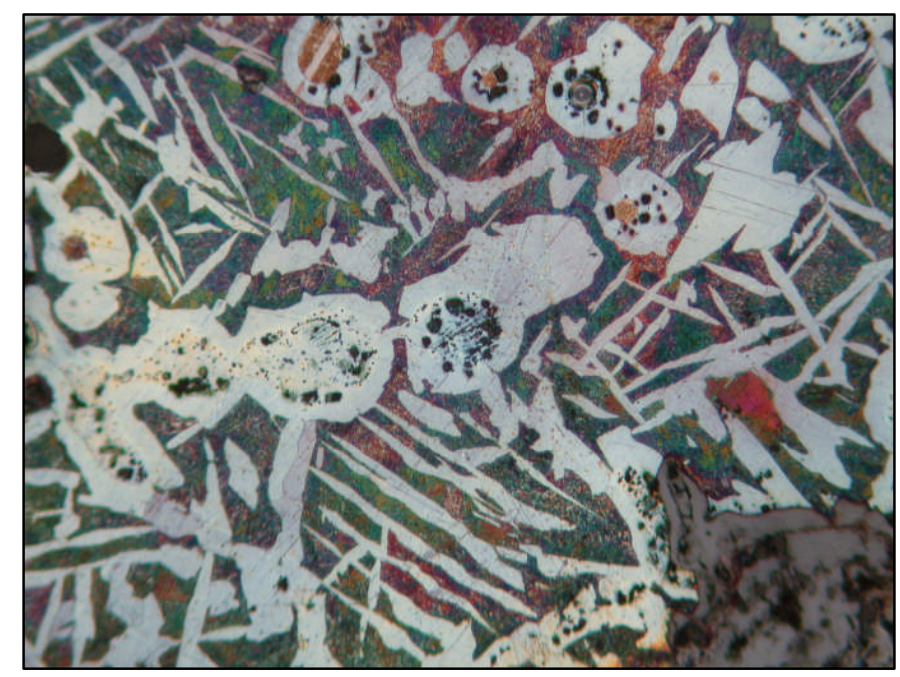

Fig. 6.2.22 PPL photomicrograph of the bloom once etched (100x, image width $1 \mathrm{~mm})$

The presence of limited amounts of phosphorous within an iron sample creates a material similar to steel, and which in Iron Age Europe has been used regularly as an alternative to steel (e.g. Gouthama \& Balasubramaniam 2003; Tylecote \& Gilmour 
1986). Therefore the phosphate content could be deliberate. However, if representative of the original bloom, this may have been an unworkable material, and one that would crack under hammering due to its very brittle nature (Brannt 1908: 19-21). The composition of this sample could be due to the heterogeneous nature of iron blooms produced in bloomery furnaces, rather than the nature of the iron being produced.

The analyses of the technical ceramics taken from CMZ 1 f2 indicate that the material used to initially line the pit (lining A) was very similar to that used in the construction of $\mathrm{CMZ} 1 \mathrm{f} 1$, with a low $\mathrm{FeO}$ content and an alumina to silica ratio of roughly 1:2. Pit lining $\mathrm{B}$, the area of the furnace which had been re-lined, has slightly elevated iron oxide level and correspondingly lower alumina and silica levels. The alumina to silica ratio is slightly lower, but overall other oxides present are fairly consistent between the two pit linings of $\mathrm{f} 2$ and that of $\mathrm{f} 1$, leading to the assumption that the same clay source was in use. Interestingly the piece of pottery found within CMZ 1 f2 shows a different chemistry, notably with lower alumina levels, which would make the fabric significantly less refractory. Thus it would appear that the smelters had a specific source of clay and/or a particular way of processing clay to be used for the technical ceramics, in comparison to domestic pottery. Of course the other possibility is that this piece of pottery has been washed into the pit at a much later date, and so bears no relation to the smelters who were working at the site to produce iron, or that the pottery was obtained elsewhere and made by a completely different group.

\section{- Test Pit One}

The results from the analyses of the ceramics fragments taken from tp 1 are shown in table 6.2.11. 


\begin{tabular}{|c|c|c|c|c|c|c|c|c|c|c|c|c|c|}
\hline & $\mathrm{Na}_{2} \mathrm{O}$ & MgO & $\mathrm{Al}_{2} \mathrm{O}_{3}$ & $\mathrm{SiO}_{2}$ & $\mathbf{P}_{2} \mathbf{O}_{5}$ & $\mathbf{S}$ & $\mathbf{K}_{2} \mathbf{O}$ & $\mathrm{CaO}$ & $\mathrm{TiO}_{2}$ & $\mathbf{V}_{2} \mathbf{O}_{5}$ & $\mathrm{Cr}_{2} \mathrm{O}_{3}$ & MnO & $\mathrm{FeO}$ \\
\hline & $\%$ & $\%$ & $\%$ & $\%$ & $\%$ & $\%$ & $\%$ & $\%$ & $\%$ & $\%$ & $\%$ & $\%$ & $\%$ \\
\hline $\begin{array}{c}\text { triangular ceramic } \\
\text { decoration }\end{array}$ & 1.85 & 0.23 & 24.69 & 67.75 & 0.49 & 0.03 & 1.31 & 0.30 & 0.45 & 0.01 & 0.01 & 0.02 & 2.74 \\
\hline non-triangular ceramic & 1.42 & 0.37 & 23.42 & 67.20 & 0.13 & 0.02 & 1.85 & 0.42 & 0.56 & 0.02 & 0.01 & 0.07 & 4.38 \\
\hline
\end{tabular}

\begin{tabular}{ccccccccc} 
& $\mathbf{C u O}$ & $\mathbf{Z n O}$ & $\mathbf{R b}_{2} \mathbf{O}$ & $\mathbf{S r O}$ & $\mathbf{Z r O}_{2}$ & $\mathbf{B a O}$ & $\begin{array}{c}\text { Original } \\
\text { total } \\
\%\end{array}$ \\
& $\mathrm{ppm}$ & $\mathrm{ppm}$ & $\mathrm{ppm}$ & $\mathrm{ppm}$ & $\mathrm{ppm}$ & $\mathrm{ppm}$ & $\%$ \\
\hline $\begin{array}{c}\text { triangular ceramic } \\
\text { decoration }\end{array}$ & 46 & 63 & 201 & 65 & 146 & 290 & 82.94 \\
$\begin{array}{c}\text { non-triangular ceramic } \\
\text { nen }\end{array}$ & 57 & 73 & 221 & 76 & 196 & 385 & 83.70
\end{tabular}

Table 6.2.11 (P)ED-XRF compositional data obtained from the ceramic samples taken from TP1 at CMZ 1. Results have been normalised to $100 \%$, and taken from the average of three XRF runs. Only trace elements above $50 \mathrm{ppm}$ are shown. Full results are given in appendix $2 \mathrm{~B}$

It would appear that the same clay was used to make the body of the vessel as was used to fabricate the triangular decoration, which was to be assumed. The clay used to make this pot was different to that sourced to produce the more refractory technical ceramics, and is instead similar to the composition of the pottery found in CMZ $1 \mathrm{f} 2$, notably in the alumina to silica ratio. From the decoration it would appear that the pot would be dated to modern times (Dr Ceri Ashley pers. comm.), although the use of roulette decoration has been documented since around $1000 \mathrm{AD}$, and thus in theory this ceramic could have a much greater antiquity.

\subsubsection{Site interpretation}

While no charcoal was found in CMZ f1, or embedded within any of the slag samples taken from across the site, a sample of charcoal taken from CMZ 1 f2 provided an AMS date. This date was much earlier than expected, at AD 900-920 / AD 960-1040 (95\% probability). This places the smelting event at CMZ 1 within a period for which no archaeometallurgical data within the region had been obtained before. The smelting at this site represents the large slag pit operations which are generally taken as indicative 
of later, kingdom periods smelting, whilst representing a shift away from the decorated brick furnaces which produced small slag flows only a few hundred years earlier.

The scale of production at this site is clearly very significant. Although mass balance calculations are impossible due to a lack of ore samples, rough calculations can be performed to provide a tentative idea of the quantities of iron produced at the site. The average weight of the slag blocks investigated, not including those where pieces of the slag had broken away, was $95 \mathrm{~kg}$. In total, nineteen further blocks were visible on the surface around this site, while the test pits demonstrated that further blocks lay below ground level (e.g. two complete blocks lay below SB2). Therefore, for arguments sake, 26 blocks, or 26 smelts, will be considered as a minimum number for the following crude calculation. Based on 26 blocks of slag, with an average of $95 \mathrm{~kg}$, at least 2,470 $\mathrm{kg}$ of slag was produced at this site.

Although the ore sample analysed from CMZ $1 \mathrm{f} 2$ did not appear to be a particularly rich ore, two ore samples analysed from the Butare region in a separate study were found to be haematite with less that $2 \%$ of other impurities (Craddock et al 2007: 10), and such a case was also noted in the ore samples collected for the experimental smelt. Furthermore, based on the fact that the word 'Butare' means 'iron ore', and that the ore samples analysed from the site of GHD (less than $5 \mathrm{~km}$ from CMZ), were similarly rich in iron oxide, it can be assumed that the ores in use during the smelting history of the site were high grade.

For the ease of this calculation, and in recognition of the fact that this is a rough estimate, the average amount of iron oxide remaining in the slags at CMZ 1 will be rounded up to $60 \%$, with the remaining oxides as $40 \%$. If a typical 'good' ore is assumed to contain $90 \%$ iron oxide and $10 \%$ of other gangue elements, four times the amount of ore is required to match the gangue levels in the slag. This means that four times the amount of iron oxide $(4 \times 90 \mathrm{~kg})$ is in the charge. Thus, $360 \mathrm{~kg}$ of iron oxide is present within the charge, while $60 \mathrm{~kg}$ is lost to the slag. $300 \mathrm{~kg}$ of $\mathrm{FeO}$ can then be reduced (by multiplying by 0.777: the amount of $\mathrm{Fe}$ in $\mathrm{FeO}$ ): 300 x $0.777=233 \mathrm{~kg}$ iron metal produced for every $100 \mathrm{~kg}$ of slag. The calculations are summarised below: 


\begin{tabular}{l|l} 
Average weight of blocks & $95 \mathrm{~kg}$ \\
\hline Blocks observed at the site & 26 \\
\hline $\begin{array}{l}\text { Approximate quantity of slag at the site } \\
\text { Approximate slag content }\end{array}$ & $2470 \mathrm{~kg}$ \\
\hline $\begin{array}{l}\text { Iron produced by smelting good quality } \\
\text { ore (90\% iron oxide) }\end{array}$ & $60 \%$ iron oxide, $40 \%$ other \\
\hline $\begin{array}{l}\text { Iron produced by smelting medium quality } \\
\text { ore (80 \% iron oxide) }\end{array}$ & Approximately $\mathbf{2 0 0 0} \mathbf{~ k g}$
\end{tabular}

The large disparity between the two estimates illustrates the very coarse and tentative nature of these calculations. However, either figure serves to highlight the rather significant scale of production here, which would most probably exceed the needs of the local community.

Of course this is a crude calculation, although it does illustrate the vast amount of ore and charcoal, as well as a significant amount of clay to build furnace structures. The labour, resources and time invested at CMZ 1 were immense. However, the smelters at the site of CMZ 1 used a very similar methodology for producing iron from smelt to smelt, demonstrating that they were skilled practitioners who effectively produced sufficient quantities of iron (presuming the use of a high grade ore) over a period of time. They controlled and maintained the diameter of the furnaces (important for controlling parameters such as redox conditions during the smelt), and the depth of the furnaces they were using, and kept these facets constant from smelt to smelt. This 
would imply that they were smelting similar amounts of material at each smelting episode and following a set of well defined rules; they had a clear and repeated methodological approach.

In terms of the organisation and frequency of production, this would generally indicate a rather intense sequence of smelts carried out by the same people, over a relatively short period of time. Concerning the techniques of production, it is almost impossible to suggest the style and height of any superstructure that would have sat above the pit, presuming a superstructure would have been necessary to hold such quantities of raw materials. The uniformity in size and shape across all of the slag blocks at CMZ 1 certainly indicates standardised pit sizes and standardised quantities of raw materials used per smelt. The depth of both furnace pits, being shallower than the slag blocks themselves, does indicate a level of erosion which could also have affected the insights possible into other aspects such as any tuyeres used at the site. Currently, with a complete absence of such remains, it is impossible to guess at the number of tuyeres that would have been used during a single smelt, and therefore the number of bellows. The circumference of the furnace was similar to the furnace constructed during the experimental smelt, which easily fitted six tuyeres and six sets of bellows.

In terms of the organisation of the iron production activities on top of the hill, it would seem from the archaeometallurgical data that furnace pits were possibly re-used. This is suggested from the area of re-lining seen in $\mathrm{f} 2$, and the fact that while $\mathrm{f} 1$ had its slag block sat firmly in place, $\mathrm{f} 2$ did not - perhaps this block had been removed ready for the next smelt. The other conclusion could be that the block in $\mathrm{f} 2$ has been removed at a later date to prevent people tripping over it, although no-one living at the site today remembers this happening. A further insight into the organisation of production at the site is provided by the lack of evidence that smithing was practiced at the site, although of course an absence of evidence does not necessarily indicate that this practice did not take place at CMZ 1. The location of the site, on top of the hill and in front of a school has led to a huge amount of human interference, and it is now known that the site, or parts of it, are over a thousand years old. Remains of light, delicate hammer scale, and shallow, un-lined forging pits, may simply have been lost. The same could apply to any 
remains of habitation around the site that may once have existed. Alternatively, smithing activities and occupation sites could have been located elsewhere on the hill.

Whether the smelters smelted continually throughout the year, seasonally, or sporadically, is unknown. Additionally, whether one or more furnaces were operated at the same time, will also remain a mystery, as will the number of people involved in the industry, how these men were related, and how access to resources was negotiated. It would seem that sourcing a relatively high grade ore was not so much of a problem in Rwanda, although there were still a lot of kilograms of material to procure and move to the smelting site, and charcoal and clay would have had to have been obtained as well. The broader context to such issues will be considered in the following chapter.

The smelters at CMZ 1 combined their specialist technical knowledge with good quality ore and refractory ceramics to successfully produce large quantities of iron per smelt, over one thousand years ago. However by this time, iron metallurgy had undergone a number of changes in style and technique. This intriguing insight into technology will be explored further, in conjunction with the results from the other smelting sites, in chapter 7. 


\subsection{Cyamukuza 2 (CMZ 2)}

\subsubsection{Site description and observations}

Less than $1 \mathrm{~km}$ south-east of CMZ 1 are a cluster of houses at which the survey team stopped to investigate. The people living in these houses immediately recognised fragments of slag presented to them and took the team to the remains of an extensive iron production site. This site - CMZ 2 - lies approximately $50 \mathrm{~m}$ below the ridge of the hill along which the road runs. It is located approximately one quarter of the way down the side of a gently slopping hill with views to the north, south and west across the surrounding valleys. The site itself (which is approximately 9x8 m) consists of the remains of over forty blocks of slag, as well as the very substantial remains of a furnace pit (f1) with a slag block in situ (SB1). The path leading from the road runs down the east side of the site and directly through the remains of a second furnace pit, again with a slag block in situ (f2 and SB2). The random heaps in which the slag blocks were found suggested that they have been piled up relatively recently to make cultivation easier, and this was confirmed by the families living on the land (fig. 6.3.1). The shape of the slag blocks clearly demonstrated that they had formed when the slag had solidified in a furnace pit; the blocks had smooth, furnace pit shaped bottoms and rough top surfaces. All of the slag blocks appeared reasonably consistent in size and shape. Extreme care was taken when clearing the vegetation from around and under these blocks due to the presence of snakes that were enjoying the warmth generated by the slag until the excavation team arrived.

Surrounding the site are fields cultivated mainly with beans, yams and bananas, as well as a number of house compounds. The land on which the site is located is owned by an exceptionally poor family who live in a hut rather than a house, which sits on a bank at the north-west corner of the site. 


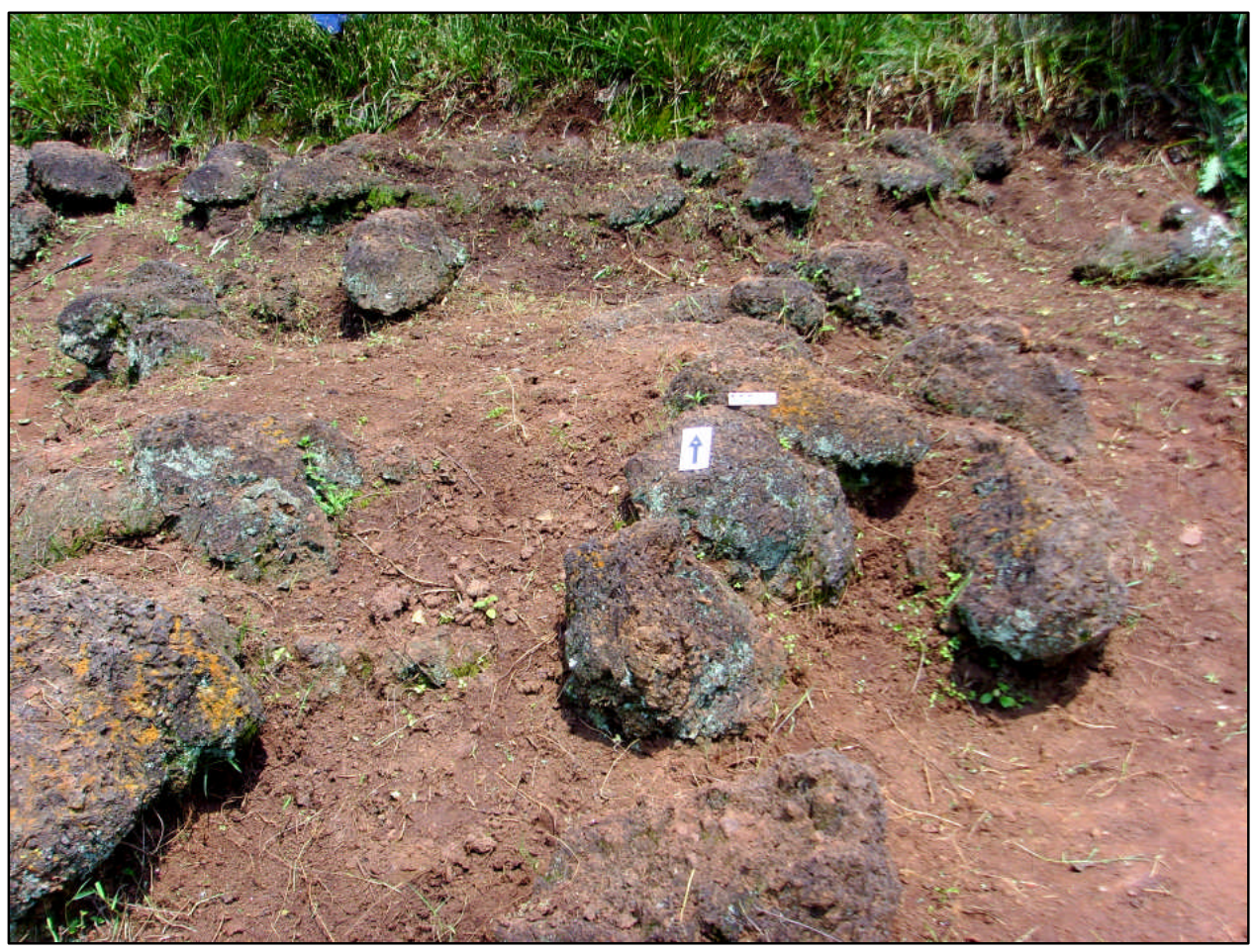

Fig. 6.3.1 CMZ 2 slag blocks

Furnace pit one (CMZ $2 \mathrm{f} 1$ ) represented the most substantial furnace pit remains seen by the author. At ground level, the pit walls were up to $18 \mathrm{~cm}$ thick; the internal diameter north-south was $85 \mathrm{~cm}$, and east-west was $90 \mathrm{~cm}$. The western and eastern edges of the furnace pit were fragmented and eroded, possibly due to people walking over the structure. SB1 was an oblong slag block found in the base of CMZ $2 \mathrm{f1}$, not actually touching the bottom of the pit but with both ends of the block solidified to the sides of the pit, confirming that this slag block was produced in this furnace. The pit was full of fragments of slag which appeared to have broken off from SB1 (fig. 6.3.2). 


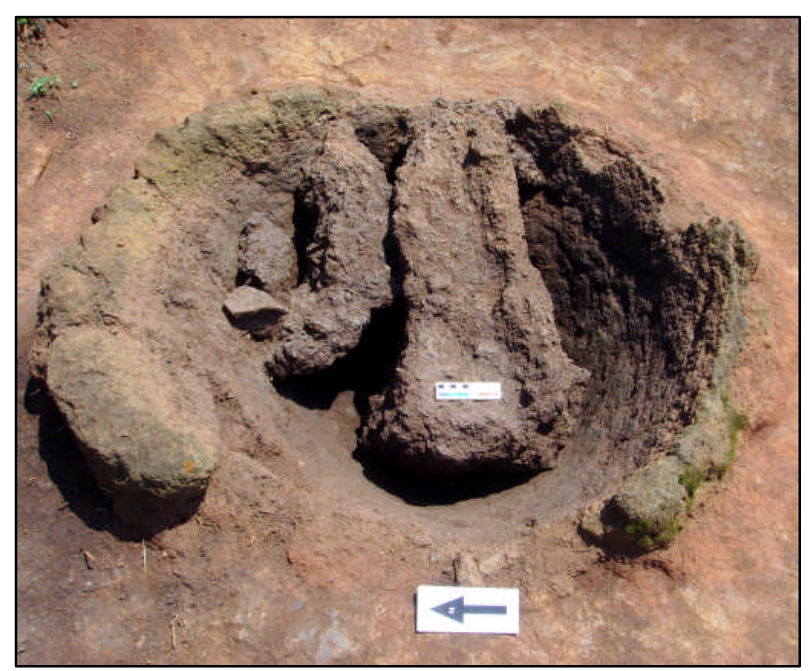

Fig. 6.3.2 CMZ 2; SB1 sat in f1

The second furnace (CMZ 2 f2) lay approximately 7 m north-east of CMZ 2 f1, directly in the middle of the main footpath running from the road down to the valley bottom. Due to its location, this furnace pit has been subjected to years of people walking over it, as well as rain water washing down the hill and running over it, thus the structure appeared almost sectioned in half (east to west), before the excavation began. This furnace also had a slag block sat in situ - SB2. As mentioned, the remains of this pit were much less substantial than $\mathrm{f1}$ (presumably due to the erosion factors mentioned), the pit being $50 \mathrm{~cm}$ north-south and approximately $60 \mathrm{~cm}$ east-west in diameter, with the furnace pit lining less than $10 \mathrm{~cm}$ thick where intact (fig. 6.3.3).
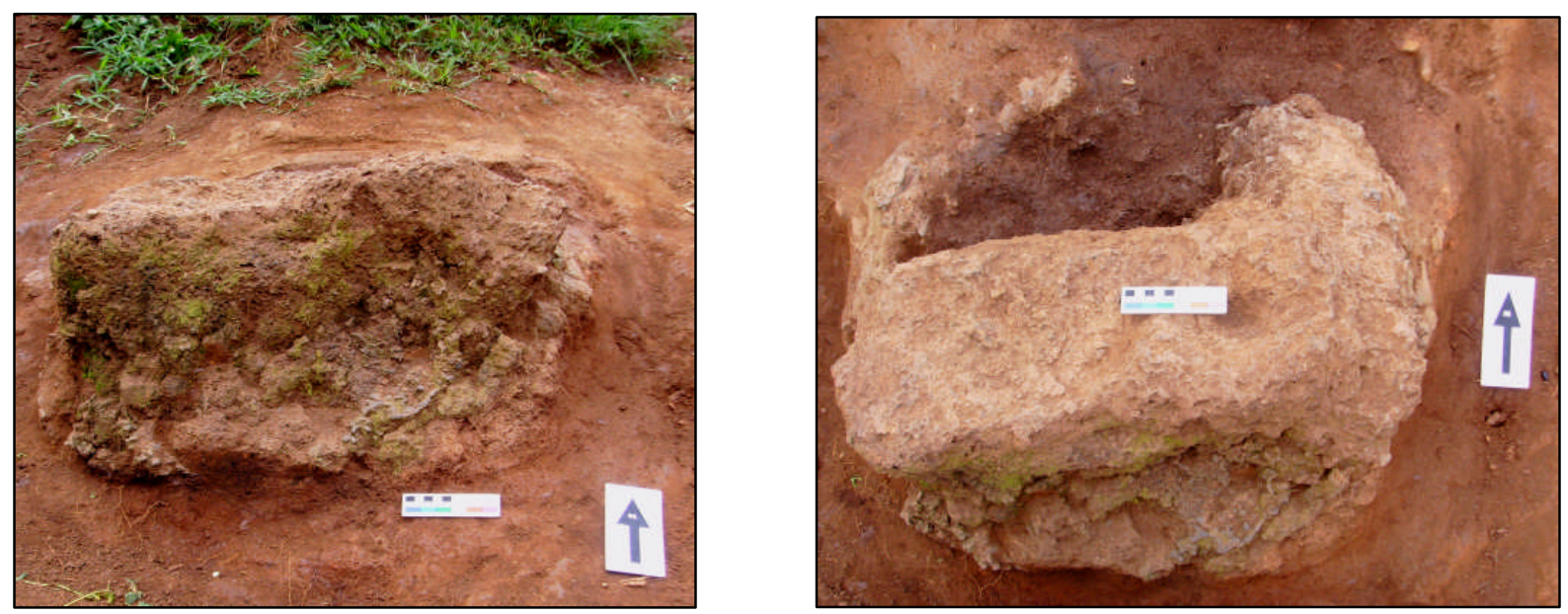

Fig. 6.3.3 CMZ 2 f2 and SB2 before excavation, viewed in section (left) and in plan (right) 
Again, five visually representative slag blocks were selected for detailed analysis. Interestingly, most of the slag blocks at CMZ 2 were oval in shape rather than circular when viewed in plan (table 6.3.1; fig. 6.3.4). It should be noted that SB1 (sat in f1) and SB2 (sat in f2), were more fragmented than the other blocks, which is reflected in their lower weight.

\begin{tabular}{ccccc}
$\begin{array}{c}\text { Slag } \\
\text { block }\end{array}$ & $\begin{array}{c}\text { Diameter at widest } \\
\text { point }(\mathbf{c m})\end{array}$ & $\begin{array}{c}\text { Perpendicular } \\
\text { diameter }(\mathbf{c m})\end{array}$ & Depth $(\mathbf{c m})$ & $\begin{array}{c}\text { Weight } \\
(\mathbf{k g})\end{array}$ \\
\hline 1 & 75 & 26 & 30 & 44.5 \\
2 & 69 & 28 & 39 & 47 \\
3 & 57 & 40 & 34 & 72.5 \\
4 & 85 & 43 & 38 & 91 \\
5 & 60 & 42 & 39 & 67
\end{tabular}

Table 6.3.1 Dimensions of the slag blocks selected for detailed analysis at CMZ 2
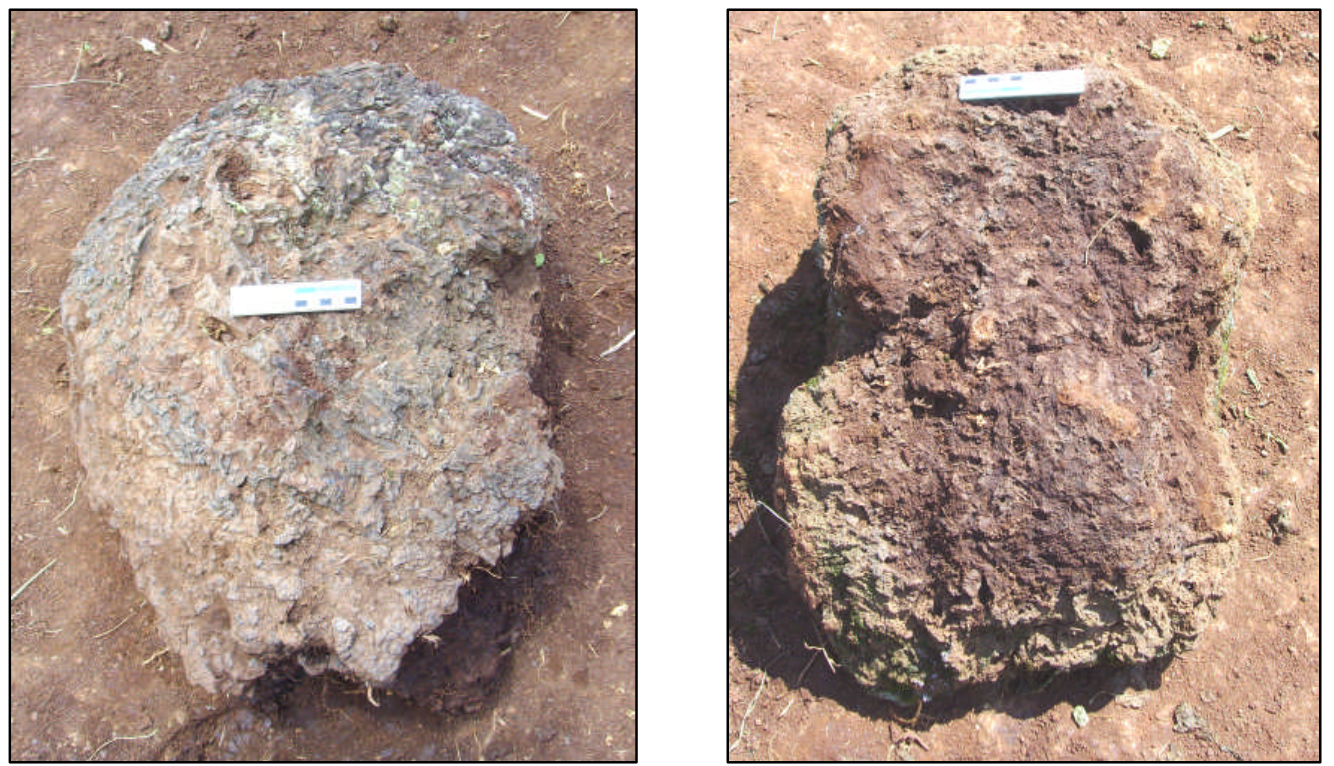

Fig. 6.3.4 View of the top of SB5 on the left and SB3 on the right

Two test pits were dug at the site of CMZ 2, one of which was set up in close proximity to the slag blocks (test pit one - tp1), while the other (test pit two - tp2) was excavated 
$18 \mathrm{~m}$ to the west of the site where a further, small cluster of slag blocks were recorded. A general site plan of CMZ 2, with each of the slag blocks selected for investigation (SB), as well as the location of the two furnace pits and the two test pits, is shown below (fig. 6.3.5).

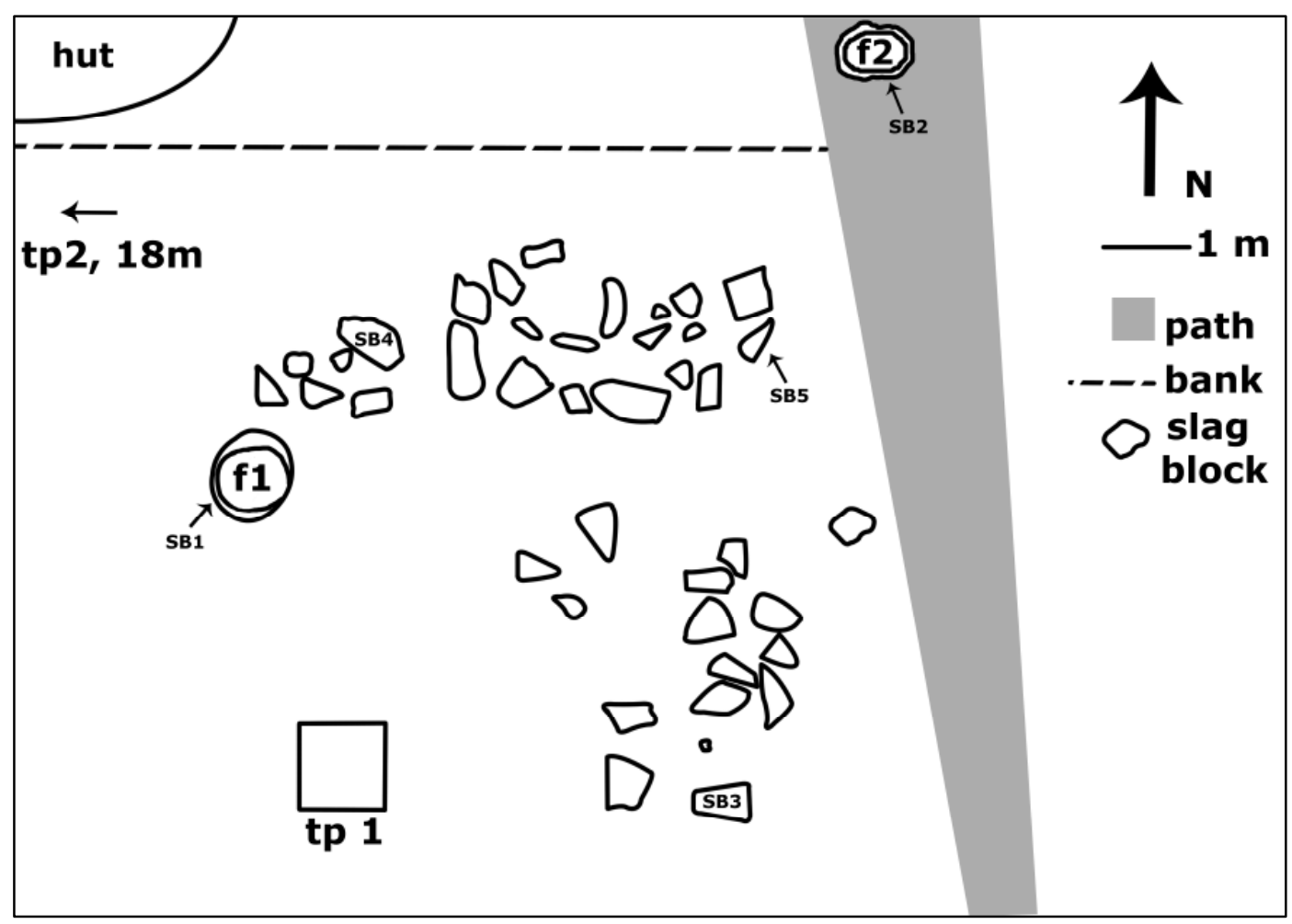

Fig. 6.3.5 Plan of CMZ 2

\subsubsection{Excavations and sample selection}

\section{- Slag blocks}

As mentioned briefly above, the slag blocks at this site appeared unusual in that a significant proportion were oblong in plan rather than circular. This shape appears to have arisen when outer edges of the slag have broken off at two sides, leaving an elongated slag block. Where intact, these outer edges were relatively brittle and broke off easily. On closer inspection it appeared that these outer areas were very densely packed with plant impressions. This outer edge seemed to form a layer around the internal, more solid and compact area of the blocks. During sectioning the outer edges compacted very easily and broke off, leaving a hard oblong-shaped centre. Field 
observations therefore suggest that the explanation for this interesting slag formation could relate to the packing of the furnace pit with plant material before the smelt. Alternatively this could also be associated with the positioning of tuyeres and bellows, but this will be explored further in the site interpretation below. The slag samples taken for analysis from CMZ 2 are shown below (table 6.3.2).

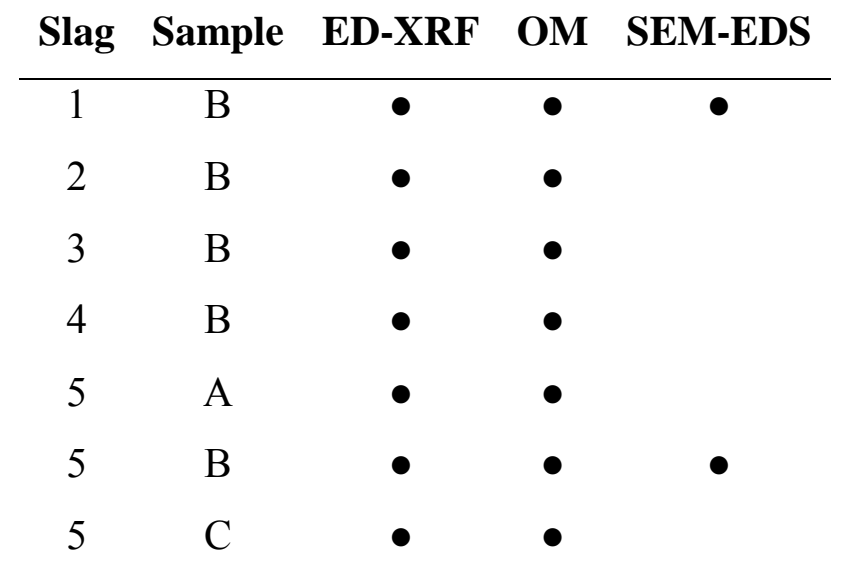

Table 6.3.2 Slag samples analysed from CMZ 2

Being the most complete of the slag blocks, SB5 was selected to test for the level of homogeneity throughout the block using the analysis of the top, middle and bottom sample.

\section{- $C M Z 2 f 1$}

As mentioned, CMZ $2 \mathrm{f} 1$ was a very substantial structure. SB1 was found in situ attached to the furnace pit walls and so can be assumed to have been smelted in the pit. The fabric of the pit lining was a burnt dark grey which, on a macroscopic level, did not look particularly heavily tempered with quartz. The pit lining became thinner towards the bottom of the pit. When the excavation of $\mathrm{f} 1$ was complete it was found that the pit was between $54 \mathrm{~cm}$ deep (north-south section) and $35 \mathrm{~cm}$ deep (west-east section: fig. 6.3.6), although again the original ground level is unknown and so the pit could have been deeper. An important find from $\mathrm{f} 1$ was a fragment of tuyere which was found at a depth of $10 \mathrm{~cm}$ below ground level. The fragment was $5 \mathrm{~cm}$ long; the width of the tuyere wall was $1-2 \mathrm{~cm}$, while the diameter of the tuyere would have been 
approximately $6 \mathrm{~cm}$. The fabric of the tuyere appeared very heavily tempered with quartz pieces of all shapes and sizes.

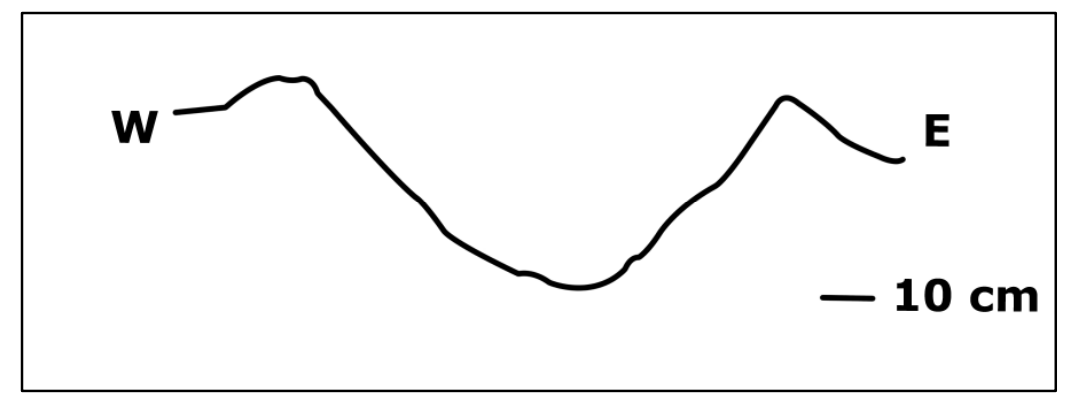

Fig. 6.3.6 CMZ 2 f1 in section (west-east) after excavation

- $C M Z 2 f 2$

Located only $7 \mathrm{~m}$ from CMZ $2 \mathrm{f1}$, this second furnace pit initially appeared macroscopically different due to its much less substantial diameter and furnace pit lining. However, when the more significant erosion factors impacting this feature were considered, the macroscopic similarities between the original dimensions of the two structures were clear.

During the removal of SB2, the furnace was covered with a thick black fabric and again samples of the pit lining were taken for luminescence dating, as well as for archaeometric analysis. A number of fragments of tuyere were found inside the pit lying on top of SB2. One fragment was $8 \mathrm{~cm}$ long with a wall thickness of $1.5 \mathrm{~cm}$ and a diameter of approximately $6 \mathrm{~cm}$, while another fragment was slightly slagged and vitrified. This fragment was $5 \mathrm{~cm}$ long, with a thickness of $2 \mathrm{~cm}$ and a diameter of approximately 8-9 cm (fig. 6.3.7). CMZ $2 \mathrm{f} 2$ was found to be $20 \mathrm{~cm}$ deep (east-west section) following the removal of SB2 (fig. 6.3.8). 


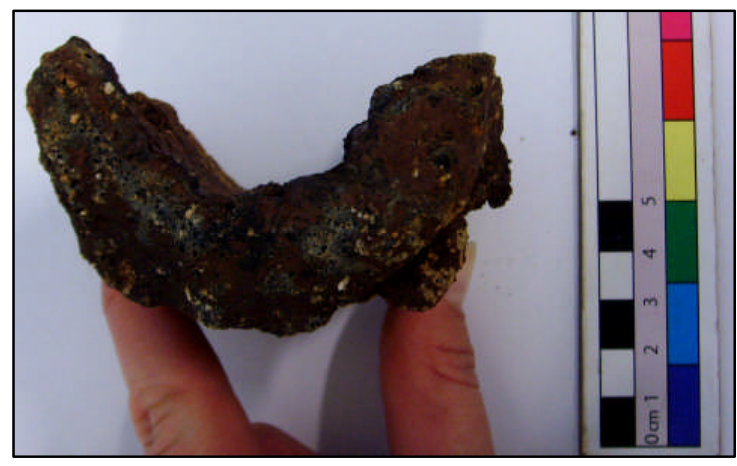

Fig. 6.3.7 Tuyere fragment found on top of SB2 in $\mathrm{f} 2$

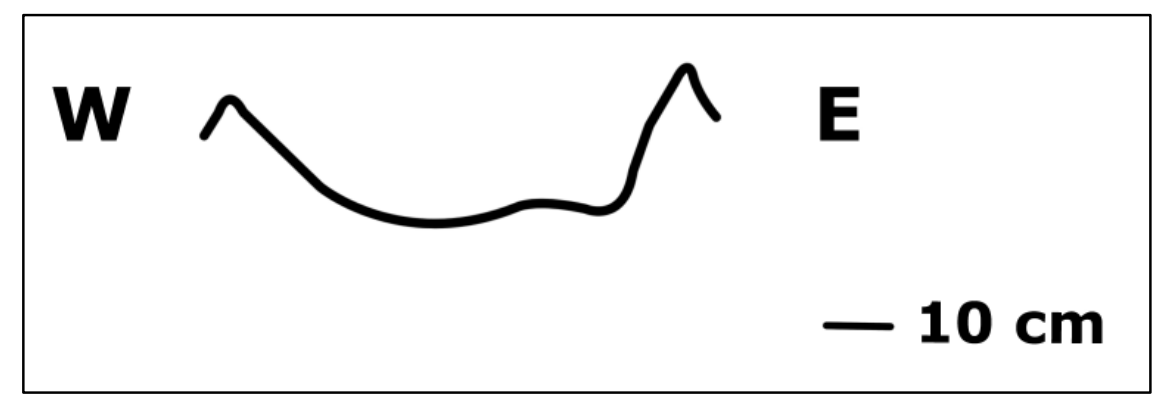

Fig. 6.3.8 - CMZ 2 f2 section drawings

A piece of domestic pottery from the site was collected for comparative analysis. The ceramic samples from the site of CMZ 2 taken for analysis are shown in table 6.3.3 below. 


\begin{tabular}{cccccc} 
Sample & Location & ED-XRF & OM & SEM-EDS & TL dating \\
\hline f1 pit lining & NMR & & & & \\
f1 pit lining & UCL & $\bullet$ & $\bullet$ & $\bullet$ & $\bullet$ \\
f1 pit lining & Milan & & & & \\
f1 tuyere & UCL & $\bullet$ & $\bullet$ & & \\
f2 pit lining & NMR & & & \\
f2 pit lining & UCL & $\bullet$ & $\bullet$ & \\
f2 pit lining & Milan & & & \\
f2 tuyere & UCL & $\bullet$ & $\bullet$ & $\bullet$ & $\bullet$ \\
f2 tuyere & Milan & & & & \\
domestic pottery & UCL & $\bullet$ & $\bullet$ &
\end{tabular}

Table 6.3.3 Ceramics taken for analysis from CMZ 2 (NMR - National Museums of Rwanda; Milan dating laboratory)

\section{- Test Pits}

Tp1 (excavated $18 \mathrm{~m}$ from the main site), was $2 \times 1 \mathrm{~m}$, and excavated to a depth of $1 \mathrm{~m}$. The pit contained sterile orange clay with the occasional fleck of charcoal, and no archaeological finds. Tp2 was a 1x1 m unit set up in the south-west corner of the site, $2.5 \mathrm{~m}$ to the south of $\mathrm{f} 1$. It was excavated to a depth of $50 \mathrm{~cm}$. The spoil removed from the test pit was sorted through by hand, being impossible to sieve due to its heavy clay consistency. Again the pit was sterile with flecks of charcoal throughout.

\subsubsection{Results}

- Slag Blocks

The coefficient of variation for each oxide throughout SB5 was calculated (table 6.3.4; fig. 6.3.9). 


\begin{tabular}{cccccccccccccc} 
& $\mathrm{Na}_{2} \mathbf{O}$ & $\mathbf{M g O}$ & $\mathrm{Al}_{2} \mathbf{O}_{3}$ & $\mathrm{SiO}_{2}$ & $\mathbf{P}_{2} \mathbf{O}_{5}$ & $\mathbf{S}$ & $\mathbf{K}_{2} \mathbf{O}$ & $\mathbf{C a O}$ & $\mathbf{T i O}_{2}$ & $\mathbf{V}_{2} \mathbf{O}_{5}$ & $\mathbf{C r}_{2} \mathbf{O}_{3}$ & $\mathrm{MnO}$ & $\mathbf{F e O}$ \\
& $\%$ & $\%$ & $\%$ & $\%$ & $\%$ & $\%$ & $\%$ & $\%$ & $\%$ & $\%$ & $\%$ & $\%$ & $\%$ \\
\hline $5 \mathrm{~A}$ & 0.48 & 0.06 & 9.41 & 22.02 & 3.25 & 0.11 & 3.33 & 1.26 & 0.24 & 0.00 & 0.02 & 2.69 & 56.11 \\
$5 \mathrm{~B}$ & 0.39 & 0.24 & 13.28 & 18.16 & 2.66 & 0.09 & 2.27 & 0.85 & 0.24 & 0.04 & 0.06 & 2.59 & 58.54 \\
$5 \mathrm{C}$ & 0.44 & 0.31 & 9.83 & 20.01 & 2.60 & 0.07 & 2.04 & 1.51 & 0.25 & 0.01 & 0.03 & 2.36 & 59.98
\end{tabular}

\begin{tabular}{|c|c|c|c|c|c|c|c|c|c|c|c|}
\hline & $\mathrm{CuO}$ & $\mathrm{ZnO}$ & $\mathbf{R} \mathbf{b}_{2} \mathbf{O}$ & SrO & $\mathbf{Y}_{2} \mathbf{O}_{3}$ & $\mathrm{ZrO}_{2}$ & $\mathrm{BaO}$ & $\mathbf{L a}_{2} \mathbf{O}_{3}$ & $\mathrm{CeO}_{2}$ & $\mathrm{Nd}_{2} \mathrm{O}_{3}$ & $\begin{array}{c}\text { Original } \\
\text { total }\end{array}$ \\
\hline & $\mathrm{ppm}$ & ppm & ppm & ppm & ppm & ppm & $\mathrm{ppm}$ & $\mathrm{ppm}$ & $\mathrm{ppm}$ & $\mathrm{ppm}$ & $\%$ \\
\hline $5 \mathrm{~A}$ & 251 & 126 & 127 & 279 & 102 & 238 & 6323 & 709 & 1459 & 458 & 96.82 \\
\hline $5 B$ & 256 & 154 & 47 & 153 & 65 & 138 & 3646 & 343 & 840 & 327 & 101.74 \\
\hline $5 \mathrm{C}$ & 266 & 175 & 54 & 183 & 65 & 147 & 3113 & 364 & 817 & 303 & 99.49 \\
\hline
\end{tabular}

Table 6.3.4 (P)ED-XRF compositional data obtained from the samples taken from CMZ 2 SB5. Results have been normalised to $100 \%$, and taken from the average of three XRF runs. Only trace elements above $50 \mathrm{ppm}$ are shown. Full results are given in appendix 3A

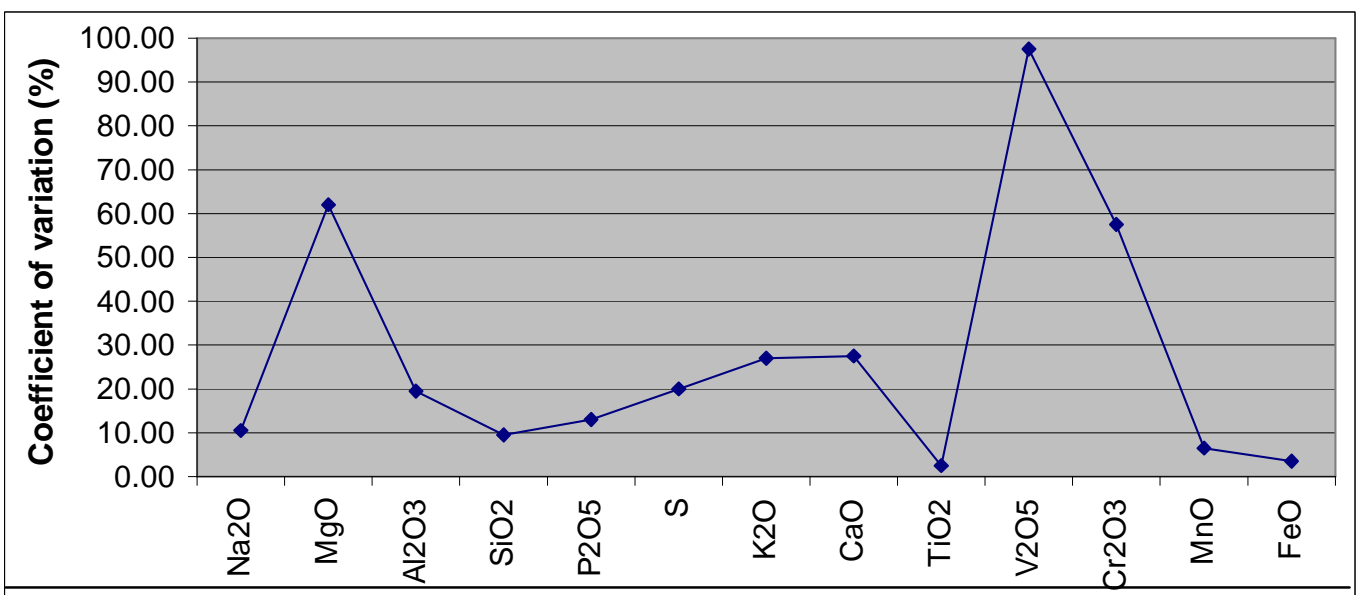

Fig. 6.3.9 Compositional variation throughout SB5 demonstrated using the coefficient of variation

The compositional variation seen within CMZ 2 SB5 appears more significant than that seen within CMZ 1 SB1 (see chapter 6.2). Whereas at CMZ 1, major oxides including alumina, silica, phosphate, potash and iron oxide all varied by less than 10\%, at CMZ 2 there are slightly higher levels of variation in fundamental components of iron slag. This is notable in levels of iron oxide, silica and alumina, however, this variation is still less than $20 \%$ for alumina and less than $10 \%$ for silica and iron oxide. In other major 
oxides, such as phosphate, potash and lime, although variation is up to nearly $30 \%$, these oxides are in fact present in low quantities within the slag samples themselves (for example less than $1.5 \%$ for lime). Thus, considering the relatively low variation, it would be very difficult to suggest specific patterns relating to smelting parameters from such minimal results. Oxides such as magnesia, vanadia and chromia demonstrate the highest levels of variation but are present in levels much less than $0.5 \%$, and so higher variation within the results (for example $0.06 \%-0.31 \%$ in the magnesia levels) is to be expected.

When considering the microstructures of the samples taken throughout SB5 (fig. 6.3.10), again a generally similar pattern is visible throughout. The higher level of alumina can be seen in the sample taken from the middle of the slag block (SB5B), which displays a greater amount of hercynite $(\mathrm{H})$. In general the amount of free iron oxides (wüstite - W), remain relatively low throughout the slag block, consistent with the low $\mathrm{FeO}$ composition within the bulk chemical analysis.
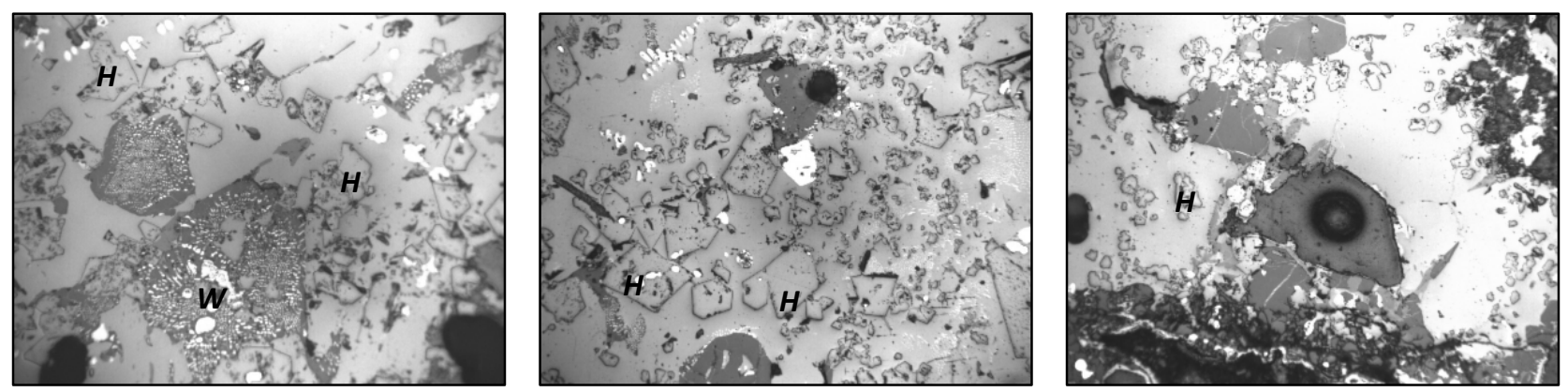

Fig. 6.3.10 PPL photomicrographs of samples taken throughout SB5. The sample representing slag produced at the beginning of the smelt (SB5C: 200x, image width $0.5 \mathrm{~mm}$ ) on the left; the sample taken from the middle of the block (SB5B: 100x, image width $1 \mathrm{~mm}$ ) in the centre; and the sample taken from the top of the block (SB5A: 100x, image width $1 \mathrm{~mm}$ ), representing the end period of the smelt, on the right

Due to the generally limited levels of variation throughout SB5 therefore, to provide an overview of smelting parameters at this site, the middle sample of each block analysed from CMZ 2 will be investigated (table 6.3.5). In addition, the coefficient of variation 
between each block has been calculated (below), to allow for a consideration of how the smelting events compared to each other.

\begin{tabular}{cccccccccccccc} 
& $\mathrm{Na}_{2} \mathbf{O}$ & $\mathbf{M g O}$ & $\mathrm{Al}_{2} \mathbf{O}_{3}$ & $\mathrm{SiO}_{2}$ & $\mathbf{P}_{2} \mathbf{O}_{5}$ & $\mathbf{S}$ & $\mathbf{K}_{2} \mathbf{O}$ & $\mathbf{C a O}$ & $\mathrm{TiO}_{2}$ & $\mathbf{V}_{2} \mathbf{O}_{5}$ & $\mathrm{Cr}_{2} \mathbf{O}_{3}$ & $\mathrm{MnO}$ & $\mathbf{F e O}$ \\
& $\%$ & $\%$ & $\%$ & $\%$ & $\%$ & $\%$ & $\%$ & $\%$ & $\%$ & $\%$ & $\%$ & $\%$ & $\%$ \\
\hline 1B & 0.47 & 0.28 & 10.23 & 23.10 & 2.57 & 0.08 & 3.39 & 1.50 & 0.39 & 0.00 & 0.02 & 0.65 & 57.06 \\
2B & 0.12 & 0.06 & 7.96 & 19.33 & 1.74 & 0.29 & 1.59 & 0.77 & 0.20 & 0.01 & 0.02 & 1.87 & 65.46 \\
3B & 0.58 & 0.46 & 12.07 & 24.92 & 2.46 & 0.09 & 3.63 & 2.09 & 0.36 & 0.00 & 0.03 & 2.70 & 50.16 \\
4B & 0.49 & 0.24 & 13.23 & 22.98 & 2.49 & 0.08 & 2.64 & 0.91 & 0.37 & 0.02 & 0.05 & 0.26 & 55.98 \\
5B & 0.39 & 0.24 & 13.28 & 18.16 & 2.66 & 0.09 & 2.27 & 0.85 & 0.24 & 0.04 & 0.06 & 2.59 & 58.54
\end{tabular}

\begin{tabular}{cccccccccccc} 
& $\mathbf{C u O}$ & $\mathbf{Z n O}$ & $\mathbf{R b}_{2} \mathbf{O}$ & $\mathbf{S r O}$ & $\mathbf{Y}_{2} \mathbf{O}_{3}$ & $\mathbf{Z r O}_{2}$ & $\mathbf{B a O}$ & $\mathbf{L a}_{2} \mathbf{O}_{3}$ & $\mathbf{C e O}_{2}$ & $\mathbf{N d}_{2} \mathbf{O}_{3}$ & $\begin{array}{c}\text { Original } \\
\text { total }\end{array}$ \\
& ppm & $p p m$ & $p p m$ & $p p m$ & $p p m$ & $p p m$ & $p p m$ & $p p m$ & $p p m$ & $p p m$ & $\%$ \\
\hline 1B & 269 & 134 & 85 & 153 & 66 & 162 & 1420 & 40 & 163 & 63 & 99.93 \\
2B & 359 & 150 & 58 & 163 & 78 & 154 & 2826 & 626 & 1106 & 406 & 81.08 \\
3B & 266 & 142 & 76 & 241 & 77 & 173 & 3136 & 59 & 199 & 120 & 100.51 \\
4B & 244 & 177 & 54 & 120 & 68 & 165 & 1291 & 116 & 265 & bdl & 99.94 \\
5B & 256 & 154 & 47 & 153 & 65 & 138 & 3646 & 343 & 840 & 327 & 101.74
\end{tabular}

Table 6.3.5 (P)ED-XRF compositional data obtained from the middle sample taken of each slag block from CMZ 2. Results have been normalised to $100 \%$, and taken from the average of three XRF runs. Only trace elements above $50 \mathrm{ppm}$ are shown; bdl - below detectable limits. Full results are given in appendix $3 \mathrm{~A}$

In general all of the blocks suggest a typical bloomery slag, with 55\% - 65\% iron oxide, $7 \%-13 \%$ alumina and $18 \%-25 \%$ silica, with the remaining few percent made up of other major oxides, in this case notably potash, phosphate and manganese oxide. Higher levels of specifically ore related oxides, such as manganese oxide, copper oxide and zinc oxide in the CMZ 1 slags (which correlate with iron oxide in this case), indicate a different ore source, or mixture of ores, being used at this site in comparison to that used at CMZ 1.

The overall average alumina to silica ratio within the slags at the site is quite high at $1: 2$, although this varies quite significantly from block to block, from 1:2.4 (SB2), to 
1:1.4 (SB5), highlighted in fig. 6.3.11 below. In this ternary diagram, the higher levels of alumina within the samples are apparent, in accordance with the generally dominant hercynite phases in the slag samples, illustrated in fig. 6.3.10 above.

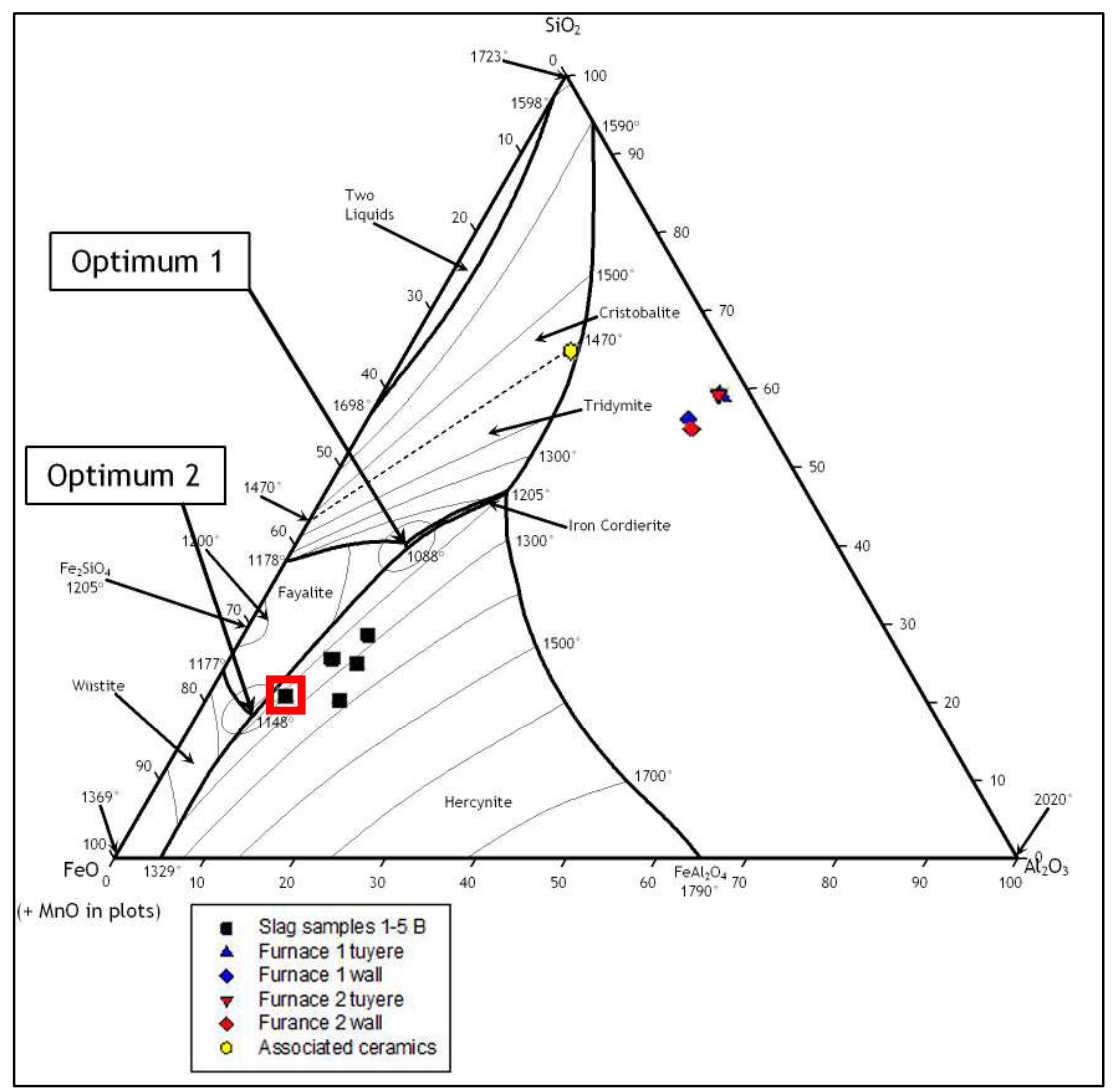

Fig. 6.3.11 Phase diagram illustrating the variable alumina to silica ratios between the slag samples taken from CMZ 2, as well as their position within the hercynite rich zone of the diagram. SB2outlined in red (after Rehren et al 2007: 212)

SB2 represents the lowest alumina level within the bulk chemical composition, and correspondingly lies the closest to the fayalite region within the phase diagram, illustrated by the red outline in fig. 6.3.11 above. This is highlighted in the microscopic examination of the sample, which is dominated by fayalite to a greater degree than other slag samples from this site (fig. 6.3.12). SB2 also contains more iron metal than other samples, as indicated by the bulk chemical composition as well as visible within the microstructure of the sample. Further illustrated by microscopic examination is the high 
potash levels in SB3 (fig. 6.3.13), and SB4 (fig. 6.3.14) below, which explain the dominance of kalsilite within these samples, especially around areas of porosity.

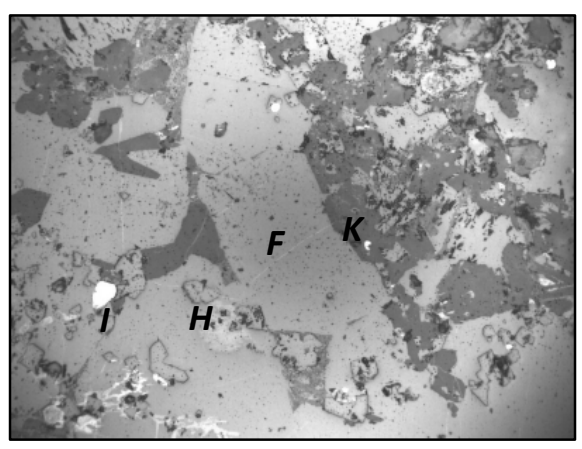

Fig. 6.3.12 PPL micrograph of SB2, illustrating dominance of fayalite $(F)$, limited hercynite $(\mathrm{H})$ compared to other sample, areas of kalsilite (K) and blobs of iron (I) metal (200x, image width $0.5 \mathrm{~mm}$ ).

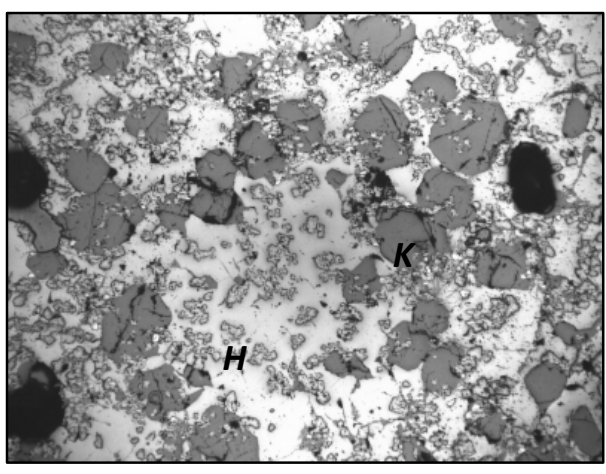

Fig. 6.3.13 PPL image of SB3, illustrating the dominance of kalsilite $(\mathrm{K})$ and hercynite $(\mathrm{H})$ (50x, image width $2 \mathrm{~mm}$ )

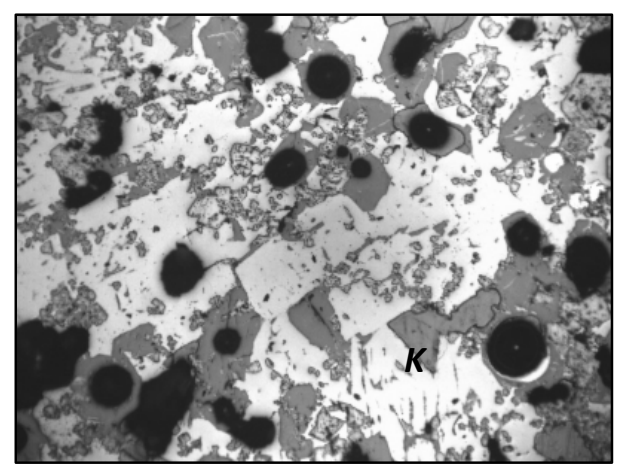

Fig. 6.3.14 PPL image of SB4, illustrating the dominance of kalsilite $(\mathrm{K})$, notably around porosity (black blobs), within the sample (200x, image width $0.5 \mathrm{~mm}$ )

When the level of variation between smelts is calculated (fig. 6.3 .15 below), those oxides displaying the lowest level of variation between smelts are alumina, silica and iron oxide. This suggests that the level of efficiency per smelt was relatively consistent, with roughly the same amount of iron oxide lost within each smelt, and that in general, any ceramics melting into the smelts were also of a similar composition. Again, it is the lighter oxides that display the most significant variation, which is generally a reflection of their presence in such limited amounts. Variation in potash, lime and magnesia are 
however significant in that they could suggest variation in fuel types, or at least in the amount of fuel consumed between smelts. These oxides are generally positively correlated, and represent constituents of fuel ash (e.g. Misra et al 1993). Other basic correlations within the bulk chemical data include ore related oxides such as iron, manganese, copper and zinc oxide. This suggests that ore and fuel may have varied to a slight degree between smelts at this site, but that general principles of furnace operation were maintained.

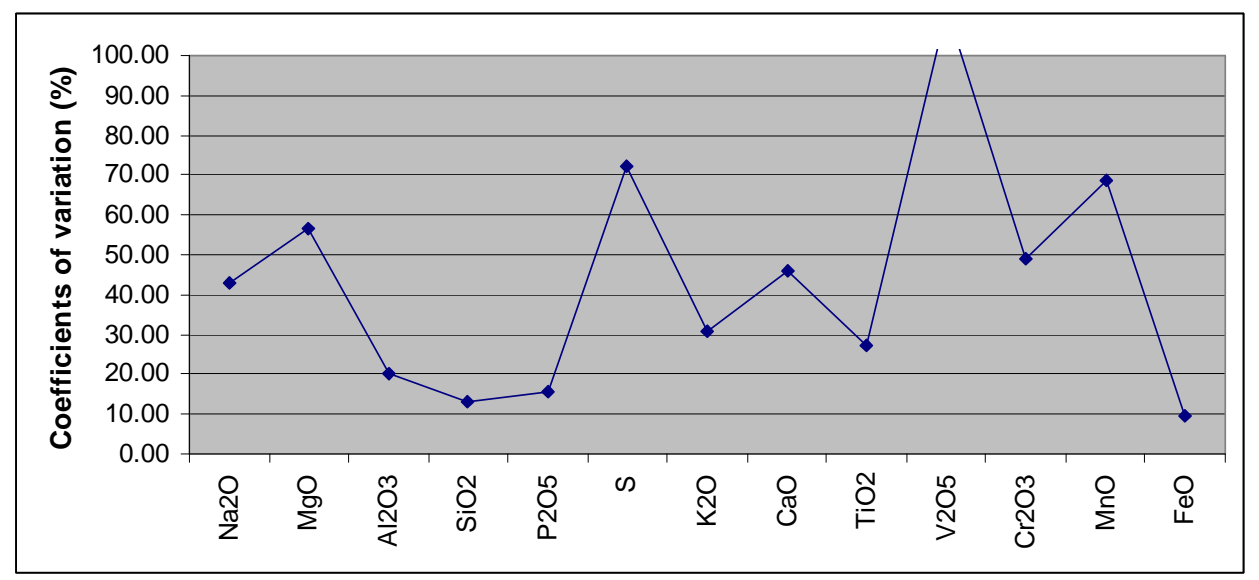

Fig. 6.3.15 Compositional variation between the middle sample from each of the 5 slag blocks analysed from CMZ 2, demonstrated using the coefficient of variation

When compared to the variation between smelts at CMZ 1 (fig. 6.3.16), the higher level of variation at CMZ 2 is illustrated. This is particularly noticeable in the variation in alumina levels. It may well be that this higher concentration of alumina within the slag at CMZ 2 (making the slag more viscous and more difficult to control) made the processes in general harder to regulate. Furthermore, the relatively higher alumina would also require higher operating temperatures (see fig. 6.3.11), resulting in a higher rate of fuel combustion. The latter would explain the relatively increased levels of lime and potash in the slag, corresponding with the alkali-rich phases visible in the slag microstructure. The source of this higher alumina, which may be responsible for the higher variability at CMZ 2, is considered below. 


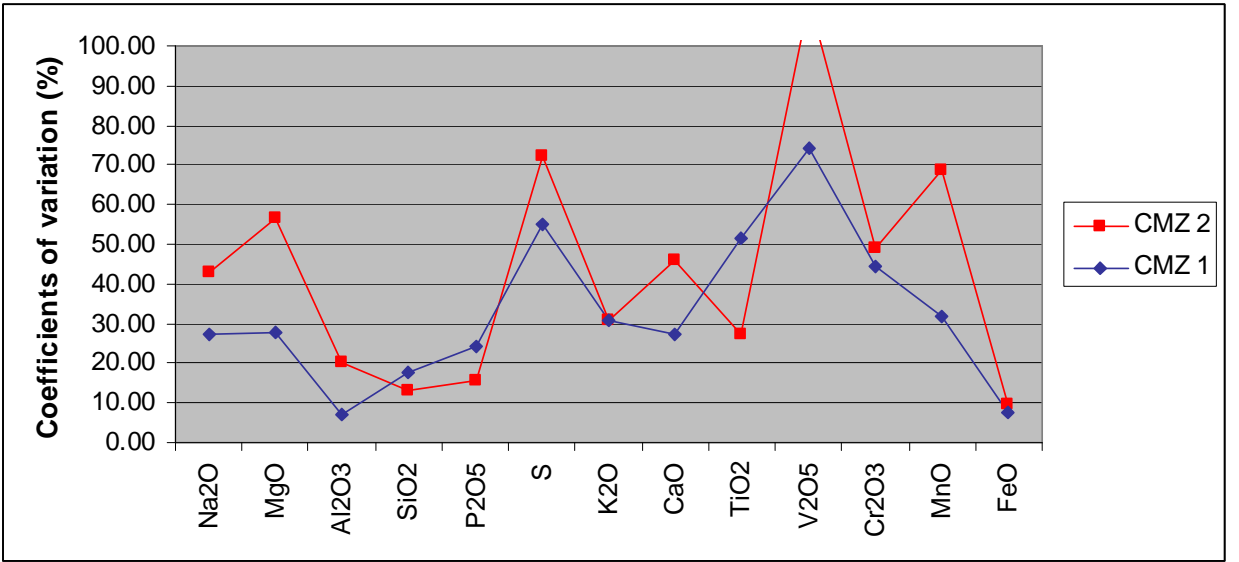

Fig. 6.3.16 Compositional variation between the middle sample from each of the 5 slag blocks analysed from CMZ 2, demonstrated using the coefficient of variation

\section{- Technical ceramics}

The results of the XRF analyses of the samples of ceramics taken from the site are shown below (table 6.3.6).

\begin{tabular}{cccccccccccccc} 
& $\mathbf{N a}_{2} \mathbf{O}$ & $\mathbf{M g O}$ & $\mathrm{Al}_{2} \mathbf{O}_{3}$ & $\mathbf{S i O}_{2}$ & $\mathbf{P}_{2} \mathbf{O}_{5}$ & $\mathbf{S}$ & $\mathbf{K}_{2} \mathbf{O}$ & $\mathbf{C a O}$ & $\mathbf{T i O}_{2}$ & $\mathbf{V}_{2} \mathbf{O}_{5}$ & $\mathbf{C r}_{2} \mathbf{O}_{3}$ & $\mathbf{M n O}$ & $\mathbf{F e O}$ \\
& $\%$ & $\%$ & $\%$ & $\%$ & $\%$ & $\%$ & $\%$ & $\%$ & $\%$ & $\%$ & $\%$ & $\%$ & $\%$ \\
\hline f1 tuyere & 0.34 & 0.29 & 36.47 & 57.56 & 0.29 & 0.03 & 1.01 & 0.19 & 0.38 & 0.01 & 0.01 & 0.04 & 3.32 \\
f1 pit lining & 0.50 & 0.15 & 34.28 & 54.12 & 0.37 & 0.06 & 0.80 & 0.14 & 1.33 & 0.03 & 0.01 & 0.05 & 8.03 \\
f2 tuyere & 0.52 & 0.24 & 36.27 & 57.46 & 0.38 & 0.03 & 1.04 & 0.18 & 0.38 & 0.01 & 0.01 & 0.03 & 3.38 \\
f2 pit lining & 0.33 & 0.22 & 35.20 & 53.07 & 0.31 & 0.05 & 0.72 & 0.16 & 1.26 & 0.03 & 0.02 & 0.10 & 8.38 \\
pottery & 0.67 & 0.24 & 17.56 & 62.78 & 0.16 & 0.03 & 1.12 & 0.13 & 0.55 & 0.03 & 0.02 & 0.05 & 16.53
\end{tabular}

\begin{tabular}{|c|c|c|c|c|c|c|c|}
\hline & $\mathrm{CuO}$ & $\mathrm{ZnO}$ & $\mathbf{R} \mathbf{b}_{2} \mathbf{O}$ & $\mathrm{ZrO}_{2}$ & $\mathrm{BaO}$ & $\mathrm{CeO}_{2}$ & $\begin{array}{c}\text { Original } \\
\text { total }\end{array}$ \\
\hline & ppm & $\mathrm{ppm}$ & ppm & ppm & ppm & ppm & $\%$ \\
\hline f1 tuyere & 21 & 77 & 114 & 129 & 216 & 26 & 79.62 \\
\hline f1 pit lining & 30 & 86 & 69 & 547 & 340 & 88 & 72.35 \\
\hline f2 tuyere & 22 & 100 & 129 & 127 & 220 & 17 & 77.63 \\
\hline f2 pit lining & 50 & 206 & 81 & 550 & 386 & 97 & 73.72 \\
\hline pottery & 68 & 76 & 100 & 177 & 503 & 41 & 83.03 \\
\hline
\end{tabular}

Table 6.3.6 (P)ED-XRF compositional data obtained from the ceramics taken from CMZ 2. Results have been normalised to $100 \%$, and taken from the average of three XRF runs. Only trace elements above 50 ppm are shown. Full results are given in appendix 3B 
The XRF results of the technical ceramics suggest that the same clay mixture was used for the furnace pit linings, and a slightly different clay source was used to produce the tuyeres. The tuyere clay is slightly richer in alumina, silica, magnesia, potash, lime and rubidium oxide, while the furnace pit lining samples are slightly richer in phosphate, sulphur, titania, vanadia, manganese oxide, iron oxide, copper oxide, zirconia and barium oxide. However, although the bulk chemical analysis possibly indicates a different clay source to produce the two sets of ceramics, they display very similar alumina to silica ratios (fig. 6.3.17), and microscopic examination suggested the fabrics for both sets of ceramics were processed in a similar way, being densely tempered (either naturally or manually) with large and small pieces of quartz (Q) displaying both smooth and jagged edges (fig. 6.3.18; 6.3.19; 6.3.20 and 6.3.21).

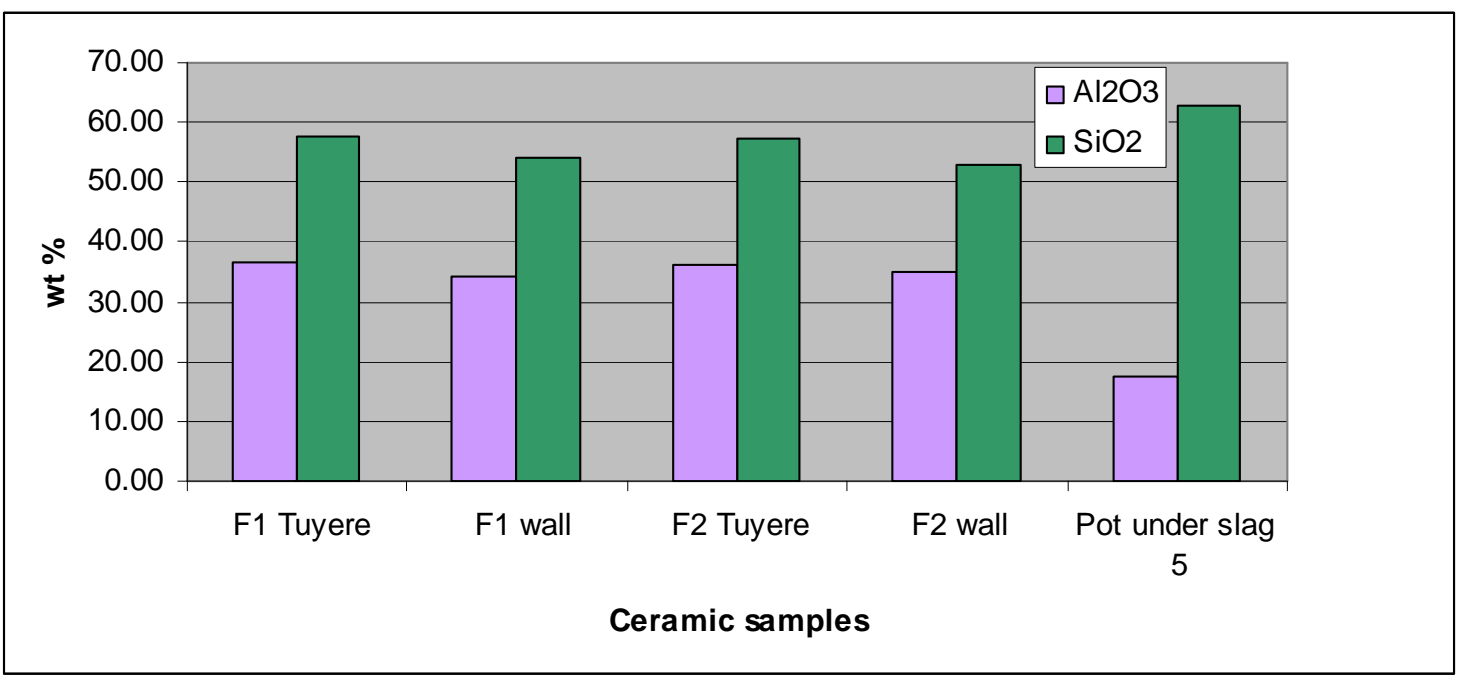

Fig. 6.3.17 Levels of alumina and silica in the technical ceramics analysed from the site of CMZ 2 


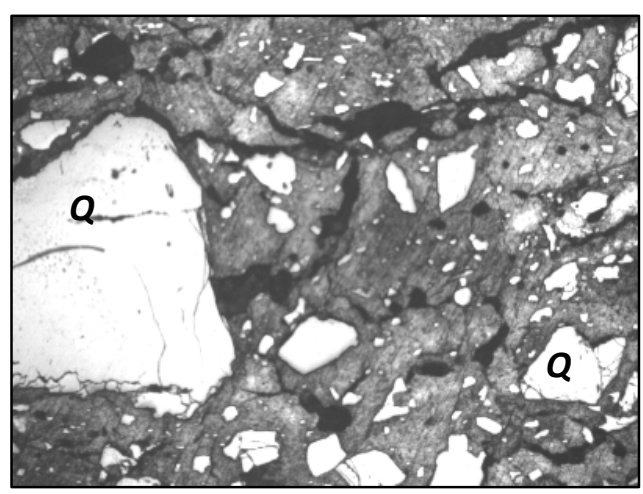

Fig. 6.3.18 f1 tuyere

(PPL 50x, image width $2 \mathrm{~mm}$ )

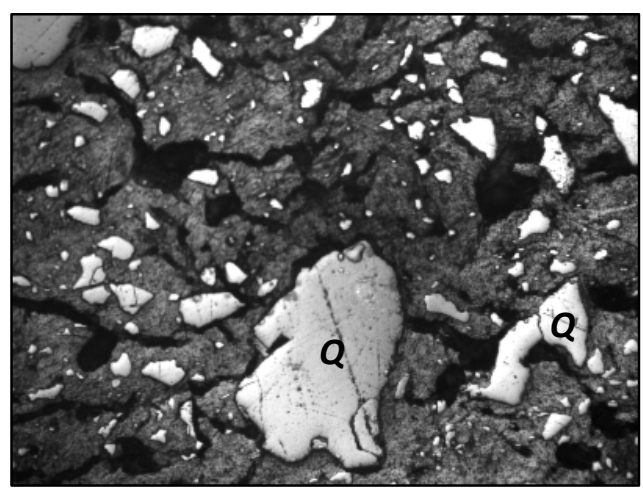

Fig. 6.3.20 f2 tuyere.

(PPL 50x, image width $2 \mathrm{~mm}$ )

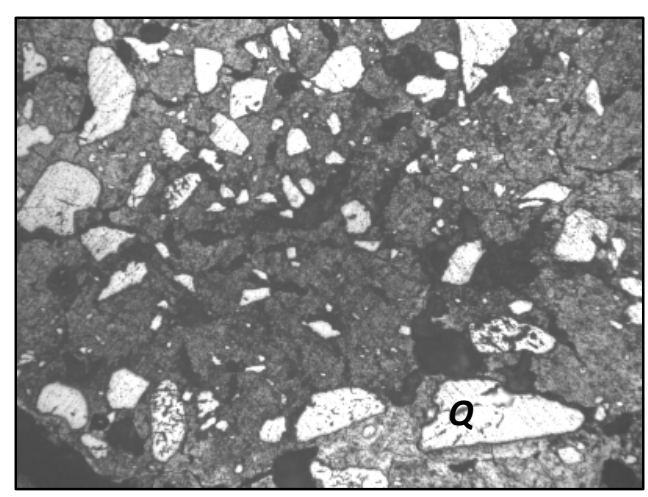

Fig. 6.3.19 f1 pit lining

(PPL 50x, image width $2 \mathrm{~mm}$ )

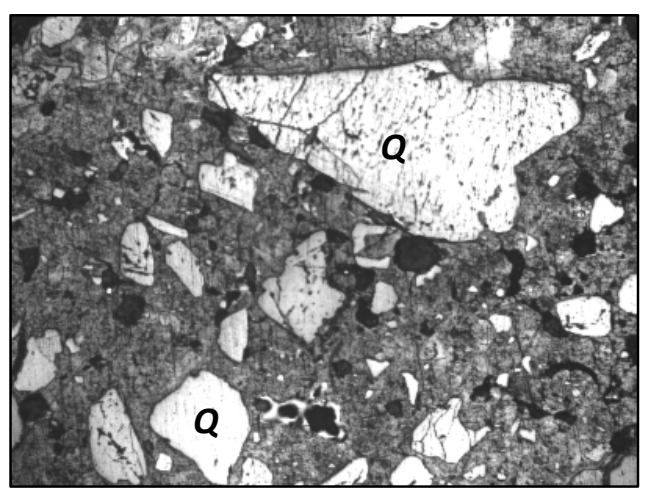

Fig.6.3.21 f2 pit lining

(PPL 5x50x, image width $2 \mathrm{~mm}$ )

The clay used to produce the tuyeres display particularly lower levels of iron oxide within their chemical composition, which combined with the higher alumina levels suggests an even more refractory, perhaps kaolinitic clay in use. Comparing the alumina to silica ratios in the technical ceramics used in $\mathrm{f} 1$ with SB1, and those used in $\mathrm{f} 2$ with SB2, the different ratios indicate that ceramics were probably not the main contributors of siliceous material to the slag, or, at least, that the ore also contributed substantial amounts of silica. Overall it would seem that as in CMZ 1, the practitioners here used relatively refractory clays which melted to a limited extent during the smelting processes. They produced technical ceramics which would aid the efficiency and success of the smelts by ensuring a constant air supply to the furnaces and withstanding extreme conditions for the entirety of the processes. 
Furthermore, as at CMZ 1, the ceramics used in a domestic context are clearly different from those fabricated as technical ceramics. Therefore, again, it would seem that the smelters did procure and process a particular clay fabric for ceramics required to perform well under smelting conditions.

\subsubsection{Site interpretation}

A 2 sigma calibrated AMS date of 1210-1290 AD was provided from the analysis of charcoal taken from CMZ 2 f1. While the direct chronological relationship between all of the smelting activities within the site is unknown, it can be suggested that the smelting industry represented at CMZ 2 may have arisen following the earlier industrial production at the neighbouring site of $\mathrm{CMZ} 1$. Therefore, not only does this site provide a further insight into the technological knowledge held within the Middle Iron Age period, but in combination with the results from the earlier site of CMZ 1, it also allows for a consideration of how technological knowledge and expertise were manifested over a period of two to three hundred years in a single location.

This site appears to represent the use of a different type of ore, which could indicate that the particularly high grade, low alumina ores had been exhausted, or access was more controlled at this time. There also appears to be slightly less standardisation between smelts. As the scale of production at this site was much greater than at CMZ 1 (see below), but general principles such as furnace style were adhered to, these levels of variation could be indicative of more people being involved in the production process, and so less control exerted over particular variables, besides the technical challenges of an alumina-rich ore.

To quantify the iron produced at this site, following the same calculations used in the previous section, based on an average of $55 \%$ iron oxide and thus $45 \%$ of other material for each slag block, crude calculations can be made to quantify production at this site, seen below. Despite the tentative nature of these quantifications, it is clear that a 
copious amount of iron metal was produced at CMZ 2 over the course of its operating life.

\begin{tabular}{l|l} 
Average weight of blocks & $77 \mathrm{~kg}$ \\
\hline Blocks observed at the site & 40 \\
\hline Approximate quantity of slag at the site & $3000 \mathrm{~kg}$ \\
\hline Approximate slag content & $55 \%$ iron oxide, $45 \%$ other \\
\hline $\begin{array}{l}\text { Iron produced by smelting good quality } \\
\text { ore (90\% iron oxide) }\end{array}$ & Approximately $\mathbf{8 0 0 0} \mathbf{~ k g}$ \\
\hline $\begin{array}{l}\text { Iron produced by smelting medium quality } \\
\text { ore (80\% iron oxide) }\end{array}$ & Approximately $\mathbf{3 0 0 0} \mathbf{~ k g}$
\end{tabular}

The macroscopic similarities between the two furnace constructions (fig. 6.3.22) mirror each other in terms of pit shape when the extent of erosion is considered. Even taking into account the unusual, oval shape of these blocks, they displayed almost identical morphological characteristics. This technical repetition could indicate that all of the blocks were produced by the same group over a relatively continuous period.

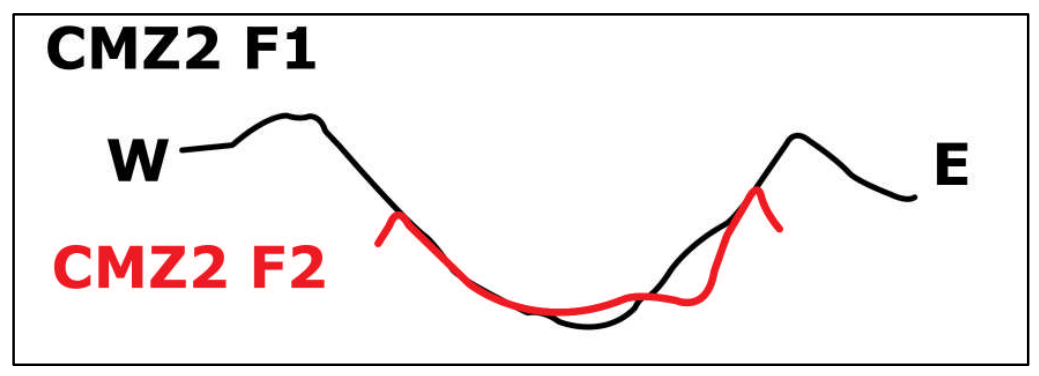

Fig. 6.3.22 CMZ 2 F1 and F2 sections compared

The smelters packed the furnace pits densely with vegetation prior to the smelt, indicated by the thick, brittle layer of slag dense with plant impressions, surrounding a dense inner core. It might also be possible that they may have aligned their tuyeres at 
opposite ends of the furnace structure, creating the oblong-shaped slag as the reduction zones within the furnaces aligned along these tuyeres and the slag thus dripped down into the pits around the tuyeres. This possibility would however be very hard to prove without experimentation, and, certainly from a technical point of view, it makes little sense to have gaps around two sides of the furnace where bellows could be operated to maximise the production during the smelt itself, especially when one considers the wide diameter of the furnaces. One fact to mention is that whereas in $\mathrm{f} 1$ the oblong slag was aligned east-west, in $\mathrm{f} 2$ it was aligned north-south; whether the slag was formed in this way due to certain tuyere positioning or other technological choices, orientation clearly did not matter.

While the chronological relationship between the two furnaces is unknown, the presence of these two furnaces can provide a tentative insight into one aspect of iron production at the site: both furnace pits contained slag blocks sat firmly in situ, and unless these two furnaces were the last two smelts ever to have been carried out at the site, it suggests that each smelt had its own furnace pit and some form of superstructure. There may well be more furnace structures to discover in the future.

Frustratingly, the two test pits excavated contained no archaeological remains or stratigraphy, hence little can be said of the organisation of production in relation to occupation sites. As was mentioned, a further slag cluster was located $20 \mathrm{~m}$ west of the site, and according to the people who live on the hill, further clusters exist throughout the vicinity. This clustering may represent the work of recent farmers clearing the archaeometallurgical debris to allow for easy land clearance and farming, or it could represent pockets of smelting groups, although again the chronological relationship between them would remain unknown. If contemporary to the CMZ sites, this would indicate a great increase in production during the Middle Iron Age, which would presumably reflect a higher demand, at a much earlier date than the Kingdom period. This potential scenario will be discussed further in the following chapter. 


\subsection{Mpinga (MNA)}

\subsubsection{Site description and observations}

The site of Mpinga (MNA) is situated on relatively low-lying land, within a west-facing house compound. The house forms part of a cluster of houses which stretch for a few hundred metres along a road which leads to the local market. The site was easy to spot during survey due to the large slag blocks that surround the edge of the house compound and because of the very substantial furnace base which sits at the north-west corner of the house (only $1.5 \mathrm{~m}$ away from the house wall itself). The house is surrounded at the back and sides by banana and maize plantations, while at the very front of the house is a thin flowerbed within which was spotted the up-turned end of a slagged tuyere.

Both behind the house and further along the road more slag blocks were found, alongside ceramics including KPR and the occasional Urewe decorated fragment. There was also one particular slag block that we were taken to by local people, approximately $500 \mathrm{~m}$ from the site of MNA. This immense block, with a diameter of over $1.25 \mathrm{~m}$, had been discovered during the digging of a new pit latrine. The slag block was much too heavy to lift out of the pit and the land owner was not prepared to negotiate a reasonable rate to sample from the block, and so it was left in place (fig. 6.4.1). Field observations indicated initially that, although not as extensive as the remains identified at the CMZ sites, this area was once a significant centre of iron production. It should be mentioned that, as at other sites, local memory does not include knowledge concerning the archaeometallurgical remains (as far as we could determine during fieldwork). 


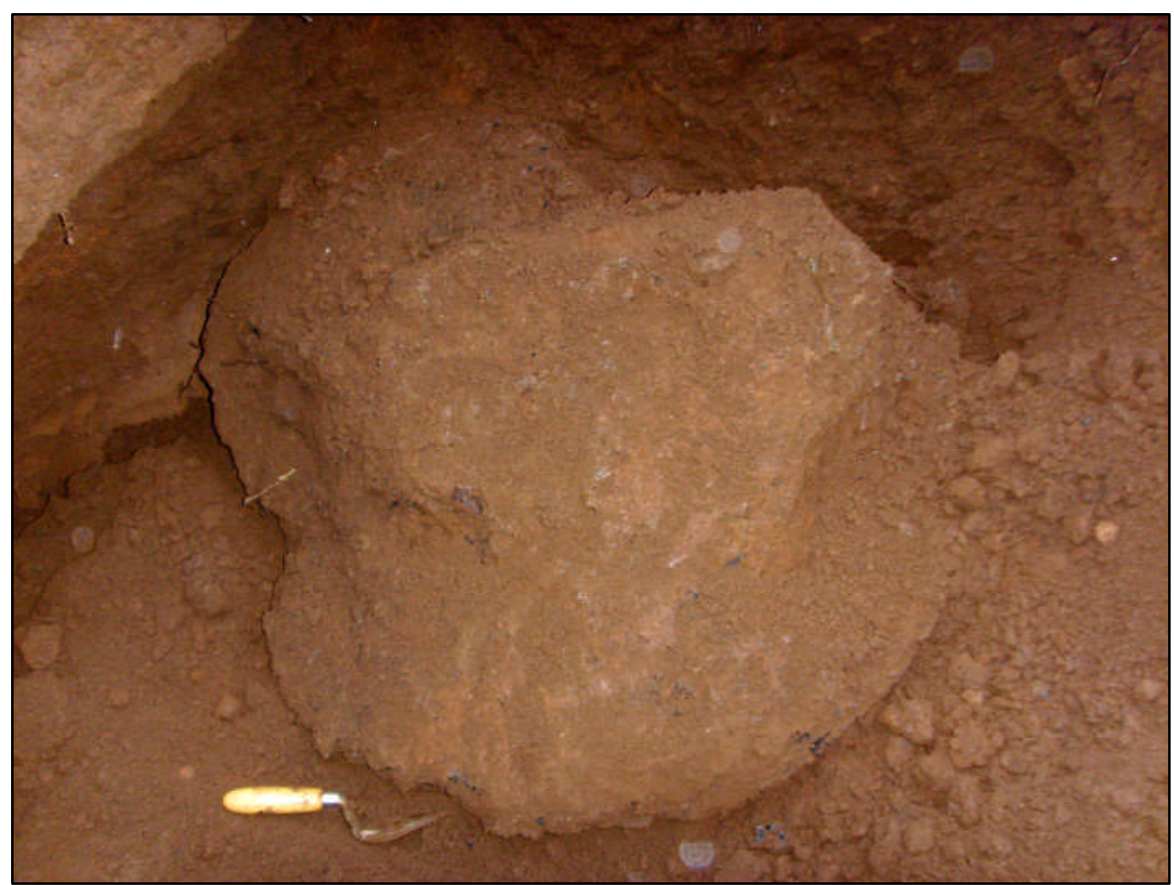

Fig. 6.4.1 Largest slag block seen during the research, $500 \mathrm{~m}$ from MNA

Despite numerous discussions and explanations about the objectives of the work, at this site bad feelings were rife towards the team, and threats were made to the family living in the house; the neighbours were jealous of the very small payment made to compensate the owner for our presence. The local mayor and the head of the local police were contacted to ensure the house owner's safety (as well as that of the team), and this site was necessarily excavated quickly over 3 days.

Twelve large slag blocks could be seen either dumped around the large tree in the house compound or protruding from the ground. The slag blocks had been piled up around the tree to keep them out of the way of the cultivation activity. The slag blocks all appeared quite similar in size and shape, the main characteristic being a particularly wide diameter, although in depth the blocks were relatively similar to slag blocks studied at other sites (table. 6.4.1; fig. 6.4.2). 


\begin{tabular}{ccccc}
$\begin{array}{c}\text { Slag } \\
\text { block }\end{array}$ & $\begin{array}{c}\text { Diameter at widest } \\
\text { point }(\mathbf{c m})\end{array}$ & $\begin{array}{c}\text { Perpendicular } \\
\text { diameter }(\mathbf{c m})\end{array}$ & $\begin{array}{c}\text { Depth } \\
(\mathbf{c m})\end{array}$ & $\begin{array}{c}\text { Weight } \\
(\mathbf{k g})\end{array}$ \\
\hline 1 & 105 & 95 & 40 & 205 \\
2 & 50 (broken) & 50 (broken) & 35 & 84 \\
3 & 82 & 44 (broken) & 40 & 105.5 \\
4 & 60 (broken) & 80 & 35 & 122.5 \\
5 & 90 & 70 & 30 & 113
\end{tabular}

Table 6.4.1 Dimensions of the slag blocks selected for detailed analysis at MNA

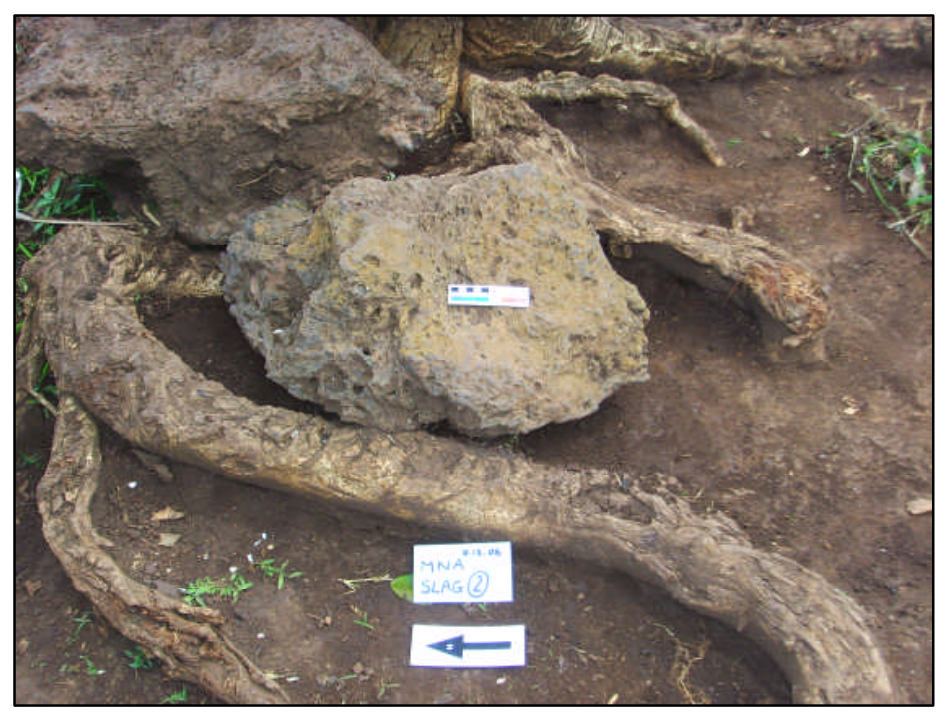

Fig. 6.4.2 MNA SB2 sat by the compound tree

A key feature of the site was the furnace base (f1), within which sat slag block one (SB1). The west-east diameter of this substantial structure was $92 \mathrm{~cm}$, while the pit lining width ranged from $4-12 \mathrm{~cm}$ thick (fig. 6.4.3; fig. 6.4.4). 


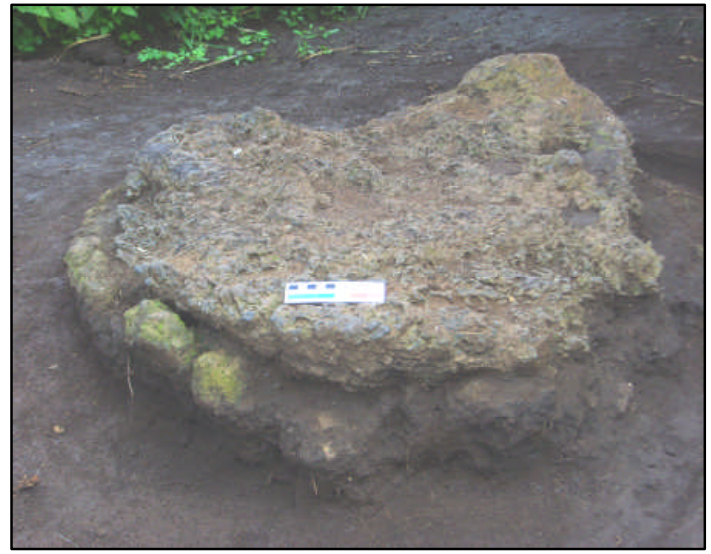

Fig. 6.4.3 MNA f1

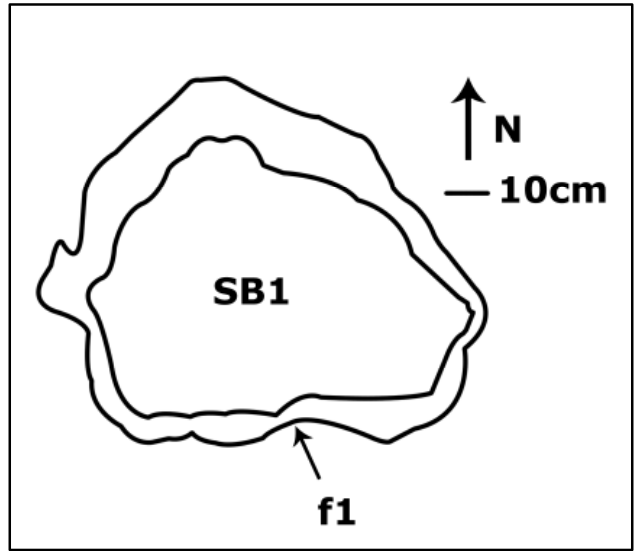

Fig. 6.4.4 MNA f1 plan

As mentioned above, one tuyere fragment was found at this site, with the circumference intact. The tuyere was slagged and vitrified (fig. 6.4.5), and had walls approximately 1$1.5 \mathrm{~cm}$ thick, and an internal diameter at the widest point of $3.5 \mathrm{~cm}$ and at the narrowest point $2.5 \mathrm{~cm}$. Due to its slagged appearance, it can be presumed that this end of the tuyere was placed within the furnace during the smelt. Due to its contaminated nature, this sample was not analysed further.
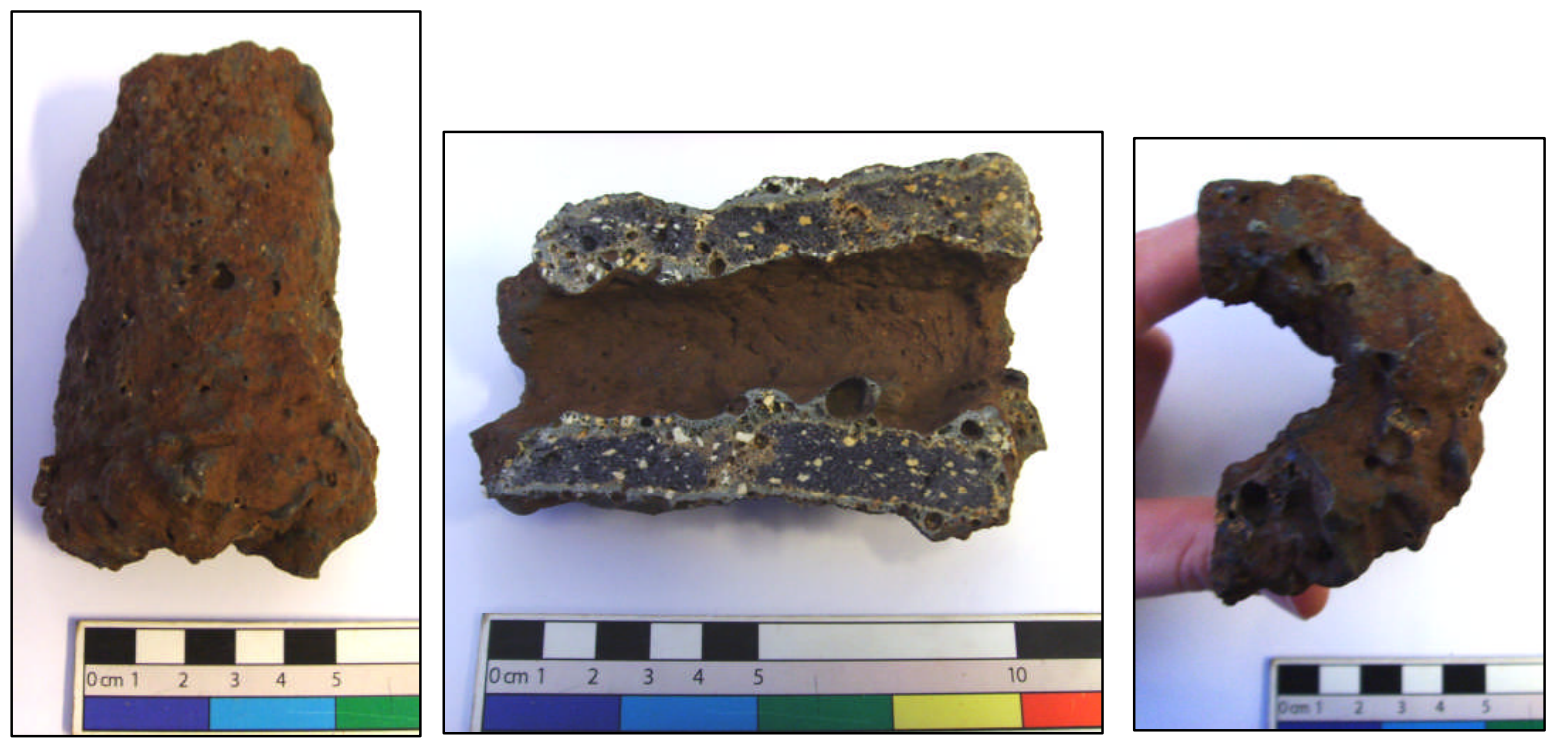

Fig. 6.4.5 MNA tuyere 
At this site three test pits (tp) were excavated. Tp1 was excavated $1 \mathrm{~m}$ east of f1, to test for archaeology directly associated with the smelt, while tp2 was positioned $10 \mathrm{~m}$ directly behind the house in the cultivated area. Finally, tp 3 was excavated $9 \mathrm{~m}$ from the south-east corner of tp2, in a depression, which it was hoped would make it easier to reach any stratigraphically contained archaeology below the surface. A site plan of MNA, including the location of the furnace pit in relation to the slag blocks and the test pits, is shown below (fig. 6.4.6).

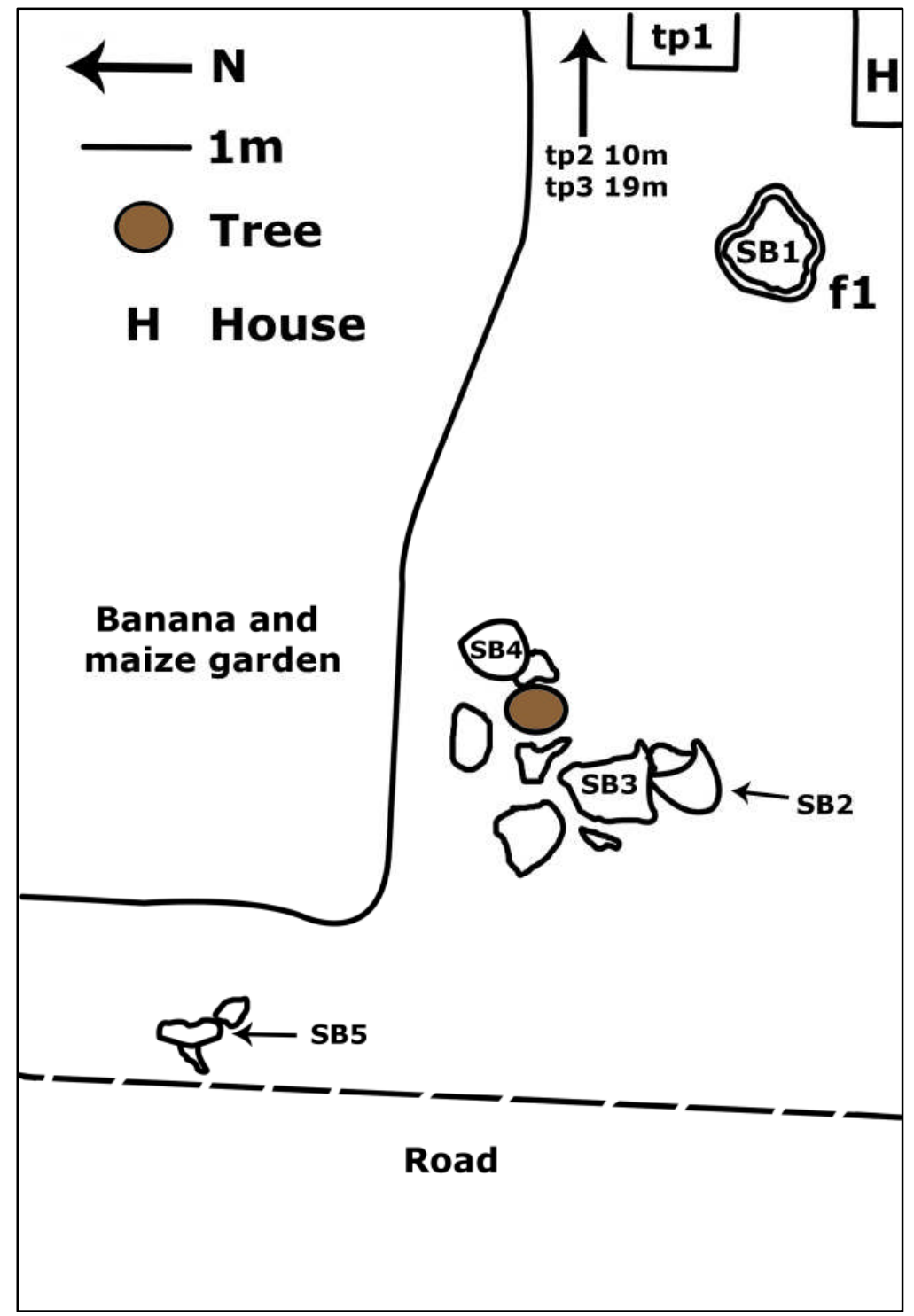

Fig. 6.4.6 MNA site plan 


\subsubsection{Excavations and sample selection}

\section{- Slag blocks}

As mentioned above, the slag blocks from MNA were macroscopically very similar in terms of depth, and most of the blocks appeared to have had an average diameter of nearly $1 \mathrm{~m}$. However, some of the blocks had clearly lost slag from around the edges due to weathering or to fragments breaking off. The slag appeared dark grey-silver in colour, with plant impressions and gas bubbles throughout (fig. 6.4.7). SB1 was selected for detailed analysis as the most visually representative block (table 6.4.2).

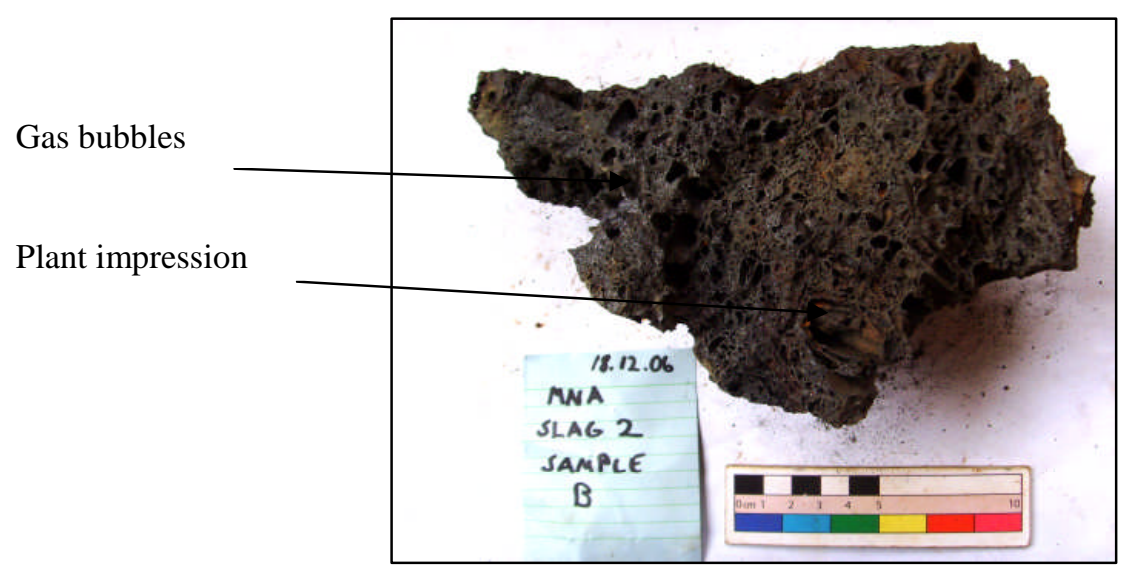

Fig. 6.4.7 Slag samples taken from MNA SB2

\begin{tabular}{ccccc} 
Slag & Sample & ED-XRF & OM & SEM-EDS \\
\hline 1 & A & $\bullet$ & $\bullet$ & \\
1 & B & $\bullet$ & $\bullet$ & \\
1 & C & $\bullet$ & $\bullet$ & $\bullet$ \\
2 & B & $\bullet$ & $\bullet$ & \\
3 & B & $\bullet$ & $\bullet$ & $\bullet$ \\
4 & B & $\bullet$ & $\bullet$ & \\
5 & B & $\bullet$ & $\bullet$ &
\end{tabular}

Table 6.4.2 Slag samples analysed from MNA 


\section{- Furnace One (MNA fl)}

The furnace pit at MNA still had the remains of SB1 sat firmly in place. Again the car jack was used to lift the block, which was then pushed over and out of the furnace pit (fig. 6.4.8). The soil underneath the slag appeared to have washed in through gaps between the slag block and the pit walls over the years, due to its very sandy nature. Again the furnace base was recorded in detail (fig. 6.4.9; fig. 6.4.10) and a number of samples of the pit lining were collected.

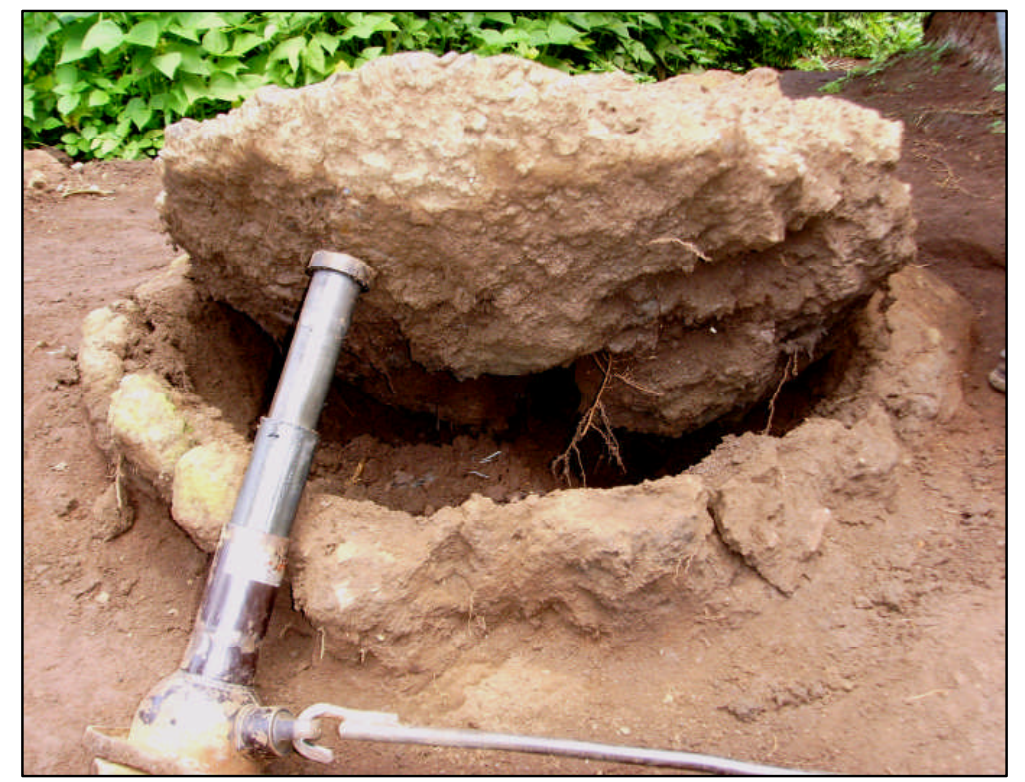

Fig. 6.4.8 Removing SB1 from F1 at MNA

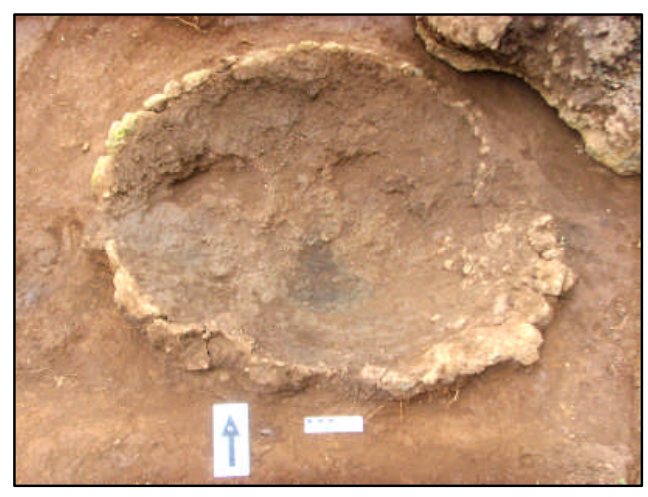

Fig. 6.4.9 MNA f1 after the removal of SB1

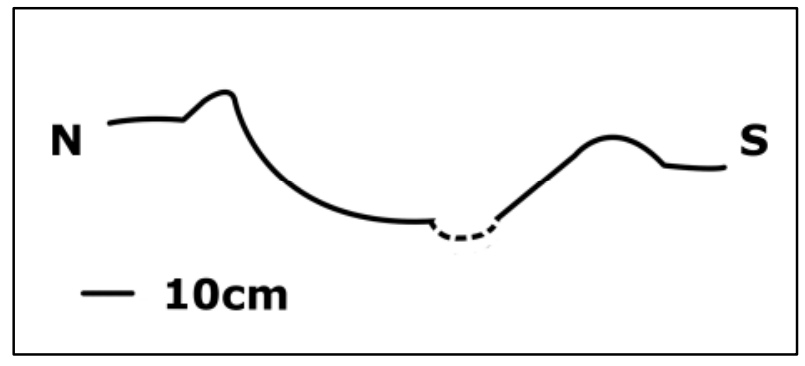

Fig. 6.4.10 Section of MNA f1 (dotted line: incomplete pit lining) 


\begin{tabular}{cccccc} 
Ceramic & Location & ED-XRF & OM & SEM-EDS & TL dating \\
\hline f1 pit lining & NMR & & & & \\
f1 pit lining & UCL & $\bullet$ & $\bullet$ & $\bullet$ & \\
f1 pit lining & Milan & & & & \\
tuyere & UCL & $\bullet$ & $\bullet$ & \\
excavated pot & UCL & $\bullet$ & &
\end{tabular}

Table 6.4.3 Ceramics taken for analysis from MNA

\section{- Test Pits}

Tp1 was excavated to a depth of $30 \mathrm{~cm}$, within which only modern debris such as plastic and roots from the adjoining banana and maize garden were located. The soil was dark brown and sandy, flecked with orange clay. The location of tp2, $10 \mathrm{~m}$ from the back of the house in a cultivated area, was chosen because a sherd of Urewe-decorated ceramic had been located in the spot during survey. Unfortunately, aside from a few pieces of undecorated pottery (one of which was collected for comparative analysis: see table 6.4.3 above), and a few potatoes, it was found that the dark brown sandy soil of the cultivation layer came down onto sterile orange clay at around $30 \mathrm{~cm}$. Finally it was hoped that excavating tp3 in a slight depression further from the back of the house may yield some deeper deposits of archaeology. However, despite all of the soil again being sieved, no finds or archaeological horizons were uncovered from this test pit.

\subsubsection{Results}

\section{- Slag Blocks}

Again the homogeneity of one slag block from MNA was tested by calculating the coefficient of variation within each compound throughout the entire block (table 6.4.4; fig. 6.4.11). 


\begin{tabular}{cccccccccccccc} 
& $\mathrm{Na}_{2} \mathbf{O}$ & $\mathbf{M g O}$ & $\mathrm{Al}_{2} \mathbf{O}_{3}$ & $\mathbf{S i O}_{2}$ & $\mathbf{P}_{2} \mathbf{O}_{5}$ & $\mathbf{S}$ & $\mathbf{K}_{2} \mathbf{O}$ & $\mathbf{C a O}$ & $\mathbf{T i O}_{2}$ & $\mathbf{V}_{2} \mathbf{O}_{5}$ & $\mathrm{Cr}_{2} \mathbf{O}_{3}$ & $\mathbf{M n O}$ & $\mathbf{F e O}$ \\
& $\%$ & $\%$ & $\%$ & $\%$ & $\%$ & $\%$ & $\%$ & $\%$ & $\%$ & $\%$ & $\%$ & $\%$ & $\%$ \\
\hline $1 \mathrm{~A}$ & 0.05 & 0.32 & 15.38 & 10.93 & 1.20 & 0.09 & 1.29 & 0.66 & 0.31 & 0.05 & 0.11 & 0.04 & 69.52 \\
$1 \mathrm{~B}$ & 0.18 & 0.29 & 9.95 & 13.93 & 1.39 & 0.12 & 1.72 & 1.01 & 0.33 & 0.03 & 0.03 & 0.05 & 70.92 \\
$1 \mathrm{C}$ & 0.33 & 0.29 & 8.02 & 19.28 & 1.70 & 0.17 & 2.18 & 1.74 & 0.34 & 0.00 & 0.01 & 0.07 & 65.78
\end{tabular}

\begin{tabular}{|c|c|c|c|c|c|c|}
\hline & $\mathrm{CuO}$ & $\mathrm{ZnO}$ & SrO & $\mathrm{ZrO}_{2}$ & $\mathrm{BaO}$ & $\begin{array}{c}\text { Original } \\
\text { total }\end{array}$ \\
\hline & $\mathrm{ppm}$ & $\mathrm{ppm}$ & Ppm & ppm & $\mathrm{ppm}$ & $\%$ \\
\hline $1 \mathrm{~A}$ & 199 & 97 & 18 & 111 & 51 & 96.08 \\
\hline 1B & 111 & 53 & 49 & 161 & 132 & 98.75 \\
\hline $1 \mathrm{C}$ & 80 & 46 & 122 & 179 & 248 & 99.54 \\
\hline
\end{tabular}

Table 6.4.4 (P)ED-XRF compositional data obtained from the samples taken from MNA SB1. Results have been normalised to $100 \%$, and taken from the average of three XRF runs. Only trace elements above $50 \mathrm{ppm}$ or those present in levels above $50 \mathrm{ppm}$ in other samples from the site are shown. Full results are given in appendix $4 \mathrm{~A}$

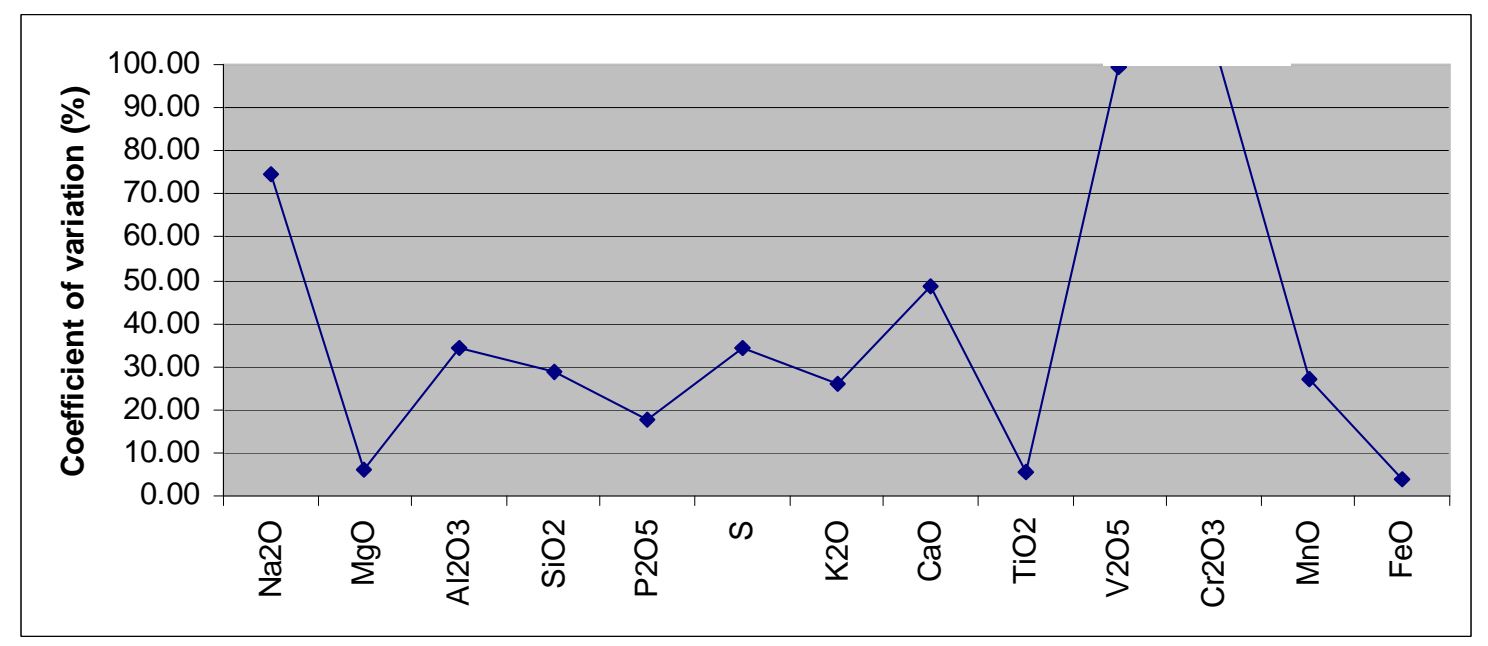

Fig. 6.4.11 MNA SB1 coefficient of variation throughout the block

The bulk chemical results reveal quite significant levels of variation (fig. 6.4.11). As would be expected, the lighter oxides such as soda, and those present in very small amounts such as vanadia and chromium oxide, demonstrate very high levels of variation. Importantly, oxides such as silica (nearly $30 \%$ variation), alumina (over $30 \%$ variation), and lime (nearly 50\% variation), have levels of disparity throughout SB1 which are significant enough to warrant further investigation. The alumina levels are 
nearly double in sample $1 \mathrm{~A}$ in comparison to $1 \mathrm{C}$, the opposite being true for the levels of silica. Furthermore, the levels of potash and lime, key fuel ash components, are significantly higher in the bottom sample of the slag blocks, possibly indicative of an incorporation of fuel ash or plant matter in the slag which initially entered the pit.

In order to investigate whether this variability was generalised at the site, and whether increased fuel ash components were detectable in the bottom of more slag blocks, two further blocks (SB3 and SB5: table 6.4.5) were also analysed using the multi-sample approach (Humphris et al 2009). The results of the XRF analysis from all of the middle samples of the 5 blocks from this site (table 6.4.6) were then considered as an indicator of general smelting parameters at the site. 


\begin{tabular}{cccccccccccccc} 
& Na2O & MgO & Al2O3 & SiO2 & P2O5 & S & K2O & CaO & TiO2 & V2O5 & Cr2O3 & MnO & FeO \\
& $\%$ & $\%$ & $\%$ & $\%$ & $\%$ & $\%$ & $\%$ & $\%$ & $\%$ & $\%$ & $\%$ & $\%$ & $\%$ \\
\hline 1A & 0.05 & 0.32 & 15.38 & 10.93 & 1.20 & 0.09 & 1.29 & 0.66 & 0.31 & 0.05 & 0.11 & 0.04 & 69.52 \\
1B & 0.18 & 0.29 & 9.95 & 13.93 & 1.39 & 0.12 & 1.72 & 1.01 & 0.33 & 0.03 & 0.03 & 0.05 & 70.92 \\
1C & 0.33 & 0.29 & 8.02 & 19.28 & 1.70 & 0.17 & 2.18 & 1.74 & 0.34 & 0.00 & 0.01 & 0.07 & 65.78 \\
\hline 3A & 0.19 & 0.08 & 6.66 & 14.80 & 1.95 & 0.16 & 1.86 & 1.70 & 0.44 & 0.00 & 0.01 & 0.05 & 72.01 \\
3B & 0.23 & 0.11 & 9.00 & 17.06 & 1.60 & 0.14 & 2.16 & 1.78 & 0.49 & 0.02 & 0.01 & 0.05 & 67.27 \\
3C & 0.27 & 0.15 & 7.48 & 20.48 & 2.06 & 0.11 & 2.06 & 1.85 & 0.63 & 0.00 & 0.01 & 0.05 & 64.77 \\
\hline 5A & 0.31 & 0.29 & 16.85 & 20.67 & 0.78 & 0.08 & 2.21 & 0.91 & 0.48 & 0.05 & 0.11 & 0.05 & 57.12 \\
5B & 0.27 & 0.46 & 10.49 & 25.79 & 0.81 & 0.07 & 2.51 & 1.37 & 0.42 & 0.00 & 0.02 & 0.09 & 57.62 \\
5C & 0.43 & 0.27 & 10.83 & 24.07 & 1.96 & 0.10 & 2.29 & 3.30 & 0.57 & 0.00 & 0.02 & 0.10 & 55.94
\end{tabular}

\begin{tabular}{ccccccc} 
& CuO & ZnO & SrO & ZrO2 & BaO & $\begin{array}{c}\text { Original } \\
\text { total } \\
\text { ppm }\end{array}$ \\
ppm & ppm & ppm & ppm & $\%$ \\
\hline 1A & 199 & 97 & 18 & 111 & 51 & 96.08 \\
1B & 111 & 53 & 49 & 161 & 132 & 98.75 \\
1C & 80 & 46 & 122 & 179 & 248 & 99.54 \\
\hline 3A & 137 & 48 & 91 & 210 & 227 & 92.48 \\
3B & 56 & 47 & 108 & 194 & 279 & 93.30 \\
3C & 47 & 56 & 110 & 277 & 327 & 96.14 \\
\hline 5A & 171 & 84 & 63 & 233 & 323 & 92.37 \\
5B & 70 & 35 & 98 & 211 & 330 & 96.47 \\
5C & 75 & 34 & 266 & 327 & 495 & 99.18
\end{tabular}

Table 6.4.5 (P)ED-XRF compositional data obtained from the samples taken throughout SB1, 3 and 5. Results have been normalised to $100 \%$, and taken from the average of three XRF runs. Only trace elements above $50 \mathrm{ppm}$ or those present in levels above $50 \mathrm{ppm}$ in other samples from the site are shown. Full results are given in appendix $4 \mathrm{~A}$

When combined with the information gained from the analysis of the slag samples taken from SB1, the variation both within the MNA blocks and between the blocks is apparent (fig. 6.4.12). 


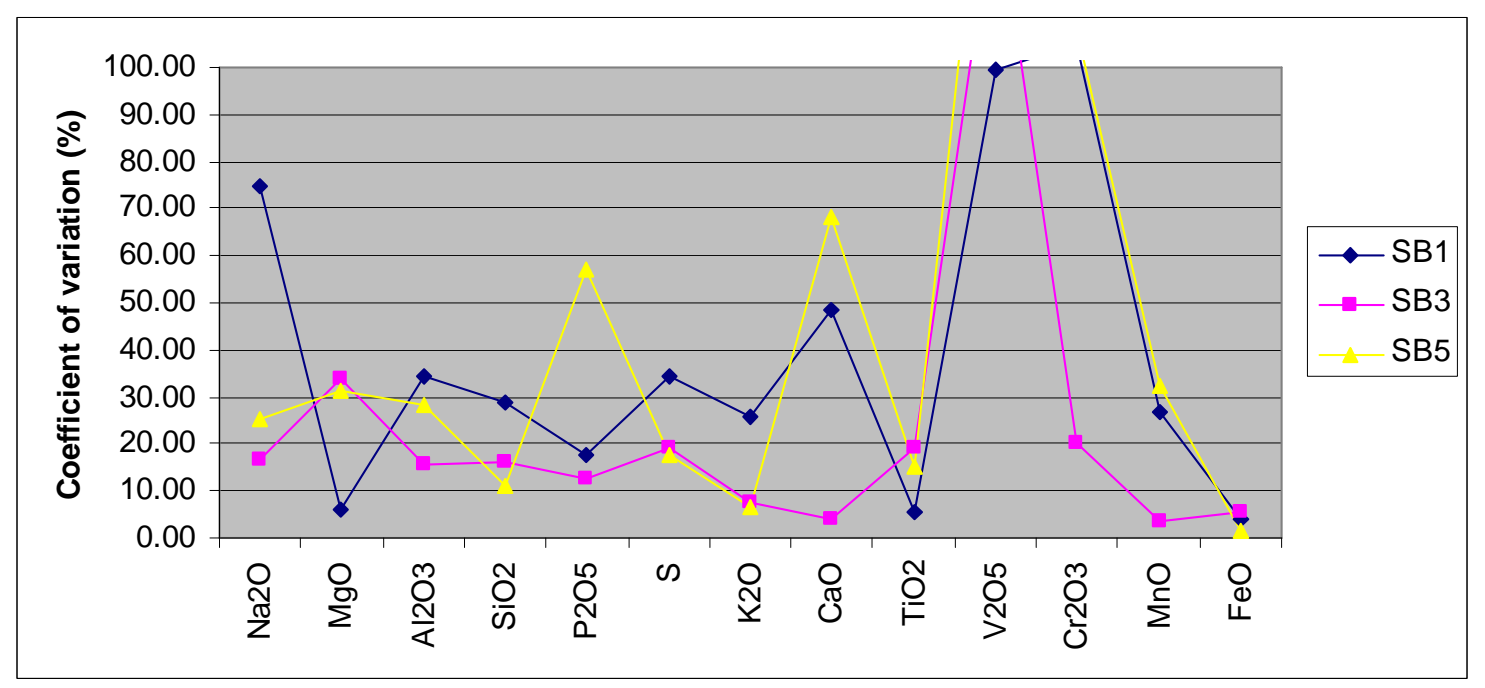

Fig. 6.4.12 Coefficient of variation throughout SB1, SB3 and SB5

At MNA it appears that the slag blocks do display a trend within the main components of iron slag - iron, silica and alumina. Overall the level of iron entering the slag remains fairly constant, with a slight rise towards the end of the smelt, while the silica levels generally decrease, and conversely the alumina levels increase. As would therefore be expected, the alumina to silica ratio throughout the process generally increases. Furthermore, when fuel ash components are examined, there is a general decrease from the beginning to the end of the process (except for sample 3B).

It appears that rather than seeing a decrease in the amount of iron entering the slag blocks during the middle time period when smelting parameters could be considered optimum, instead there is a peak in the iron levels within the blocks during this middle period in SB1 and SB5. However, all three blocks have iron oxide levels at very similar levels throughout each. It also appears that the least amount of iron is lost to the slag during the beginning of the smelt, perhaps when a limited amount of ore is being added to the furnace anyway and, conversely, there is a higher fuel component, perhaps related to furnace preheating. Microscopic examination confirms the heterogeneity within these slag blocks, but indicates that in general, the microstructure is dominated by similar phases, including fayalite, wüstite and kalsilite (fig. 6.4.13). SEM-EDS investigation (fig. 6.4.14) supported this, demonstrating fayalite, iron dominated wüstite, and a kalsilitic phase enriched with potash. 


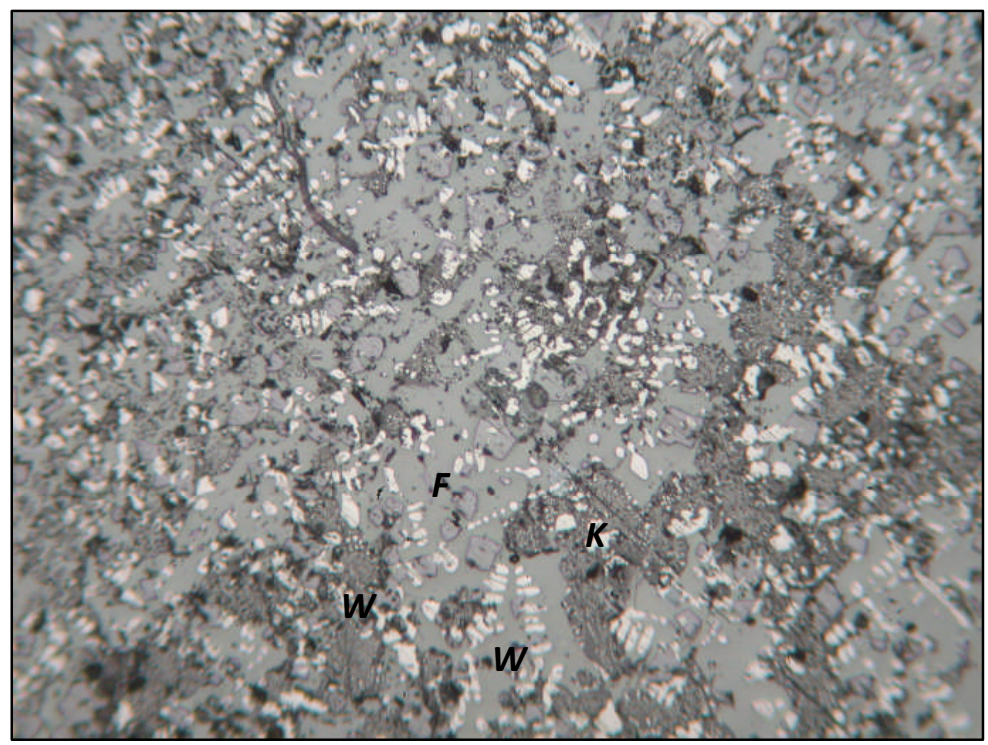

Fig. 6.4.13 PPL photomicrograph of MNA SB1 sample C, dominated by dendrites and blobs of wüstite (W), kalsilite (K), and fayalite (F). 100x, image width $1 \mathrm{~mm}$

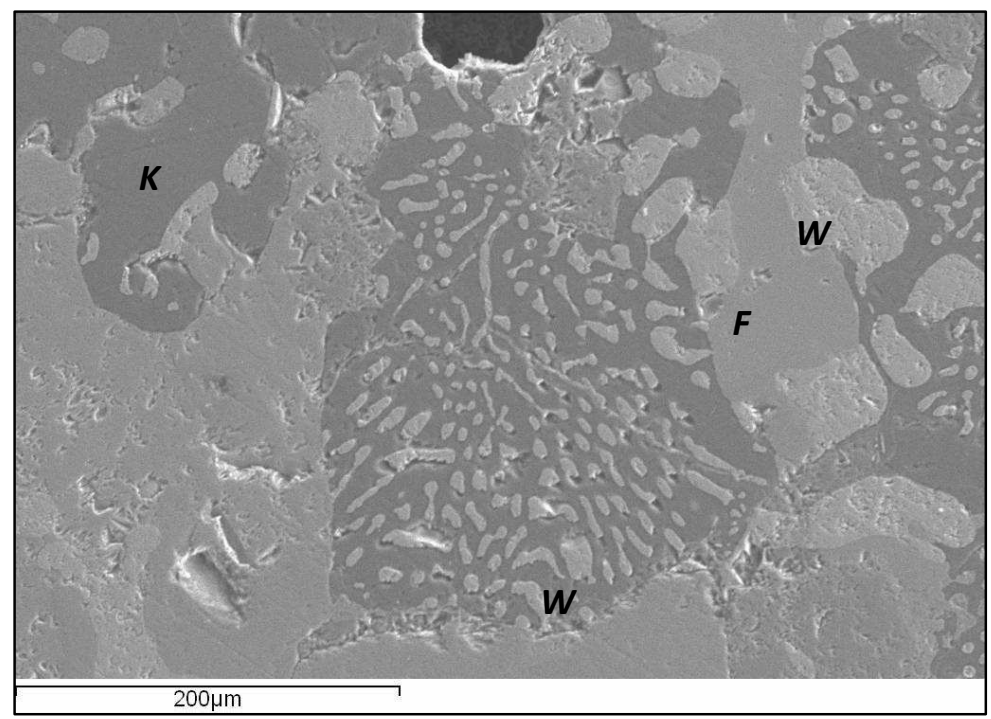

Fig. 6.4.14 SEM SE image of MNA SB2 sample B, illustrating wüstite (W), kalsilite (K), and fayalite (F)

However, considering the large size of the furnaces used at the site, and the particularly wide diameter, the likelihood of smelting parameters staying constant, and slag formation behaving in the same manner from smelt to smelt is minimal. The apparent lack of a particularly standardised methodology or standardised set of ingredients used 
throughout the processes, could therefore be a reflection of furnace design, rather than smelting methodology.

Although the relatively heterogeneous nature of the smelting at MNA has been established, the middle samples of each block can still be used to provide a general understanding of the processes being carried out at the site (table 6.4.6).

$\begin{array}{llllllllllllll} & \begin{array}{l}\mathrm{Na}_{2} \mathbf{O} \\ \%\end{array} & \begin{array}{l}\mathrm{MgO} \\ \%\end{array} & \begin{array}{l}\mathrm{Al}_{2} \mathbf{O}_{3} \\ \%\end{array} & \begin{array}{l}\mathrm{SiO}_{2} \\ \%\end{array} & \begin{array}{l}\mathbf{P}_{2} \mathbf{O}_{5} \\ \%\end{array} & \begin{array}{l}\mathrm{S} \\ \%\end{array} & \begin{array}{l}\mathbf{K}_{2} \mathbf{O} \\ \%\end{array} & \begin{array}{l}\mathrm{CaO} \\ \%\end{array} & \begin{array}{l}\mathrm{TiO}_{2} \\ \%\end{array} & \mathbf{V}_{2} \mathbf{O}_{5} & \mathbf{C r}_{2} \mathbf{O}_{3} & \mathbf{M n O} & \mathbf{F e O} \\ \text { 1B } & 0.18 & 0.29 & 9.95 & 13.93 & 1.39 & 0.12 & 1.72 & 1.01 & 0.33 & 0.03 & 0.03 & 0.05 & 70.92 \\ \text { 2B } & 0.34 & 0.28 & 7.48 & 23.01 & 2.05 & 0.08 & 2.80 & 1.74 & 0.42 & 0.00 & 0.01 & 0.07 & 61.64 \\ \text { 3B } & 0.23 & 0.11 & 9.00 & 17.05 & 1.60 & 0.14 & 2.16 & 1.78 & 0.49 & 0.02 & 0.01 & 0.05 & 67.26 \\ \text { 4B } & 0.14 & 0.28 & 12.92 & 16.48 & 1.73 & 0.06 & 1.96 & 0.93 & 0.76 & 0.04 & 0.05 & 0.07 & 64.52 \\ \text { 5B } & 0.27 & 0.46 & 10.49 & 25.79 & 0.81 & 0.07 & 2.51 & 1.37 & 0.42 & 0.00 & 0.02 & 0.09 & 57.61\end{array}$

\begin{tabular}{cccccccc} 
& $\begin{array}{c}\mathrm{CuO} \\
\mathrm{ppm}\end{array}$ & $\begin{array}{c}\mathrm{ZnO} \\
\mathrm{ppm}\end{array}$ & $\begin{array}{c}\mathrm{SrO} \\
\mathrm{ppm}\end{array}$ & $\begin{array}{c}\mathrm{ZrO}_{2} \\
\mathrm{ppm}\end{array}$ & $\begin{array}{c}\mathrm{BaO} \\
\mathrm{ppm}\end{array}$ & $\begin{array}{l}\mathrm{CeO}_{2} \\
\mathrm{ppm}\end{array}$ & $\begin{array}{l}\text { Original } \\
\text { total }\end{array}$ \\
\hline 1B & 111 & 53 & 49 & 161 & 132 & 34 & 98.75 \\
2B & 64 & 52 & 115 & 227 & 288 & 95 & 99.73 \\
3B & 55 & 47 & 108 & 194 & 279 & 36 & 93.31 \\
4B & 72 & 102 & 56 & 195 & 166 & 41 & 98.40 \\
5B & 70 & 35 & 98 & 211 & 330 & 44 & 96.48
\end{tabular}

Table 6.4.6 (P)ED-XRF compositional data obtained from the samples taken from the middle samples of each block analysed from MNA. Results have been normalised to $100 \%$, and taken from the average of three XRF runs. Only trace elements above $50 \mathrm{ppm}$ or those present in levels above $50 \mathrm{ppm}$ in other samples from the site are shown. Full results are given in appendix $4 \mathrm{~A}$

When plotted in the $\mathrm{FeO}-\mathrm{SiO}_{2}-\mathrm{Al}_{2} \mathrm{O}_{3}$ phase diagram (fig. 6.4.15), it appears that most of the smelting episodes at this site were not particularly ideal, with the slag blocks lying out of the optimum zones for iron reduction and well within the hercynite phase. This suggests a particularly difficult smelt to control and to produce sufficient quantities of iron, due to the higher alumina levels which create a more viscous slag with a higher melting temperature. In general however, the samples plot towards the 'optimum 2' zone (Rehren et al 2007), suggesting relatively less reducing conditions reached within 
the system (possibly due to the large diameter of the furnace, making this very difficult to maintain or control, as mentioned previously).

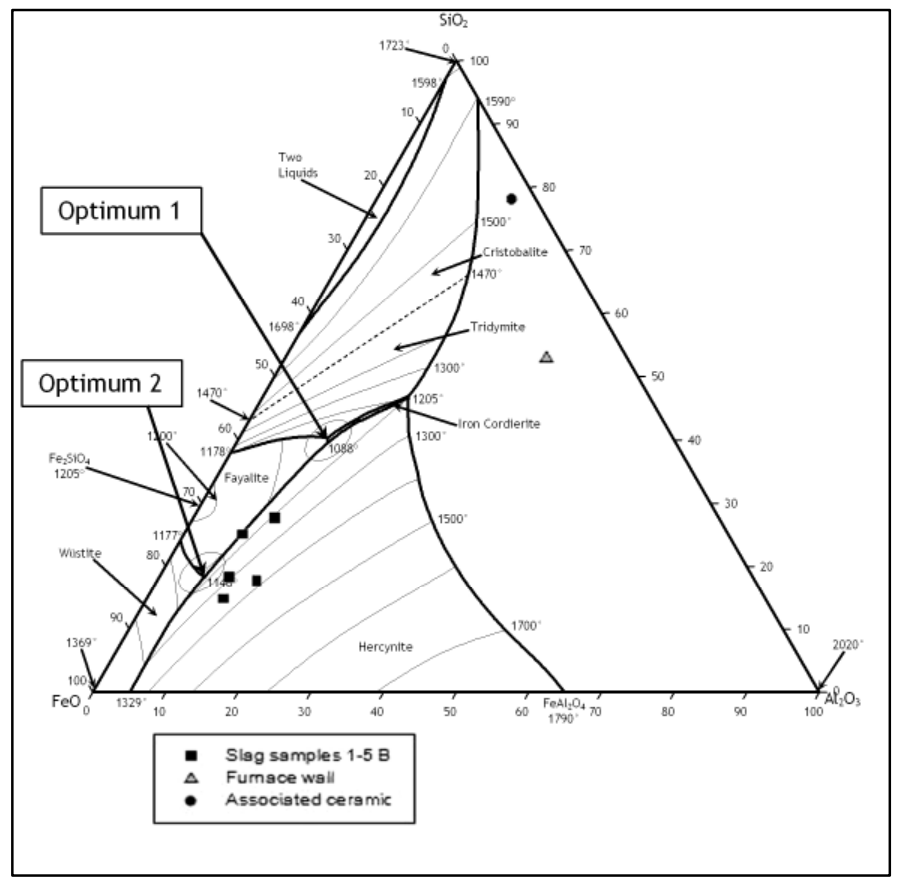

Fig. 6.4.15 $\mathrm{FeO}-\mathrm{SiO}_{2}-\mathrm{Al}_{2} \mathrm{O}_{3}$ phase diagram with the samples taken from MNA plotted (after Rehren et al 2007: 212)

In general, the slag blocks from MNA contain notably high alumina contents (13\% in sample 4B) correspondingly higher alumina to silica ratios (averaging $\approx 1: 2$ ). The relatively high alumina content, which must have entered the slags from the ore, posed technical challenges that may have required smelting parameters to be adjusted more frequently. The position of the samples within the hercynite region of the phase diagram above places them within an area of the system requiring higher operating temperatures, and prone to the formation of alumina-rich phases. Certainly the microscopic examination of these samples indicates a less efficient process, the samples being dominated by unreduced iron oxides such as wüstite (W: fig. 6.4.16), and also by hercynite (H: fig. 6.4.17). 


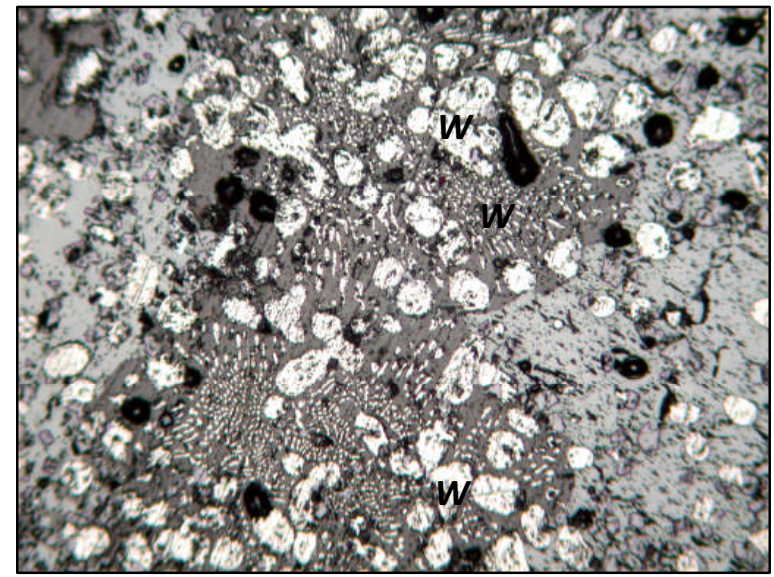

Fig. 6.4.16 PPL image of sample 1B, dominated by wüstite

(100x image width $1 \mathrm{~mm})$

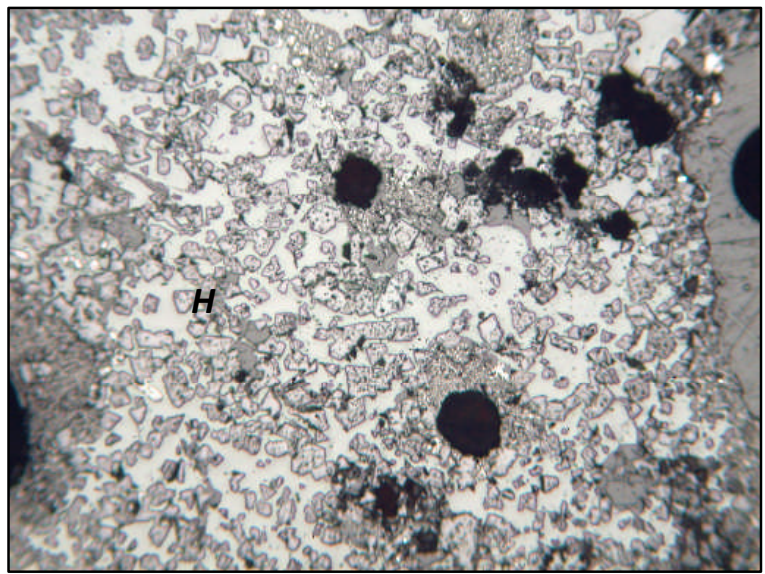

Fig. 6.4.17 PPL image of sample 3B, dominated by now partly corroded hercynite (50x image width $2 \mathrm{~mm})$

Within this pattern of variation, occasionally the smelts seem to have been more successful, for example the smelt which produced SB5. This slag sample has a much more typical bulk chemical composition, and microscopically appears as fayalitic slag with less unreduced iron oxides (fig. 6.4.18).

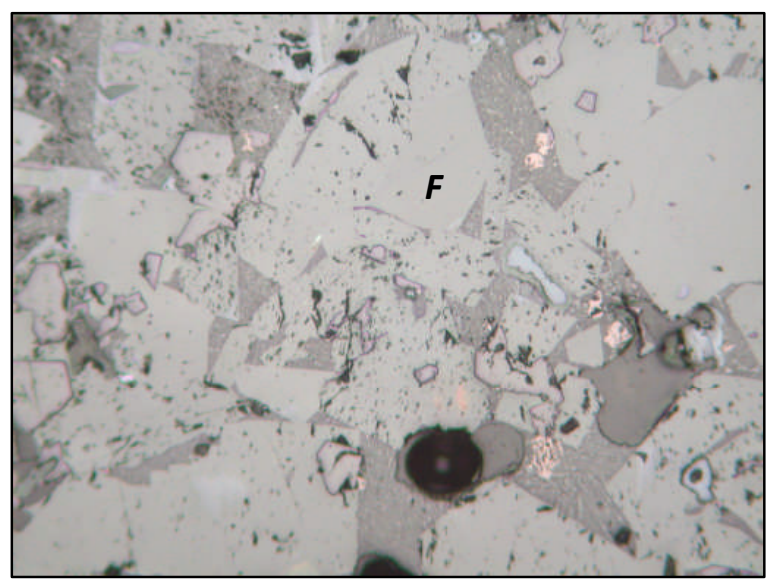

Fig. 6.4.18 PPL image of sample 5B, displaying a much more typical bloomery slag, dominated by blocky fayalite crystals (F), and much less unreduced iron oxide (100x, image width $1 \mathrm{~mm}$ ) 


\section{- Technical ceramics}

The results of the analysis of the ceramics taken from the site (table 6.4.7), indicate firstly that the excavated domestic pottery is certainly very different in composition to the clay fabric used to produce the pit lining, which has a particularly higher alumina content and higher iron oxide content, besides further differences notable in the trace oxides.

\begin{tabular}{cccccccccccccc} 
& $\mathbf{N a}_{2} \mathbf{O}$ & $\mathbf{M g O}$ & $\mathrm{Al}_{2} \mathbf{O}_{3}$ & $\mathbf{S i O}_{2}$ & $\mathbf{P}_{2} \mathbf{O}_{5}$ & $\mathbf{S}$ & $\mathbf{K}_{2} \mathbf{O}$ & $\mathbf{C a O}$ & $\mathbf{T i O}_{2}$ & $\mathbf{V}_{2} \mathbf{O}_{5}$ & $\mathbf{C r}_{2} \mathbf{O}_{3}$ & $\mathbf{M n O}$ & $\mathbf{F e O}$ \\
& $\%$ & $\%$ & $\%$ & $\%$ & $\%$ & $\%$ & $\%$ & $\%$ & $\%$ & $\%$ & $\%$ & $\%$ & $\%$ \\
\hline pit lining & 0.40 & 0.36 & 34.58 & 50.55 & 0.27 & 0.05 & 1.04 & 0.39 & 1.29 & 0.03 & 0.02 & 0.07 & 10.81 \\
excavated pot & 0.40 & 0.20 & 18.20 & 75.62 & 0.12 & 0.03 & 1.03 & 0.20 & 0.63 & 0.01 & 0.03 & 0.03 & 3.32
\end{tabular}

$\begin{array}{ccccccccccc} & \mathbf{C u O} & \mathbf{Z n O} & \mathbf{B r O}_{3} & \mathbf{R b}_{\mathbf{2}} \mathbf{O} & \mathbf{S r O} & \mathbf{Z r O}_{\mathbf{2}} & \mathbf{N b}_{\mathbf{2}} \mathbf{O}_{\mathbf{5}} & \mathbf{B a O} & \mathbf{C e O}_{\mathbf{2}} & \begin{array}{c}\text { Original } \\ \text { total }\end{array} \\ & \mathrm{ppm} & \mathrm{ppm} & \mathrm{ppm} & \mathrm{ppm} & \mathrm{ppm} & \mathrm{ppm} & \mathrm{ppm} & \mathrm{ppm} & \mathrm{ppm} & \% \\ \text { pit lining } & 55 & 102 & 115 & 88 & 83 & 555 & 106 & 225 & 75 & 76.02 \\ \text { excavated pot } & 32 & 50 & 15 & 80 & 45 & 241 & 39 & 230 & 30 & 83.63\end{array}$

Table 6.4.7 (P)ED-XRF compositional data obtained from the ceramics samples taken from MNA. Results have been normalised to $100 \%$, and taken from the average of three XRF runs. Only trace elements above $50 \mathrm{ppm}$ or those present in levels above $50 \mathrm{ppm}$ in other samples from the site are shown. Full results are given in appendix 4B

Despite its low overall silica content, the fabric of the pit lining appears to have a quartz content, which often appears shattered, most likely due to thermal stress. The pit lining also showed areas of round bloating pores, again the result of higher temperatures on the material (fig. 6.4.19). Due to the refractory nature of the ceramics (indicated by the high alumina levels), this furnace was able to operate at particularly higher temperatures (seen in the position of plots on the phase diagram above). This caused the ceramic to vitrify despite its heat resistant nature. 


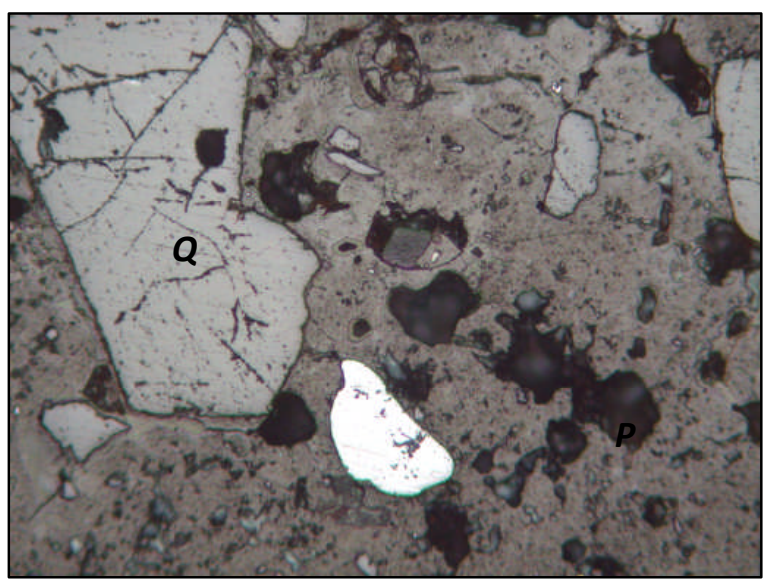

Fig. 6.4.19 PPL image of a sample of pit lining from f1, illustrating cracked quartz (Q), and areas of round porosity $(\mathrm{P})(100 \mathrm{x}$, image width $1 \mathrm{~mm})$

\subsubsection{Site interpretation}

Unfortunately no date was obtained for the smelting practices at MNA due to the reasons outlined in chapter 5. Before the dates for the $\mathrm{CMZ}$ sites were obtained, it was wrongly assumed that all sites characterised by industrial level production (requiring significant labour and resource co-ordination), would be dated to the Kingdom period. This theory has now been proved wrong, and based on general similarities, the site of MNA could date to the Middle Iron Age, and be contemporary to the CMZ sites. It is, however, known that during the Kingdom era and at the time of colonial contact, iron production was practised on a large scale in pit furnaces across the region (Celis 1987). Unfortunately, whether or not the site of MNA dates to these later times or to the middle period is not a question that can currently be answered.

In terms of quantifying the iron production processes at MNA, the average weight of the blocks investigated at MNA was $147 \mathrm{~kg}$ (again not including the broken slag blocks). Rather than assuming a particularly high grade ore, a medium quality ore provides a very tentative quantification: 


\begin{tabular}{l|l} 
Average weight of blocks & $147 \mathrm{~kg}$ \\
\hline blocks observed at the site & 12 \\
\hline Approximate quantity of slag at the site & $1764 \mathrm{~kg}$ \\
\hline Approximate slag content & $65 \%$ iron oxide, $35 \%$ other \\
\hline $\begin{array}{l}\text { Iron produced by smelting medium quality } \\
\text { ore (80 \% iron oxide) }\end{array}$ & Approximately $\mathbf{1 0 2 3} \mathbf{~ k g}$
\end{tabular}

Initially it could be suggested that the slag blocks at MNA represent a less efficient and less controlled iron production process than that seen at the $\mathrm{CMZ}$ sites, and this initially seems to be a reflection of the artisans choice of furnace construction. Not only at MNA but within the immediate locality the smelters were constructing particularly wide furnaces, which led to a diminished reducing atmosphere during the smelts (a wider diameter making it harder to control the temperatures and redox conditions, as well as the fuel to ore ratio throughout the furnace). However, a large furnace would encourage a better chimney, or stack, effect, facilitating the particularly high temperatures required to smelt this alumina-rich ore. Of course a side effect of this would be more difficulties in adjusting and maintaining redox conditions, ore to fuel ratios, and temperatures, resulting in the variation seen in the slag blocks. Perhaps the smelters operating around the site of MNA realised the advantages of such a technical style, and used this to their advantage. 


\subsection{Kamana (KMA)}

\subsubsection{Site description and observations}

Kamana (KMA) lies in the northern region of the survey zone, approximately $7 \mathrm{~km}$ from the locations mentioned so far. The site is very close to the ridge of the hill, and has spectacular views west into the valley below (fig. 6.5.1). The archaeological remains were easily spotted during the survey as the site lies by the side of a road. Immediately noticeable were four small clusters of slag blocks piled in front of the three houses at the site (fig. 6.5.2). The very faint outline of one furnace pit (f1 - fig. 6.5.3) was observed at the edge of the road, while the broken remains of one further furnace pit (f2) were also recorded. Two groups of slag blocks were observed at this site. The first (incorporating SB1-5) represented the same furnace pit smelting seen at the CMZ sites and at MNA. The second were much smaller blocks displaying a distinct flow-like and layered texture effect, as will be described later. On closer inspection it was realised that the foundation of the houses themselves were constructed in part with slag blocks. Furthermore, also incorporated into the house foundations were grinding stones, suggesting from the outset that this site had a significant past involving both metallurgy and agriculture (fig. 6.5.4). Behind the houses is a large banana plantation, within which were discovered two further clusters of slag blocks. 


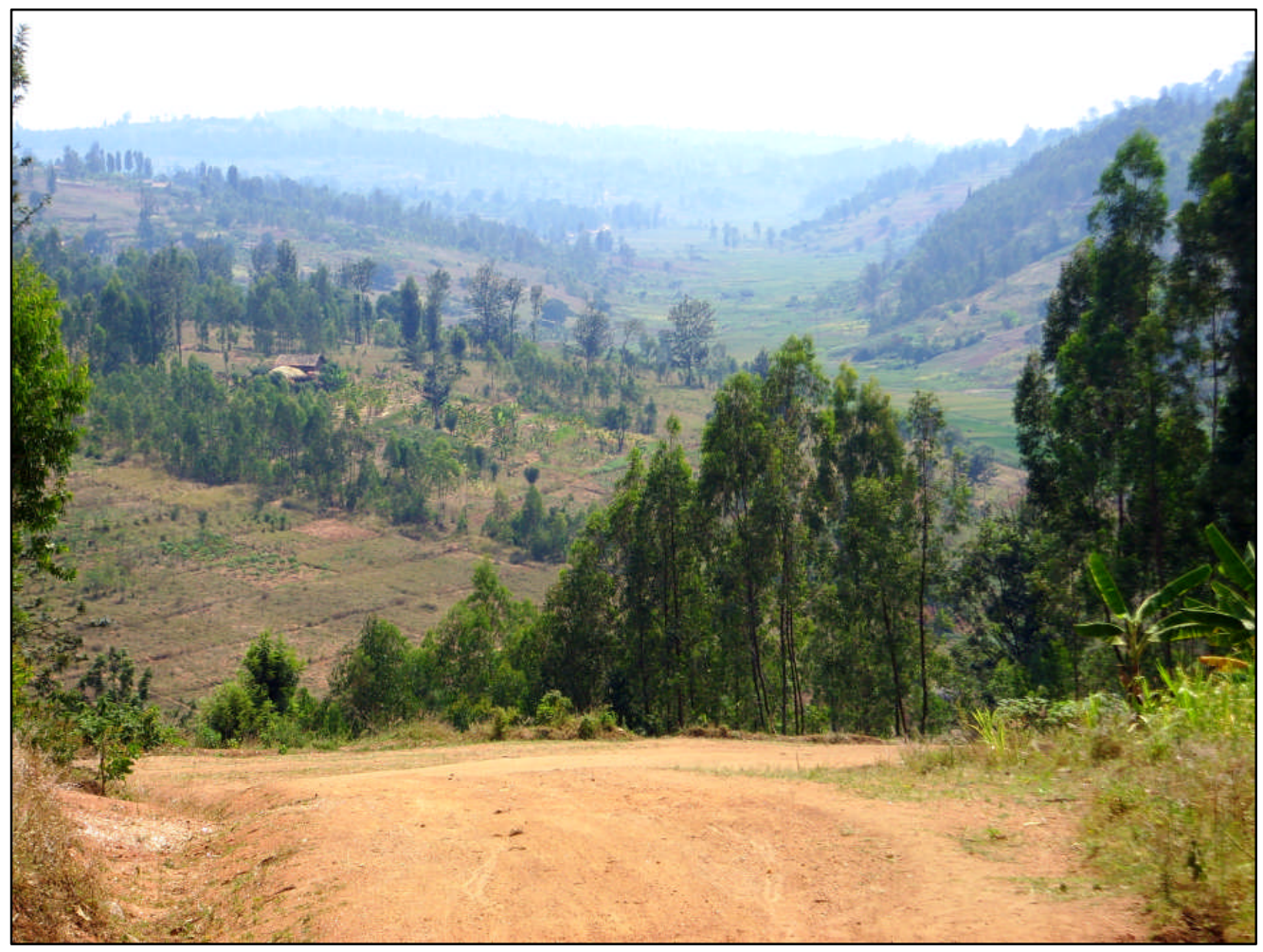

Fig. 6.5.1 View looking west from the site of KMA

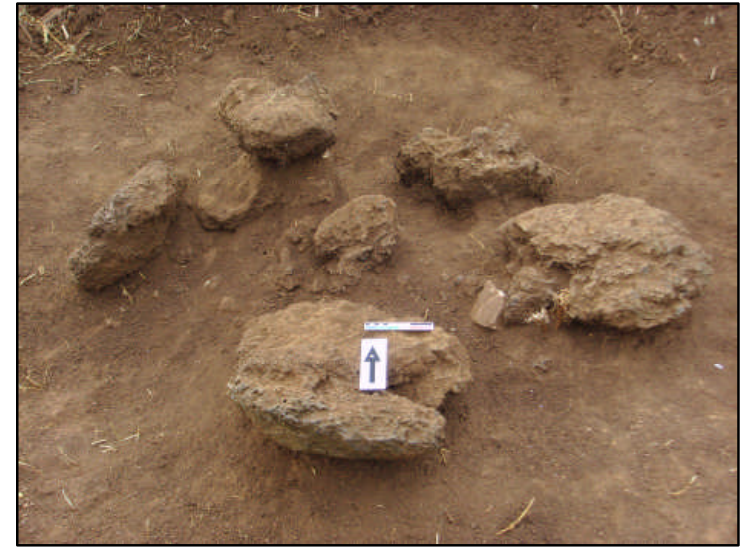

Fig. 6.5.2 KMA cluster 1 of slag blocks

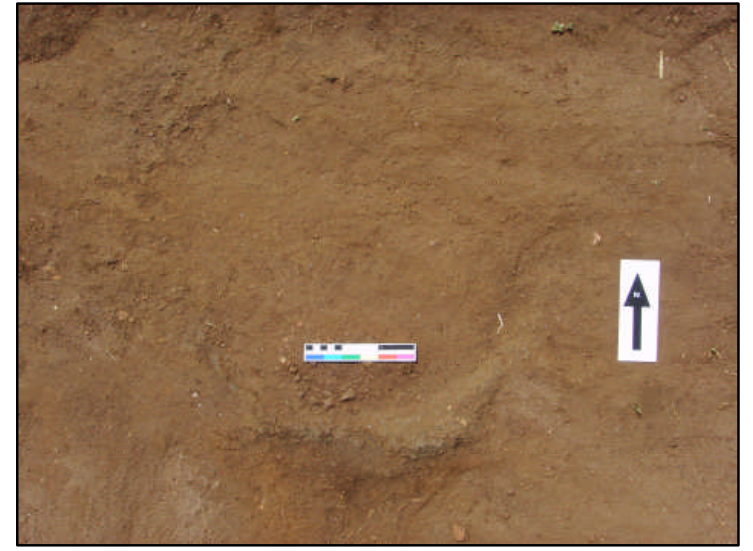

Fig. 6.5.3 KMA f1 before excavation 

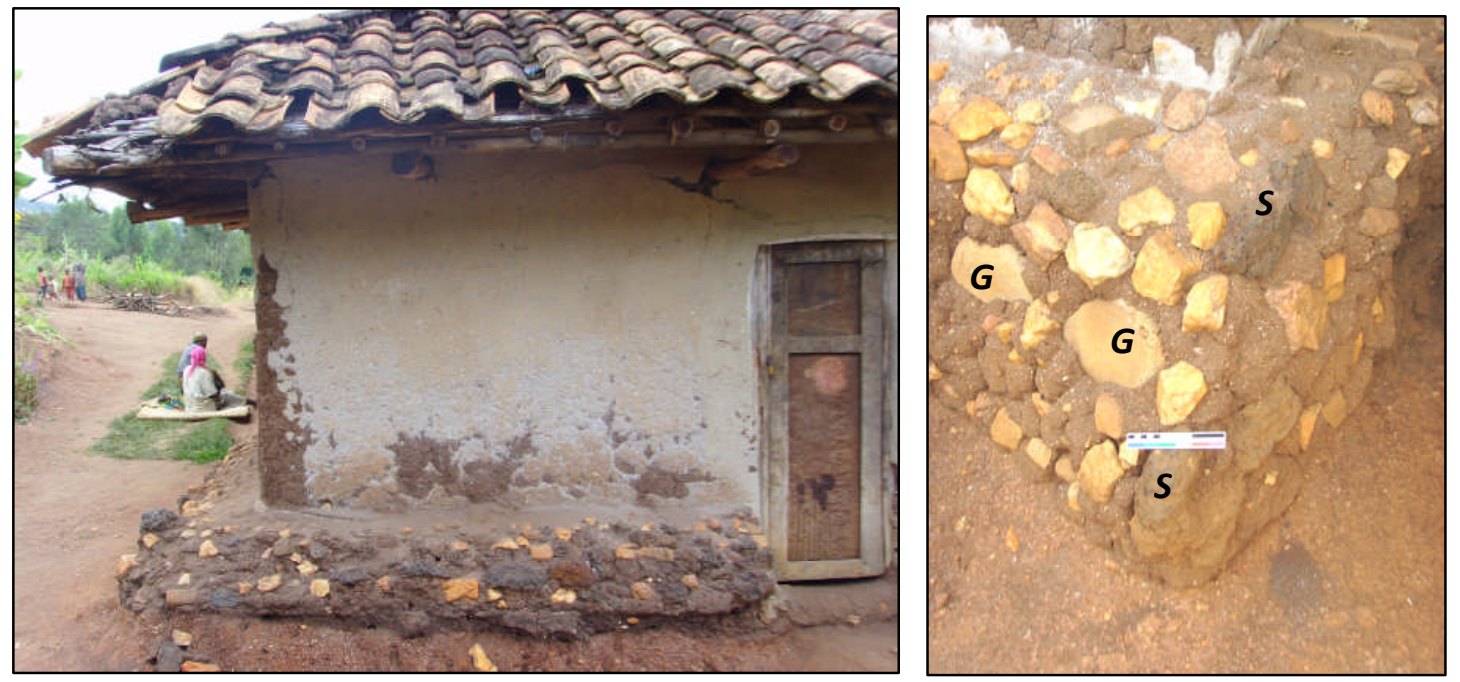

Fig.6.5.4 House foundations at KMA constructed with small, layered slag blocks (S), and grinding stones (G)

Leaving aside the small layered slag blocks (discussed later), four blocks were selected for detailed investigation from within slag cluster one, in front of the houses (SB1-4). A further, macroscopically identical block (SB5), was chosen in another cluster approximately $20 \mathrm{~m}$ away (within the banana plantation at the back of the house. It is believed that the clusters of large blocks are the result of the blocks being piled up recently for convenience by those living on the land, rather than representing the exact locations of past iron production activity. However the extent of the clusters does give an insight into the fact that a significant amount of smelting was carried out in the past at this site. As at all of the other sites investigated during this research, the land owners had no memories relating to past metallurgical activity.

The slag blocks themselves were all circular in plan and conical in section, with rough tops and smoother, furnace pit shaped bottoms. The main difference between the blocks across the site were the overall dimensions (table 6.5.1), although mainly this was the result of the broken nature of some of the blocks, which had fragments broken off from around the edges. 


\begin{tabular}{cccc} 
Slag block & Diameter $(\mathbf{c m})$ & Depth $(\mathbf{c m})$ & Weight $(\mathbf{k g})$ \\
\hline 1 & 53 & 22 & 42.5 \\
2 & 67 & 35 & 61 \\
3 & 60 & 29 & 79.5 \\
4 & 55 & 30 & 67 \\
5 & 54 & 30 & 71.5
\end{tabular}

Table 6.5.1 Dimensions of the slag blocks selected for detailed analysis at KMA

KMA $\mathrm{f} 1 \mathrm{had}$ a north-south diameter of $65 \mathrm{~cm}$ and an east-west diameter of $62 \mathrm{~cm}$ at ground level. Even before excavation, it was clear that its position on the sloping camber of the road had allowed silt to wash into the pit, and the fill was obviously very disturbed. KMA f2 was only identifiable from the chunks of furnace pit lining that were piled up approximately $10 \mathrm{~m}$ to the east of KMA f1, just to the side of the road. This furnace pit was not complete, and it appeared to have been destroyed when the road was built.

Two test pits were excavated at KMA. The first (tp1) was situated 3 m north of the remains of $\mathrm{f} 2$, located on an area of land thought to be reasonably undisturbed by cultivation. The second (tp2) was slightly to the north of the cluster of slag blocks within which SB5 was located (fig. 6.5.5). 


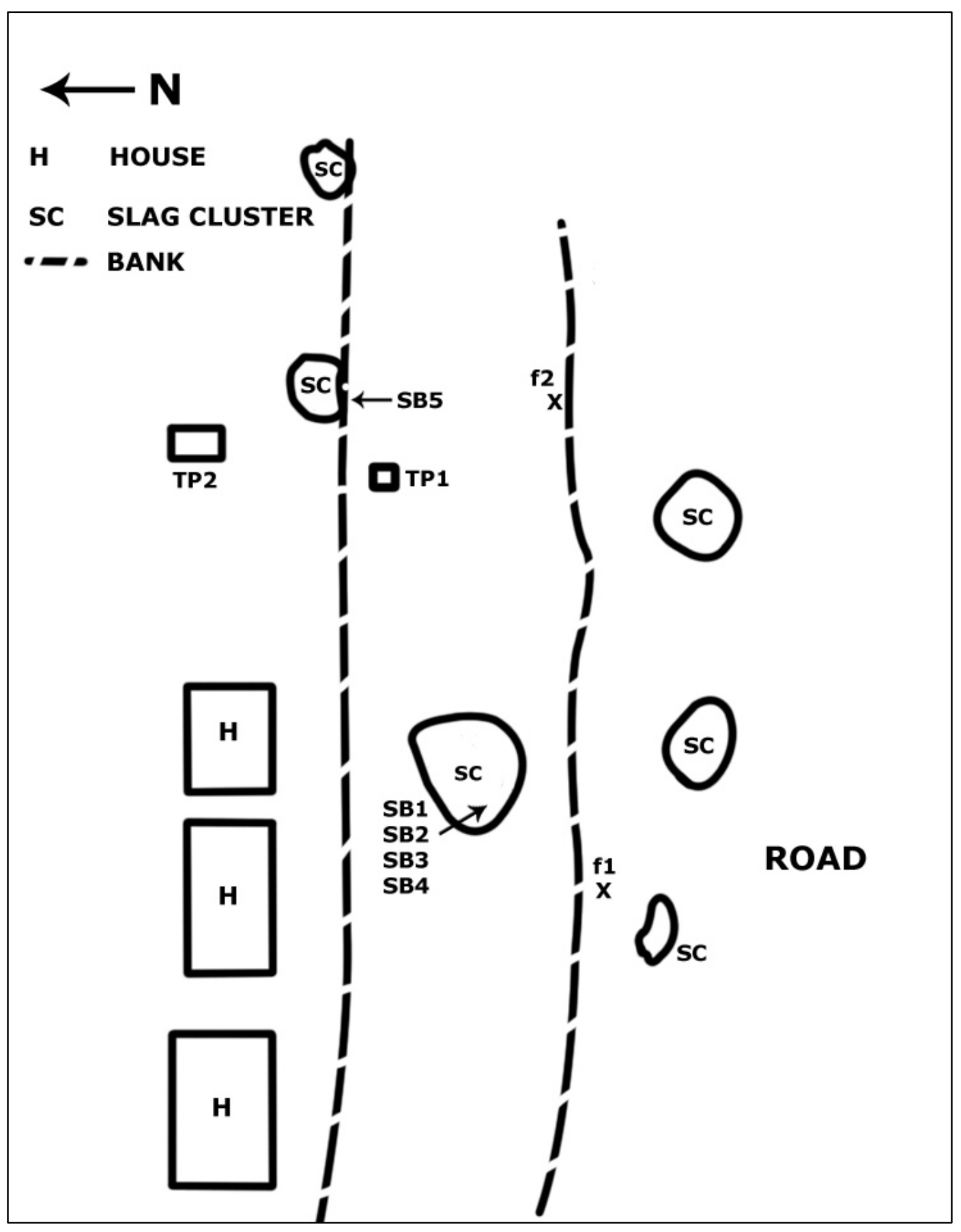

Fig. 6.5.5 Plan of the site of KMA (not to scale) 


\subsubsection{Excavations and sample selection}

\section{- Slag blocks}

Following the established methodology, one slag block (SB5) had three samples analysed to test the level of homogeneity throughout the block, while the other slag blocks only had the middle sample analysed (table 6.5.2). A further slag sample was taken from slag cluster one (sample $\mathrm{SC} 1$ ), as macroscopically it was very dissimilar to the larger blocks. This slag was a small cake with a layered structure, more comparable to the blocks identified within the foundations of the house (fig. 6.5.6).

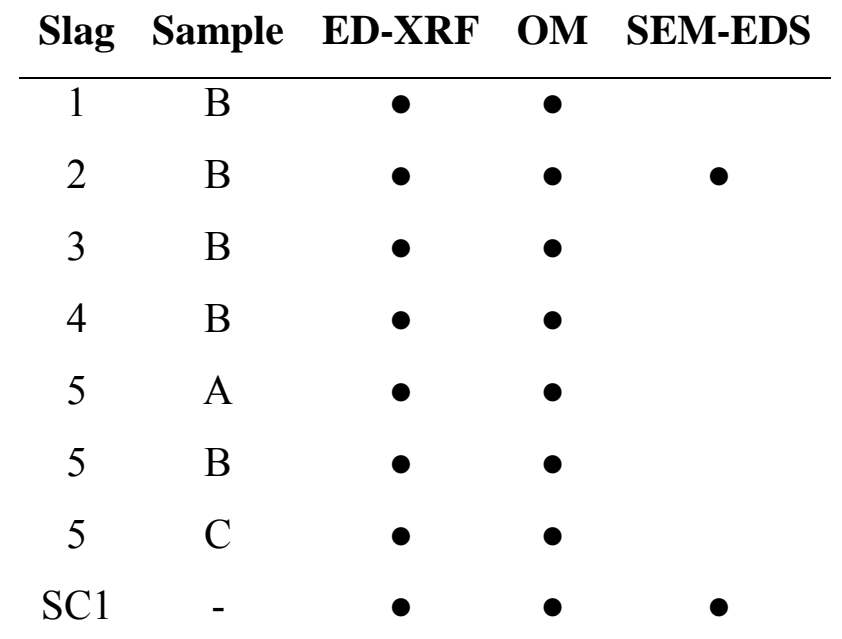

Table 6.5.2 Slag samples analysed from KMA

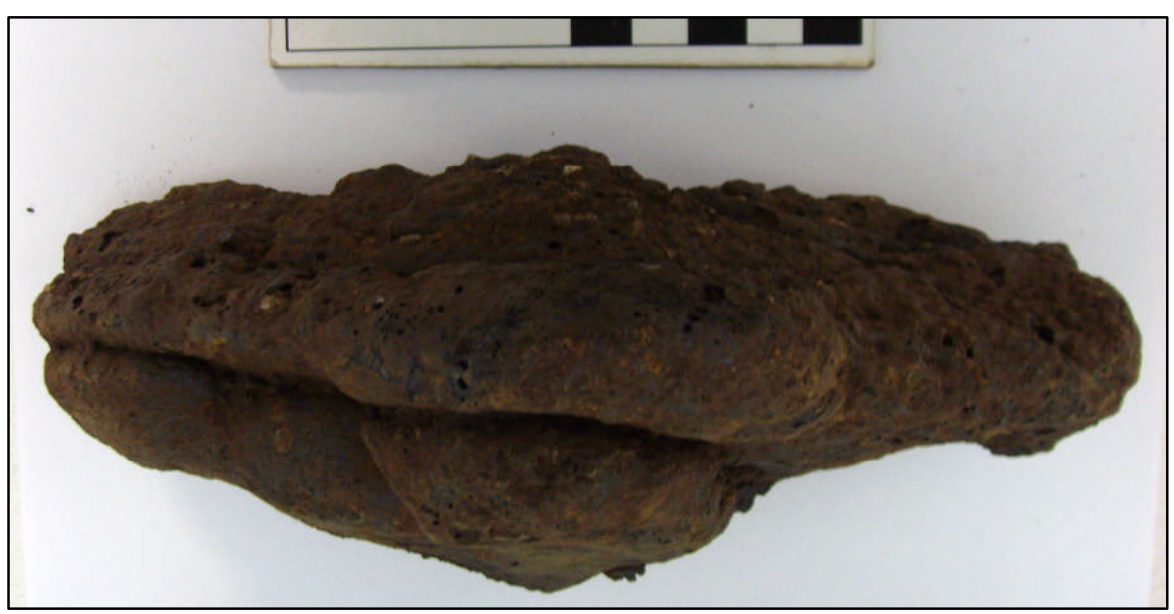

Fig. 6.5.6 KMA SC1 


\section{- KMA furnaces}

Throughout the excavation of $\mathrm{f} 1$ the pit-fill contained gravel washed in from the road thus it can be said for certain that the remains were completely contaminated. Small pieces of slag were found intermittently throughout the pit fill, although none of these pieces were selected for analysis due to their arbitrary nature. The furnace pit was much shallower than any of the slag blocks recorded at the site (at only $10 \mathrm{~cm}$ deep), demonstrating the level of erosion suffered by the pit due to its location on the road (having been walked on, driven and cycled over for years). The pit lining was $5 \mathrm{~cm}$ thick throughout (fig. 6.5.7). As mentioned, the remains of $\mathrm{f} 2$ were only distinguishable by the presence of the broken pieces of the pit lining (fig. 6.5.8). While the lining was very similar in appearance and thickness to that of 1 , the original size and exact location of the furnace is unknown. However, samples of the pit lining were still taken for comparative analysis (table 6.5.3).

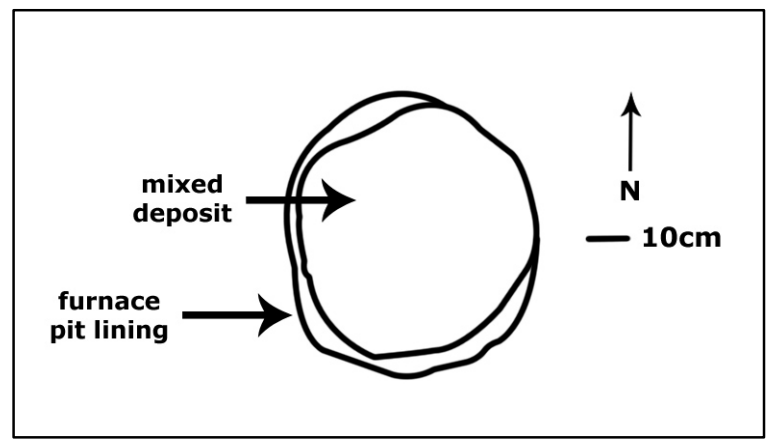

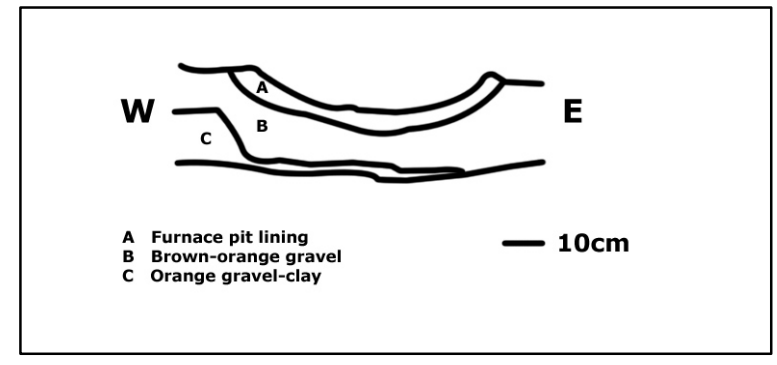

Fig. 6.5.7 KMA f1 plan (top) and section (bottom)

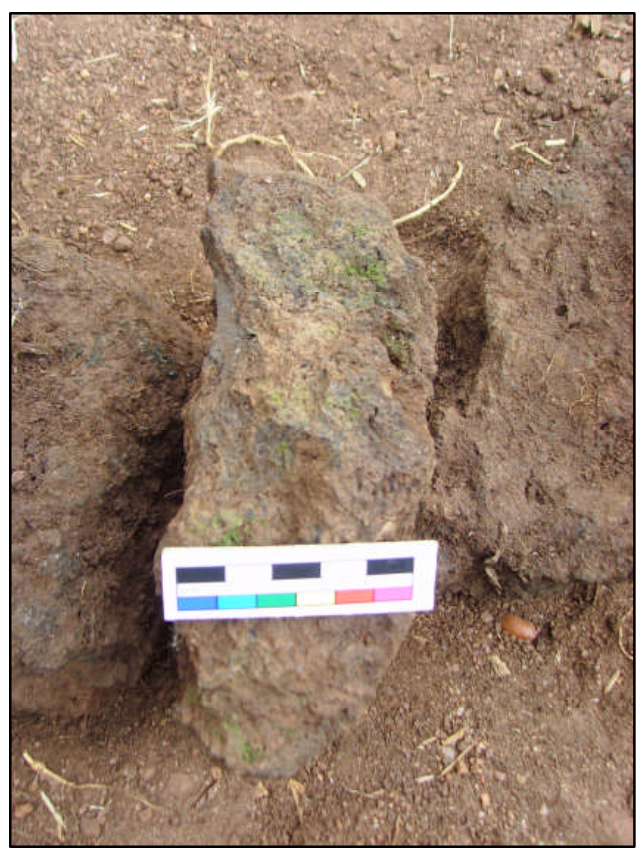

Fig. 6.5.8 KMA f2 pit lining fragment 


\begin{tabular}{ccc} 
Sample & ED-XRF & OM \\
\hline f1: pit lining & $\bullet$ & $\bullet$ \\
f2: pit lining & $\bullet$ & $\bullet$
\end{tabular}

Table 6.5.3 Ceramics taken for analysis from KMA

\section{- Test Pits}

Tp1 was found to contain a mixed cultivation layer above sterile orange clay. Tp2 however, proved to be the only successful test excavation unit of the entire project. Although no stratigraphically contained archaeology was found in tp2, a number of small slag fragments which appeared on a macroscopic level to be smithing cakes (due to their plano-concave/convex shape), were located at a depth of $50 \mathrm{~cm}$ below ground level. One of these slag cakes was taken for analysis (fig. 6.5.9; sample tp2:1). This test pit was extended and excavated until it was absolutely clear that these finds were not contained within an archaeological horizon, and instead were isolated finds (fig. 6.5.10).

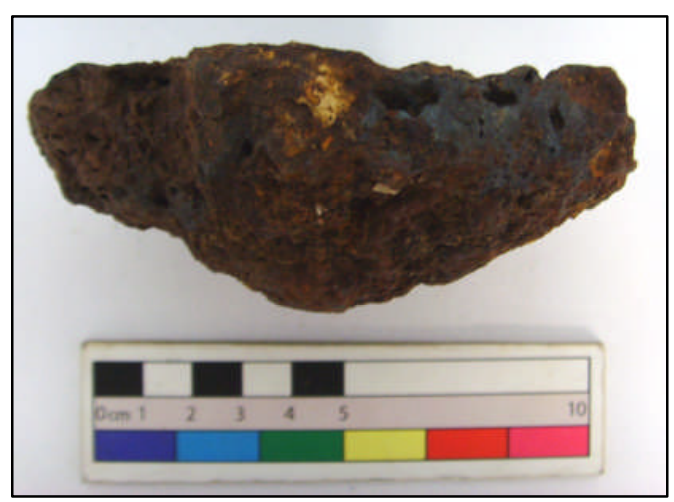

Fig. 6.5.9 Possible smithing cake excavated in tp2

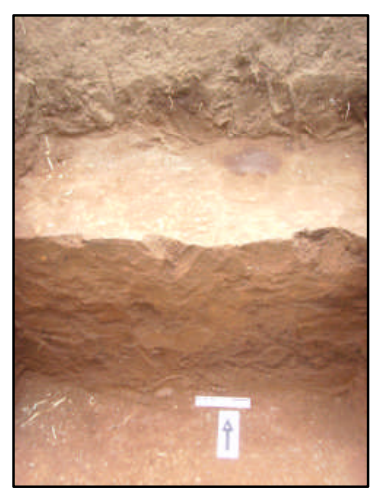

Fig. 6.5.10 Sterile tp2 


\subsubsection{Results}

\section{- Slag Blocks}

The level of homogeneity within SB5 was tested (table 6.5.4; fig. 6.5.11).

\begin{tabular}{cccccccccccccc} 
& $\mathbf{N a}_{2} \mathbf{O}$ & $\mathbf{M g O}$ & $\mathrm{Al}_{2} \mathbf{O}_{3}$ & $\mathbf{S i O}_{2}$ & $\mathbf{P}_{2} \mathbf{O}_{5}$ & $\mathbf{S}$ & $\mathbf{K}_{2} \mathbf{O}$ & $\mathbf{C a O}$ & $\mathbf{T i O}_{2}$ & $\mathbf{V}_{2} \mathbf{O}_{5}$ & $\mathbf{C r}_{2} \mathbf{O}_{3}$ & $\mathbf{M n O}$ & $\mathbf{F e O}$ \\
& $\%$ & $\%$ & $\%$ & $\%$ & $\%$ & $\%$ & $\%$ & $\%$ & $\%$ & $\%$ & $\%$ & $\%$ & $\%$ \\
\hline $5 \mathrm{~A}$ & 0.20 & 0.21 & 7.97 & 16.67 & 2.25 & 0.08 & 2.20 & 1.40 & 0.25 & 0.01 & 0.02 & 0.14 & 68.53 \\
$5 \mathrm{~B}$ & 0.10 & 0.17 & 8.29 & 13.78 & 1.92 & 0.12 & 1.88 & 1.37 & 0.27 & 0.02 & 0.03 & 0.16 & 71.82 \\
$5 \mathrm{C}$ & 0.26 & 0.28 & 7.71 & 17.61 & 2.66 & 0.08 & 2.69 & 2.02 & 0.23 & 0.00 & 0.01 & 0.10 & 66.25
\end{tabular}

\begin{tabular}{|c|c|c|c|c|c|c|c|}
\hline & $\mathrm{CuO}$ & SrO & $\mathrm{Y}_{2} \mathrm{O}_{3}$ & $\mathrm{ZrO}_{2}$ & $\mathrm{BaO}$ & $\mathrm{CeO}_{2}$ & $\begin{array}{c}\text { Original } \\
\text { total }\end{array}$ \\
\hline & ppm & ppm & ppm & ppm & ppm & ppm & $\%$ \\
\hline $5 \mathrm{~A}$ & 46 & 125 & 65 & 119 & 429 & 79 & 101.85 \\
\hline $5 B$ & 80 & 118 & 54 & 113 & 339 & 48 & 97.40 \\
\hline $5 \mathrm{C}$ & 63 & 185 & 70 & 122 & 439 & 69 & 107.27 \\
\hline
\end{tabular}

Table 6.5.4 (P)ED-XRF compositional data obtained from the samples taken from KMA SB5. Results have been normalised to $100 \%$, and taken from the average of three XRF runs. Only trace elements above 50 ppm are shown. Full results are given in appendix 5A

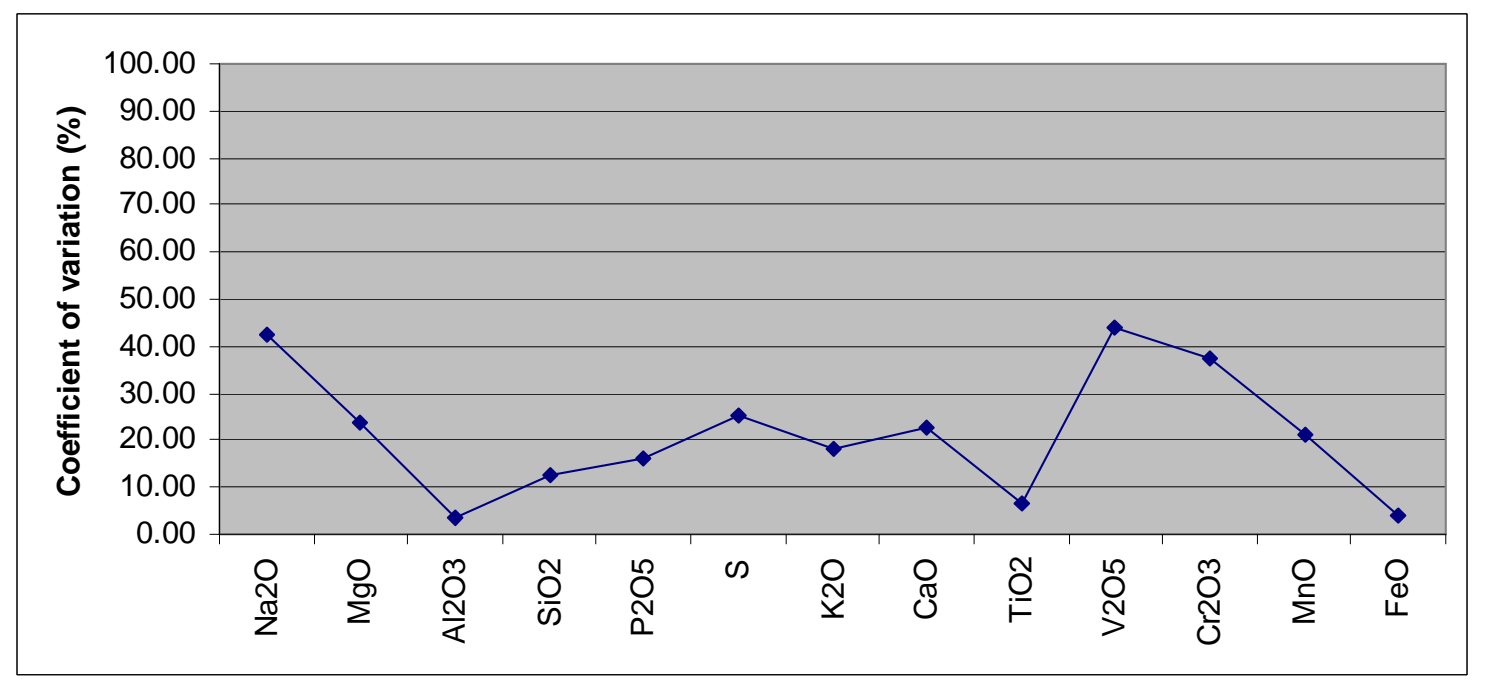

Fig. 6.5.11 The coefficient of variation (\%) within each oxide throughout KMA SB5 
The analysis of KMA SB5 revealed relatively low internal variation, with coefficients of variations for iron oxide and alumina lower than $5 \%$, and for silica lower than $15 \%$. Optical photomicrographs (fig. 6.5.12, fig. 6.5.13, fig 6.5.14), also illustrate the general level of homogeneity throughout this slag block, with the samples dominated largely by blocky fayalite (F), blobs of wüstite (W) and areas of eutectic wüstite (EW) in an alkalirich matrix. However, in spite of the low fluctuation, it was possible to notice some interesting correlations between oxides. Iron oxide, alumina, manganese oxide and titania all peak in the middle of the block (therefore entering the slag in greater quantities during the middle period of the smelt), and are all likely to be ore related. The opposite behaviour is noted in magnesia, silica, phosphate, potash and lime, which all show lower values during the middle period of the smelt, and are all likely to be influenced by the contribution of fuel ash or technical ceramics into the slag.

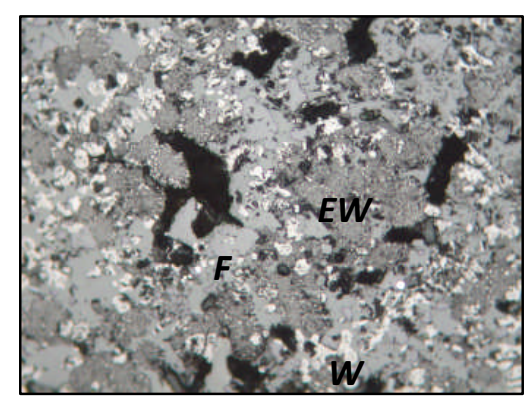

Fig. 6.5.12

PPL photomicrograph of sample KMA SB5 sample C, produced at the beginning of the smelt $(100 x$, image width $1 \mathrm{~mm}$ )

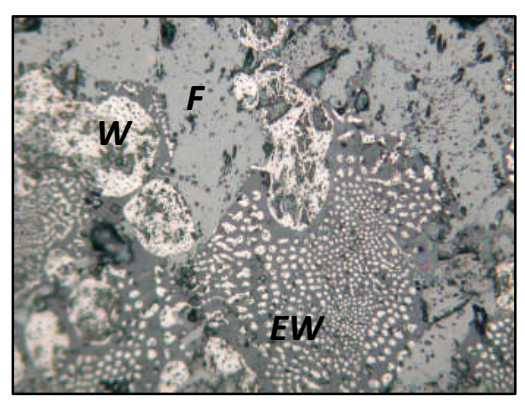

Fig. 6.5.13

PPL photomicrograph of sample KMA SB5 sample B, produced during the middle of the smelt (200x, image width $0.5 \mathrm{~mm}$ )

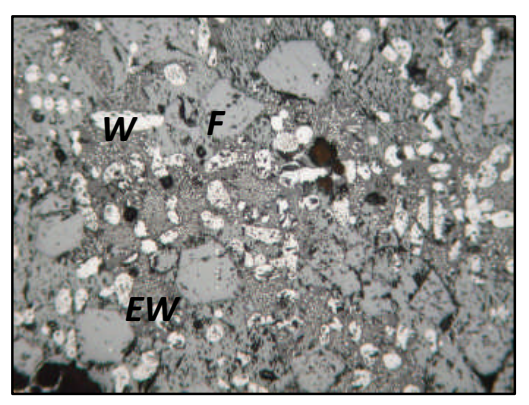

Fig. 6.5.14

PPL photomicrograph of sample KMA SB5 sample A, produced at the end of the smelt (100x, image width $1 \mathrm{~mm}$ )

Given the general levels of homogeneity noted, it was deemed that the middle sample of each block could be used to represent the overall smelting event in each case. However, in light of the interesting compositional trends noted above, two further blocks were investigated from top to bottom, to determine whether the oxide correlations and compositional profiles constituted a pattern (table 6.5.5; fig. 6.5.15). 


\begin{tabular}{cccccccccccccc} 
& $\mathrm{Na}_{2} \mathbf{O}$ & $\mathbf{M g O}$ & $\mathrm{Al}_{2} \mathbf{O}_{3}$ & $\mathbf{S i O}_{2}$ & $\mathbf{P}_{2} \mathbf{O}_{5}$ & $\mathbf{S}$ & $\mathbf{K}_{2} \mathbf{O}$ & $\mathbf{C a O}$ & $\mathbf{T i O}_{2}$ & $\mathbf{V}_{2} \mathbf{O}_{5}$ & $\mathbf{C r}_{2} \mathbf{O}_{3}$ & $\mathbf{M n O}$ & $\mathbf{F e O}$ \\
& $\%$ & $\%$ & $\%$ & $\%$ & $\%$ & $\%$ & $\%$ & $\%$ & $\%$ & $\%$ & $\%$ & $\%$ & $\%$ \\
\hline 2A & 0.24 & 0.11 & 8.64 & 15.00 & 2.35 & 0.10 & 1.27 & 1.43 & 0.15 & 0.01 & 0.02 & 0.23 & 70.35 \\
2B & 0.08 & 0.09 & 7.41 & 14.82 & 1.87 & 0.08 & 1.29 & 1.18 & 0.15 & 0.01 & 0.02 & 0.20 & 72.72 \\
2C & 0.36 & 0.17 & 7.61 & 18.42 & 3.24 & 0.07 & 1.47 & 2.27 & 0.16 & 0.00 & 0.02 & 0.28 & 65.80 \\
\hline 4A & 0.18 & 0.18 & 11.83 & 13.69 & 2.58 & 0.08 & 1.68 & 1.49 & 0.12 & 0.01 & 0.08 & 0.29 & 67.66 \\
4B & 0.29 & 0.18 & 7.48 & 20.37 & 2.69 & 0.06 & 2.32 & 1.90 & 0.17 & 0.00 & 0.01 & 0.35 & 64.03 \\
4C & 0.36 & 0.19 & 9.11 & 19.33 & 2.74 & 0.06 & 3.06 & 2.02 & 0.15 & 0.00 & 0.02 & 0.37 & 62.46 \\
\hline 5A & 0.20 & 0.21 & 7.97 & 16.67 & 2.25 & 0.08 & 2.20 & 1.40 & 0.25 & 0.01 & 0.02 & 0.14 & 68.53 \\
5B & 0.10 & 0.17 & 8.29 & 13.78 & 1.92 & 0.12 & 1.88 & 1.37 & 0.27 & 0.02 & 0.03 & 0.16 & 71.82 \\
5C & 0.26 & 0.28 & 7.71 & 17.61 & 2.66 & 0.08 & 2.69 & 2.02 & 0.23 & 0.02 & 0.01 & 0.10 & 66.25
\end{tabular}

Table 6.5.5 (P)ED-XRF compositional data obtained from the samples taken from KMA SB2, SB4 and SB5. Results have been normalised to $100 \%$, and taken from the average of three XRF runs. Full results are given in appendix 5A

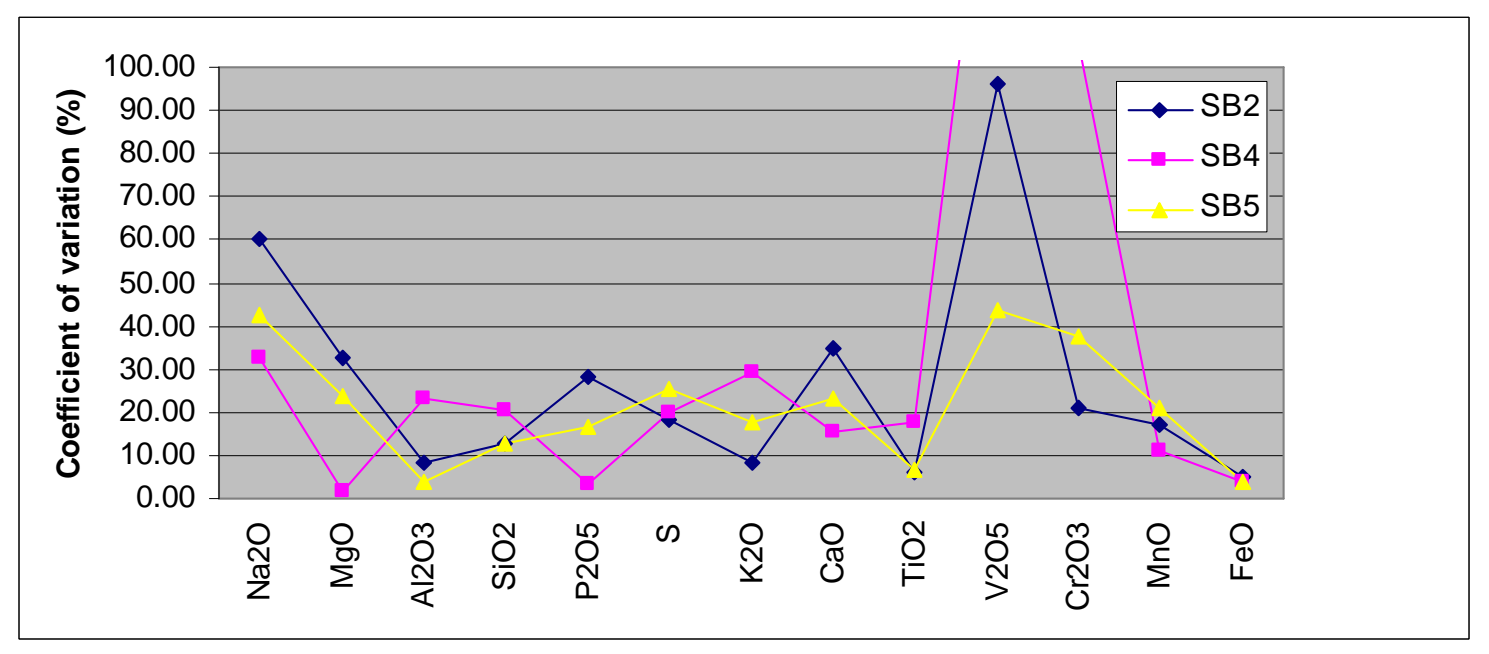

Fig 6.5.15 Coefficient of variation (\%) throughout three slag blocks at KMA

The general level of variation both within and between the blocks was consistently low, again indicating relatively limited changes through each smelting event, and from one smelting event to another. The only significant differences between smelts are somewhat variable iron oxide levels, but the proportions between the other oxides and their small fluctuation remain broadly comparable. Considering the three slag blocks together, the loss of iron oxide into the slag appears slightly greater towards the end of the process than at the beginning of the smelts, with the balance being made up by silica 
(fig. 6.5.16). This could either indicate that reducing conditions were more efficient towards the beginning of the smelts, or that the ratio of ore to fuel was lower at the beginning of the operations. The latter possibility seems to find further support when the rest of the data set is explored.

First, the overall alumina to silica ratio increases towards the end of the process (fig. 6.5.17), together with the iron oxide, which could indicate that a greater amount of alumina-rich ore was being added following the initial period of the smelts. Second, and more distinctively, a definitive pattern is noticeable in the fuel ash components, namely magnesia, potash and lime, which are present in greater levels at the beginning of the smelts (fig. 6.5.18). All of these strands of information strongly suggest a preheat of the furnace structure before the smelt got underway. Such a practice was observed in the experimental smelt documented during this research (see chapter 2), and has also been documented analytically in slag blocks from Uganda (Humpris et al 2009). In the Rwandan case, the reason given by the smelters for this preheating was the need to slowly warm the structure prior to the main smelting episode, thus preventing fatal cracking.

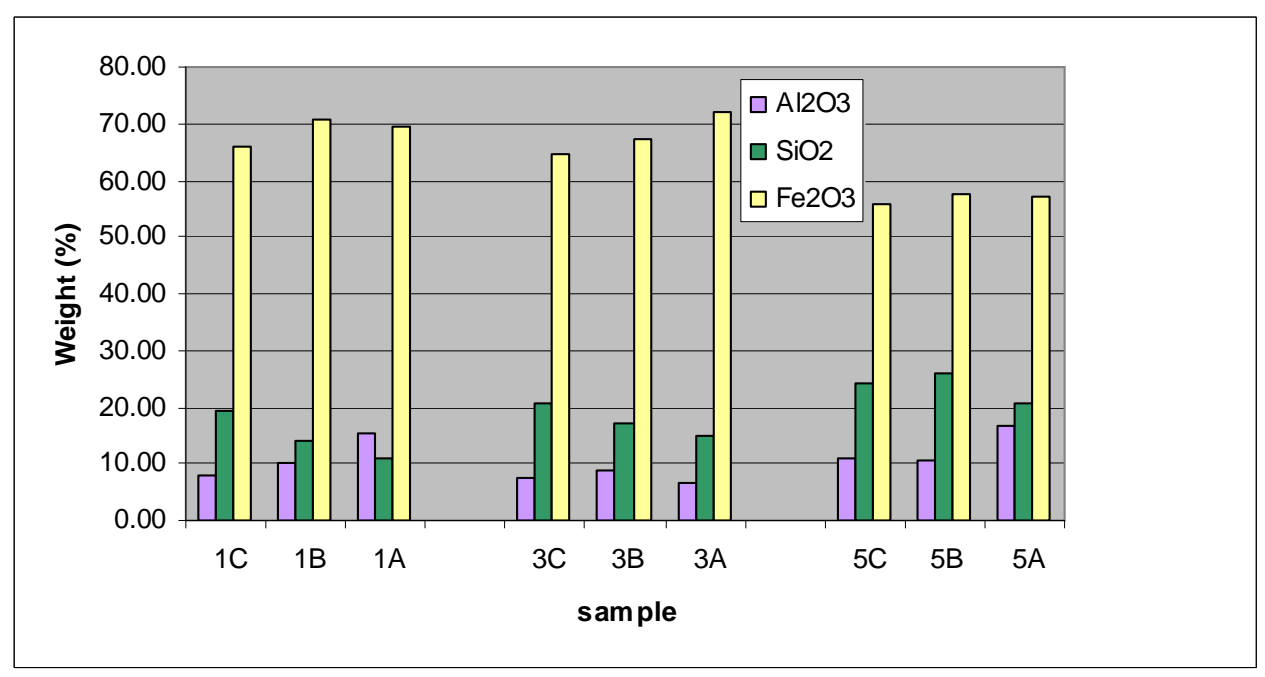

Fig. 6.5.16 Levels of the main slag components throughout three smelts at KMA (sample $\mathrm{c}=$ beginning of the smelt) 


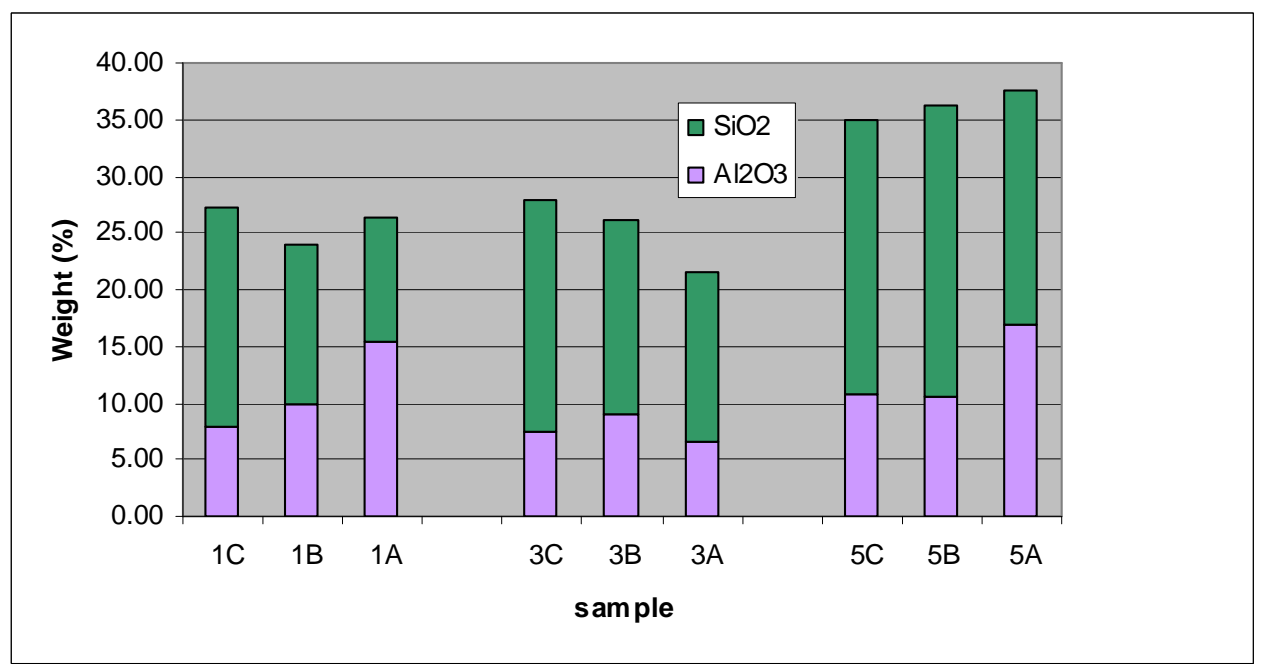

Fig. 6.5.17 Alumina to silica ratios throughout three smelts at KMA (sample $\mathrm{c}=$ beginning of the smelt)

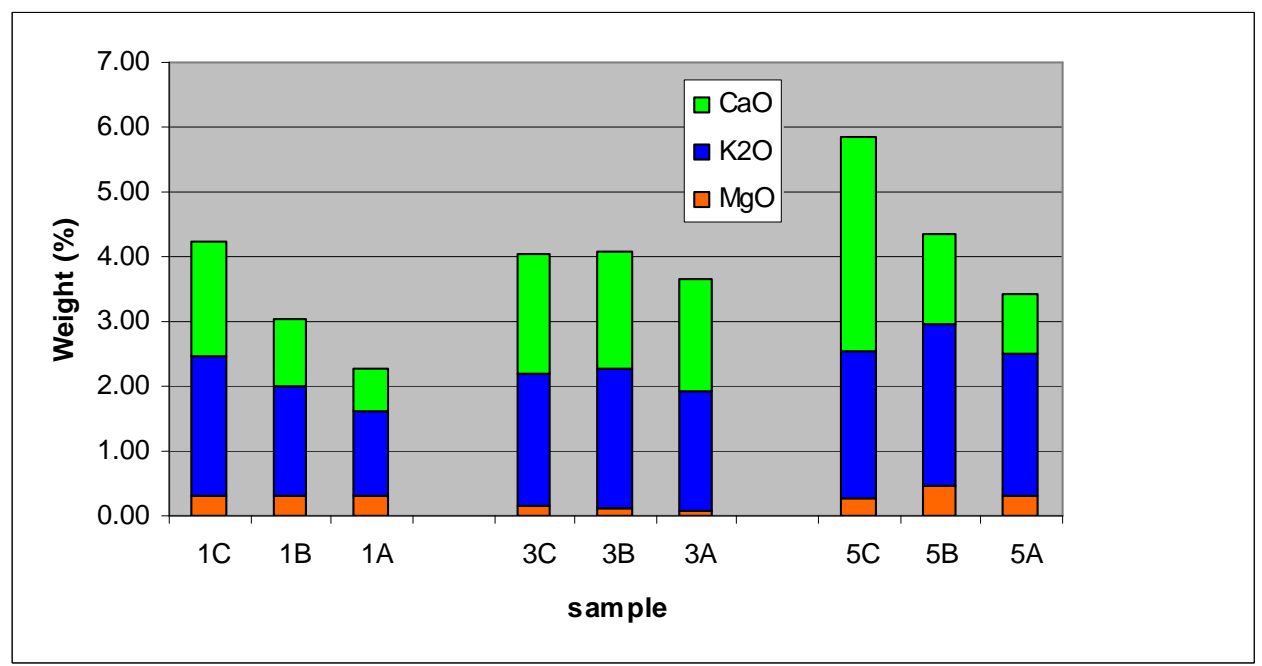

Fig. 6.5.18 Fuel ash components within the three slag blocks analysed in detail at KMA from beginning to the end of the smelts (sample $\mathrm{c}=$ beginning of the smelt)

The level of homogeneity common within the slag blocks at KMA, especially in the major slag components, allows the middle sample of the five blocks analysed to be considered (table 6.5.6), alongside the two additional slag samples analysed (table 6.5.7). This provides a general representation of iron production at the site. 


\begin{tabular}{cccccccccccccc} 
& $\mathrm{Na}_{2} \mathbf{O}$ & $\mathbf{M g O}$ & $\mathrm{Al}_{2} \mathbf{O}_{3}$ & $\mathrm{SiO}_{2}$ & $\mathbf{P}_{2} \mathbf{O}_{5}$ & $\mathbf{S}$ & $\mathbf{K}_{2} \mathbf{O}$ & $\mathbf{C a O}$ & $\mathbf{T i O}_{2}$ & $\mathbf{V}_{2} \mathbf{O}_{5}$ & $\mathbf{C r}_{2} \mathbf{O}_{3}$ & $\mathrm{MnO}$ & $\mathbf{F e O}$ \\
& $\%$ & $\%$ & $\%$ & $\%$ & $\%$ & $\%$ & $\%$ & $\%$ & $\%$ & $\%$ & $\%$ & $\%$ & $\%$ \\
\hline 1B & 0.34 & 0.38 & 10.72 & 21.16 & 2.57 & 0.10 & 2.89 & 2.91 & 0.27 & 0.00 & 0.02 & 0.08 & 58.39 \\
2B & 0.08 & 0.09 & 7.41 & 14.82 & 1.87 & 0.08 & 1.29 & 1.18 & 0.15 & 0.01 & 0.02 & 0.20 & 72.71 \\
3B & 0.28 & 0.17 & 8.24 & 18.57 & 2.95 & 0.08 & 2.65 & 2.55 & 0.18 & 0.00 & 0.01 & 0.08 & 64.15 \\
4B & 0.29 & 0.18 & 7.48 & 20.37 & 2.69 & 0.06 & 2.32 & 1.90 & 0.17 & 0.00 & 0.01 & 0.35 & 64.02 \\
5B & 0.10 & 0.17 & 8.29 & 13.78 & 1.92 & 0.12 & 1.88 & 1.37 & 0.27 & 0.02 & 0.03 & 0.16 & 71.82
\end{tabular}

\begin{tabular}{ccccccccccc} 
& $\mathbf{C u O}$ & $\mathbf{Z n O}$ & $\mathbf{R b}_{2} \mathbf{O}$ & $\mathbf{S r O}$ & $\mathbf{Y}_{2} \mathbf{O}_{3}$ & $\mathbf{Z r O}_{2}$ & $\mathbf{B a O}$ & $\mathbf{L a}_{2} \mathbf{O}_{3}$ & $\mathbf{C e O}_{2}$ & $\begin{array}{c}\text { Original } \\
\text { total }\end{array}$ \\
& ppm & ppm & ppm & ppm & ppm & Ppm & ppm & ppm & ppm & $\%$ \\
\hline 1B & 51 & 53 & 72 & 257 & 58 & 145 & 826 & 66 & 187 & 100.63 \\
2B & 162 & 85 & bdl & 87 & 44 & 94 & 344 & bdl & 62 & 95.40 \\
3B & 65 & 49 & 39 & 156 & 61 & 116 & 285 & 36 & 113 & 103.02 \\
4B & 50 & 69 & 39 & 164 & 68 & 126 & 949 & 26 & 122 & 100.49 \\
5B & 80 & 40 & bdl & 118 & 54 & 113 & 339 & bdl & 48 & 97.40
\end{tabular}

Table 6.5.6 (P)ED-XRF compositional data obtained from the middle slag samples taken from KMA: SC1 is tap slag, whereas TP2:1 is a smithing cake. Results have been normalised to $100 \%$, and taken from the average of three XRF runs. Only trace elements above $50 \mathrm{ppm}$ are shown; bdl - below detection limit. Full results are given in appendix $5 \mathrm{~A}$

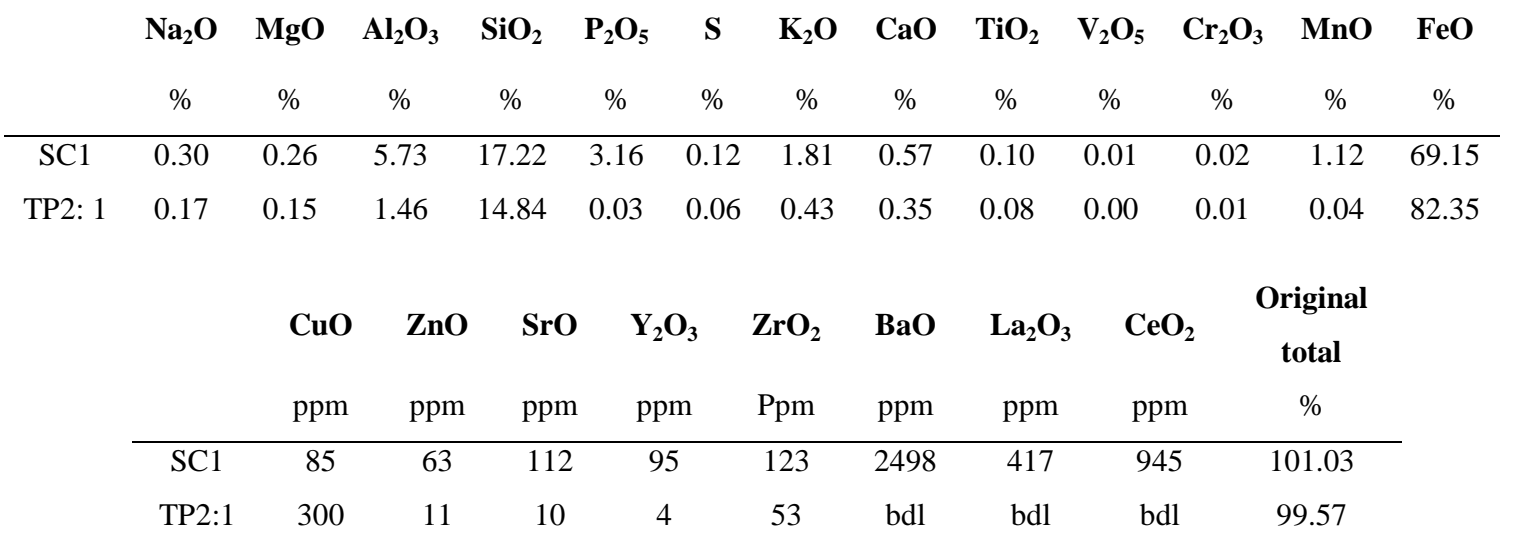

Table 6.5.7 (P)ED-XRF compositional data obtained from the additional slag samples taken from KMA. Results have been normalised to $100 \%$, and taken from the average of three XRF runs. Only trace elements above $50 \mathrm{ppm}$ are shown; bdl - below detection limit. Full results are given in appendix 5A

Focusing on the middle sample analysed from the five slag blocks first, iron oxide, alumina and silica make up over $90 \%$ of the overall weight of the samples. Levels of 
other major oxides, notably phosphate, potash and lime, are present in bulk weights of between $1 \%$ up to nearly $3 \%$, and these appear to correlate (alongside magnesia, another fuel ash component: fig. 6.5.19). This would suggest the higher levels of these oxides are present as a result of the general incorporation of fuel ash into the process, as previously suggested when examining variation within blocks. Placed within a phase diagram (fig. 6.5.20), the slag compositions plot relatively close to the high iron eutectic, although edging on the alumina-rich side (Charlton 2006; Rehren et al 2007).

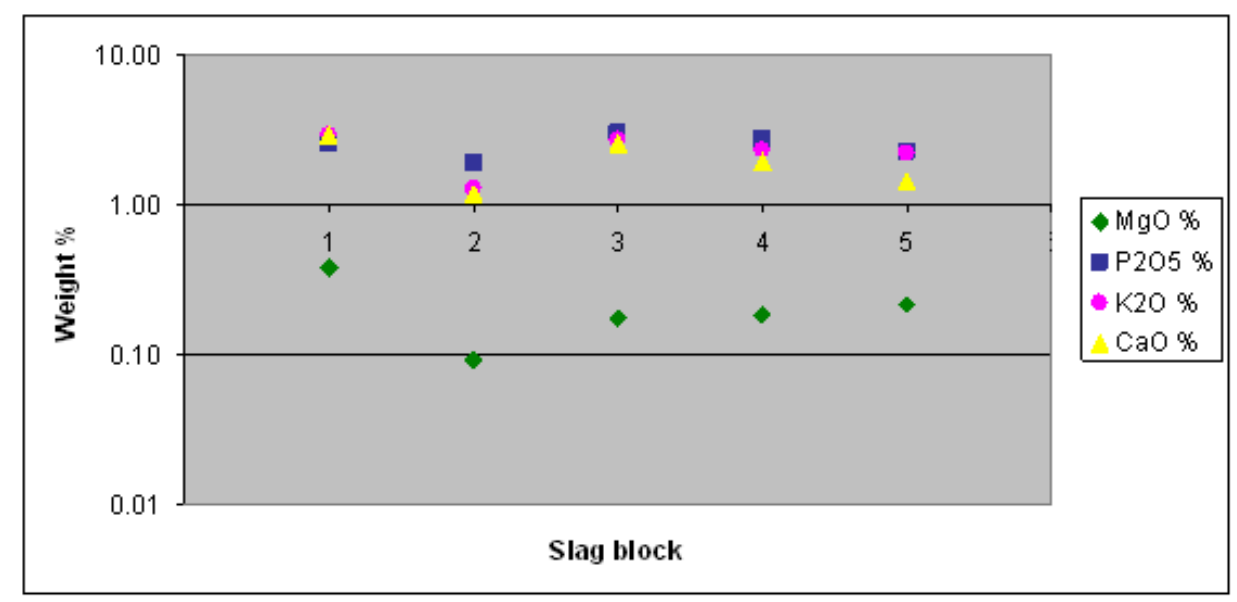

Fig. 6.5.19 Fuel ash components within the five KMA slag blocks

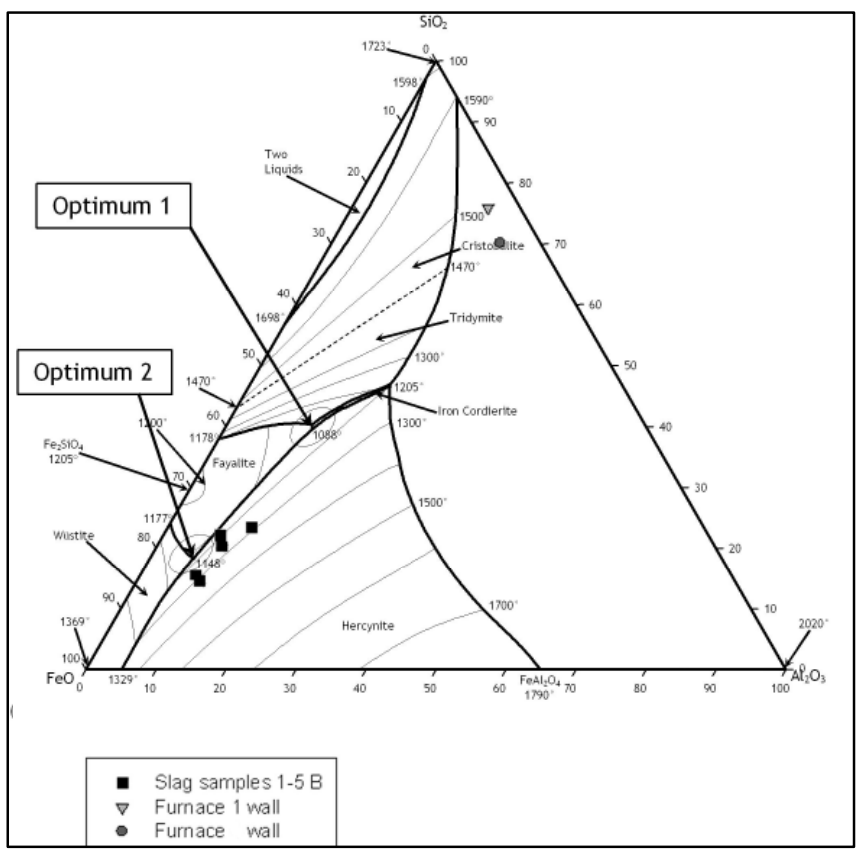

Fig. 6.5.20 Phase diagram with the middle samples of SB 1-5 plotted (after Rehren et al 2007: 212) 
The general level of similarity between the slag blocks analysed at this site is also displayed within the microstructures of the samples (fig. 6.5.21, fig. 6.5.22, fig. 6.5.23). These samples, from SB1, SB2 and SB4, illustrate similar, well formed crystal structures and a matrix dominated by fayalite $(F)$, wüstite $(W)$, eutectic wüstite $(E W)$, and some hercynite $(\mathrm{H})$, as indicated by the location of the samples within the phase diagram above, on the alumina-rich side of the fayalite-hercynite trough. Sample 1B (below left) displays a larger quantity of kalsilite (consistent with the higher alkali levels in the XRF data); Sample 2B (centre) displays a greater amount of unreduced free iron oxides in the form of wüstite (again in agreement with the XRF results). Finally, sample 4B (below right) has the lowest level of alumina in the sample, and correspondingly the lowest concentration of hercynite within the microstructure.

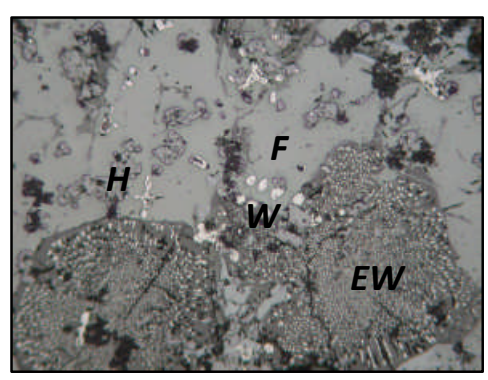

Fig. 6.5.21

PPL photomicrograph of sample KMA SB1 B

(100x, image width $1 \mathrm{~mm})$

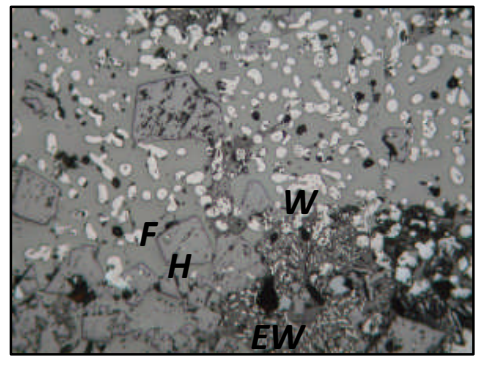

Fig. 6.5.22

PPL photomicrograph of sample KMA SB2 B

(100x, image width $1 \mathrm{~mm}$ )

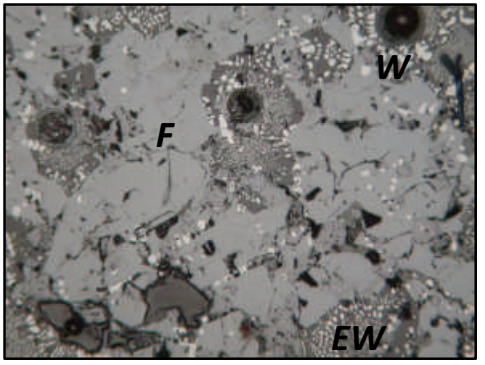

Fig. 6.5.23

PPL photomicrograph of sample KMA SB4 B

(100x, image width 1mm)

Turning to the plano-convex slag cake, it is apparent from the analysis that the initial interpretation of the sample taken from tp2 as a smithing cake is justified. Besides the overall shape and layered appearance, this sample is very rich in iron, as would be expected in a smithing cake. Silica is the only other major component, and its presence is indicative of a flux used during the forging process, as observed during the experimental smelt (chapter 2), to aid in the fluxing of the hammerscale forming during smithing. The very high iron content recorded in the XRF analysis is mirrored in the microstructure of the sample (fig. 6.5.24), which displays large areas of iron metal (I), as well as areas of slag (S), as would be expected, alongside a significant level of 
corrosion (C). Two further aspects of this slag cake may be highlighted: on the one hand, the very low alumina to silica ratio, (around 1:10, compared to 1:2 or 1:3 in the smelting slag); on the other hand, the very limited presence of any other oxides. Even accounting for dilution effects caused by the high iron content and the silica enrichment through the use of sand flux, it seems unlikely that this smithing slag cake could have formed during the primary smithing of the blooms produced at the KMA furnaces characterised in this chapter. Instead, these features could indicate secondary smithing of iron objects.

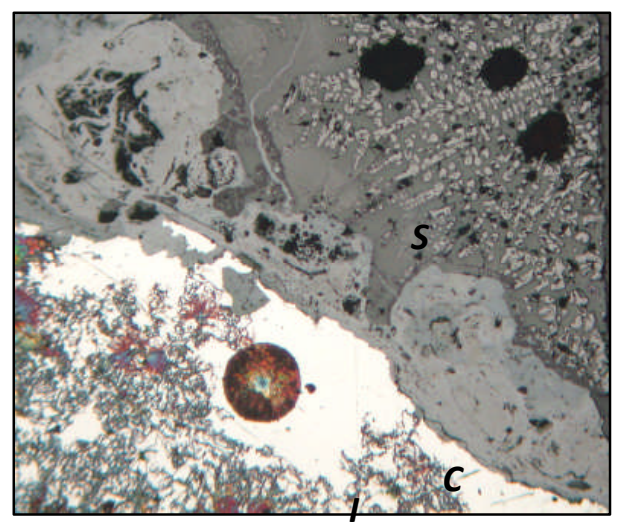

Fig. 6.5.24 PPL photomicrograph of sample tp2, illustrating areas of iron metal and slag (50x, image width $2 \mathrm{~mm})$

Finally, the smelting system that formed sample SC1 is clearly technically and chemically different from the approach that resulted in the large continuous slag blocks. It would appear macroscopically that SC1 represents slag tapping. On closer inspection, as mentioned, further slag blocks used to form part of the foundations of the houses were found to be very similar in size and formation (with a distinct flow-like and layering effect) to SC1 (fig. 6.5.25). Furthermore, SC1 has lower alumina, potash and lime, yet higher manganese oxide, barium oxide, lanthana and ceria, indicative of different raw materials in use, as well as a different technological approach. 


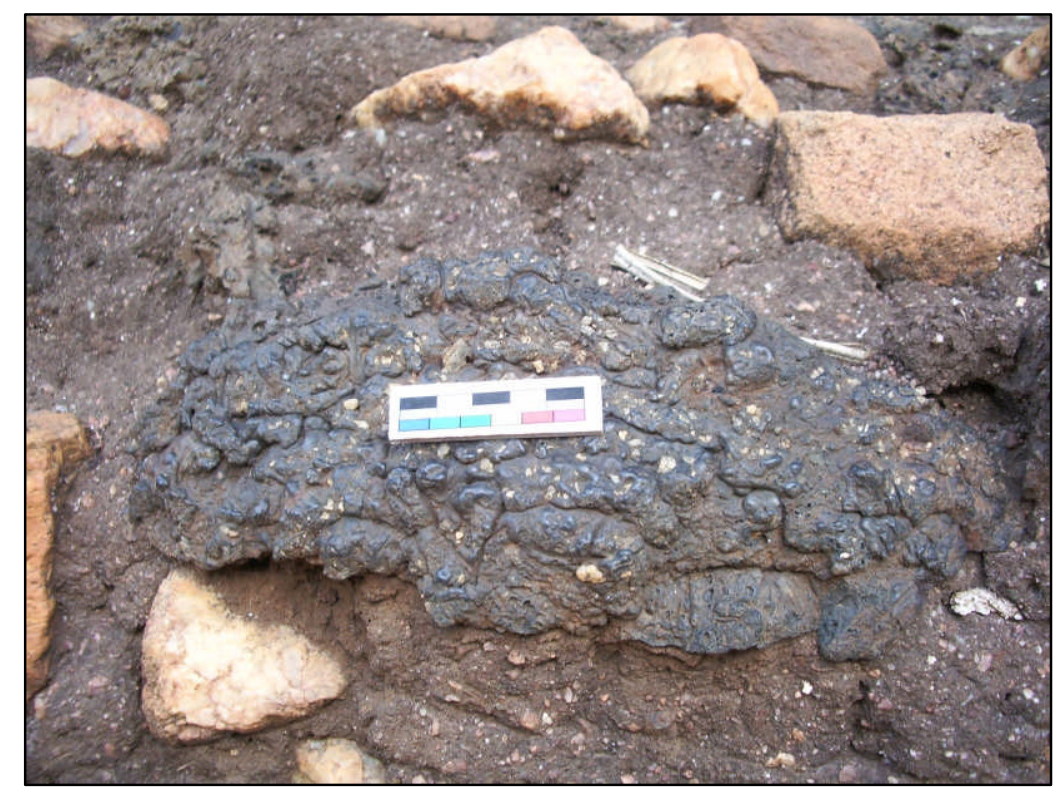

Fig. 6.5.25 Typical slag block within the house foundations at KMA, showing a layered, flowing effect

Therefore it would appear that two technological approaches to iron smelting were in operation at the site of KMA, that of the typical pit furnace, as well as slag tapping (using smaller quantities of material). For obvious reasons none of the blocks were removed from the house foundations for analysis, so the macroscopic observations will have to suffice. 


\section{- Technical Ceramics}

The only technical ceramics analysed from the site of KMA were the two samples of the furnace pit linings collected at the site (table 6.5.8).

\begin{tabular}{cccccccccccccc} 
& $\mathrm{Na}_{2} \mathbf{O}$ & $\mathbf{M g O}$ & $\mathrm{Al}_{2} \mathbf{O}_{3}$ & $\mathbf{S i O}_{2}$ & $\mathbf{P}_{2} \mathbf{O}_{5}$ & $\mathbf{S}$ & $\mathbf{K}_{2} \mathbf{O}$ & $\mathbf{C a O}$ & $\mathbf{T i O}_{2}$ & $\mathbf{V}_{2} \mathbf{O}_{5}$ & $\mathbf{C r}_{2} \mathbf{O}_{3}$ & $\mathbf{M n O}$ & $\mathbf{F e O}$ \\
& $\%$ & $\%$ & $\%$ & $\%$ & $\%$ & $\%$ & $\%$ & $\%$ & $\%$ & $\%$ & $\%$ & $\%$ & $\%$ \\
\hline f1 pit lining & 0.58 & 0.18 & 19.04 & 74.11 & 0.15 & 0.03 & 0.56 & 0.13 & 0.51 & 0.02 & 0.02 & 0.03 & 4.52 \\
f2 pit lining & 0.41 & 0.13 & 23.56 & 68.31 & 0.25 & 0.06 & 0.64 & 0.05 & 0.77 & 0.02 & 0.01 & 0.05 & 5.62
\end{tabular}

\begin{tabular}{ccccccc} 
& $\mathbf{Z n O}$ & $\mathbf{R b}_{2} \mathbf{O}$ & $\mathrm{ZrO}_{2}$ & $\mathbf{B a O}$ & $\mathbf{C e O}_{2}$ & $\begin{array}{c}\text { Original } \\
\text { total }\end{array}$ \\
& ppm & ppm & ppm & ppm & ppm & $\%$ \\
\hline f1 pit lining & 50 & 80 & 206 & 259 & 53 & 81.74 \\
f2 pit lining & 79 & 100 & 321 & 189 & 84 & 80.24
\end{tabular}

Table 6.5.8 (P)ED-XRF compositional data obtained from the technical ceramics taken from KMA. Results have been normalised to $100 \%$, and taken from the average of three XRF runs. Only trace elements above $50 \mathrm{ppm}$ are shown. Full results are given in appendix 5B

The compositions of the furnace pit linings vary mainly in the ratio of alumina to silica, which fluctuate from $1: 4$ in $\mathrm{f} 1$, to $1: 3$ in $\mathrm{f} 2$. Microscopic examination confirms that this is most likely due to the presence of larger quartz fragments $(\mathrm{Q})$, in the clay fabric used to build f1 (fig. 6.5.26 and fig. 6.5.27).

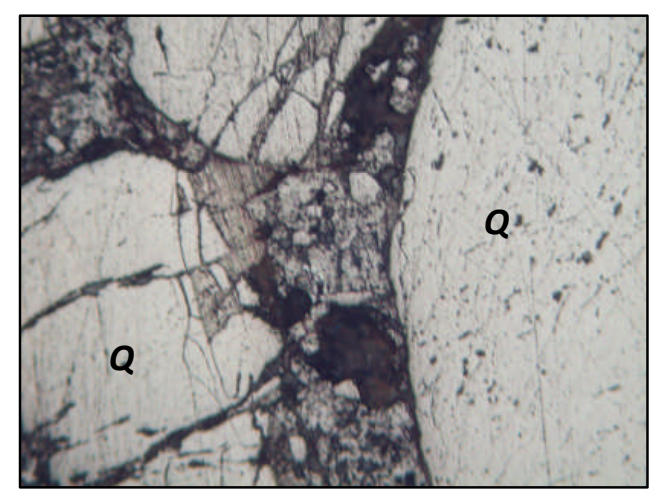

Fig. 6.5.26 PPL photomicrograph of KMA f1 pit lining showing larger fragments of quartz

(50x image width $2 \mathrm{~mm})$

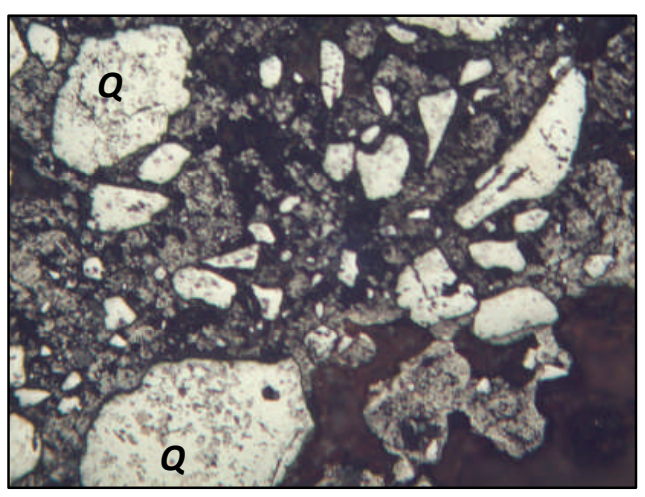

Fig. 6.5.27 PPL photomicrograph of KMA f2 pit lining (100x image width $1 \mathrm{~mm}$ ) 
Despite f2 being broken, the overall amount of baked pit lining appeared macroscopically identical to that present in $\mathrm{fl}$, and so it can be said that these two sets of remains both represent the kind of furnace pit that would have been used to produce the large slag blocks that characterise the site. Considering the depth of the large slag blocks produced at the site, a clearly significant amount of erosion has affected these furnace pits, making them very shallow. Interestingly, the pit seems to compare more to the remains seen at the site of MNA (with a wide bottom), rather than the CMZ sites, which have a more conical shape. Alternatively, these shallow pits could be indicative of a different kind of superstructure.

When the compositions of the slag produced at the site are considered together with those of the technical ceramics, it would seem that there was some ceramic contribution to the slag formation, as they generally lie on a line towards the $\mathrm{FeO}$ apex when plotted within the phase diagram above (fig. 6.5.20). However, most other major, minor and trace oxides (such as magnesia, phosphate, manganese oxide and barium oxide), are lower in the ceramics than in the slag blocks. This would suggest a generally rather limited contribution of technical ceramics into the process.

\subsubsection{Site Interpretation}

Unfortunately, again no date was obtainable for the site of KMA, and so it is unknown whether this site is contemporary to the CMZ sites, or dated to later times. It is presumed this is not an EIA site due to the lack of brick features used to construct the furnaces, as well as the presence of large slag blocks, characteristic of later smelting approaches. Even if dating had been possible at this site it would have had to have been carried out using charcoal samples taken from within the slag blocks (due to the lack of charcoal contained within the furnaces), and no such finds were observed. A number of dates would have been desirable in order to understand the chronological relationship between the smelting that was carried out in large pit furnaces to that which was carried out using a tapping method, as well as the smithing that was also conducted at this site. Frustratingly, as it stands, none of these possibilities are accessible. Even if radiometric dates had been obtained, in light of the level of accuracy seen in the dates so far 
mentioned, it is unlikely that a precise understanding of the technological time-frame of this site would have been possible, the radiometric dates having significant error margins. It is in such a case that precise thermoluminescence, or optically stimulated luminescence would have, in theory, been ideal.

Of course the most significant finding at this site is the existence of two technological approaches to iron production being carried out on a significant level in the same locality although, as mentioned above, it is not clear how these relate to one another temporally. The very dense incorporation of tapping slags within the house foundations (fig. 6.5.28), together with the quantity of larger blocks in the vicinity, suggests that both technologies were frequently carried out. However, due to the more complicated remains at this site, no estimates of production will be attempted.

The tapping technology requires further investigation to be understood fully, but this would have required the removal of house foundations. These slags could either represent a style of smelting whereby slag was deliberately tapped out of the furnace during the smelt to allow the process to continue, or simply a different pit approach, whereby the slag drains down into a pit. If the later, clearly the style employed was dissimilar to that used to produce the large blocks with no cold interfaces or flow patterns. Slag tapping is often thought to follow the slag pit furnace tradition in evolutionary terms, indicating technological advancements and materialising: "an improvement which obviously led to an increase in the yield of metallic iron produced in one smelt" (Pleiner 2000: 262). Whichever way this slag was produced, presumably fewer people were needed to operate the much smaller furnaces which produced slag cakes with, on average (from field observations), had a diameter approximately one third that of the large slag pit furnaces also represented at the site. Although perhaps more manageable to conduct, this process probably had a lower output per smelting event. 


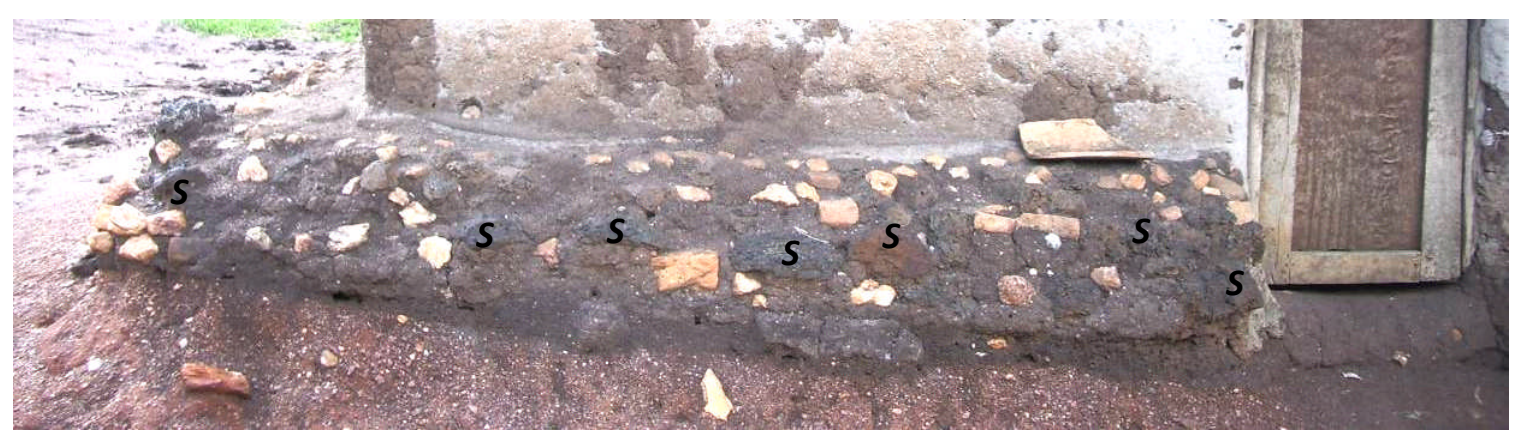

Fig. 6.5.28 Small, layered slag cakes $(S)$ in the foundations of a house at KMA

The slag pit furnaces were most likely preheated during the initial stages of the smelts at KMA. This was presumably conducted using a packing of plant material or copious amounts of charcoal, to slowly heat the clay structure of the furnace to prevent fatal cracking, and to build up a platform on which the ore could be added when the temperature and redox conditions within the furnace were judged to be sufficient by the head smelter for the process to begin. When this was decided, it is possible that during the early stages of the smelt itself, a lower ratio of ore to fuel was added, and possibly that a limited amount of technical ceramics melted slightly into the process, as they were exposed to the high temperatures.

Smithing was also carried out at KMA, indicated by the presence of at least one confirmed smithing cake, although as mentioned, whether this was done at the same time as people were smelting at the site is unknown. The trace oxides within the smithing cake certainly do not seem to indicate that it was the blooms produced at this site that were being smithed, with comparatively higher levels of copper oxide, and much lower levels of all other trace oxides in the smithing cake compared to the smelting slags. Although tentative and preliminary, this evidence would again suggest a different technological picture compared to the other sites, where no evidence for smithing was identified.

The agricultural activity that is represented at this site within the house foundations is also intriguing. Again the lack of data as to the temporal relationship between the metallurgical activity and the grinding that had gone on at this site is frustrating. 
However, presuming both activities were carried out at the same time, a fascinating insight into the group that was producing iron is provided. Historically it is believed that it was the agriculturalists that were producing iron in Rwanda: "Le travail des métaux est une exclusivité des Hutus; les Tutsis ne forgent jamais, sinon symboliquement" (Celis 1987: 17). However, across the broader region, notably to the east in Kenya, pastoralist iron production was common (Brown 1995; Iles and Martinón-Torres 2009). The archaeological remains at this site provide an image of men smelting, smithing and producing iron tools to trade (or to use within their own fields), while the women ground grain and made the food. There is evidence for such hollows being created and used during the processing of iron ore for smelting (e.g. Celis 1991: 163-167). However, in Eastern Africa, traditionally such remains are interpreted as agricultural in association. Interestingly this relationship, between metallurgy and agriculture, is one mirrored at the following site of Kamabuye. 


\subsection{Kamabuye (KBE)}

\subsubsection{Site description and observations}

The furnace pit at KBE (f1), was identified due to its location in the middle of a road, at the very northern edge of the survey zone (fig. 6.6.1). The site lies close to the crest of a hill, with views south onto the adjacent hillside. The furnace contained a slag block in situ (SB1), and in general proved to be completely different from any furnace pit previously seen by the author. While half of the furnace pit had a clay lining (as would be expected), the other half was set into the surrounding rock (fig. 6.6.2).

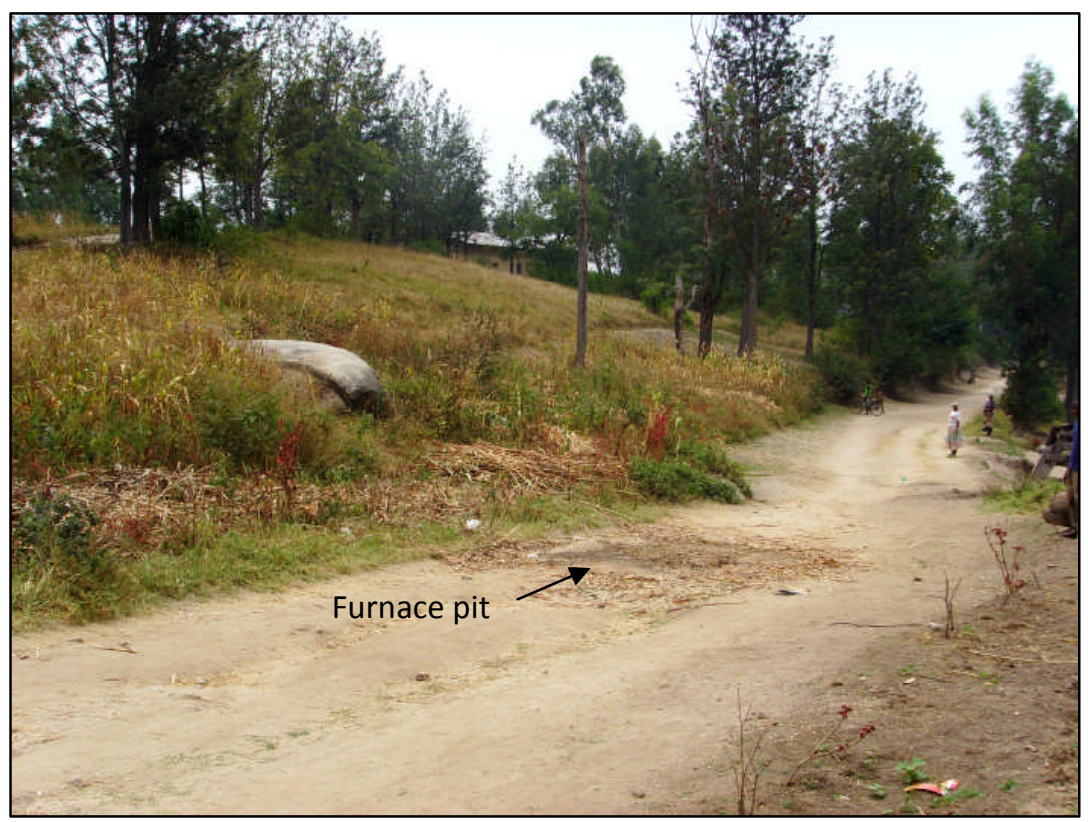

Fig. 6.6.1 KBE furnace pit located in the middle of the road 


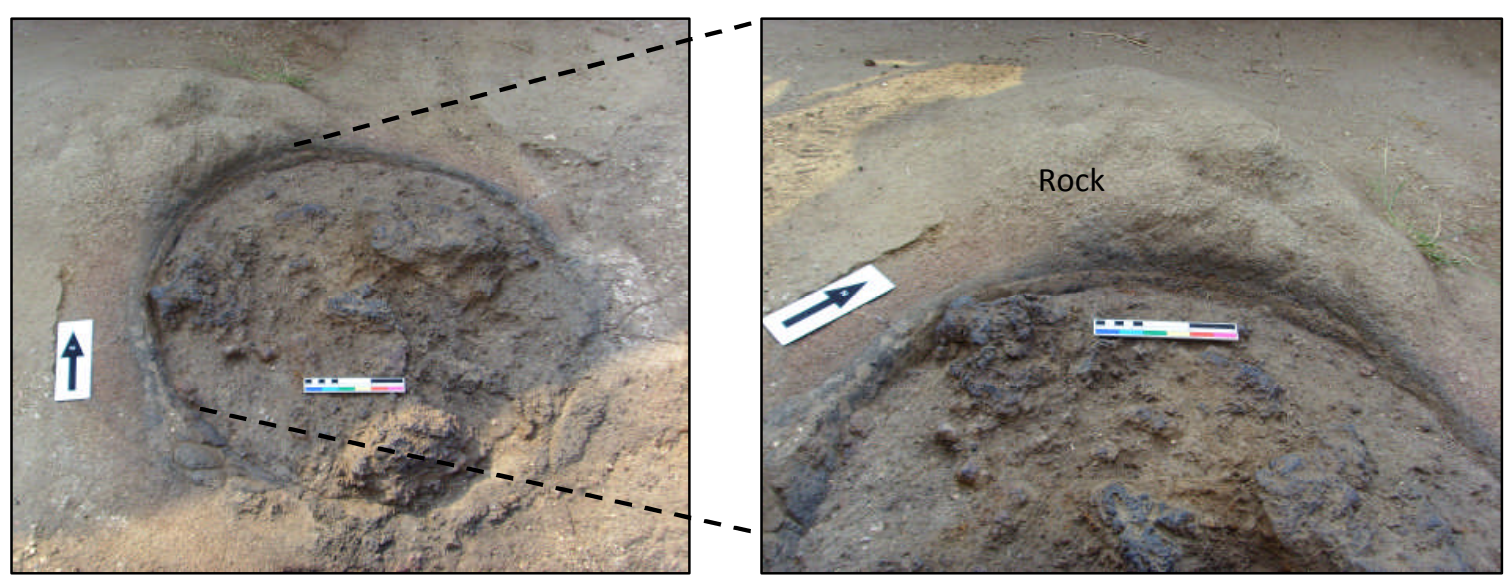

Fig. 6.6.2 KBE furnace pit, set into the surrounding rock

As the team surveyed the surrounding area, $3 \mathrm{~m}$ north of $\mathrm{f} 1$, on a number of rocky outcrops, over thirty grinding hollows were observed (fig. 6.6.3). These were all of a similar oval shape (when viewed in plan), with dimensions of between $10-25 \mathrm{~cm}$ in depth, and 25-45 cm in width (measured at the widest point). All of the hollows had a smooth bottom, the rock having been ground flat over the years. The grinding hollows were planned (fig. 6.6.4), and as at each site, the people living around the location were interviewed regarding their memories associated with the archaeological remains. As at the previous sites, no-one remembered the iron production activities or the particular grinding practices carried out at the site which had resulted in the extensive hollows. 


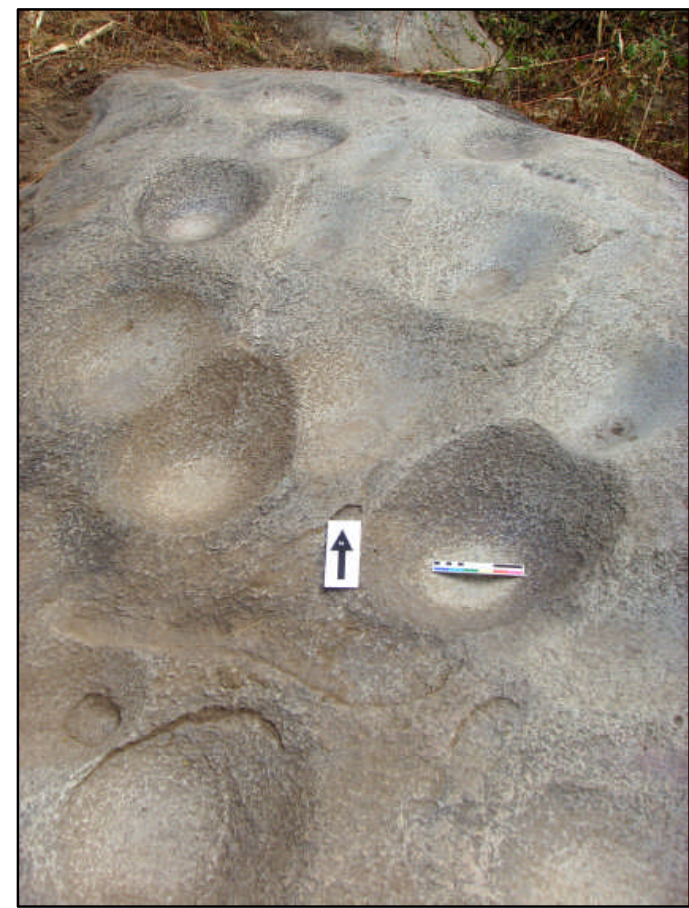

Fig. 6.6.3 Grinding hollows

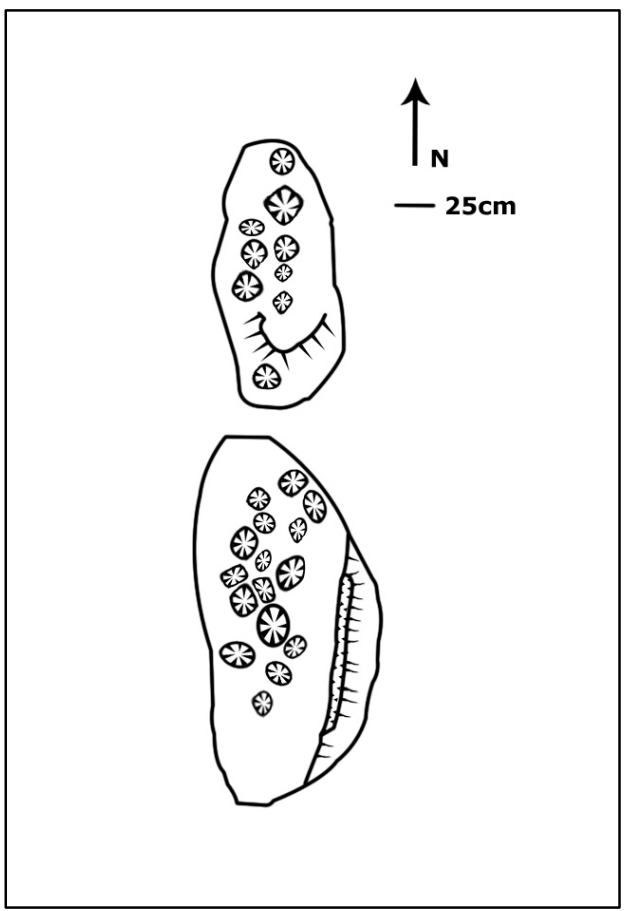

Fig. 6.6.4 Plan of some of the grinding hollows

Two test units were excavated to investigate whether or not the smelting site was associated with any further archaeological remains. One test pit (tp1), was excavated 2 $\mathrm{m}$ to the south of $\mathrm{f} 1$. The second (tp2), was excavated $15 \mathrm{~m}$ to the east of the furnace, to investigate whether or not there were any archaeological deposits elsewhere along the road.

\subsubsection{Excavations and sample selection}

- KBEf1

The excavation of KBE f1 involved sectioning the structure to allow the surrounding rock (which appeared to have been incorporated into the furnace pit structure), to be viewed. While ideally this section would have been excavated along a north-south line (see fig. 6.6.5 below), which would have revealed a view of both halves of the pit, this would have involved somehow digging through the granite-like rock with simple hand trowels. Although the team were game for most challenges, time was against such a strategy! Therefore, a section was created running west-east across the furnace, and the 
slag block fell apart along the section line (highlighting its very porous, fragile nature: fig. 6.6.6). The fact that a hollow within the rock (whether natural or man-made), had indeed formed part of the pit structure, and that the slag block had solidified onto the rock at the base of the pit, became definitively clear when the section was cleaned (fig. 6.6.7), and further obvious when the slag was completely removed (fig. 6.6.8).

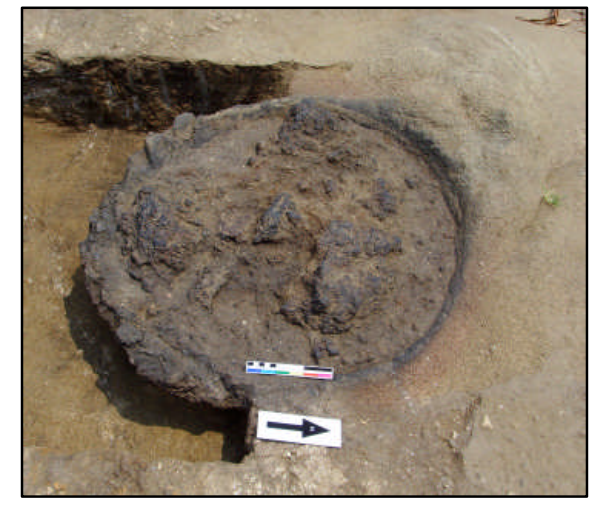

Fig. 6.6.5 KBE f1 showing both ceramic and rock used to form the structure of the pit

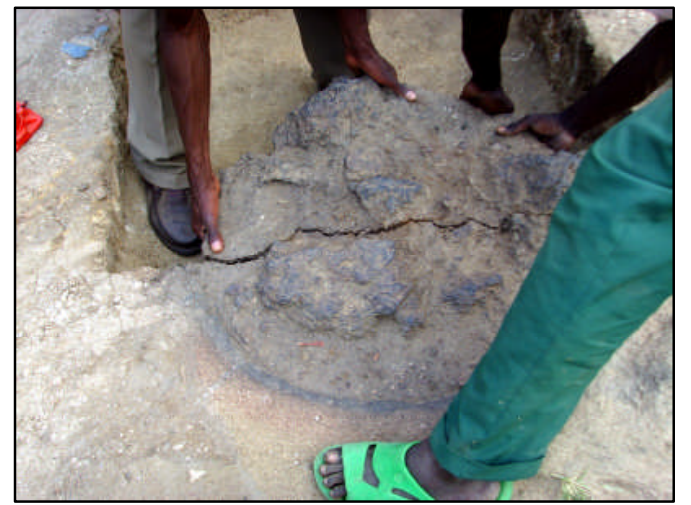

Fig. 6.6.6 Sectioning SB1

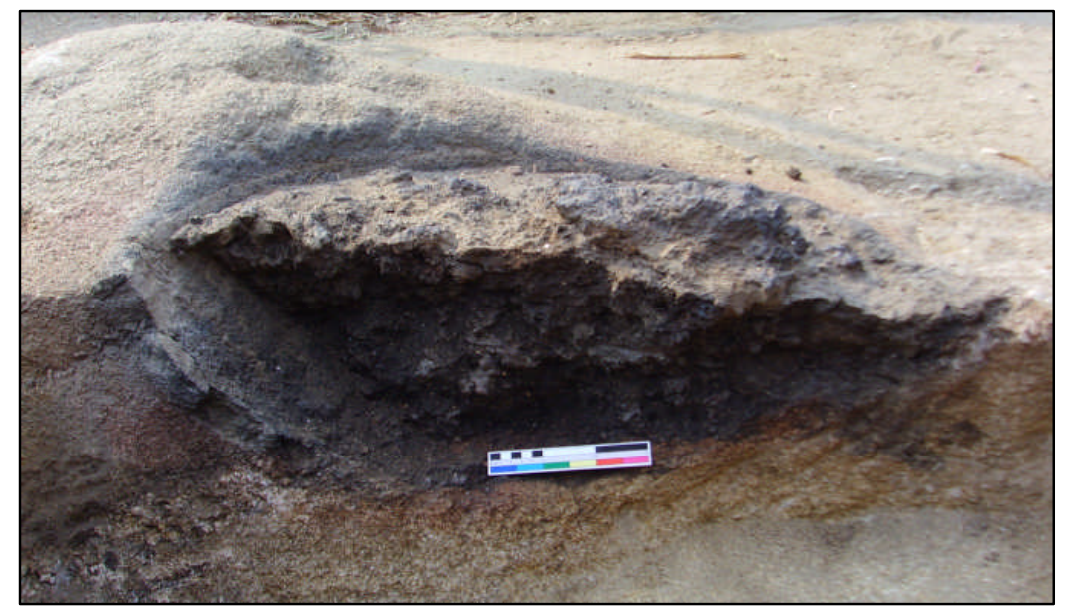

Fig. 6.6.7 KBE f1 sectioned to reveal SB1 sat up against the rock that has been used to form part of the furnace pit itself 


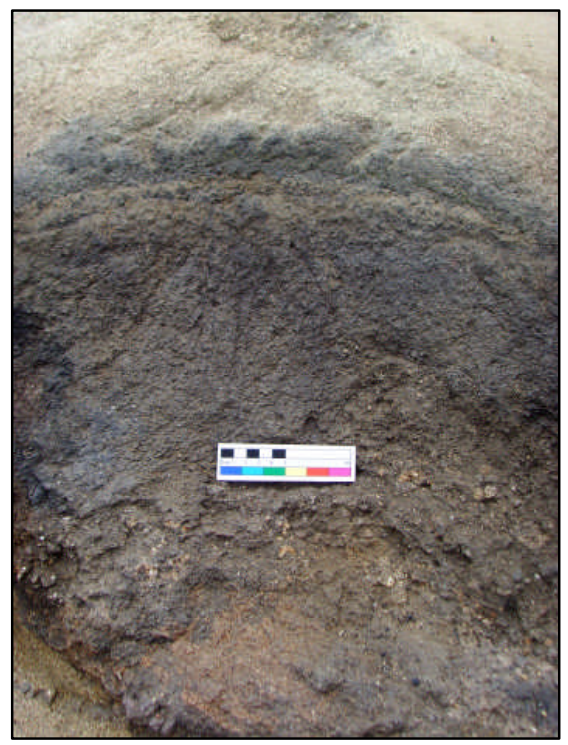

Fig. 6.6.8 KBE f1 after the removal of SB1, clearly illustrating that there had been no technical ceramic pit lining between the slag block and the rock

KBE f1 was found to be $25 \mathrm{~cm}$ deep, with a north-south diameter at ground level of 60 $\mathrm{cm}$, and a west-east diameter of $63 \mathrm{~cm}$. A clay pit lining had been used to construct the majority of the furnace base, which extended around the west, south and eastern areas of the structure (fig. 6.6.9).

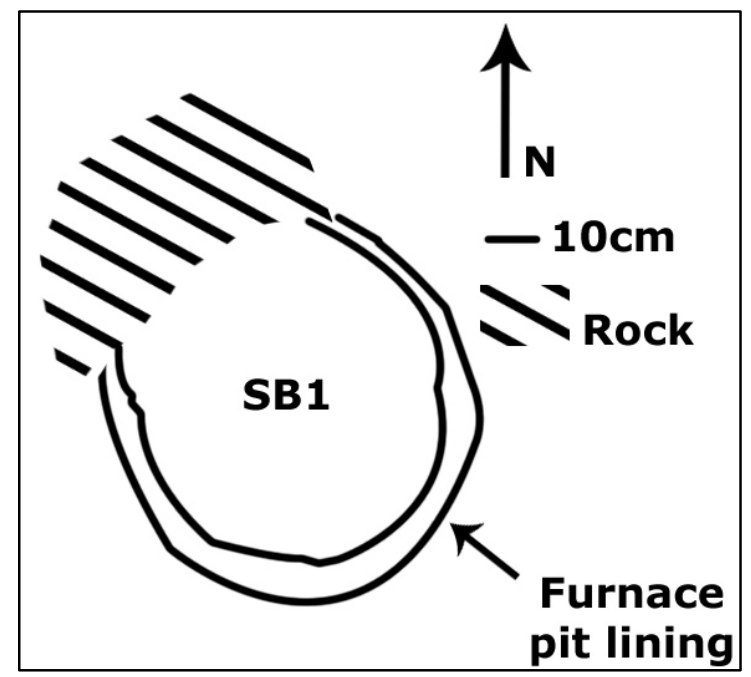

Fig. 6.6.9 Extent of the ceramic furnace pit lining used to construct part of the structure of the furnace pit 


\section{- Slag samples}

Samples were taken from the top, middle and bottom of the section of SB1, as outlined in chapter 5. It would appear that over time, gravel and silt have washed into the pit and seeped into the block, which was facilitated by the slag's porosity (although a very limited amount of corrosion was noticeable on a macroscopic level). A limited number of small flows and fragments of slag were observed across the site, as opposed to the large blocks that had characterised the majority of the sites excavated prior to KBE. Other than SB1, due to the arbitrary nature of the rest of the slag at the site, only one further piece of slag (excavated from tp2), was sampled. This fragment was similar macroscopically to SB1. The slag samples analysed from this site are summarised in table 6.6.1 below.

\begin{tabular}{cccc}
$\begin{array}{c}\text { Slag } \\
\text { block }\end{array}$ & Sample & ED-XRF & OM \\
\hline 1 & A & $\bullet$ & $\bullet$ \\
1 & B & $\bullet$ & $\bullet$ \\
1 & C & $\bullet$ & $\bullet$ \\
2 & SB2 & $\bullet$ & $\bullet$
\end{tabular}

Table 6.6.1 Samples of slag taken from KBE and the analytical methods employed

\section{- Technical ceramics}

A sample from the southern edge of the furnace pit lining of f1 was taken for analysis. In addition, one fragment of a partly slagged tuyere was excavated within tp2 (located below SB2), and a sample of this was taken for analysis (table 6.6.2).

\begin{tabular}{ccc} 
KBE sample & ED-XRF & OM \\
\hline fl pit lining & $\bullet$ & $\bullet$ \\
tuyere & $\bullet$ & $\bullet$
\end{tabular}

Table 6.6.2 Samples taken from the technical ceramics excavated at the site of KBE 


\section{- Test Pits}

The soil deposits within the test pits were initially found to be very densely packed with gravel (presumably due to erosion of the rocky areas surrounding the site), and dark brown - black in colour. At approximately $20 \mathrm{~cm}$ below ground level, a dense orange layer, thick with gravel and stones, and very difficult to excavate (visible in the section seen in fig. 6.6.7), was reached, below which, at approximately $25 \mathrm{~cm}$, solid bedrock was found. While all of the spoil removed from the test units was sieved, tp1 contained no finds other than a few small pieces of slag. Tp2 contained some small pieces of slag, as well as the tuyere fragment mentioned above.

\subsubsection{Results}

\section{- Slag Blocks}

The results of the XRF analysis are shown below (table 6.6.3, fig. 6.6.11).

\begin{tabular}{llllllllllllll} 
& $\mathbf{N a}_{2} \mathbf{O}$ & $\mathbf{M g O}$ & $\mathbf{A l}_{2} \mathbf{O}_{3}$ & $\mathbf{S i O}_{2}$ & $\mathbf{P}_{2} \mathbf{O}_{5}$ & $\mathbf{S}$ & $\mathbf{K}_{2} \mathbf{O}$ & $\mathbf{C a O}$ & $\mathbf{T i O}_{2}$ & $\mathbf{V}_{2} \mathbf{O}_{5}$ & $\mathbf{C r}_{2} \mathbf{O}_{3}$ & $\mathbf{M n O}$ & $\mathbf{F e O}$ \\
& $\%$ & $\%$ & $\%$ & $\%$ & $\%$ & $\%$ & $\%$ & $\%$ & $\%$ & $\%$ & $\%$ & $\%$ & $\%$ \\
\hline 1A & 0.34 & 1.59 & 9.71 & 25.58 & 1.63 & 0.19 & 6.64 & 6.31 & 0.16 & 0.00 & 0.02 & 0.32 & 47.32 \\
1B & 0.07 & 0.40 & 6.85 & 15.91 & 1.18 & 0.21 & 2.28 & 1.69 & 0.11 & 0.00 & 0.01 & 0.25 & 70.92 \\
1C & 0.16 & 1.20 & 7.96 & 26.48 & 1.02 & 0.21 & 2.77 & 8.96 & 0.18 & 0.00 & 0.01 & 0.19 & 50.65 \\
SB2 & 2.16 & 0.59 & 13.19 & 51.72 & 0.26 & 0.07 & 3.00 & 1.63 & 0.23 & 0.03 & 0.03 & 0.05 & 26.85
\end{tabular}

\begin{tabular}{lllllll} 
& $\mathbf{R b}_{2} \mathbf{O}$ & $\mathrm{SrO}$ & $\mathrm{ZrO}_{2}$ & $\mathbf{B a O}$ & $\mathrm{CeO}_{2}$ & $\begin{array}{l}\text { Original } \\
\text { total }\end{array}$ \\
& ppm & ppm & ppm & ppm & ppm & $\%$ \\
\hline $1 \mathrm{~A}$ & 129 & 524 & 97 & 1104 & 150 & 102.05 \\
1B & bdl & 114 & 83 & 713 & 183 & 102.89 \\
1C & 48 & 642 & 130 & 1028 & 190 & 94.67 \\
SB2 & 116 & 239 & 117 & 623 & 26 & 98.40
\end{tabular}

Table 6.6.3 (P)ED-XRF compositional data obtained from the slag samples taken from KBE. Results have been normalised to $100 \%$, and taken from the average of three XRF runs. Only trace elements above $50 \mathrm{ppm}$ are shown; bdl - below detection limit. Full results are given in appendix 6A 


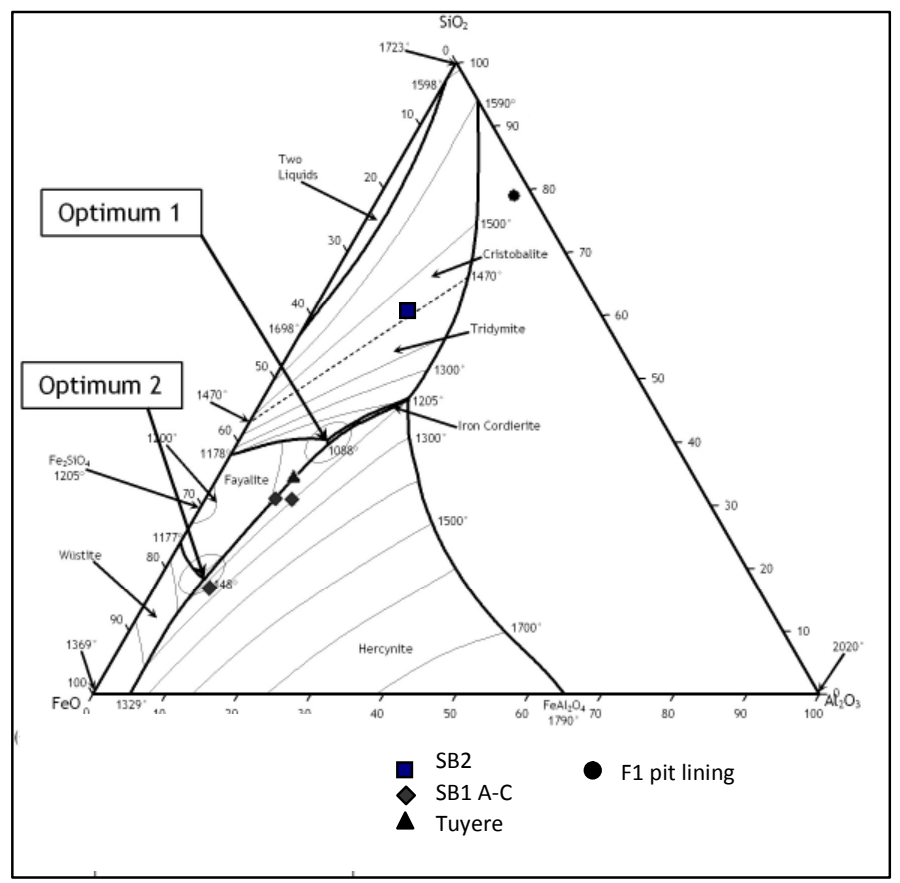

Fig. 6.6.10 KBE samples plotted in the $\mathrm{FeO}-\mathrm{Al}_{2} \mathrm{O}_{3}-\mathrm{SiO}_{2}$ phase diagram (after Rehren et al 2007: 212)

Considering first the samples analysed from SB1, the results of the analysis demonstrate a particularly heterogeneous slag (fig. 6.6.10 and fig. 6.6.11). This is especially noticeable in the iron oxide levels throughout the block, which vary by over $20 \%$, a unique characteristic of this slag blocks compared to any other block analysed as part of this research. It is also a much higher level of variation compared to a previous study utilising such a methodology on African bloomery slag blocks (Humphris et al 2009). The very fragmented, porous macroscopic texture of the block, combined with this very heterogeneous composition, could well indicate that SB1 does not represent the waste product of a single, continuous smelting event. Indeed, at the other sites studied, it was specifically the macroscopic observations of the sections of the block, identifying no cold interfaces (confirmed by microscopic examination), which confirmed the slag-pit technologies that had produced a single, continuous slag block per smelt. In this case, such evidence is not so clear, and it could be interpreted that the slag derives from more than one smelting episode. 


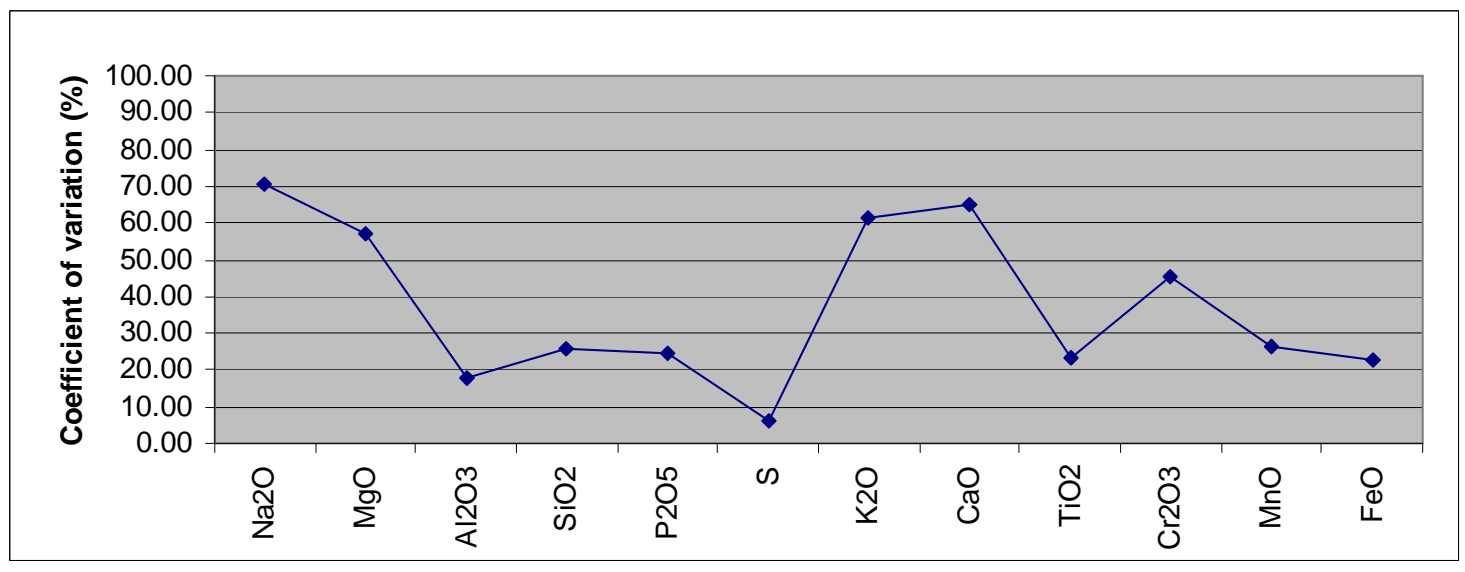

Fig. 6.6 11 Coefficient of variation throughout SB1 from the site of KBE

However, when the chemical variability is explored in more detail, it is also possible to support the alternative view, that it is indeed, one single smelting event. The main differences between the various layers of the slag are shown in the iron oxide levels, which are much higher in the middle sample, and in the potential fuel ash components (lime, magnesia, and to a certain extent, potash), which are enriched in the top and bottom of the block. This variability could thus be due to a higher ore to fuel ratio in the middle of the smelt, contrasting with a more fuel-rich charge at the beginning and the end of the smelt. When plotted in the phase diagram (fig. 6.6.10), the middle sample (B), appears in the optimum two, denoting 'ideal' conditions. The other two samples of this block plot further from the $\mathrm{FeO}$ apex but still on the sample low-temperature trough, towards an area of the diagram that may be indicative of higher ceramic and/or ash contribution (Rehren et al 2007), while being consistent with broadly similar operating temperatures.

Microscopic examination of the samples taken throughout SB1 agrees with the bulk chemical results. SB1 sample C (fig. 6.6.12), contains few free iron oxides, and instead is dominated by fayalite (F). SB1 sample B (fig. 6.6.13), contains a higher proportion of iron oxides, as the dominance of wüstite (W) indicates. Finally SB1 sample A (fig. 6.6 14 ), with a potash content of over $6 \%$, is seen to be dominated by regions of kalsilite $(\mathrm{K})$. 


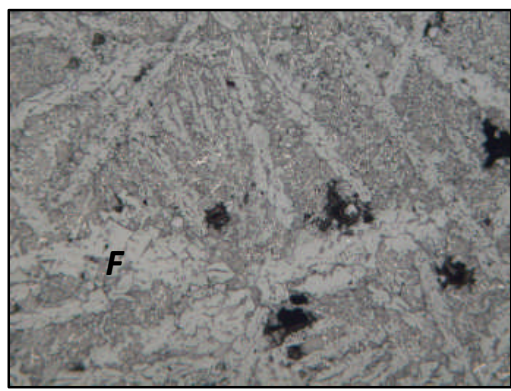

Fig. 6.6.12 PPL photomicrograph of SB1 sample C, displaying long lathy fayalite crystals

(50x, image width $2 \mathrm{~mm}$ )

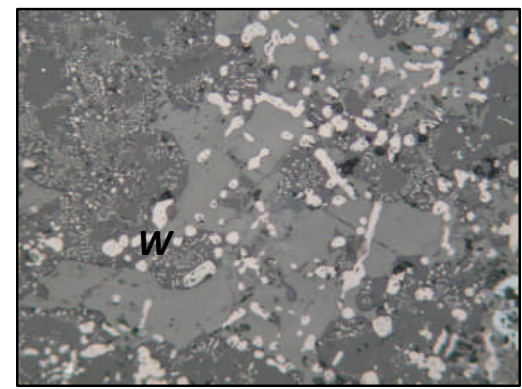

Fig. 6.6.13 PPL photomicrograph of SB1 sample B, illustrating a higher dominance of iron oxide as wüstite

(100X, image width $1 \mathrm{~mm})$

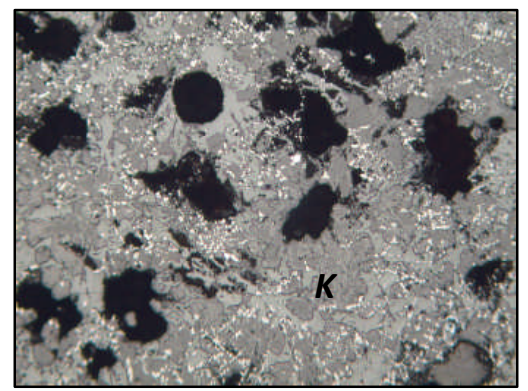

Fig. 6.6.14 PPL photomicrograph of SB1 sample A, showing a very porous texture with abundant kalsilite

(50x, image width $2 \mathrm{~mm}$ )

The second sample taken for analysis, SB2, would appear to represent a ceramic-rich slag. The alumina levels are on average double that found in the samples from SB1, while the same is true of the level of silica. Conversely, the iron oxide level in the sample is at least half of that within the true slag samples.

\section{- Technical Ceramics}

The analytical results for the tuyere sample (table 6.6.4) are consistent with its very slagged appearance. With over 50\% iron oxide content, its composition lies in between those of the slag and the less contaminated ceramic pit lining, as shown in the plot in the phase diagram (fig. 6.6.10).

The ceramic used to form part of the structure of the furnace pit has a particularly low alumina to silica ratio, of 1:4.2, and this reflects the very quartz rich nature of the clay fabric used. When compared to the bulk chemical composition of SB1 and the other samples taken from the site, they appear to plot in a nearly perfect straight line within the phase diagram (fig. 6.6.10). This would suggest that they represent a continuum, from SB1 to the pit lining, with the slagged tuyere and SB2 in the middle. In general it would therefore seem that the ceramics at this site did melt during the smelting operations and contributed to the slag formation. This may be partly explained by the comparatively low alumina levels in the ceramics $(\approx 17 \%$, compared to $\approx 30 \%$ in other 
technical ceramics in the region) which would render it less refractory and thus prone to melting.

\begin{tabular}{ccccccccccccccc} 
& $\mathbf{N a}_{2} \mathbf{O}$ & $\mathbf{M g O}$ & $\mathbf{A l}_{2} \mathbf{O}_{3}$ & $\mathbf{S i O}_{2}$ & $\mathbf{P}_{2} \mathbf{O}_{5}$ & $\mathbf{S}$ & $\mathbf{K}_{2} \mathbf{O}$ & $\mathbf{C a O}$ & $\mathbf{T i O}_{2}$ & $\mathbf{V}_{2} \mathbf{O}_{5}$ & $\mathbf{C r}_{2} \mathbf{O}_{3}$ & $\mathbf{M n O}$ & $\mathbf{F e O}$ \\
& $\%$ & $\%$ & $\%$ & $\%$ & $\%$ & $\%$ & $\%$ & $\%$ & $\%$ & $\%$ & $\%$ & $\%$ & $\%$ \\
\hline tuyere & 1.07 & 0.59 & 9.47 & 31.70 & 0.37 & 0.13 & 3.24 & 1.75 & 0.21 & 0.04 & 0.03 & 0.07 & 51.18 \\
f1 pit lining & 3.13 & 0.56 & 16.93 & 71.84 & 0.15 & 0.00 & 2.79 & 1.52 & 0.24 & 0.01 & 0.04 & 0.03 & 2.53
\end{tabular}

\begin{tabular}{llllllll} 
& CuO & ZnO & Rb2O & SrO & ZrO2 & BaO & $\begin{array}{l}\text { Original } \\
\text { total }\end{array}$ \\
& ppm & ppm & ppm & ppm & ppm & ppm & $\%$ \\
\hline tuyere & 34 & 32 & 58 & 229 & 113 & 499 & 105.27 \\
f1 pit lining & 62 & 69 & 174 & 248 & 121 & 759 & 90.99
\end{tabular}

Table 6.6.4 (P)ED-XRF compositional data obtained from the technical ceramics taken from KBE. Results have been normalised to $100 \%$, and taken from the average of three XRF runs. Only trace elements above $50 \mathrm{ppm}$ are shown. Full results are given in appendix 6B

\subsubsection{Site Interpretation}

The site at KBE represents a technological style not observed anywhere in the wider region until now, with the smelters making use of a rock surface to construct part of a furnace pit. The shape of this rock, which appears to mould perfectly to the ceramics used to form a circular plan, and conical profile, may have been a natural occurrence that the smelters took advantage of. It may, however, also have been part of an old grinding hollow, although appearing much deeper and wider than those a few meters away from the metallurgical structure. The smelters either knew from the agricultural grinding that the rock in this area could be ground into a desired shape, or they made use of a particularly large old grinding hollow. The question of why the smelters would do this could perhaps be linked to the unavailability of refractory ceramics.

Unfortunately, no date is known for the smelting represented within $\mathrm{f1}$, and even if a date was known, the chronological relationship between the metallurgical and 
agricultural evidence remains elusive. At all of the sites studied, the people living around the archaeometallurgical remains had no idea that they represented past iron production. It is feasible therefore, that the people who once ground grain on the rocky outcrops next to f1, did not know what the furnace or the slag were, if the metallurgy preceded the agricultural activity. The alternative, rather than one of these practices following the other temporally at the site of KBE, is that the men of this area smelted while the women ground grain, either at the same time or perhaps seasonally. Ultimately, the traditionally accepted taboos against women being present around furnaces, and smelting taking place away from habitation sites, has not been proved either way during this study.

A quantification of production at this site will not be attempted due to a lack of data. This site was excavated at the very end of the project and under specific time constraints. Although the question remains as to why the choice to incorporate a furnace pit into rock was made, even with more time available, it is difficult to imagine how this question could be answered.

$\mathrm{KBE}$ represents the second site within the survey zone where a tentative link between metallurgy and agriculture can be suggested, and certainly provides a whole new technological style to the repertoire of Rwanda's past metallurgists. 


\subsection{Summary of archaeometallurgical results}

The six iron production locations investigated within this chapter (table 6.7.1) have provided a substantial amount of information concerning past technological traditions in Rwanda, which complement and refine what we knew about this topic in a number of ways. Despite the lack of dates for some of the sites, the new data can be integrated with previous scholarship on iron smelting traditions in Eastern Africa to attempt a synthetic picture. Within the following sections, the archaeological and analytical results will be compared, trying to offer an outline of how iron smelting technologies changed over time, before presenting a broader contextualisation and discussion in chapter 7 .

\begin{tabular}{|c|c|c|c|c|c|}
\hline Site & Date & Pit shape & $\begin{array}{c}\text { Average SB } \\
\text { weight (kg) }\end{array}$ & $\begin{array}{c}\text { Average slag } \\
\text { weight at site } \\
\text { (kg) }\end{array}$ & $\begin{array}{c}\text { Estimated } \\
\text { output (kg) }\end{array}$ \\
\hline Gahondo & Early & $\begin{array}{c}\text { Deep } \\
\text { cylindrical }\end{array}$ & - & - & - \\
\hline Cyamukuza 1 & Middle & Deep conical & 95 & 2470 & $2000-5750$ \\
\hline Cyamukuza 2 & Middle & Deep conical & 77 & 3000 & $3000-8000$ \\
\hline Mpinga & Middle/Late & $\begin{array}{c}\text { Shallow } \\
\text { conical }\end{array}$ & 147 & 1764 & 1023 \\
\hline Kamana & Middle/Late & Shallow & 70 & - & - \\
\hline Kamabuye & Middle/Late & Shallow & - & - & - \\
\hline
\end{tabular}

Table 6.7.1 Site details

\subsubsection{Spatial and morphological comparisons}

A number of factors concerning the general location, organisation and morphology of iron smelting structures can be reviewed. The first of these aspects is the geographic location of the smelting locations. The Early Iron Age smelting site (GHD) was located on the middle of the hill slope, almost equidistant from the top and bottom of the hill. 
CMZ 1 (tenth century AD), was situated on the crest of a hill, while CMZ 2 (thirteenth century AD), was located in a similar location to GHD, in the middle of a hill slope. MNA, KMA and KBE were all close to the ridge tops of hills. As already noted by Van Grunderbeek (et al 1983), the archaeological evidence thus indicates that the smelters located their production sites around the upper regions of the hills. Considering the whole area is undulating and hilly, this choice is logical and to some extent unavoidable, as opposed to smelting in the valley bottoms, which at least today are often water-logged.

Turning to more specific contextual associations between smelting and other activity areas, it was somewhat frustrating that the numerous test pits excavated during the course of fieldwork provided no archaeological stratigraphy or contextualised archaeological evidence. This could indicate that smelting was carried out away from habitation sites, perhaps to keep the methods secret, or possibly owing to taboos such as ensuring that women did not come into contact with the production episodes and cause the smelts to fail (as documented ethnographically - see chapter 4). However, this dearth of materials other than the smelting debris may simply be a result of poor preservation of archaeological remains, not least due to the severe level of erosion which affected all the production sites selected for excavation during this research. A frustrating lack of associated archaeology was also encountered by Van Grunderbeek (et al 1983) during her excavation of Early Iron Age furnaces in the area.

Conversely, Schmidt has claimed to have found a house floor in association with Early Iron Age furnaces at Kemondo Bay in North-Western Tanzania (Schmidt and Childs 1985, 1996: 197-199). Clearly, more data are needed before any sweeping conclusions can be made as to the spatial relationships between smelting and habitation sites. In terms of location, however, an interesting association has been indicated between smelting and grinding structures at the sites of KMA and KBE, which suggests potentially meaningful links between metallurgy and agriculture. Although the temporal relations between the two activities taking place in the same space remain to be ascertained, this aspect deserves further attention and will be briefly addressed in the next section. 
When considering the morphology of the furnace pits (fig. 6.7.1 - fig. 6.7.6), it is apparent that unlike the later (or presumed later) structures, the early furnace excavated at GHD has a cylindrical shape with vertical sides, almost perpendicular to ground level (as noted in the second furnace at this site). The furnaces at CMZ 1 and CMZ 2 appear to have the most conical shaped furnace pits, while MNA, KMA and KBE have concave, less acute bases. Of course, it is recognised that the significant level of erosion noted at each site has more than likely affected the remains of the furnaces excavated for this research. For example, the slag blocks at MNA were deeper than the furnace base recorded at the site. However, these differences in profile potentially denote systematic variations in furnace design. One aspect of the furnace pits that can be definitively noted is the lack of identifiable 'ritual' deposits or any other significant cultural feature below or within any of them.

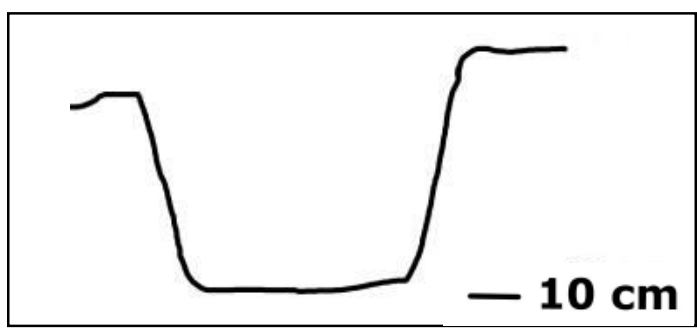

Fig. 6.7.1 GHD f1 section

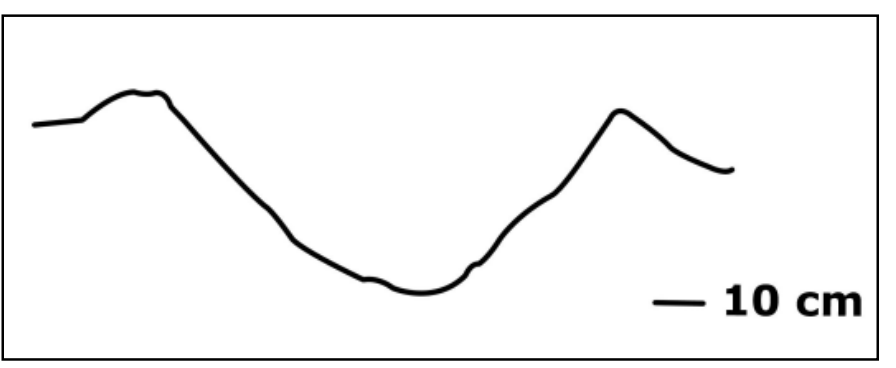

Fig. 6.7.3 CMZ 2 f1 section

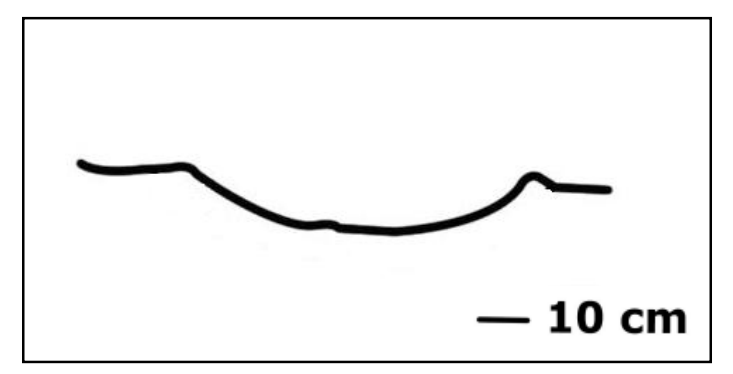

Fig. 6.7.5 KMA f1 section

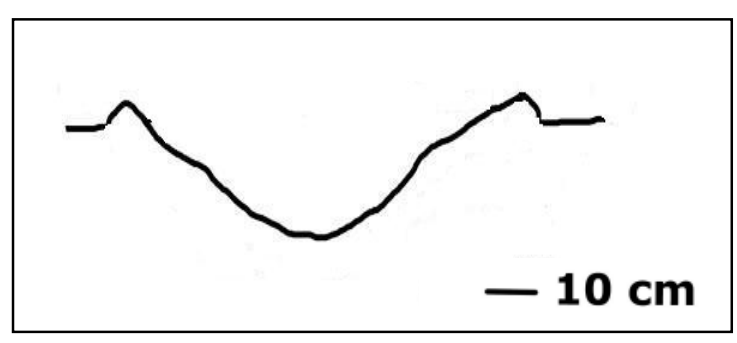

Fig. 6.7.2 CMZ 1 f1 section

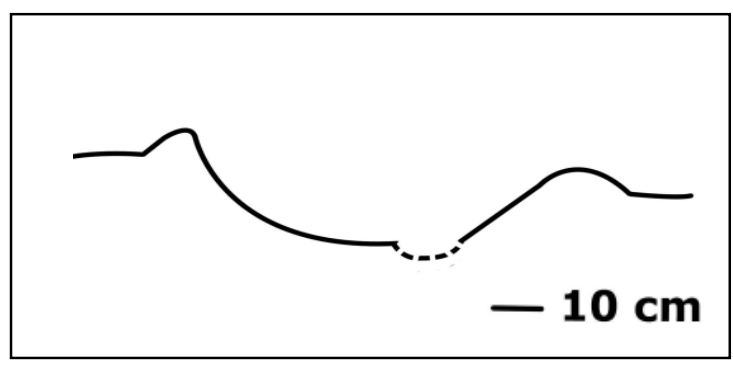

Fig. 6.7.4 MNA f1 section

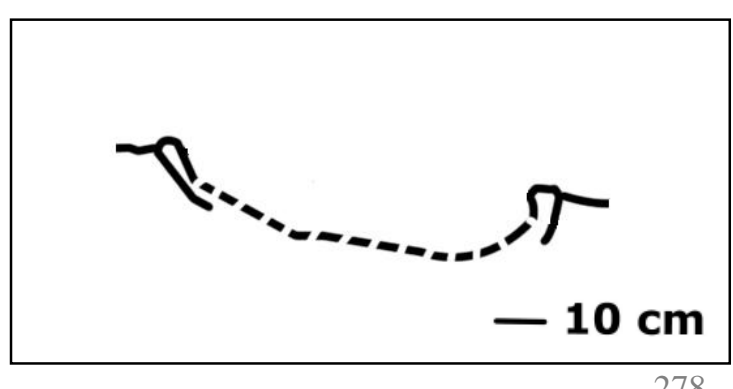

Fig. 6.7.6 KBE f1 section 
Van Grunderbeek et al $(1983 ; 2001)$ have suggested that it is possible to estimate the dimensions of the superstructures of Early Iron Age furnaces utilising measurements of the bricks used in construction and the angle of the pit walls (fig. 6.7.7). In the case of GHD, poor preservation prevents any reliable estimate of this kind. However, in any case, the work of Celis (1987: 56-158) has illustrated how variable furnace construction was in Rwanda, at least in more recent times. He documented as both deep and shallow pits with no significant form of superstructure (fig. 6.7.8; 6.7.9), as well as deep and shallow pits with significant superstructures (fig. 6.7.10; 6.7.11). Unfortunately slag morphology was not noted in this study and so no comparisons are available concerning this aspect of the ethnographic smelting traditions. Thus, any reconstructions based on the preserved features must remain tentative at best.

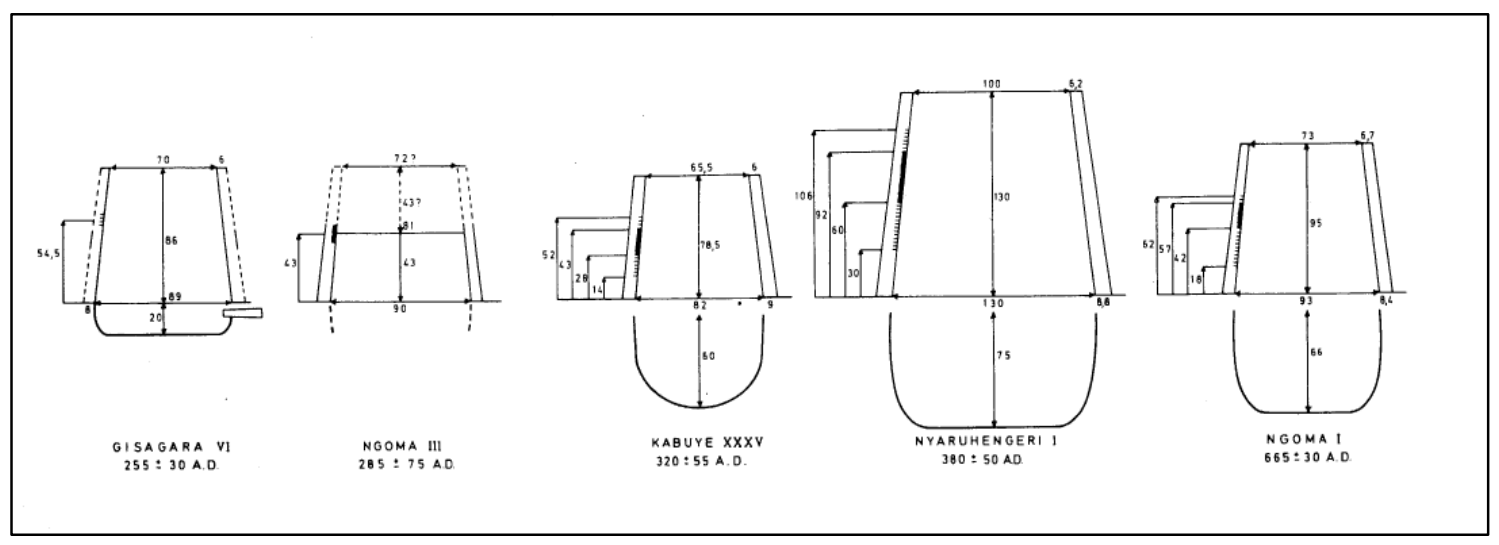

Fig. 6.7.7 Reconstructions of Early Iron Age furnace superstructures (after Van Grunderbeek et al 1983: 20). 


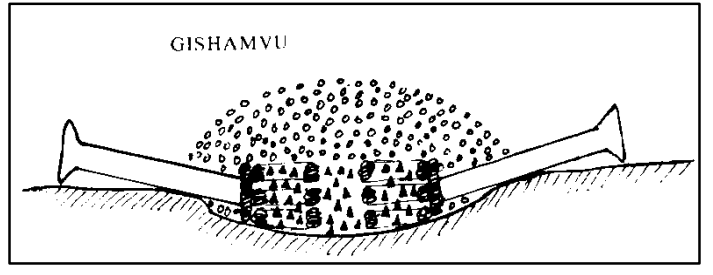

Fig. 6.7.8 Shallow furnace pit with no defined superstructure (after Celis 1987: 63)

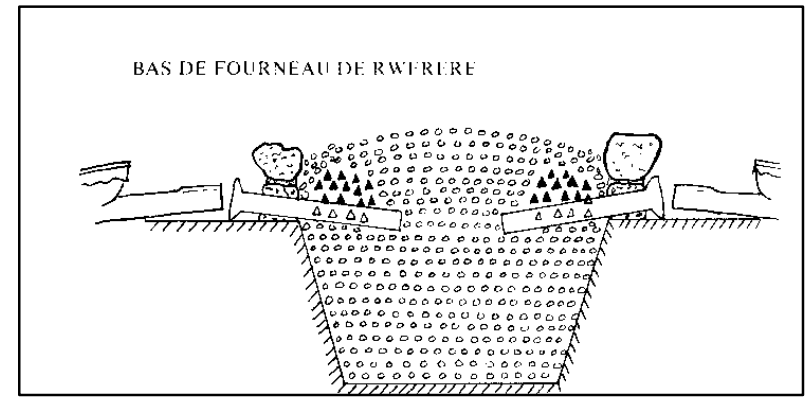

Fig. 6.7.9 Deep furnace pit with no defined superstructure (after Celis 1987: 140)

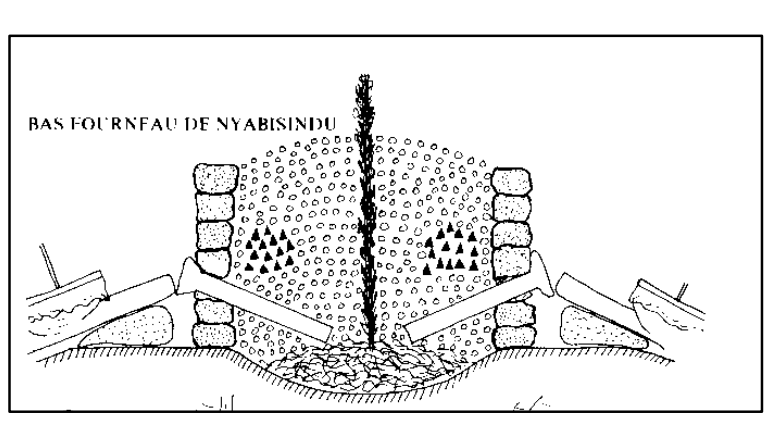

Fig. 6.7.10 Shallow furnace pit with defined superstructure (after Celis 1987: 109)

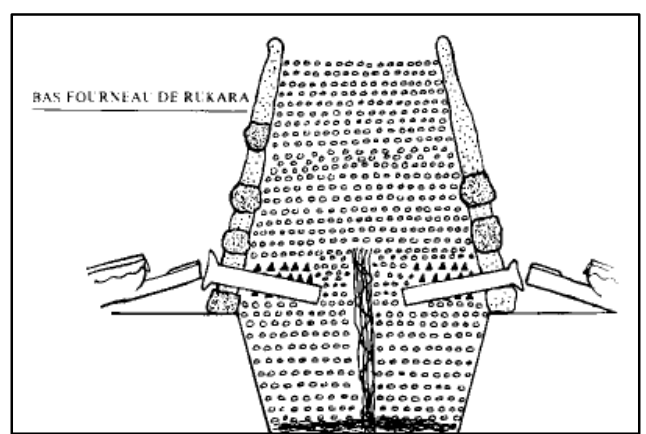

Fig. 6.7.11 Deep furnace pit with defined superstructure (after Celis 1987: 144)

The significant weight of the slag blocks located at some of the sites excavated during this study initially led to the inference that some form of superstructure would have been necessary to contain the vast amount of charge and ore that would have been processed to create such large slag blocks. This possibility was endorsed during the construction of the furnace used during the experimental smelt (see chapter 2), which was created with a pit $28 \mathrm{~cm}$ deep and superstructure $70 \mathrm{~cm}$ high from ground level (fig. 6.7.12), allowing the processing of a very substantial amount of charcoal and ore. However, the ethnographic data above illustrates that such shafts were not an essential need for past furnaces, and thus highlighting the danger of imposing modern logic to the archaeological past. 


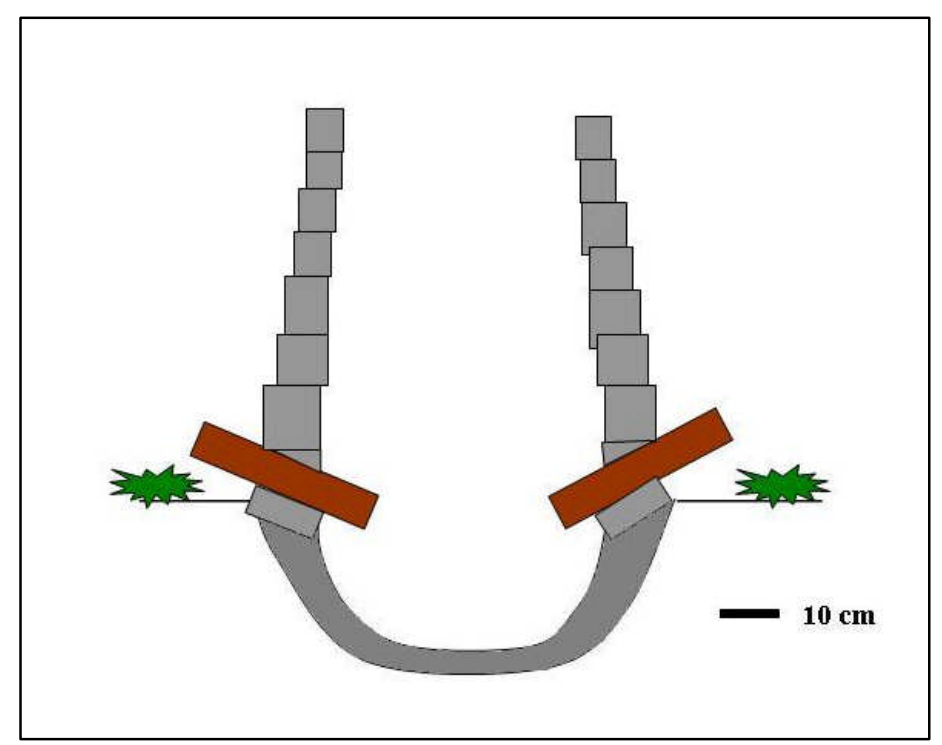

Fig. 6.7.12 A schematic diagram of the furnace constructed during this research (see chapter 2)

Tuyeres constitute another dimension of the smelting installations that has proven very difficult to assess. Where domestic pottery was found at the sites, however, comparison with the technical ceramics systematically showed that both types of materials were made of respectively different fabrics. Technical ceramics were generally more refractory, as evidenced in their typically higher alumina levels, and thus more capable of withstanding the temperatures reached and maintained during the presumably long smelting episodes. Whether this indicates that the smelters deliberately selected specific clays for technical ceramics, using other clay sources to produce pottery, or that the smelters acquired domestic pots from pottery specialists elsewhere, is unknown, but the pattern in the association between higher alumina and technical ceramics is unlikely to be coincidental. The only potential exception appeared at the site of KBE, where the technical ceramics showed only a moderate alumina level. Also unknown is how many tuyeres were used per smelt, and the extent to which this number varied across the smelting locations. What we can assume is that the absence of tuyere fragments at some sites is more than likely due to significant erosion, rather than a real lack of these features being used during production. 
Another type of evidence that is clearly missing is material related to smithing activities, which leads to the notion that smelters and smiths were different specialists or, at least, that these activities were carried out at different locations. Other than KMA, none of the sites provided any indication that the forging of iron objects took place in close proximity to the smelting furnaces - and even at that site the technological or chronological link between the smelting and the smithing debris could not be established with any certainty. Although smithies do not generate the same amount of visible debris as smelting sites, smithing slags must have been produced somewhere. Perhaps future surveys, targeting less conspicuous iron remains, will succeed in shedding light on this aspect of the chaîne opératoire.

In general terms, and in spite of the unavoidably fragmentary nature of the data, the archaeological remains indicate that, at some point between the eighth and tenth century $\mathrm{AD}$, a technological transition occurred. The approach to smelting moved away from the well established use of (in part decorated) bricks to construct the superstructures of furnaces. Instead, smelters began to build their furnace shafts on top of less cylindrical pits and, if a superstructure was built on top, this was made from material that leaves no apparent archaeological trace. It is tempting to suggest that the absence of evidence for furnace walls in the later furnaces could indicate a more roughly assembled, plain clay structure - perhaps more prone to weathering into less recognisable remains -, or possibly one combined with old slag blocks, as seen in later times (Celis 1987: 123). The alternative is that superstructures stopped being used at all - a possibility again illustrated in some ethnographic examples (Celis 1987: 63). Potential reasons for this technological shift, which also seemed to entail a move away from overt artistic or decorative expressions, are discussed in the following chapter.

\subsubsection{Chemical comparisons}

Combined with the macroscopically apparent technological transition, was a new technical approach to the reduction of iron ore. Within these new furnace styles, rather than producing smaller fragmented slag in droplets and flows (Schmidt \& Childs 1996: 208-209; Van Grunderbeek et al 2001: 288), the smelters began to create large 
continuous slag blocks weighing up to $200 \mathrm{~kg}$ (see section 6.6.4). The technological change representing such a shift most likely incorporated the use of a more significant amount of material per smelt and also, possibly, the use of different types of ores.

The higher levels of alumina in later slag samples created a more viscous slag which perhaps moved slower through the furnace and into the furnace pit. The higher temperatures necessary to smelt these high alumina ores allowed for the agglomeration of this viscous slag within the pits before freezing and solidification began.

The composition of the slag samples analysed throughout this study, notably their alumina levels, appear to support such a hypothesis. Within the samples analysed from GHD f1, the slag sample had an alumina level of less than $7 \%$, and all the ore samples identified in $\mathrm{f} 2$ contained less than $2 \%$ alumina. Only one ore sample from $\mathrm{f} 1$ showed a high alumina content, but this was just as high as the silica level, and simply reflected the low iron content of the sample. This contrasts with averages of over $11 \%$ alumina in the CMZ 2 slags, and nearly 9\% in the CMZ 1 slags, with the slag samples from the other sites lying in between. The slags produced at the later sites had higher alumina to silica ratios (although CMZ 1 is more similar to GHD in this respect). It would thus appear tempting to suggest that later smelters used ores with higher alumina contents. However, it has to be acknowledged that the single slag sample from GHD $\mathrm{fl}$ is unlikely to be representative of the whole iron smelting technologies of the Early Iron Age. In addition, analyses of slags from other early furnaces in the region have shown alumina levels comparable to those of the later slags analysed here (Craddock et al 2007).

Whatever the case, the relatively elevated alumina levels in the slag samples created a viscous slag which required higher operating temperatures to coalesce and drip down into the pits. Clearly, achieving and maintaining these temperatures was within the ability of the smelters, as demonstrated by the virtual lack of unreacted grains documented in the slag microstructures, and by the fact that the slag collected at the bottom of the furnaces forming a continuous block. However, dealing with these alumina-rich ores may have demanded a more regular adjustment of the operating 
parameters to ensure a successful smelt, resulting in higher variation within and, especially, between slag blocks.

Taking the average alumina level from the middle samples from each of the five slag blocks analysed from each site, CMZ 2 displays the highest values (11.4\%), followed by MNA (10\%), CMZ 1 (8.7\%), and finally KMA (8.4\%). When the coefficients of variation within and between smelts are compared, it becomes apparent that those systems with higher alumina levels (CMZ 2 and MNA) generally result in more variable operating parameters (fig. 6.7.13). A comparison of the coefficient of variation within one block per site (fig. 6.7.14), also indicates that an increased level of alumina within the charge leads to a more heterogeneous smelt and slag, with the slag blocks from CMZ 2 and MNA displaying the higher levels of variation.

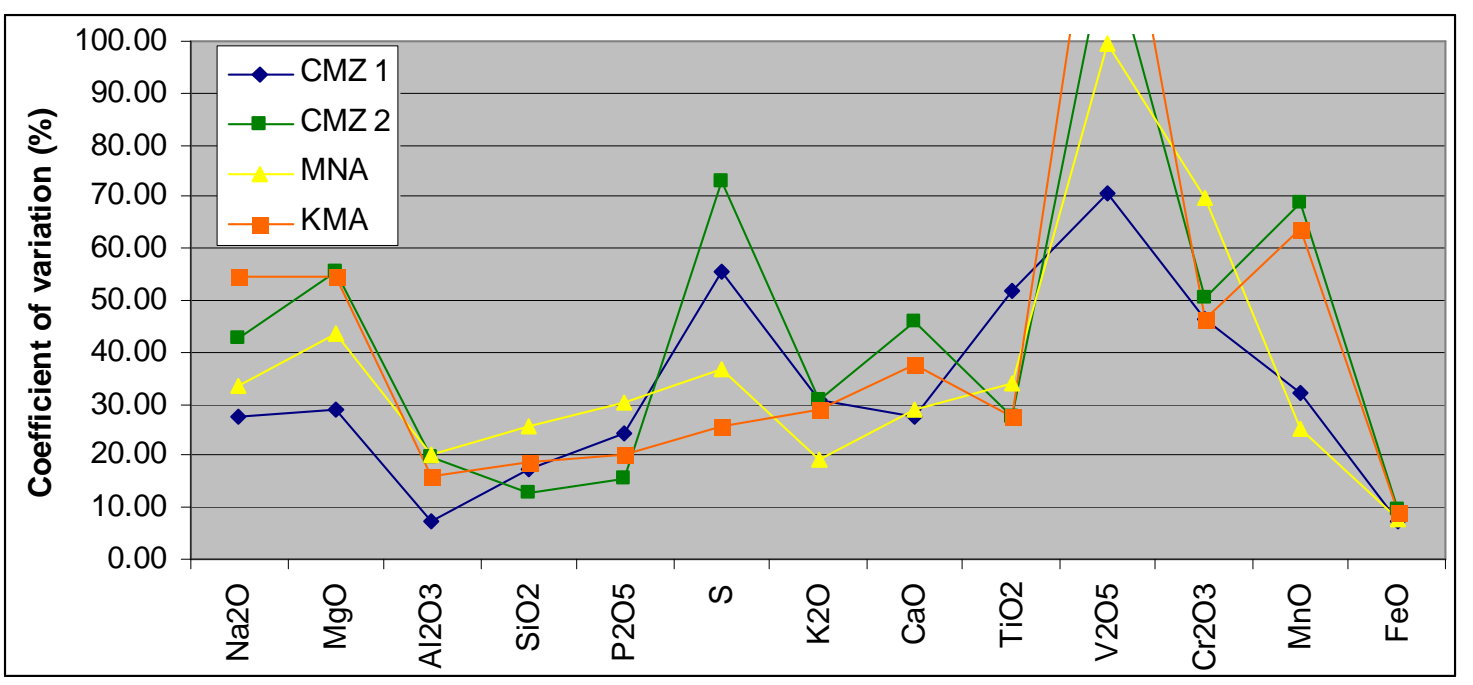

Fig. 6.7.13 Coefficient of variation throughout oxides within all of the five slag blocks at each site 


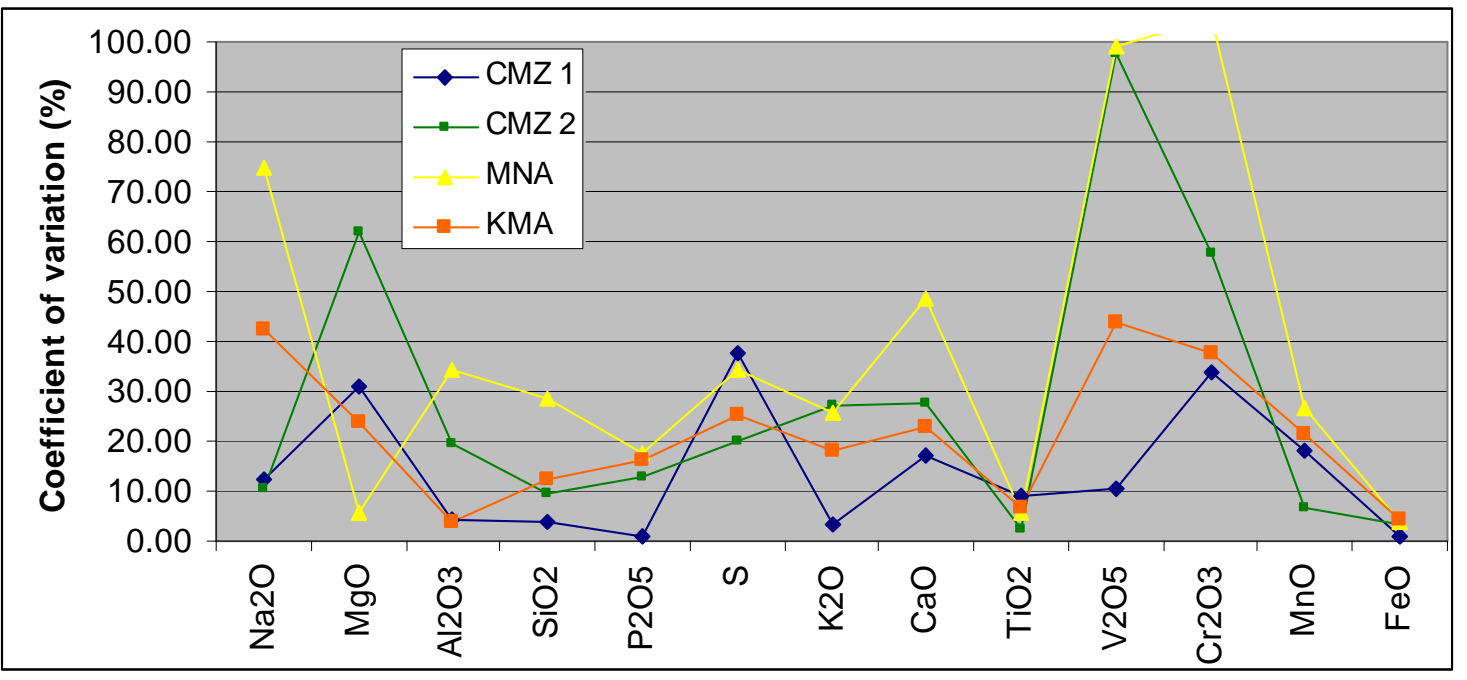

Fig. 6.7.14 Coefficient of variation throughout one block from each site

To consider further the relationship between variable alumina levels and the smelts carried out at the sites investigated, silica and alumina can be plotted against each other (fig. 6.7.15). The graph illustrates the relatively high diversity of compositions within and between sites but also the lack of any correlations between both oxides (with CMZ1 as the only possible exception). If the main source of alumina in the slag had been a ceramic contribution (as contended, e.g. in Craddock et al 2007), one would expect a positive correlation between silica and alumina. This lack of correlation therefore supports the inference that at least some of the alumina in the slag is likely to have come from the ore. 


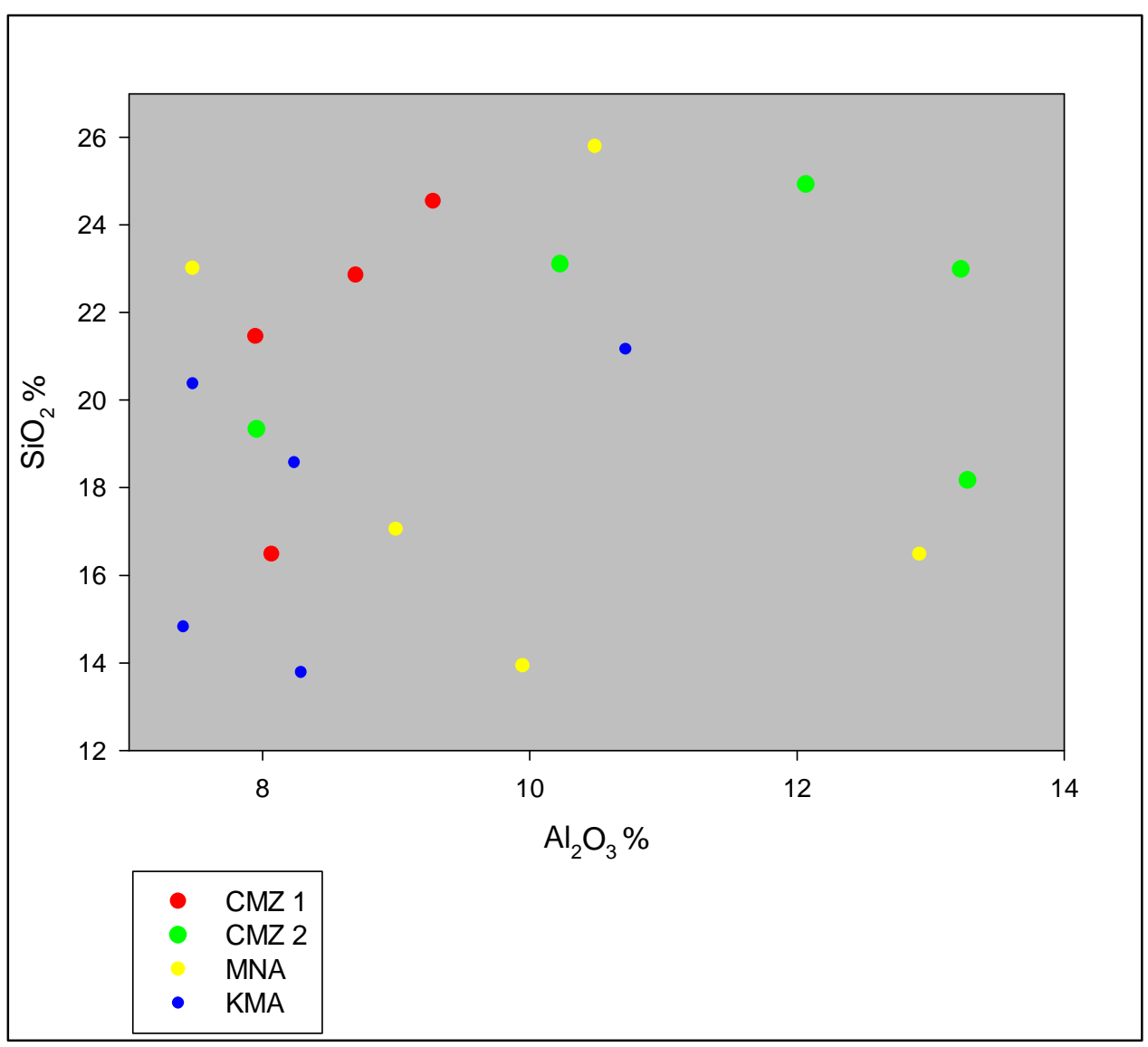

Fig. 6.7.15 Scatterplot of alumina and silica within the slag samples from the sites of CMZ 1, CMZ 2, MNA and KMA. GHD and KBE are not included due to the likely less representative nature of the samples collected at these sites

When the average compositions of all of the slag blocks analysed, alongside the slag sample from GHD and the most typical slag sample from KBE, are plotted within the $\mathrm{FeO}-\mathrm{SiO}_{2}-\mathrm{Al}_{2} \mathrm{O}_{3}$ phase diagram (fig. 6.7.16) the samples can be seen clustering towards the optimum 2 zone (Rehren et al 2007), leaning on the hercynite side. This hercynitic nature of the slag, also documented through the microscopic study, seems unusual when compared to the typical fayalitic composition ascribed to iron smelting slag in general (Rehren et al 2007: 212). However, alumina-rich (and thus hercynite-rich) slags are not uncommon in East Africa (Humphris et al 2009), and they simply reflect the different nature of the ores employed. Therefore, while the high alumina levels within the Rwandan ores and slags were not particularly unusual, they did create different challenges for some of the smelters. 


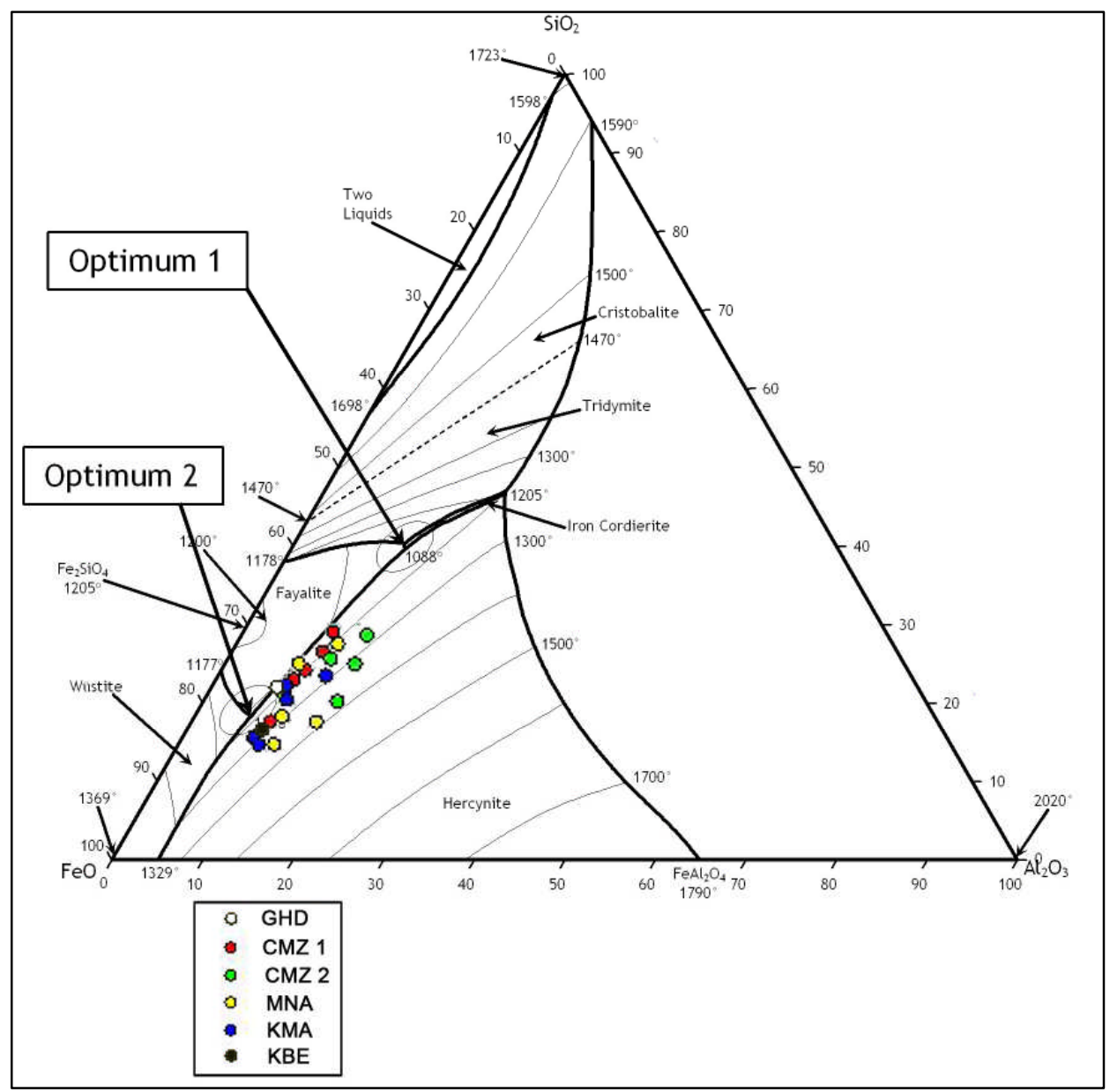

Fig. 6.7.16 FeO-SiO $2-\mathrm{Al}_{2} \mathrm{O}_{3}$ phase diagram of all slag samples (taken from Rehren et al 2007: 212)

The pull towards the optimum 2 zone appears in agreement with the relatively limited contribution of technical ceramics to slag formation, as has been indicated in the preceding sections.

In general, it can be safely said that the archaeometallurgy of iron smelting in Rwanda demonstrates the existence of a long and successful array of technological traditions where smelters successfully adjusted parameters to technical and social constraints in order to achieve satisfactory yields. In the case of GHD, the smelters broadly followed a technological approach that existed within the immediate vicinity and across a much wider region for around 1000 years. Those making iron at CMZ 1 appear to have had a very significant control over smelting procedures, which were kept constant both within 
and between smelts. At CMZ 2, perhaps because the highest grade ore had been exhausted, or perhaps access to this had been restricted by other smelting groups not studied as part of this project, the smelters were using a different ore to the CMZ 1 smelters working before them in the same location. However, they adapted their engineering parameters to the extent that they could operate on an industrial scale. The smelters working around the sites of MNA may have built particularly large furnaces to induce a stack effect to aid in reaching the higher temperatures necessary to smelt. At KMA, two distinct smelting techniques - manifest in slag pits and slag tapping - seem to have been in operation. The reasons why the smelters at KBE built a furnace and smelted within a rock substrate remain unknown, and this technological approach appears to be unique to the region.

It is unfortunate that, in spite of the efforts to obtain reliable dating, it is not possible to confirm a Kingdom period date for any of the production remains. However, as described in chapter 4, it is well known that this Kingdom, like others across the region, consumed huge quantities of iron. Considering the large number of production sites located during survey, not only in this very small area next to Butare town, but across the country (Giblin 2008; 2010), there is little doubt that some of the smelting installations will in due course yield dates consistent with this period. While we await more extensive work in the area, the data so far obtained allow a preliminary yet suggestive picture of a long history of indigenous iron metallurgy in Rwanda - one that was inevitably embedded in the changing sociocultural systems that enabled and required its very existence. 


\section{7 \\ The broader role of iron production in Rwanda}

As chapter 6 has demonstrated, this study has succeeded in generating important new data on the archaeometallurgy of iron production in Rwanda. A large number of archaeological sites have been discovered and excavations have examined the remains of ten furnaces within six production locations. The detailed examination of smelting episodes allows a fresh consideration of the changing nature of iron smelting over time. This chapter will contextualise and interpret the results generated during this research and lays important foundations upon which future studies can build. Combining this new data with the broader understandings of history within the Great Lakes region, and specifically in Rwanda (as outlined in chapter 4), will enable insights into past Rwandan smelting traditions, and their changing role over the last two and a half thousand years. Once again this is necessarily a preliminary stage in constructing such technological histories and the scope is necessarily crude, but nevertheless these are important first steps which will enable much more sophisticated understandings to be generated in the future.

This chapter will begin by exploring technological production, and the role and function of the objects produced during the Early Iron Age. Following this, the Middle Iron Age will be evaluated from a technological point of view. It is during this time that technological transitions are visible in remains of material culture. Finally the technologies of the Later Iron Age or Kingdom period will be considered. By this time it is clear that the symbolism of iron production and iron objects were intertwined social and political structures of the region (e.g. Celis 1987: 17-55; de Maret 1985; Reid \& MacLean 1995). It is likely that iron has always been an embedded technology rooted in the cultural beliefs of its producers and the consumers. Despite the emphasis on the Early Iron Age, Middle Iron Age and Late Iron Age, it is recognised that the region and these phases of time are by no means homogenous. These temporal units are used for simplistic structural purposes, and discussion will emphasise local variation and the 
complex mosaic of technological and cultural traditions within this area and throughout this period.

\subsection{The Early Iron Age (c. 500 BC - AD 800)}

As described in chapter 4, the results of archaeological, linguistic and palaeoecological research has helped paint a tentative picture of society and life during the Early Iron Age period. Food production, and more specifically, "the production of agricultural surplus to support smelters and smiths and the existence of a sufficiently robust farming sector to create demand for iron hoes" (Schoenbrun 1993: 3), as well as cattle, played an integral role in the lives of the people living during this early period. Gradually, groups were responsible for the clearing of forest environments, mainly to facilitate shifting cultivation, but in the process also providing the raw material for the charcoal needed in iron production, and new grazing in the clearings that emerged. This process also led to the expansion of settlement onto new lands. Iron would have played an important role in this process, hoes and axes helping to enable the clearing of the land.

Interwoven into this period are the technologies of iron and ceramic production, and it seems that people very quickly became skilled in these specialist technological endeavours. What characterises them both during this early period is the apparent artistic skill, aesthetic values and the high level of attention to detail which was applied to both the production processes and the objects produced.

Ceramic data from this period has indicated that a general Urewe template existed, with artisans producing very fine wares with artistically complex decoration (Stewart 1993:23). The vessels produced at this time are indicative of "a society with relatively complex and structured processes of food preparation, cooking and consumption" (Ashley forthcoming). However, within this intricate and artistically demanding tradition there were variations to the 'norm' across the region, as well as different styles altogether. Identified ceramic groups, such as Contact Urewe, with a coarser fabric and a lack of decoration, suggest that while some communities were true to the Urewe style and principles behind the chaîne opératoire, others were applying different technical choices to produce a variety of styles of pottery (Ashley 2006, forthcoming; Lane et al 
2007). The ceramic evidence "shows communities who selectively change, reformulate, borrow and share, and who collectively create a vibrant multi-cultural mosaic" (Ashley 2006: 303; see also Ashley forthcoming). Ceramics found to the south-west in DRC dating to a chronologically similar period, also indicate that it was the earliest ceramic traditions which displayed the most complexities, as well as a significant level of variation within the broader tradition (de Maret 2005: 430).

Within early iron production traditions it is tempting to seek parallels with ceramic production during this early period. Ultimately, iron smelting is bound within a "narrow window of temperature and gas composition, which tends to impose rather strict limits upon individual departures from a successful process" (Killick 2004: 109). Therefore the smelting operations carried out within these furnaces cannot necessarily be said to have involved a more intricate technological approach than in later times. However, the results of the excavations and analysis carried out at the site of Gahondo during this research have added depth to our understandings of iron production during this early phase. Previous research dated furnaces around the hill of Gahondo to AD 270-330, AD 350-630 and AD 560-660 (calibrated dates, see Van Grunderbeek 1992: 56-58). The newly analysed furnaces excavated as part of this research fall towards the mid-late period of this long-term iron production location. Thus the iron producers living around or on the hill of Gahondo operated furnaces over hundreds of years, and could even represent generations of the same lineage, passing on traditions and practices.

The Gahondo smelters produced iron by working with high grade ores in decorated furnaces. They may have mixed ores of differing qualities, as well as adding a silicarich flux to their smelting operations and they may have employed a two-stage process of roasting ores during smelting operations. At Gahondo, although an unusual archaeometallurgical situation was initially encountered during this research, with iron oxide levels of over $95 \mathrm{wt} \%$ in the material classified as 'slag', reasonable explanations can now be posited to explain such findings. The molten, partly reduced, ore found in GHD F1 was located mainly attached to the pit lining around the edges of the furnace pit itself, and so could well represent a method of roasting in preparation for future smelts which has parallels elsewhere. In North-Western Tanzania the presence of pits filled with roasted ore has led to the identification of an ore roasting stage at the EIA 
smelting sites at Kemondo Bay (Schmidt \& Childs 1985, 1997). In addition, the modern Haya informants demonstrated that they roasted ore within smelting furnaces by placing it around the edge of the smelt itself (Childs 1997: 286).

Therefore on this particular hill, as on a number of adjacent hills (including that of Kabuye - see Van Grunderbeek et al 1983; Van Noten 1983), people were smelting iron for over a 400 year period, and the technological style applied to this process, and to the Urewe ceramics they were producing and/or using, seem to have been fairly constant. Using different clay from that used to make Urewe ceramics, they seem to have been producing refractory bricks to construct the furnace superstructures that were designed to slot together, and the collection of well preserved bricks beside furnace 2 at GHD indicates that the structure may have been carefully dismantled following a smelting event. Due to a lack of detailed scientific analysis of these previously excavated smelting sites, further comparisons are unfortunately impossible.

The metallographic analysis carried out by the author on two iron objects excavated from an Early Iron Age burial within the vicinity of Gahondo (see chapter 5; Giblin 2008, 2010, et al forthcoming), also sheds light on the role of iron objects during this period. A date of AD 417 to 554 (2 sigma calibration) has been obtained for the burial, which also contained intensely decorated Urewe vessels, beads and a cowrie shell which must have originally travelled all the way from the coast (Giblin 2008; 2010). This burial was clearly either high-status or of considerable ritual significance, with trouble taken to fill the grave with prestigious or symbolically significant grave goods (Giblin 2008, 2010, et al forthcoming).

The preserved iron objects were all body adornments, including two bracelets, one necklet, and one hollow iron disk (fig. 7.1). The fact that these iron items were made to be decorative, and that the person wearing them may well have been an important individual, provides one of the first insights into the social use of iron during these early periods in the Great Lakes region (although see also Childs 1996).

The results of the metallographic investigation carried out on the two objects revealed that a significant amount of time and technical skill was used to form and manipulate the shapes of these objects. The necklet and the bracelets were square in section, 
suggesting that the iron was hammered down the four sides and then gradually bent, possibly around an object with the desired circumference. However, the metal within the iron objects investigated is heavily dominated by slag inclusions, indicating that the iron was not hammered consistently over a long period of time at sufficient temperatures to expel the slag inclusions. Although in some types of iron objects such a factor would have been detrimental to the overall structural strength (the slag inclusions causing weakness to the body of the items), in decorative adornments such as these, this would not have presented a problem. The slight flattening of some of the slag inclusions, while others remain un-flattened and with a variety of shapes and orientations again indicate that it was the shape of the objects, rather that the purity of the iron metal, which was the main concern for the smith.

The majority of the slag inclusions remain uncorroded and with unreduced iron oxide phases (wüstite), as well as hercynite (indicative of the alumina rich slags of the region, and also difficult to expel through hammering), and fayalite still present. Thus in the future, microprobe analysis could be used to identify chemical signatures within the slag inclusions and a provenance study could be attempted to identify the source of the iron (e.g. Blakelock et al 2009). As it is known that a significant amount of iron was being produced in Southern Rwanda, Northern Burundi and North-west Tanzania, amongst a number of other areas, at this time, it would be interesting to either confirm a local source, or suggest that these objects had been traded from elsewhere (similar to the cowrie shell also discovered in the burial).

Both of the objects were classified by Vickers Hardness readings of between $197 \mathrm{HV}$ $279 \mathrm{HV}$, indicative of low-carbon ferritic iron, as would be expected in bloomery iron that has been forged into an object (Scott 1991). The carbon content of the iron is variable within the objects, again characteristic of bloomery iron (Scott 1991: 89). In this case, a maximum hardness of $657 \mathrm{HV}$ was recorded on the outside edge of the necklet, suggesting an elevated carbon content, possibly resulting from an episode of heating during forging. When etched with nital (dilute nitric acid) the structure of the metal was revealed (Scott 1991: 69), as a matrix dominated by large-grained ferrite (fig. 7.1). The grain boundaries indicate typical, polygonal structures, as would be expected from bloomery iron where the iron cools quickly during the forging of the desired shape 
(Rostoker \& Dvorak 1965: 10; Ryzewski \& Gordon 2008: 52). The slightly increased carbon content was also highlighted towards the outer edge of the necklet, where pearlite is visible (fig. 7.2: see Rostoker \& Dvorak 1965: 135). This suggests that the objects underwent some limited carburisation during forging.

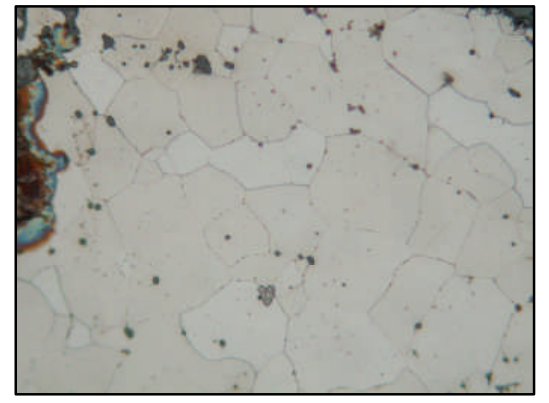

Fig 7.1 Well formed ferrite crystals (PPL 200x, image width $0.5 \mathrm{~mm}$ )

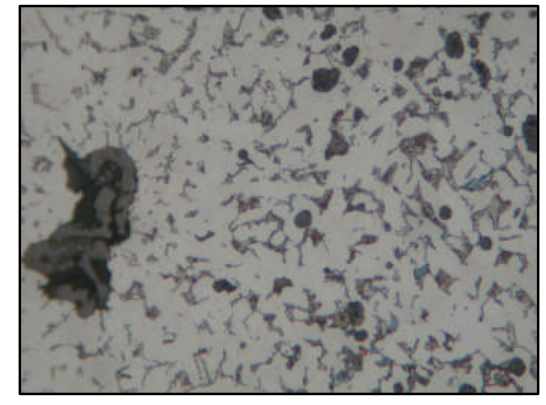

Fig. 7.2 Small areas of ferrite and pearlite (PPL 500x, image width $0.2 \mathrm{~mm}$ )

Clearly the iron objects were made by one or more skilled smiths, capable of shaping iron into long strands and then manipulating it to produce what would have been symmetrical circles. The circular disc also highlights the technical skills of the artisan, being flat and round with a hole through the middle - a difficult form to achieve. This disc may well have hung from a cord around the neck, in a similar fashion to the way that people in Rwanda were documented in later times wearing amulets to ward off evil and ensure health and fertility (Celis 1987: 240-250). The bracelets appear to have small pieces of iron welded onto them, although their original appearance, or the role of these additional pieces of iron, is unknown.

The specialist hammering skills of the smith appear impressive, despite the high levels of slag remaining in the metal. Either a choice was made that for this purpose the effort to expel more slag was unnecessary, or the implications of a large slag inclusion content were unknown (Childs 1997: 303-306). According to work in Tanzania, smiths during this early period were adept at working "low-carbon steel and ... phosphoric cast iron" (Childs 1997: 311), which suggests a high level of technical sophistication and understanding. Unfortunately, without comparative objects made for different purposes, 
the high level of slag inclusions within these objects remains difficult to interpret. The same can be said for the type of iron produced. As mentioned, certain areas of these objects contained higher levels of carbon, which is interpreted here as accidental, and probably resulted from the objects being left in the forge too long. Ferritic iron is malleable and easy to work, although this becomes more difficult as the carbon content increases, and for such intricate work, a lower carbon content would have been desirable. However, where a strong edge is required, for example for a knife or spear, an elevation in carbon content would aid the purpose of the object by creating a particularly tough surface. Further analysis of a variety of iron objects dating to this period could again indicate whether in fact this higher carbon level was achieved on purpose, and so whether or not the smiths of the time in fact recognised the hardening effects of leaving objects in the forge for slightly longer.

The utilitarian iron objects excavated at the Early Iron Age Kemondo Bay sites in Tanzania (Schmidt 1996), indicate that iron objects were used on a day-to-day basis by the majority of the population, as expected considering the land clearing that is known to have been occurring at the time. The grave goods investigated here indicate that, as was the case with the Urewe ceramics (discussed in chapter 4), iron objects were also prized by the elite and used in important symbolic events.

Therefore, as well as being utilised by the majority of the population, for example iron hoes to clear the land and Urewe bowls to cook in, both iron and ceramic objects appear in symbolic settings, for example in the grave mentioned above. What such evidence appears to indicate is society centred on small groups or families with their own individual identities, and their own leaders or lineage heads (Ashley forthcoming), rather than broader more centralised communities that began to arise from the $9^{\text {th }}$ century AD. Throughout this early period, iron and iron production maintained an important social role, as well as a fundamental place in economic and exchange systems: 'the power of a leader depended on the size of his metal stores' (Vansina 1990: $60)$. Those with the ability to produce the metal were esteemed, and iron, alongside ceramics, were vital for practical and symbolic structures within society, while centres of iron production were becoming foci for power and leadership. 
The insight into society that has been provided by the excavation of this burial and its combined grave goods is fascinating. Not only was iron apparently viewed as a prestige good - adorning the body of a clearly important individual - but it could also be intricately worked during these early periods. The variety of iron objects within the grave designed to decorate different parts of the body in a variety of ways, could possibly have parallels with the approach to the intricate decoration of furnace bricks, and of Urewe ceramics during the period. The suggestion of technical competence derived from this consideration of metal artefacts is also indicated in the smelting operations identified at Gahondo, where the smelters produced uniform, decorated bricks, manipulated good quality ores to maximise production, worked with fluxes, and in general appear to have had a significant level of technical knowledge and control over the iron production events.

Thus, people employed widely recognised traditional techniques and styles which were also open to individual interpretation, while a significant level of contact and variation continuously occurred across the landscape. Interestingly, such a local level of variation within broader technological traditions does not appear to be a new phenomenon at this time. Nenquin recognised variation within Stone Age assemblages excavated within the area, highlighting the long-standing innovative and adaptive role of artisans operating within regional technological traditions (Nenquin 1967: 296). Whether making pottery or producing iron, artisans paid significant attention to the detailed, decorative aspects of their work during the Early Iron Age, and applied variations to design features and methods of production, possibly in an attempt to represent their individuality.

\subsection{The Middle Iron Age (C. 800 AD - 1500 AD)}

Prior to this $\mathrm{PhD}$ research, the apparent jump from the EIA when smelters utilised furnaces made of decorated bricks, to later technologies when this approach to technology was no longer used, was far from understood. In fact, it is fair to say that although the remains of later iron production had been observed across the region, prompting a number of ethno-archaeological experimental smelts, the technologies and chaîne opératoire behind the later iron production, or even the dates to which these 
production phases were linked, had received little attention. Even during the considerable research in the Kagera Region of North-Western Tanzania (Reid \& MacLean 1995; Schmidt 1996), the period between the extensively researched Early Iron Age and the $17^{\text {th }}$ century AD (from when oral traditions, and later informants, have been used to understand the role of iron in society), was believed to represent discontinuation of iron working in the area (Childs 1997: 279-282).

However, in the same way that Ashley's work on Transitional Urewe has begun to reveal transformative technological stages in this middle period, so the sites of CMZ 1 and CMZ 2, examined in this work, have provided a filler for this previously blank period of time. Dated to the Middle Iron Age, these sites indicate extensive, specialised iron production industries, involving a sophisticated degree of labour and resource coordination.

The major difference in production techniques between the Early Iron Age and this middle period appears to be two-fold. First, according to the archaeological record, decorated bricks are no longer used to construct furnaces. Instead it is possible that clay could have been rolled into more crude slabs and built up to form the furnace shaft, in a similar, coiled manner to that used in pottery production, or that superstructures were constructed using old slag blocks, or not at all (Celis 1987: 56-158). This new form of structure would then have been destroyed on completion of the smelt, rather than dismantled carefully to be reused. This new approach to furnace construction therefore appears to be quicker, and focused on building a practical structure and then accessing the bloom quickly.

Another major change between the iron production techniques of the early Iron Age and those of the Middle Iron Age could be that greater amounts of material were processed during the later smelts in comparison to the earlier smelts, producing slag blocks of over $100 \mathrm{~kg}$ in weight. From the data recorded from the Early Iron Age KM2 site in Tanzania, average slag weight per feature (discounting those features with under $10 \mathrm{~kg}$ slag), is approximately $32 \mathrm{~kg}$ (Schmidt \& Childs 1996: 213). Of course, quantities of slag produced during a smelting episode do not indicate the efficiency of production, 
and furthermore, during the experimental smelt carried out as part of this research (see chapter 2), it was found that a significant amount of iron bloom can be produced alongside a very limited amount of slag, meaning that the early smelters could have been producing the same quantities of iron as later artisans. However, if it is assumed that the smelters of this region were producing iron blooms throughout the period of the Iron Age using medium-high grade ores which are abundant in the area, as are fairly refractory ceramics, it is probable that more material was being processed per smelt in later times, producing these much larger slag blocks. This could reflect an evolution in smelting techniques in association with socio-political change whereby smelting was a specialist task and more labour, time and resources were committed to each smelting event. A change in ore quality over time, and more specifically in the alumina content within the ores (as indicated in chapter 6.7), could also have resulted in greater amounts of slag being produced in later times.

In support of the concept of the movement of iron production towards industrial production and so away from more careful control and standardisation, is the evidence from the CMZ sites. At the tenth century site of CMZ 1, fewer production episodes were carried out and the level of standardisation was very high between and within smelts. This could indicate a carefully controlled smelting methodology, perhaps practiced within a family lineage. A few hundred years later at the thirteenth century site of CMZ 2, iron production is evident on a significantly larger scale, with a more heterogeneous approach to production episodes and more heterogeneity evident both between and within smelting episodes. In turn this could suggest that this was a specialist production location with a focus on maximising the output of iron. The level of variation at the site could therefore reflect more of the community involved in smelting, and that a wider range of resources were utilised, such as more opportunistic use of tree species for charcoal. By this time a greater level of social centralisation was emerging, and specialism in other facets of the economy, such as food production, supported the iron producing specialists.

Before this research commenced, such large-scale forms of production were initially interpreted as relating solely to the Kingdom period, during which time the centralisation of control was presumed to have provided the power, resources and 
control to initiate and organize industrial production. This hypothesis seems to have been proved wrong by this work. Instead, the production at CMZ 1 occurred somewhere during the $900 \mathrm{~s} \mathrm{AD}$, and represents the most scientifically uniform of the sites studied, suggestive of a restricted group of producers who were well trained and very familiar with their own successful methodologies (Humphris et al 2009). Using the crude calculations offered in the preceding chapter, potentially at least $2000 \mathrm{~kg}$ of iron could have been produced at the site, while at CMZ 2 the quantities of iron produced could have been significantly greater. Considering the hoe made during the experimental smelt (see chapter 2) weighed $5 \mathrm{~kg}$, the sites could thus have produced iron from which hundreds (if not thousands) of iron objects could have been forged.

Moving on to consider the symbolic and/or ritual dimensions of smelting, from the archaeological record it would appear that physical manifestations of such concepts disappear during the production processes of the Middle Iron Age in comparison to the decorated furnaces and ritual/medicinal pots and cavities within some Early Iron Age smelting structures (if such features were in fact ritually significant: Raymaekers \& Van Noten 1986; Schmidt \& Childs 1985; Van Grunderbeek et al 2001). This could be related to a growing need for increased production, with output rather than symbolism taking prime position as the driving force behind the processes themselves. Ethnographic and historical records demonstrate that cosmological views of iron production were still extremely important during later times, but were no longer so overtly expressed in material forms in the Great Lakes region. Hence it is likely that at smelting sites such as CMZ there were still strong symbolic beliefs relating to production, but such aspects are difficult to assess or interpret for the Middle Iron Age.

It could tentatively be inferred that because during the EIA there appears to be a form of symbolism involved in the process, and as the process has ritual significance during later periods, during this middle stage there must also have been ceremonial or ritual aspects to iron production. However, from the archaeological record all that can be inferred directly is that there appears to be a simplification of the process, boiled down to its basic necessities, in this period, during which time populations expanded and grouped together at what have been interpreted as defensive sites and agriculture diversified (as outlined in chapter 4), the need for iron tools and weapons grew. 
It is interesting to consider the demands on labour and resources, as well as the impact on wider society that the scale of production seen first at CMZ 1 and then at CMZ 2 (and presumably at some of the other major smelting locations identified during the survey) would have had. As mentioned originally, over 50 iron production sites, identified by the presence of slag scatters and blocks, were located during survey in this region. The majority of these sites were located on or near to the tops of gently sloping hills, and all are situated in areas now cultivated, making the original location and distribution of the blocks, as well as any associated archaeology, very difficult to interpret. This location on hillsides creates a very significant phenomenologically relevant sphere to technology, which became evident as soon as the preparation for the experimental smelt began. The chopping down of trees for charcoal, the collection of clays across and within valley bottoms, and the chanting and cheering during the smelt, were all actions heard and seen across the landscape, echoing across vast distances the sounds and sights of the upcoming smelt. People across the area knew what we were doing and came to watch these processes. Such a broadcast of occupation, no matter the changes in vegetation that may have occurred over time, would have been announced across the region with every smelt that took place, embedding the technologies within the lives of those far removed from the practicalities of production.

At Cyamukuza the continued use of the location suggests a continuity of smelting pressures on natural resources, resulting in the differences seen at the later site of CMZ 2 in the ore and fuel types used compared to CMZ 1 . The use of these varying resources may have resulted from the exhaustion of the higher grade ores and of preferred tree species used for charcoal production by the time CMZ 2 became a focus of industrial iron production. It is also possible that the ore and tree sources were controlled as part of more centralised social structures that may have characterised the Middle Iron Age, and so the variable resources in use at different smelting locations reflect the controlled or negotiated access to resources.

There are a number of limitations to this survey data, such as the unknown relationship between the ceramics and the slag, and unavoidable biases in the location of discovered sites, such as proximity to roads etc. Not least of these problems relates to the means by which Middle Iron Age sites may be distinguished from Late Iron Age production 
locations. At present, ceramic data cannot help, and such a distinction is entirely dependant on absolute dating. These factors may well lead to the over-representation of later smelting episodes, and indeed when the type of ceramic found at each site is displayed in a pie chart (fig. 7.3), it is clear that the majority of the iron production sites $(57.6 \%)$ are associated with knotted strip roulette decorated pottery (KPR) associated with the second millennium AD.

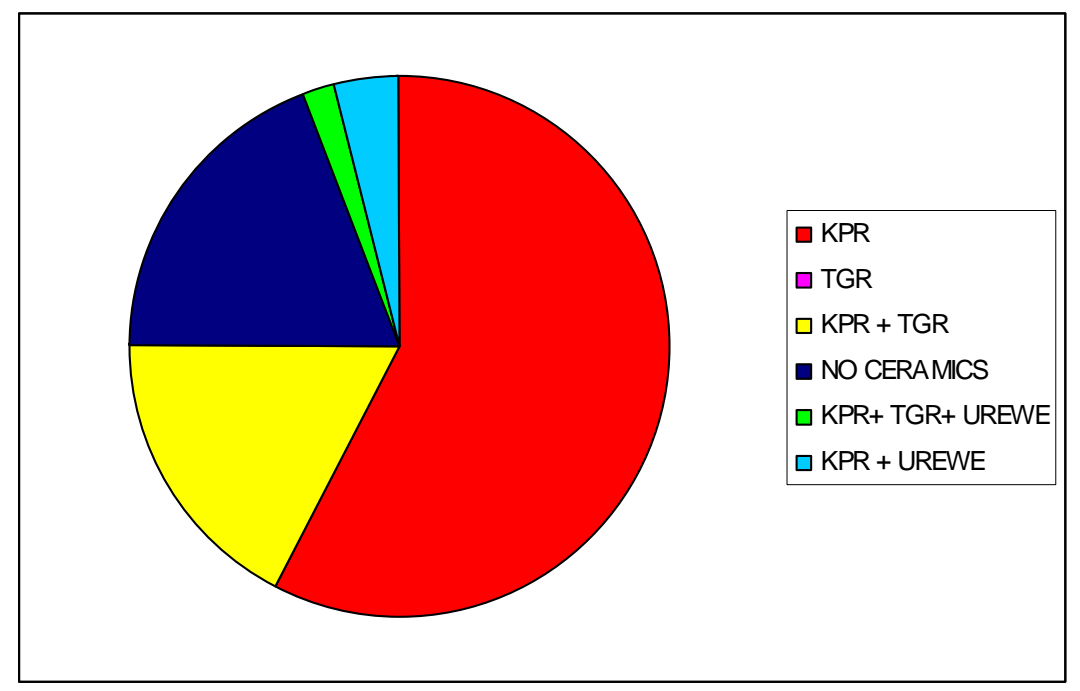

Fig. 7.3 Pie chart demonstrating the presence of each type of ceramic style located during survey on the surface alongside iron slag scatters

KPR roulette style of decoration is generally associated with later periods than TGR roulette decorated ceramics (Connah 1996; Stewart 1993, 32-33). However, it is now known that both forms of roulette decoration were probably produced contemporaneously across the region, as they were for instance at Ntusi (Reid 1996). In Rwanda modern groups of potters can still be observed producing both KPR and TGR decorated pots (Marjaana Kohtamaki pers. comm.), and the huge presence of KPR, as well as KPR and TGR, and KPR and Urewe, suggest that this style of decoration has a greater depth of history than once believed. Therefore, it is possible that many of the smelting sites located date to this middle period of production. On a macroscopic level, variation in sizes of slag blocks, types of plant impressions and presence or absence of 
other archaeological material was noted, but the main observation was the significant scale of iron production refuse which litters the landscape. Thus even with the limitations of survey data, it is possible to imagine that the very high level of production in this area had a significant impact on society and the wider landscape.

It seems that the evidence for the proliferation of iron production visible in the archaeological record during this time is matched by a similar increase in the abundance of ceramics, indicating increased production of iron and pots, as well as a wider variety of styles of production techniques, during the Middle Iron Age than was previously believed. Such evidence supports the concepts of growing populations and the movements towards various centralised social structures discussed in chapter 4 . The roulette decorated ceramics were more crudely made than the Urewe styles, while iron production also appears to have been more pragmatic and large-scale: technological practice and the items produced were thus evolving to suit increased demand. As more pots and more iron objects were required by society, more of the un-skilled population were involved in production. This 'evolution of simplicity' (Wengrow 2001) will be considered in greater depth in the discussion section of this chapter (7.4).

\subsection{Late Iron Age / Kingdom Period (c. 1600 AD - colonial contact)}

It is unknown how many of the production sites located during this survey date to the Kingdom period due to a lack of available dates. It can however be assumed that during this later period, when it is known that a huge amount of iron was required for weapons and agricultural items as well as the royal regalia, that there must have been a proliferation of iron smelting. Thus the sites of MNA, KMA, and the particularly strange site of KBE, may date to the Kingdom period, even though equally they may represent earlier production, more contemporary to the CMZ sites. Regardless of their dating they represent further forms of variation within the iron production traditions of the Butare area. MNA features particularly wide furnaces which the smelters appear to have had difficulty controlling. KMA intriguingly has evidence for two different styles of smelting, slag pit and slag tapping, and also the only evidence for forging activity. 
The variety of technological approaches represented at this site may well prove to be discrete and temporally unrelated; however, if the opposite is proved true, this site demonstrates a complex level of heterogeneity in production styles. KBE features the most bizarre twist of all - a furnace constructed around natural rock.

It is worth noting that in his ethnographic documentation of iron production traditions in Rwanda, Celis documented furnaces used in the Butare area constructed without furnace superstructure, instead using charcoal to contain the smelting environment. It is therefore possible that any of the archaeological furnace bases excavated during this study may have had no superstructures. This could relate to the limited addition of technical ceramics into the slag blocks analysed as part of this study. As mentioned in chapter 6.7, the difficulties of reconstructing archaeological furnace superstructures are great, and so this is just one possible technical style which was know to have been used in the twentieth century (Celis 1987: 58-94).

Smelters working during the Late Iron Age across the region still used large pit furnaces (Celis 1987: 56-152) and produced large slag blocks as waste, for example in the Buganda Kingdom (Humphris 2004; et al 2009), Bunyoro (Iles 2009), and Karagwe (Reid and MacLean 1995). If labour and resources were readily available, the maximisation of production that the smelters were aiming for was obtainable. They smelted large quantities of material (based on the archaeometallurgical remains dominated by large slag blocks), and they innovated and interpreted the process in a variety of ways (either due to availability of resources or personal choices).

The survey data suggests that there was a very significant amount of iron production throughout the history of the region. Furthermore, in the northern and central regions of Rwanda, survey conducted by John Giblin (2008, 2010) again found extensive iron production remains which did not appear to be Early Iron Age in style. Certainly in the location where the experimental smelt was conducted in Central Rwanda, and where again, iron ore was prolific, slag was observed across the site. Celis documented an array of iron production across the country in the twentieth century (1987: 56-152). Thus the archaeological, survey and ethnographic data indicates that many groups 
smelted and forged iron both throughout the MIA and during the later Iron Age period across the country.

Traditionally in Rwanda it is believed that it was farmers who produced iron (Celis 1987: 17). Certainly such a link could be suggested by the identification of grinding hollows and stones identified at smelting sites. However, the important point to note is that as research continues across the region, the traditional view of economically segregated societies is fast becoming obsolete, and instead a mixed approach to economy, as well as technology, is suggested (e.g. Giblin 2008, 2010; Kusimba \& Kusimba 2005; Lane 2004). It cannot be unequivocally stated that it was only farmers who were producing iron, but instead it should be considered that family or community groups smelted and forged the metal, and these groups probably also farmed and kept cattle. If the agricultural evidence is contemporary with the metallurgical remains, this would provide an important insight into organisation and location of iron smelting in relation to occupation sites, assuming grinding was done within habitation locations. Furthermore, the presence of agricultural remains alongside iron smelting remains indicated a mixed economy, as opposed to the technological specialisation discussed above. While the grinding hollows could be for the preparation of ore, as has been documented elsewhere on the continent (Celis 1991: 163-168), traditionally, it is the result of grinding grain which is attributed to such remains in the Great Lakes region. Whether or not it was the same people who smelted and forged is another question that remains unclear in the archaeometallurgical record. From the archaeology accessed during this study, it would appear that the blooms produced by the smelters were forged in different locations, perhaps by different artisans. The presence of a smithing cake at KMA could indicate the smelters at this site knew how to forge an object, although whether this was concurrent with the smelting activity is unknown. However, the absence of any further smithing evidence, including hammer scale and stone anvils, further suggests that smithing took place in different locations (although the evidence for these may have easily been lost over the years). In this part of Rwanda the only concise stage of the chaîne opératoire of iron production that is accessible archaeologically are the smelting events, which limits the understanding available for the overall chaîne opératoire. 
During the Kingdom era iron was produced for the entire population, who recognised the importance of the material both symbolically (as iron was often seen as an indication of wealth, and the mysterious and powerful skill of turning rock into iron was revered), and also practically (as without iron tools, agriculture and warfare would be very difficult). During this time, the iconography of iron became incorporated into the regalia and ideology of the ruling families to endorse their control over the people, the fertility of the kingdom and the supernatural world. Iron technology within this later period was integrated within the political structures across the Grate Lakes region and beyond, and the power of the King as a smith was used this to uphold the legitimacy of their rule, as outlined in chapter 4 . No better illustration of this is needed than the two hammer anvils placed behind the head of the body of the $18^{\text {th }}$ century king Cyrima Rujigira.

While iron was being mass produced across the country utilising a variety of well established methods under the supervision of a head smelter, the symbolism of iron was embedded within the iconography of the kingdoms. Agriculture and warfare played prominent roles in the lives of the subjects of the Nyiginya kingdom, for which iron was essential. Alongside this however, numerous other technologies, including pottery, were also being produced on industrial levels, within what was by this time a stratified society blessed on the whole with more fertile lands and less harsh environments than some of the neighbouring kingdoms.

\subsection{Discussion}

The role and application of iron production and iron objects in society viewed alongside other technologies (here ceramic production, as another archaeologically visible technology), allows for an appreciation of how technology, as embedded within society, responds and reacts to social change, and vice versa.

This chapter has described the changing nature of iron production and the variable technological approaches that can be observed over the two and a half thousand years of metallurgical history of the region. The reasons behind such practical and symbolic transformations lie in the changing nature and requirements of society and its political, 
economic and ritual backdrop, all of which ultimately drove the smelting groups to respond to changing demand. Initially iron objects (like Urewe ceramics) must have held a prestige value, but apparently very quickly, demand and hence presence of iron within society increased, and the metal became entrenched in society.

During early periods, technologies are performed with a high degree of specialist artistic skill and symbolism, and seemingly on a small-scale level (presumably family-based), producing objects for general as well as elite/ceremonial use. Broader technological traditions existed across the wider region while on a local level individual interpretation (and so variation) was commonplace. As populations grew and demand increased on all technologies, both iron and ceramics were produced in larger quantities and there was a visible transition within both technological spheres. With the drive towards mass production taking precedent over particular artistic expression, less attention to detail can be seen in the archaeological record. These transitions are visible across the whole region, with the appearance of roulette decorated ceramics, and large undecorated pit furnaces operated by specialist groups, but again displaying local levels of variation during the Middle Iron Age. Later, still during this middle period, technologies were conducted on an industrial scale, probably in large community-based production centres led by a head smelter, rather than family based groups, as demand for labour and resources grew. The focus on large-scale production drove technology, while the symbolism of the technology was subsequently transferred away from the individual smelts but instead maintained and upheld by the iconography of the kingdom.

The above patterns within these major technologies within Great Lakes history can be viewed, on a practical level, as 'the evolution of simplicity' (Wengrow 2001). This is in recognition and appreciation of the fact that within the technology of bloomery iron production, the specific atmospheric conditions, temperature requirements and basic operating parameters will always operate around general optimum conditions (Killick 2004), and therefore cannot deviate in a huge way from the general scientific constraints. What the concept of the evolution of simplicity purports is that "the transition from simple to complex society involved the dislocation of aesthetic labour from everyday practices, and its transposition to a restricted, and politically empowered, sector of society" (Wengrow 2001: 168). Thus it would seem that such a concept fits 
well with changes in technology seen in this study, and in light of the general move towards the kingdom systems and the gradual increase in demand over time.

Wengrow uses the example of ancient Egyptian pottery traditions and notes that, as in the case of Urewe ceramics, the pre-dynastic period displays the most elaborate, intricate pottery forms and decorations, while "dynastic period pottery production was rationalized, drab and uniform vessels" (Wengrow 2001: 170). Furthermore, in Mesopotamian archaeology, again a pattern of, "decreasing elaboration" is noted in technological production (Wengrow 2001: 171). As people's lives became less of a challenge for survival; as agriculture, pastoralism, food preparation, eating and building houses became less demanding, so too did both the production process and the objects produced, become less elaborate and aesthetic, and this is also seen in the technologies studied here as societies changed in the Great Lakes.

As iron became more widely available, the symbolism of the vital nature of the metal to society was incorporated into kingship. The king claimed power over this technology endorsing his own position, but also took over the responsibility of ensuring the fertility of the kingdom and so the success of the iron producing industries. Thus the practitioners could focus on producing the metal rather than focusing as much on rituals, which were constantly endorsed by the king, while iron objects used everyday by the population were a constant reminder of the power of the king. Hence the technology and the objects were embedded on numerous layers throughout society. In both the ethnographic record (Celis 1987), as well as in the experimental smelt performed during this research, time consuming rituals were not incorporated into production, but issues of fertility and protection were alluded to in songs, by keeping women away and by using specific herbs to light the furnace, none of which were lengthy processes that required specific skills or resources. The same principals were observed in Buganda, a kingdom which also focused heavily on the mass production of iron. While some bellows were decorated with depictions of genital symbols (Lanning 1954), and male and female ores were referred to (Roscoe 1911), such aspects allude to a concept of ensuring the fertility of the furnace, without time consuming tasks such as the procurement and placing of ritual pots, and the decorating of furnace superstructures. Therefore, as technological processes are boiled down to basic, 
methodical industrial production, ritual aspects are also simplified, and transposed onto the king and his regalia and rituals, to maintain the sacred integrity of the practice: a mutually beneficial theme, adding credence to the role of kingship.

As we are still far from being able to effectively and economically date slag itself, the interpretation offered here is clearly restricted and rather general. A far-reaching, intensive study was simply beyond the availability of time and resources of this $\mathrm{PhD}$. However, overall it is clear that rather than viewing iron production in isolation, by considering it in association with other technologies, as a reflection of the societies and social situations within which they were embedded, a greater understanding of how and why evolution and variation occurred has been achieved. Continuing themes have been identified which span the technological history of the region, namely the use of locally available resources, the continued use of the furnace pit forced draft smelting tradition and the constant degree of local levels of variation to smelting practices. Specific variations are seen in the style of furnace superstructures, including types of decorated bricks, and in later times the four distinct superstructures identified by Celis, including furnaces without superstructures at all. Where exactly the stone-cut furnace at KBE fits within these traditions, remains unclear. Further variation is seen in the size of the furnace pits used, the type of fuel and ore sources, and the general efficiency, in terms of reducing conditions and temperatures reached. Without exact dates for the furnaces it is difficult to suggest the reasons behind the variations noted. They could represent local use of resources, ability, specific choices and knowledge bodies in existence at the time.

Overall, iron technology as well as ceramic production increases in response to changes in population, agriculture and warfare, whilst a general move towards political centralisation and social stratification stimulated technology, separating it from its original symbolism. While some features continued, such as the use of the pit furnace to drain slag, and the use of local resources (although negotiation for access would have changed over time), variation is apparent over time in the more adaptable aspects of technological constraints, leading to highly localised adaptations. Alongside this, the adoption and incorporation of the symbolism of iron into kingship iconography ensured the power of iron was preserved and controlled to ensure the success of the people. 


\section{8}

\section{Conclusion}

The aim of this $\mathrm{PhD}$ research was to utilise an archaeometallurgical approach to undertake an investigation of iron smelting traditions in Southern Rwanda. The region to the east of Butare was selected to provide a suitable study area, as iron production was already known to have been carried out for over two millennia, but specific scientific reconstruction of the processes involved was lacking. This new fieldwork intensively focused on locating, excavating, sampling, and generating original archaeometallurgical data which was then interpreted and placed within the broader archaeological, linguistic, historical and ethnographic understandings of the region. This method has provided an enhanced insight into the complex role of iron production in Rwanda's history, as well as a greater understanding of the manner in which technology was an active element influenced by, and in turn influencing, wider social, cultural and political factors in the past. Over the course of this study, the academic contribution made to the field of archaeometallurgy in Africa has been significant, and has enriched our knowledge of ferrous metallurgy and its place within Great Lake's history. Most importantly the study has proved that iron technology, once established, did not simply continue in a cultural or political vacuum, but that it changed over time, whether due to socio-political and economic needs and requirements, or due to transformations in the organisation of production. Alongside this academic worth, the social interest generated by this project has made a significant impact on the locally entrenched belief that Europeans introduced science and technology to Rwanda. The overall academic and social value of this project will be discussed below, together with suggestions for future work.

During this $\mathrm{PhD}$ many lessons have been learnt, and the evolving realisations of the research, both academic and practical, have laid a foundation for future large-scale archaeometallurgical projects to be conducted in Rwanda. Furthermore, through renewed intellectual engagement in Rwandan archaeology after a period of inactivity, the general status of the discipline within the country has been enhanced. 


\subsection{New academic understandings}

This $\mathrm{PhD}$ has defined a new chronological framework for the period of the Iron Age within the Great Lakes region. By identifying and defining the Middle Iron Age, and recognising this as a period of heterogeneous transformations, a much greater appreciation of history of the region is accessible. Utilising such a chronology has allowed wider technological, societal, economic, political and ritual change to be documented and understood in relation to one another. Furthermore, by producing one of the first pieces of research that combines intensive scientific analysis of metallurgical remains with the broader archaeology of the region, this research has demonstrated the potential for such high-resolution research. If such projects can be encouraged, more general insights into regional history is obtainable. This thesis has also highlighted the benefits of considering iron technology, not in isolation, but within a broader technological complex. The advantages of considering a number of technologies together have been illuminated by the deeper understanding of technology in the past that a consideration or iron and ceramics production has achieved.

Some of the first decorative iron objects from an Early Iron Age burial have been analysed, and the first intensive scientific analysis of early smelting in Rwanda has been provided. In addition, by focusing in detail on iron production sites, diachronic technological change within periods of time (i.e. the Middle Iron Age), rather that between periods (i.e. Early Iron Age production compared to Late Iron Age production), has been accessed for the first time.

As mentioned, the first systematic scientific analysis of material excavated from two EIA furnaces in Rwanda has been accomplished. In conjunction with complimentary data (Craddock et al 2007; Schmidt \& Childs 1985, 1996; Van Grunderbeek et al 2001; Vignati-Pagis 1995), the results generated add a further depth and understanding to the early technological traditions of the time. Both of the Early Iron Age structures excavated at Gahondo confirm previous conclusions whilst contributing additional knowledge to the growing corpus of information available on early iron production.

Regarding the decorated bricks used to construct the superstructure of these Early Iron Age furnaces, it was confirmed that as at other early production sites across the region, 
the bricks were designed to slot together and decoration was applied to the external faces of some of the bricks (Van Grunderbeek et al 2001: 283). The excavation of a test unit containing bricks next to GHD f2 supports the concept that the bricks were dismantled, possibly to be re-used in future furnace construction. As suggested from data obtained from other sites, locally available clays were utilised to fabricate the technical ceramics (see also Craddock et al 2007). The technical ceramics used in the process were naturally refractory and so able to withstand the extreme atmospheric conditions generated in the furnaces. They appear to have contributed in a very minimal way to the overall smelting parameters, allowing smelting conditions to be controlled without the need to compensate for the addition of large amounts of ceramic material into the process, and the bricks to be re-used in further smelts. In addition, even during this early period, it appears (from the very limited data), that specific clays were selected for the production of technical ceramics compared to domestic ceramics. Whether or not beliefs or rituals were symbolised by the decoration on the furnace bricks remains unknown, but its artistic relationship to Urewe ceramics is highly probable (MacLean 1998). The evidence outlined in this study could well suggest that the decorative expressions (seen on furnaces, pottery and the body within the grave), reflect cosmological beliefs and artistic inclinations embedded within the ideology of the time.

Within GHD f1, the presence of partly reduced, molten iron ores, suggests an ore roasting stage prior to production, ultimately maximising the efficiency of the smelting process itself. Although this reconstruction remains to be confirmed, this facet of the chaîne opératoire was also indicated during the excavations of the Kemondo Bay sites in North-Western Tanzania, where ore roasting pits were identified (Schmidt \& Childs 1996). The recognition of what could be two types of ore in GHD F2 (one very rich in iron oxide, the other rich in gangue components essential for slag formation), could suggest a deliberate mixing of the high-grade roasted ores with gangue rich ores, purposefully creating the ideal slag and presumably the perfect bloom. The addition of a siliceous flux is also a significant possibility at this site.

In general these two Early Iron Age furnaces add to the group of more than twenty such structures already excavated across this very small area in Southern Rwanda. Falling 
towards the end of the period, they emphasise the technological knowledge and skill held within this small iron producing locality. During every stage of the chaîne opératoire, including technical ceramic fabrication, furnace construction, ore preparation and the smelting itself, the group represented here, as across the area, were competent and experienced, and intricately manipulated each stage of production to ensure the economic viability as well as perhaps the ritual success of the smelting operations.

The iron objects analysed from the Early Iron Age burial (Giblin 2008, 2010, et al forthcoming), alongside the more utilitarian objects excavated in other parts of this Urewe complex (Childs 1997), illustrate that as well as producing every-day items, the iron workers of the time also produced decorative articles, which may have been a marker of status or ritual significance. The skills of the smith included the intricate working of ferritic iron and welding, as well as potential knowledge of the effects of carburising iron edges to increase strength, and the significance of a large quantity of slag inclusions in particular objects (although further analysis of utilitarian objects from Southern Rwanda are necessary to confirm this). The technical and artistic skills of the smith mirror those of the smelters (who may well have been the same people). The entire chaîne opératoire and stylistic approaches outlined during this research illuminates the embedded position of EIA iron production within the broader social complex of the period.

By considering the early furnaces and iron objects together within this technological system, the creative and personal technical expression and choices are seen to illuminate confident, small-scale (probably family-based) production within a sedentary society. A range of evidence from this period indicates (as outlined in chapter 4) advances in agriculture and livestock maintenance, the focus on the family group, exchange and contact networks in existence, and growing demand for iron objects. While being aware of the greater technological traditions within which they were living and conforming to general technological systems that existed across the wider area, individual artisans tested the boundaries of their independence. This resulted in the variety of furnace styles found across the region (including decoration on bricks, furnace pit size, and so on), and the variety of decoration on Urewe ceramics. Such a social situation, with people as foci 
for wealth (and therefore power), and the presence of a possible high-status or ritual burial, could indicate the presence of a more overtly defined, stratified society at an earlier time than previously thought.

The Middle Iron Age sites at Cyamukuza again relate to previous work in the Butare area where one furnace had been dated to the eighth - ninth centuries AD and one to the eleventh century $\mathrm{AD}$, and both were seen to represent a different technological style to that of earlier times (Van Grunderbeek et al 2001: 293; Van Noten 1983: 37). However, before this research no understanding of iron production during the Middle Iron Age had been generated. The two extensive industrial sites investigated for this research provide the first comprehensive insights into the iron production traditions of the region during the transitional period defined during this research. From the archaeological record it would appear that both the dedication to the decoration of furnace superstructures, as well as the use of specifically made bricks, had disappeared (although no remains of superstructure have actually been found). Instead it would seem that furnaces were perhaps constructed in a more pragmatic manner and were destroyed after each smelt to access the bloom quickly, with the fragmentary nature of the destroyed superstructure prone to erosion and so absent within the archaeological record. Alternatively, these furnace pits may have been used with no superstructure at all.

While the site of CMZ 1 displayed extensive production, it represented the most standardised methodological approach to smelting, with macroscopically similar furnace pits, and chemically and microscopically similar results indicating a fairly uniform methodology from smelt to smelt, and within each individual smelt. CMZ 2 however, displayed a significant level of variation between smelts, while again general principles such as furnace pit size, the packing for the furnace pit, and the arrangement of the tuyeres were very similar. Given the much greater amount of iron smelting debris found at this slightly later site, a greater labour force can be imagined, which perhaps contributed to this more variable archaeometallurgical record.

In both cases, although it is unknown how production was organised, the level of broader morphological similarities and scale or production across the sites could suggest 
that these were dedicated production centres. A head smelter may have run operations, while more and more of the community were gradually involved to collect resources and operate the bellows. Thus, eventually more attention was paid to maximising production, and less to artistic expression and, by the time of CMZ 2, to specific operating parameters. At the same time a similar pattern can be observed happening in the approach to ceramics in the region, with more easily produced roulette wares coming to dominate the archaeological record.

The possibility of dedicated production centres could be further inferred by the lack of any associated archaeology at any of the smelting locations. This might indicate that iron working was kept separate from habitation locations, for both practical and/or ritual reasons. However, as no specific habitation sites were located throughout Rwanda despite a focus on such a quest (Giblin 2008; 2010), unfortunately it cannot be said for certain whether indeed people lived in different locations to the smelting operations, or if the remains of these habitation sites have simply been lost.

While no sites located or investigated during this research were specifically dated to the Late Iron Age, or Kingdom Period, it can be assumed that at least some of the remains date to this period. From the ethnographic work of Celis (1987), it is known that a vast amount of iron was produced during this period, and historical work (e.g. Vansina 2004), has demonstrated the huge demand for iron generated by the Nyiginya Kingdom, for agricultural use, weapons and royal regalia. Broader studies have further illuminated the symbolic and ritual role iron played within society and within political structures and manifest in the persona of the king himself (de Maret 1985; Herbert 1993: 131163). Therefore, the variety of production styles and techniques identified during this research could well represent society experimenting and innovating to meet increased demands.

In general it could be suggested that throughout the technological history of Southern Rwanda the technicians were blessed with an abundance of good quality ore and naturally refractory ceramics, and a good supply of fuel of various types, as long as the smelters were not too selective. Variations in the approach to the chaine opératoire of iron production appear to relate to chronological evolution and the adaptation to 
evolving societal situations and demands, while local level variation appears to be associated with the selection of raw resources (generally what was locally available), and perhaps external pressures for increased production.

The above academic insights into two thousand years of iron smelting traditions in Southern Rwanda establishes a growing picture of technological history, and provides us with a greater appreciation of both the role and influence of technology and iron in relation to the past. Transformations in the technology, established using the still rather crude ceramic framework currently available, demonstrate that smelting has a significant history in southern Rwanda, rather than being a constant, unchanging practice. In this particular case it is felt that transformations in technological practice can be associated with social and political transformations taking place in the area, a fact that should encourage further exploration of technological history across the continent.

\subsection{Social Impact}

Since the outset, a central desire of this $\mathrm{PhD}$ project was to have a beneficial social impact on communities in Rwanda. After decades of civil war culminating in genocide, people in Rwanda today are disassociated and disillusioned with the past, and recognise the contribution the colonial administration and the resulting colonially constructed past had in the lead up to the events of 1994. Only now is it officially felt that the country is at a stage where history can be reconsidered, and it is widely recognised that this can mainly be done through archaeological research. A new history syllabus is currently being composed (history has not been taught in school for years since the genocide because of its feared incendiary nature), and the technological addition to history presented here provides a positivist, technically sophisticated insight into a Rwandan past.

After excavating the remains of iron production in Eastern Africa since 2001, this research has finally provided the opportunity to directly tackle the local belief that science and technology were introduced to Africa by Europeans. This was a popular notion encountered by Andrew Reid during his fieldwork and his community work 
attempted to target this misconception in Uganda. In my work in Rwanda, the academic output outlined above was enhanced at a local level by the small but noteworthy social worth of this research. As was described in the methodology section (chapter 5), at each site community meetings and school classes were invited to learn about and discuss the archaeometallurgical remains. In every case the response was generally fourfold: an initial lack of understanding about what the remains actually represented; an astonishment and interest in the idea that the annoying blocks of stone were in fact the remains of iron production; questioning about who taught their ancestors how to make iron; and then an appreciation of what artisans of the past had achieved and a new level of respect for the technological prowess of these past Rwandan iron producers. The adults and children who came to the meetings hopefully shared this knowledge with others, and certainly when the locations were visited six months later, people were still talking about the skilled Rwandan metallurgists of the past. In addition, in Buramba where the experimental smelt was conducted, the head smelter and other elders involved were very happy to have the opportunity to teach the younger generations about iron production. Of course it is not suggested here that this small research project was a major breakthrough in the way that people view their history, but a pride in the past is priceless, and the limited social impact provided by this $\mathrm{PhD}$ is therefore one of the most valuable outcomes of this research, especially as it has demonstrated the potential of further work along these lines.

\subsection{Lessons learnt and projections for future work}

It is recognised that there is significant further potential in the data generated during the course of this $\mathrm{PhD}$. Combing a scientific approach with the archaeological record within the remits of a $\mathrm{PhD}$ produces a broader perspective of the past, and both the scientific perspective and the archaeological contextualisation can be developed further in the future.

Alongside the academic and social contributions made by this $\mathrm{PhD}$, many lessons have been learnt that will hopefully pave the way for future work in Rwanda and beyond. Possibly the most fundamental is the realisation that either large-scale industrial 
production does not necessarily have to be associated with a centralised kingdom structure, or that the antecedents to the kingdom lie in earlier times than originally thought. This not only requires a rethinking of the early kingdom histories across the region, but also illuminates the unavoidable biases that even a critically aware student brings to research. Within the author's globalised, industrial European mind, the concept of massive iron production centres went hand in hand with major political structures and a more recent time period. That this hypothesis has been proved wrong has not only contributed to academia as described above, but has taught an important lesson to this researcher.

Following on from this is the issue of dating from which two major lessons have been highlighted: first, the danger of imposing a chronological structure on archaeometallurgical data before absolute dates have been acquired; and second, the need to be more aware of the problems and possible failures of more modern dating technology. If the dating strategy originally applied to this research had worked, every single smelting structure would have had up to 4 separately generated dates (TL dates for furnace pit lining, tuyeres and slag, as well as radiometric dating for charcoal samples). This ground breaking dating method failed and left this research in peril at a very late stage in the work. Thus in the future a more water-tight dating strategy would be implemented involving specialists in the field to lay radiation meters to provide an accurate understanding of the background radiation, alongside a much greater focus on charcoal collection for C14 or AMS dates.

A further realisation is the profound benefit of considering the broader technological history of society rather than focusing on one isolated technological facet. By examining the evolution of iron production traditions alongside ceramic traditions, a more sophisticated appreciation of the position of technologists and technologies in society has been reached. Especially in Great Lakes Africa, where so much of the material culture of the past, notably habitation sites, have either been lost or have not left a significant trace, applying a more holistic approach to past technological complexes seems to represent a more constructive way to proceed in future studies. Alongside this, within a future project, other areas of Rwanda (which have already been 
demonstrated to hold significant archaeometallurgical potential: Giblin 2008; 2010), could be studied to illuminate how the iron smelting traditions of Southern Rwanda fit within the technological traditions of the country as a whole. In addition would be the identification of diachronic smelting traditions in more locations around the Great Lakes region, dating to the Middle Iron Age, as well the Late Iron Age, again with scientific reconstructions. Within the remits of this $\mathrm{PhD}$ such ambitious goals were impossible; however the results presented here demonstrate the potential of such an approach and can act as a platform for future research.

Future research on the iron production traditions of Rwanda should focus on the history and the role of technology in general, and concentrate first on the central plateau around the centre of the Kingdom, an area which could not be selected as the focus of this research because of its relatively unknown archaeometallurgical potential (although the work of Celis (1987), documented recent iron production traditions across the country). It would also be very interesting in the future to study whether or not iron production was carried out in the northern parts of Rwanda and around the volcanoes, and if so, how the technicians adapted to this more extreme environment. Within this future work, funding should be ideally sought for a systematic dating strategy, relying on radiometric dating in the first instance, and then focusing on the application of OSL dating in conjunction with a specialist in the field.

This work has demonstrated that there is tremendous potential for small-scale, highresolution studies of iron production traditions in the Great Lakes region. Significant variations and continuations occur in technological traditions, even within a geographically small area, and technological histories can be constructed and contextualised to create important regional histories. 
Appendices: Bulk chemical analysis 


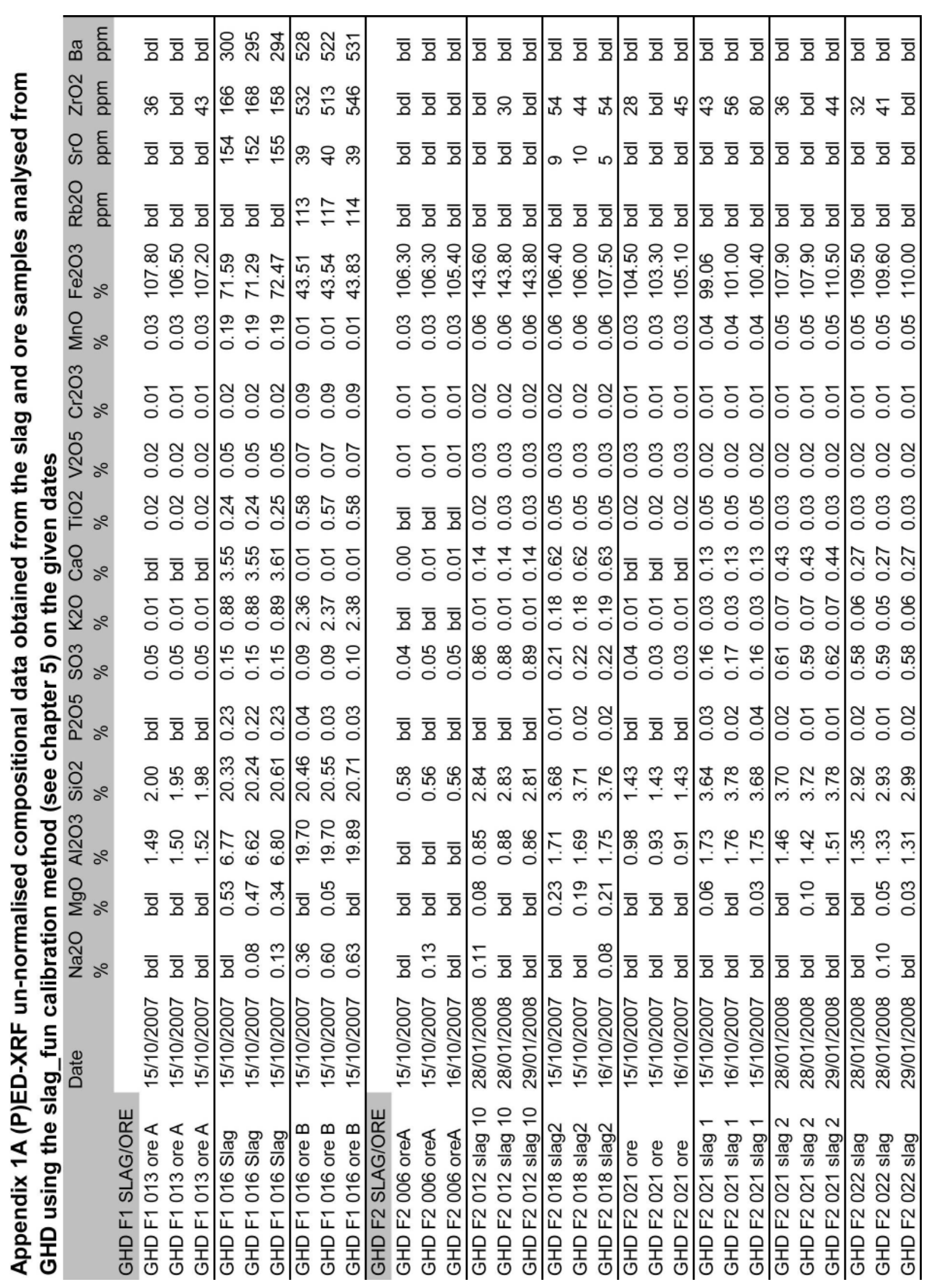




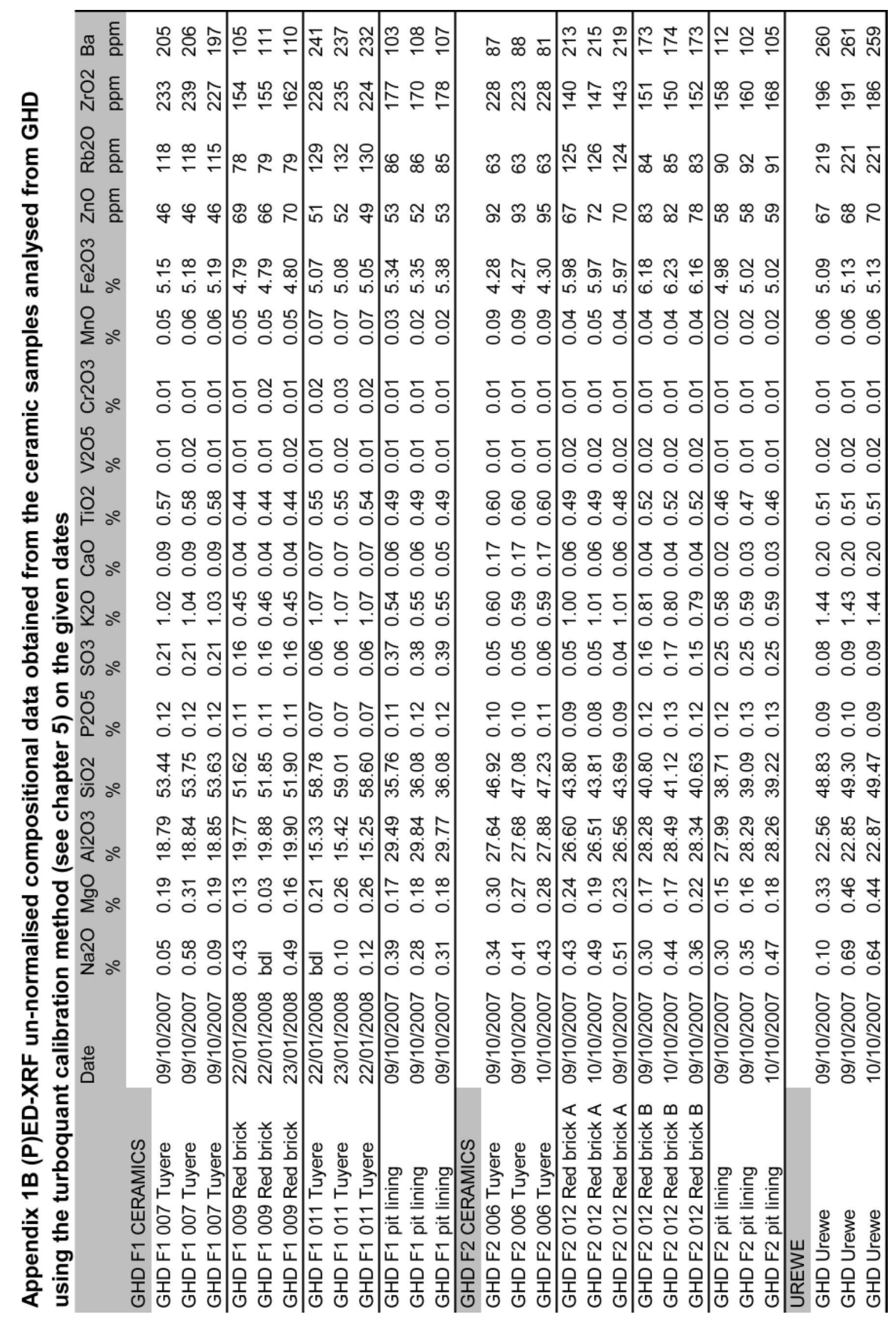




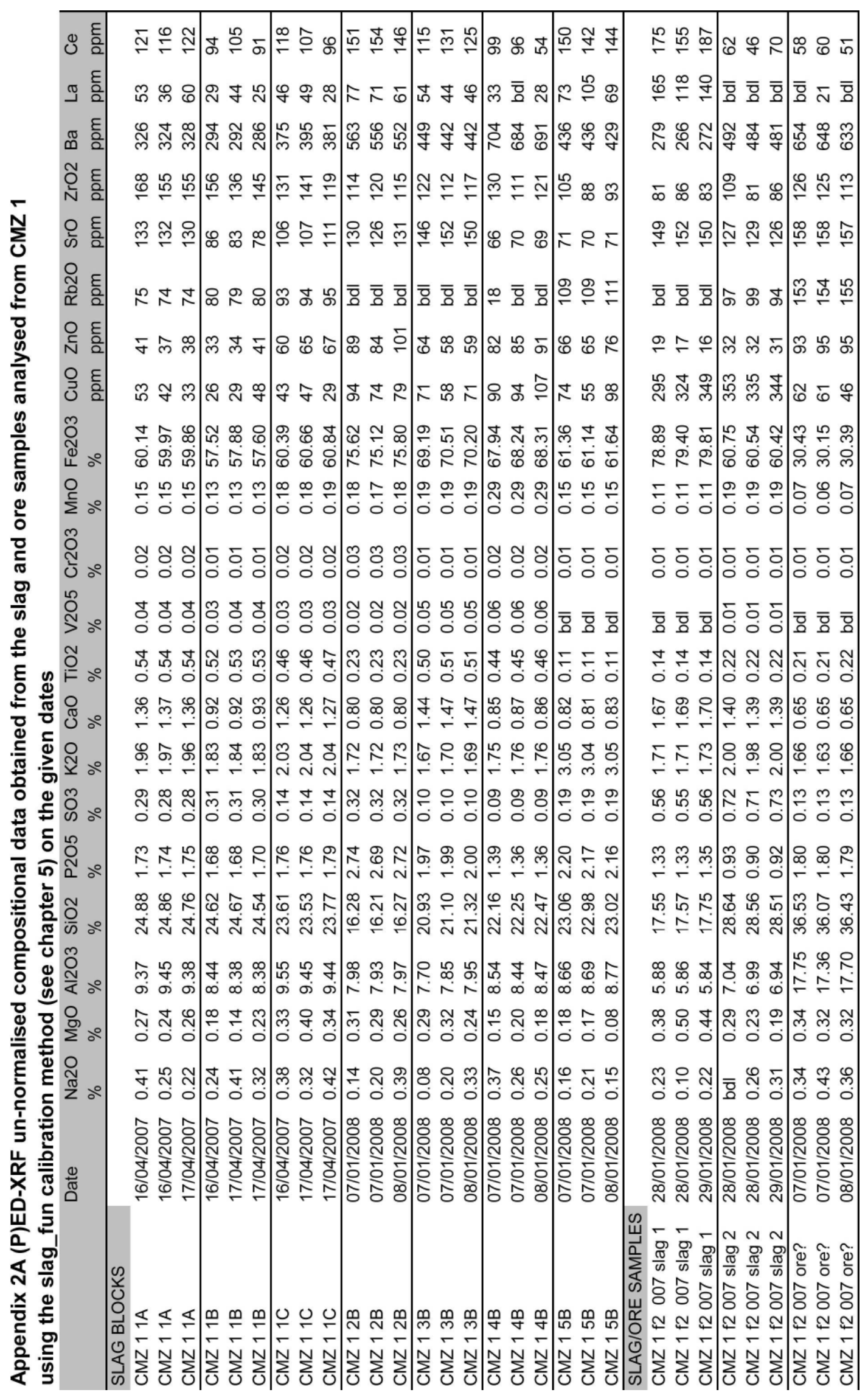




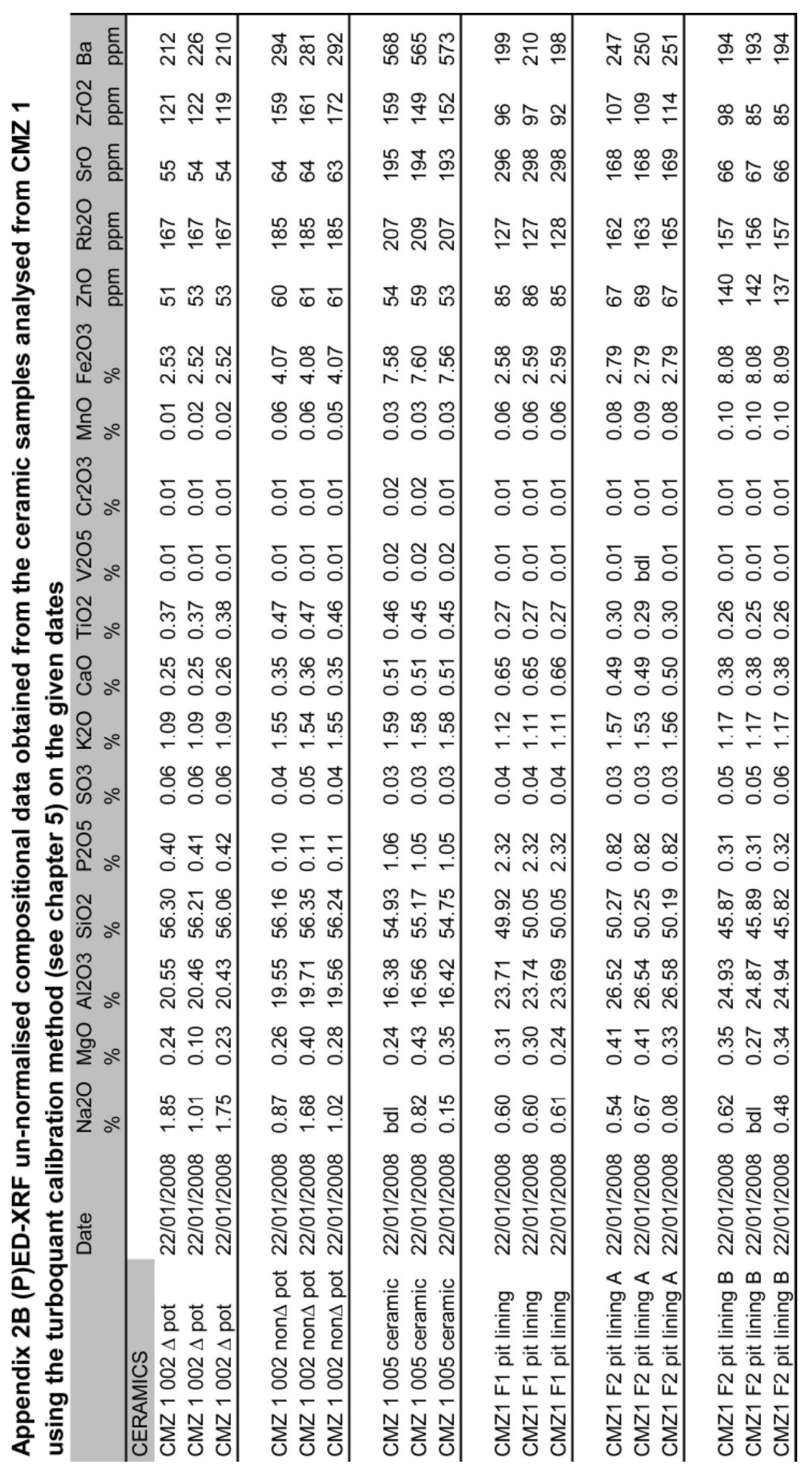




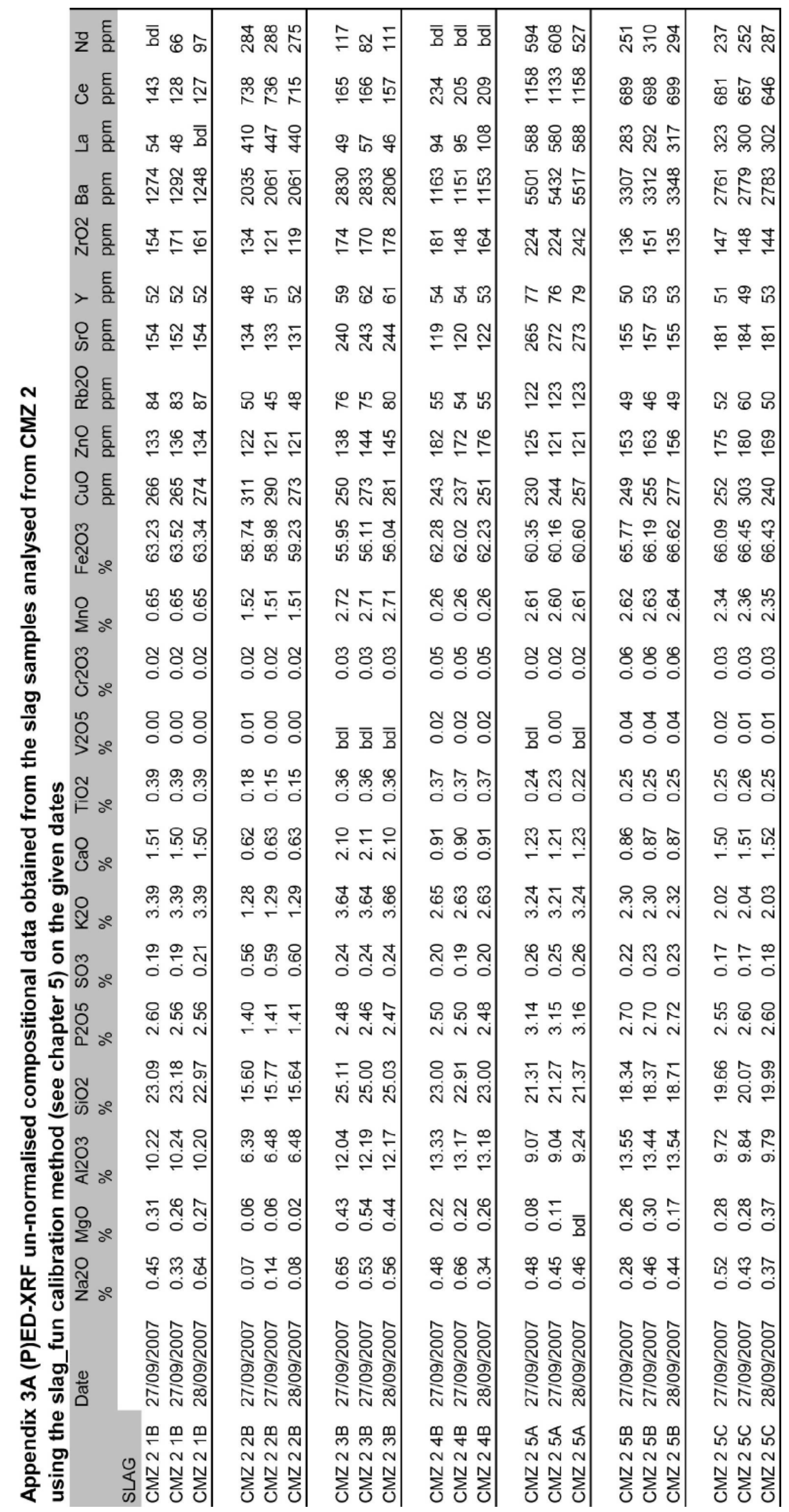




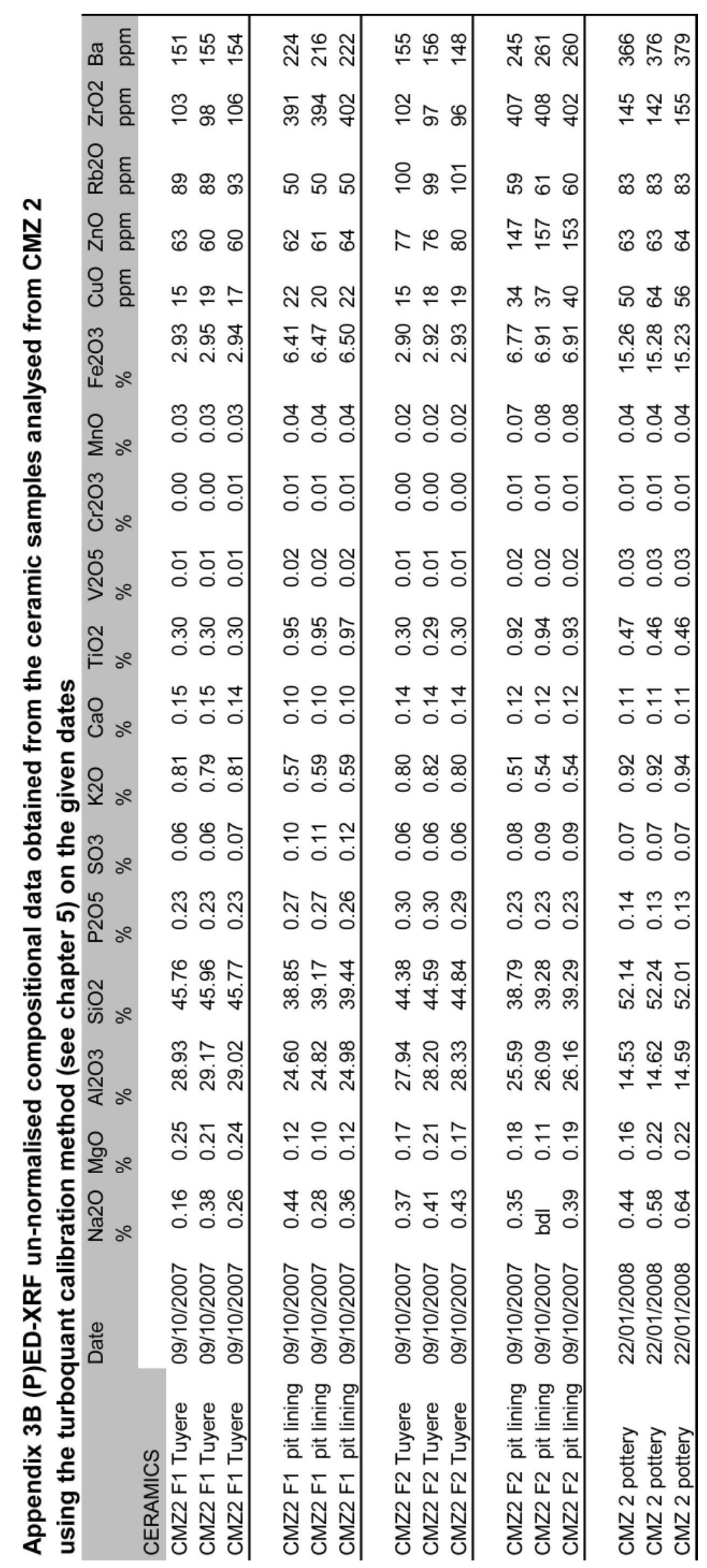




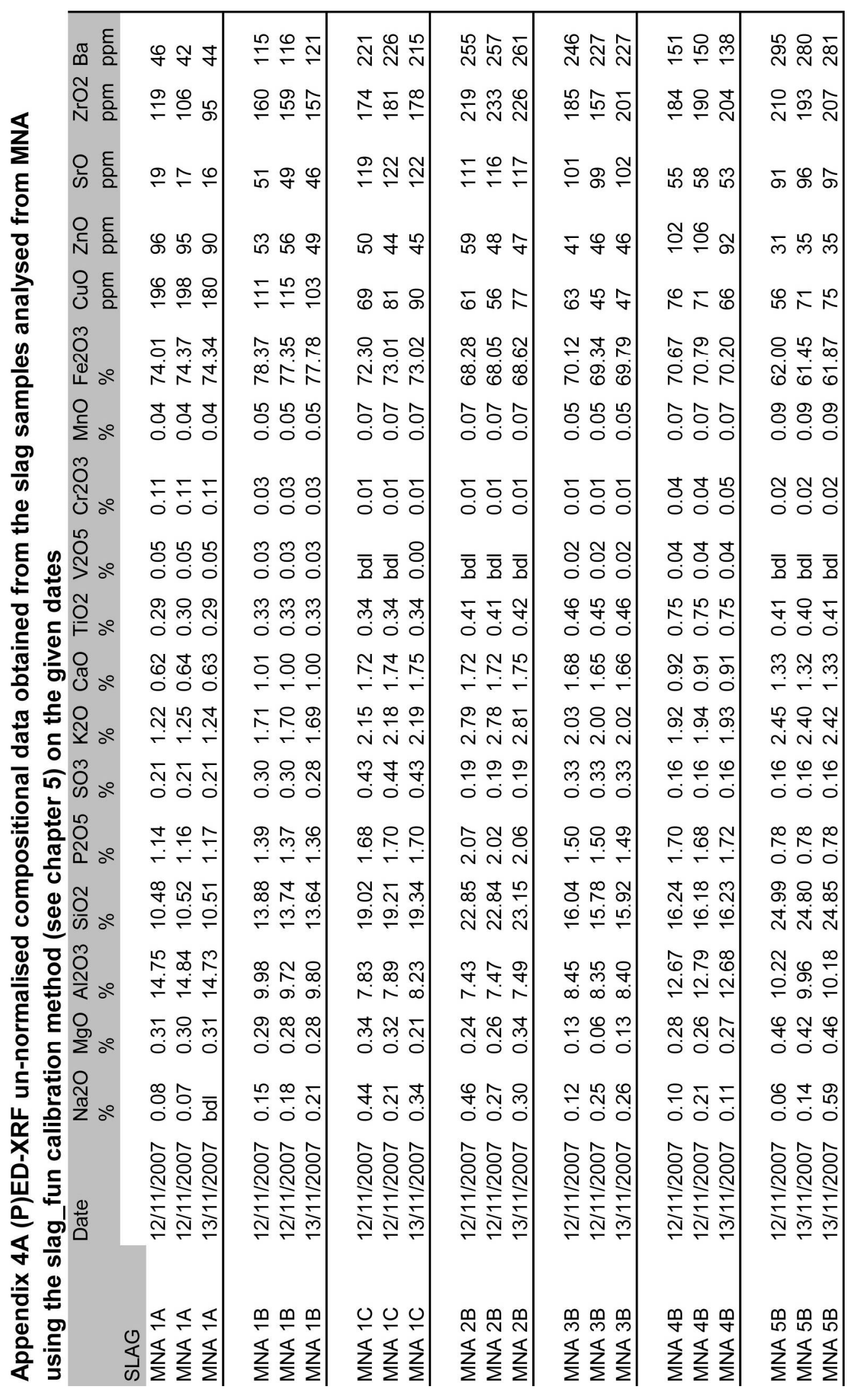




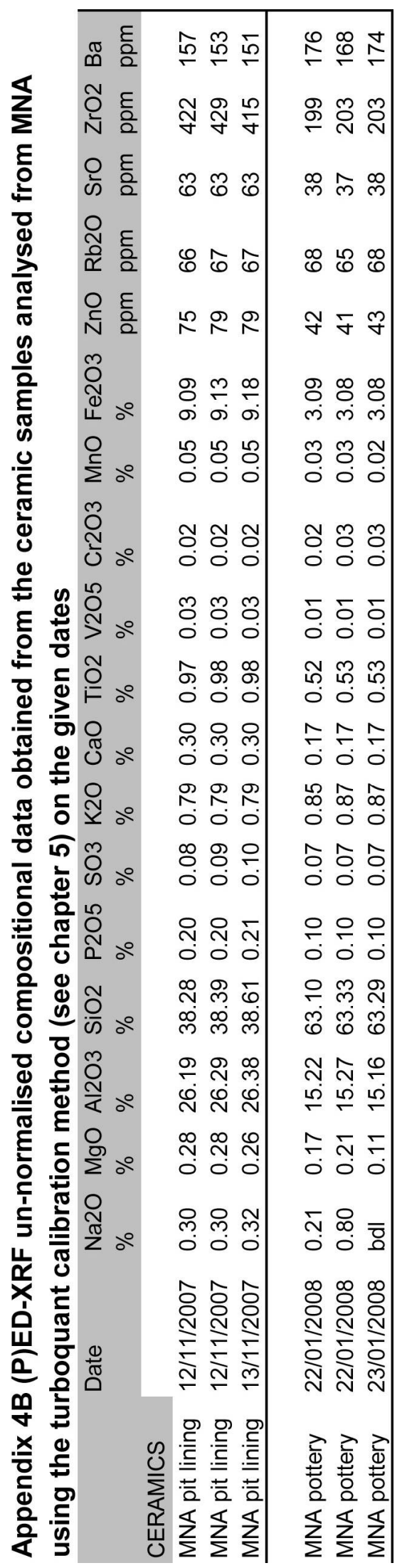




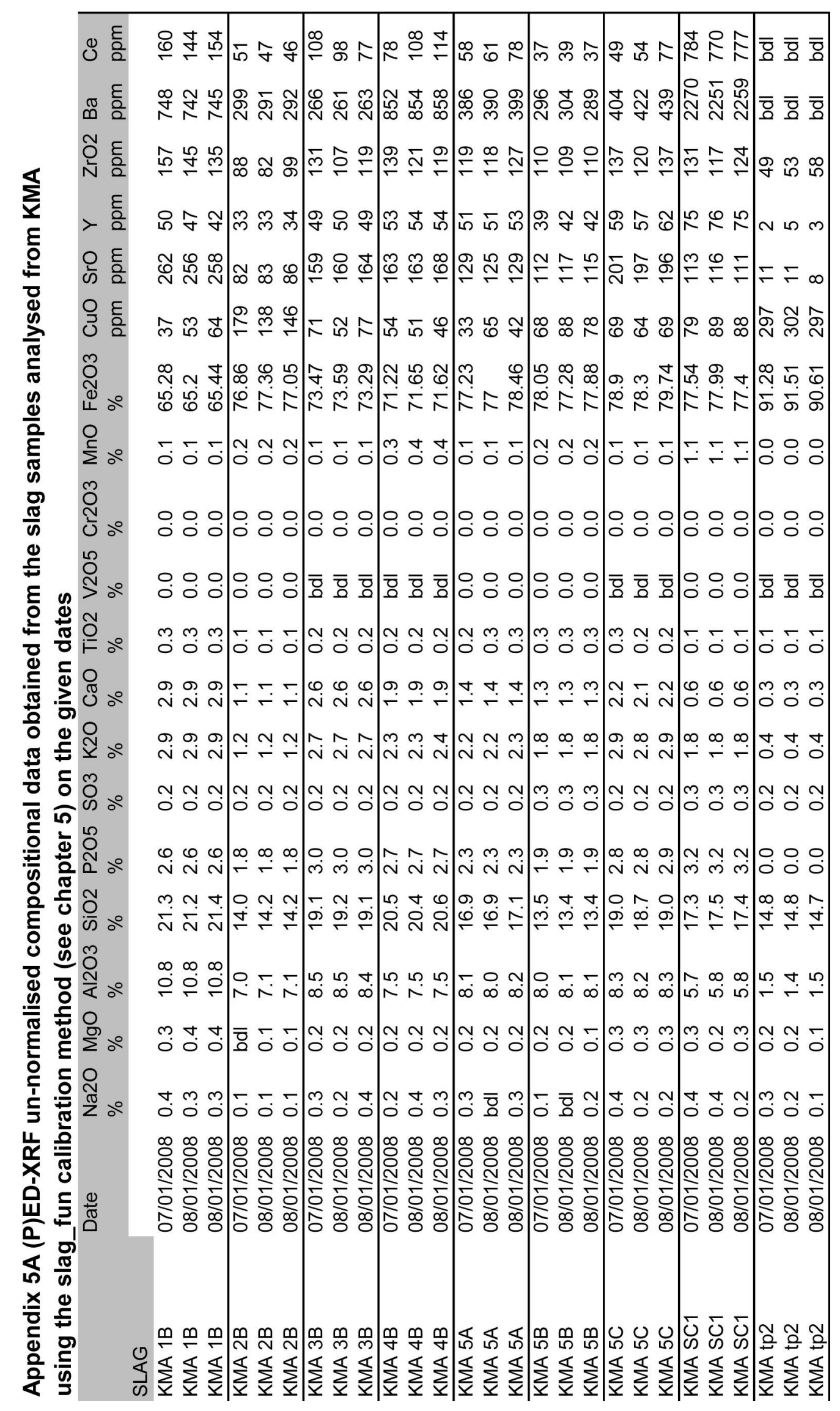




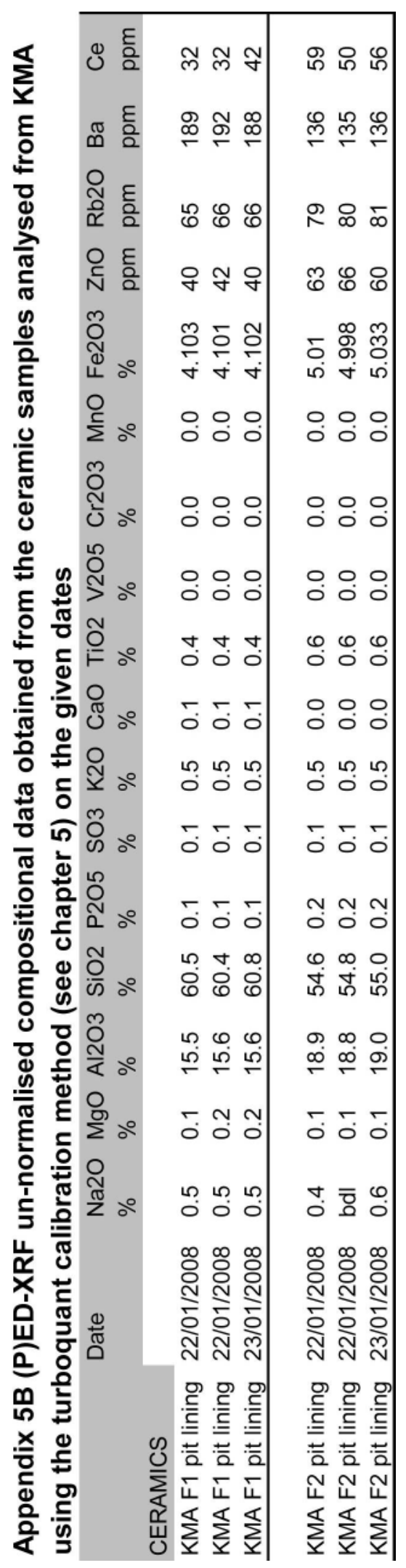



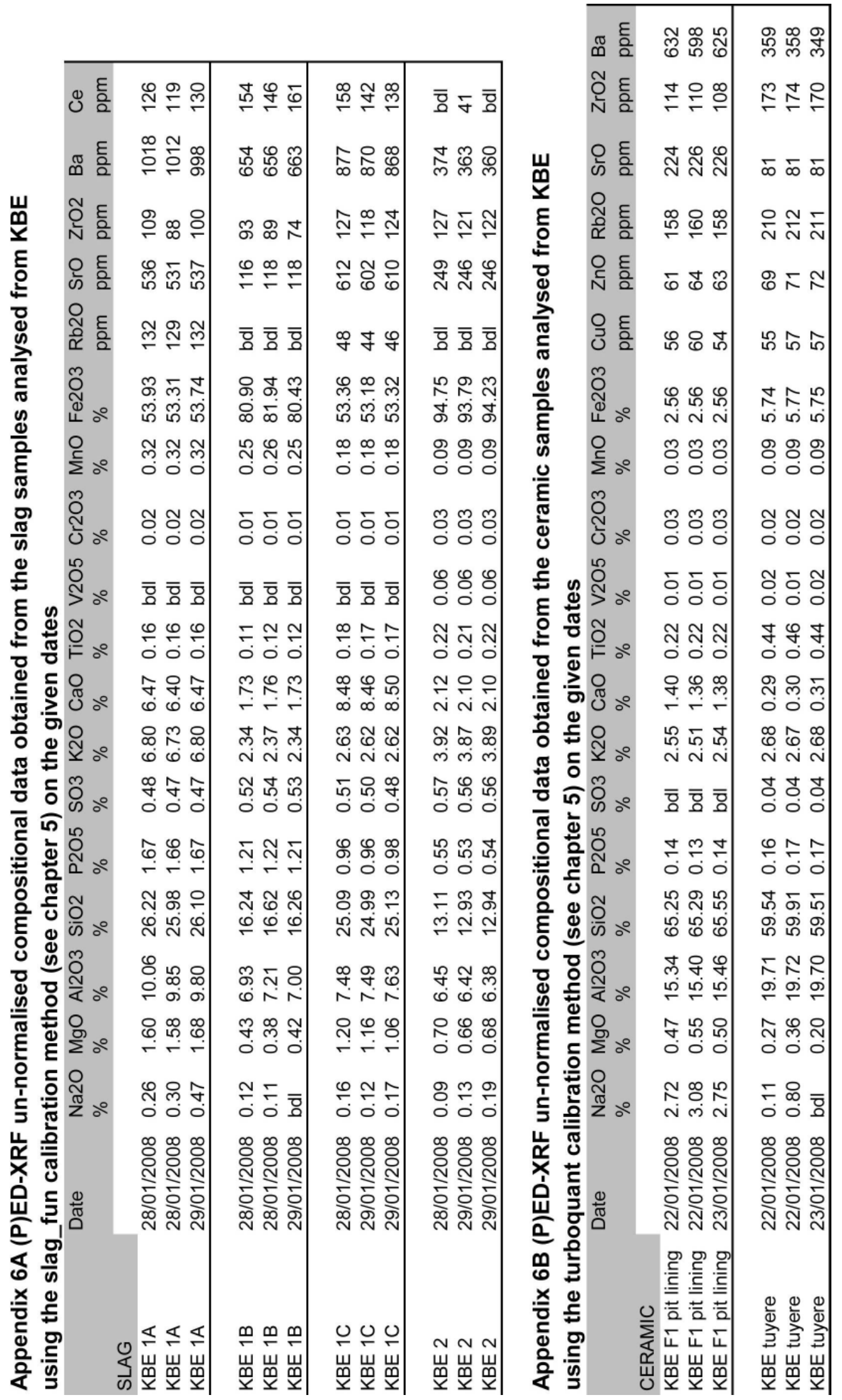
References 
Akinjogbin, I. A., 2004. The Impact of Iron in Yorubaland. In: H. Boucoum (ed.), The Origins of Iron Metallurgy in Africa: New light on its antiquity: West and Central Africa. Paris: UNESCO, 55-65.

Alexander, W. and Street, A., 1968. Metals in the service of man. London: Penguin Alpern, S.P., 2005. Did They or Didn't They Invent It? Iron in Sub-Saharan Africa. History in Africa 32, 41-94.

Andah, B., 1994. European encumbrances to the development off relevant theory in African archaeology. In: P. J. Ucko (ed.), Theory in Archaeology: A world perspective. London: Routledge, 96-109.

Andah, B., 1995. Studying African Societies in Cultural Context. In: P. Schmidt and T. Patterson (eds.), Making Alternative Histories: The Practice of Archaeology and History in Non-Western Settings. Santa Fe: School of American Research Press, 149181.

Ashley, C., 2005. Ceramic Variability and Change: A Perspective from Great Lakes Africa. London: UCL, Unpublished PhD Thesis.

Ashley, C. and Reid, A., 2008. A reconsideration of the figures from Luzira. Azania: archaeological research in Africa 43/1, 95-123.

Ashley, C., forthcoming. Towards a Socialised Archaeology of Ceramics in Great Lakes Africa. African Archaeological Review.

Atherton, J. H., 1983. Ethnoarchaeology in Africa. African Archaeological Review 1, 75-104.

Avery, D. H. and Schmidt, P. R., 1979. A Metallurgical Study of the Iron Bloomery, Particularly as Practised in Buhaya. Journal of Metals 31, 14-20.

Bailey, F. W. J. 1972: Fundamentals of Engineering Metallurgy and Materials. Cassell \& Company Ltd. London 
Barker, A. W., 2008. Chiefdoms. In: R. A. Bentley., H. D. G. Maschner and C. Chippindale (eds.), Handbook of Archaeological Theories. Plymouth: AltaMira Press, 515-532.

Barndon, R., 1996. Fipa Ironworking and its Technoloical Style. In: P. R. Schmidt (ed.), The Culture and Technology of Iron Production, 58-73.

Bernbeck, R., 2008. The Rise of the State. In: R. A. Bentley., H. D. G. Maschner and C. Chippindale (eds.), Handbook of Archaeological Theories. Plymouth: AltaMira Press: 533-544.

Blakelock, E., Martinón-Torres, M., Veldhuijzen, H. A., Young, T., 2009. Slag Inclusions in Iron Objects and the Quest for Providence. An experiment and Case Study. Journal of Archaeological Science 36, 1745-1757

Bourdieu, P., 1977. Outline of a theory of a practice. Cambridge University Press

Brannt W.T., 1908. Metallic Alloys: A Practical Guide. Philadelphia: Henry Carey Baird \& Co.

Brown, J., 1995. Traditional Metal Working in Kenya. Oxbow, Oxford

Buleli, N'S., 1993. Iron-Making Techniques in the Kivu Region of Zaire: Some of the Differences Between the South Maniema Region and North Kivu. In: Shaw, T., Sinclair, P., Bassey, A., Okpoko, A (eds). The Archaeology of Africa Food, Metals and Towns. London: Routledge, 468-477.

Celis, G., 1987. Introduction a la Metallurgie Traditionelle au Rwanda. Techniques \& Croyances 34.

Celis, G., 1991. Eisenhütten in Afrika. Les founderies africaines du fer. Frankfurt: Museum für Völkerkunde.

Champion, T. and Ucko, P., 1998. European Reminiscence on Africa. In: B. W. Andah and T. Shaw (eds.), Africa: the challenge of archaeology. Nigeria: Heinemann Educational Books, chapter 2. 
Charlton, M., 2006. Iron Working in Northwest Wales: an Evolutionary Analysis. UCL: Unpublished $\mathrm{PhD}$ thesis.

Childs, S. T., 1989. Clays to Artifacts: Resource Selection in African Early Iron Age Smelting Technologies. In: G. Bronitsky (ed.), Pottery Technology: Ideas and Approaches. Boulder, CO: Westview Press, 139-164.

Childs, S. T., 1991a. Iron as utility or expression: reforging function in Africa. In: R. M. Ehrenreich (ed.), Metals in Society: Theory Beyond Analysis. MASCA Research Papers, Philadelphia: University of Pennsylvania, 57-67.

Childs, S. T., 1991b. Style, Technology, and Iron Smelting Furnaces in Bantu-Speaking Africa. Journal of Anthropological Archaeology 10, 332-359.

Childs, S. T., 1991c. Transformations: iron and copper production in Central Africa. In: P. Glumac (ed.), Recent Advances in Archaeometallurgical Research. Philadelphia. MASCRA Research Papers in Science and Archaeology 8/1, 33-46.

Childs, S. T., 1996. Continuities and Adaptions of Iron Working in Tanzania: Evidence from the Laboratory. In: P. R. Schmidt (ed.), The Culture and Technology of African Iron Production. Gainesville: University Press of Florida, 277-320.

Childs, S. T., 1998. Finding the ekijunjumira. Iron mine discovery, ownership and power among the Toro of Uganda. In A. Knapp, V. Pigott, and E. Herbert (eds.), Social Approaches to an industrial past. The archaeology and anthropology of mining. London: Routledge.

Childs, S. T., 1998. Social Identity and Craft Specialization among Toro Iron Workers in Western Uganda. Archeological Papers of the American Anthropological Association 8/1, 109-121.

Childs, S. T., and Dewey, W. J., 1996. Forging Symbolic Meaning in Zaire and Zimbabwe. In: P. R. Schmidt (ed.), The Culture and Technology of African Iron Production. Gainsville: University of Florida Press, 145-171.

Childs, S. T. and Herbert, E.W., 2005. African Archaeology. Oxford: Blackwell. 
Childs, S. T. and Killick, D., 1993. Indigenous African Metallurgy: Nature and Culture. Annual Anthropological Review 22, 317-337.

Childs, S. T. and Schmidt, P. R., 1985. Experimental iron smelting: The genesis of a hypothesis with implications for African prehistory and history. In: R. Haaland and P. Shinnie (eds.), African Iron Working - Ancient and Traditional. Oslo: Norwegian University Press, 121-141.

Chirikure, S., 2002. A Metallurgical Investigation of Iron Processing Remains From Nyanga, Northeastern Zimbabwe. London:UCL, Institute of Archaeology, unpublished MA thesis.

Chirikure, S. 2005. Iron Production in Iron Age Zimbabwe: Stagnation or Innovation? Unpublished $\mathrm{PhD}$ thesis, University College London.

Chirikure, S and Rehren, Th., 2004. Ores, Furnaces, Slags and Prehistoric Societies: Aspects of Iron Working in the Nyanga Agricultural Complex, AD 1300-1900. African Archaeological Review 21, 135-152.

Chrétien, J-P., 2003. The Great Lakes of Africa: Two Thousand Years of History (translated by Scott Straus). New York: Zone Books .

Cleere, H., 1970. Notes on the study of early iron industries. Science and Archaeology 4, 4-7.

Cleere, H., 1971. Iron Making in a Roman Furnace. Britannia Vol 2, 203-217

Cleere, H., 1983. Ironmaking in the Economy of the Ancient World: The Potential of Archaeometallurgy.

Cline, W., 1937. Mining and Metallurgy in Negro Africa. Wisconsin: George Banta Publishing.

Clist, B., 1987. A Critical Reappraisal of the Chronological Framework of Early Urewe Iron Age Industry. Muntu 6, 35-62.

Coles, J., 1979. Experimental Archaeology. London: Academic Press. 
Collett, D., 1993. Metaphors and representations with precolonial iron smelting in Eastern and Southern Africa. In: P. Sinclair, B. Andah and A. Okpoko (eds.), The Archaeology of Africa: Food, Metals and Towns. World Archaeology 20. London: Routledge, 499-511.

Connah, G., 1996. Kibiro: The salt of Bunyoro, past and present. London: British Institute in Eastern Africa Memoir 13.

Connah, G., 2001. African Civilizations. An Archaeological Perspective. (Second Edition). Cambridge: Cambridge University.

Costin, C. L., 2005. Craft Production. In: H. D. G. Maschner (ed.), Handbook of Archaeological Methods. Walnut Creek, Ca.: AltaMira, 1034-1107.

Craddock, P. T., 1995. Early Metal Mining and Production. Edinburgh: Edinburgh University Press.

Craddock, P., 1996. The Beginnings of Metallurgy in South-west Britain. In: P. Newman (ed.), The Archaeology of Mining and Metallurgy in South-west Britain. Bulletin of the precedings of the Peak District Mines Historical Society 13/2, 52-63.

Craddock, P. T., Freestone, I., Middleton, A. and Van Grunderbeek M-C., 2007. Early Iron Age iron-smelting debris from Rwanda and Burundi, East Africa. Historical Metallurgy 41, 1-14.

Craddock, P., Freestone, I., Middleton, A. and Van Grunderbeek M-C., 2007. The Scientific Study of Some Early Iron Age iron Smelting Debris from Rwanda and Burundi, East Africa. Historical Metallurgy 41/1, 1-14.

Crew, P., 1991. The experimental production of prehistoric bar iron. The Journal of the Historical Metallurgy Society 25, 21-36.

Crew, P., 2000. The Influence of Clay and Charcoal Ash on Bloomery Slags. In: C.C. Tizzon and M. Tizzon (eds.) Iron in The Alps. Proceedings of the Conference 38-48.

David, N. and Kramer, C., 2001. Ethnoarchaeology in Action. Cambridge: Cambridge University Press. 
David, N., Heimann, R., Killick, D. and Wayman M. L., 1989. Between Bloomery and Blast Furnace: Mafa Iron Smelting Technology in Northern Cameroon. The African Archaeological Review 7, 185-210.

De Barros, P., 1990. Changing paradigms, goals and methods in the archaeology of Francophone West Africa. In: P. Robertshaw (ed.), The History of African Archaeology. London: James Currey, 155-172.

De Barros, P., 2000. Iron Metallurgy: Sociocultural Context. In: J. O. Vogel (ed.), Ancient African Metallurgy: The Sociocultural Context. Walnut Creek, CA: AltaMira 147-198.

Delmonte, J., 1985. Origins of materials and processes. Lancaster, Pa.: Technomic.

de Maret, P., 1985. The smith's myth and the origin of leadership in Central Africa. In: R. Haaland and P. Shinnie (eds.), African Iron Working - Ancient and Traditional. Oslo: Norwegian University Press, 73-87.

de Maret, P., 1990. Phases and fades in the archaeology of Central Africa. In: P. Robertshaw (ed.), The History of African Archaeology. London: James Currey, 109134.

de Maret, P., 2005. From pottery groups to ethnic groups in Central Africa. In: A. Stahl (ed.), African archaeology: a critical introduction. Oxford: Blackwell, 420-440.

de Maret, P., and Thiry, G. Thiry, 'How old is the Iron Age inCentral Africa?', In: P. R. Schmidt (ed.), The Culture and Technology of African Iron Production (Gainesville, 1996), 29-39.

Desmedt, C., 1991. Poteries Anciennes Décorées à la Roulette Dans la Région des Grands Lacs. The African Archaeological Review 9, 161-196.

Diène, D., 2004. Preface. In: H. Bocoum (ed.), The Origins of Iron Metallurgy in Africa, New Light on its Antiquity: West and Central Africa. Paris: Unesco Publishing, 19-20. 
Dobres, M-A., 2000. Technology and social agency : outlining a practice framework for archaeology. Oxford: Blackwell.

Dobres, M-A. and Hoffman, C. R., 1994. Agency and the dynamics of prehistoric technology. Journal of Archaeological Method \& Theory 1/3, 211-258.

Edmonds, M., 1990. Description, Understanding and the Chaîne Opératoire. Archaeological Review from Cambridge 9/1, 55-70.

Eggert, M. K. H., 2005. The Bantu Problem and African Archaeology. In: A. Stahl (ed.), African Archaeology: A Critical Introduction. Oxford: Blackwell Press, 301-326.

Eltringham, N., 2004. Accounting for Horror: Post-Genocide Debates in Rwanda. London: Pluto Press.

Eze-Uzomaka, P., 2007. Lejja Iron Smelting Site, Igboland, South Eastern Nigeria. In: P. G. Radimilahy., C. Chami and F. Chami (eds.), Settlement, Economies and Technology in the African Past. Studies in the African Past. Tanzania, Dar es Salaam University Press 6:149-159.

Fluzin, P., 2004. The Process Chain in Iron ad Steelmking: Archaeological Materials and Procedures. The Contribution of Metallurgical Studies. In: H. Boucoum (ed.), The Origins of Iron Metallurgy in Africa: New light on its antiquity: West and Central Africa. Paris: UNESCO, 65-97.

Freestone, I. C., 1989. Refractory materials and their procurement. In: A. Hauptmann, E. Pernicka and G.A. Wagner (eds.), Old World Archaeometallurgy. Heidelberg: Proceedings of the International Symposium, 155-162.

Gadamer, H.J., 1975. Truth and Method. Sheed \& Ward, London

Gale, W. K. V., 1969. Iron and steel. Harlow: Longmans

Galloway, A. 1934. A note on the iron-smelting methods of the Elgeyo Masai. South African Journal of Science 31:500-504.

Gardner, A., 2004. Archaeology and Modernity by J. Thomas. Reviewed in: Papers from the Institute of Archaeology 15, 121-124. 
Gardner, A., 2008. Agency. In: R. A. Bentley, H. D. G. Maschner, and C. Chippindale (eds.), Handbook of archaeological theories. Lanham, MD; Plymouth : AltaMira Press, 96-108.

Garlake, P. S., 1973. Great Zimbabwe. London: Thames and Hudson.

Giddens, A., 1984. The Constitution of Society: An Outline of Theory of Structuration. Berkley: University of California.

Giblin, J., 2003. The Royal Potters of Buganda: A Social and Symbolic Study. London: UCL Institute of Archaeology, Unpublished MA thesis.

Giblin, J., 2008. New Work on the Later Archaeology of Rwanda 2006 to 2007: A Preliminary Fieldwork Report. Nyame Akuma 69, 45-55.

Giblin, J., 2010. Re-Constructing the Past in Post-Genocide Rwanda: An Archaeological Contribution. London: UCL, unpublished $\mathrm{PhD}$ thesis.

Giblin, J., Humphris. J.E., Clements, A., forthcoming. An Urewe Burial in Rwanda: Pathologies, Metallurgy and Long Distance Trade ca. 400 AD. Azania

Godfrey-Smith, D. I. and Casey J.L., 2003. Direct thermoluminescence chronology for Early Iron Age smelting in Ghana. Journal of Archaeological Science 30, 1037-50.

Gosselain, O. P., 1992. Technology and style: potters and pottery among the Bafia of Cameroon. Man 27/3, 559-586.

Gosselain, O. P., 2000. Materialising identities: an African perspective. Journal of Archaeological Method and Theory 7/3, 187-217.

Gourevitch, P., 2000. We Wish to Inform You That Tomorrow We Will be Killed With Our Families: Stories from Rwanda. Picador.

Gouthama. and Balasubramaniam. R., 2003. Alloy design of ductile phosphoric iron: Ideas from archaeometallurgy. Bulletin of Materials Science 26 (5), 483-491.

Gregory, E., 1943. Metallurgy. London: Blackie \& Son Ltd. 
Haaland, R., 1985. Iron production, its socio-cultural context and ecological implications. In: R. Haaland and P. Shinnie (eds.), African Iron Working - Ancient and Traditional. Oslo: Norwegian University Press, 50-72.

Haaland, R., 2004. Iron smelting a vanishing tradition: ethnographic study of this craft in South West Ethiopia. Journal of African archaeology 2/1, 1-15.

Hall, M., 1990. Iron Age archaeology in Southern Africa. In: P. Robertshaw (ed.), A History of African Archaeology. London: James Currey, 59-77.

Hegmon, M., 1992. Archaeological Research on Style. Annual Review of Anthropology 21, 517-536.

Henshilwood. C. S., d'Errico. F. and Watts. I., 2009. Engraved ochres from the Middle Stone Age levels at Blombos Cave, South Africa. Journal of Human Evolution 57 (1), 27-47.

Herbert, E. W., 1993. Iron, Gender and Power: Rituals of Transformation in African Societies. Bloomington: Indiana University Press.

Hiernaux, J. and Maquet, E., 1957. Cultures préhistoriques de l'âge des métaux aux Ruanda-Urundi et au Kivu (Congo Belge), 1ère partie. Académie Royale des sciences colonials, Bulletin des séances 2/6, 1126-1149.

Hiernaux, J. and Maquet, E., 1960. Cultures préhistoriques de l'âge des métaux aux Ruanda-Urundi et au Kivu (Congo Belge), 2me partie. Bulletin des Sciences de L'Academie Royals des Sciences Coloniale.

Huffman, T., 1986. Cognitive studies of the Iron Age in southern Africa. World Archaeology 18/1, 84-95.

Huffman, T., 1993. Broederstroom and the Central Cattle Pattern. South African Journal of Science 89, 220-226.

Huffman, T. N., 2007. Handbook to the Iron Age: the archaeology of pre-colonial farming societies in Southern Africa. South Africa: University of KwaZulu-Natal Press. 
Humphris, J. E., 2004. Reconstructing a Forgotten Industry: An Investigation of Iron Smelting in Buganda. University College London: Unpublished MA dissertation.

Humphris, J. E., Martinón-Torres, M., Rehren, Th. and Reid, A., 2009. Variability in single smelting episodes - a pilot study using iron slag from Uganda. Journal of Archaeological Science 36 (2), 359-369.

Ige, A. and Rehren, Th., 2003. Black sand and iron stone: iron smelting in Modakeke, Ife, south-western Nigeria. Institute of Archaeo-Metallurgical Studies 23, 15-20.

Iles. L., 2009. Pre-Colonial Iron Production in Western Uganda: Recent Survey and Excavation. Nyame Akuma 71, 35-45.

Iles, L. and Martinón-Torres, M., 2009. Pastoralist iron production on the Laikipia Plateau, Kenya: wider implications for archaeometallurgical studies. Journal of Archaeological Sciences 36/10, 2314-2326.

Ingold, T., 1990. Society, nature and the concept of technology. Archaeological review from Cambridge 9/1, 5-17.

Ingold, T., 2000. The perception of the environment : essays on livelihood, dwelling and skill. London, Routledge.

Jemkur, J. F., 2004. The Beginnings of Iron Metallurgy in West Africa. In: H. Bocoum (ed.), The Origins of Iron Metallurgy in Africa: New light on its antiquity: West and Central Africa. Paris: UNESCO, 3-43.

Johnston, H. H., 1902. The Uganda Protectorate: an attempt to give some descriptions of the physical geography, botany, zoology, anthropology, languages and history of the territories under British protection in East Central Africa, between the Congo Free State and the Rift Valley and between the first degree of south latitude and the fifth degree of north latitude. London: Hutchinson.

Joosten, I., 2004. Technology of Early Historical Iron Production in the Netherlands. Amsterdam: Vrije University. 
Kagwa, A., 1934. The Customs of the Buganda. Translated by E.B. Kalibala and M.Mandelbaum. New York: Columbia University Press

Kanimba, C.M. and Kabwete C.M., 2000. Innovations dans le domaine de la métallurgie au Rwanda. Estudes Rwandaises 1. Rwanda: University of Rwanda

Keller, C., 1994. Invention, Thought and Process: Strategies in Iron Tool Production. In S.U.Wiseman and W.S.Williams (eds.), Ancient Technologies and Archaeological Materials. Amsterdam: Overseas Publishing Association, 59-70

Killick, D., 1987. On the dating of African metallurgical sites. Nyame Akuma 28:29-30

Killick, D., 1991. The Relevance of Recent African Iron-Smelting Practice to Reconstructions of Prehistoric Smelting Technology. In: P. Glumac (ed.), Recent Trends in Archaeometallurgical Research. Philadelphia: MASCA Papers in Science and Archaeology 8:1.

Killick, D., 1996. On claims for 'advanced' ironworking technology at Kasungu, Malawi, 1840-1940. In: P. R. Schmidt (ed.), The Culture and Technology of African Iron Production. Gainesville: University Press of Florida, 247-266.

Killick, D., 2001. Science, speculation and the origins of extractive metallurgy. In: D.R. Brothwell and A.M. Pollard (eds.), Handbook of Archaeological Science. John Wiley \& Sons ltd.

Killick, D., 2004. What do We Know About African Iron Working? Journal of African Archaeology 2/1, 97-112.

Killick, D.J. (2008). Archaeological science in the USA and in Britain. In A. Sullivan (ed.), Archaeological Concepts for the Study of the Cultural Past. Salt Lake City: University of Utah Press, 40-64.

Killick, D. 2009. Cairo to Cape: The Spread of Metallurgy Through Eastern and Southern Africa. Journal of World Prehistory, 22: 399-414.

Kresten, P. and Hjlirthner-Holdar, E., 2001. Analyses of the Swedish Ancient Iron Reference Slag W-25:R. Historical Metallurgy 35/1, 48-51. 
Kusimba, C. M. and Kusimba, S. B., 2005. Mosaics and Interactions: East Africa, 2000 b.p. to the Present. In: A.B. Stahl (ed.), African Archaeology. Oxford: Blackwell, 392419

Lane, P. J., 1994/5. The use and abuse of ethnography in Iron Age Studies of Southern Africa. Azania 29-30, 51-64.

Lane, P. J., 2004. The 'moving frontier' and the transition to food production in Kenya. Azania XXXIV, 243-264.

Lane, P., 2006. Present to Past: Ethnoarchaeology. In: Tilley C. Y. (ed.), Handbook of Material Culture. SAGE, 402-425.

Lanning, E.C. 1954. Genital symbols on Smith's bellows in Uganda. Man 54(262), 167-168.

Leakey, M. D., Owen, W. E. And Leakey, L. S. B., 1948. Dimple-based Pottery from Central Kavirondo, Kenya Colony. Nairobi: Coryndon Memorial Museum, Occasional Paper No. 2.

Lejju, B. J., Robertshaw, P. and Taylor, D., (2006). Africa's earliest bananas? Journal of Archaeological Science 33, 102-113.

Lemonier, P., 1990. Topsy Turvy Techniques: Remarks on the Social Representation of Techniques. Archaeological Review from Cambridge 9/1, 27-37.

Lemonier, P., 1992. Elements for an Anthropology of Technology. Ann Arbor, Michigan: University of Michigan; Anthropological Paper 88.

Lemonnier, P. (ed.), 1993. Technological Choices: Transformation in material cultures since the Neolithic. London: Routledge.

Leroi-Gourhan, A., 1993. Gesture and Speech. Translated from French by A. B. Berger. Cambridge, Mass.; London, England: MIT Press.

Mabunwe-Semba, P., 1994. Oral Tradition and the African Past. In R. Layton (ed.), Who Needs the Past?Indigenous Values and Archaeology. 105-118 
Maclean, R., 1994/5. Late Stone Age and Early Iron Age settlement in the Interlacustrine region: a district case study. Azania 29-30, 296-302

Maclean, R., 1998. Gendered Technologies and Gendered Activities in the Interlacustrine Early Iron Age. In: S. Kent (ed.), Gender in African Prehistory. Walnut Creek, CA: AltaMira, 163-178.

Maes-Diop, L-M., 2004. Assessment of the Dating of Ancient Relics of Ironworking in Africa: Main Lessons. In: H. Boucoum (ed.), The Origins of Iron Metallurgy in Africa: New light on its antiquity: West and Central Africa. Paris: UNESCO, 189-195

Mamdani, M., 2001. When victims become killers: colonialism, nativism and the genocide in Rwanda. Princeton, N.J.; Oxford: Princeton University Press.

Mapunda, B., 1995. An Archaeological View of the History and Variation of Iron Working in Southwestern Tanzania. Univeristy of Florida, $\mathrm{PhD}$ thesis.

Maquet, E., 1965. Outils de forge du Congo, du Rwanda et du Burundi. Annales. Nouvelle série in-4o. Science humaines. Koninklijk Museum voor Midden-Afrika 5.

Marshall, F. and Stewart, K., 1994. Hunting, fishing and herding pastoralists of western Kenya: the fauna from Gogo Falls. Archaeozoologia 7, 7-27.

Martinelli, B., 2004. On the Threshold of Intensive Metallurgy: The Choice of Slow Combustion in the Niger River Bend (Burkina Faso and Mali). In: H. Bocoum (ed.), The Origins of Iron Metallurgy in Africa, New Light on its Antiquity: West and Central Africa. Paris: Unesco Publishing, 165-188.

Martinón-Torres, M., 2008. Why should archaeologists take history and science seriously? In: M. Martinon-Torres and Th. Rehren (eds.), Archaeology, History and Science: Integrating Approaches to Ancient Materials. London: UCL Institute of Archaeology Publications.

Mathieu, J. R., 2002. Experimental Archaeology Replicating past objects, behaviors, and processes. BAR International Series 1035 
McMaster, M., 2005. Language Shift and its reflection in Africa Archaeology: Cord rouletting in the Uele and Interlacustrine regions. Azania 40, 43-72.

Miller, D. E. and Van der Merwe, N. J., 1994. Early metal-working in sub-Saharan Africa: a review of recent research. Journal of African History 35, 1-36.

Misago, K. and Shumbusho, G., 1992. Archaeological and Ethnorchaeological Research in the Zones of Rutshuru and Masisi in Northern Kivu. Nyame Akuma 38, 66-71.

Misra, M.K., Ragland, K.W., and Baker, A.J., 1993. Wood Ash Compositions as a Function of Furnace Temperature. Biomass and Bioenergy 4: 103-116.

Musonda, F. B., 1990. African archaeology: looking forward. African Archaeological Review 8/1, 3-22.

Ndoro, W., 2001. Your monument our shrine: the preservation of Great Zimbabwe. Uppsala, Sweden: Uppsala University.

Nenquin, J., 1963. Excavations at Sanga 1957, the Protohistoric Necropolis. Belgium: Musee Royal de L'Afrique Central.

Nenquin, J., 1967. Contributions to the Study of Prehistoric Cultures of Rwanda and Burundi. Tervuren: Annales du Musèe Royal de L'Afrique Centrale 59.

Nenquin, J., 1971. The Congo, Rwanda, and Burundi. In: P. L. Shinnie (ed.), The African Iron Age. Wotton-under-Edge, Glous.: Clarendon Press.

Nørback, L. C. (ed.)., 1997. Early Iron Production: Archaeology, Technology and Experiments. Lejre: Historical-Archaeological Experimental Centre, 3.

Okafor, E. E., 1993. New evidence on early iron-smelting from South Western Nigeria. In: T. Shaw, P. Sinclair, B. Andha and A. Opoko (eds.), The Archaeology of Africa: Food, Metals and Towns. London: Routledge, 432-438.

Okafor, E. E., 2004. Twenty-five Centuries of Bloomery Iron Smelting in Nigeria. In: H. Bocoum (ed.), The Origins of Iron Metallurgy in Africa, New Light on its Antiquity: West and Central Africa. Paris: Unesco Publishing, 43-54. 
Okafor, E. E., 2004. Identification and Composition of Bloomery Slags. West African Journal of Archaeology 27(2): 32-53.

Oliver, R. A. and Fagan, B. M.., 1975. Africa in the Iron Age, c500 B.C. to A.D. 1400, Part 1400. Cambridge: Cambridge University Press.

Perret, S. and Serneels, V., 2009. Technological Characterisation and Quantification of a Large-Scale Iron Smelting Site in Fiko (Dogon Plateau, Mali). In: Proceedings of ISA 2006. Québec: Celat.

Pfaffenberger, B., 1992. Social Anthropology of Technology. Annual Review of Anthropology 21, 491-516.

Pfaffenberger, B., 1998. Mining Communities, Chaînes opératoires and Sociotechnical Systems. In: A. B. Knapp, V. C. Piggott and E. W. Herbert (eds.), Social Approaches to an Industrial Past. London: Routledge, 291-300.

Philippson, G. and Bahuchet, S.,1994/1995. Cultivated crops and Bantu migrations in Central and Eastern Africa: A linguistic approach. Azania 29-30, 103-120.

Pleiner, R., 1969. Iron Working in Ancient Greece. Praha: Archeologický Ústav Av Cr. Pleiner, R., 1978. The Technology of Three Assyrian Iron Artifacts from Khorsabad. Journal of Near Eastern Studies 38 (2), 83-91.

Pleiner, R., 1993. The Celtic Sword. Oxford: Clarendon Press.

Pleiner, R., 2000. Iron In Archaeology. The European Bloomery Smelters. Praha: Archeologický Ústav Av Cr.

Posnansky, M., 1961. Pottery Types from Archaeological Sites in East Africa. Journal of African History 2/2, 177-198.

Posnansky, M., Reid, A. and Ashley, C., 2005. Archaeology on Lolui Island, Uganda 1964-5. Azania XL, 1-29. 
Quechon, G., 2004. Iron Metallurgy Datings from Termit (Niger): Their Reliabilty and Significance. In: H. Boucoum (ed.), The Origins of Iron Metallurgy in Africa: New light on its antiquity: West and Central Africa. Paris: UNESCO, 109-119.

Raymaekers, J. and Van Noten, F., 1986. Early Iron Furnaces with 'Bricks' in Rwanda: Complimentary evidence from Mutwarubona. Azania XXI, 65-84.

Rehren, Th. and Papachristou, O., 2003. Similar like white and black: a comparison of steel-maiking crucibles from Central Asia and the Indian Subcontinent. In: Th. Stöllner, G. Körlin, G. Steffens, J. Cierny (eds.), Man and Mining - Mensch und Bergbau. Bochum: Der Anschnitt, 393-404.

Rehren. Th., Charlton, M., Chirikure, S., Humphris, J., Ige, A., Veldhuijzen, H.A., 2007. Decisions Set in Slag: the human factor in African Iron Smelting. In: La Niece,S., Hook, D and Craddock, P (eds.), Metals and Mines: Studies in Archaeometallurgy. London: Archetype. 211-218.

Reid, D. A. M., 1991. The Role of Cattle in the Later Iron Age Communities of Southern Uganda. University of Cambridge, Unpublished PhD Thesis.

Reid, D. A. M., 1994/5. Early settlement and social organisation in the Interlacustrine region. Azania 29-30, 303-313.

Reid, D. A. M., 1996. Ntusi and the development of social complexity in southern Uganda. In: G. Pwiti and R. Soper (eds.), Aspects of African Archaeology. Harare: University of Zimbabwe Press, 621-628.

Reid, D. A. M., 2001. Bananas and the Archaeology of Buganda. Antiquity 75, 811-12.

Reid, D. A. M., 2003. Ancient Egypt and the Source of the Nile. In: D.C. O'Connor and D. A. M. Reid (eds.) Ancient Egypt in Africa. London: UCL Press, 55-76.

Reid, A, and Ashely, C., 2008. A Context for the Luzira Head. Antiquity 82, 99-112

Reid, D. A. M and Lane, P., 2004. African Historical Archaeologies: An Introductory Consideration of Scope and Potential. In: D. A. M Reid and P. Lane (eds.), African 
Historical Archaeologies. Contributions to Global Historical Archaeology. New York: Kluwer, 1-32.

Reid, D. A. M. and MacLean, R., 1995. Symbolism and the Social Context of Iron Production in Karagwe. World Archaeology 27, 144-161.

Robertshaw, P.T., 1990. A History of African Archaeology: an introduction. In: P. T. Robertshaw (ed.), A History of African Archaeology. Oxford: James Currey, 3-12.

Robertshaw, P. T., 1991a. Recent Archaeological Surveys in Western Uganda. Nyame Akuma 36, 40-46.

Robertshaw, P.T., 1991b. Gogo Falls: A Complex Site East of Lake Victoria. Azania: Journal of the British Institute in Eastern Africa 26: 63-196.

Robertshaw, P.T., 1999. Seeking and keeping power in Bunyoro-Kitara. In S. McIntosh (ed.), Pathways to Complexity: An African Perspective. Cambridge: Cambridge University Press

Robertshaw, P.T., 2003. The Origins of the State in East Africa. InC.M. Kusimba and S. B. Kusimiba (eds.), East African Arcgaeology: Foragers, Potters, Smiths and Traders. Philadelphia: University of Pensylvania

Roscoe, J., 1911. The Baganda. London: Macmillan.

Rostoker, W. and Dvorak. J.R., 1965. Interpretation of Metallographic Structures. London: Academic Press.

Rowlands, M and Warnier, J-P., 1993. The Magical Production of Iron in the Cameroon Grassfields. In: P. Sinclair, B. Andah, and A. Okpoko (eds.), The Archaeology of Africa: Food, Metals and Towns. London: World Archaeology 20, 499-511.

Rowley-Conwy, P., 2007. From genesis to prehistory: the archaeological three age system and its contested reception in Denmark, Britain, and Ireland. Oxford: Oxford University Press.

Ryzewski, K. and Gordon, R., 2008. Historical nail-making techniques revealed in metal structure. Historical Metallurgy 42 (1), 50 
Schmidt, P. R., 1996. Reconfiguring the Barongo: Reproductive symbolism and reproduction among a work association of iron smelters. In: P.R. Schmidt (ed.), The Culture and Technology Of African Iron Production. Gainesville: University Press of Florida, 74-127.

Schmidt, P. R., 1997. Iron Technology in East Africa: Symbolism, Science and Archaeology. Indiana: Indiana University Press.

Schmidt, P. R. and Avery, D. H., 1983 More Evidence for an Advanced Prehistoric Iron Technology in Africa. Journal of Field Archaeology 10/4, 421-434.

Schmidt, P. R. and Childs, S. T., 1985. Innovation and industry during the Early Iron Age in East Africa: KM2 and KM3 sites in Northwest Tanzania. African Archaeological Review 3, 53-94.

Schmidt, P. R. and Childs, S. T., 1996. Actualistic Models for Interprtation of Two Early Iron Age Industrial Sites in Northwestern Tanzania. In: P. R. Schmidt (ed.), The Culture and Technology of African Iron Production. Gainesville: University of Florida Press, 186-233

Schmidt, P. R. and Mapunda, B. B., 1997. Ideology and the Archaeological Record in Africa: Interpreting Symbolism in Iron Smelting Technology. Journal of Anthropological Archaeology 16/1, 73-102.

Schoenbrun, D. L., 1993. Cattle herds and banana gardens: the historical geography of the western Great Lakes region, ca AD 800-1500. African Archaeological Review 11, $39-72$.

Schoenbrun, D. L., 1994/5. Social Aspects of Agricultural Change between the Great Lakes, AD 500-1000. Azania XXIX-XXX, 270-282.

Schoenbrun, D. L., 1998. A Green Place, A Good Place: Agrarian Change, Gender, and Social Identity in the great Lakes Region to the C15th Century. Oxford: James Currey.

Scott, D. A., 1991. Metallography and Microstructure of Ancient and Historic Metals. Marina del Ray, California: The Getty Conservation Institute. 
Segobye, A., Reid, D. A. M., and Murambiwa, I., 1990. The Productions, Consumption and Status of Archaeology in Eastern and Southern Africa. Archaeological Review from Cambridge 9/2, 263-274.

Serneels, V., 1993. Archéométrie des Scories de Fer. Recherches sur la Sidérurgie Ancienne en Suisse Occidentale. Lausanne: Cahiers d'archeologie romande 61

Serneels, V. and Crew, P. (1997). Ore-Slag Relationships from Experimentally Smelted Bog-Iron Ore. In: Crew, P. and Crew, S. (eds.), Early Ironworking in Europe: Archaeology and Experiment, 78-82. Maentwrog: Plas Tan y Bwlch Occasional Paper 3.

Shaw, T., 1989. African archaeology: looking back and looking forward. African Archaeological Review 7, 3-31.

Shaw. T, and Macdonald. K . C., 1995 Out of Africa and out of context. Antiquity 69, 1036-1039

Signaut, F., 2002. Technology. In: T. Ingold (ed.), Companion Encyclopaedia of Anthropology. Humanity, Culture and Social Life. London: Routledge. 397-419

Sillar, B., 2000. Dung by Preference: The Choice of Fuel as an Example of How Andean Pottery Production is embedded Within Wider Technical, Social, and Economic Practices. Archaeometry 42/1, 43-60.

Sillar, B., 2006. An exploration of the concept of 'Embedded Technologies' and suggestions for its application in archaeology. Embedded Technologies. Unpublished conference abstract

Sillar, B and Tite, M. S., 2000. The challenge of 'technological choices' for material science approaches in archaeology. Archaeometry 42, 2-20.

Soper, R.C., 1971. Special Number on the Iron Age in Eastern Africa. Azania: Journal of the British Institute in Eastern Africa 6

Soper, R., 1985. Roulette decoration on Africa pottery: technical considerations, dating and distributions. African Archaeological Review 3, 29-51 
Stahl, A. B., 2005. Introduction: Changing Perspectives on Africa's Pasts. In: A. B. Stahl (ed.), African Archaeology: A Critical Introduction. Oxford: Blackwell, 1-23.

Stanley, H.M., 1890. In Darkest Africa. London: Samson Low

Stern, W. B. and Gerber Y., 2004. Potassium-Calcium Glass: New Data and Experiments. Archaeometry 46, 137-156.

Stewart, K., 1993. Iron Age ceramic studies in Great Lakes Eastern Africa. African Archaeological Review 11, 21-37.

Sutton, J. E. G., 1993. The Antecendents of the Interlacustrine Kingdoms. Journal of African History 34, 33-64

Taylor, D. and Marchant, R., 1994/5. Human impact in the Interlacustrine region: longterm pollen records from the Rukiga highlands. Azania 29-30, 283-295.

Thomas, J., 2004. Archaeology and Modernity. London: Routledge.

Thompson, G. and Young, R., 1999. Fuels for the Furnace: Recent and Prehistoric Ironworking in Uganda and Beyond. In: M. Van der Veen (ed.), The Exploitation of plant resources in Ancient Africa. New York: Kluwer Academic/Plenum Publishers, 221-239.

Trigger, B., 1996. Understanding Early Civilisations. Cambridge: University of Cambridge

Trigger, B., 2006. A History of Archaeological Thought, $2^{\text {nd }}$ edition. Cambridge: Cambridge University Press.

Tripathi, V., 2001. The Age of Iron in South Asia: Legacy and Tradition. New Delhi: Aryan Books.

Tylecote, R.F., 1962. Metallurgy in archaeology: a prehistory of metallurgy in the British Isles. London: Edwards Arnodl Publishers Ltd.

Tylecote, R. F., 1965. Iron-smelting in pre-industrial communities. Journal of the Iron and Steel Institute 203, 340-348. 
Tylecote, R. F., 1968. The solid phase welding of metals. London: Edward Arnold

Tylecote, R.F., Ghaznavi, H.A., Boydell, P.J., 1977. Partitioning of trace elements between the ores, fluxes, slags and metals during the smelting of copper. Journal of Archaeological Science 4:305-333

Tylecote, R. F., 1987. The Early History of Metallurgy in Europe. London: Longman.

Tylecote, R. F., 1992. A History of Metallurgy. London: Institute of Materials.

Tylecote, R. F. and Gilmour, B., 1986. The Metallography of Early Ferrous Edge Tools ad Edged Weapons. Oxford: British Archaeological Reports, British Series 155.

Uzigogwe, G.N., 1972. Precolonial Markets in Bunyoro-Kitara. Comparative Studies in Society and History 14: 422-455.

Van der Merwe, N., 1980. The Advent of Iron in Africa. In: T. Wertime and J. Mulhy (eds.), The Coming of the Age of Iron. New Haven, 463-506.

Van der Merwe, N. J and Avery, D. H., 1987. Science and Magic in African Technology: Traditional Iron Smelting in Malawi. Africa 57, 143-172.

Van Grunderbeek, M-C.,1988. Essai d'étude typologique de céramique urewe dans la région des collines au Burundi et Rwanda. Azania 23, 11-55.

Van Grunderbeek, M-C., 1992. Essai de delimitation chronologie de L'Age du Fer Ancien au Burundi, au Rwanda et dans la region des Grand Lacs. Azania 27, 53-80

Van Grunderbeek, M-C., and Doutrelepont, H., 1989. Étude de charbons de bois provenent des sites métallurgiques de l'Âge du fer Ancien au Rwanda et au Burundi. PACT: Journal of the European Study Group on Physical, Chemical, Mathematical and Biological Techniques Applied to Archaeology 22, 281-295.

Van Grunderbeek, M-C., Roche, E. and Doutrelepont, H., 1983. Le Premier Age du Fer au Rwanda et au Burundi, Archaeologie et Environment. Brussels: Institut National de Recherché scientifique. 
Van Grunderbeek, M-C., Roche, E. and Doutrelepont, H., 2001. Un Type de Font de Fer Associe a la Culture Urewe (Age de Fer Ancien) au Rwanda et au Burundi. Mediterranean Archaeology 14: 271-297

Van Grunderbeek, M-C. and Roche, E., 2007. Multidisciplinary Evidence of Mixed Farming during the early Iron Age in Rwanda and Burundi. In: T. Denham, J. Iriate and L. Vrydaghs (eds.), Rethinking Agriculture: archaeological and ethnoarchaeological perspectives. Walnut Creek: Left Coast Press, 299-319.

Van Neer, W., 2000. Domestic animals from archaeological sites in Central and wstcentral Africa. In: R. Blench and K. MacDonald (eds.), The Origins and Development of Africa Livestock: archaeology, genetics, linguistics and ethnography. London: UCL, 163-190

Van Noten, F., 1972. Les tombes du roi Cyirima Rujugira et de la reine-mère Nyirayuhi Kanjogera: Description archéologique. Tervuren : Musée royal de l'Afrique centrale. Série in 8ê. Sciences humaines 77.

Van Noten, F., 1979. The Early Iron Age in the Interlacustrine Region: The Diffusion of Iron Technology. Azania 14, 61-79.

Van Noten, F., 1982. The Archaeology of Central Africa. Gräz: Akademische Druck-U Verlagsanstalt.

Van Noten, F., 1983. Histoire Archeologique du Rwanda. Brussels: Musee Royal de l'Afrique Centrale - Tervuren.

Vansina, J., 1990. Paths in the Rainforest: Towards a History of Political Tradition in Equatorial Africa. London: James Currey.

Vansina, J., 2004. Antecedents to Modern Rwanda. The Nyiginya Kingdom. Oxford: James Currey.

Veldhuijzen, H. A., 2003. 'Slag_Fun' - A New Tool for Archaeometallurgy: Development of an Analytical (P)ED-XRF Method for Iron-Rich Materials. Papers from the Institute of Archaeology 14, 102-118. 
Veldhuijzen, H. A., 2005. Early Iron Production in the Levant: Smelting and Smithing at Early $1^{\text {st }}$ Millenium BC Tell Hammeh, Jordan, and Tel Beth-Shemesh, Israel. London: UCL, unpublished $\mathrm{PhD}$ Thesis.

Vignati-Pagis, E., 1995. Du Fourneau a la Fosse: Changements Techniques dans la Métallurgie du Fer au Burundi au Cours des Duex Derniers Millenaires? Université de Paris: Unpublished PhD Thesis.

Vogel, J. O. (ed.), 2000. Ancient African metallurgy: the socio-cultural context. Walnut Creek, CA.: AltaMira

Wagner, D. B., 1996. Iron and Steel in Ancient China, $2^{\text {nd }}$ Edition. Leiden: E. J. Brill.

Wagner, D. B., 2001. The State and the Iron Industry in Han China. Copenhagen: NIAS.

Wengrow, D., 2001. The Evolution of Simplicity: Aesthetic Labour and Social Change in the Neolithic Near East. World Archaeology 33 (2): 168-188

Whiteman, J. A. and Okafor, E. E., 2003.Characterisation of Nigerian bloomery iron smelting. The Journal of the Historical Metallurgy Society 37/2, 70-80.

Wotzka, H-P., 2006. Records of activity: radiocarbon and the structure of Iron Age settlement in Central Africa. In: Grundlegungen. Beiträge zur europäischen afrikanischen Archäologie für Manfred K. H. Eggert. Tübingen: Francke, 271-289

Wrigley, C., 1996. Kingship and State: The Buganda Dynasty. Cambridge: Cambridge University Press.

Young, R. \& Thompson, G. 1999 Missing Plant Foods? Where is the Archaeobotanical Evidence for Sorghum and Finger Millet in East Africa? In M. Van der Veen (ed) The Exploitation of plant resources in Ancient Africa: 63-72. New York: Kluwer Academic/Plenum Publishers.

http://museum.gov.rw/ 
